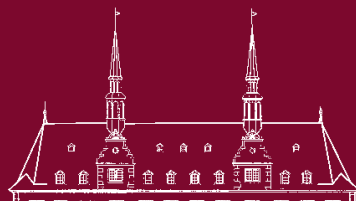

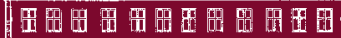

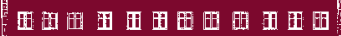

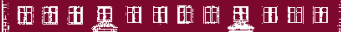

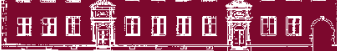

Stanislau Paulau

\title{
Das andere Christentum
}

Zur transkonfessionellen Verflechtungsgeschichte von äthiopischer Orthodoxie und europäischem Protestantismus

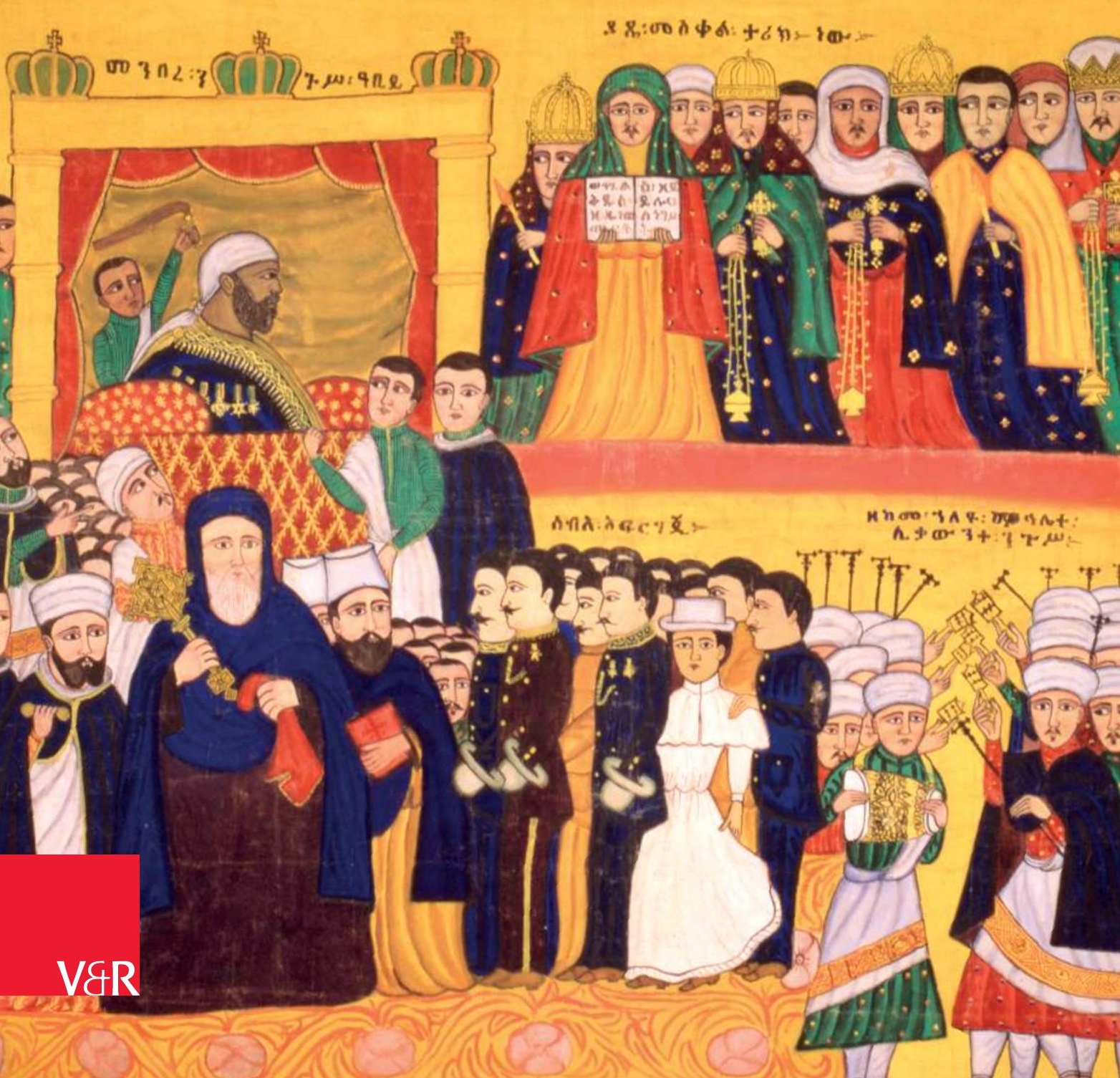




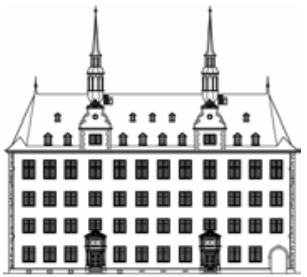




\title{
Veröffentlichungen des \\ Instituts für Europäische Geschichte Mainz
}

\author{
Abteilung für Abendländische Religionsgeschichte \\ Herausgegeben von Irene Dingel
}

Band 262 


\section{Das andere Christentum}

Zur transkonfessionellen Verflechtungsgeschichte von äthiopischer Orthodoxie und europäischem Protestantismus

von

Stanislau Paulau 
Die Publikation wurde durch den Open-Access-Publikationsfonds für Monografien der Leibniz-Gemeinschaft gefördert.

Bibliografische Information der Deutschen Nationalbibliothek: Die Deutsche Nationalbibliothek verzeichnet diese Publikation in der Deutschen Nationalbibliografie; detaillierte bibliografische Daten sind im Internet über https://dnb.de abrufbar.

(C) 2021, Vandenhoeck \& Ruprecht GmbH \& Co. KG, Theaterstraße 13, D-37073 Göttingen

Das Werk und seine Teile sind urheberrechtlich geschützt.

Das Werk ist als Open-Access-Publikation im Sinne der Creative-Commons-Lizenz BY-NC-ND International 4.0 (»Namensnennung - Nicht kommerziell - Keine Bearbeitung«) unter https://doi.org/10.13109/9783666336041 abzurufen. Um eine Kopie dieser Lizenz zu sehen, besuchen Sie https://creativecommons.org/licenses/by-nc-nd/4.0/. Jede Verwertung in anderen als den durch diese Lizenz erlaubten Fällen bedarf der vorherigen schriftlichen Einwilligung des Verlages.

Coverabbildung: Fre Heywat, Leinwandgemälde »Empfang beim Kaiser«, Äthiopien, 1909-1910, 107 x 93 cm, Museum für Völkerkunde Dresden, Staatliche Kunstsammlung Dresden (Foto: Eva Winkler).

Satz: Vanessa Weber, IEG Mainz

\section{Vandenhoeck \& Ruprecht Verlage | www.vandenhoeck-ruprecht-verlage.com}

ISSN 2197-1048

ISBN 978-3-666-33604-1 


\section{Inhaltsverzeichnis}

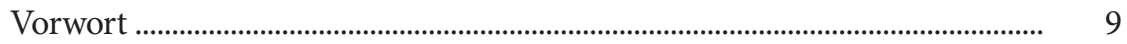

Vorbemerkung zur Transliteration ..................................................................... 11

I. Einleitung .................................................................................................... 13

II. Äthiopische Mönche und europäische Reformatoren (1534) .................. 21

1. Primäre Fäden einer Verflechtungsgeschichte:

1.1 Persönliche Begegnungen mit dem Anderen: Abba Mika ${ }^{\mathrm{e}} \mathrm{el}$ und die Wittenberger Reformatoren ......................... 21

1.2 Literarische Begegnungen mit dem Anderen:

Die $»$ Legationes « und ihre protestantischen Leser ............................ 31

2. Sekundäre Fäden einer Verflechtungsgeschichte:

Herausbildung weiterer Knotenpunkte ...................................................... 37

2.1 Lissabon ..................................................................................................... 37

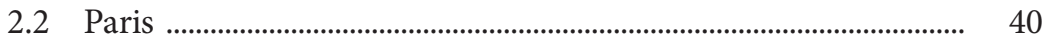

2.3 Wittenberg ................................................................................... 41

2.4 London ..................................................................................................... 41

3. Themenfelder eines proto-ökumenischen Dialogs zwischen Abba Mika ${ }^{\top}$ el und Martin Luther ................................................................. 42

3.1 Trinitätsverständnis ...................................................................... 42

3.2 Abendmahlsverständnis .................................................................. 49

3.3 Ekklesiologie ................................................................................. 52

3.4 Eschatologie .............................................................................................. 56

4. Konfessionalisierung der Erinnerung ........................................................ 65

III. Imaginäre Kirche: Transfer und Transformation des äthiopisch-orthodoxen theologischen Wissens (1540-1791) ................... 73

1. Wissensproduktion und Imaginationspraktiken der Transkonfessionalität ....................................................................................... $\quad 73$

2. Hybride Imaginationen des Äthiopischen: Ṣägga Zä’ab und protestantische Rezeption seines Werks .................................................... 75

2.1 Umdeutungen des »salomonischen Narrativs« ................................ 75

2.2 Modi der Rezeption: Sebastian Münster und Martin Bucer ......... 80

2.3 Topographien des Imaginären ......................................................... 84 
3. Erfindung einer Konfession: Konstruktionen des äthiopischen »Bekenntnisses"

3.1 David Chytraeus und die »Confessio Fidei Æthiopum « ................. 92

3.2 Hiob Ludolf und die»Confessio Fidei Claudii Regis Æthiopiæ« .. 97

3.3 Giacomo Baratti und die Erweiterung des »äthiopischen Glaubensbekenntnisses «............................................ 103

4. Alte Imaginationen und neues Wissen ………………………………....... 109

IV. Äthiopische »Reformation«: Mission als Raum transkonfessioneller Differenzaushandlungen (1817-1844)

1. Der »Göttinger Geist« evangelischer Äthiopien-Mission

2. Die erste dauerhafte Begegnung: Semantiken und Strategien wechselseitiger Alteritätskonstruktionen

2.1 Modalitäten der Begegnung ………………………………….......... 127

$2.2 »$ Ihr seyd Juden«: Äthiopische Orthodoxie als das Andere ............ 129

2.3 Die »Feinde Marias« (Ș́ärä Maryam):

Europäischer Protestantismus als das Andere

3. Rückwirkungen missionarischer Konstruktionen von der äthiopischen Orthodoxie auf den europäischen Protestantismus

3.1 Kirchliches Liedgut: »Der Kämmerer aus Mohrenland« ................ 146

3.2 Missionsdiskurse im Wandel .............................................................. 149

V. Die Herrlichkeit der Könige: Verflechtungen politischer Theologien (27. Februar 1905)

1. Äthiopien und Deutschland: »Christliche« Kaiserreiche auf dem Weg der Annäherung

1.1 Die Politiker als Theologen: Rhetorik christlicher Verbundenheit in der kaiserlichen Korrespondenz

1.2 Der Theologe als Politiker: Adolf Harnack und die deutsche Äthiopien-Diplomatie

2. Ein Tag, zwei Gottesdienste

2.1 Berlin: Wilhelm II. und die Weihe des Berliner Doms ................... 172

2.2 Addis Abeba: Die deutsche Sondergesandtschaft in Äthiopien ... 182

2.3 Gnțoțto: Mənilək II. und das Ggzəəətnä Maryam-Fest ................... 191

3. Ambivalenz des Christlichen ..................................................................... 196

3.1 Perspektiven auf das »salomonische Narrativ « .................................. 196

3.2 Transkonfessionelle Praktiken der Diplomatie ............................... 200

VI. Fazit 
Quellen- und Literaturverzeichnis ...................................................................... 215

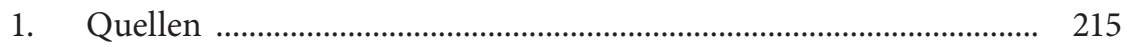

2. Literatur ........................................................................... 224

Abbildungsnachweis .......................................................................................... 245

Abkürzungsverzeichnis ..................................................................................... 247

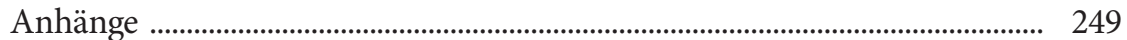

1. Philipp Melanchthons Brief an Benedikt Pauli über die Ankunft von Abba Mika ${ }^{\mathrm{e}} \mathrm{el}$, 31. Mai 1534 ............................................................. 249

2. Die »Confessio Claudii« nach dem Manuskript BL Harl. 7629 ............... 253

3. Die »Glaubens-Bekenntniß Claudii, deß Königs in Mohrenland«. Die »Confessio Claudii« in deutscher Übersetzung von Johann Michael Dilherr ............................................................................. 255

4. Ergänzung zum »äthiopischen Glaubensbekenntnis« laut Giacomo Baratti ............................................................................................. 258

5. Missionslied »Der Kämmerer aus Mohrenland« .......................................... 262

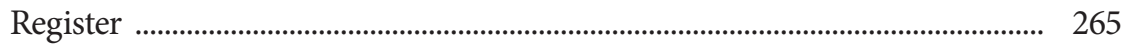

1. Ortsregister ………………….................................................. 265

2. Personenregister ............................................................................. 267 
Für Valinirina, Ivan und Damian 


\section{Vorwort}

Diese Studie wurde im Wintersemester 2018/19 von der Theologischen Fakultät der Georg-August-Universität Göttingen als Dissertation angenommen und für den Druck geringfügig überarbeitet. Die Recherchen zu diesem Buch und die Erstellung des Manuskripts haben mich mit einer Reihe von wunderbaren Menschen in Kontakt gebracht. Für ihre großzügige Unterstützung möchte ich mich an dieser Stelle von Herzen bedanken.

In erster Linie gilt mein aufrichtiger Dank meinem Doktorvater und Erstgutachter Herrn Prof. Dr. Dr. h. c. mult. Martin Tamcke. Durch seine stets interessierte Begleitung, kritische Lektüre und anregenden Fragen trug er maßgeblich zum Gelingen des Forschungsvorhabens bei. Neben dem wertvollen fachlichen Austausch ist es aber auch der zwischenmenschliche Umgang, der unsere Zusammenarbeit für mich besonders machte. Daher möchte ich mich an dieser Stelle auch für die schöne, bereichernde und inspirierende gemeinsame Zeit bedanken.

Weiter gebührt mein Dank Frau Prof. Dr. Heike Behlmer für die Übernahme und zeitnahe Erstellung des Zweitgutachtens sowie Herrn Prof. Dr. Tobias Georges für die bereitwillige Mitwirkung in der Prüfungskommission.

Die Rechercheaufenthalte, die Archivreisen und letztlich das konzentrierte Schreiben wären ohne finanzielle Unterstützung von verschiedenen Seiten kaum möglich gewesen. Daher bedanke ich mich herzlich bei dem Studienförderwerk Klaus Murmann der Stiftung der Deutschen Wirtschaft, der Alfred Toepfer Stiftung F.V.S. sowie der Graduiertenschule für Geisteswissenschaften Göttingen, die zu unterschiedlichen Zeitpunkten die Entstehung dieser Monographie durch ihre großzügige finanzielle und ideelle Förderung ermöglicht haben.

In ganz besonderer Weise zu Dank verpflichtet weiß ich mich den zahlreichen Menschen, mit denen ich während mehrerer Forschungsaufenthalte in Äthiopien in Austausch kam. Ohne ihr umfangreiches Wissen, ihre Aufgeschlossenheit und bereitwillige Unterstützung wäre diese Arbeit so nicht möglich gewesen. Insbesondere möchte ich mich bei den Mitarbeitenden des National Archive and Library of Ethiopia und des Institute of Ethiopian Studies sowie bei den Mitarbeitenden und Studierenden des Holy Trinity Theological

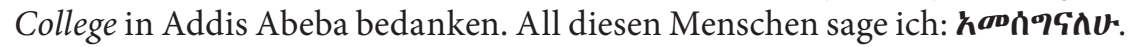

Mein besonderer Dank gilt Herrn Dr. Michael Kleiner. Ihm verdanke ich nicht nur die Einführung in die Welt der äthio-semitischen Sprachen und eine Vielzahl von wertvollen fachkundigen Hinweisen. Ebenso durfte ich 
von seiner freundschaftlichen Unterstützung während der gesamten Zeit der Entstehung dieser Arbeit profitieren.

Darüber hinaus war mir der freundliche und kollegiale Beistand eine große Hilfe, den ich über die Jahre am Lehrstuhl für Ökumenische Theologie und Orientalische Kirchen- und Missionsgeschichte der Georg-AugustUniversität Göttingen erhielt. All meinen Kollegen und Freunden am Lehrstuhl danke ich für die immer ausgesprochen angenehme Atmosphäre und konstruktive Zusammenarbeit. Für den intensiven Austausch und gewinnbringende Diskussionen in der Endphase der Promotion habe ich vor allem Herrn Lukas Pieper zu danken. Ein ausdrücklicher Dank gebührt zudem der Sekretärin des Lehrstuhls, Frau Daniela Barton, für ihre tatkräftige Mithilfe weit über das Notwendige hinaus.

Frau Prof. Dr. Irene Dingel möchte ich für wertvolle Hinweise und kritische Anregungen für die Überarbeitung des Manuskripts sowie für die Aufnahme der Arbeit in die Reihe Veröffentlichungen des Instituts für Europäische Geschichte aufrichtig danken. Bedanken möchte ich mich außerdem bei den Kolleginnen und Kollegen am Leibniz-Institut für Europäische Geschichte, die mich während der abschließenden Redaktionsarbeiten durch Rat und Zuspruch begleitet haben.

Für die Gewährung eines Druckkostenzuschusses habe ich dem Ökumenischen Forschungsfonds des Deutschen Ökumenischen Studienausschusses der Arbeitsgemeinschaft Christlicher Kirchen in Deutschland (ACK), der Vereinigten Evangelisch-Lutherischen Kirche Deutschlands (VELKD) sowie der Deutschen Gesellschaft für Missionswissenschaft (DGMW) zu danken.

Der größte Dank gilt meiner Frau Valinirina, auf deren rücksichtsvolle Begleitung und Zuwendung ich stets bauen konnte, sowie unseren beiden Kindern, Ivan und Damian, die zu einer unerschöpflichen Quelle der Inspiration und Lebensfreude für mich geworden sind. Ihnen sei dieses Buch gewidmet.

Neuendettelsau, im Juni 2020

Stanislau Paulau 


\section{Vorbemerkung zur Transliteration}

Die Transliteration aus dem $\mathrm{G}^{\mathrm{c}} \mathrm{\partial z}$ und dem Amharischen folgt in diesem Buch dem Transkriptions- und Transliterationssystem der Encyclopaedia Aethiopica. ${ }^{1}$ Die einzige Ausnahme wird für die Bezeichnung der äthiopischen Hauptstadt gemacht, bei welcher sich eine deutsche Schreibweise Addis Abeba (anstatt von Addis Abäba) eingebürgert hat. Bei wörtlichen Zitaten bleibt selbstverständlich die Originalschreibweise erhalten. 



\section{Einleitung}

[...] und wan einer aus India keme oder aus Morenland oder, wo ehr herkeme und spreche: Ich gleube an Christum, so wurde ich sagen: Also glaube ich auch, und also werde ich auch selig, und stimmen im glauben und in der Bekendtnis die Christen mit einander uber ein, ob sie sonst wohl in der gantzen welt hin und wider zerstreuet sind. Dan es heisset nicht eine Romissche noch Nurmbergissche oder Wittembergissche kirche, sondern eine Christliche kirche, dorein den gehören alle, so an Christum glauben. ${ }^{1}$

Mit diesen Worten versuchte Martin Luther (1483-1546) in einer Reihenpredigt über das Matthäusevangelium, die er im Juli 1537 in Wittenberg hielt, ${ }^{2}$ die Einheit der Kirche Christi zu veranschaulichen. Als Ausgangspunkt der Predigt diente die Frage der Jünger an Jesus über den Vorrang unter ihnen: »Wer ist nun der Größte im Himmelreich?« (Mt 18,1). Diesen Rangstreit unter den Aposteln bezog Luther auf den frühneuzeitlichen Konfessionsstreit und nahm ihn zum Anlass, sein Kirchenverständnis zu erläutern. Er mahnte seine Zuhörerschaft, strikt zwischen dem römischen »Bapsttumb« - dieses trage bloß den Namen der Kirche Christi, sei in Wirklichkeit aber »des ledigen Teuffels kirche und brauth « - und der wahrhaftigen christlichen Kirche zu unterscheiden. ${ }^{3}$ Zur letzteren zählte er allerdings nicht nur die Anhänger der Reformation, die ihre Wirkungsmacht erst entfaltete, vielmehr bemühte er sich redlich darum, dem Glaubensartikel von der Katholizität der Kirche Rechnung zu tragen. ${ }^{4}$ Aus diesem Grund kam der Bezugnahme auf einen Christen aus »India« oder »Morenland « eine zentrale Bedeutung zu: Mittels der Vorstellung, mit diesem »fremden« Christen den gleichen Glauben zu teilen und gemeinsam mit ihm zu der wahren Kirche zu gehören, erhob Luther den Anspruch, trotz des Bruches mit Rom Teil der weltweiten christlichen Gemeinschaft zu sein. Folglich diente diese demonstrative Aufgeschlossenheit, die das Hinausgehen über die Grenze des Eigenkonfessionellen implizierte, den außereuropäischen Formen des Christentums gegenüber para-

2 Das genaue Datum ist nicht bekannt. Vieles deutet jedoch darauf hin, dass die Predigt entweder am 4. oder am 11. Juli 1537 gehalten wurde. Vgl. ebd., S. X sowie ders., WA 46, 1912, S. XXXII.

3 Ders., WA 47, 1912, S. 236.

4 Ebd., S. 234. Ein ähnlicher Gedankengang findet sich auch in Luthers testamentarischem Glaubensbekenntnis, das seine 1528 veröffentlichte Schrift »Vom Abendmahl Christi, Bekenntnis« abschließt. Vgl. ders., WA 26, 1909, S. 506. 
doxerweise der Stärkung des eigenen protestantischen Profils im Rahmen des - damals noch binneneuropäischen - Konfessionsstreites.

Die Figur eines "fremden « Christen, auf der diese ekklesiologische Reflexion aufgebaut war, scheint auf den ersten Blick imaginär zu sein. Dennoch gab es im Erfahrungshorizont Luthers tatsächlich einen konkreten Referenzpunkt, der für die Wahl dieses Motivs ausschlaggebend gewesen sein dürfte: Die Begegnung und der theologische Austausch mit dem äthiopisch-orthodoxen Mönch $A b b a$ Mika ${ }^{5}$ ( ( im Sommer 1534, in Wittenberg aufgesucht hatte. ${ }^{5}$ Somit war es kein Zufall, dass Martin Luther in seiner Kanzelrede ausgerechnet die Toponyme "India" und »Morenland« für die Lokalisierung des aus der Ferne angereisten Glaubensgenossen verwendete. Denn diese beiden Bezeichnungen wurden im 16. Jahrhundert weithin auf Äthiopien bezogen. ${ }^{6}$

Hervorzuheben ist dabei nicht nur der Umstand, dass orthodoxe Christen aus Afrika und europäische Protestanten bereits im Zeitalter der Reformation ein Beziehungsgeflecht bildeten, sondern auch, dass dieses - wie die Predigt Luthers beispielhaft verdeutlicht - auf die Formierung des frühen protestantischen Kirchen- und Selbstverständnisses einwirkte.

Diese Beobachtung zum Ausgangspunkt nehmend, macht die vorliegende Arbeit transkonfessionelle Verflechtungszusammenhänge von äthiopischer Orthodoxie und europäischem Protestantismus, jenen Varianten des Christentums, die gemeinhin gesondert betrachtet werden, zu ihrem Forschungsgegenstand. Dabei bedürfen die Ausdrücke "äthiopische Orthodoxie« und »europäischer Protestantismus« einer kurzen Begriffsklärung. Während mit

5 Siehe Kapitel II.1.1 »Persönliche Begegnungen mit dem Anderen: Abba Mika ${ }^{\circ}$ el und die Wittenberger Reformatoren « und Kapitel II.3 »Themenfelder eines proto-ökumenischen Dialogs zwischen Abba Mika ${ }^{\circ}$ el und Martin Luther «.

6 Die Verwendung des Namens »Mohrenland« für Äthiopien prägte Luther nicht zuletzt mit, indem er in seiner Deutschen Bibel sowohl das hebräische שוּכ (Küš)

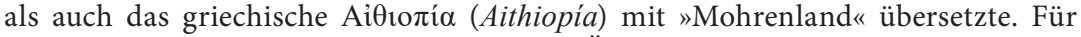
die Verwendung des Namens »India« für Äthiopien siehe bspw. die berühmte Carta Marina Navigatoria (1516) von Martin Waldseemüller (ca. 1472-1520), die zu Luthers Zeiten verbreitet war. Dort wird das Horn von Afrika als Regnvm Habesch et Habacri Prespiteri Ioh[annis] Sive India Maior Ethiopie betitelt. Die Bezeichnung "India " resultierte aus der Anlehnung an die spätantiken und mittelalterlichen Autoren, die Äthiopien als India Maior bzw. India Exterior (oder dessen Teil zusammen mit den anderen am Roten Meer liegenden Gebieten) sahen, während der indische Subkontinent als India Minor bzws. India Interior bezeichnet wurde. Zur Geschichte der Verwendung des Toponyms »India« in Bezug auf Äthiopien und zu dessen Ambiguität siehe: Gianfranco FIACCADORI, »India« as Name of Ethiopia, in: EAE 3, 2007, S. 145-147; Albrecht Dihle, The Conception of India in Hellenistic and Roman Literature, in: PCPS 10 [190] (1964), S. 15-23; Philip MAYERson, A Confusion of Indias. Asian and African India in the Byzantine Sources, in: JAOS 113 (1993), S. 167-174; Pierre SCHNEIDER, L'Éthiopie et l'Inde: Interférences et confusions aux extrémités du monde antique, Roma 2004, S. 289-361. 
dem ersten die Äthiopisch-Orthodoxe Kirche gemeint ist, ${ }^{7}$ bezieht sich der zweite auf eine Vielzahl der aus der Reformation hervorgegangenen Kirchen. ${ }^{8}$ Weder das eine noch das andere ist als homogene Größe, sondern vielmehr als Netz (oft konkurrierender) interner Teilgemeinschaften zu verstehen.

Die Äthiopisch-Orthodoxe Kirche ist die weitaus größte unter den Kirchen des orientalischen Christentums. Zugleich hat sie ihren ganz eigenen Charakter. Als die »indigene Kirche Afrikas« schlechthin ${ }^{9}$ - die einzige heute noch existierende Form des Christentums, die bereits seit der Spätantike im subsaharischen Afrika beheimatet ist - stellt sie sowohl kulturell als auch religionsgeschichtlich ein Unikum dar. ${ }^{10}$ Von der restlichen Christenheit unterscheidet sich diese miaphysitische Kirche nicht nur durch einen deutlich breiteren Bibelkanon, ${ }^{11}$ sondern auch durch eine Vielzahl von Praktiken,

7 Seit 1996 lautet die offizielle Eigenbezeichnung Äthiopisch-Orthodoxe Täwah̨ədo-

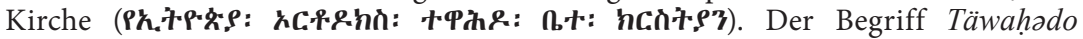

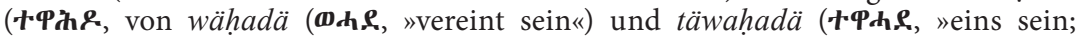
miteinander vereint sein«) bezieht sich auf die Art und Weise der Vereinigung der beiden Naturen in Christus und bringt somit die miaphysitische Christologie der Kirche Äthiopiens zum Ausdruck. Siehe dazu: Tedros Abraha, Täwaḩədo, in: EAE 4, 2010, S. 873-875; José L. BAndrés / Ugo Zanetti, Christology, in: EAE 1, 2003, S. 728-732; Alois Grillmeier, Jesus der Christus im Glauben der Kirche, unter Mitarbeit von Theresia Hainthaler, Freiburg i.Br. u.a. 1990, Bd. II/4: Die Kirche von Alexandrien mit Nubien und Äthiopien ab 451, S. 376-379; Tesfazghi UQBIT, Current Christological Positions of Ethiopian Orthodox Theologians, Roma 1973; Yaqob Beyene, L'unzione di Christo nella teologia etiopica, OCA 215, Roma 1981. Für eine Einführung in die Geschichte und Theologie der Äthiopisch-Orthodoxen Kirche siehe Wolfgang Hage, Das orientalische Christentum, Stuttgart 2007, S. 200-225; Friedrich Heyer, Die Kirche Äthiopiens. Eine Bestandsaufnahme, Berlin u. a. 1971. Vgl. auch die Selbstdarstellungen: Patriarchate of the Ethiopian Orthodox Täwaḥ̊do Church (Hg.), The Ethiopian Orthodox Täwaḥədo Church: Faith, Order of Worship and Ecumenical Relations, Addis Abeba 1996; Dass. (Hg.), The Church of Ethiopia. A Panorama of History and Spiritual Life, Addis Abeba 1970; Aymro Wondmagegnehu/Joachim Motovu, The Ethiopian Orthodox Church, Addis Abeba 1970.

8 Dazu wird in der Arbeit auch die Church of England gezählt. Zur Genese des Begriffs "Protestantismus« siehe: Christian Volkmar Witt, Protestanten. Das Werden eines Integrationsbegriffs in der Frühen Neuzeit, Tübingen 2011.

9 Yesenaq, The Ethiopian Tewahedo Church. An Integrally African Church, Nashville 1997, S. XXI.

10 Daher hat die Äthiopisch-Orthodoxe Kirche eine herausragende symbolische Bedeutung für viele christliche Schwarzafrikaner und deren Nachfahren auf der ganzen Welt. Vgl. Nadia Nurhussein, Black Land. Imperial Ethiopianism and African America, Princeton u.a. 2019; Obgu U. Kalu, Ethiopianism and the Roots of Modern African Christianity, in: Sheridan Gilley / Brian Stanley, The Cambridge History of Christianity, Cambridge u.a. 2006, Bd. 8: World Christianities, c. 1815-c. 1914, S. 576-592; Erhard Kamphausen, Anfänge der kirchlichen Unabhängigkeitsbewegung in Südafrika. Geschichte und Theologie der Äthiopischen Bewegung. 1872-1912, Bern u. a. 1976.

11 Peter Brandt, Geflecht aus 81 Büchern. Zur variantenreichen Gestalt des äthiopischen Bibelkanons, in: Aethiopica. International Journal of Ethiopian Studies 3 
die in der Literatur oftmals als "jüdisch" beschrieben werden (beispielsweise die Beschneidung und das Einhalten des Sabbat-Gebotes). ${ }^{12}$ In der westlichen Historiografie wird die religiöse Sonderstellung Äthiopiens in aller Regel mit dem Verweis auf die geografisch isolierte Lage des Landes und die daraus resultierenden mangelnden Kontakte der äthiopischen Kirche zur restlichen Christenheit erklärt. So haben transkontinentale Verflechtungen in der Geschichte des äthiopischen Christentums bisher - von wenigen Ausnahmen abgesehen - kaum Beachtung gefunden. ${ }^{13}$

Kirchengeschichte als spezifische Form von Wissensproduktion wurzelt in einer langen Tradition konfessioneller Geschichtsschreibung, deren Bezugssystem gewöhnlich eine partikuläre (in aller Regel »eigene«) Konfession bildet. Aufgrund dieses "methodologischen Konfessionalismus ${ }^{14}$ kon-

(2000), S. 79-115; ders., Bible Canon, in: EAE 1, 2003, S. 571-573; Roger W. Cowley, The Biblical Canon of the Ethiopian Orthodox Church Today, in: OS 23 (1974), S. 318-323.

12 Siehe die seit Jahren andauernde akademische Diskussion über den »jüdischen « Charakter des äthiopischen Christentums: AfEwOR K HAILU, Jewish Cultural Elements in the Ethiopian Orthodox Täwahədo Church, in: Gorgias Eastern Christian Studies 55 (2020); Kirsten Stoffregen-Pedersen, Is the Church of Ethiopia a Judaic Church?, in: Warszawskie Studia Teologiczne 12 (2) (1999), S. 203-216; Edward Ullendorff, The Two Zions. Reminiscences of Jerusalem and Ethiopia, Oxford 1988; ders., Hebraic-Jewish Elements in Abyssinian (Monophysite) Christianity, in: Journal of Semitic Studies 1 (3) (1956), S. 216-256; John T. PAwlikowski, The Judaic Spirit of the Ethiopian Orthodox Church. A Case Study in Religious Acculturation, in: Journal of Religion in Africa 4 (3) (1971-1972), S. 178-199; Ernst HammerschmidT, Jewish Elements in the Cult of the Ethiopian Church, in: Journal of Ethiopian Studies 3 (2) (1965), S. 1-12.

13 Als eine erfreuliche Ausnahme in dieser Hinsicht kann die Forschung zur Geschichte der Jesuitenmission in Äthiopien im 16. und 17. Jahrhundert gelten. In den letzten zehn Jahren hat dieses Forschungsfeld einen beachtlichen Aufschwung erlebt. Siehe: Victor Manuel Fernández u.a., The Archeology of the Jesuit Missions in Ethiopia (1557-1632), Leiden u. a. 2017; Wendy Laura BelChER (Hg.), The Jesuits in Ethiopia (1609-1641). Latin Letters in Translation, Wiesbaden 2017; Andreu Martínez D'Alòs-Moner, Envoys of a Human God. The Jesuit Mission to Christian Ethiopia. 1557-1632, Leiden u.a. 2015; Wendy Laura Belcher / Michael Kleiner (Hg.), The Life and Struggles of Our Mother Walatta Petros. A Seventeenth-Century African Biography of an Ethiopian Woman, Princeton NJ 2015; Matteo Salvadore, Gaining the Heart of Prester John. Loyola's Blueprint for Ethiopia in Three Key Documents, in: World History Connected 10 (3) (2013), URL: <https://worldhistory connected.press.uillinois.edu/10.3/forum_salvadore.html> (15.12.2019); ders., The Jesuit Mission to Ethiopia (1555-1634) and the Death of Prester John, in: Allison B. Kavey (Hg.), World-Building and the Early Modern Imagination, New York 2010, S. 141-171; Leonardo Cohen, The Missionary Strategies of the Jesuits in Ethiopia (1555-1632), Wiesbaden 2009.

14 An dieser Stelle führe ich den Terminus »methodologischer Konfessionalismus« analog zum Ausdruck »methodologischer Nationalismus« ein, der in den Geschichtswissenschaften inzwischen fest etabliert ist. Dementsprechend verwende ich ihn hier nicht im ideologisch wertenden Sinne, sondern als Bezeichnung einer spezifischen Forschungslogik, die eine Konfession oder Kirche, sei es latent oder manifest, als 
stituiert sich Kirchengeschichte bei näherem Betrachten als Geschichte einer Reihe voneinander isolierter beziehungsweise isoliert dargestellter Kirchen. Aufgrund einer solchen Verengung der analytischen Perspektive geraten allerdings jene Zusammenhänge und Konstellationen aus dem Blickfeld, die jenseits des unmittelbaren ideengeschichtlichen oder geografischen Umfeldes der zu untersuchenden Konfession zu lokalisieren sind. Die Reduktion historischer Komplexität, die dadurch zwangsläufig erfolgt, schafft Voraussetzungen dafür, dass verfestigte konfessionelle Paradigmen in der Geschichtsschreibung tendenziell reproduziert werden. Indem die vorliegende Arbeit sich auf die Wechselwirkungen der vermeintlich - geografisch wie dogmatisch - strikt voneinander abgesonderten konfessionellen Räume fokussiert, stellt sie den Versuch dar, konfessionelle Historiografien im Sinne ökumenischer Weitung aufzubrechen.

Zugleich versteht sich die Arbeit als ein Beitrag zur Debatte um das Projekt einer "Globalen Christentumsgeschichte«, das in den letzten Jahrzehnten (u. a. im Zuge der Neuorientierung der Missionsgeschichte) vorangetrieben wurde. ${ }^{15}$ Trotz der programmatischen Aufrufe, eine methodologische Trendwende zu vollziehen, ${ }^{16}$ setzt sich in diesem Forschungsbereich eine

primären und oft unhinterfragbaren Referenzrahmen der Kirchengeschichtsschreibung zugrunde legt. Zur Debatte über den »methodologischen Nationalismus« siehe: Ulrich BECK / Edgar GrANDE, Jenseits des methodologischen Nationalismus. Außereuropäische und europäische Variationen der Zweiten Moderne, in: Soziale Welt. Zeitschrift für sozialwissenschaftliche Forschung 61 (2010), S. 187-216; Andreas Wimmer/ Nina Glick Schiller, Methodological Nationalism, the Social Sciences, and the Study of Migration. An Essay in Historical Epistemology, in: International Migration Review 37 (2003), S. 576-610; Michael ZüRN, Politik in der postnationalen Konstellation. Über das Elend des methodologischen Nationalismus, in: Christine LANDFried (Hg.), Politik in einer entgrenzten Welt, Köln 2001, S. 181-203 sowie Marcelo PARreira do Amaral, Globalisierung im Fokus vergleichender Forschung, in: Christine Freitag (Hg.), Methoden des Vergleichs. Komparatistische Methodologie und Forschungsmethodik in interdisziplinärer Perspektive, Opladen u.a. 2014, S. 117-139.

15 Vgl. u.a. Klaus Koschorke, Außereuropäische Christentumsgeschichte (Asien, Afrika, Lateinamerika). Forschungsstand und Perspektiven einer neuen Disziplin, in: Jahrbuch für europäische Überseegeschichte 2 (2002), S. 137-163; ders. (Hg.), Außereuropäische Christentumsgeschichte, Göttingen 2006; Frieder LudwIG, Globale Christentumsgeschichte, in: VF 57 (2) (2012), S. 106-116; Markus Wriedt, Einheit in der Vielfalt. Die weltweite Inanspruchnahme des Christlichen als Gegenstand der theologisch verantworteten Geschichtsschreibung, in: ETSt 6 (2) (2015), S. 197213; Hartmut Lehmann, Einleitung. Europäisches und globales Christentum in der Frühen Neuzeit, in: Jens Holger SchjøRRING / Norman A. HJelm (Hg.), Geschichte des globalen Christentums, Stuttgart 2017, Teil 1: Frühe Neuzeit, S. 19-44. Siehe auch Beiträge in: Adrian Hermann u.a. (Hg.), Transcontinental Links, Enlarged Maps, and Polycentric Structures. A Special Issue on the »Munich School of World Christianity«, in: The Journal of World Christianity 6 (1) (2016).

16 Vgl. bspw. Andreas Feldtkeller, Sieben Thesen zur Missionsgeschichte, Berlin 2000; Klaus Koschorke, Veränderte Landkarten der globalen Christentumsge- 
Perspektive durch, welche das Globale als bloße Erweiterung des Gegenstandsbereichs der Kirchengeschichtsschreibung auf das Außereuropäische begreift. Im Gegensatz dazu visiert die vorliegende Untersuchung die Christentumsgeschichte vielmehr als einen vielfach verflochtenen Prozess an, in dem Akteure konfessions- und regionsübergreifend miteinander verwoben sind. Methodisch knüpft sie dabei an verflechtungsgeschichtliche Ansätze an und bemüht sich darum, sie für eine transkonfessionelle Kirchengeschichtsschreibung fruchtbar zu machen. ${ }^{17}$

In diesem Zusammenhang kommt dem Adjektiv "transkonfessionell" eine zweifache Bedeutung zu. Zum einen bezieht es sich auf eine methodologische Position, die jeweilige Christentumsformationen - im Gegensatz zum Zugang des "methodologischen Konfessionalismus« - nicht essentialistisch, als feste Größen und unhinterfragbare Rahmen der Kirchengeschichtsschreibung, begreift. Vielmehr werden sie relational, als Produkte multilateraler Beziehungen unterschiedlicher Reichweite und Zuschnitts, die ihrerseits Entwicklungen durchlaufen und sich stets neu konstituieren, aufgefasst. Somit wird die Selbstverständlichkeit der Kategorie »Konfession« infrage gestellt und zum Gegenstand historischer Reflexion gemacht. ${ }^{18}$ Zum anderen deutet das Adjektiv »transkonfessionell« auf jene historischen Phänomene hin, die zur Überschreitung jeweiliger »konfessioneller« Grenzen führten. ${ }^{19}$ Wenn in dieser Arbeit von einer "transkonfessionellen Verflechtungsgeschichte« die Rede ist, so beinhaltet dieser Terminus diese beiden Bedeutungshorizonte.

schichte, in: KZG 22 (1) (2009), S. 187-210; sowie ders., Polyzentrische Strukturen der globalen Christentumsgeschichte, in: Richard FriedLi u.a. (Hg.), Intercultural Perceptions and Prospects of World Christianity, Frankfurt a. M. 2010, S. 105-126.

17 Dazu siehe v.a.: Sebastian Conrad/Shalini Randeria, Geteilte Geschichten. Europa in einer postkolonialen Welt, in: Dies. (Hg.), Jenseits des Eurozentrismus. Postkoloniale Perspektiven in den Geschichts- und Kulturwissenschaften, Frankfurt a. M. u.a. 2002, S. 9-49; Gunilla BudDE u.a. (Hg.), Transnationale Geschichte. Themen, Tendenzen und Theorien, Göttingen ${ }^{2} 2010$; Agnes Arndt u. a. (Hg.), Vergleichen, verflechten, verwirren? Europäische Geschichtsschreibung zwischen Theorie und Praxis, Göttingen 2011; Alexander-Kenneth NAGEL, Urbi et Orbi. Transnationale religiöse Netzwerke, in: Martina Maletzky u.a. (Hg.), Arbeit, Organisation und Mobilität. Eine grenzüberschreitende Perspektive, Frankfurt a. M. 2013, S. 133155; Bernhard STRUCK u. a., Introduction. Space and Scale in Transnational History, in: IHR 33 (4) (2011), S. 573-584; Thies Schulze, Einleitung, in: Ders./ Christian MülleR (Hg.) Grenzüberschreitende Religion. Vergleichs- und Kulturtransferstudien zur neuzeitlichen Geschichte, Göttingen 2013, S. 9-25.

18 So entspricht der Begriff "Konfession «, dessen Ursprünge im frühneuzeitlichen Lateineuropa liegen, aufgrund seiner historischen Bedingtheit nicht dem ekklesiologischen Selbstverständnis der orthodoxen Kirchen. Die Anwendung dieses Begriffs in Bezug auf die Äthiopisch-Orthodoxe Kirche wird im Kapitel III.3 »Erfindung einer Konfession: Konstruktionen des äthiopischen `Bekenntnisses« « problematisiert und ausführlich besprochen.

19 Vgl. Thomas Kaufmann, Einleitung. Transkonfessionalität, Interkonfessionalität, binnenkonfessionelle Pluralität. Neue Forschungen zur Konfessionalisierungsthese, 
Die Arbeit möchte anhand eines exemplarischen Fallbeispiels eruieren, auf welche Weise konfessionell und kulturell divergente Varianten des Christentums in der longue durée kontinentübergreifend miteinander verflochten waren. Die Wahl von Verflechtungen von äthiopischer Orthodoxie und europäischem Protestantismus als Untersuchungsgegenstand ist nicht zufällig und scheint gerade in Bezug auf die obengenannte Fragestellung besonders fruchtbar zu sein, da es sich dabei um zwei sowohl geografisch als auch dogmenhistorisch weit voneinander entfernte Christentumsformationen handelt.

Der Forschungsansatz der Histoire croisée bietet ein besonders gut ausgearbeitetes methodisches Instrumentarium für die Erfassung verflechtungsgeschichtlicher Phänomene ${ }^{20}$ und lässt sich erkenntnisgewinnend auf den Forschungsgegenstand der Studie anwenden. In Anlehnung daran wird die Verflechtungsgeschichte von äthiopischer Orthodoxie und europäischem Protestantismus im Folgenden mit Hilfe variabler Blickwinkel und Untersuchungsmaßstäbe analysiert. Eine solche Variabilität der Analysedimensionen ist integraler Bestandteil des Erkenntnisprozesses. ${ }^{21} \mathrm{Ihr}$ entscheidender Vorteil liegt darin, dass durch die Variation der Perspektiven und Sichtweisen die Aufmerksamkeit stärker als bisher auf Asymmetrien gelenkt wird. Zudem lassen die Multiperspektivität und Variabilität der Analyseeinheiten jeweils neue Eigenschaften der Verflechtungen erkennen, deren Kontraste wiederum in die historische Analyse zu integrieren sind. ${ }^{22}$ So wird sichtbar, dass sich die Entwicklungen auf den verschiedenen Ebenen verschränken, was dazu führt, dass die jeweiligen historischen Akteure je nach Zeitpunkt neu gefasst werden müssen. Sie können darum nicht mehr getrennt oder für sich allein analysiert werden.

in: Kaspar von Greyerz u.a. (Hg.), Interkonfessionalität - Transkonfessionalität binnenkonfessionelle Pluralität. Neue Forschungen zur Konfessionalisierungsthese, Heidelberg 2003, S. 9-15, hier S. 14f.; Peter Šoltés, Migration und konfessionelle Pluralität an der nordöstlichen Peripherie des Königreichs Ungarn im 17. und 18. Jahrhundert, in: Gertraud Marinelli-König / Alexander Preisinger (Hg.), Zwischenräume der Migration. Über die Entgrenzung von Kulturen und Identitäten, Bielefeld 2011, S. 157-175, hier S. 161.

20 Vgl. Michael Werner / Bénédicte Zimmermann, Vergleich, Transfer, Verflechtung. Der Ansatz der Histoire croisée und die Herausforderung des Transnationalen, in: GeGe 28 (2002), S. 607-636; dies., Beyond Comparison. Histoire Croisée and the Challenge of Reflexivity, in: HTh 45 (2006), S. 30-50; sowie Michael Werner, Kulturtransfer und Histoire croisée. Zu einigen Methodenfragen der Untersuchung soziokultureller Interaktionen, in: Stephan Braese/Ruth Vogel-KleiN (Hg.), Zwischen Kahlschlag und Rive Gauche. Deutsch-französische Kulturbeziehungen 1945-1960, Würzburg 2015, S. 21-42.

21 Vgl. Werner/Zimmermann, Vergleich, Transfer, Verflechtung, S. 627.

22 Vgl. ebd. 
Diese methodische Vorgehensweise schlägt sich im Aufbau der Untersuchung nieder. So nähert sich jedes der vier Kapitel je einem ausgewählten Teilaspekt der Verflechtungsgeschichte äthiopischer Orthodoxie und europäischem Protestantismus an: den ersten verflechtungsgeschichtlichen Verknüpfungen im Zeitalter der Reformation; dem Transfer des äthiopischorthodoxen theologischen Wissens in die frühneuzeitigen protestantischen Theologien; den Differenzaushandlungen im Kontext der Mission sowie den politischen Theologien. Dabei werden jeweils unterschiedliche zeitliche Analysedimensionen angewandt: Diese reichen von einer mikrohistorischen Fokussierung auf einen einzigen Tag (den 27. Februar 1905) bis zu einer makrohistorischen Betrachtung der gesamten Frühen Neuzeit. Mit Hilfe der Verflechtung dieser Untersuchungsebenen untereinander soll die Komplexität der Interdependenzen von äthiopischer Orthodoxie und europäischem Protestantismus in ihrer historischen Dynamik sichtbar gemacht werden.

Das Ziel der Untersuchung ist folglich nicht nur, die Aufmerksamkeit auf die Überschneidungen und gemeinsamen Anteile bislang getrennt untersuchter Christentumsvarianten zu lenken, sondern vielmehr auch, ihre wechselseitige Bedingtheit exemplarisch herauszuarbeiten. 


\section{II. Äthiopische Mönche und europäische Reformatoren (1534)}

\section{Primäre Fäden einer Verflechtungsgeschichte: Begegnungen mit dem Anderen}

Zunächst gilt es, die Anfänge der Interaktion zwischen äthiopischer Orthodoxie und europäischem Protestantismus nachzuzeichnen. Anstatt jedoch eine historische Episode zum Ausgangspunkt der Geschichtsschreibung zu nehmen, sollen im Folgenden multiple Fäden aufgezeigt werden, deren Verschränkung ineinander eine Verflechtungsgeschichte erst konkret macht.

Als Analysedimension wird dabei das Jahr 1534 gewählt, in welches sich die ersten Berührungen dieser zwei Varianten des Christentums datieren lassen. In einem ersten Schritt sollen jene Vorgänge - sie werden als primäre Fäden bezeichnet - analysiert werden, bei denen das äthiopische Christentum und der Protestantismus, sei es durch persönliche Begegnungen oder durch das Medium des Texts, miteinander in Verbindung kamen. In einem zweiten Schritt werden jene Ereignisse - an dieser Stelle ist von sekundären Fäden die Rede - untersucht, die zwar 1534 stattfanden, deren Einfluss auf den Verlauf äthiopisch-europäischer Interaktion sich allerdings erst in den Folgejahrzehnten oder sogar -jahrhunderten bemerkbar machte.

\subsection{Persönliche Begegnungen mit dem Anderen:} Abba Mika ${ }^{\top} e l$ und die Wittenberger Reformatoren

Im Gegensatz zu der verbreiteten These, dass Äthiopien im Laufe der Jahrhunderte von der restlichen christlichen Welt isoliert gewesen sei, waren äthiopische Christen durchaus keine ganz seltenen Gäste im Europa des späten Mittelalters. Spätestens ab dem 14. Jahrhundert reisten Äthiopier immer wieder nach Europa und nahmen mehrfach Kontakt zu europäischen Reichen sowie zum Stuhl Petri auf. ${ }^{1}$

In der lateineuropäischen Wahrnehmung des frühen 16. Jahrhunderts war Äthiopien mit dem Land des legendären Priesterkönigs Johannes asso-

1 Siehe dazu: Matteo Salvadore, The African Prester John and the Birth of Ethiopian-European Relations. 1402-1555, London u. a. 2017; ders., The Ethiopian Age of Exploration. Prester John's Discovery of Europe. 1306-1458, in: Journal of World History 21 (4) (2011), S. 593-627. 
ziiert. ${ }^{2}$ Dieses Bild, das tief in der europäischen Imaginationsgeschichte verwurzelt war, hatte mit den gelebten Realitäten des nordostafrikanischen Reiches zwar kaum etwas gemein, verschaffte jedoch den nach Europa reisenden Äthiopiern einige Vorteile: Als vermeintliche Untertanen des Priesterkönigs Johannes, eines mächtigen und geachteten christlichen Herrschers, wurden sie nicht nur toleriert, sondern vielmehr mit großem Respekt behandelt. ${ }^{3}$ In diesen Kontext lässt sich auch jenes außergewöhnliche Ereignis einordnen, das sich im Jahre 1534 in Wittenberg abspielte.

Am 31. Mai 1534 traf in Wittenberg ein äthiopischer Mönch ein, um Kontakt zu den Reformatoren Martin Luther und Philipp Melanchthon (1497-1560) aufzunehmen. Über dieses unerwartete Vorkommnis berichtete Melanchthon am gleichen Tag in einem Brief an seinen Freund, den Wittenberger Juristen Benedikt Pauli (1490-1552). ${ }^{4}$ Aus den vorhandenen Quellen lässt sich folgendes Bild der Begegnung zwischen dem äthiopischen Geistlichen, der $A b b a$ Mika ${ }^{\circ}$ l hieß, und den Wittenberger Reformatoren rekonstruieren: Trotz anfänglicher Kommunikationsschwierigkeiten Melanchthon musste einen der Wittenberger Gelehrten als Dolmetscher engagieren - sprach Abba Mika ${ }^{\mathrm{e}} \mathrm{el}$ mit Luther bereits beim ersten Treffen über die Trinitätslehre und fiel als homo ingeniosus auf. ${ }^{5}$ In Wittenberg blieb $A b b a$ Mika el bis zum 4. Juli 1534. Die beiden Reformatoren waren während fast des gesamten Aufenthalts Abba Mika ${ }^{3}$ els vor $\mathrm{Ort}^{6}$ und trafen sich mit dem äthiopischen Gast wiederholt zu theologischen Gesprächen. Vor der Abreise des äthiopischen Mönchs stellten die Wittenberger Reformatoren ihm sogar ein förmliches Empfehlungsschreiben aus [siehe Abbildung 1].

2 Zum Mythos vom Priesterkönig Johannes (Lat. Pres[by]ter Iohannes), einem mächtigen christlichen Herrscher, der über ein sich inmitten der Muslimen und Heiden befindendes Reich regiere, siehe: Wilhelm BAum, Die Verwandlungen des Mythos vom Reich des Priesterkönigs Johannes. Rom, Byzanz und die Christen des Orients im Mittelalter, Klagenfurt 1999; Lew Gumilev, Searches for an Imaginary Kingdom. The Legend of the Kingdom of Prester John, Cambridge 1987; Gianfranco Fiaccadori, Prester John, in: EAE 4, 2010, S. 209-216. Die geografische Lokalisierung dieses märchenhaften Reiches war in der Geschichte der europäischen, spätmittelalterlichen Imagination durchaus unbeständig: Während man den Priesterkönig zunächst in Asien suchte, mehrten sich seit Mitte des 13. Jahrhunderts die Behauptungen, dass sein Land in Afrika zu finden sei.

3 Vgl. Samuel Asghedom, Contributo dell'Ospizio di Santo Stefano degli Abissini agli studi etiopici in Europa, in: IV Congresso Internazionale di Studi Etiopici (Roma, 10-15 April 1972), Roma 1974, Bd. 1, S. 389-404, hier S. 393.

4 Brief Melanchthons an Benedikt Pauli vom 31. Mai 1534. MBW.T 6, 2005, S. 99 f. Vgl. auch Philipp Melanchthon, CR 2, 1835, S. 730f. Siehe den Brieftext im Anhang.

5 Ders., MBW.T 6, 2005, S. 100.

6 Die einzige Ausnahme stellen die wenigen Tage dar, die sie vom 3. bis 8. Juni 1534 in Dessau verbrachten. Vgl. Martin Luther, WA 59, 1983, S. 351 sowie Philipp Melanchthon, MBW 10, 1998, S. $426 f$. 
EPISTOLE DOCTORIE AARTSLNS LV́THERI.

\section{EPISTOLA COMMENDATICIA D. M. LVTHERI.} DRTA CVIDAM ATIOPI.

Fuit. nobifoum in Germania D $\overline{\overline{n s}}$ Michael Ftiops dia, + conus, cuim güs doctrina Chrifiana familiariter collo, quentes audiuimus eum cuim symbolo, quiod habet Fcile, fia occidentalis recte comiemire. Nec de rinitate aliter fentive quam qüod fentit toclefur occidentalis. doleo quantiom nos quidem possumus, commendamus boms niris. Nam ehamfi Ecolefia orientalis habet aliquäs difsimiles caremomias. Iple qüsq ridicat, quor difsimilitudo earum non tollat umitatem Ecclefiae, nec puenat cuim fide. Ouia regnim chrift eft spiritia," lis iuftitia Cordis, timor Dei et frolucia per chrighum. Hare fentertiam et ros probanus. Comperimus etiam ex eo, quod ritüs, quem nos obferuamüs in ù ü cena Domnim et mijsa Coniünt cuim onientali Ecclefia. Op" tamüs autem üt omnes pentes aprofiant et plorifi; cent Chriftim, et ei obediant wera fúucua mifenior. dice ipfius et dilectione proximi. Ideo rocamus bonos curos, ut chrifianam ditectionem et huic hospitipre, pare uelint. Data Wittenberpe vonas July. Anno is 34

Martinus Lüherus

$$
\text { Gratian }
$$

Abb. 1: Martin Luthers Empfehlungsschreiben für Abba Mikael. Herzog August Bibliothek Wolfenbüttel: Cod. Guelf. 107 Helmst., fol. 10v 
Testimonium datum cuidam Aethiopi a d[omino] Mart[ino] Luth[ero]. $\Phi[i ́ \lambda \iota \pi \pi \circ \varsigma]$ $\mathrm{M}[$ elanthon] f[ecit].

Fuit nobiscum in Germania dominus Michael, Aethiops diaconus, cum quo de doctrina christiana familiariter colloquentes audivimus eum cum symbolo, quod habet ecclesia occidentalis, recte convenire nec de trinitate aliud sentire, quam quod sentit ecclesia occidentalis. Ideo, quantum nos quidem possumus, commendamus eum bonis viris. Nam etsi orientalis ecclesia habet aliquas dissimiles ceremonias, ipse quoque iudicat, quod dissimilitudo earum non tollat unitatem ecclesiae nec pugnet cum fide, quia Christi regnum est spiritualis iustitia cordis, timor dei et per Christum fiducia. Hanc sententiam et nos probamus. Comperimus etiam ex eo, quod ritus, quem nos observamus in usu coenae domini et missa, convenit cum orientali ecclesia. Optamus autem, ut omnes gentes agnoscant et glorificent Christum et ei obediant vera fiducia misericordiae ipsius et dilectione proximi. Ideo rogamus bonos viros, ut christianam dilectionem et huic hospiti praestare velint. Witeb[ergae] 1534, 4. Non[as] Iulii.

Martinus Lutherus ${ }^{7}$

Empfehlungsschreiben, gegeben einem Äthiopier von Herrn Martin Luther. Verfasst

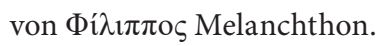

Herr Michael, ein äthiopischer Diakon, war bei uns in Deutschland. Als wir uns mit ihm freundlich über die christliche Glaubenslehre austauschten, hörten wir, dass er dem Glaubensbekenntnis, den die abendländische Kirche hat, gleichförmig denke und über die Trinität keine andere Meinung hege als die abendländische Kirche.

7 Der Text des Empfehlungsschreibens ist nach der kritischen Gesamtausgabe von Melanchthons Briefwechsel wiedergegeben: Melanchthon, MBW.T 6, 2005, S. 123f. Siehe den textkritischen Apparat dort. Vgl. auch die anderen Ausgaben: Johannes Manlius (Hg.), Epistolarum D. Philippi Melanchthonis Farrago, Basel 1565, S. 367f.; Gottfried Schütze (Hg.), D. Martin Luthers bisher ungedruckte Briefe, Leipzig 1781, Bd. 2, S. 319f.; Wilhelm Martin Leberecht de Wette (Hg.), Dr. Martin Luthers Briefe, Sendschreiben und Bedenken, vollständig aus den verschiedenen Ausgaben seiner Werke und Briefe, aus andern Büchern und noch unbenutzten Handschriften gesammelt, kritisch und historisch bearbeitet, Berlin 1827, Bd. 4, S. 550; Melanchthon, CR 2, 1835, S. 737; Carolus Gottlieb Bretschneider (Hg.), Philippi Melanthonis opera quae supersunt omnia, Halle (Saale) 1835, S. 737; Ludwig EndERS (Hg.), Dr. Martin Luther's Briefwechsel. Briefe vom Februar 1534 bis Juli 1536, Frankfurt a. M. 1903, Bd. 10, S. 60f.; Martin Luther, WA.B 7, 1937, S. 86. Für einen Überblick über die zahlreichen von Melanchthon verfassten Empfehlungsschreiben siehe: Christiane Mundhenk, Briefe, in: Günter Frank (Hg.), Philipp Melanchthon. Der Reformator zwischen Glauben und Wissen. Ein Handbuch, Berlin u.a. 2017, S. 303-319, hier S. 312f. 
Daher empfehlen wir ihn, so viel an uns ist, guten Menschen. Denn obgleich die morgenländische Kirche einige abweichende Bräuche beobachtet, so urteilt er doch, dass dieser Unterschied weder die Einheit der Kirche aufhebt noch mit dem Glauben streitet, weil das Reich Christi geistliche Gerechtigkeit des Herzens, Gottesfurcht und Vertrauen durch Christus ist. Diese Ansicht billigen auch wir. Wir erfuhren von ihm auch, dass der Ritus, den wir beim Mahl des Herrn und bei der Messe befolgen, mit der morgenländischen Kirche übereinkommt. Wir wünschen jedoch, dass alle Völker Christus erkennen und verherrlichen, und ihm durch wahres Vertrauen in seine Barmherzigkeit und durch Nächstenliebe gehorchen. Darum bitten wir alle guten Menschen, dass sie auch diesem Fremdling christliche Liebe erweisen mögen. Wittenberg, den 4. Juli 1534.

Martin Luther ${ }^{8}$

Dieses Schreiben dokumentiert einen in vielerlei Hinsicht bemerkenswerten theologischen Dialog. Auf die Analyse dessen Inhalte wird noch einzugehen sein. ${ }^{9}$ Die Tatsache, dass der äthiopische Mönch sich ein Empfehlungsschreiben erstellen ließ, deutet darauf hin, dass $A b b a$ Mika ${ }^{2}$ l weitere Kontakte zu den Vertretern der Reformation suchte. Einem Brief Melanchthons ist zudem zu entnehmen, dass der äthiopisch-orthodoxe Mönch beabsichtigte, nach Straßburg zu reisen, um sich dort mit dem elsässischen Reformator Martin Bucer (1491-1551) zu treffen. ${ }^{10}$ Ob diese Pläne verwirklicht wurden, ist nicht bekannt. Es kann jedoch festgehalten werden, dass der monachus Aethiops einen bleibenden Eindruck auf die Wittenberger Reformatoren machte. Noch Jahre später erinnerten sich sowohl Luther als auch Melanchthon an die Begegnung mit Abba Mika $^{3} \mathrm{el}^{11}$

Wer war aber dieser äthiopische Mönch, und wie kam er nach Wittenberg? Die an den Petersdom angrenzende Kirche Santo Stefano dei Mori (beziehungsweise Santo Stefano degli Abissini), die den äthiopischen Pilgern bereits

8 Übersetzung - S.P.

9 Siehe Kapitel II.3 »Themenfelder eines proto-ökumenischen Dialogs zwischen Abba Mika ${ }^{\top}$ l und Martin Luther«.

10 Vgl. Brief Melanchthons an Martin Bucer vom 4. Juli 1534, in welchem er den nach Frankreich reisenden Abba Mika ${ }^{\circ} e l$ empfiehlt: »[Zu streichen vergessen: S. D. Fuit hic nobiscum Aethiops homo cupidus cognoscend(i).] S. D. Hic hospes mirabili studio tenetur cognoscendi varias nationes. Fuit itaque nobiscum et, cum familiariter multa de relligione et doctrina christiana collocuti essemus, visus est non abhorrere a studio pietatis. Ideo dedi hoc epistolium roganti et commendo eum tibi, mi Bucere, commendandum etiam aliis fatribus. Videre cupit Galliam. Melanthon«. MELANCHTHON, MBW.T 6, 2005, S. 122.

11 Siehe die Tischreden Nr. 4126 und Nr. 6035 in Martin Luther, WA.TR 4, 1916, S. 152f.; ders., WA.TR 5, 1919, S. 450f. 
ab den 1480er Jahren als wichtigste Anlaufstelle und Herberge gedient hatte, entwickelte sich zu einem bedeutendem Zentrum des äthiopisch-orthodoxen intellektuellen Lebens und erhielt 1515 den formellen Status einer äthiopisch-orthodoxen Klostergemeinschaft. ${ }^{12}$ Dieses Kloster bildete zusammen mit anderen äthiopischen Diaspora-Gemeinden im Mittelmeerraum - vor allem in Kairo, Jerusalem und Nikosia - ein Netzwerk, das die zunehmende Wissenszirkulation und Mobilität zwischen Nordostafrika und Europa im ersten Drittel des 16. Jahrhunderts erheblich begünstigte. ${ }^{13}$

$\mathrm{Da} A b b a$ Mika ${ }^{\mathrm{e}}$ sich laut Melanchthons Angaben in gebrochenem Italienisch verständigen konnte (dabei jedoch weder der griechischen noch der lateinischen Sprache mächtig war), ${ }^{14}$ ist es anzunehmen, dass er eine

12 Vgl. Gianfranco Fiaccadori, Santo Stefano dei Mori, in: EAE 4, 2010, S. 528-532; Sebastian Euringer, San Stefano dei Mori (Vatikanstadt) in seiner Bedeutung für die abessinische Sprachwissenschaft und Missionsgeschichte, in: OrChr 32 (3) (1935), S. 38-59; Mauro DA Leonessa, Santo Stefano Maggiore degli Abissini e le relazioni romano-etiopiche, Vatican 1929; Marius CHAîne, Un monastère éthiopien à Rome au XVe et XVIe siècle, in: MFOB 5 (1911), S. 1-36; Sylvain GrÉBAUt, Contribution à l'histoire du couvent éthiopien San-Stefano-dei-Mori, in: ROC 26 (3) (1927-1928), S. 211-218; ders., La règle de Santo Stefano dei Mori, in: ROC 27 (3) (1929-1930), S. 214-219.

$13 \mathrm{Zu}$ Reisen der Äthiopier nach Europa im 16. Jahrhundert sowie zu äthiopischen Diaspora-Gemeinden in Europa siehe: James De Lorenzi, Red Sea Travelers in Mediterranean Lands. Ethiopian Scholars and Early Modern Orientalism, ca. 1500-1668, in: Allison B. KAVEY (Hg.), World-Building and the Early Modern Imagination, New York 2010, S. 173-200; Samantha Kelly, Medieval Ethiopian Diasporas, in: Dies. (Hg.), A Companion to Medieval Ethiopia and Eritrea, Leiden u. a. 2020, S. 425-453, hier S. 427-441; Gianfranco FIACCAdori, Venezia, l'Etiopia e l'Europa, in: Giuseppe BARBIERI / Gianfranco FiACCADORI (Hg.), »Nigra sum sed formosa «. Sacro e bellezza dell'Etiopia cristiana, Crocetta del Montello 2009, S. 27-48; Samantha Kelly / Denis Nosnitsin, The Two Yohannəses of Santo Stefano degli Abissini, Rome. Reconstructing Biography and Cross-Cultural Encounter through Manuscript Evidence, in: Manuscript Studies: A Journal of the Schoenberg Institute for Manuscript Studies 2 (2) (2017), S. 392-426. Als bleibendes Denkmal des intellektuellen Austausches zwischen den europäischen Geistlichen und den in Santo Stefano dei Mori lebenden äthiopischen Mönchen kann die 1513 auf Gəcəoz gedruckte Inkunabel des äthiopischen Psalters gelten. Das Werk war Frucht der gemeinsamen Arbeit des deutschen Klerikers Johannes Potken (ca. 1470-1524) und des Abba Tomas Wäldä

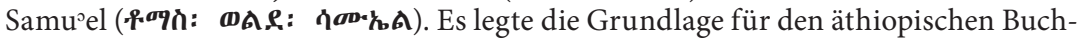
druck und war die erste in Europa gedruckte Schrift in einer anderen orientalischen Sprache als dem Hebräischen. Johannes Potкen (Hg.), Psalterium Davidis et Cantica aliqua. Canticum canticorum, Romae 1513. Vgl. Michael Matheus, „Sola fides sufficit«. >Deutsche (Akademiker und Notare in Rom 1510/1512, in: Ders. u.a. (Hg.), Martin Luther in Rom. Die Ewige Stadt als kosmopolitisches Zentrum und ihre Wahrnehmung, Berlin 2017, S. 379-405, hier S. 397-404; Anna-Dorothee von den Brincken, Johann Potken aus Schwerte, Probst von St. Georg in Köln, der erste Äthiopologe des Abendlandes, in: Hans BLum (Hg.), Aus kölnischer und rheinischer Geschichte, Köln 1969, S. 81-115.

14 Brief Melanchthons an Benedikt Pauli vom 31. Mai 1534. Melanchthon, MBW.T 6, 2005, S. 99f. Siehe den Brieftext im Anhang. 
längere Zeit in einer italienischsprachigen Umgebung verbrachte. Höchstwahrscheinlich gehörte er der äthiopischen Klostergemeinschaft in Rom an. Ein weiteres Indiz für diese Hypothese liefert das Manuskript "Vat. et. 47« der Biblioteca Apostolica Vaticana, das früher zum Bestand des äthiopischorthodoxen Klosters in Rom gehörte. ${ }^{15}$ Auf fol. 215a, am Ende dieser im 15. Jahrhundert hergestellten Handschrift, gibt es einen Nachtrag späteren Datums, der einen gewissen Mika ${ }^{\circ}$ l aus dem äthiopisch-orthodoxen Kloster

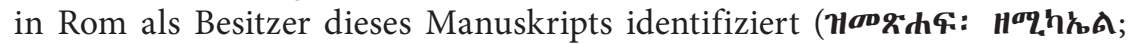
Zəmäsh̆äf zämika el) [siehe Abbildung 2]. Angesichts der Tatsache, dass die gesamte Klostergemeinschaft in den 1520er und 1530er Jahren aus nur fünf bis 40 Mönchen bestand (diese Zahl schwankte stets) ${ }^{16}$ ist es durchaus vorstellbar, dass dieser Mika ${ }^{\circ}$ el mit dem äthiopischen Diakon, der Wittenberg besucht hat, identisch ist. Darauf deutet zudem die Zusammensetzung des

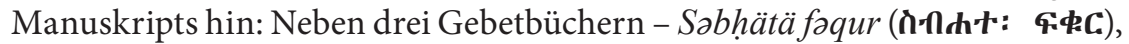

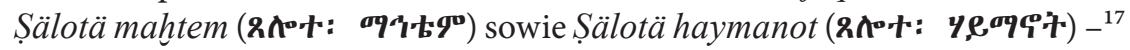
enthielt es das Johannesevangelium und die Johannesoffenbarung. Wie später zu zeigen sein wird, spielten gerade die eschatologischen Vorstellungen eine hervorgehobene Rolle im Weltbild von $A b b a$ Mika $^{3} \mathrm{el}^{18}$

Der theologische Dialog von Abba Mika ${ }^{\supset}$ l mit den Wittenberger Reformatoren, der bis heute weitgehend unberücksichtigt geblieben ist, ${ }^{19}$ gibt Anlass dazu, gleich zwei als wissenschaftlicher Konsens geltende Annahmen radikal zu revidieren. So wird bei der Frage nach der ersten Begegnung des Protestantismus mit dem äthiopischen Christentum in der Regel angegeben, dass diese 1636 stattfand, als der Lübecker Lutheraner Peter Heyling

15 Vgl. Sylvain Grébaut/Eugène Tisserant, Bybliothecae apostolicae Vaticanae codices manu scripti recensiti iussu Pii XI Pontificis maximi, Codices Aethiopici Vaticani et Borgiani, Barberinianus orientalis 2, Rossianus 865, Città del Vaticano 1935, Bd. I: Enarratio codicum, S. 199-201.

16 Vgl. Da Leonessa, Santo Stefano, S. 185-188.

17 Vgl. Навтеmichael Kidane, Səbhätä Fəqur, in: EAE 4, 2010, S. $589 f$.

18 Siehe Kapitel II.3.3 »Ekklesiologie«.

19 Unter Kirchenhistorikern stellen diesbezüglich Martin Brecht und Tom G. A. Hardt eine Ausnahme dar. Jedoch erwähnen sie die Begegnung von Martin Luther und Abba Mika ${ }^{\supset}$ l nur flüchtig und gehen nicht näher auf sie ein. Vgl. Martin BRECHT, Martin Luther, Stuttgart 1987, Bd. 3: Die Erhaltung der Kirche: 1532-1546, S. 67; Tom G. A. Hardt, The Confessional Principle. Church Fellowship in the Ancient and in the Lutheran Church, in: Logia. A Journal of Lutheran Theology VIII (2) (1999), S. 21-30, hier S. 27. Des Weiteren machte neulich David Daniels auf dieses Treffen aufmerksam und hob dessen außergewöhnliche Bedeutung für die kirchenhistorischen Studien etwas zugespitzt hervor: »I believe the dialogue between Luther and Michael the Deacon is historically significant. For historical studies, it might be on par with the colloquy between Luther and Zwingli«. David Daniels, Luther and Ethiopian Christianity, in: Frieder Ludwig u.a. (Hg.), Reformation in the Context of World Christianity. Theological, Political and Social Interactions between Africa, Asia, the Americas and Europe, Wiesbaden 2019, S. 21-31, hier S. 28. 
(ca. 1607-1652) Äthiopien erreichte. ${ }^{20}$ Es lässt sich jedoch dementgegen feststellen, dass die erste dokumentierte Zusammenkunft von Vertretern dieser Kirchengemeinschaften unmittelbar in die Zeit Luthers zurückreicht und nicht europäischer, sondern äthiopischer Initiative zu verdanken war. Diese Tatsache stellt das gängige Narrativ über die Frühe Neuzeit als die Epoche der exklusiv von Europäern betriebenen »Entdeckung« der Welt infrage und veranschaulicht zudem die Mehrdimensionalität schon der frühneuzeitlichen Globalisierungsprozesse innerhalb des Christentums.

Des Weiteren erweitert dieses Treffen den Wissensstand über die Beziehungen der Reformatoren zum östlichen beziehungsweise orientalischen Christentum. Bisher trägt die Lutherforschung vor, dass der Wittenberger Reformator sich zwar gelegentlich in seiner Polemik gegen die Theologen der römischen Kirche zur Begründung seiner Lehre auf das Zeugnis und die Praxis der orthodoxen Kirchen berufen, doch selbst keine persönlichen Kontakte zu den orthodoxen Christen gehabt habe. ${ }^{21}$ Die These des Berliner

20 Siehe bspw.: Gustav ArÉn, Evangelical Pioneers in Ethiopia. Origins of the Evangelical Church Mekane Yesus, Stockholm 1978, S. 34; Ernst Hammerschmidt, Die äthiopistischen Studien in Deutschland (von ihren Anfängen bis zur Gegenwart), in: AEt 6 (1) (1965), S. 255-277, hier S. 255; Donald Crummey, Priests and Politicians. Protestant and Catholic Missions in Orthodox Ethiopia. 1830-1868, Oxford 1972, S. 10; David D. Grafton, Piety, Politics, and Power. Lutherans Encountering Islam in the Middle East, Eugene 2009, S. 153. Von dieser Periodisierung weicht jedoch Friedrich Heyer ab, der solch eine erste Begegnung früher datiert, und zwar auf das Jahr 1575, als der lutherische Naturforscher und Arzt Leonhard Rauwolf (1535-1596) bei seiner Orientreise das äthiopische Kloster Dayr as-Sulțān (Arabisch: دير السلطان; Gəcəz:

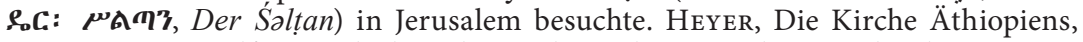
S. 308. Zu Rauwolfs Besuch des äthiopischen Klosters siehe: Leonhard RAUWOLF, Aigentliche beschreibung der Raiß, so er vor diser Zeit gegen Auffgang inn die Morgenländer, fürnemlich Syriam, Judaeam, Arabiam, Mesopotamiam, Babyloniam, Assyriam, Armeniam selbs volbracht, Augsburg 1583, S. 422-426. Siehe auch: Karl Dannenfeldt, Leonhard Rauwolf. A Lutheran Pilgrim in Jerusalem. 1575, in: ARG 55 (1) (1964), S. 18-36, hier S. 30.

$21 \mathrm{Zu}$ Luthers Stellung zu den orthodoxen Kirchen und deren Rolle in seinen Auseinandersetzungen mit Rom siehe folgende Studien, die jedoch allesamt fälschlicherweise auf der Annahme beruhen, dass Luther keine orthodoxen Christen kannte: Dorothea Wendebourg, Reformation und Orthodoxie. Der ökumenische Briefwechsel zwischen der Leitung der Württembergischen Kirche und Patriarch Jeremias II. von Konstantinopel in den Jahren 1573-1581, Göttingen 1986, S. 18-24; Daniel BENGA, David Chytraeus (1530-1600) als Erforscher und Wiederentdecker der Ostkirchen. Seine Beziehungen zu orthodoxen Theologen, seine Erforschungen der Ostkirchen und seine ostkirchlichen Kenntnisse, Giessen ${ }^{2} 2012$, S. 45-50; Johannes KARMIRIS, Luther und Melanchthon über die Orthodoxe Kirche (I), in: Kyrios 6 (2) (1966), S. 77-104; ders., Luther und Melanchthon über die Orthodoxe Kirche (II), in: Kyrios 6 (3) (1966), S. 150-173; Oskar WAGNER, Luther - Osteuropa und die griechisch-orthodoxe Kirche, in: Kyrios 4 (1964), S. 69-90; Viorel Mehedintu, Martin Luther und die Ostkirche, in: ÖR 32 (1983), S. 291-309; Ernst BEnZ, Die östliche Orthodoxie und das kirchliche Selbstbewußtsein der Reformation, in: Ders. / Lev Zander (Hg.), Evangelisches und orthodoxes Christentum in Begegnung und Auseinandersetzung, Ham- 


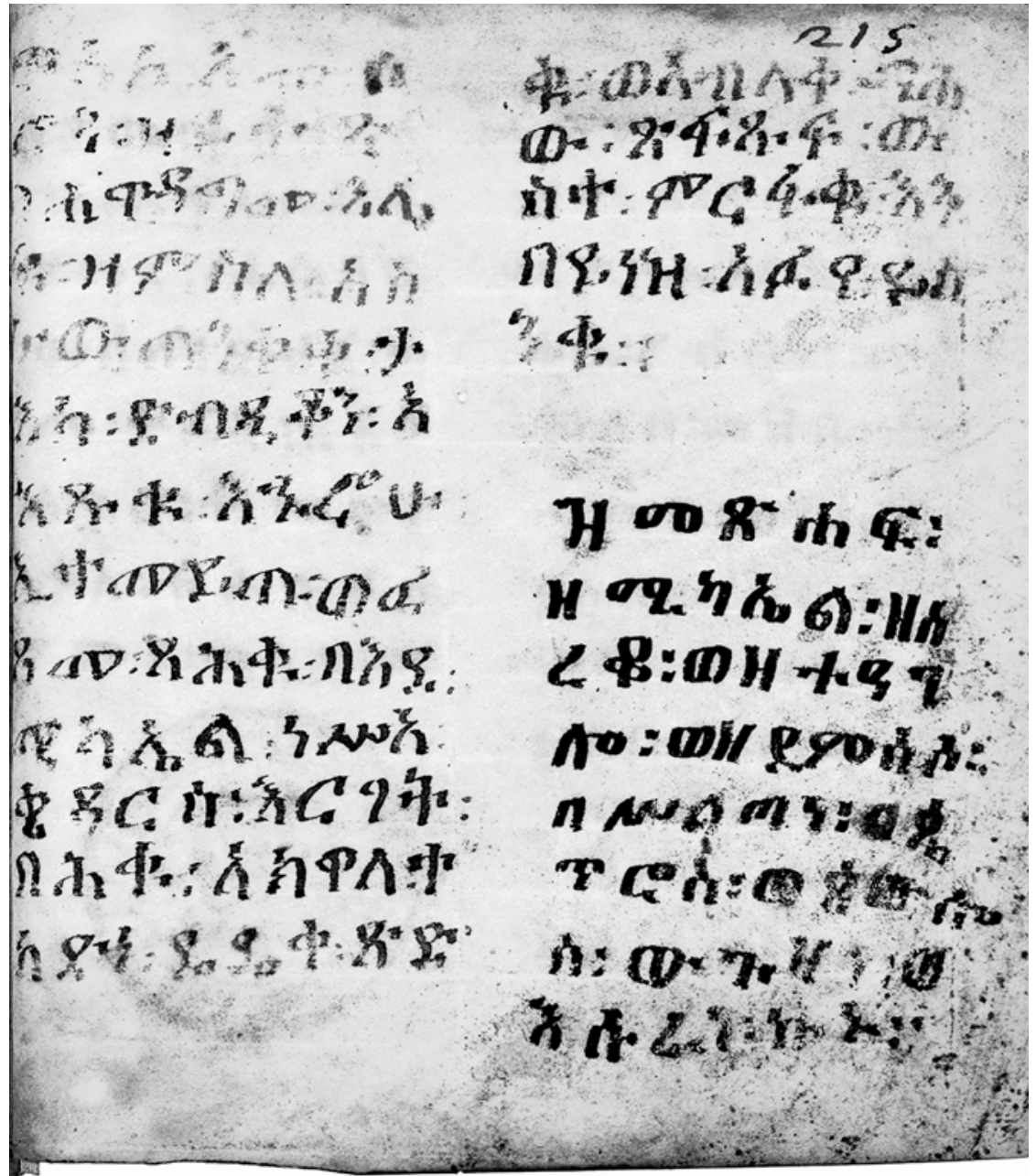

Abb. 2: Manuskript aus dem äthiopisch-orthodoxen Kloster in Rom mit der Angabe, dass es Mika el gehört. Biblioteca Apostolica Vaticana: Manuskript Vat. et. 47, fol. 215r 
Kirchenhistorikers Hans-Dieter Döpmann, die er in Bezug auf die internationale Vernetzung Luthers in den 1980er Jahren formulierte - „Viele Ausländer besuchten ihn [Luther], aber keine Orthodoxen «,$-{ }^{22}$ blieb bis heute unwidersprochen. ${ }^{23}$ Auch in den neueren Untersuchungen wird der Ausgangspunkt der orthodox-protestantischen Interaktion bei Melanchthon, und zwar erst in den 1540er Jahren, gesucht. ${ }^{24}$ In ähnlicher Weise wird wie selbstverständlich von der Annahme ausgegangen, dass Luther zeit seines Lebens keinerlei Kontakte zu Afrikanern gehabt habe. ${ }^{25}$ Die Begegnung der Wittenberger Reformatoren mit $A b b a$ Mika $^{3}$ el widerlegt diese Gewissheiten und eröffnet einen neuen Zugang zu diesen beiden Themenkomplexen.

burg 1952, S. 101-160; Theodor NikolaOU, Die orthodox-lutherischen Beziehungen im 16. Jahrhundert, in: ÖI 14/15 (1980), S. 7-10 sowie Vasilică Mugurel PĂVĂLUCĂ, Einige schriftliche Verweise Martin Luthers auf die Ostkirche, in: Review of Ecumenical Studies Sibiu 9 (3) (2017), S. 360-370.

22 Hans-Dieter Döpmann, Das Verhältnis Luthers und der Lutheraner zu den orthodoxen Kirchen, in: ThLZ 109 (5) (1984), S. 321-334, hier S. 323.

23 Zwar wurde spekuliert, ob ein Gelehrter aus der Universität Krakau, der eine deutschrumänisch-polnische Ausgabe des Neuen Testaments vorbereitete und Luther 1532 besuchte, orthodox gewesen sein könne, doch liefert das Quellenmaterial, wie die Autoren zugeben, keinerlei Anhaltspunkte für eine solche Annahme. Gunnar Hering, Orthodoxie und Protestantismus, in: Herbert Hunger (Hg.), JÖB 31/2, Wien 1981, S. 823-874, hier S. 827; BengA, David Chytraeus, S. 49 f.

24 So plädiert bspw. Daniel Benga dafür, »das erste persönliche Treffen überhaupt zwischen einem Reformatoren und einem Orthodoxen « in der Begegnung Melanchthons mit dem Griechen Franciscus Magera (gest. 1541) am Regensburger Reichstag 1541 zu sehen. Benga, David Chytraeus, S. 54. Vgl. auch ders., Philipp Melanchthon und der christliche Osten. Bis heute unbekannte Begegnungen Melanchthons aus den Jahren 1541 und 1556 mit orthodoxen Christen, in: OrthFor 16 (2002), S. 19-38. Zu Franciscus Magera siehe: Martin HeIn, Das Schicksal des Franz Magera. Ein Beitrag zum Verhältnis von Reformation und Türkenkriegen, in: ARG 73 (1982), S. 308-313. Dietmar Plajer ging hingegen davon aus, dass die ersten Kontakte zwischen reformatorischen und orthodoxen Christen auf die Tätigkeit des Reformators der siebenbürgisch-sächsischen Kirche Johannes Honterus (ca. 1498-1549) in Kronstadt (Brașov) der 1540er Jahre zurückzuführen sind. Dietmar Plajer, Auftrag und Grenzen. Zu den Anfängen lutherisch-orthodoxer Beziehungen im 16. Jahrhundert, in: Review of Ecumenical Studies Sibiu 10 (1) (2018), S. 90-103, hier S. 90f.

$\mathrm{Zu}$ weiteren Genealogien der frühen reformatorisch-orthodoxen Beziehungen, die allesamt ohne Martin Luther auskommen, siehe bspw. Ernst BENZ, Wittenberg und Byzanz. Zur Begegnung und Auseinandersetzung der Reformation und der östlichorthodoxen Kirche, München ${ }^{2} 1971$, S. 4-33; Paschalis Kitromilides, Orthodoxy and the West. Reformation to Enlightenment, in: Michael Angold (Hg.), The Cambridge History of Christianity, Cambridge 2006, Bd. 5: Eastern Christianity, S. 187209; Gisa BAUER, Evangelisch-orthodoxe Religionsgespräche im 16. Jahrhundert, in: Irene Dingel u.a. (Hg.), Zwischen theologischem Dissens und politischer Duldung. Religionsgespräche der Frühen Neuzeit, Göttingen 2018, S. 43-60.

25 Infolge der Verschiebung des demographischen Zentrums des weltweiten Protestantismus nach dem afrikanischen Kontinent wird in der letzten Zeit das Thema »Luther und Afrika intensiv diskutiert und öfters behauptet, dass Luther niemals Afrikaner getroffen habe bzw. über kein vertrauenswürdiges Wissen über den Kontinent verfüge. Siehe bspw.: Kirsten Rüther, Kannte Luther Afrika? Afrika kennt Luther! Eine 
Das Treffen des Abba Mikael mit Martin Luther kann zweifellos als ein Ausgangspunkt der Interaktion zwischen europäischem Protestantismus und äthiopischer Orthodoxie - und zugleich der Orthodoxie überhaupt betrachtet werden. Es wäre jedoch eine unzulässige Vereinfachung, es als den Ausgangspunkt der Verflechtungsgeschichte dieser beiden Varianten des Christentums anzusehen. Angesichts der Präsenz äthiopischer Christen, vor allem von Mönchen, in Lateineuropa im Zeitalter der Reformation, muss damit gerechnet werden, dass sie auch bereits vor dem Jahr 1534 mit Anhängern der Reformation in Kontakt getreten waren. Verständlicherweise sind die meisten dieser Begegnungen nicht dokumentiert; möglicherweise wurden aber einige davon - wie eine Zeitlang das Treffen der Wittenberger Reformatoren mit $A b b a$ Mika $\mathrm{el}$ - bisher einfach übersehen.

\subsection{Literarische Begegnungen mit dem Anderen:}

Die »Legationes« und ihre protestantischen Leser

Als ein weiterer Ausgangspunkt dieser transkonfessionellen Verflechtungsgeschichte kann neben dem persönlichen Verkehr auch die Bewusstwerdung über die Existenz des jeweils Anderen durch das Medium des Textes betrachtet werden.

Im ersten Drittel des 16. Jahrhunderts rückte Äthiopien infolge der Aufnahme direkter Beziehungen mit Portugal verstärkt in den Fokus der europäischen Aufmerksamkeit. ${ }^{26}$ Der intensive diplomatische Austausch

Skizze zu Luther im südlichen Afrika, in: Hans Medick / Peer Schmidt (Hg.), Luther zwischen den Kulturen. Zeitgenossenschaft - Weltwirkung, Göttingen 2004, S. 337372; Tom Joseph Omolo, Luther in Africa, in: Robert Kolb u.a. (Hg.), The Oxford Handbook of Martin Luther's Theology, Oxford 2014, S. 621-626; Martin Junge, Global Perspectives on the Reformation, in: Anne Burghard / Simone Sinn (Hg.), Global Perspectives on the Reformation. Interactions between Theology, Politics and Economics, Leipzig 2017, S. 9-17; Heinrich Bedford-STrohm u.a. (Hg.), African Christian Theologies and the Impact of the Reformation, Wien u.a. 2017; Friederike Nüssel / Hans-Peter Grossh Ans (Hg.), Lutherische Theologie in außereuropäischen Kontexten. Eine Zusammenschau aus Anlass des 500. Reformationsjubiläums, Leipzig 2017.

26 Es ist anzumerken, dass der Mythos vom Priesterkönig Johannes eine besonders hohe Anziehungskraft auf die Portugiesen ausübte. Diese Tatsache erklärt Adam Knobler damit, dass es in der portugiesischen national-religiösen Mythologie ein ähnlich starkes Motiv gab: »The general inclination of the Portuguese to believe the Prester John stories and to pursue the search for him and his kingdom was an intrinsic part of a broader Portuguese cultural phenomenon. Enshrined at the very core of Portuguese identity was the mythology of the encobierto, the hidden one: a king, blessed by fate and fortune, who would return from a distant exile to liberate his chosen peoplen and reign in glory«. Adam KNobler, Mythology and Diplomacy in the Age of Exploration, Leiden u. a. 2016, S. 43. 
mit dem »Land des Priesterkönigs Johannes«, der der 1508 stattgefundenen Kontaktaufnahme folgte, ${ }^{27}$ wurde nicht zuletzt zu einem medialen Ereignis. Zwei Publikationen erweisen sich dabei als von größter ideengeschichtlicher Bedeutung: Erstens die von dem portugiesischen Humanisten Damião de Góis (1502-1574) zum Druck vorbereitete Legatio magni Indorum imperatoris Presbyteri Ioannis (zunächst 1532 in Antwerpen), ${ }^{28}$ zweitens die von einem anonymen Herausgeber stammende Legatio David Aethiopiae

Bereits Heinrich der Seefahrer (1394-1460), der Auftraggeber der portugiesischen Entdeckungsfahrten, ließ den Glaubensgenossen entlang der Westküste Afrikas suchen. In seinem Hauptwerk »Chronica do Descovrimento e Conquista da Guiné«, beendet im Jahre 1453, dokumentierte Gomes Eanes de Zurara (1410-1474), dass die portugiesischen Seefahrer zunächst (1443) meinten, das Land des Priesterkönig Johannes' im Gebiet von Rio de Oro (heute: Westsahara) lokalisiert zu haben, später (ab den 1450er Jahren) aber die Suche in Gambia, am Fluss Niger sowie im Kongo erfolglos fortsetzten. Vgl. ebd., S. 45-48. Tatsächlicher Kontakt zum christlichen Reich am Horn von Afrika konnte jedoch erst im Jahre 1508 aufgenommen werden, als eine Gesandtschaft des portugiesischen Königs Manuel I. (1469-1521; r. 14951521) zum ersten Mal den äthiopischen Kaiserhof erreichte. Für die Geschichte der Anfangsphase der äthiopisch-portugiesischen Diplomatie siehe: Elaine SANCEAU, Portugal in Quest of Prester John, London 1943. Für eine kurze Zusammenfassung und aktuelle Bibliographie siehe: D’Alòs-Moner, Envoys of a Human God, S. 3-17; Luís Filipe Thomaz, Portugal, Relations with, in: EAE 4, 2010, S. $180 \mathrm{f}$.

27 Als zentral für die äthiopisch-portugiesischen Beziehungen erwies sich der Vorschlag Manuels I., ein antiislamisches, militärisches Bündnis zu begründen, dessen erklärte Ziele die Befreiung Jerusalems und die Zerstörung Mekkas waren. Für sein Vorhaben hatte der portugiesische König allerdings auch wirtschaftspolitische Beweggründe. Zwar ist es Portugal unter der Herrschaft Manuels I. weitgehend gelungen, nicht nur die Gewürze exportierenden Häfen in Asien, sondern selbst die importierenden Häfen des Nahen Ostens einzunehmen, doch die portugiesischen Versuche, die strategisch wichtige Hafenstadt Aden einzunehmen, scheiterten, und der Eingang zum Roten Meer blieb unter arabischer Kontrolle. Auf der Tagesordnung stand daher der Plan, mithilfe Äthiopiens doch noch die Kontrolle über das Rote Meer zu gewinnen und dadurch das portugiesische Handelsmonopol im Indischen Ozean durchzusetzen. Um dieses Projekt zu realisieren, wurde 1515 eine weitere portugiesische diplomatische Mission nach Äthiopien entsandt. Portugiesen konnten das Horn von Afrika allerdings erst 1520 erreichen und blieben dort bis 1526. Diese Gesandtschaft erlangte durch die ausführliche Beschreibung des Landes, die der ihr angehörende Priester Francisco Álvares (ca. 1465-1540) 1540 vorlegte, internationale Berühmtheit. Englische Übersetzung des Werkes: Charles Fraser Becкingham/George Wynn Brereton Huntingford (Hg.), The Prester John of the Indies. A True Relation of the Lands of the Prester John; Being the Narrative of the Portuguese Embassy to Ethiopia in 1520. Written by Father Francisco Alvarez. Works Issued by the Hakluyt Society. Second Series 114-115, Cambridge 1961, Bd. 1-2.

28 Damião de GóIs (Hg.), Legatio magni Indorum Imperatoris Presbyteri Ioannis, ad Emanuelem Lusitaniae Regem, Anno Domini. M. D. XIII, Antwerpen 1532. Damião de Góis war 1514 bereits als dreizehnjähriger Page des Königs Manuel I. Augenzeuge des Aufenthaltes einer äthiopischen Gesandtschaft in Lissabon geworden und davon nachhaltig beeindruckt. Zu seiner Legatio vgl. Elizabeth BlackBurn, The Legacy of »Prester John« by Damião de Goes and John More, in: Moreana 4 (14) (1967), S. 37-98; Jeremy Lawrance, The Middle Indies. Damião de Góis on Prester John and the Ethiopians, in: Renaissance Studies 6 (3-4) (1992), S. 316-324. 
Regis (zunächst 1533 in Bologna). ${ }^{29}$ Die Stärke der beiden Bücher bestand darin, dass sie nicht nur einen Überblick über die Geschichte der portugiesisch-äthiopischen Interaktion boten, sondern auch genuine äthiopische Dokumente enthielten. So wurde in der Legatio magni Indorum imperatoris

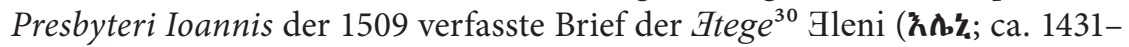
$1522)^{31}$ an König Manuel I. abgedruckt, in dem sie ihr Interesse an Kooperation und Glaubenseinheit mit der lateinischen Christenheit kundtat. Außerdem enthielt das Büchlein eine thesenhaft formulierte Darstellung des äthiopischen Christentums und der politischen Verfasstheit des Landes, die auf Informationen beruhte, welche von dem äthiopischen Gesandten Mateus (gest. 1520) stammten. ${ }^{32}$ Die Legatio David Ethiopiae Regis ergänzte gewissermaßen das Bild, indem sie die im Zeitraum von 1521 und 1524 abgefass-

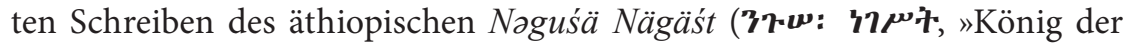

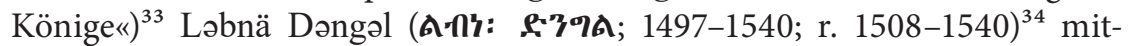

29 Legatio David Æthiopiae Regis ad sanctiss. D. N. Clementem Papam VII una cum obedientia eidem sanctiss. D.N. praestita, Bononiae 1533. Die beiden Legationes werden in der Forschungsliteratur regelmäßig miteinander verwechselt oder miteinander identifiziert, so bspw. in Siegbert UhLIG/Gernot BüHRING (Hg.), Damian de Góis' Schrift über Glaube und Sitten der Äthiopier, ÄthF 39, Wiesbaden 1994, S. 31.

30 Btege (育血) - der Titel bezeichnete die Frau eines Kaisers, die in einer speziellen Zeremonie (traditionell drei Tage nach dem Kaiser) gekrönt wurde. Dieser Titel muss

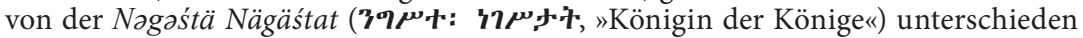
werden, einer Bezeichnung, die eine in ihrem eigenen Recht regierende Kaiserin designierte. Vgl. Hanna Rubinkowska, Atege, in: EAE 2, 2005, S. 392.

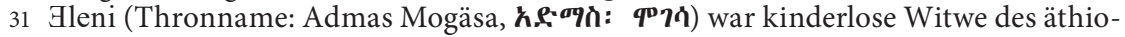
pischen Kaisers Zär ${ }^{a}$ Y Yac ${ }^{c}$ qob. 1508, als sie bereits ihr 75. Lebensjahr überschritten hatte, wurde sie zur Regentin für den damals noch nicht volljährigen Kaiser gewählt. Interessanterweise stammte Gtege Gleni ursprünglich aus einer muslimischen Familie. Sie war Tochter des Herrschers von Hadiyya (eines muslimischen Vasallenstaates Äthiopiens) Mähmad und konvertierte erst vor der Ehe mit Zär’a Yacəqob zum Christentum. Ulrich BraUkëmper, A History of the Hadiyya in Southern Ethiopia, Wiesbaden 2012, S. 88f. In Äthiopien erinnert man sich an sie bis heute nicht nur als die prominenteste weibliche Gestalt in der äthiopischen Politik der Frühen Neuzeit, sondern auch als die Autorin der zwei bedeutenden mariologischen, hymno-

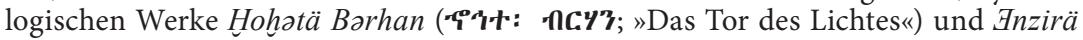

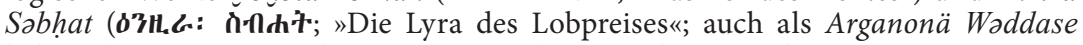
bekannt). Marcus van den Oudenrijn (Hg.), Helenae Aethiopum reginae queae feruntur preces et carmina, CSCO 208, 211 [CSCO.Ae 39, 40], Louvain 1961. Zu ihr siehe: Sevir Chernetsov, Gleni, in: EAE 2, 2005, S. 253f.

32 Mateus (in europäischen Quellen; eigentlicher Name: Abraham) war ein Armenier, der mit Abunä Marqos (\$C.\$n; gest. ca. 1530; r. 1481-1530) verwandt sein sollte und daher beste Beziehungen zu dem äthiopischen Kaiserhof unterhielt. Er reiste $1508 \mathrm{ab}$, erreichte Portugal allerdings erst im Jahre 1514 und blieb dort bis zum Jahr 1515. Zu ihm siehe: Jon Aвbink, Mateus, in: EAE 3, 2007, S. 866f. Vgl. Jean Aubin, L'ambassade du Prêtre Jean à D. Manuel, in: Mare Luso-Indicum 3 (1976), S. 1-56.

33 Zur Semantik und Geschichte der äthiopischen Monarchen-Bezeichnungen siehe: Gianfranco Fiaccadori, Noguś, in: EAE 3, 2007, S. 1162-1166.

$34 \mathrm{Zu}$ Ləbnä Dəngəl (Thronname: Dawit II., , ,中.中) siehe: Michael KLeIner, Ləbnä Dəngəl, in: EAE 3, 2007, S. 535-537. 
teilte. Das Leitmotiv seiner Briefe, die sich an die portugiesischen Könige Manuel I. und seinen Nachfolger João III. (1502-1557; r. 1521-1557) »den Frommen" sowie an Papst Clemens VII. (1478-1534; r. 1523-1534) richteten, war das Streben nach Kircheneinheit und engerer Zusammenarbeit.

Diese beiden Bücher, die der europäischen Leserschaft zum ersten Mal einen Einblick in die äthiopisch-orthodoxe Glaubenswelt ermöglichten, wurden innerhalb kurzer Zeit mehrfach nachgedruckt und lagen bald in verschiedenen Sprachen vor. ${ }^{35}$ Ihr Erfolg hing einerseits mit dem großen Informationsbedürfnis im Hinblick auf die Existenz von Christen in den fernen sagenumwobenen Ländern zusammen, andererseits aber befand sich der in den äthiopischen Briefen formulierte Aufruf zur transkontinentalen Kooperation und Kircheneinheit im Einklang mit dem Diskurs, der in europäischen humanistisch-kosmopolitischen Kreisen geführt wurde. ${ }^{36}$

35 So erschienen nur noch im Jahr 1533 - abgesehen von zahlreichen zusätzlichen lateinischen Auflagen und zwei italienischen Übersetzungen - zwei deutsche Editionen der Legatio David Æthiopiae Regis: Bottschafft des groszmechtigsten Konigs David aus dem grossen und hohen Morenland den man gemeinlich nennet Priester Johann an Babst Clemens den siebenden zu Bononia vorhort in offnem consistorio am XXIX. Tag Januarii anno M.D.XXXIII, Nürnberg 1533 und Bottschafft des groszmechtigsten Konigs David aus dem grossen und hohen Morenland den man gemeinlich nennet Priester Johann an Babst Clemens den siebenden zu Bononia vorhort in offnem consistorio am XXIX. Tag Januarii anno M.D.XXXIII, Dresden 1533.

36 Um einen Eindruck von der begeisterten Rezeption der Legatio magni Indorum imperatoris Presbyteri Ioannis in humanistischen Kreisen zu gewinnen, kann man die Einleitung zu ihrer englischen Ausgabe konsultieren. Der Übersetzer des Textes aus dem Lateinischen, John More (1509-1547), der Sohn des berühmten Humanisten Thomas More (1478-1535), schreibt: »And therfore yt greatly may, \& of reason greatly ought to reioyce all good christen people, to perceyue that though there are dyuerse thynges wherein they and we dyffere in rytes, lawes, customes, and ceremonyes: yet in all other thynges necessaryly perteynynge as well to the vertues of fayth and relygyon, as all other vertues morall, they so farreforth accorde and agre wyth these cristen nacyons of ours, and wyth the catholyque doctryne of the chyrche, that $y t$ may well appere euen by that thynge alone, that the spyryte of god hath wrought and worketh this full agrement \& consent, in so many thynges necessary to saluacyon, thorowe so many great countreys and regyons as ours are and theyres both, ye tone by so longe space hauynge so lytle accesse vnto the tother, that of many yeres tyl nowe very late, we coulde not wel tell whyther they were well cristened or not. [...] But syth that we begyn nowe eache to heare more of other, I pray god as there is in bothe many thynges very good, and some thynges that myght be better: eche peple may lerne \& take of other those thynges that be good, and lette the badde go by. And that we may make bothe so but one chyrche mylytant here in erth, that we may both be partes of one gloryouse chyrche, that euer shall be tryumphaunt in heuen«. John MorE (Hg.), The Legacye or Embassate of the Great Emperour of Inde Prester Iohñ, vnto Emanuell Kynge of Portyngale, in the Yere of Our Lorde M.v.C.xiii. Of the Fayth of the Indyans, Ceremonyes, Relygyons \&c. Of the Patryarche \& His Offyce. Of the Realme, State, Power, Maiesty, and Order of the Courte of Prester Iohñ, London 1533, S. 3f. 
Zugleich zeichnete sich in den frühen 1530er Jahren sowohl in Lissabon als auch in Rom eine zunehmend distanzierte Haltung gegenüber dem christlichen Reich am Horn von Afrika ab, was paradoxerweise als eine unbeabsichtigte Folge der Reformation gesehen werden kann. Ausgerechnet im Zuge der gegenreformatorischen Neuausrichtung der Theologie und der Kirchenpolitik nahm Papst Clemens VII., der sich mit rasanten innereuropäischen (sowohl religiösen als auch politischen) Entwicklungen befasste, den Brief des äthiopischen Kaisers 1533 folgenlos zur Kenntnis. ${ }^{37}$ Gleichermaßen begann man, sich in Lissabon unter der Einwirkung der Hoftheologen Diogo Ortiz de Vilhegas (1457-1519) und Pedro Margalho (1473-1556) auf die vermeintliche Heterodoxie der äthiopischen Kirche zu besinnen. ${ }^{38}$

Während die Kirche Roms sich so vom äthiopischen Christentum zu distanzieren begann, trat neben den humanistischen Gelehrten allmählich eine weitere Gruppe hervor, die sich auf besondere Weise für die äthiopischen Christen interessierte: die Protestanten. Die Auseinandersetzung führender Reformatoren Europas mit der Legatio magni Indorum imperatoris Presbyteri Ioannis und ihre persönlichen Kontakte mit dessen Herausgeber können spätestens auf das Jahr 1534 datiert werden. ${ }^{39}$ Ironischerweise ist diese Information nur dank akribischer Aktenführung der portugiesischen Inquisition erhalten geblieben. Konkret handelt es sich um die Dokumente des Inquisitionsverfahrens gegen Damião de Góis, das im April 1571 eingeleitet wurde. ${ }^{40}$ Sie bestehen teils aus den Berichten, die der Humanist eigenständig für seine Verteidigung verfasst hatte, und teils aus den Verhörakten. ${ }^{41}$ Unter anderem ist daraus zu entnehmen, dass der Portugiese, als er sich zwischen

37 Vgl. Francis Rogers, The Quest for Eastern Christians. Travels and Rumor in the Age of Discovery, Minneapolis 1962, S. 148-152.

38 Vgl. Giuseppe MarcoccI, A consciência de um império. Portugal e o seu mundo (Sécs. XV-XVII), Coimbra 2012, S. 179f. Zu den beiden Hoftheologen siehe: Ebd., S. 152f. sowie D'Alòs-Moner, Envoys of a Human God, S. 18.

39 Die ersten Kontakte des portugiesischen Humanisten mit den Reformatoren fanden sogar schon früher statt, zu einem Zeitpunkt, als seine Legatio noch in Vorbereitung war. So begegnete er im Frühjahr 1531 in Lübeck dem dortigen Reformator Johannes Bugenhagen (1485-1558) und besuchte Luther und Melanchthon in Wittenberg. Vgl. Heinrich Schreiber, Die Reformation Lübecks, Halle (Saale) 1902, S. 74; Paul Wilhelm Gennrich, Damião de Goes, in: ARG 39 (1942), S. 197-220, hier S. $200-$ 202; Elisabeth Feist Hirsch, Damião de Gois. The Life and Thought of a Portuguese Humanist. 1502-1574, The Hague 1967, S. 31-35 und dies., Damião de Goes und die Reformation, in: ThZ 6 (1950), S. 39-58, hier S. 47-50. Zu seinen Verbindungen mit dem Protestantismus siehe zudem: Jean Aubin, Damião de Góis dans une Europe évangelique, in: Humanitas 31-32 (1979-1980), S. 1-56. Angesichts allgemeiner Neugier auf portugiesische Annäherung zum »Land des Priesterkönigs Johannes« ist es nicht auszuschließen, dass die Rede dabei u.a. auch auf die unlängst hergestellten Kontakte zum afrikanischen christlichen Reich gekommen sein könnte.

40 Vgl. Feist Hirsch, Damião de Gois, S. 208-220.

41 Die Dokumente liegen in einer Edition vor: Guilherme Henriques (Hg.), Ineditos Goesianos, Lisboa 1898, Bd. 2: O processo na Inquisição, documentos avulsos, notas. 
April und August 1534 bei Erasmus von Rotterdam (1466-1536) in Freiburg im Breisgau aufhielt, ${ }^{42}$ die Gelegenheit nutzte, um weitere Bekanntschaften mit führenden Vertretern der Reformation zu machen: Nach eigenen Angaben traf er in Genf den Reformator der französischsprachigen Schweiz und den Vorgänger Johannes Calvins (1509-1564), Guillaume Farel (1489-1565); in Basel den Intellektuellen und Reformator Simon Grynaeus (1493-1541); und schließlich in Straßburg die bedeutenden Theologen und Reformatoren Martin Bucer, Kaspar Hedio (1494-1552) sowie Wolfgang Capito (1478-1541). Aus den Akten geht hervor, dass bei diesen Treffen im Zusammenhang mit der kürzlich von Damião de Góis herausgegebenen Legatio, die von den Reformatoren anscheinend bereits gelesen worden war, über die "Entdeckung" der äthiopischen Christen und deren Glauben gesprochen wurde. ${ }^{43}$

Die beiden Legationes wurden jedoch keineswegs nur in den intellektuellen Zentren des Protestantismus gelesen und diskutiert. Vielmehr rezipierten offenbar auch etliche evangelische Pastoren diese Schriften. Darauf deutet jedenfalls die Privatbibliothek von Johannes Block (ca. 1475-1545) hin, des ersten evangelischen Pastors der Pommerschen Herzogsstadt Barth. ${ }^{44}$ Als eine der wenigen intakten privaten Büchersammlungen der Lutherzeit hat Blocks Buchensemble, das sich aus etwa 125 Bänden zusammensetzt, einen herausgehobenen historischen Wert und gilt als Musterbeispiel einer frühreformatorischen Predigerbibliothek. ${ }^{45}$ In ihrem Bestand befindet sich auch die Legatio David Ethiopiae Regis. ${ }^{46}$

All dem ist zu entnehmen, dass das äthiopische Christentum bereits ab den frühen 1530er Jahren als Bestandteil des protestantischen theologischen Diskurses zu betrachten ist, den Vertreter der ersten Reformatoren-Generation führten, und zwar sogar in verschiedenen Sprach- und Konfessionsräu-

42 Einen Überblick über intellektuellen Austausch zwischen den beiden Humanisten und ihre Diskussion über die Rolle des äthiopischen Christentums, die sich u.a. im Erasmischen Werk Ecclesiastes: Sive de ratione concionandi (1535) niederschlug, bietet Elisabeth Feist Hirsch, Damião de Gois, in: ContEras 1, 1985, S. 114-117.

43 Henriques (Hg.), Ineditos Goesianos, S. 127f. Vgl. dazu Feist Hirsch, Damião de Gois, S. 66f.; Aubin, Damião de Góis, S. 27f.

$44 \mathrm{Zu}$ seiner Person und Bibliothek siehe: Jürgen GeIss-Wunderlich/Volker Gummelt (Hg.), Johannes Block. Der pommersche Reformator und seine Bibliothek, Leipzig 2018.

45 Vgl. Jürgen Geiss-Wunderlich, Eine Büchersammlung der Lutherzeit. Aspekte der Erforschung von Blocks Gelehrtenbibliothek, in: GeIss-Wunderlich / Gummelt (Hg.), Johannes Block, S. 13-22, hier S. 14f.

46 Ders., Katalog der erhaltenen Bücher aus Blocks Gelehrtenbibliothek, in: GeIssWunderlich / Gummelt (Hg.), Johannes Block, S. 179-238, hier S. 208f. Blocks Sammlung wurde inzwischen von der Universitätsbibliothek Greifswald digitalisiert. Sein Exemplar der Legatio David Æthiopiae Regis findet man unter der URL: <http:// www.digitale-bibliothek-mv.de/viewer/object/PPN857211056/1/> (12.09.2019). 
men Europas. Luthers Begegnung mit Abba Mikael ist daher keine isolierte Sondererscheinung. Vielmehr ist sie als Teil dieses transkonfessionellen Diskurses anzusehen und in seinem Kontext zu analysieren.

\section{Sekundäre Fäden einer Verflechtungsgeschichte: Herausbildung weiterer Knotenpunkte}

Im Folgenden werden vier sekundäre Fäden der Verflechtungsgeschichte von äthiopischer Orthodoxie und europäischem Protestantismus erstmals vorgestellt, die im späteren Verlauf der Arbeit wieder aufgenommen werden. Ihre jeweiligen Ausgangspunkte liegen an verschiedenen Orten Europas - Lissabon, Paris, Wittenberg und London - und sind unterschiedlichen konfessionellen Zusammenhängen (dem äthiopisch-orthodoxen, dem römisch-katholischen, dem lutherischen sowie dem anglikanischen) zuzuordnen. Nichtsdestotrotz wurden sie in der longue durée allesamt mit der Geschichte des äthiopischen Christentums aufs engste verwoben und sind nicht zuletzt auf äthiopischem Boden - komplexe Verbindungen miteinander eingegangen.

\subsection{Lissabon}

Als $A b b a$ Mika $^{0}$ el sich im protestantischen Wittenberg aufhielt, weilte ein anderer äthiopischer Mönch in der portugiesischen Hauptstadt Lissabon, einer der Weltmetropolen des 16. Jahrhunderts. Sein Name war Sägga Zä̉ab

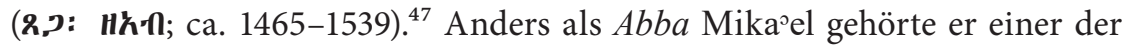
obersten Stufen der kirchlichen Hierarchie an: Er bekleidete das Amt des

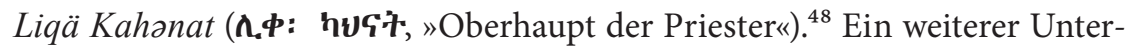

47 Șägga Zä’ab (in europäischen Quellen: Zagazabo, Zaga Zabo, oder auch Christoforo Licanate) war Gesandter des äthiopischen Kaisers Ləbnä Dəngəl und hielt sich seit 1527 in Portugal auf. Er sprach Italienisch, Portugiesisch und etwas Latein und war bereits früher in Europa, höchstwahrscheinlich auch im Kloster Santo Stefano dei Mori in Rom, gewesen. Zu seiner Person siehe: Michael Kleiner, Șägga Zärab, in: EAE 4, 2010, S. 455f.; Matteo SAlvadore, Tsega Ze'ab, in: Emmanuel K. Akyeampong/Henry Louis Gates Jr. (Hg.), Dictionary of African Biography, Oxford 2012, Bd. 6: Tertu - Zwang, S. 64f.

48 Aufgrund der wörtlichen Übersetzung dieser Amtsbezeichnung (»Oberhaupt der Priester«) wurde der Äthiopier in Portugal fälschlicherweise als Bischof (episcopus) betrachtet. Vgl. Damião de Góis, Fides, Religio, Moresque Æthiopum. Sub imperio Preciosi Johannis degentium una cum enarratione confoederationis ac amicitiae inter ipsos Æthiopum imperatores et reges Lusitaniae initae [...], Lovanii 1540, S. 93. In der äthiopischen Bibel bezeichnet der Begriff Liqä Kahənat die Hohepriester des alten Israel. Als Amt innerhalb der kirchlichen Hierarchie Äthiopiens ist er seit 
schied zum Diakon Mika ${ }^{\circ}$ l bestand darin, dass er mit offiziellem Status und Auftrag in Europa war, als Gesandter des äthiopischen Kaisers Ləbnä Dəngəl. ${ }^{49}$ Seinen langfristig bedeutendsten Beitrag leistete er jedoch nicht auf dem Gebiet der Politik, sondern der Theologie. Um die Lehre und Frömmigkeitspraxis der äthiopischen Kirche in Europa bekannt zu machen, schrieb Șägga Zä’ab ein Werk, welches der europäischen Leserschaft erstmalig ein authentisches Bild des äthiopischen Christentums bieten sollte. Am 24. April 1534 wurde diese Schrift fertiggestellt. Damião de Góis übersetzte diese ursprünglich auf Portugiesisch verfasste Schrift ins Latein unter dem Titel De AEthiopum Moribus (»Von den Bräuchen der Äthiopier«) und gab sie 1540 als Teil seines Buches Fides, Religio, Moresque AEthiopum (»Glaube, Religion und Sitten der Äthiopier«) heraus ${ }^{50}$ [siehe Abbildung 3].

Somit wurde nicht nur die konfessionelle Polyphonie der Frühen Neuzeit um eine äthiopisch-orthodoxe Stimme bereichert, sondern auch ein Rezeptionsprozess ausgelöst, der das protestantische Bild der äthiopischen Orthodoxie in der Frühen Neuzeit nachhaltig bestimmen sollte. ${ }^{51}$

spätestens dem 14. Jahrhundert bekannt. Die primäre Funktion des Liqä Kahənat bestand darin, die Disziplin unter den Geistlichen einer bestimmten Region zu überwachen sowie Kandidaten für das Priesteramt auszusuchen. Vgl. Denis Nosnitsin, Liqä Kahənat, in: EAE 3, 2007, S. 578f.

49 Asa Davis, Background to the Zaga ZaAb Embassy. An Ethiopian Diplomatic Mission to Portugal (1529-1539), in: Studia 32 (1971), S. 211-302; Salvadore, The African Prester John, S. 147-175. Vgl. auch Rene BASSET, Deux lettres éthiopiennes du XVIe siècle, in: Giornale della Società Asiatica Italiana 3 (1889), S. 58-79; Jean Aubin, Le Prêtre Jean devant la censure portugaise, in: Bulletin des etudes Portugaises et Brésiliennes Paris 41 (1980), S. 33-57.

50 Górs, Fides, Religio, Moresque Æthiopum, S. 51-93. Einen fotomechanischen Abdruck dieser Ausgabe samt einer deutschen Übersetzung bieten UHLIG / BÜHRING (Hg.), Damian de Góis' Schrift. Im Folgenden wird der Text nach dieser Edition zitiert. Eine englische Übersetzung erschien als Anhang in Edward Aston (Hg.), The manners, lauues, and customes of all nations collected out of the best vvriters [...], London 1611, S. 546-581.

Zwar wird die Schrift Fides, Religio, Moresque AEthiopum mit dem Namen Damião de Góis verbunden, sie ist jedoch, abgesehen von seiner eher im Formalen liegenden Leistung der Übertragung ins Lateinische und der Präsentation, nur zu einem geringen Teil sein Werk. Von den insgesamt 96 Seiten der lateinischen Fassung stammen nur die Widmung und Einführung (letztere überwiegend ein paraphrasierendes Exzerpt aus den portugiesischen Entdeckungsreisen insbesondere nach Indien und Äthiopien) mit elf Seiten und die kurze Vorstellung Șägga Zäoabs aus der Feder des Humanisten. Einen erheblichen Teil des Gesamtumfangs nehmen Schreiben äthiopischer Herrscher und das Werk des Șägga Zä’ab ein. Zu der Entstehungsgeschichte dieses Buches siehe auch Giuseppe MarCOCCI, Gli umanisti italiani e limpero portoghese. Una interpretazione della Fides, Religio, Moresque Æthiopum di Damião de Góis, in: Rinascimento 45 (2005), S. 307-366.

51 Siehe dazu Kapitel III.2 »Hybride Imaginationen des Äthiopischen: Șägga Zä’ab und protestantische Rezeption seines Werks«. 


\section{DAMIANI A GOES} omnium hominum animas, ab Adam profluxiffe afferamus, \& vt caro noftra eft ex feminio car-nis Adx, ita quoque anima noftra, quafi lucerna in anima Adx accenfa, originem fuam $\&$ naturam ex Adam trahit. Ex quo apparet nos omnes femen effe Adx ex carne \& anima.

Hifce characteribus manu propria ipfius Oratoris omnia fuprà fcripta fubfignata erant. $+$

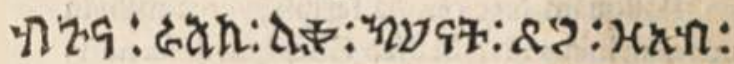

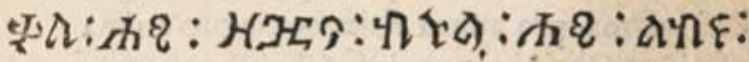
Pi?a:

Abb. 3: Eigenhändige Unterschrift von Șägga Zä’ab im Fides, Religio, Moresque, Aethiopum. Bayerische Staatsbibliothek München, H.afr. 3148, S. 94, urn:nbn:de:bvb:12-bsb10311109-2 


\subsection{Paris}

Ein weiterer sekundärer Faden der äthiopisch-europäischen Verflechtungsgeschichte, der seinen Ausgangspunkt im Sommer 1534 hat, führt in die französische Hauptstadt. Dort, in der Kapelle St. Denis auf dem Montmartre, legte Ignatius von Loyola (1491-1556) am 15. August 1534, an Mariä Himmelfahrt, zusammen mit sechs seiner Kommilitonen aus der Universität Paris die monastischen Gelübde $a b .^{52}$ Dieses Ereignis gilt als Keimzelle der Entstehung jener Ordensgemeinschaft, die sich ab 1539 Societas Jesu nannte. Eines der ersten Vorhaben des neugegründeten Ordens war es, die Äthiopisch-Orthodoxe Kirche der römischen Kirche anzugliedern. Bereits ab 1557 wurden die Jesuiten am Horn von Afrika tätig. ${ }^{53}$ Ihre missionarischen Aktivitäten prägten nachhaltig europäische Imaginationen von Äthiopien im 17. und 18. Jahrhundert. ${ }^{54}$

Die Erfahrung einer äußerst kontrovers geführten theologischen Auseinandersetzung mit den katholischen Missionaren sowie der Widerstand gegen

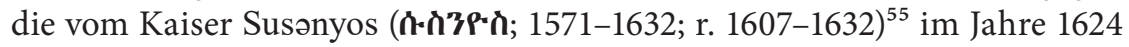
proklamierte Union mit Rom, die jedoch nur bis 1632 Bestand haben sollte, ${ }^{56}$ trugen zur Herausbildung eines Feindbildes der Katholischen Kirche unter den orthodoxen Gläubigen Äthiopiens bei. ${ }^{57}$ Gleichermaßen beeinflussten sie auch die Beziehungen zwischen der äthiopischen Orthodoxie und dem Protestantismus. Viele Protestanten begrüßten seinerzeit die Nachricht von der erfolgreichen Abwehr römisch-katholischer Vereinnahmungsversuche mit genuiner Bewunderung und einem Gefühl der Verbundenheit. Nicht nur sympathisierte man mit den äthiopischen Christen, die sich gegen die Jesuiten zu behaupten gewusst hatten, sondern man spekulierte

52 Vgl. Helmut Feld, Ignatius von Loyola. Gründer des Jesuitenordens, Köln u. a. 2006, S. 114-115; Gottfried Maron, Ignatius von Loyola. Mystik - Theologie - Kirche, Göttingen 2001, S. 241.

53 Näheres dazu in: D’Alòs-Moner, Envoys of a Human God; CoHen, The Missionary Strategies. Für eine kurze Einführung siehe: Ders. / Andreu Martínez, Jesuits in the 16th and 17th Cent., in: EAE 3, 2007, S. 277-281.

54 Vgl. Salvadore, The Jesuit Mission to Ethiopia, S. 141-171.

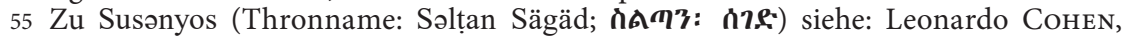
Susənyos, in: EAE 4, 2010, S. 770-772. Für die Chronik seiner Kaiserschaft siehe: Francisco Maria Esteves Pereira (Hg.), Chronica de Susenyos, rei de Ethiopia, Lisboa 1892-1900, Bd. 1-2.

56 Für einen historischen Überblick siehe: Girma Beshah/Merid Wolde Aregay, The Question of the Union of the Churches in Luso-Ethiopian Relations (1500-1632), Lisbon 1964.

57 Vgl. Sevir Chernetsov, The Role of Catholicism in the History of Ethiopia of the First Half of the 17th Century, in: Étienne Delange/Claude LePage (Hg.), Études Éthiopiennes. Actes de la Xe conférence internationale des études éthiopiennes. Paris, 24-28 août 1988, Paris 1994, S. 205-212. 
im 17. Jahrhundert sogar über mögliche politische Bündnisse und suchte verstärkt nach einer Möglichkeit, mit der äthiopischen Kirche in Kontakt zu treten. ${ }^{58}$

\subsection{Wittenberg}

Im September 1534 - etwa zwei Monate nach der Abfahrt Abba Mikaels erschien in Wittenberg im Druck bei Hans Lufft (1495-1584) ${ }^{59}$ die erste vollständige Bibelübersetzung von Martin Luther: Die Biblia/das ist/die gantze Heilige Schrifft Deudsch. ${ }^{60}$

In der Wahrnehmung protestantischer Missionare, die ab dem 19. Jahrhundert in Äthiopien tätig waren, hatte diese Epoche machende Übersetzungsleistung eine Vorbildfunktion. Sie meinten, eine typologische Ähnlichkeit zwischen der ihnen zeitgenössischen äthiopischen Kirche und der römischen Kirche zur Zeit der Reformation feststellen zu können - diese sollte jedoch vor allem darin bestehen, dass die beiden Kirchen die Hei-

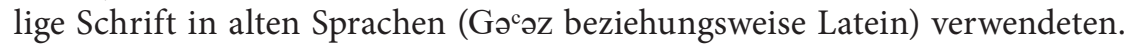
Zudem verknüpften sie die Hoffnung auf eine Reformierung der äthiopischen Orthodoxie mit Übersetzungen der Heiligen Schrift in die Volkssprachen Äthiopiens nach dem Vorbild der Lutherbibel. ${ }^{61}$

\subsection{London}

Am 3. November 1534 wurde im englischen Parlament die Suprematsakte (Act of Supremacy) beschlossen. Mit diesem Dokument sagte sich England endgültig von der römischen Kirche los und proklamierte König Hein-

58 Siehe dazu Kapitel III.3 »Erfindung einer Konfession: Konstruktionen des äthiopischen $>$ Bekenntnisses « .

59 Vgl. Wolfgang Mejer, Der Buchdrucker Hans Lufft zu Wittenberg, Leipzig ${ }^{2} 1923$.

$60 \mathrm{Biblia} /$ das ist / die gantze Heilige Schrifft Deudsch. Mart. Luth. Wittemberg. Begnadet mit Kürfurstlicher zu Sachsen freiheit, Wittenberg 1534. Vgl. dazu Hans Volz, Martin Luthers deutsche Bibel. Entstehung und Geschichte der Lutherbibel, Hamburg 1978, S. 154-191 und Stephan FüsseL, Das Buch der Bücher. Die Luther-Bibel von 1534. Eine kulturhistorische Einführung, Köln 2002. Die Lutherbibel von 1534 ausgestattet mit 128 Holzschnitt-Illustrationen, deren Urheber aus der Werkstatt Lucas Cranachs stammte - ist auf der Website der Herzogin-Anna-Amalia-Bibliothek online verfügbar. Bd. 1 (Historische und Poetische Schriften des Alten Testaments), URL: <https://haab-digital.klassik-stiftung.de/viewer/epnresolver?id=935008438> (12.09.2019); Bd. 2 (Propheten des Alten Testaments, Apokryphen, Neues Testament), URL: <https://haab-digital.klassik-stiftung.de/viewer/epnresolver?id=935052658> (12.09.2019).

61 Siehe dazu Kapitel IV.2.1 »Modalitäten der Begegnung». 
rich VIII. (1491-1547) zum »only supreme head in earth of the Church of England ${ }^{6}{ }^{62}$ Damit war jene Kirchengemeinschaft konstituiert worden, die im frühen 19. Jahrhundert als erste einen systematischen Plan zur Reformierung der Äthiopisch-Orthodoxen Kirche aufstellte und damit begann, protestantische Missionare nach Äthiopien zu entsenden. ${ }^{63}$

Diese auf den ersten Blick miteinander nicht verbundenen Ereignisse Șägga Zä’abs Fertigstellung der Schrift über äthiopisches Christentum, Ablegung der monastischen Gelübde durch Ignatius von Loyola und seine Gefährten, Veröffentlichung der Lutherbibel sowie Verabschiedung der Suprematsakte -, die allesamt, wie man meinen könnte, exklusiv europäischer Kirchengeschichte zugehören, bestimmten die Modalitäten des zukünftigen Austauschprozesses zwischen äthiopischer Orthodoxie und europäischem Protestantismus und sind daher ein unabdingbarer Teil ihrer "geteilten Geschichte«. ${ }^{64}$ Aus geschichtstheoretischer Sicht hebt die Gleichzeitigkeit dieser historischen Vorgänge, die alle im Zeitraum zwischen April und November 1534 stattfanden, die Bedeutung der synchronen Dimension die oft in der Geschichtsschreibung zugunsten der diachronen vernachlässigt wird - bei der Untersuchung der Verflechtungsprozesse hervor. Auch diese sekundären Fäden bilden Knotenpunkte der Verflechtungsgeschichte von äthiopischer Orthodoxie und europäischem Protestantismus und müssen im Rahmen der weiteren Untersuchung stets mitbedacht werden.

\section{Themenfelder eines proto-ökumenischen Dialogs zwischen Abba Mika ${ }^{\circ}$ l und Martin Luther}

\subsection{Trinitätslehre}

In dem bereits erwähnten Brief an Benedikt Pauli, den Melanchthon am Tag der Begegnung mit Abba Mika ${ }^{\supset}$ l - Sonntag, den 31. Mai 1534 - verfasste, berichtete der Wittenberger Reformator unter anderem auch über den Inhalt des stattgefunden Gesprächs. ${ }^{65}$ Diesem Schreiben lässt sich entnehmen, dass

62 Henry Scowcroft Bettenson/Chris Maunder (Hg.), The Documents of the Christian Church, Oxford 2011, S. 227. Vgl. Tanja WeILer, Heinrich VIII. und die englische Reformation. Der lange Weg zum Bruch mit Rom, Hamburg 2014, S. 69-73.

63 Siehe dazu Kapitel IV.2 »Die erste dauerhafte Begegnung: Semantiken und Strategien wechselseitiger Alteritätskonstruktionen «.

64 Dieser Begriff beinhaltet Konnotationen, die im Englischen als shared und divided wiedergegeben werden, und bringt somit die Ambivalenzen einer Geschichte des Austausches und der Interaktion, zugleich aber auch der Abgrenzung und des Konfliktes zum Ausdruck. Vgl. Conrad/Randeria, Geteilte Geschichten, S. 9-49, hier S. 17f.

65 Melanchthon, MBW.T 6, 2005, S. 99f. Siehe den Brieftext im Anhang. 
Martin Luther und der äthiopische Mönch sich gleich beim ersten Treffen über die Trinitätslehre unterhalten hatten. Ob Melanchthon sich an dieser proto-ökumenischen Unterredung beteiligte oder diese nur beobachtete, lässt er allerdings offen.

Es ist nicht auszuschließen, dass Luther mit der Legatio David Athiopiae Regis, die inzwischen in jeweils zwei lateinischen und deutschen Ausgaben vorlag, ${ }^{66}$ vertraut war. Sollte dies der Fall sein, könnten die bemerkenswerten trinitätstheologischen Ausführungen Kaiser Ləbnä Dəngəls, mit denen er seine Briefe an die portugiesischen Monarchen eröffnet hatte, Luther dazu veranlasst haben, seinen Gast nach der äthiopisch-orthodoxen Trinitätslehre zu befragen.$^{67}$ Wohl entscheidend für diese Themenwahl war aber die Tatsache, dass man an diesem Tag in der lateinischen Christenheit das Trinitatisfest feierte. So hatte Luther selbst unmittelbar vor der Begegnung mit dem äthiopischen Diakon eine Predigt in der Wittenberger Schlosskirche gehalten, in der er anhand eines Teiles des Gespräches Jesu mit Nikodemus (Joh 3,2-11) die Lehre von der Dreieinigkeit Gottes zu veranschaulichen versuchte. ${ }^{68}$

66 Vgl. Anm. 29 auf S. 33 und Anm. 35 auf S. 34.

67 Siehe bspw. den Anfang des Briefes des Ləbnä Dəngəls an Manuel I. aus dem Jahr 1521: "Im Namen Gottes des Vaters, für den - so wahr wie er immer existierte - ein Anfang sich nicht finden läßt, im Namen Gottes des einzig(geboren)en Sohnes, der ihm gleich ist, <und es schon war,> bevor das Licht der Sterne sichtbar wurde, bevor er den Grund zum Ozean legte, der zu einer anderen Zeit im Leibe der Jungfrau empfangen wurde ohne männlichen Samen und ohne Hochzeit. Denn auf diese Weise hatte man Kenntnis von diesem »Dienst«. Im Namen des Trösters [des Parakleten], des Geistes der Heiligkeit, der alle Geheimnisse kennt, die dort sind, wo er vorher war, d.h. die aller Höhen des Himmels, der ohne Säulen und ohne alle Stützen getragen wird; der die Erde ausgedehnt hat, die vorher nicht geschaffen worden und nicht bekannt (»erdacht») war, nach allen Himmelsrichtungen vom Anfang bis zum Niedergang und vom Norden bis zum Süden. Jener ist nicht der erste oder der zweite, sondern ist (der dritte in der) Dreifaltigkeit, verbunden in dem einen ewigen Schöpfer aller Dinge, nur von einem Ratschluß und einem Worte in der Ewigkeiten Ewigkeit. Amen«. Uhlig / Bühring (Hg.), Damian de Góis' Schrift, S. 174. Vgl. Legatio David Æthiopiae Regis, S. 15f.

Bemerkenswert in dieser Hinsicht ist ebenso die Eröffnung des Briefes Ləbnä Dəngəls an João III. aus dem Jahr 1524, wo er das Glaubensbekenntnis von Nizäa-Konstantinopel kunstreich paraphrasiert: »Im Namen Gottes, des Vaters, des Allmächtigen, des Schöpfers Himmels und der Erden und alles Geschaffenen, des Sichtbaren und des Unsichtbaren. Im Namen Gottes, des Sohnes, Christi, der da ist der Sohn und der Rat und der Prophet des Vaters. Im Namen Gottes, des Heiligen Geistes, des Trösters, des lebendigen Gottes, dem Vater und dem Sohne gleich, der geredet hat durch den Mund der Propheten, der inspirierend ausgegossen wurde über die Apostel, so daß sie dankten und lobten die Dreifaltigkeit, die vollkommene, im Himmel und auf der Erde und auf dem Meere und in der Tiefe immerdar. Amen«. Deutsche Übersetzung zitiert nach: Uhlig / Bühring (Hg.), Damian de Góis' Schrift, S. 185. Vgl. Legatio David Æthiopiae Regis, S. 32f.

68 Überliefert sind sowohl Luthers Predigt am Trinitatissontag (31. Mai 1534) als auch seine Predigt am Montag nach Trinitatis (1. Juni 1534). Luther, WA 37, 1910, S. 414-424. 
Die altkirchliche neunizänisch-kappadozische Trinitätslehre, die die Wittenberger Reformatoren allerdings in ihrer durch lateinische Autoren allen voran Ambrosius von Mailand (339-397) und Augustinus (354-430) geprägten Form rezipierten, hatte eine eminente Bedeutung für ihre Theologie. ${ }^{69}$ Doch seit den späten 1520er Jahren, als Luther von der Entstehung antitrinitarischer Lehren innerhalb einiger reformatorischer Gemeinden Kenntnis bekommen hatte, sah er sich mit der Frage nach der Schriftgemäßheit des altkirchlichen Dogmas von der Wesenseinheit Gottes in drei Personen konfrontiert. ${ }^{70}$ Angesichts der Brisanz und grundlegenden Natur dieses Anliegens kam Luther immer wieder darauf zurück und bemühte sich darum, die Trinitätstheologie der ersten beiden Reichskonzilien von Nizäa und Konstantinopel, von deren Richtigkeit er überzeugt war, zu verteidigen. In den frühen 1530er Jahren, also in der Zeit vor dem Treffen mit Abba Mika ${ }^{0}$ l, hatte Luther sich besonders intensiv mit den Positionen des spätantiken Streits um die Trinitätstheologie auseinandergesetzt. ${ }^{71}$ Dabei hatte diese Besinnung auf die neunizänisch-kappadozische Trinitätslehre ihren Niederschlag sowohl in seinen kontroverstheologischen Schriften als auch in seinen Predigten gefunden. ${ }^{72}$ Vor diesem Hintergrund erscheint es nicht überraschend, dass Luther das Gespräch mit dem äthiopischen Mönch,

69 Zur Bedeutung der altkirchlichen Trinitätslehre für die Theologie Luthers: Christoph Markschies, Luther und die altkirchliche Trinitätstheologie, in: Ders./Michael Trowitzsch (Hg.), Luther - zwischen den Zeiten. Eine Jenaer Ringvorlesung, Tübingen 1999, S. 37-85; Jouko Martikainen, Christologische und trinitätstheologische Aporien der östlichen Kirche aus der Sicht Luthers, in: Joachim Heubach (Hg.), Luther und die trinitarische Tradition. Ökumenische und philosophische Perspektiven, Erlangen 1994, S. 71-94. Luther orientierte sich nicht nur in seiner positiven Fassung der Trinitätslehre an altkirchlichen Vorbildern, sondern sogar in seiner Abgrenzung gegen trinitätstheologische Fehlentwicklungen. So schreibt er in dem testamentarischen Glaubensbekenntnis, das seine 1528 veröffentlichte Schrift Vom Abendmahl Christi, Bekenntnis abschließt: "Erstlich gleube ich von hertzen den hohen artickel der goettlichen maiestet/das Vater/son/heiliger geist drey Unterschiedliche personen/ein rechter/einiger/natuerlicher/warhafftiger Gott ist/schepffer hymels vnd der erden/aller dinge widder die Arrianer / Macedonier/Sabelliner/vnd der gleichen ketzerey«. LutheR, WA 26, 1909, S. 500. In seiner Predigt zum Trinitatisfest am 23. Mai 1535 - genau ein Jahr nach der Begegnung mit Abba Mika ${ }^{\circ}$ l - trug Luther sogar vor, dass in dem trinitarischen Dogma »Gott also von sich selbst redet«. Ders., WA 41, 1910, S. 270.

Auch Philipp Melanchthon sah sich als Vertreter der neunizänisch-kappadozischen Trinitätstheologie und berief sich in seiner Polemik gegen die Antitrinitarier ausdrücklich auf die Lehre der kappadokischen Kirchenväter. Vgl. Ashley H. Hall, Philip Melanchthon and the Cappadocians. A Reception of Greek Patristic Sources in the Sixteenth Century, Göttingen 2014, S. 122-128.

70 Vgl. Reiner Jansen, Studien zu Luthers Trinitätslehre, Bern 1976, S. 91-97.

71 Ebd., S. 149-206.

72 Ulrich Asendorf, Die Theologie Luthers nach seinen Predigten, Göttingen 1988, S. $29-46$. 
in dem er einen Vertreter der altkirchlichen Tradition sah, zunächst speziell auf die Trinitätslehre lenkte.

In dem bereits erwähnten Brief an Benedikt Pauli schreibt Philipp Melanchthon: »[...] de Trinitate dixit [Abba Mika $\left.{ }^{0} e l\right]$ Luthero sententiam orientalis ecclesiae convenientem cum occidentali ecclesia « ${ }^{73}$ (»[...] bezüglich der Trinität sagte er [Abba Mika $\left.{ }^{\circ} l\right]$ Luther, dass die Meinung der morgenländischen Kirche mit der der abendländischen Kirche übereinstimme«). ${ }^{74}$ Dieser Satz verrät, dass der äthiopische Mönch in den Augen der Reformatoren nicht eine partikulare Tradition des christlichen Orients (mit ihren kulturellen, liturgischen, aber auch dogmatischen Besonderheiten) vertrat; vielmehr repräsentierte er aus ihrer Sicht die gesamte orientalis ecclesia. Ausgerechnet aufgrund dieser - in Folge der mangelnden Information durchaus nachvollziehbaren - Undifferenziertheit konnte diese »Ostkirche« nichts anderes als ein künstliches Abstraktum sein. Möglicherweise damit verbunden war auch eine "orientalisierende" Darstellung von $A b b a$ Mika ${ }^{0} e l:$ Zwar wurde er vor allem als Aethiops (Äthiopier) bezeichnet, doch nannte ihn Melanchthon in seinen Briefen auch Arabs, was sich in diesem Kontext nicht nur als »Araber", sondern als »Orientale« übersetzen lässt. ${ }^{75}$

Die Vorstellung, dass die Kirchen des Ostens und des Westens keinen Unterschied in der Trinitätslehre kennen würden, war für die Wittenberger Reformatoren äußerst bedeutsam. In ihrem Empfehlungsschreiben, das sie für $A b b a$ Mika ${ }^{\supset} e l$ erstellten, leiteten sie sogar die Fürsprache für ihn aus seiner trinitätstheologischen Rechtgläubigkeit ab:

Fuit nobiscum in Germania dominus Michael, Aethiops diaconus, cum quo de doctrina christiana familiariter colloquentes audivimus eum cum symbolo, quod habet ecclesia occidentalis, recte convenire nec de trinitate aliud sentire, quam quod sentit ecclesia occidentalis. Ideo, quantum nos quidem possumus, commendamus eum bonis viris. ${ }^{76}$

Herr Michael, ein äthiopischer Diakon, war bei uns in Deutschland. Als wir uns mit ihm freundlich über die christliche Glaubenslehre austauschten, hörten wir, dass er dem Glaubensbekenntnis, den die abendländische Kirche hat, gleichförmig denke

73 Philipp Melanchthons Brief an Benedikt Pauli vom 31. Mai 1534. Melanchthon, MBW.T 6, 2005, S. 99f. Siehe den Brieftext im Anhang.

74 Übersetzung - S.P.

75 Ebd. Die Verwechslung der Ethnonyme Aethiops und Arabs in Melanchthons lateinischen Briefen ist möglicherweise auf die Verwandtschaft der Wörter »Mohr« und "Maure« (beide aus dem lateinischen Maurus entliehen) und deren gewisse Austauschbarkeit im deutschen Sprachgebrauch der Frühen Neuzeit zurückzuführen.

76 Melanchthon, MBW.T 6, 2005, S. 123f. Für weitere publizierte Varianten des Empfehlungsschreibens Luthers siehe Anm. 7 auf S. 24. 
und über die Trinität keine andere Meinung hege als die abendländische Kirche. Daher empfehlen wir ihn, so viel an uns ist, guten Menschen. ${ }^{77}$

Diese Feststellung ist insofern bemerkenswert, als die ganze Filioque-Problematik den Gesprächspartnern völlig unbekannt gewesen zu sein scheint. Zwar sahen sich die Wittenberger Reformatoren in der Frage der Trinitätslehre in der Tradition der Alten Kirche stehend, jedoch lehrten sie den Hervorgang des Heiligen Geistes aus dem Vater und dem Sohn. ${ }^{78}$ Mit großer Selbstverständlichkeit übernahmen sie nicht nur das Glaubensbekenntnis von Nizäa-Konstantinopel mit dem Filioque, sondern griffen auch auf das schon ursprünglich filioquistische Athanasianum zurück, von dessen Authentizität sie überzeugt waren. ${ }^{79}$ Dem äthiopischen Mönch war es allerdings, umgekehrt, nicht bekannt, dass die lateinische Christenheit den Filioque-Zusatz lehrte; ${ }^{80}$ die Reformatoren, die die neunizänisch-kappadozische Triadologie aus den Schriften der lateinischen Autoren rezipiert hatten, wussten hingegen nicht, dass dieser Zusatz in der ursprünglichen Fassung des Glaubensbekenntnisses von 381 nicht enthalten war und in allen Ostkirchen nicht verwendet wurde. Aber auch abgesehen von der Filioque-Lehre, die im ganzen christlichen Osten gleichermaßen auf Ablehnung stieß, gibt es noch einen anderen - nunmehr spezifisch äthiopischen - Grund dafür, die deklarierte Übereinstimmung in der Trinitätstheologie in Zweifel zu ziehen.

Die weitreichenden Kirchenreformen, die Kaiser Zär ${ }^{\supset a}$ Yacəqob

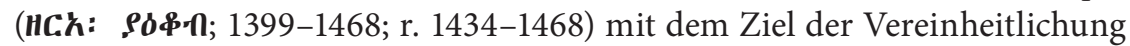
der Kirchenlehre und der liturgischen Praxis durchgeführt hatte, beeinflussten auch die Triadologie der äthiopisch-orthodoxen Kirche. ${ }^{81}$ Ausschlaggebend dafür war die kontrovers geführte Diskussion um die angemessene Auslegung biblischer Gottebenbildlichkeitsaussagen, ${ }^{82}$ und dementspre-

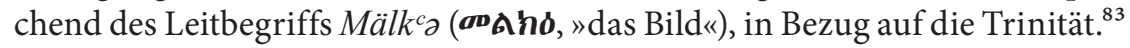

77 Übersetzung - S.P.

78 Vgl. Jansen, Studien zu Luthers Trinitätslehre, S. 98f.

79 Vgl. Bernd Oberdorfer, Filioque. Geschichte und Theologie eines ökumenischen Problems, Göttingen 2001, S. 266.

80 Selbst wenn Kaiser Ləbnä Dəngəl an Papst Clemens VII. schrieb, verwendete er die trinitarische Formel ohne das Filioque: »In nomine Dei spiritus sancti dei viui, qui processit ex Deo patre«. (Im Namen Gottes, des Heiligen Geistes, des lebendigen Gottes, der hervorgegangen ist aus Gott, dem Vater.) Legatio David Æthiopiae Regis, S. 35. Vgl. Uhlig / BüHring (Hg.), Damian de Góis' Schrift, S. 195.

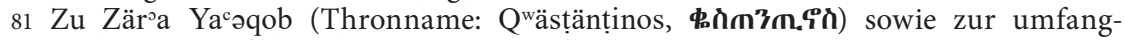
reichen weiterführenden Literatur siehe: Steven KaPLAN/Marie-Laure DeraT, Zär’a Yacəqob, in: EAE 5, 2014, S. 146-150.

82 Vgl. Gen 1,27.

83 Zur Vorgeschichte und zum Kontext dieser Auseinandersetzung siehe: Getatchew Haile, Religious Controversies and the Growth of Ethiopic Literature in the Fourteenth and Fifteenth Centuries, in: OrChr 65 (1981), S. 102-136, hier S. 127-129; Kurt 
Zär ${ }^{\supset a} Y^{c}$ 'əqob neigte zu einer wörtlichen, geradezu physischen, Interpretation der Gottebenbildlichkeit, und aufgrund der zahlreichen biblischen Anthropomorphismen vertrat er die Vorstellung einer Menschengestalt Gottes. ${ }^{84}$ Das Menschenbild, das mit Adam seine Gestalt gewann, sei gleichzeitig das Bild Gottes. Eine Gruppe von Geistlichen, die als die Zämika ${ }^{\top}$ eliten bekannt wurden, ließ sich auf eine theologische Auseinandersetzung mit dem Kaiser ein. ${ }^{85}$ In der patristischen Tradition stehend argumentierten sie, dass die Ähnlichkeit der Gestalt von Gott und Mensch sich ausschließlich auf den Geist beziehe und man nicht von einem physischen Körper des unsichtbaren und grenzenlosen Gottes sprechen dürfe. ${ }^{86}$

Die Zämika ${ }^{3}$ liten wurden jedoch zu Häretikern erklärt und die Vorstellungen Zäroa Yac əqobs über die Menschengestalt Gottes in die äthiopische Trinitätslehre integriert. ${ }^{87}$ Die physischen Charakteristika, die bei der

Wendt, Die theologischen Auseinandersetzungen in der äthiopischen Kirche zur Zeit der Reformen des XV. Jahrhunderts, in: Accademia nazionale dei Lincei (Hg.), Atti del Convegno Internazionale di Studi Etiopici (Roma 2-4 aprile 1959). Problemi Attuali di Scienza e di Cultura 48, Roma 1960, S. 137-146; Pierluigi Piovanelli, Les controverses théologiques sous le roi Zar’a Yā́ əqob (1434-1468) et la mise en place du monophysisme éthiopien, in: Alain Le Boulluec (Hg.), La controverse religieuse et ses formes, Paris 1995, S. 189-228.

84 Getatchew Haile, The Homily of Zär ${ }^{\supset a}$ Yac ${ }^{c}$ qob in Honour of St. John the Evangelist, EMML 1480, ff. 48r-52v, in: OrChr 67 (1983), S. 144-166, hier S. 150. Vgl. HeYER, Die Kirche Äthiopiens, S. 255f.

85 Sie wurden nach einem der führenden Theologen innerhalb dieser Bewegung namens

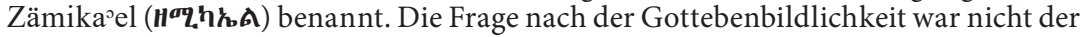
einzige Streitpunkt zwischen ihnen und Zäroa Yacəqob. Sie opponierten auch etwa gegen seinen eschatologischen Millenarismus, gegen die Einführung neuer mariologischer Feste und gegen die Erweiterung des Bibelkanons (dabei handelte es sich um die Bücher Henoch, Jubiläen und das Testamentum Domini). Für eine kurze Einführung siehe: Getatchew Haile, Zämikaelites, in: EAE 5, 2014, S. 131-133.

$86 \mathrm{Vgl}$. bspw. »God has no form like the form of man. God did not create in his image and likeness the form of Adam's body which is palpable and visible. The image of God and his likeness are an invisible spirit which was breathed upon Adam's face«. Zitiert in: Ebd., S. 132. Oder: "God is invisible and has no image which man may know; He alone knows His image«. Getatchew Haile, The Homily of Zär’a Yacoqob, S. 159. Das wichtigste Werk, das den Zämika ${ }^{\supset}$ eliten zugeschrieben wird, ist das Fəkkare Mäläkot (Gh6: aDnh'十; »Interpretationen der Göttlichkeit«). Enrico Cerulli, Scritti teologici etiopici dei secoli XVI-XVII, Città del Vaticano 1958, Bd. I: Tre opuscoli dei Mikaeliti, Studi e testi 198. Im Buch wird sowohl über die Gottebenbildlichkeit nachgedacht als auch gegen eine wörtliche Auslegung der anthropomorphischen Beschreibungen Gottes in der Bibel argumentiert. Siehe dazu: Pierluigi PiovanelLI, Connaissance de Dieu et sagesse humaine en Éthiopie. Le traité explication de la divinité attribué aux hérétiques "mikaélites«, in: Muséon 117 (2004), S. 193-227. Vgl. auch Carlo Conti Rossini / Lanfranco Ricci (Hg.), Il libro della luce del negus Zar'a Yācqob (Maṣhafa Berhān) II, CSCO 261, 262 [CSCO.Ae 51, 52], Louvain 1965 und Getatchew Haile, The Homily of Zär’a Yacaqob, S. 149 (Text) und S. 159 (Übersetzung).

87 Zär`a Yacəqob warf ihnen vor, zu lehren: »God had no form, and man is not formed after God's image«. Ebd., hier S. 164. Außer der Ablehnung des physischen Aspek- 
Erschaffung Adams und der Inkarnation Christi in Erscheinung traten, schrieb der Kaiser allen drei Personen der Trinität zu. Ihm zufolge sei das Bild Gottes »im Vater und im Sohne und im Heiligen Geiste, sei es der Kopf oder das Angesicht, die Augen oder die Ohren oder die Nase, die Lippen oder Zähne, sei es die Zunge oder die Hände und Finger, sei es das Herz dem Bilde nach oder die Füße und Zehen ${ }^{88}{ }^{8}$ Die Triadologie Zär ${ }^{a}$ Y Yacəqobs, die in der knappen Formel »Der Vater im perfekten Bilde des Menschen « zusammengefasst wurde, wurde Mitte des 15. Jahrhunderts zur offiziellen Lehre der äthiopischen Kirche. ${ }^{89}$ Dass diese Lehre, wenngleich nicht in ihrer radikalen Zuspitzung, auch im frühen 16. Jahrhundert die äthiopische Theologie prägte, wird aus der 1534 beendeten Schrift des Abba Șägga Zä`ab deutlich. ${ }^{90}$

tes in der Trinität wurde den Zämika ${ }^{\top}$ eliten die folgende Aussage zugeschrieben (die sich jedoch in ihren Schriften nicht wiederfindet): »The Father, the Son and the Holy Spirit were three names, one person, one hypostasis and one aspect«. Tedros Aвraha, Trinity, in: EAE 4, 2010, S. 990-994, hier S. 992. Ihnen wurde zudem vorgeworfen, eine andere Version des Trisagions in ihren Gottesdiensten zu verwenden: "Holy, holy, holy God who is not likened to the image of creatures". Vgl. Getatchew Haile, Zämika ${ }^{\top}$ elites, S. 132; Conti Rossini / Ricci (Hg.), Il libro della luce, S. 126 (Text), S. 172 (Übersetzung).

88 Kurt Wendt (Hg.), Das Maṣhafa Milād (Liber Nativitatis) und Maṣhafa Sellāsē (Liber Trinitatis) des Kaisers Zar'a Yā'qob [Versio] I, CSCO 222 [CSCO.Ae 42], Louvain 1963, S. 79f. Vgl. Heyer, Die Kirche Äthiopiens, S. $255 f$.

89 Conti Rossini/Ricci (Hg.), Il libro della luce, S. 128f. Vgl. Getatchew Haile, Ethiopian Orthodox (Täwahədo) Church. History from Ancient Times till the Second Half of the 19th Century, in: EAE 2, 2005, S. 414-421, hier S. 417. Der Einfluss der Trinitätslehre Zär ${ }^{\supset} a Y^{c}{ }^{c}$ əqobs auf die spätere äthiopische Theologie bedarf einer eingehenden Untersuchung. Einerseits prägte sie die Ikonographie der Trinität, die nun vorwiegend als drei ältere Männer dargestellt wurde (vgl. Marilyn E. HELDMAN, Trinity in Art, in: EAE 4, 2010, S. 994-996), andererseits wird in der Hymnographie der äthiopisch-orthodoxen Kirche die Vorstellung von der Menschengestaltigkeit Gottes entschieden abgelehnt. Die liturgischen Texte tradieren vielmehr eine klassische Triadologie, also die, die der Kaiser als häretisch ansah. Mebratu Kiros Gebru, Liturgical Cosmology. The Theological and Sacramental Dimensions of Creation in the Ethiopian Liturgy, Diss. University of St. Michael's College, Toronto 2012, S. 40-44.

90 So schreibt er bspw.: »Dieser Heilige Geist, der erschien [bei der Taufe Christi] in der Gestalt einer weißen Taube, erschien mit dem Antlitz und der Gestalt des Vaters und des Sohnes in einer (und derselben) Gottheit. Und in gleicher Weise ist Christus gesehen worden von den heiligen Propheten in vielen Bildern und Formen. Zuerst in der Gestalt eines weißen Widders wegen der Rettung Isaaks, des Sohnes Abrahams [...]. Ebenso hat er (Christus) sich dem Moses geoffenbart auf dem Berge Sinai in Gestalt einer Feuerflamme, sich dem Propheten Daniel gezeigt im Bilde eines Felsens. Auch dem Ezechiel, dem Menschensohne, ist er erschienen und dem Jesaja in der Gestalt eines Kindes. Er hat sich auch geoffenbart dem König David und dem Gideon im Tau über dem Vlies (auf dem Fell). Außer <in> diesen hier aufgezählten Gestalten ist er in vielen anderen Gestalten von den heiligen Propheten gesehen worden. Obgleich er unter so verschiedenen Gestalten gesehen worden ist, repräsentierte er dennoch immer das Bild des Vaters und des Heiligen Geistes. Und auch, als Gott die Welt erschaffen hatte, hat er gesagt: Lasset uns den Menschen machen, uns zum Bilde und Gleichnis, und er schuf Adam sich zum Bilde und Gleichnis. Deswegen sagen wir, 
Die durch $A b b a$ Mika ${ }^{\circ}$ l, Luther und Melanchthon festgestellte Übereinstimmung zwischen den Kirchen in der Trinitätslehre war also aus zwei Gründen irreführend. Zum einen bestand eine Differenz zwischen dem christlichen Osten und dem Westen in der Filioque-Frage. Zum anderen vertrat die Kirche Äthiopiens nach den Reformen Zär’a Yacəqobs eine Trinitätstheologie, die sich nicht nur von der Lehre des christlichen Westens, sondern auch der des restlichen christlichen Ostens unterschied. Während die Triadologie Zära Yac əqobs im Westen bis zum 20. Jahrhundert unbekannt blieb (und somit nicht als ein theologisches Problem identifiziert werden konnte), wurde die Brisanz der Filioque-Frage sowohl den deutschen Protestanten als auch den orthodoxen Äthiopiern schon wenige Jahrzehnte nach dem Treffen zwischen Abba Mika ${ }^{5}$ el und den Wittenberger Reformatoren deutlich: Die äthiopisch-orthodoxen Christen wurden damit im Laufe der Auseinandersetzung mit den portugiesischen Jesuiten in den 1550er Jahren konfrontiert; ${ }^{91}$ die Lutheraner wurden auf den Filioque-Zusatz als einen schwerwiegenden Differenzpunkt im Laufe des Briefwechsels mit dem Ökumenischen Patriarchen Jeremias II. (1536-1595) in den 1570er Jahren aufmerksam gemacht. ${ }^{92}$

\subsection{Abendmahlsverständnis}

Ein weiteres Thema, das von Abba Mika ${ }^{\circ}$ el und den Wittenberger Reformatoren besprochen wurde, betraf die Sakramententheologie, insbesondere das Abendmahlsverständnis. Die Frage nach der Bedeutung und dem Wesen der Eucharistie war theologisch besonders brisant. Denn einerseits wurde sie zu einem weiteren Differenzpunkt zwischen den Reformatoren und den römisch-katholischen Theologen, andererseits aber verursachte sie eine tiefe Kluft in der reformatorischen Bewegung selbst. ${ }^{93}$

daß Vater Sohn und Heiliger Geist drei Antlitze sind in einem Bilde und in einer Gottheit«. Uhlig / Bühring (Hg.), Damian de Góis’ Schrift, S. 67f. (Text), S. $240 \mathrm{f}$. (Übersetzung).

91 Cohen, The Missionary Strategies, S. 133-136.

92 Wendebourg, Reformation und Orthodoxie, S. 63-65.

93 Zwar lehnten alle Reformatoren die römisch-katholische Lehre von der Transsubstantiation (laut ihr verwandelt sich Wein und Brot während der Abendmahlsfeier tatsächlich und dauerhaft in Blut und Fleisch Jesu) ab, doch vertraten Luther einerseits und Huldrych Zwingli (1484-1531) andererseits unterschiedliche Sakramentsverständnisse. Während Luther die Realpräsenz lehrte (in der Einsetzung des Abendmahls sei in Brot und Wein der wahre Leib und das wahre Blut Christi gegenwärtig) und in der Eucharistie das tiefste Erlebnis der sichtbar gewordenen Gnade Gottes sah, betrachtete Zwingli das Abendmahl als ein Gedächtnismahl und vertrat die Meinung, dass die Gegenwart Christi in den Abendmahlselementen Brot und Wein nur symbolisch zu verstehen sei. Die Abendmahlskontroverse, in der sich auch die Vertreter der radikal-reformatorischen Täuferbewegung gegen die Realpräsenz 
In dem Empfehlungsschreiben der Wittenberger Reformatoren für $A b b a$ Mika ${ }^{\circ}$ el ist zu lesen:

Comperimus etiam ex eo, quod ritus, quem nos observamus in usu coenae domini et missa, convenit cum orientali ecclesia. ${ }^{94}$

Wir erfuhren von ihm [Abba Mika $\left.{ }^{0} e l\right]$ auch, dass der Ritus, den wir beim Mahl des Herrn und bei der Messe befolgen, mit der morgenländischen Kirche übereinkommt. ${ }^{95}$

Wenn bei der Frage der Trinitätslehre pauschalisierend von der Ost- und Westkirche die Rede war, so wird nun das orthodoxe Eucharistieverständnis und die Gottesdienstordnung explizit mit dem eigenen, reformatorischen, Ritus verglichen. Dabei muss die Behauptung Luthers, dass die von ihm und seinen Anhängern geübte Abendmahlspraxis laut $A b b a$ Mika ${ }^{5}$ el dem Ritus der orthodoxen Kirche entspreche, im kontroverstheologischen Kontext der Zeit verstanden werden. ${ }^{96}$

Mit der oben erwähnten »Übereinstimmung« dürften die Ähnlichkeiten der Positionen gemeint gewesen sein, die die Reformatoren im Austausch mit Abba Mika ${ }^{\circ}$ in Bezug auf die aus ihrer Sicht wichtigsten Fragen der Abendmahlspraxis feststellen konnten. Diese Ähnlichkeiten bestanden darin, dass die Äthiopier, wie auch die Wittenberger Reformatoren, das Abendmahl unter zwei Gestalten, Brot und Wein, der Gemeinde austeilten; keine Totenmessen und keine Privatmessen ${ }^{97}$ feierten (im Gegensatz zur Kirche Roms), zugleich aber die Lehre von der Realpräsenz von Leib und Blut Christi befürworteten

positionierten, ging nach Zwinglis Tod 1531 weiter und wurde zum wichtigsten Punkt der innerprotestantischen konfessionellen Differenzierung. Für eine ausführlichere Darstellung der Positionen siehe: Peter BüHLER, Der Abendmahlsstreit der Reformatoren und seine aktuellen Implikationen, in: ThZ 35 (4) (1979), S. 228-241.

94 Melanchthon, MBW.T 6, 2005, S. $123 f$.

95 Übersetzung - S.P.

96 Es ist hervorzuheben, dass Luther zu der Zeit weiterhin in den Abendmahlsstreit verwickelt war. Noch am 10. März 1534, also unmittelbar vor der Begegnung mit dem äthiopischen Mönch, verfasste er einen Kommentar zu seiner im Jahr zuvor publizierten Schrift Von der Winkelmesse und der Pfaffenweihe. Dort polemisierte er scharf sowohl gegen "die Papisten ", deren Messopfertheologie und Privatmessen er vehement ablehnte, als auch gegen "Schwermern oder Sacraments feinden " im reformatorischen Lager, die die Realpräsenz leugneten. Luther, WA 38, 1912, S. 171-255 und S. 257-271.

97 Vgl. dazu die Aussage Melanchthons, die in den "Tischreden« dokumentiert ist: »Aethiopem quendam ante triennium Witebergae fuisse, qui affirmasset in Asia nullum exemplum privatae missae esse, sed tantum unam publicam missam«. (»Vor drei Jahren war ein Äthiopier in Wittenberg, der bestätigte, dass [es] in Asien keine Privatmessen gebe, sondern nur die öffentliche Messe«.) Ders., WA.TR 5, 1919, S. 450 f. 
(im Gegensatz zu den Zwinglianern und den Täufern). ${ }^{98}$ Letztendlich sollte die Behauptung vermeintlicher Übereinstimmung mit der orthodoxen liturgischen Praxis der Selbstvergewisserung dienen und möglicherweise in weiterer Polemik für die Verteidigung reformatorischer Standpunkte verwendet werden. Eine solche Argumentationsstrategie schien insofern sinnvoll, als auch Luthers - reformatorische ebenso wie römisch-katholische - Opponenten im Abendmahlsstreit mit Hilfe von Kirchenväterzitaten sowie Verweisen auf die Praxis der Alten Kirche ihre Position zu stützen suchten. ${ }^{99}$

Dieses Beispiel legt eine markante Selbstreferentialität der Wittenberger Reformatoren im Dialog mit $A b b a$ Mika ${ }^{3}$ el offen. Indem sie aufgrund der inner-europäischen Abendmahlskontroverse dazu disponiert waren, im Äthiopischen vor allem das Eigene zu sehen, ließen sie die Gelegenheit ungenutzt, präzisere Kenntnisse vom eigentlichen Ritus der äthiopisch-orthodoxen Liturgie (\$, $\mathbf{9} \mathbf{h}$, Qaddase) und dessen theologischen Implikationen zu erfahren. ${ }^{100}$

98 Da Șägga Zä’ab in seinem für den westlichen Leser verfassten Werk speziell diese Eigenschaften der äthiopischen Liturgie erwähnt, ist es wahrscheinlich, dass auch Abba Mikael auf sie einging. Vgl. Góis, Fides, Religio, Moresque Æthiopum, S. 76-78; Uhlig / BüHring (Hg.), Damian de Góis’ Schrift, S. 254-256.

99 Zur Verwendung von Kirchenväterzitaten im Abendmahlsstreit siehe: Gottfried HofFMAnN, Kirchenväterzitate in der Abendmahlskontroverse zwischen Oekolampad, Zwingli, Luther und Melanchthon. Legitimationsstrategien in der inner-reformatorischen Auseinandersetzung um das Herrenmahl, Göttingen ${ }^{2} 2011$; Hall, Philip Melanchthon and the Cappadocians, S. 169-178. Bereits in der Apologie der Confessio Augustana (zunächst veröffentlicht 1531; 1537 offiziell zur Bekenntnisschrift erklärt), federführend von Melanchthon - jedoch unter Einfluss Martin Luthers - verfasst, wurde im Artikel 10, dem Abendmahlsartikel der Apologie, auf die Wandlungsepiklese der griechisch-orthodoxen Liturgie als Beleg für die Realpräsenzlehre hingewiesen. Irene Dingel (Hg.), Die Bekenntnisschriften der Evangelisch-Lutherischen Kirche. Vollständige Neuedition, Göttingen 2014, S. 242. Des Weiteren wird im Artikel 22 gegenüber der mittelalterlichen lateinischen Praxis bei der Sakramentsausteilung in nur einer Gestalt des Brotes auf die orthodoxe Vorgehensweise hingewiesen, das Sakrament in beiderlei Gestalt auszuteilen. Ebd., S. 581. In Artikel 24 wird mit dem Hinweis auf die griechischen Kirchen die Praxis der Privatmessen abgelehnt: »Das wir aber nicht privatmessen, sondern alleine eine öffentliche Mess, wenn das volck mit Communicirt, halten, das ist nichts widder die gemein Christliche kirchen. Denn inn der Kriechischen kirchen werden [bis] auff diesen tag kein Privatmessen gehalten, sondern allein ein Messe, und dasselbige auff die Sontage und hohe feste; das ist alles ein anzeigung des alten brauchs der kirchen«. Ebd., S. 616. Siehe dazu auch: Reinhard SLEnCZKA, Melanchthon und die orthodoxe Kirche des Ostens, in: Jörg Haustein (Hg.), Philipp Melanchthon. Ein Wegbereiter für die Ökumene, Göttingen 1997, S. 98-119, hier S. $115 f$.

100 Für eine Einführung und weiterführende Bibliographie siehe: Emmanuel Fritsch, Qəddase, in: EAE 4, 2010, S. 271-275; Habtemichael Kidane, Eucharist, in: EAE 2, 2005, S. 448-450. 


\subsection{Ekklesiologie}

Wohl der wichtigste Ertrag des proto-ökumenischen Dialoges bestand in der von den beiden Seiten getragenen Überzeugung, dass die orthodoxen Äthiopier und die Wittenberger Reformation trotz Unterschiede in der Lehre zu der einen gemeinsamen Kirche Christi gehören. Diese grundlegende Behauptung schlug sich im Empfehlungsschreiben nieder, das die Wittenberger Reformatoren für den äthiopischen Mönch vor seiner Abreise aus Wittenberg erstellten. ${ }^{101}$ In diesem Text werden die Worte Abba Mika ${ }^{\mathrm{D}} \mathrm{els}$ folgendermaßen wiedergegeben:

Nam etsi orientalis ecclesia habet aliquas dissimiles ceremonias, ipse quoque iudicat, quod dissimilitudo earum non tollat unitatem ecclesiae nec pugnet cum fide, quia Christi regnum est spiritualis iustitia cordis, timor dei et per Christum fiducia. ${ }^{102}$

Denn obgleich die morgenländische Kirche einige abweichende Bräuche beobachtet, so urteilt er [Abba Mika ${ }^{0}$ l] doch, dass dieser Unterschied weder die Einheit der Kirche aufhebt noch mit dem Glauben streitet, weil das Reich Christi geistliche Gerechtigkeit des Herzens, Gottesfurcht und Vertrauen durch Christus ist. ${ }^{103}$

Die Wittenberger Reformatoren äußerten ihre ausdrückliche Unterstützung dieser ökumenisch ausgerichteten Ekklesiologie: »Hanc sententiam et nos probamus« (»Diese Ansicht billigen auch wir«). ${ }^{104}$ Nachdem man die Übereinstimmung in den zentralen Glaubensfragen (der Trinitäts- und Abendmahlslehre) feststellte, einigte man sich auch in der Einsicht, dass die bestehenden Unterschiede im Ritus als Adiaphora zu betrachten seien.

Die Unterredung führte zu der Einschätzung, die im Kontext der fortschreitenden theologischen Polarisierung innerhalb des Christentums in der Frühen Neuzeit durchaus überrascht, dass die Wittenberger Reformation und die Kirche Äthiopiens im Wesentlichen den gleichen Glauben bekennen. Auch wenn das fehlende Wissen in Bezug auf die theologischen Positionen des jeweils Anderen sowie gegenseitiges Missverstehen, nicht zuletzt bedingt durch die Verständigungsschwierigkeiten, bei diesem orthodox-protestantischen Einvernehmen eine nicht zu unterschätzende, wenn nicht gar die zen-

101 Das von Luther unterzeichnete Schreiben wurde von Melanchthon vorbereitet.

102 Melanchthon, MBW.T 6, 2005, S. 124. Siehe den vollständigen Text des Schreibens im Kapitel II.1.1 »Persönliche Begegnungen mit dem Anderen: Abba Mika ${ }^{\circledR}$ l und die Wittenberger Reformatoren «.

103 Übersetzung - S.P.

104 Ebd. 
trale Rolle spielten, so hebt dies den Umstand nicht auf, dass beide Seiten von dieser Übereinstimmung genuin überzeugt gewesen zu sein scheinen.

Für die Reformatoren ging es hierbei um nichts weniger als eine der Kernfragen des protestantischen ekklesiologischen Selbstverständnisses - um das Verständnis des Glaubensartikels von der Einheit der Kirche. ${ }^{105}$ Die ökumenische Verständigung mit dem äthiopischen Mönch machte den Glaubenssatz, dass die Anhänger der Wittenberger Reformation trotz des Bruches mit Rom und trotz der fortlaufenden konfessionellen Fragmentierung innerhalb des reformatorischen Lagers Teil einer weltweiten, katholischen christlichen Gemeinschaft seien, nicht nur ableitbar aus dem Glaubensbekenntnis, sondern auch konkret erfahrbar.

In Bezug auf die ökumenisch offene Haltung Luthers gegenüber der Kirche Äthiopiens muss angemerkt werden, dass er bereits vor der Begegnung mit dem äthiopischen Diakon eine tendenziell wohlwollende Einstellung gegenüber den orthodoxen Kirchen hatte. ${ }^{106}$ Dazu kam die aufgezeigte Tendenz hinzu, im äthiopischen Christentum vor allem eigene theologische Anschauungen wiederzufinden.

Dabei verdient die ekklesiologische Positionierung Abba Mika ${ }^{\circ}$ els, die eine weitreichende Einheit der Kirche voraussetzt, besondere Aufmerksamkeit. Da alle Äußerungen des äthiopischen Mönchs ausschließlich durch die

105 Noch im Jahre 1532 musste Luther im Sendschreiben an Herzog Albrecht von Preußen (1490-1568) diesen Artikel des Glaubensbekenntnisses verteidigen. Vgl. Luther, WA 30, 1910, S. 552.

106 So vertrat er im Gegensatz zur spätmittelalterlichen lateinischen Theologie die Meinung - bspw. bei der Leipziger Disputation im Sommer 1519 -, dass die orthodoxen Kirchen, obwohl sie den Primat des Papstes nicht als göttliches Recht anerkennen, weder häretisch noch schismatisch seien. Auch in seiner im Jahre 1520 verfassten Schrift Von dem Papsthum zu Rom wider den hochberühmten Romanisten zu Leipzig verteidigte Luther die These von der Glaubens- und Sakramentsgemeinschaft mit den orthodoxen Christen: " [Man könne nicht behaupten,] das alle andere Christen in der gantzen welt ketzer und abtruniger sein, ob sie gleich die selben tauff, sacrament, Evangelium und alle artickel des glaubens mit uns eintrechticklich halten, auszgenommen, das sie yhre priester und bischoffe nit von Rom bestetigen lassen, [...] als da sein die Moscobiten, weysse Reussen, die Krichen [= Griechen], Behemen und vil andere grosse lendere in der welt. Dan disse alle glewben wie wir, teuffen wie wir, predigen wie wir, leben wie wir«. Ders., WA 6, 1888, S. 287. Freilich darf diese im Blick auf die Ostkirchen zu Beginn der Reformation geäußerte Überzeugung von der Einheit im Grundsätzlichen des christlichen Glaubens von ihrem polemischen anti-römischen Kontext nicht abgelöst werden. Zur Stellung der orthodoxen Kirchen in der Ekklesiologie Luthers siehe: Fairy von LiLIENFELD, Zum Wesen der Kirche. Einheit, Kontinuität und Universalität der heiligen katholischen und apostolischen Kirche in der Theologie Martin Luthers und in der »eucharistischen Ekklesiologie« des 20. Jahrhunderts, in: Karl Christian Felmy u.a. (Hg.), Sophia - Die Weisheit Gottes. Gesammelte Aufsätze 1983-1995, Erlangen 1997, S. 1-21, hier S. 3-12. Vgl. auch George Pósfay, »The Whole Christian Church on Earth « - Luther's Conception of the Universality of the Church, in: BLTS 72 (1992), S. $20-43$. 
Vermittlung deutscher Reformatoren überliefert worden sind, stellt sich die Frage, inwiefern man von ihrer Authentizität ausgehen kann. Handelte es sich hierbei möglicherweise um eine bloße Zuschreibung? Um diese Frage zu beantworten, müssen die Ansichten $A b b a$ Mika ${ }^{3}$ els einer kritischen Gegenlektüre anhand der zeitgenössischen Quellen äthiopischer Provenienz unterzogen werden.

Bemerkenswerterweise wird in den äthiopischen Texten, die im ersten Drittel des 16. Jahrhunderts entstanden sind, der kirchentrennende Charakter der theologischen Differenz zwischen dem äthiopischen und dem lateineuropäischen (römisch-katholischen) Christentum in Abrede gestellt. Während Gtege Gleni dies nur andeutet, spricht Ləbnä Dəngəl vielfach explizit von bestehender Übereinstimmung »in der einen Wahrheit der Religion und des Glaubens «. ${ }^{107}$ Ein noch aussagekräftigeres Zeugnis von der tiefen Verankerung dieser Sichtweise in der äthiopischen Theologie des frühen 16. Jahrhunderts stammt von Șägga Zä̊ab. Im Gegensatz zu Jleni und Ləbnä Dəngəl war er mit dem römischen Katholizismus aus eigener Anschauung wohlvertraut. ${ }^{108}$

Șägga Zä’ab plädierte eindrücklich für eine inklusive Ekklesiologie und betonte, wie auch $A b b a$ Mika ${ }^{\supset}$ l, dass die Kircheneinheit unabhängig von theologischen und liturgischen Unterschieden bestehe. Obwohl die portugiesischen Hoftheologen ab den frühen 1530er Jahren die Rechtgläubigkeit der Kirche Äthiopiens offensiv infrage stellten - und aufgrund dessen Șägga Zäaab, was ihn besonders gekränkt hatte, sogar von der Abendmahlsgemeinschaft ausschlossen,$-{ }^{109}$ bestand er darauf, dass die Übereinstimmung im Wesentlichen der christlichen Glaubenslehre bereits vorhanden sei, und dass man sich nur durch die lokalen Riten und Bräuche unterscheide:

Vgl. Uhlig / Bühring (Hg.), Damian de Góis' Schrift, S. 40, 45 (Text), S. 197, 201 (Übersetzung). An dieser Stelle seien zwei aussagekräftige Beispiele angeführt. Aus dem Brief Ləbnä Dəngəls an Manuel I. (1521): „Wie Ziegelstein mit Ziegelstein in der Wand verbunden ist, so stimmen wir beide in einem Herzen und in der einen Liebe zu Jesus Christus überein, der das Haupt der Welt ist, und diejenigen, die mit ihm sind, lassen sich vergleichen den in einer Mauer verbundenen Ziegelsteinen «. Ebd., S. 29 (Text), S. 185 (Übersetzung). Aus dem Brief Ləbnä Dəngəls an Papst Clemens VII. (1524): »[...] ich bin im Bereiche der christlichen Religion nicht minderwertiger als sie [christlichen Könige Europas]. Und so wie < auch $>$ jene glauben, bekenne ich den einen rechten Glauben und die eine Kirche, glaube ich so aufrichtig wie möglich an die Heilige Dreifaltigkeit und an den einen Gott und an die Jungfrauenschaft unserer Herrin, der Jungfrau Maria, und halte und bewahre ich alle Glaubensartikel, wie sie von den Aposteln niedergeschrieben worden sind «. Ebd., S. 50 (Text), S. 206 (Übersetzung).

108 Zum Zeitpunkt der Abfassung seiner Schrift De Athiopum Moribus hielt er sich bereits 8 Jahre in Portugal auf. Außerdem war er früher längere Zeit in Europa (vermutlich in Rom) gewesen, sodass er die italienische Sprache hatte erlernen können. Vgl. »A quibus (nescio quam pie) mihi interdictum est sumere corpus Dominicum, postquam in Lusitaniam veni, quod spacium est septem annorum, \& (id quod 
Quamobrem indignum est, peregrinos Christianos tam acriter, ac hostiliter reprehendi, ut ego de hac re, \& de aliis, quæ minime ad ueram fidem spectabant, reprehensus fui. Sed multo consultius erit huiusmodi Christianos homies, sive Græcos, sive Armenios, sive Aethiopes, sive ex quauis septem Christianorum Ecclesiarum, in charitate, \& Christi amplexibus sustinere, \& eos sine contumelis permittere, inter alios fratres Christianos viuere, ac versari, quoniam omnes fili baptismi sumus, \& de vera fide unanimiter sentimus. Nec est causa, cur tam acriter de ceremoniis disceptetur, nisi ut vnusquisos suas obseruet, sine odio \& insectatione aliorum, nec commerciis Ecclesiæ ob id exludendus est, si peregre in alienis prouinciis domesticos ritus obseruet.

Daher ist es unwürdig, daß fremde (aus einem anderen Lande stammende) Christen so scharf und feindselig getadelt werden, wie ich in dieser Sache und in anderen, die keineswegs sich auf den wahren Glauben bezogen, getadelt worden bin. Sondern es wird viel rücksichtsvoller (von tieferer Überlegung zeugend) sein, Christen dieser Art, seien es Griechen, Armenier, Äthiopier oder Leute, die aus jeder beliebigen der sieben Gemeinden der Christen stammen, in Liebe und in der Umarmung Christi zu ertragen und zuzulassen, daß sie ohne Kränkungen unter den anderen christlichen Brüdern leben und wandeln, da wir ja alle Söhne der Taufe sind und einmütig über den wahren Glauben urteilen. Es besteht kein Grund, warum so scharf über die Zeremonien hin und her gestritten werden sollte, sofern nur jeder einzelne seine <eigenen> Zeremonien beobachtet ohne Haß und Verfolgung der anderen; und er darf deswegen nicht von der Gemeinschaft der Kirche ausgeschlossen werden, wenn er im Ausland in fremden Provinzen seine heimatlichen Riten beobachtet. ${ }^{110}$

Diese Zeitdokumente zeugen von einer geradezu exzeptionellen Offenheit vieler äthiopischer Intellektuellen des ersten Drittel des 16. Jahrhunderts gegenüber dem lateinischen Christentum und werfen neues Licht auf die Theologie Abba Mika ${ }^{\circ}$ els. Zum einen kann man aufgrund ihrer nun davon ausgehen, dass die ekklesiologischen Positionen des äthiopischen Diakons, so wie Luther und Melanchthon sie überliefern, authentisch sind. Zum anderen lässt sich die durch den äthiopischen Mönch und die Wittenberger Reformatoren geteilte Überzeugung, gemeinsam zu einer Kirche zu gehören, präzisieren und zugleich etwas relativieren. Höchstwahrscheinlich war die Ekklesiologie $A b b a$ Mika $^{0}$ els noch deutlich inklusiver, als es Luther recht

non sine dolore, ac lachrymis dicam) reputor inter fratres Christianos, tanquam Ethnicus, \& Anathema«.

»Von ihnen [den Gelehrten der römischen Kirche] ist mir (sozusagen in frommer Weise) untersagt worden, den Leib des Herrn zu empfangen, seitdem ich nach Portugal kam - das war vor nunmehr sieben Jahren. Ich werde (das sage ich nicht ohne Schmerz und Tränen) unter den christlichen Brüdern gleichsam für einen Heiden und für anathematisiert gehalten«. Ebd., S. 85 (Text), S. 264 (Übersetzung).

Ebd., S. 80 (Text), S. 258f. (Übersetzung). 
gewesen wäre: Seine offene Haltung galt vermutlich nicht nur dem Protestantismus oder gar nur der Wittenberger Reformation, wie Luther es sowohl in den Tischreden als auch im Empfehlungsschreiben darstellt, sondern dem lateinischen Christentum insgesamt, einschließlich der Kirche Roms. ${ }^{11}$

Die entscheidende Frage, die sich in diesem Zusammenhang stellt, ist jedoch: Worauf gründete sich diese offene Ekklesiologie äthiopischer Intellektueller des frühen 16. Jahrhunderts? Die These, die im folgenden UnterKapitel näher erläutert wird, lautet, dass das vermeintliche Hinwegsetzten über die theologischen Differenzen in einem spezifischen eschatologischen Weltbild wurzelte, in dessen Rahmen die äthiopischen Eliten der Zeit die Aufnahme intensiver Beziehungen zu Lateineuropa auffassten.

\subsection{Eschatologie}

Während der Einfluss der eschatologischen Lehre des Joachim von Fiore (ca. 1130-1202) auf den portugiesischen König Manuel I. - einschließlich dessen Suche nach dem Priesterkönig Johannes sowie die daraus folgende Aufnahme der Beziehungen mit Äthiopien - gut erforscht und dokumentiert ist, ${ }^{112}$ ist umgekehrt die Rolle eschatologischer Vorstellungen beim Aufbau der äthiopischen Kontakte zu Lateineuropa kaum untersucht.

Das frühe 16. Jahrhundert zeichnete sich in Äthiopien durch eine intensive eschatologische Naherwartung aus. Laut der Kalkulation Zär ${ }^{\supset a}$ Yac əqobs sollte im Jahre 1501 nach äthiopischer Zeitrechnung ${ }^{113}$ (1508/1509 A. D.) das

111 Darüber hinaus ist es vorstellbar, dass $A b b a$ Mika ${ }^{0}$ l die Katholiken und die Anhänger der Reformation nicht als Mitglieder separater Kirchengemeinschaften (was sie nach ihrem Selbstverständnis in den frühen 1530er Jahren bereits waren) betrachtete, sondern sie, analog zu den äthiopischen Realitäten, zu unterschiedlichen theologischen Schulen zählte, ohne die Differenz zwischen ihnen für kirchentrennend zu halten.

112 Vgl. Luís Filipe Thomaz, L’idée impériale manueline, in: Jean Aubin (Hg.), La découverte, le Portugal et l'Europe. Actes du colloque célébrée à Paris le 26, 27 et 28 Mai 1988, Paris 1990, S. 35-103, hier S. 55-57; Andrew KurT, The Search for Prester John, a Projected Crusade and the Eroding Prestige of Ethiopian Kings, c. 1200-c. 1540, in: JMedHist 39 (3) (2013), S. 297-320, hier S. 316; Alexander Patschovsky, Semantics of Mohammed and Islam in Joachim of Fiore, in: Israel Jacov Yuval/Ram Ben-Shalom (Hg.), Conflict and Religious Conversation in Latin Christendom. Studies in Honour of Ora Limor, Turnhout 2014, S. 115-131; Giuseppe Marcocci, Prism of Empire. The Shifting Image of Ethiopia in Renaissance Portugal (1500-1570), in: Maria Berbara/Karl A.E. Enenkel (Hg.), Portuguese Humanism and the Republic of Letters, Leiden 2012, S. 447-464.

113 Die äthiopische Zeitrechnung basiert auf einer Variante des koptischen Kalenders und zählt in einem Jahr 13 Monate, wobei die ersten 12 Monate jeweils 30,

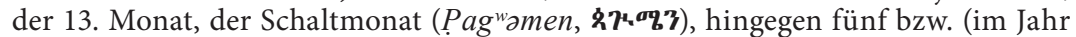
vor einem Schaltjahr) sechs Tage umfasst. Die Zeitrechnung wird wie im gregorianischen Kalender auf Christi Geburt zurückgeführt, doch die Jahreszählung läuft 
achte Jahrtausend nach der Schöpfung der Welt, das man mit dem eschatologischen Zeitalter assoziierte, beginnen. ${ }^{114}$ Ein weiterer Grund für die Intensivierung der Naherwartung ist in den sich häufenden kriegerischen Auseinandersetzungen mit dem Sultanat Adal zu suchen. Der vom muslimischen Herrscher Aḥmad ibn Ibrāhīm al-Ġāzī (ca. 1506-1543) ${ }^{115}$ im Zeitraum von 1529 bis 1543 geführte Eroberungsfeldzug gegen Äthiopien drohte, das christliche Kaiserreich zu vernichten. ${ }^{116}$ Diese Ereignisse ließen sich als Vorboten des apokalyptischen Glaubenskrieges interpretieren, der der Wie-

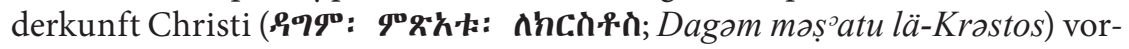
ausgehen sollte.

Im Rahmen äthiopischer Eschatologie, die in der Tradition der Apokalypse des Pseudo-Methodius verwurzelt war, ${ }^{117}$ wird die Schlüsselrolle in den endzeitlichen Ereignissen den zwei königlichen Figuren, der

dem gregorianischen Kalender sieben Jahre und etwa acht Monate hinterher. Dieser Unterschied beruht auf einem Festhalten der Äthiopier am vor-dionysianischen Geburtsjahr Christi, das 5500 Jahre nach dem damals angenommenen Datum der Schöpfung angesetzt wurde. Die Jahre nach Christi Geburt werden Amätä Məhrat ( Emmanuel Fritsch, The Liturgical Year of the Ethiopian Church. The Temporal Seasons and Sundays, Addis Ababa 2001; ders. / Ugo Zanetri, Christian Calendar, in: EAE 1, 2003, S. 668-672.

114 Vgl. Wendt (Hg.), Das Mașhafa Milād [Textus] II, Louvain 1963, S. 42; ders. (Hg.), Das Mașhafa Milād [Versio] II, S. 100f. Vgl. auch Merid Wolde Aregay, Millenarian Traditions and Peasant Movements in Ethiopia. 1500-1855, in: Sven Rubenson (Hg.), Proceedings of the Seventh International Conference of Ethiopian Studies. University of Lund, 26-29 April 1982, Addis Ababa u. a. 1984, S. 257-262.

115 In der äthiopischen Historiografie ist al-Ġāzī als Aḥmad Grañ bekannt. Über ihn siehe: Franz-Christoph Muth, Aḥmad b. Ibrāhīm al-Ġāzī, in: EAE 1, 2003, S. 155-158.

116 Vgl. Amélie Chekroun/Bertrand Hirsch, The Muslim-Christian Wars and the Oromo Expansion. Transformations at the End of the Middle Ages (ca. 1500ca. 1650), in: Samatha Kelly (Hg.), A Companion to Medieval Ethiopia and Eritrea, Leiden u.a. 2020, S. 454-476, hier S. 455-463; John Spencer Trimingham, Islam in Ethiopia, London u. a. 2008, S. 84-93; Asa Davis, The Sixteenth Century Jihād in Ethiopia and the Impact on Its Culture, in: Journal of the Historical Society of Nigeria 2 (1963), S. 567-592.

117 Der ursprüngliche Titel des im ausgehenden 7. Jahrhundert in syrischer Sprache verfassten Buches ist Rede über die Abfolge der Könige und das Ende der Zeiten. Das Werk, das Methodios, Märtyrer und Bischof im lykischen Olympos (gest. ca. 311), zugeschrieben wurde, war als Reaktion auf die Entstehung und Ausbreitung des Islam verfasst. Diese Apokalypse fand in kurzer Zeit Verbreitung in praktisch der gesamten christlichen Ökumene. Edition: Gerrit Jan ReInInk (Hg.), Die syrische Apokalypse des Pseudo-Methodius, CSCO 540, 541 [CSCO.S 220, 221], Louvain 1993. Siehe auch: Ders., Ps.-Methodius. A Concept of History in Response to the Rise of Islam, in: Averil Cameron / I. Lawrence Conrad (Hg.), The Byzantine and Early Islamic Near East, Princeton NJ 1992, Bd. 1: Problems in the Literary Source Material, S. 149-187; Harald Suermann, Die geschichtstheologische Reaktion auf die einfallenden Muslime in der edessenischen Apokalyptik des 7. Jahrhunderts, Frankfurt a. M. 1985, S. 34-85. 


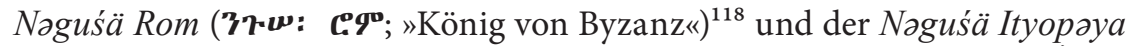

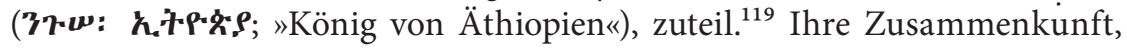
Einigung in Glaubensfragen sowie die daraus resultierende Vereinigung ihrer Armeen unter der Führung der Naguśä Ityopaya sollte den endgültigen Sieg des Christentums im Glaubenskrieg und den Beginn des millenaristischen Friedensreiches herbeiführen. ${ }^{120}$ Diese Vorstellung fand ihren Ausdruck in mehreren Werken äthiopischer Theologie. Das von seiner ideengeschichtlichen Wirkung wichtigste davon ist zweifellos das Kabrä Nägäśt

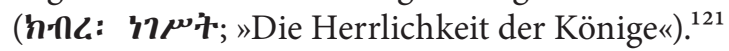

118 Die heute übliche Bezeichnung »Byzantinisches Reich« ist modernen Ursprungs. So

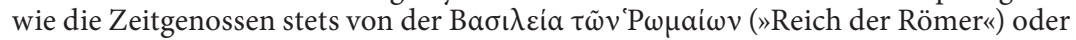

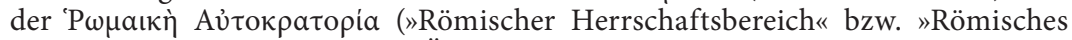
Kaiserreich «; dies ist die direkte Übersetzung des lateinischen Imperium Romanum ins Griechische) sprachen, wird auch in den äthiopischen Quellen Byzanz - oder stellvertretend dessen Hauptstadt Konstantinopel, Néa $\mathrm{P} \omega \dot{\omega} \mu \eta$ (»Neues Rom«), - als

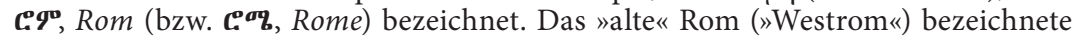
man hingegen als $\boldsymbol{C}^{\mathbf{9}} \boldsymbol{P}$, Romya (bzw. C. ${ }^{\boldsymbol{\top}}$, Roma).

119 Zur äthiopischen Eschatologie und insbesondere zum Stellenwert der Figur des äthiopischen Königs darin siehe: André CAQUOT, La royauté sacrale en Éthiopie, in: AEt 2 (1957), S. 205-218; Eike HABERLAND, Untersuchungen zum äthiopischen Königtum, Wiesbaden 1965, S. 149-172; Robert BEYLOT, Le millénarisme, article de foi dans l'Église Éthiopienne au XVme siècle, in: RSEt 25 (1971-1972), S. 31-43 sowie Merid Wolde Aregay, Literary Origins of Ethiopian Millenarianism, in: Anatoly Gromy ко (Hg.), Proceedings of the Ninth International Congress of Ethiopian Studies. Moscow, 26-29 August 1986, Moscow 1988, Bd 5, S. 161-172, hier S. 166-169.

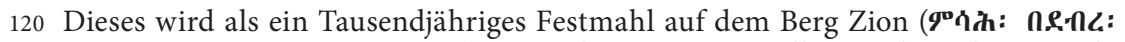
8:P."7; Masah bä-Däbrä Șyyon) mit Christus vorgestellt, an dem die Gerech-

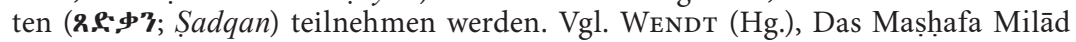
[Textus] I, S. 37-44.

121 Ausgehend von den im Werk enthaltenen Kolophonen wird der Zeitraum der Entstehung der letzten Textfassung auf die Jahre 1314 bis 1321 eingegrenzt. Es wird allerdings davon ausgegangen, dass die Schrift zahlreiche ältere Überlieferungen enthält. Für eine Einführung und einen Forschungsüberblick siehe: Paolo Marrassini, Kəbrä Nägäśt, in: EAE 3, 2007, S. 364-368; Alessandro Bausi (Hg.), Languages and Cultures of Eastern Christianity. Ethiopian, Oxford 2012, S. LIILIII und S. 121-186; Pierluigi Piovanelli, The Apocryphal Legitimation of a "Solomonic « Dynasty in the Kəbrä Nägäśt. A Reappraisal, in: Aethiopica. International Journal of Ethiopian Studies 16 (2013), S. 7-44. Kritische Edition: Carl Bezold, Kebra Nagast. Die Herrlichkeit der Könige. Nach den Handschriften in Berlin, London, Oxford und Paris zum ersten Mal im äthiopischen Urtext herausgegeben und mit deutscher Übersetzung versehen, ABAW.PP 23, München 1905.

Das Kabrä Nägäśt, dessen größter Teil in Form einer Rede von Gregor dem Erleuchter (ca. 240-331) an die »318 Orthodoxen« - die Väter des ersten Ökumenischen Konzils von Nicäa (325) - verfasst war, versucht, eine Sonderstellung des äthiopischen Königs innerhalb der christlichen Oikumene zu begründen. Laut dem Kabrä Nägäśt stammen alle königlichen Dynastien ausnahmslos von Shem ab, Noachs älterem Sohn; dennoch genießen die Könige von Byzanz und Äthiopien eine besondere Stellung und sollen über die ganze Welt herrschen. Die Grenze der beiden Machtbereiche verlaufe quer durch Jerusalem hindurch; die südliche Hälfte 
$\mathrm{Zu}$ Beginn des 16. Jahrhunderts ist allerdings eine semantische Verschiebung in der Attribution des Naguśä Rom, des »Königs von Byzanz«, zu beobachten. Wohl als Reaktion auf den Fall Konstantinopels 1453 tendierte man nun dazu, unter dem äthiopischen Begriff Rom (C.99) nicht mehr die Gebiete des (inzwischen ehemaligen) oströmischen Reiches, sondern die des weströmischen Reiches zu verstehen.

Die Entwicklung dieser äthiopischen Imagination, die einen Zusammenschluss mit einem mächtigen christlichen Herrscher aus dem Abendland vorsah, kann als eine beachtliche Parallele zum europäischen Mythos vom Priesterkönig Johannes betrachtet werden. In Folge dieser Umdeutung konnte man die Begegnung mit den Portugiesen, deren erste Gesandtschaft ausgerechnet im Jahre 1508 A. D. (= 1501 A. M.) in Äthiopien eintraf, als Zeichen der herannahenden eschatologischen Zeiten interpretieren. So sprach Gtege Gleni 1509 in ihrem Brief an Manuel I. explizit von den sich durch ihre Kontaktaufnahme erfüllenden endzeitlichen Weissagungen ${ }^{122}$ und sandte ihm ein ungewöhnlich kostbares Geschenk, »einen Teil des [wahren] Kreuzes

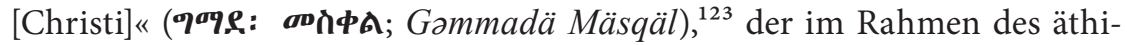
opischen religiös-kulturellen Referenzsystems klar auf die eschatologische

der Heiligen Stadt sowie alle Gebiete südlich davon gehörten dem König von Äthiopien, alle Länder nördlich davon dem König von Byzanz. Dabei gelte der Vorrang dem König von Äthiopien als dem erstgeborenen Sohn Salomos. Aus diesem Grund habe der äthiopische König eine eschatologische Rolle - er werde das Christentum zum endzeitlichen Sieg verhelfen und dem Tausendjährigen Reich Christi den Weg bereiten. Zum »salomonischen Narrativ« siehe außerdem Kapitel III.2.1 »Umdeutungen des >salomonischen Narrativs «

122 Vgl. »Adestiam tempus illud promissum, quod (ut aiunt) Christus \& mater eius Maria, praedixere, quod scilicet in postremis temporibus oriturus esset e regionibus Francicis Rex quispiam, qui aboliturus esset universum Barbarorum, \& Maurorum genus. Et hoc ipsum quidem nunc tempus est, quod Christus benedictae suae matri Mariae futurum promisit«. Górs, Legatio, S. 9. Vgl. ders., Fides, Religio, Moresque Æthiopum, S. 14f. Die äthiopische Version des Briefs ist abgedruckt in SERGEW Hable-Sellasie, The Ge'ez Letters of Queen Eleni and Libne Dingil to John, King of Portugal, in: Accademia Nazionale dei Lincei (Hg.), IV Congresso Internazionale di Studi Etiopici (Roma, 10-15 April 1972), Roma 1974, Bd. 1, S. 547-566, hier S. 554-558.

123 Antoine Khater/Oswald Hugh Ewart Burmester (Hg.), History of the Patriarchs of the Egyptian Church, Known as the History of the Holy Church, Cyril II Cyril V (A. D. 1235-1894), Caire 1970, S. 249f. Zur Aufnahme des Kreuzes Christi in Lissabon und dessen Rolle in der äthiopisch-portugiesischen Diplomatie siehe: Isabel BoAvida, The Cross Brought to Goa and Portugal by Libnä Dingil's Envoy Mathew, in: Manuel Joo Ramos/Isabel Boavida (Hg.), The Indigenous and the Foreign in Christian Ethiopian Art. On Portuguese-Ethiopian Contacts in the 16th17 th Centuries. Papers from the Fifth International Conference on the History of Ethiopian Art (Arrábida, 26-30 November 1999), Aldershot 2004, S. 136-142. Die Reliquie blieb allerdings nicht lang in Portugal; 1522 schenkte König João III. sie dem neu gewählten Papst Hadrian VI. (1459-1523; r. 1522-1523) anlässlich seines Besuches in Zaragoza. 
Rolle des äthiopischen Königs verwies. ${ }^{124}$ Auch der Kaiser Ləbnä Dəngəl betrachtete seine Interaktion mit dem portugiesischen Königshaus in diesem Lichte. Dabei ist besonders seine Bemerkung aus einem 1521 verfassten Brief aufschlussreich:

De hac autem mutua legatione antiquitus praedictum fuit a Propheta in libro de vita, \& passione sancti Victoris, \& in libris sanctorum Patrum, qoud Rex magnus Christianus cum Rege Aethiopiae esset cum mutua pace conuenturus. Sed hoc nequaquam futurum existimabam diebus vitae meae. ${ }^{125}$

Über diese wechselseitige Gesandtschaft gab es von alters her eine Voraussage vom Propheten im Buche über das Leben und die Passion des heiligen Victor und in den Büchern der heiligen Väter, daß der große christliche König mit dem König Äthiopiens übereinkommen werde über einen gegenseitigen Frieden. Aber daß dieses in den Tagen meines Lebens geschehen werde, das habe ich keineswegs geglaubt. ${ }^{126}$

124 Laut der äthiopischen Tradition ist der Teil des wahren Kreuzes Christi in der Regierungszeit des Kaisers Dawit I. (.9中. ; ca. 1350-1413; r. 1382-1411) nach Äthiopien gelangt, und zwar als Geschenk eines byzantinischen Herrschers, der damit seine Dankbarkeit für die Rettung vor einem muslimischen Angriff dem äthiopischen Kaiser gegenüber zum Ausdruck gebracht habe. Diese historische Tradition ist breit dokumentiert in den äthiopischen Quellen. Siehe bspw. den vor Kurzem publizierten Auszug aus dem Manuskript EMML 5538, der diese Geschichte enthält: Getatchew Haile, The Ethiopian Orthodox Church's Tradition on the Holy Cross, Texts and Studies in Eastern Christianity 10, Leiden u. a. 2018, S. 4-8 (Text), S. 8-14 (Übersetzung). Die Schenkung eines Teiles des Kreuzes an den äthiopischen Kaiser belegt auch die auf Arabisch verfasste Alexandrinische Patriarchengeschichte, die dem koptischen Bischof Sāwīris ibn al-Muqaffac (gest. 987) zugeschrieben wird. In der Schenkung »des wahren Kreuzes Christi« sollte sich die Bestätigung der eschatologischen Rolle des äthiopischen Kaisers äußern. Denn laut dem Manuskript EMML 5538 stilisierten andere christliche Monarchen den äthiopischen Kaiser, den Lobgesang des Zacharias' (Lk 1,68-79) paraphrasierend, zu Johannes den Täufer, der die zweite Ankunft Christi vorbereiten solle:

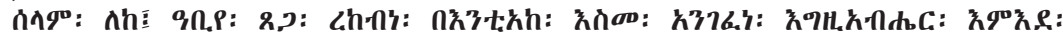

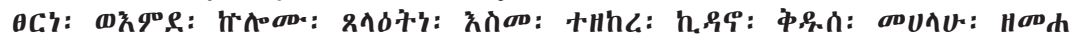

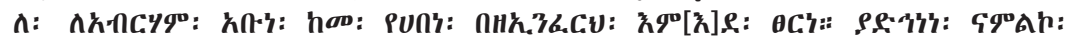

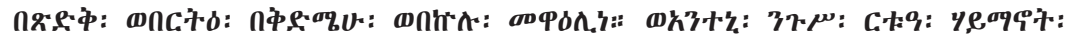

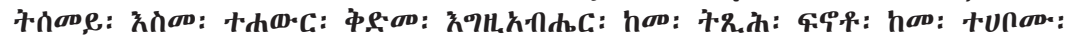

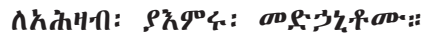

»Peace to you. We have received great grace because of you, for God has rescued us from the hands of our enemy, and from the hand of all our foes. >For he has remembered his holy covenant, the oath that he sworn to our father Abraham to grant us (a cause) that we should not fear the hand of our enemies, that he would save us so we may worship him with righteousness and just before him in all our days. And you, O king, shall be called of Orthodox Faith, for you go before God to prepare his way, to give (knowledge) to nations that they may know their salvation««. Ebd., S. 5 (Text), S. 10 (Übersetzung).

125 Góis, Fides, Religio, Moresque Æthiopum, S. 24.

126 Uhlig / Bühring (Hg.), Damian de Góis' Schrift, S. 181. 
Unter dem heiligen Viktor ist hier der populäre oberägyptische Märtyrer

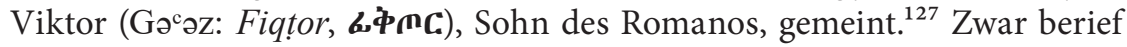
sich Ləbnä Dəngəl auf die Vita Viktors, doch tatsächlich dürfte er eines seiner "Wunder" ( $\mathbf{k} \mathbf{9}^{\circ} \mathbf{C}$; Täəammər) gemeint haben, welche einen separaten literarischen Korpus bilden. ${ }^{128}$ Genauer gesagt, sollte es sich hierbei um

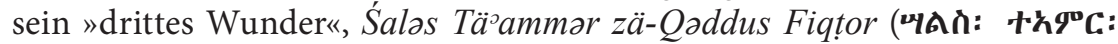

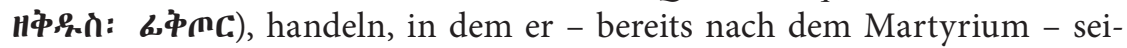
ner Mutter im Traum erscheint und ihr die Abfolge endzeitlicher Ereignisse offenbart. ${ }^{129}$

Dass die Intensität der endzeitlichen Naherwartung zu der Zeit des Aufenthaltes $A b b a$ Mika ${ }^{2}$ ls in Wittenberg 1534 nicht nachgelassen hatte, belegt die in dem Jahr verfasste Schrift Șägga Zä’abs. ${ }^{130}$ Zugleich offenbart sie ein weiteres bemerkenswertes Detail, das das Bild der äthiopischen eschatologischen Vorstellungen der Zeit ergänzt. Indem Șägga Zä’ab in den Annäherungen an Lateineuropa die Erfüllung der alten Weissagungen aufgezeigt wähnt, verweist er neben dem bereits von Ləbnä Dəngəl erwähnten Fiqțor-Text auch auf eine Prophezeiung des bedeutenden koptischen Kirchenvaters Schenute

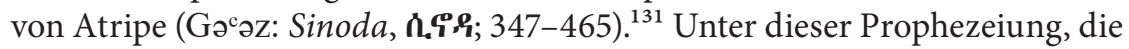
lange Zeit nicht identifiziert werden konnte, ${ }^{132}$ ist offensichtlich der apoka-

127 Zur Viktor-Tradition in der koptischen Literatur siehe: Jürgen HoRN, Untersuchungen zu Frömmigkeit und Literatur des christlichen Ägypten. Das Martyrium des Viktor, Sohnes des Romanos. Einleitung in das koptische Literaturwerk, Diss. Georg-August-Universität Göttingen 1988.

128 Insgesamt sind in der äthiopischen Tradition vier »Wunder« des heiligen Fiqțors bekannt. Vgl. die Handschrift Aeth. 4 der Österreichischen Nationalbibliothek. Nikolaus RHODOKANAKIs, Die äthiopischen Handschriften der K. K. Hofbibliothek zu Wien, SAWW.PH CLI, Wien 1906, S. 69-71.

129 Es gibt bis jetzt jedoch keine kritische Edition des Werkes. Die einzige Publikation ist die von Enno Littmann anhand eines einzelnen Manuskripts herausgegebene Version des »dritten Wunders«: Enno Littmann, Abyssinian Apocalypses, in: AJSL 19 (2) (1903), S. 83-95, hier S. 86-89 (Text), S. 91-93 (Übersetzung). Auf den Einfluss der Fiqțor-Tradition auf den äthiopischen Kaiserhof des frühen 16. Jahrhunderts weist u. a. die Tatsache hin, dass Ləbnä Dəngəl seinen ältesten Sohn Fiqțor (6\$\$nC; gest. 1539) nannte. Manfred Kropp (Hg.), Die Geschichte des Lebna-Dengel, Claudius und Minas, CSCO 503 [CSCO.Ae 83], Louvain 1988, S. 17, 30. An sich war Fiqtor kein üblicher Name in Äthiopien, der v. a. für die eingereisten Kopten dokumentiert ist.

130 Góis, Fides, Religio, Moresque Æthiopum, S. 87.

131 »Cuius rei oracula duo habemus, alterum ex Prophetia S.[ancto] Fictoris, alterum ex sancto Synoda eremita, nato in extremis Aegypti cautibus, quorum neutrum ab altero dissentit«. Ebd. »Zwei Weissagungen darüber haben wir, die eine aus der Prophetie des heiligen Ficator (Victor), die andere von dem heiligen Eremiten Synodas, der in den äußersten Riffen Ägyptens geboren ist, von denen keine von der anderen abweicht«. Uhlig / Bühring (Hg.), Damian de Góis' Schrift, S. 268.

132 So stellten bspw. die Herausgeber der Schrift fest, dass bisher nicht geklärt sei, was mit der Prophezeiung gemeint war. Ebd., S. 269, Anm. 576. 


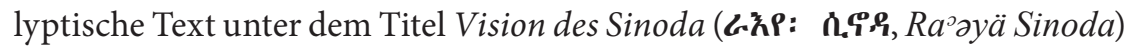
zu verstehen. ${ }^{133}$

Die beide Werke, das Śalas Tärammar zä-Qəddus Fiqtor und das $R a^{\supset}$ yä Sinoda, stehen in klarem Zusammenhang miteinander ${ }^{134}$ und zeichnen ein beinahe identisches Bild der endzeitlichen Geschehnisse, die eine bedeutende ekklesiologische Implikation haben. Denn dieser eschatologischen Vision zufolge werde die Zusammenkunft der Könige von Äthiopien und von »Rom « durch das Treffen »ihrer « Patriarchen (von Alexandrien und von »Rom«) begleitet werden, die angesichts des bevorstehenden apokalyptischen Kriegs sieben Monate lang um die Kircheneinigung ringen werden. ${ }^{135}$ Sie werde jedoch nicht mittels theologischer Debatten herbeigeführt, diese seien zum Scheitern bestimmt, sondern durch einen Akt der göttlichen Intervention, durch eine Theophanie. ${ }^{136}$

Edition: Adolf Grohmann, Die im Äthiopischen, Arabischen und Koptischen erhaltenen Visionen Apa Schenute's von Atripe. I. Die im Äthiopischen erhaltenen Visionen, in: ZDMG 67 (1913), S. 187-267. Von Bedeutung der eschatologischen

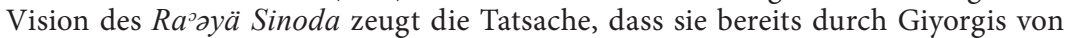

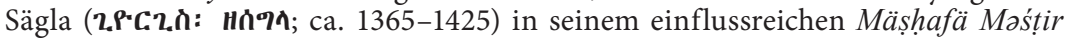

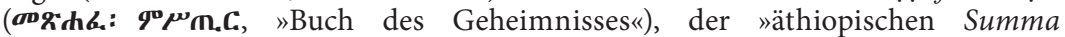
Theologica", zitiert wird. Yaqoв Beyene (Hg.), Giyorgis di Saglā. Il libro del Mistero (Mäșhafa Mesțir) [II] [Text], CSCO 532 [CSCO.Ae 97], Louvain 1993, S. 125129 und ders. (Hg.), Giyorgis di Saglā. Il libro del Mistero (Mäṣhafa Mesțir) [II] [Versio], CSCO 533 [CSCO.Ae 98], Louvain 1993, S. 76-80.

Dem Reisebericht von Francisco Álvares, der sich als Mitglied der portugiesischen Gesandtschaft von 1520 bis 1526 in Äthiopien aufgehalten hatte, ist zudem zu entnehmen, dass auch Abunä Marqos, der Oberhaupt der äthiopischen Kirche, die Annäherung mit der lateinischen Christenheit im Licht der eschatologischen Vorstellungen betrachtete und sich dabei ebenso auf die »Prophezeiungen« des Fiqtor und des Sinoda berief. Vgl. Beckingham / Huntingford (Hg.), The Prester John of the Indies, S. 358.

134 Der Zusammenhang zwischen den beiden Texten wurde auch innerhalb der äthiopischen Tradition hergestellt, was die Manuskripte zum Ausdruck bringen (wie bspw. die Handschrift Aeth. 4 der Österreichischen Nationalbibliothek), die gleichzeitig beide Werke enthalten. Rhodokanakis, Die äthiopischen Handschriften, S. 69-71. Spezifikum beider Werke, deren gründliche wissenschaftliche Erschließung immer noch ein Desideratum darstellt, besteht darin, dass sie in äthiopischer Theologie eine richtungsweisende Rolle spielten, während sie anderen Kulturen des christlichen Orients (auch der koptischen!) offensichtlich nicht bekannt waren. Das $R a^{2}$ əyä Sinoda weist Ähnlichkeiten weder zum nur fragmentarisch bekannten koptischen Text der Vision Schenutes auf noch zu der Vision, die in einer arabischen Predigt von Kyrill von Alexandrien (ca. 375-444) zitiert wird. Vgl. Paola Buzi / Alessandro BAUsi, Shenute of Atripe, in: EAE 4, 2010, S. 648-650, hier S. 649. Ebenso ist auch das Śalos Tärammər zä-Qəddus Fiqtor nur in der äthiopischen Version bekannt. Vgl. Littmann, Abyssinian Apocalypses, S. 85.

135 Adolf Grohmann, Aethiopische Marienhymnen, ASAW.PH 33 (4), Leipzig 1919, S. $254 \mathrm{f}$.

136 Es ist unnötig zu sagen, dass die Kircheneinigung auf der Grundlage des »alexandrinischen« Glaubens stattfinden solle. Die Erscheinung Gottes wird allerdings nicht nur zur Kircheneinigung führen, sondern auch die Juden und Muslime zu einer 
Erst vor diesem Hintergrund erhält die ekklesiologische Position Abba Mika ${ }^{\circ} e l s$, die im Dialog mit den Wittenberger Reformatoren zum Ausdruck gebracht wurde, ihre theologischen Konturen und wird nachvollziehbar. Die eschatologische Tradition, die sich im Śaləs Tä̊ammər zä-Qəddus Fiqtor und dem Ra əoyä Sinoda niederschlagen hatte und im frühen 16. Jahrhundert einer radikalen Umdeutung (»Verwestlichung« der Naguśä RomFigur) unterzogen wurde, schuf einen Referenzrahmen, in dem die Begegnung mit dem lateineuropäischen Christentum konzeptualisiert wurde. Auf-

Massenkonversion zum Christentum veranlassen und, schließlich, die ganze Welt in einen paradiesischen Zustand verwandeln. Das Ra $a^{\supset}$ yä Sinoda stellt die Theopha-

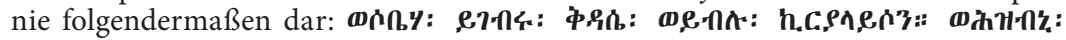

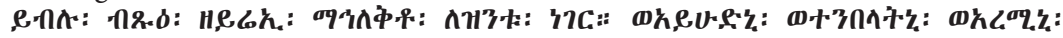

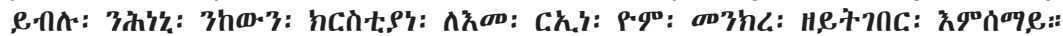
कe.

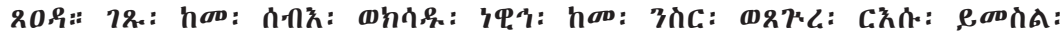

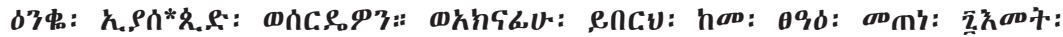

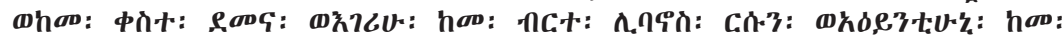

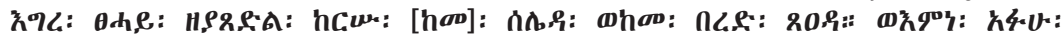

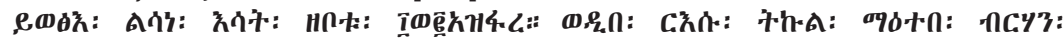

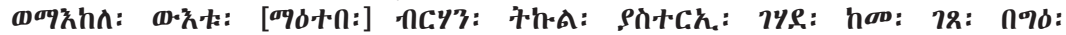

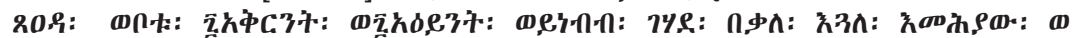

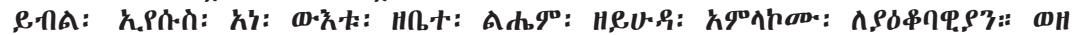

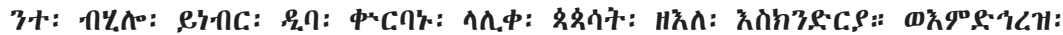

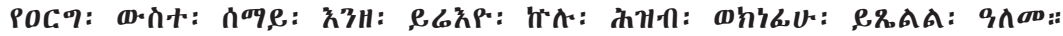

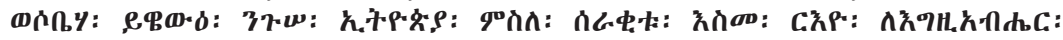

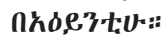

»Und darauf werden sie [Patriarchen von Alexandrien und von Rom] die heilige Messe zelebrieren und das Kyrie eleison sprechen. Und das Volk hin wiederum wird sagen: Selig, wer den Ausgang dieses Ereignisses sieht. Und die Juden und die Muhammedaner und die Heiden wieder werden sagen: Auch wir werden Christen (werden), wenn wir das Wunder gesehen haben, das heute vom Himmel vollbracht werden wird. Und sie werden (nun) abermals das Kyrie eleison sprechen und noch ein drittesmal. Und alsbald wird der heilige Geist in Gestalt einer weißen Taube herabsteigen. Sein Gesicht wird wie ein Mensch sein, sein Hals wie ein Adler und seine Kopffedern werden dem Edelsteine Jaspis und Sardion gleichen. Und seine Flügel in der Länge von sieben Ellen werden wie der Blitz und wie der Regenbogen leuchten, seine Füße wie das glühende Erz vom Libanon, seine Augen wie der Strahl der leuchtenden Sonne, sein Bauch [wie] eine Schreibtafel (Pergamenttafel) und wie der weiße Schnee. Und aus seinem Munde wird eine Feuerzunge kommen, die zwölf Ausläufer (Fransen) hat. Und auf seinem Kopfe (wird) ein (Kreuzes)zeichen, (das) aus Licht (besteht), befestigt (sein) und inmitten dieses (Kreuzes)zeichens, (das) aus Licht (besteht), wird deutlich (etwas) zum Vorschein kommen, wie das Angesicht eines weißen Lammes, und es wird sieben Hörner und sieben Augen haben und vor allen Augen mit menschlicher Stimme reden und sagen: »Jesus bin ich von Bethlehem im Lande Juda, der Gott der Jakobiten«. Diese (Worte) sprechend wird er über dem Opfer des Patriarchen der Alexandriner schwebend blieben. Und darauf wird er zum Himmel aufsteigen, indem das ganze Volk (ihn) sieht, und seine Fittiche die Welt beschatten. Und alsdann wird der König von Äthiopien mit seinen Truppen ein Geschrei erheben, denn er wird Gott mit seinen Augen gesehen haben. Und die ganze Welt wird in seinem Glauben begründet werde«. Ebd., hier S. 255-259. 
grund der Gewissheit der unmittelbar bevorstehenden Wiederkunft Christi, der selbst die endgültige Kircheneinheit wiederherstellen und seine Worte "es wird eine Herde und ein Hirte werden « (Joh 10,16) zur Erfüllung bringen werde, ${ }^{137}$ erschienen die historisch gewachsenen theologischen Differenzen zwischen dem äthiopischen und dem lateineuropäischen (sowohl in römischkatholischer als auch in protestantischer Ausformung) Christentum hinfällig. Das Bewusstsein dessen, dass die Einheit der Kirche nur von Gott selbst hergestellt werden könne, führte zu einer »transkonfessionellen« Perspektivierung auf das Wesentliche des christlichen Glaubens und ließ die Existenz der unterschiedlichen Christentumsvarianten als Bestandteil der göttlichen Ökonomie erscheinen.

In der eschatologischen Tradition gründete nicht nur die ökumenische Aufgeschlossenheit $A b b a \mathrm{Mika}^{\circ}$ els sowie anderer äthiopischer Intellektueller des frühen 16. Jahrhunderts, sondern auch ihre aktive Suche nach dem Kontakt zu den westlichen Christen. In ihrem Bemühen um Verständigung verbanden die Äthiopier beachtlicherweise aufrichtiges Interesse am Dialog mit gleichzeitiger Ablehnung kontroverstheologischer Polemik als Mittel des Austausches; solche Auseinandersetzungen seien friuolas \& inanes (»wertlos und eitel«), so Șägga Zä’ab. ${ }^{138}$ Die Worte Șägga Zä’abs über die Zielsetzung seiner Reise nach Portugal treffen wohl auch auf den Besuch Abba Mika ${ }^{\circ}$ ls im reformatorisch gesinnten Wittenberg zu. Er sei gekommen

non [...] ad disputationum \& contentionum rixas, sed ad amicitiam \& societatem contrahendam, non autem ad traditiones humanas, vel augendas, vel dimmuendas. ${ }^{139}$

nicht [...] zum Zwecke des Zankes der Erörterungen und der Streitgespräche, sondern um Freundschaft und geistige Übereinstimmung zu knüpfen, nicht aber dazu, menschliche Traditionen entweder zu mehren oder zu mindern. ${ }^{140}$

Betrachtet man den theologischen Dialog zwischen dem äthiopischen Mönch und den Wittenberger Reformatoren unter diesem Gesichtspunkt, lassen sich die von ihnen festgestellten Übereinstimmungen in zentralen Glaubensfragen sowie die von ihnen gewonnene Auffassung, zu einer Kirche zu gehören, weder bloß auf das Wunschdenken der Reformatoren reduzieren noch ausschließlich als Produkt des gegenseitigen Missverstehens deuten. Vielmehr

137 Vgl. die Interpretation Șägga Zä̋abs: Góıs, Fides, Religio, Moresque Æthiopum, S. 87.

138 Ebd., S. 88.

139 Ebd., S. 85.

140 Uhlig / Bühring (Hg.), Damian de Góis’ Schrift, S. 264. 
war es das Ergebnis komplexer Verflechtung der beiden Glaubenswelten, wie sie am Beispiel des Einflusses der äthiopischen Eschatologie auf die theologische Annäherung exemplarisch aufgezeigt werden konnte.

\section{Konfessionalisierung der Erinnerung}

Der Dialog mit $A b b a$ Mika ${ }^{\circ}$ l hinterließ einen bleibenden Eindruck auf Luther. Noch Jahre später erinnerte sich der Reformator in den Tischreden an die Einigung in Glaubensfragen, die er und seine Gesinnungsgenossen mit dem äthiopischen Mönch erzielt hatten:

Ante triennium nobiscum hic erat monachus Aethiops, cum quo disputabamus per interpretem, et iste omnibus nostris articulis conclusus dicebat: Ista eta bona creda, id est, fides. ${ }^{141}$

Vor drei Jahren war ein äthiopischer Mönch bei uns, mit welchem wir durch einen Dolmetscher disputierten. Dieser resümierte alle unsere Artikel [des Glaubens], indem er sagte: $»$ Das ist ein gutes Credo (das heißt Glaube) $\ll .{ }^{142}$

Diese Aussage Luthers, die vom 17. November 1537 stammen soll, ${ }^{143}$ weist eine frappierende Parallelität zu der am Anfang der Einleitung zitierten Stelle aus seiner Wittenberger Predigt (ebenso aus dem Jahr 1537) auf, ${ }^{144}$ in der er von der Einheit der wahren Kirche Christi sprach und dabei einen Äthiopier als Beispiel eines Glaubensgenossen aufführte. Die Tatsache, dass Luther zum wiederholten Male, und zwar in verschiedenen Zusammenhängen, die Überzeugung, mit den Äthiopiern den gleichen Glauben zu bekennen und zusammen mit ihnen zur wahren Kirche Christi zu gehören, zum Ausdruck gebracht hatte, zeugt von deren hohem Stellenwert für seine theologische Reflexion.

In diesem Zusammenhang stellt sich die Frage, warum die Begegnung der Wittenberger Reformatoren mit dem äthiopischen Mönch in der Geschichtswissenschaft immer noch übersehen wird.

141 LUther, WA.TR 4, 1916, S. 152f.

142 Übersetzung - S.P.

143 In der Ausgabe der Tischreden ist »17. November 1538«als Datum angegeben, doch möglicherweise handelt es sich hierbei um einen Fehler. Insofern Luther davon spricht, dass der Mönch ihn ante triennium (»vor drei Jahren«) besuchte, müsste diese Aussage aus dem Jahr 1537 stammen.

144 Vgl. das Zitat am Anfang der Einleitung. 
Darin ist wohl ein Phänomen zu sehen, das eng mit kollektiven Erinnerungspraktiken verbunden ist. In der historisch-kulturwissenschaftlichen Gedächtnis- und Erinnerungsforschung wird kollektives Gedächtnis als Selektionsraum oder Archiv definiert, aus welchem heraus Erinnerungsdiskurse im weitesten Sinn geschöpft werden. ${ }^{145}$ Im Verhältnis zu dem so formulierten Gedächtnisbegriff stellt Erinnerung, die in sich auch die Praxis der Geschichtsschreibung einschließt, eine auf dem Selektionsmechanismus des Gedächtnisses aufbauende weitere Konstruktionsleistung dar, »eine Auswahl aus einer Auswahl ${ }^{146}$ Dabei wird der Prozess des Erinnerns - und des eng damit verbundenen Vergessens im Sinne von »Nicht-Erinnern« - durch Mechanismen der Festschreibung und Normierung geleitet, durch welche Komplexität reduziert wird. In diesem Sinne lassen sich auch die Konfessionen als Erinnerungs- und Kommunikationsgemeinschaften betrachten. ${ }^{147}$

Bezogen auf die Begegnung der Wittenberger Reformatoren mit $A b b a$ Mika ${ }^{0} e l$, kann der Vorgang der konfessionellen Normierung am Beispiel des Schlüsseldokumentes ihrer Interaktion, des von Luther unterzeichneten Empfehlungsschreibens für $A b b a \mathrm{Mika}^{\circ} \mathrm{el}$, veranschaulicht werden. Im 16. Jahrhundert genoss dieses Dokument eine weite Verbreitung. Davon zeugen neun - eine vergleichsweise sehr hohe Zahl - überlieferten Manuskripten mit Abschriften des Empfehlungsschreibens für Abba Mika ${ }^{\circ}{ }^{148}$

145 Vgl. Elena Esposito, Soziales Vergessen. Formen und Medien des Gedächtnisses der Gesellschaft, Frankfurt a.M. 2002, S. 24-31; Wolfgang Ludwig Schneider, Gedächtnis, Interpretation und Organisation im Kontext religiöser Kommunikation, in: Cornelia Bohn/Herbert Willems (Hg.), Sinngeneratoren. Fremd- und Selbstthematisierung in soziologisch-historischer Perspektive, Konstanz 2001, S. 263-289, hier S. 265f. Siehe auch: Jacques DerRidA, Dem Archiv verschrieben. Eine Freudsche Impression, Berlin 1997.

146 Alois Hahn, Erinnerung und Prognose. Zur Vergegenwärtigung von Vergangenheit und Zukunft, Opladen 2003, S. 3. Diese Ausdifferenzierung der Begriffe des Gedächtnisses und des Erinnerns findet sich ähnlich in der französischen Geschichtsphilosophie, so bei Paul Ricoeur, der zwischen mémoire und souvenir unterscheidet, innerhalb derer er weiter zwischen souvenir immédiat und souvenir secondaire differenziert. Paul Ricoeur, La mémoire, l'histoire, l'oubli, Paris 2000, S. 39.

147 Zur theologischen Relevanz des Erinnerns und des Vergessens im Kontext der Kirchengeschichte vgl. Fairy von Lilienfeld, Über einige Probleme der Lehre von »Kirchengeschichte« im »ökumenischen« Zeitalter. Kirchengeschichtsschreibung und das Gedächtnis der Kirche, in: Karl Christian Felmy u. a. (Hg.), Sophia - Die Weisheit Gottes. Gesammelte Aufsätze 1983-1995, Erlangen 1997, S. 22-39.

148 Bibliothèque nationale de France, Paris, Ms. Coll. Dupuy 796, pagina 702f. (Überschrift: »Epistola commendatitia data cuidam Aetiopi. Phil. Melanthon pro Mart. Luthero scripsit«); Bibliothèque Sainte-Geneviève, Paris, Ms. 1458, fol. 224v (Überschrift: »Epistola commendatitia data cuidam Aetiopi. Ф. M. pro M.L. scripsit«); Forschungsbibliothek Gotha der Universität Erfurt, Ms. Chart. B 1483, fol. 84r-v (Überschrift: „Epistola commendatitia Martini Lutheri data cuidam Aetiopi, authore Ph. Mel.«); Herzog August Bibliothek Wolfenbüttel, Cod. Guelf. 64.4 Extrav., fol. 5v (Überschrift: »Epistola commendatitia Martini Lutheri data cui- 
Von besonderem Interesse ist in diesem Zusammenhang ein Manuskript, das aus der Mitte des 16. Jahrhunderts stammt und heute in der Universitätsbibliothek Basel aufbewahrt wird. Die dort enthaltene Abschrift des Empfehlungsschreibens, Epistola commendatitia M. Luth. data cuidam Æpiscopo, gibt an, dass Martin Luther dieses Schreiben nicht für einen Diakon, sondern für einen Bischof erstellt habe [siehe Abbildung 4 und 5]. ${ }^{149}$ Diese ohnehin bemerkenswerte Veränderung des hierarchischen Status von $A b b a$ Mika ${ }^{\circ e l}$ hatte eine schwerwiegende Implikation. Da die Kirche Äthiopiens damals nur über einen einzigen Bischof verfügte (dieser Sachverhalt änderte sich erst im 19. Jahrhundert), bedeutete diese Darstellung nichts anderes, als dass der Wittenberger Reformator das Empfehlungsschreiben niemand anderem als dem Oberhaupt der Äthiopisch-Orthodoxen Kirche gegeben hätte. Ob diese Implikation dem Verfasser dieses Manuskripts bewusst war, ist ungewiss. Es kann jedoch nicht ausgeschlossen werden, denn Informationen über die Verfasstheit der Äthiopischen Kirche waren für den europäischen Leser dank Șägga Zä’abs Schrift De Æthiopum Moribus bereits zugänglich. ${ }^{150}$ Jedenfalls zeugt dieses Manuskript von einem beachtlichen Versuch, die Relevanz des äthiopischen Gesprächspartners Martin Luthers - und somit auch der von ihnen erzielten Verständigung zu erhöhen.

Doch der Text wurde nicht nur handschriftlich kopiert, sondern wurde 1565, bereits fünf Jahre nach Melanchthons Tod veröffentlicht. Johannes Manlius, der von 1548 bis 1559 an der Universität in Wittenberg gewesen war, nahm das Empfehlungsschreiben in den Band Epistolarum D. Philippi Melanchthonis Farrago, die erste gedruckte Ausgabe von Melanchthon-Brie-

dam Aetiopi, authore Philip. Melanch.«); Herzog August Bibliothek Wolfenbüttel, Cod. Guelf. 107 Helmst., fol. 10v (Überschrift: „Epistola commendadicia M. Lutheri data cuidam Aetiopi«); Herzog August Bibliothek Wolfenbüttel, Cod. Guelf. 214 Gud. Lat. $4^{\circ}$, fol. 16r-v (Überschrift: »Epistola commendadicia D. M. L. data cuidam Aetiopi«); Stadtbibliothek Trier, Ms. 1880/1444, fol. 135 $-\mathrm{v}$ (Überschrift: »Testimonium datum cuidam Aethiopi a.d. martino Luther«); Universitätsbibliothek Basel, Ms. O III 4, fol. 124v-125r (Überschrift: »Epistola commendatitia M. Luth. data cuidam Episcopo«); Universitätsbibliothek Leipzig, Ms. 2630, fol. 60 ${ }^{\mathrm{r}}-61^{\mathrm{r}}$ (Überschrift: "Commendatio data Aethiopi Anno 1535«).

149 Ms. Universitätsbibliothek Basel, O III 4, fol. 124v-125r. Der Hinweis auf das bischöfliche Amt des Luthers Gesprächspartner war nicht nur im Titel des Schreibens, sondern auch in dessen letztem Satz enthalten: „Ideo rogamus bonos viros, ut Christianam dilectionem et huic Æpiscopo praestare velint.« (»Darum bitten wir alle guten Menschen, dass sie auch diesem Bischof christliche Liebe erweisen mögen«). Das Wort Æpiscopo wurde jedoch nachträglich durchgestrichen und durch das Wort hospiti (»Fremdling«) ersetzt. Die Betitelung des Empfehlungsschreibens blieb nichtsdestotrotz unverändert.

Siehe dazu Kapitel II.2.1 »Lissabon«. 


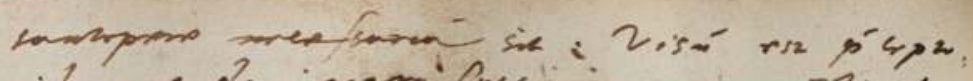

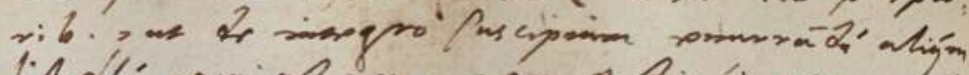

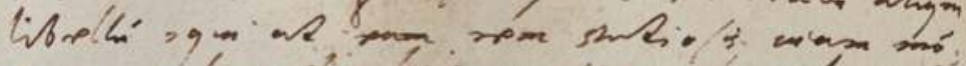

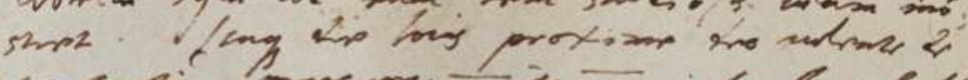

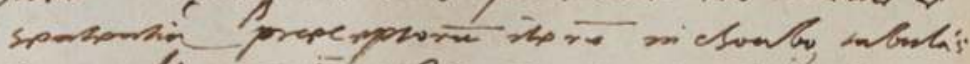

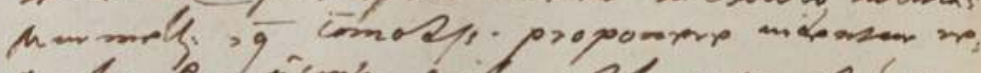

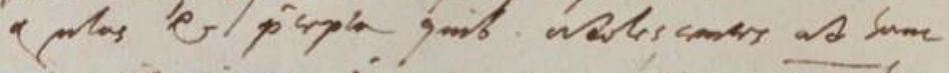

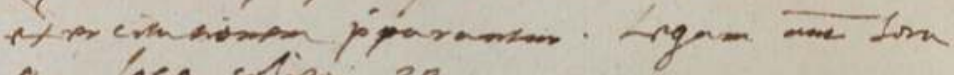
C. loco soliso, 38

\section{If pis a om menchina \\ M. Luts: aren ciala -}

\section{Episcopos}

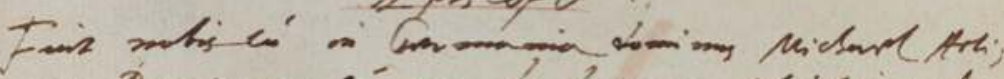

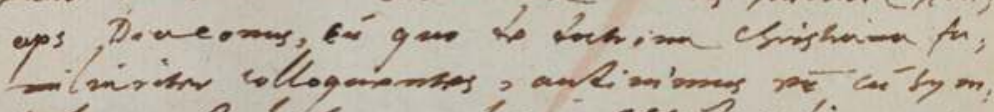

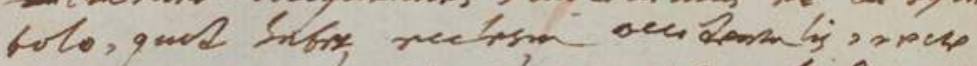

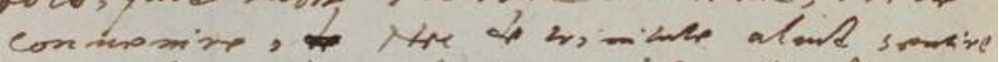

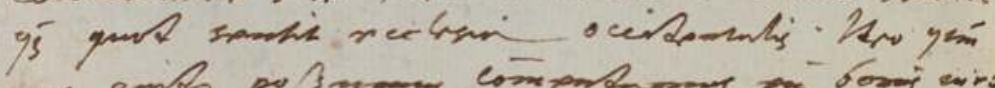

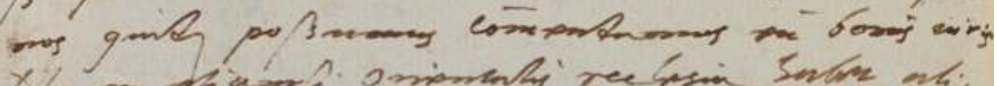

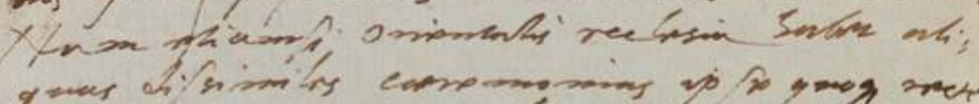

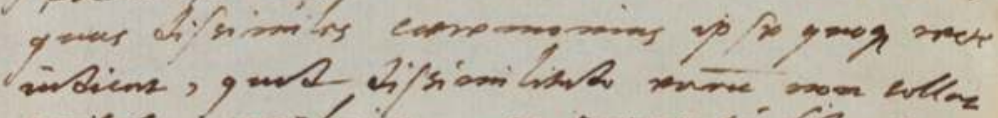

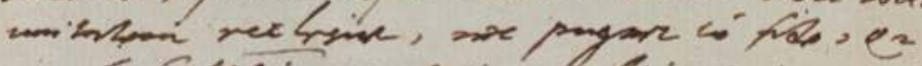

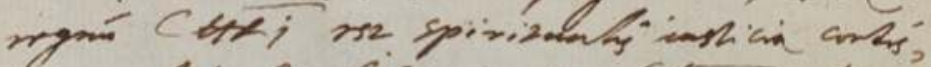

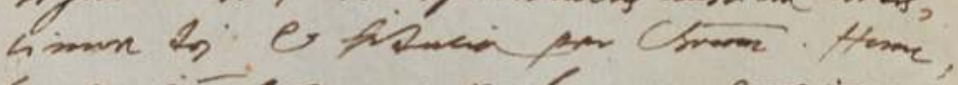

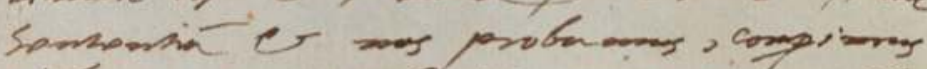

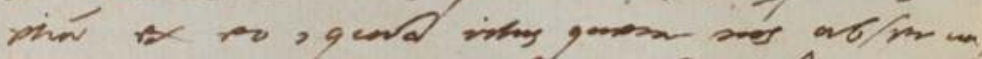

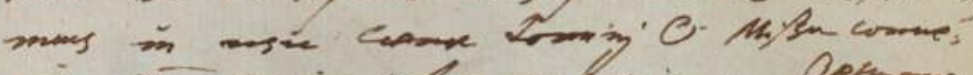

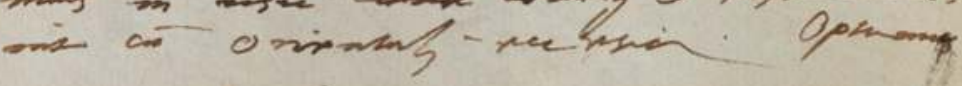

Abb. 4: Abschrift von Martin Luthers Empfehlungsschreiben für Abba Mika ${ }^{\circ}$ el. Ms. Universitätsbibliothek Basel, O III 4, fol. 124v 


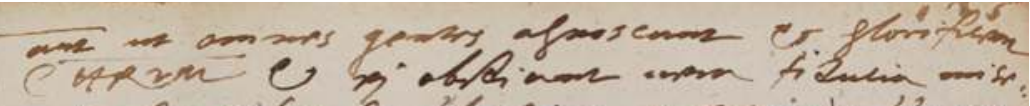

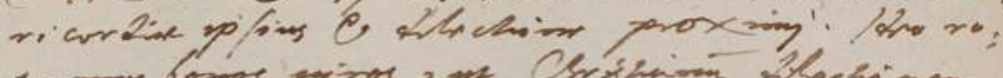

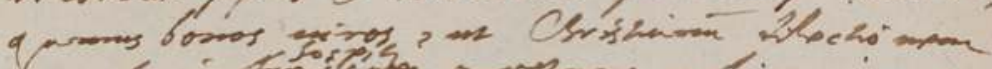

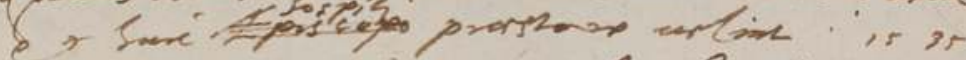
$R$ rosere Acarasair

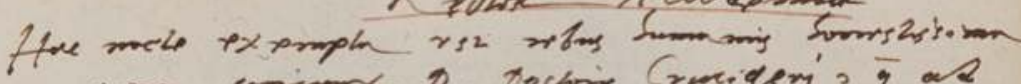

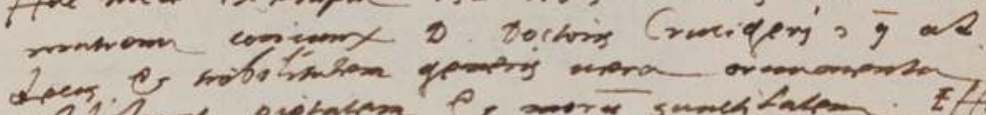

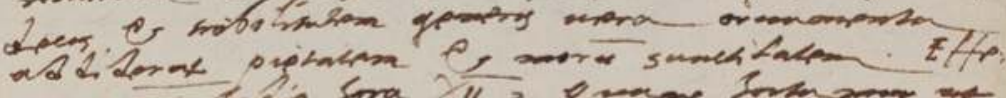

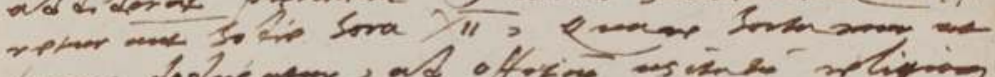

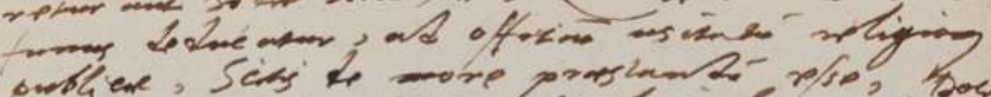

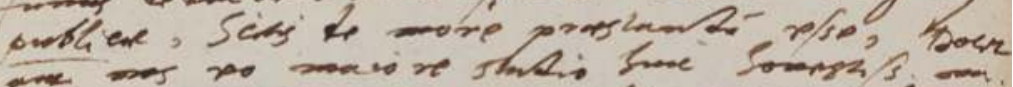

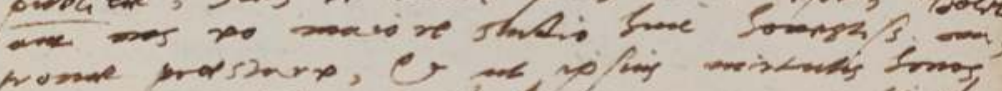

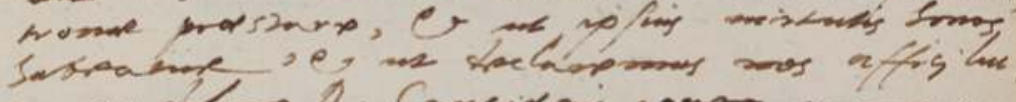

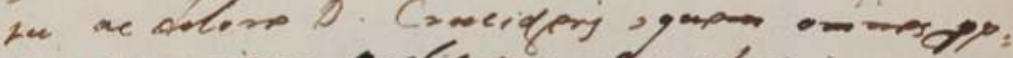

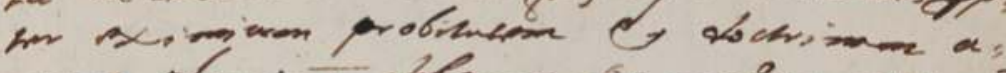

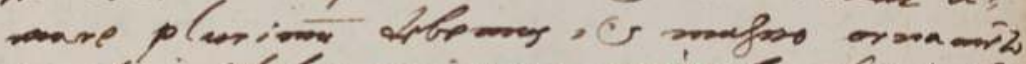

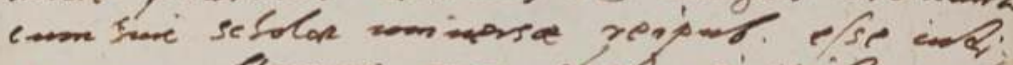

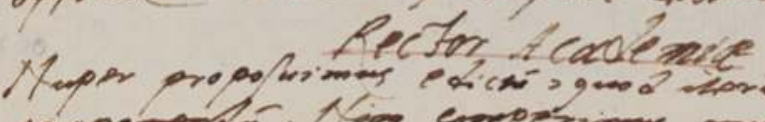

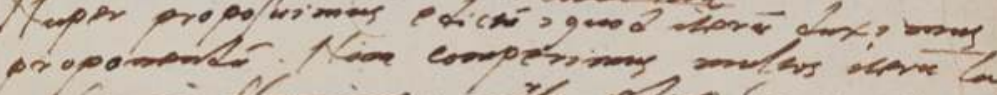

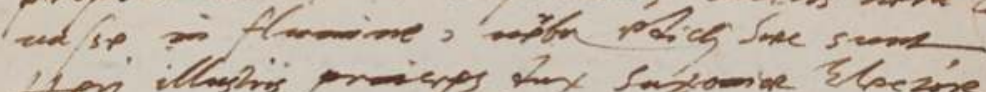

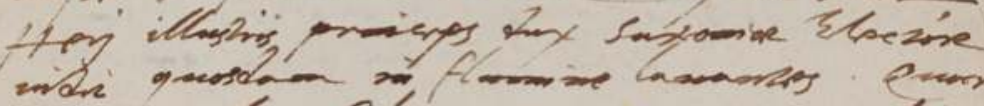

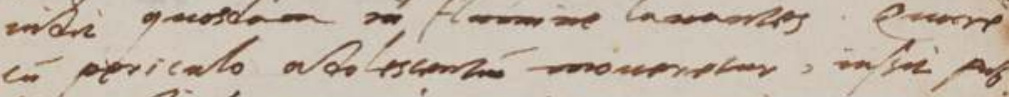

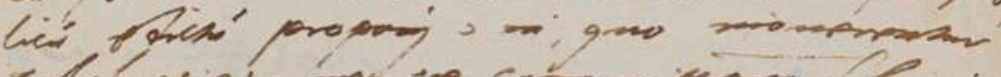

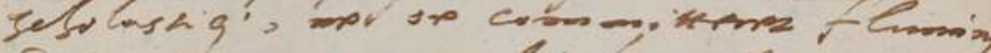

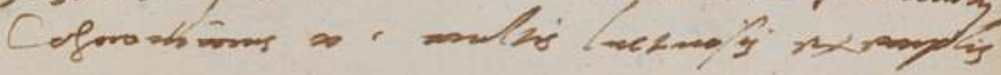

Abb. 5: Abschrift von Martin Luthers Empfehlungsschreiben für Abba Mika ${ }^{0}$ l. Ms. Universitätsbibliothek Basel, O III 4, fol. 125r 
fen, auf. ${ }^{151}$ Das Buch enthält etwa 350 Briefe (etwa 200 dieser Stücke sind nirgends sonst überliefert). Melanchthons Schwiegersohn Caspar Peucer (1525-1602) reagierte empört auf Manlius' Publikation ${ }^{152}$ und stellte noch im selben Jahr eine alternative, deutlich kleinere, Ausgabe von Briefen seines Schwiegervaters: Epistolae selectiores aliquot Philippi Melanthonis. ${ }^{153}$ In Peucers Ausgabe war das Empfehlungsschreiben für den äthiopischen Mönch nicht enthalten.

Zum nächsten Mal wurde das Empfehlungsschreiben erst zwei Jahrhunderte später, im Jahre 1784, publiziert. Der Theologe und Leiter der Hamburger Stadtbibliothek Gottfried Schütze (1719-1784) hatte den Text in den Beständen seiner Bibliothek gefunden und sowohl auf Latein als auch in deutscher Übersetzung veröffentlicht. ${ }^{154}$ Diese Herausgabe des Empfehlungsschreibens war allerdings mit einer neuen Sinnzuschreibung verbunden. Insofern im Schreiben unter anderem von der orientalis ecclesia, der Ostkirche, und dessen Glaubenslehre die Rede war, wurde Schütze zu dem Fehlschluss geleitet, diese mit der griechischen - ihm wohl am besten bekannten - Kirche gleichzusetzen. Den Text hatte er folgendermaßen eingeführt:

Empfehlungsschreiben für einen Fremdling, der sich in Absicht auf sein Glaubensbekenntniß zur griechischen Kirche bekannte, aber doch dabey recht gut und evangelisch dachte; daher Luther der Meinung ist, daß man ihm ein thätiges Mitleiden und Unterstützung nicht versagen könne. ${ }^{155}$

Die Behauptung, dass Abba Mika ${ }^{\top} e l$, der als Geistlicher der äthiopischen Kirche offensichtlich in der miaphysitischen theologischen Tradition stand, dem Glaubensbekenntnis der griechischen, also einer chalzedonischen, Kirche gefolgt wäre, deutet auf einen undifferenzierten Blick auf den christlichen Osten hin. Diese Ansicht wurde in den darauffolgenden Publikationen des Empfehlungsschreibens nicht nur unkorrigiert gelassen, sondern sogar verfestigt. So machte Wilhelm Martin Leberecht de Wette (1780-1849), Theologieprofessor an der Universität Basel, den äthiopischen Mönch in seiner 1827

151 Johannes Manlius (Hg.), Epistolarum D. Philippi Melanchthonis Farrago, Basel 1565, S. 367f. Zu Manlius siehe: Matthias Simon, Johann Manlius, der erste Herausgeber von Melanchthonsbriefen, in: ZBKG 24 (1955), S. 141-149.

152 Vgl. Mundhenk, Briefe, S. 316.

153 Caspar Peucer (Hg.), Epistolae selectiores aliquot Philippi Melanthonis, Wittenberg 1565.

154 SchÜtze (Hg.), D. Martin Luthers bisher ungedruckte Briefe, S. 319f. sowie ders. (Hg.), D. Martin Luthers bisher grossentheils ungedruckte Briefe. Nach der Sammlung des Hrn. D. Gottf. Schütze, aus dem Latein übersetzt, Leipzig 1784, Bd. 2, S. 54. Ebd. 
erschienenen Ausgabe bereits zum "griechischen Geistlichen«, indem er den Text wie folgt betitelte: »Offenes Empfehlungsschreiben. L.[uther] empfiehlt einen griechischen Geistlichen als rechtgläubig «. ${ }^{156}$

Störend an diesem Text, weil weder ins Luther-Bild noch in die kirchenhistorische Meistererzählung des 18. und 19. Jahrhunderts passend, war sowohl die Tatsache, dass der Reformator einen theologischen Dialog mit einem Afrikaner geführt hatte, als auch, dass er die Aussage befürwortet hatte, zusammen mit den orthodoxen Äthiopiern zu einer Kirche zu gehören. Bis hin zum 20. Jahrhundert taten sich die Herausgeber schwer damit, $A b b a \mathrm{Mika}^{\circ} \mathrm{el}$ als Äthiopier zu sehen und dem Empfehlungsschreiben eine entsprechende Überschrift zu geben. Erst in einem Band von Luthers Briefwechsel, der von dem Reformationshistoriker Ludwig Enders (1833-1906) 1903 herausgegeben wurde, wird der Text als »Empfehlungsschreiben für einen Aethiopier, Namens Michael« betitelt. ${ }^{157}$

Eine rückblickende konfessionelle Normierung seitens der Herausgeber beschränkte sich allerdings nicht auf die Verleihung der irreführenden Überschriften. Bezeichnend in dieser Hinsicht ist der Umgang mit diesem Schreiben in der Weimarer Luthers Ausgabe. Der Bearbeiter hatte zwar $A b b a \mathrm{Mika}^{\circ} \mathrm{el}$ im Begleittext zum Empfehlungsschreiben als Äthiopier bezeichnet, doch im Gegensatz zu anderen Texten in diesem Band wurde dem Schreiben keine Folgenummer zugewiesen und es wurde nicht ins Inhaltsverzeichnis aufgenommen. ${ }^{158}$ Die Marginalisierung dieses historischen Dokuments, die seine Rezeption zusätzlich erschwerte, äußerte sich nicht zuletzt in fehlenden Übersetzungen: Seit der ersten deutschen Veröffentlichung 1784 wurde das Schreiben weder ins Deutsche noch in eine andere moderne Sprache neu übersetzt, während die ursprüngliche Übersetzung aus dem späten 18. Jahrhundert seitdem nie wieder nachgedruckt wurde.

Der Umgang mit dem Empfehlungsschreiben legt die Mechanismen der Marginalisierung offen, den das Gedächtnis an die Begegnung des Reformators mit $A b b a$ Mika ${ }^{\circ}$ l und deren ökumenische Verständigung im Laufe der letzten zweieinhalb Jahrhunderte ausgesetzt worden war. Letztendlich führten diese Erinnerungsmechanismen dazu, dass der Besuch des äthiopischen Mönchs in Wittenberg aus dem Archiv des kollektiven Gedächtnisses verdrängt wurde. Dieser diskursive Vorgang, der sich in der longue durée entfaltete und sich dabei an das Selbstverständnis der konfessionellen Erinnerungsgemeinschaft orientierte, lässt sich als »Konfessionalisierung der Erinnerung« beschreiben.

156 Wette (Hg.), Dr. Martin Luthers Briefe, S. 550.

157 Enders (Hg.), Dr. Martin Luther's Briefwechsel, S. 60.

158 Das Empfehlungsschreiben wurde zwischen zwei anderen Briefen, Nr. 2126 »Luther an den Rat zu Regensburg. 30. Juni 1534" und Nr. 2127 "Luther an Friedrich Myconius in Gotha, 5. Juli 1534«, abgedruckt. Luther, WA.B 7, 1937, S. 86. 
Eine kritische Auseinandersetzung mit diesem Vorgang deckt nicht nur konfessionelle Erinnerungsmechanismen auf, sondern zeigt auch, wie fragil die im Kanonisierungsprozess konstruierten konfessionellen Selbstbilder eigentlich sind. So steht das Bemühen der Lutheraner der letzten zweieinhalb Jahrhunderte um das "Nicht-Erinnern" an das Treffen der Wittenberger Reformatoren mit $A b b a$ Mika ${ }^{\supset}$ l ironischerweise im Gegensatz zum Erinnern daran seitens Luther selbst, der dieses Ereignis wiederholt - etwa in den Tischreden - ins Gedächtnis gerufen hatte.

Dass der theologische Dialog mit dem äthiopischen Mönch weiterhin "vergessen « bleibt - und dies trotz der Konjunktur auf der Betonung globaler Dimensionen der Reformation sowie des rasanten Wachstums der Forschungsfelder der Interkulturellen Theologie (im deutschsprachigen Raum) und World/Global Christianity (im englischsprachigen Raum) - zeigt, wie wirkungsmächtig die »Konfessionalisierung der Erinnerung« ist. 


\section{Imaginäre Kirche: \\ Transfer und Transformation des äthiopisch-orthodoxen theologischen Wissens (1540-1791)}

\section{Wissensproduktion und Imaginationspraktiken der Transkonfessionalität}

Nous le repetons encore, jamais personne en Europe n'a egalé Mr. Ludolf, ni peut-être ne l'égalera dans la connoissance de la langue Ethiopienne; mais de quelle utilité lui a-t'elle été pour l'Historie qu'il nous a donnée? Et quant aux secours que l'Eglise auroit pû en tirer, il les a rendus inutiles par sa mauvaise foi. Les Abissins sont Jacobites, il nous les represente ou comme des Luteriens, ou comme des Calvinistes, \& en voulant excuser les abus qui se sont glissés parmi eux, ou leur attribuant des erreurs qu'ils n'ont point, il fait de l'Eglise d'Abissinie une Eglise imaginaire, qui n'a de réalité que dans ses fausses idées. ${ }^{1}$

Mit keinem anderen Buch wird die Entstehung europäischer Äthiopistik so sehr in Verbindung gebracht wie mit der monumentalen Historia \#thiopica (zunächst 1681) des Thüringer Gelehrten Hiob Ludolf (1624-1704). ${ }^{2}$ Der Lutheraner, der selbst nie in Afrika gewesen war und die allermeiste Zeit

1 Joachim Le Grand (Hg.), Relation historique d'Abyssinie du R.P. Jérôme Lobo, S. J. Traduite du Portugais, continuée et augmentée de plusieurs dissertations, lettres et mémoires, Paris 1728, S. 195.

Vgl. die englische Übersetzung von Samuel Johnson (1709-1784): »No man, it is true, in Europe, hath ever equalled, or perhaps ever will equall, Mr Ludolf in the knowledge of the Ethiopic language; but that knowledge hath been of no great advantage to him in writing his history. As to any use it might have been to the church, Mr Ludolf's insincerity hath deprived us of it. The Abyssins are Jacobites, but he hath represented them as Lutherans or Calvinists; and while he endeavors to excuse some abuses which have crept amongst them, charges them with erroneous tenets which they do not hold. He hath transformed the Church of Abyssinia into an imaginary church, which hath no existence, but in his own imagination«. Ders., A Dissertation upon Mr. Ludolf's History of Abyssinia, in: A Voyage to Abyssinia. By Father Jerome Lobo, a Portuguese Jesuit, London 1735, S. 185-396, hier S. 193.

2 Hiob Ludolf, Historia Æthiopica, Sive Brevis \& succincta descriptio Regni Habessinorvm, Quod vulgo male Presbyteri Iohannis vocatur, Frankfurt a. M. 1681.

Über Hiob Ludolf und seinen Beitrag zur Entstehung europäischer Äthiopistik siehe: Siegbert Uhlig, Ludolf, Hiob, in: EAE 3, 2007, S. 601-603; Jürgen Tubach, Ludolf, Hiob, in: BBKL, Herzberg 1993, Bd. 5, Sp. 317-325; Hammerschmidt, Die äthiopischen Studien, S. 258-261; Eike Haberland, Hiob Ludolf. Father of Ethiopian Studies in Europe, in: Richard Pankhurst / Stanisław Chojnacki (Hg.), Proceedings of the Third International Conference of Ethiopian Studies, Addis Ababa [3-7 April] 1966, Addis Ababa 1969-1970, S. 131-136. 
seines wissenschaftlichen Werdegangs am Hofe des Herzogs Ernst I., des Frommen, (1601-1675) von Sachsen-Gotha-Altenburg verbracht hatte, hat europäische Vorstellungen von Äthiopien und dessen Christentum derart nachhaltig geprägt, dass sein Einfluss noch über die Frühe Neuzeit hinaus reichte. Aus diesem Grund trifft die oben zitierte Passage aus der Feder des römisch-katholischen Gelehrten Joachim Le Grand (1653-1733), Ludolf habe in seinem opus magnum die Äthiopische Kirche so sehr verzerrt und nach protestantischer Façon dargestellt, dass es sich hierbei eigentlich nur noch um une Eglise imaginaire (»eine imaginäre Kirche«) handele, nicht nur auf den großen Äthiopisten zu. Sie trifft vielmehr - und darin besteht ihre eigentliche Brisanz - auch auf das, was sich zum normativen frühneuzeitlichen Wissenskanon über äthiopisches Christentum herausgebildet hat, zu.

Betrachtet man Imagination als ein unabdingbares epistemologisches Werkzeug, ${ }^{3}$ so lässt sich das Zitat Le Grands nicht bloß als ein überzogener Vorwurf, sondern auch als eine erkenntnistheoretische Beobachtung lesen, die pointiert auf den Zusammenhang zwischen dem konfessionellen Standort des jeweiligen europäischen Autors und den von ihm produzierten Repräsentationen der Äthiopisch-Orthodoxen Kirche hinweist. Dabei stellt sich eine grundsätzliche Frage: Inwieweit wurde protestantische Wissensproduktion in Bezug auf äthiopisches Christentum in der Frühen Neuzeit durch Imaginationspraktiken beeinflusst?

Spricht man von »imaginärer Kirche« - oder gar von einer ekklesiologischen Imaginationsgeschichte -, so darf Imagination weder isoliert von ihren Auswirkungen auf Motivationen und Handlungen, noch abgekoppelt von den ihr zur Verfügung stehenden Wissensbeständen untersucht werden. Deswegen gilt es, einerseits "imaginäre Kirche« bei der Analyse stets an Repräsentationsformen, Argumentationslinien sowie theologische Diskurse zu binden, ${ }^{4}$ sie andererseits aber auch als Produkt der Wirkungsgeschichte des äthiopisch-orthodoxen theologischen Wissens innerhalb protestantischer Theologie zu betrachten. Denn es wäre äußerst kurzsichtig, protestantische imaginäre Entwürfe des äthiopischen Christentums als exklusiv selbstreferenziell aufzufassen und zu versuchen, sie nur aus ihrem unmittelbaren Kontext heraus zu verstehen.

3 Zur Rolle der Imagination in der Religionsgeschichte sowie zur weiterführenden Literatur siehe: Lucia Traut / Annette Wilke, Einleitung, in: Dies. (Hg.), Religion Imagination - Ästhetik. Vorstellungs- und Sinneswelten in Religion und Kultur, Göttingen 2015, S. 17-69. Zu einer Diskussion der Imaginationstheorien siehe: Thomas Dewender/Thomas Welt (Hg.), Imagination - Fiktion - Kreation. Das kulturschaffende Vermögen der Phantasie, München u.a. 2003; Eva T.H. BranN, The World of the Imagination. Sum and Substance, Lanham 1991.

4 Vgl. Alexandra Grieser u. a., Imaginationsgeschichte, in: Traut / Wilke (Hg.), Religion - Imagination - Ästhetik, S. 383-386, hier S. 385. 
Im vorliegenden Kapitel wird die Beantwortung der Frage nach dem Transfer und der Transformation des äthiopisch-orthodoxen theologischen Wissens in der Frühen Neuzeit aus einer dezidiert makrohistorischen Perspektive angegangen werden. Das primäre Ziel ist dabei, die »imaginäre Kirche « in ihrer Dynamik in den Blick zu nehmen sowie die im Rahmen der Wissensproduktion angewandten Imaginationspraktiken der Transkonfessionalität zu analysieren.

2. Hybride Imaginationen des Äthiopischen: Șägga Zä’ab und protestantische Rezeption seines Werks

\subsection{Umdeutungen des »salomonischen Narrativs«}

Als einen geradezu epochalen - obgleich durch Kirchenhistoriker unbemerkten - Meilenstein der Globalisierungsgeschichte des theologischen Wissens kann die Veröffentlichung der Einführung in die äthiopische Orthodoxie aus der Feder des Șägga Zäaab, De Ethiopum Moribus, im Jahre 1540, betrachtet werden. ${ }^{5}$ Die Singularität dieser Publikation bestand zunächst darin, dass zum ersten Mal ein Werk eines Theologen aus Subsahara-Afrika gedruckt worden war. Einzigartig war aber auch der Rezeptionsprozess, den dieses kurz gefasste Kompendium der wichtigsten Loci äthiopischer Theologie in den Kirchen der Reformation auslöste. Es gab wohl keinen anderen zeitgenössischen orthodoxen Autor, der unter frühneuzeitlichen Protestanten so viel und so intensiv gelesen wurde, wie Șägga Zä’ab. Denn bis hin ins späte 18. Jahrhundert zählte das Werk zur Standardinformation über äthiopische Theologie. ${ }^{6}$ Dieser afrikanisch-europäische Wissenstransfer legte somit die Grundlage für eine »imaginären Kirche«. Hervorgebracht wurde sie jedoch erst in Folge zahlreicher Transformationen des äthiopisch-orthodoxen Wissens auf europäischem Boden.

Aus ideengeschichtlicher Sicht bestand die größte Leistung des Șägga Zä’ab wohl in der Vermittlung jener Erzählung, die das Zentrum des religiösen Selbstverständnisses sowohl des äthiopischen Christentums als auch der äthiopischen Monarchie ausmachte: des sogenannten "salomonischen Narrativs«. Dieses Narrativ, das seinen primären Ausdruck im bereits erwähnten Kəbrä Nägäśt fand, stellt einen literarisch-theologischen Ausbau der biblischen Erzählung von 1 Kön 10,1-3 sowie 2 Chr 9,1-12 dar und enthält zwei konstitutive Topoi: die Abstammung der königlichen Dynastie Äthiopiens von Salomo und der Königin von Saba sowie die Überführung der Bundes-

5 Vgl. Kapitel II.2.1 »Lissabon«.

6 Vgl. Uhlig / Bühring (Hg.), Damian de Góis’ Schrift, S. 48. 
lade aus Jerusalem nach Äthiopien. ${ }^{7}$ Seine Kernbotschaft ist somit nichts anderes als die translatio imperii von Israel nach Äthiopien, einschließlich der Eingliederung der Äthiopier in die Heilsgeschichte als neues auserwähltes Volk, als verus Israel. ${ }^{8}$

Der Meinung Carl Bezolds (1859-1922), des Herausgebers der maßgebenden kritischen Edition des Kabrä Nägäst, folgend, wird in der Forschungsliteratur davon ausgegangen, dass die Kenntnis vom »salomonischen Narrativ« erst durch die Jesuiten nach Europa gebracht worden sei. ${ }^{9}$ Diese Sichtweise muss jedoch korrigiert werden, denn Șägga Zä’ab hat die europäische Christenheit bereits zuvor damit bekannt gemacht. Seine Darstellung dieser Geschichte liest sich wie folgt:

Diese Königin [von] Saba hieß aber mit Eigennamen Maqeda, ${ }^{10}$ die nach Art der Vorfahren Götzenbilder verehrte. Als das Gerücht von Salomons Weisheit ihr zu Ohren gekommen war, schickte sie einen klugen Mann nach Jerusalem, um sich nach Erforschung der ganzen Angelegenheit über des Königs Klugheit informieren zu lassen. Nach dessen Rückkehr und nach Aufklärung der Angelegenheit machte sie sich eilig auf den Weg, Richtung Jerusalem. Und als sie dorthin gelangt war, erlernte sie außer vielem anderen, worin sie von Salomon erzogen worden ist, das Gesetz und die Propheten und (nachdem sie Gelegenheit zur Abreise erhalten hatte) gebar sie auf der Reise in die Heimat unterwegs einen Sohn, den sie von Salomon empfangen hatte, der Meilech ${ }^{11}$ genannt worden ist, den die Königin selbst in Äthiopien bis zu <seinem>

7 Vgl. Bezold, Kebra Nagast, S. 10-50. Zum Kabrä Nägäśt siehe Anm. 121 auf S. 58. Unter den wichtigsten äthiopischen Texten, die diese Topoi weiterentwickelten, seien

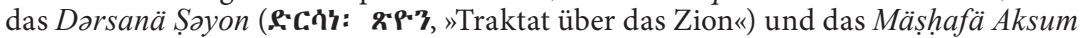
(aDgh6: hhir.q, "Das Buch des Aksum«) erwähnt. Die beiden Texte stehen in einer so engen Verbindung zum Kabrä Nägäśt, dass sie mit ihm sogar in denselben Handschriften überliefert wurden. Vgl. Amsalu Tefera, Colophonic Reflections on Dərsanä Șəyon and Kəbrä Nägäśt, in: Aethiopica. International Journal of Ethiopian Studies 17 (2014), S. 78-89; Gianfrancesco Lusını, Aksum. Mäṣhafä Aksum, in: EAE 1, 2003, S. 185f. Die beiden Texte liegen in einer kritischen Edition vor: Carlo Conti Rossini (Hg.), Documenta ad illustrandam historiam, CSCO 54, 58, Louvain 1909-1910, Bd. I: Liber Axumae; Amsalu Tefera, The Ethiopian Homily on the Ark of the Covenant. Critical Edition and Annotated Translation of Dərsanä Șəyon, Leiden 2015, S. 39-62.

8 Diese Idee wird im Kabrä Nägäśt folgendermaßen formelhaft formuliert: »[D]ie Auserwählten des Herrn sind die Leute Äthiopiens. Denn dort ist der Wohnsitz Gottes, das himmlische Zion, seine Gesetzeslade und Bundeslade«. Bezold, Kebra Nagast, S. 102.

9 Vgl. ebd., S. VI.

10 Im Kabrä Nägäśt wird die Königin von Saba als äthiopische Königin Namens

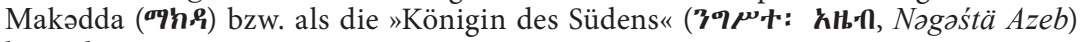
bezeichnet.

11 Laut späterer äthiopischer Tradition hieß der Sohn von Salomo und der Königin von Saba Mənilək ( $\left.\mathbf{T}^{\mathbf{3}} \mathbf{A} \boldsymbol{h}\right)$. Im Kəbrä Nägäśt wird er allerdings Bäynä Ləḥkəm

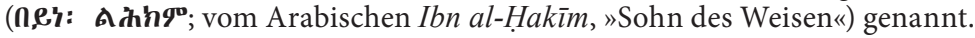


zwanzigsten Lebensjahr bei sich erzog und später zu seinem Vater Salomon zurückschickte, damit er von ihm Wissen und Weisheit erlernte. Ihn flehte sie brieflich an, daß er <seinen> Sohn Meilech vor der Lade des Bundes, des Bundes des Herrn, zum König Äthiopiens weihte und ernennte und daß nicht fernerhin Frauen das Recht hätten, in Äthiopien zu herrschen, wie es damals Brauch war, sondern daß auf direktem Wege <in Erbfolge> die Männer zur Herrschaft gelangten. Als er nach Jerusalem kam, erlangte er vom Vater leicht, was die Mutter gefordert hatte, und statt Meilech wurde er David genannt, den als einen schon vollauf im Gesetz und in anderen Disziplinen genau Unterwiesenen der Vater Salomon zur Mutter zurückzuschicken beschloß, und zwar mit ziemlich großer Pracht und königlichem Prunk. Um das außergewöhnlich freigebig durchzuführen, übergab er ihm adlige Begleiter und Söhne der ersten Männer, die ihm nach königlichem Brauche dienen sollten. Außerdem beschloß er, mit ihm zu schicken Asarja, den Hohenpriester, den Sohn des Sadoch, der ebenfalls Hoherpriester war. Als Asarja das bemerkt hatte, forderte er David auf, ihm von seinem Vater die Möglichkeit zu erwirken, für den Erfolg der Reise vor der Lade des Bundes des Herrn zu opfern. Als das von Salomon erlangt war, ließ Asarja es sich plötzlich angelegen sein, Tafeln, so heimlich er es nur konnte, zu behauen in Nachahmung der Tafeln des Bundes des Herrn. Als die fertiggestellt waren, schickte er sich zum Opfern an und raubte unmittelbar während des Opfers ganz heimlich und mit staunenswerter Kunstfertigkeit die wahren Tafeln des Bundes des Herrn aus der Lade und legte statt ihrer die nachgemachten, die er bei sich getragen hatte, hinein - Zeugen waren nur er selbst und Gott. [...] Im übrigen betrat, als David schon an die Grenzen zu Äthiopien gelangt war, Asarja sein Zelt und offenbarte ihm, was er die ganze Zeit als Geheimnis bei sich behalten hatte, daß nämlich die Tafeln des Bundes des Herrn sich bei ihm befänden. Als er das gehört hatte, stürmte David plötzlich zu dem Zelt, in dem Asarja die Tafeln des Bundes des Herrn hatte, und begann dort, dem Beispiel seines Großvaters David folgend, vor allzu großer Freude zu tanzen vor der Lade, in der die Tafeln waren. [...] Von dieser Zeit an - es sind von da bis zu diesem Tage inzwischen fast schon 2600 Jahre verflossen - [...] bewahren wir das Gesetz des Herrn und die Beschneidung. ${ }^{12}$

Bereits diese Wiedergabe des »salomonischen Narrativs«, der unter den Äthiopiern für »äußerst heilig und rechtschaffen« (»sanctissima \& probatissima«) gehalten werde, ${ }^{13}$ offenbart: Șägga Zäºb war keineswegs nur Vermittler des äthiopisch-orthodoxen theologischen Wissens, er war zugleich auch Subjekt von dessen Transformation. Besonders bemerkenswert in dieser Hinsicht ist die hier eingeführte Argumentationslinie - sie wird an verschiedenen Stellen der Abhandlung immer wieder aufgegriffen -, die an die Idee anknüpft,

12 Uhlig / Bühring (Hg.), Damian de Góis’ Schrift, S. 67-70 (Text), S. 241-244 (Übersetzung).

13 Ebd., S. 69 (Text), S. 243 (Übersetzung). 
dass die Äthiopier seit der Zeit der Königin von Saba »das Gesetz des Herrn und die Beschneidung " hätten. Obwohl der äthiopische Geistliche für die Untermauerung dieser Behauptung explizit auf das Kabrä Nägäśt verweist, ${ }^{14}$ würde man nach einer entsprechenden Belegstelle vergeblich suchen, denn dort ist weder von der Übergabe des gesamten Gesetzes des Pentateuchs noch von einer Anforderung an die Äthiopier, die Beschneidung zu praktizieren, die Rede. Bei der dort dargestellten religiösen Anweisung seitens Salomo diese richtet sich übrigens nicht an die Königin von Saba, wie in der Darstellung von Șägga Zä̋ab, sondern an ihren gemeinsamen Sohn Mənilək nach seiner Salbung zum König -, handelt es sich ausschließlich um die Vermittlung ethischer Regelungen der altisraelitischen Religion samt dem Dekalog. ${ }^{15}$

Șägga Zä’abs »Umschreibung" der Erzählung aus dem Kəbrä Nägäśt diente einer bewusst gewählten argumentativen Strategie, deren Ziel es war, mittels des "salomonischen Narrativs« die Eigenart des äthiopischen Christentums, vor allem jedoch jene Bräuche, die dem europäischen Leser »jüdisch « erschienen, nachträglich zu legitimieren. Neben der Beschneidung betraf dies vor allem die Heiligung des Sabbats sowie die Observanz der alttestamentlichen Speiseverbote, speziell den Verzicht auf Schweinefleisch. Diese Frömmigkeitspraktiken führte Șägga Zä’ab auf die Zeit der Königin von Saba zurück und betonte ausdrücklich, dass sie in Äthiopien allesamt "aufgrund des Gesetzes Mosis « (»ex lege Mosi«) beobachtet werden. ${ }^{16}$

Dass es sich hierbei keinesfalls um eine repräsentative, geschweige denn bindende Meinung handelte, verdeutlicht die sogenannte Confessio Claudii, die im Jahr 1555 im Kontext der frühen Phase der Auseinandersetzung mit den Jesuiten entstand, und ebenso wie das Werk des Șägga Zäaab die Besonderheiten des äthiopischen Christentums angesichts des lateineuropäischen Gegenübers zu erklären suchte. ${ }^{17}$ Denn es fehlt in dieser Schrift, die mit Kai-

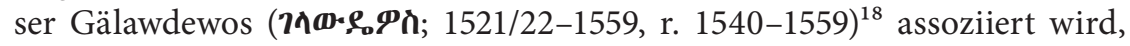
nicht nur jeglicher Versuch, die genannten Frömmigkeitspraktiken mit dem "salomonischen Narrativ« in Verbindung zu setzen, sondern es wird dort vielmehr behauptet, dass sowohl Beschneidung als auch Verzicht auf Schweinefleisch rein kulturelle Bräuche seien, die in Äthiopien »nach der Sitte des

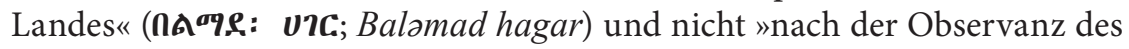

$14 »$ Das Buch $<$ mit $>$ dieser Geschichte ist von $<$ eben $>$ solchem Umfang wie alle Paulusbriefe« (»Cuius historiæ liber tantæ crassitudinis est, quantæ omnes Pauli epistolæ«). Ebd.

15 Vgl. Bezold, Kebra Nagast, S. 34-36.

16 Uhlig / Bühring (Hg.), Damian de Góis' Schrift, S. 76 (Text), S. 252 (Übersetzung).

17 Siehe dazu Kapitel III.3.2 »Hiob Ludolf und die `Confessio Fidei Claudii Regis Æthiopiæ«".

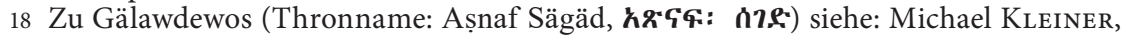
Gälawdewos, in: EAE 2, 2005, S. $656 f$. 


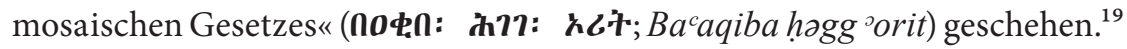
Höchst wahrscheinlich galt ausgerechnet diese Auffassung im frühneuzeitlichen Äthiopien als normativ. Dafür spricht jedenfalls die Tatsache, dass die Confessio Claudii Eingang in die Kaiserchronik des Gälawdewos fand, ${ }^{20}$ der in der Äthiopischen Kirche als Heiliger verehrt wird. ${ }^{21}$ Des Weiteren muss bedacht werden, dass - anders als im Fall vom Șägga Zä’ab, der explizit für die Europäer (und zwar direkt auf Portugiesisch) schrieb - die Confessio Claudii auf Gəcəz verfasst (und nur in dieser Fassung bekannt) wurde, sodass sie für äthiopische Christen als ein Musterbeispiel theologischer Argumentation im Kontext eines Dialogs mit den Jesuiten dienen konnte.

Inwieweit der Transfer des äthiopisch-orthodoxen theologischen Wissens in Bezug auf das "salomonische Narrativ« auch dessen Transformation beinhaltete, lässt sich am deutlichsten wohl damit veranschaulichen, dass Șägga Zä’ab sogar die weibliche Beschneidung auf eine Anordnung der Königin von Saba zurückführte, was weder im Kabrä Nägäśt noch in anderen Schriften äthiopisch-orthodoxer Provenienz einen Anhalt findet:

Obendrein werden, auf Befehl und Anordnung der Königin Maqeda selbst, auch die Frauen beschnitten. Dazu wurde sie dadurch veranlaßt, daß, wie die Männer eine Vorhaut haben, ebenso auch die Frauen einen eichelförmigen fleischigen Teil, den sie Nymphe nennen, innerhalb ihrer Genitalien haben, der ganz geeignet ist, das Zeichen der Beschneidung zu empfangen, welche wie bei den Knaben so bei den Mädchen am achten Tage erfolgt. ${ }^{22}$

19 Edward Ullendorff, The Confessio Fidei of King Claudius of Ethiopia, in: JSSt 32 (1) (1987), S. 159-176, hier S. 168.

20 Vgl. William Eliot Conzelman (Hg.), Chronique de Galâwdêwos (Claudius). Roi d'Ethiopie (1540-1559), Paris 1895, S. 169-172.

21 Sein Gedenktag ist der 27. Mäggabit. Vgl. Ernest Alfred Thompson Wallis Budge, The Book of the Saints of the Ethiopian Church. A Translation of the Ethiopic Synaxarium opghb: inhnc: Made from the Manuscripts Oriental 660 and 661 in the British Museum, Cambridge 1928, Bd. III: Magâbît, Mîyâzyâ, Genbôt (March 7 June 4), S. 745f.

22 »Insuper jussu \& decreto ipsius Reginæ Maquedæ mulieres quoque circumciduntur. Atque id ea ratione deducta est, vt quemadmodum viri præputium habent, eodem quoque modo mulieres etiam quandam glandulosam carnem, quam Nympham vocant, in genitalibus habent, non ineptam accipiendo characteri circumcisionis; id quod sit tam in masculis quam in feminis ad octavum diem«. UHLIG/BÜHRING (Hg.), Damian de Góis' Schrift, S. 70 (Text), S. 244 (Übersetzung). Ob sich Șägga Zä̈ab hierbei auf eine lokale Tradition stützte, lässt sich nicht mit Sicherheit feststellen. Zu zahlreichen - auch mündlichen - Überlieferungen zur Königin von Saba in Äthiopien siehe: Alessandro BAUsI, La leggenda della Regina di Saba nella tradizione etiopica, in: Fabio Battiato u.a. (Hg.), La Regina di Saba. Un Mito fra Oriente e Occidente, Napoli 2016, S. 91-162. 
Somit kam der Erzählung von der Königin von Saba und König Salomo die ohnehin eine nicht zu unterschätzende Rolle in der äthiopischen Theologie gespielt hatte - eine zusätzliche Funktion zu: Angesichts der Herausforderung, all jene Elemente des äthiopischen Christentums, die aus einer lateineuropäischen Perspektive fraglich erschienen (in Äthiopien jedoch selbstverständlich waren), rationalisieren zu müssen, wurde das »salomonische Narrativ« in der Schrift Șägga Zä’abs zu einem nahezu universellen Erklärungsmodell erhoben.

\subsection{Modi der Rezeption: Sebastian Münster und Martin Bucer}

Die vom Werk Șägga Zä’abs angestoßene intellektuelle Auseinandersetzung protestantischer Theologen mit dem Gedankengut äthiopischer Orthodoxie begann sich bereits in den 1540er Jahren zu entfalten. Dabei verlief sie keineswegs geradlinig, was im Folgenden anhand zweier prominenter Fallbeispiele zu verdeutlichen ist: erstens des bedeutenden Basler Gelehrten Sebastian Münster (1488-1552) ${ }^{23}$ und zweitens des Straßburger Reformators Martin Bucer. Die beiden Protestanten hatten sich mit der Schrift des äthiopischen Geistlichen unmittelbar nach ihrer Veröffentlichung beschäftigt, gingen damit aber sehr unterschiedlich um.

Sebastian Münster befasste sich mit dem äthiopischen Christentum im Rahmen seines einflussreichen Hauptwerkes, der Cosmographia, dessen erste Ausgabe 1544 erschien. ${ }^{24}$ Es war die erste umfassende Weltbeschreibung in deutscher Sprache, worin die Grundlagen aus Geschichte und Geografie, Astronomie und Naturwissenschaften, Landes- und Volkskunde nach dem damaligen Wissensstand zusammengefasst worden waren. Auch eine auf der Schrift des Șägga Zä̋abs basierte Darstellung religiöser Gegebenheiten Äthiopiens fand Eingang in das Werk. Als Interpret des äthiopischen Christentums betonte Sebastian Münster dessen distinktive Andersartigkeit:

23 Zu Sebastian Münster siehe: Karl Heinz Burmeister, Sebastian Münster. Versuch eines biographischen Gesamtbildes, Basel ${ }^{2} 1969$.

24 Sebastian Münster, Cosmographia. Beschreibung aller Lender durch Sebastian Munsterum in welcher begriffen aller Völcker Herschafften, Stetten und namhafftiger Flecken Herkomēn, Sitten, Gebreüch, Ordnung, Glauben, Secten und Hantierung durch die gantze Welt und fürnemlich Teütsche Nation, Basel 1544. Vgl. Günther Wessel, Von einem, der daheim blieb, die Welt zu entdecken. Die Cosmographia des Sebastian Münster oder Wie man sich vor 500 Jahren die Welt vorstellte, Frankfurt a. M. 2004; Matthew McLean, The Cosmographia of Sebastian Münster. Describing the World in the Reformation, Burlington VT 2007; Marília dos Santos Lopes, Writing New Worlds. The Cultural Dynamics of Curiosity in Early Modern Europe, Newcastle upon Tyne 2016, S. 178-193. 
Sie haben auch das Euangelium Christi / und leren das / aber sie vermischen es / ja verdunckeln es mit dem alten gesatz und stecken in vilen und grossen irthümmen. [...] Sie halten den underscheid der speys / so Moses im alten gesatz den Juden vorgeschriben hat / und essen kein blüt. Sie halten der Juden beschneidung / feyern den sabbat / fasten den ganzen tag biß zü undergang der sonnen. ${ }^{25}$

Diese Betonung des »ü̈dischen« kann auf die Rezeption der von Ṣägga Zä̊ab hergestellten Verbindung zwischen dem »salomonischen Narrativ« und dem mosaischen Gesetz zurückgeführt werden. Sie wurde jedoch aufgrund einer im theologischen Antijudaismus verwurzelten Sichtweise negativ konnotiert und mit einer abwertenden Haltung verbunden. Um das Ausmaß der Diskursverschiebung, die hinter dieser Denkfigur steht und sich in der Folgezeit zum Leitmotiv protestantischer Kritik an der Kirche Äthiopiens entwickelte, zu begreifen, sollte im Bewusstsein gehalten werden, dass nur noch wenige Jahre zuvor, 1537, Martin Luther - an seine Begegnung mit Abba Mika ${ }^{\circ}$ l erinnernd - von einer grundlegenden Übereinstimmung der reformatorischen Lehre mit derjenigen des äthiopischen Christentums gesprochen hatte. Für Sebastian Münster galt die Äthiopische Kirche mit ihrer angeblichen Fokussierung auf das Gesetz nun jedoch als das genaue Gegenteil des auf reformatorischen Grundprinzipien basierten Christentumsverständnisses.

Anders als Sebastian Münster kam Martin Bucer in seinen Schriften überraschend oft auf Ähnlichkeiten zwischen äthiopisch-orthodoxem Christentum und Reformation zu sprechen. Dabei ging es ihm in erster Linie um die Sakramententheologie, am häufigsten um das Abendmahlsverständnis. Dies ist der Fall sowohl in seiner lateinischen Schrift De vera et falsa caenae dominicae administratione (1546) als auch in der deutschen Abhandlung Wider auffrichtung der Messen, anderer Sacramenten und Ceremonien und des Papsttums (1545) und in seiner Bestendigen Verantwortung (1545). ${ }^{26}$ In der zuletzt genannten Schrift bezog er sich sogar explizit auf die Information, die »der Edel vnd hochgelehrt Herr Damian Goes auß Portugal auß dem mundt eines Bisschoffes vnd Legaten auß Aethiopia mit namen Zegazabo [= Șägga Zä̉ab] auff geschrieben vnd in truck gegeben hat «. ${ }^{27}$ Das Wissen, das Martin Bucer den Ausführungen des äthiopischen Priesters Ṣägga Zä̊ab entnahm, wurde im Dienst seiner Polemik gegen die römisch-katholischen

25 Sebastian Münster, Cosmographia, S. 958.

26 Nicholas Thompson (Hg.), De vera et falsa caenae dominicae administratione (1546), SMRT 184 [Martin Bucer: Opera Latina 6], Leiden 2014, S. 111, 120, 125, 136, 252; Christoph Sтroнm (Hg.), Martin Bucers Deutsche Schriften, Martini Buceri Opera Omnia. Series I, bearbeitet von Thomas Wilhelmi, Gütersloh 2011, Bd. 13: Unionsschriften 1542-1545, S. 377; Christoph Sтroнm (Hg.), Martin Bucers Deutsche Schriften, Martini Buceri Opera Omnia. Series I, bearbeitet von Thomas Wilhelmi, Gütersloh 2006, Bd. 11,3: Schriften zur Kölner Reformation, S. 339 und 344.

27 Ebd., S. 565. 
Theologen eingesetzt, etwa als Beweis dafür, dass in Äthiopien die Austeilung des Abendmahls - gemäß der altkirchlichen Praxis, deren Neubelebung der Straßburger Theologe zu rechtfertigen suchte - unter beiderlei Gestalt geschehe. ${ }^{28}$ Insgesamt gesehen lassen sich diese und ähnliche auf die Abendmahlspraxis bezogene Denkfiguren als analog zu bereits analysierten argumentativen Strategien Martin Luthers betrachten. ${ }^{29}$

In Bezug auf die Frage nach Transfer und Transformation des äthiopischen Wissens gebührt jedoch einem anderen Sakrament besondere Aufmerksamkeit - dem Sakrament der Krankensalbung. Während man im Kontext der Auseinandersetzung mit der Kirche Roms über das Abendmahl genauso zutreffend auf die Praxis anderer Ostkirchen verweisen könnte, ließ sich im Falle der Krankensalbung eine These aufstellen, die ein äthiopisches Spezifikum zu thematisieren schien: Denn Bucer behauptete, dass »die Christen in Aethiopia vnder dem grossen Keiser der Aethiopen Pretioso Ioanne, den man Priester Johan nennet, das Chrysma oder Oel der Krancken weder für ein Sacrament, noch auch im brauch haben ${ }^{30}{ }^{30}$

$\mathrm{Ob}$ die Krankensalbung im Äthiopien des 16. Jahrhunderts den Status eines Sakraments hatte, ist schwer zu bestimmen. ${ }^{31}$ Jedoch wie der entsprechenden liturgischen Ordnung aus dem Jahr 1442, dem Mäșhafä Baḥray

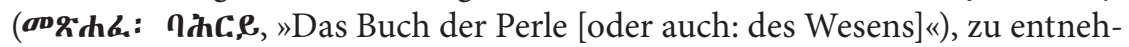
men ist, war die Krankensalbung in Äthiopien durchaus bekannt und als

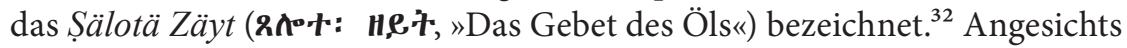
einer großen Anzahl von Textzeugen des Mäshafä Bahrəy - von denen einige sogar unmittelbar aus dem 15. Jahrhundert stammen, was eine Seltenheit darstellt $-^{33}$ kann kein Zweifel daran bestehen, dass die Krankensalbung in Äthiopien praktiziert wurde. Während der Kaiserschaft des Gälawdewos, ${ }^{34}$ also ausgerechnet in der Zeit, als Bucer über die Abwesenheit der Kranken-

28 Für die entsprechende Stelle bei Șägga Zä ab, der Bucer seine These entnommen hatte, vgl. GóIs, Fides, Religio, Moresque Æthiopum, S. 76 und Uhlig/Bühring (Hg.), Damian de Góis' Schrift, S. 253.

29 Vgl. Kapitel II.3.2 »Abendmahlsverständnis«.

30 Strohm (Hg.), Martin Bucers Deutsche Schriften, Bd. 11,3, S. $565 f$.

31 Vgl. Anaïs Wion, Onction des malades, funérailles et commémorations. Pour une histoire des textes et des pratiques liturgiques en Éthiopie chrétienne, in: Afriques 3 (2011), URL: <http://journals.openedition.org/afriques/921> (12.09.2019); Ernst Christoph SutTner, Die Krankensalbung (das »Öl des Gebets«) in den altorientalischen Kirchen, in: EL 89 (1975), S. 371-396; Ugo Zanetti, Unction, in: EAE 4, 2010, S. $1020 \mathrm{f}$.

$32 \mathrm{Zu}$ Mäsḩafä Bahrryy, das, wie so viele andere bedeutende theologische Werke des 15. Jahrhunderts, Zäro Ya Yåqob zugeschrieben wird, siehe: Getatchew Haile, Bahrəy: Mäșhafä Bahroy, in: EAE 1, 2003, S. 446f.

33 Dabei handelt es sich um die Manuskripte EMML 1480 und Abbadie 69. Vgl. Wion, Onction des malades.

34 Vgl. Anm. 18 auf S. 78. 
salbung in der äthiopischen Kirche schrieb, ist ins Gə⿳亠口冋 ${ }^{c} ə \mathrm{z}$ aus dem Arabischen zudem noch die koptische Ordnung dieses Ritus, das Mäșhafä Qändil

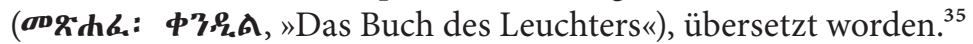

Wie kam also Martin Bucer zum Schluss, dass die Äthiopier die Krankensalbung "weder für ein Sacrament, noch auch im brauch haben «? ${ }^{36}$ Offensichtlich hatte er an die folgende Passage aus dem Buch Ṣägga Zä’abs gedacht:

Praeterea sciendum apud nos confirmationem et chrisma, sive extremam olei unctionem, pro sacramento non haberi, nec in usu esse, ut video hic ex Romana ecclesia consuetudine fieri.

Außerdem muß man wissen, daß bei uns die Firmung und die Salbung oder die Letzte Ölung nicht für ein Sakrament gehalten werden und nicht in Gebrauch sind, wie ich sie hier geschehen sehe nach der Gewohnheit der römischen Kirche. ${ }^{37}$

Während Șägga Zä’ab an dieser Stelle tatsächlich behauptet, dass die Krankensalbung in Äthiopien nicht als Sakrament gilt, leugnet er deren Existenz nicht. Vielmehr ist anzunehmen, dass er in dieser Passage die Differenz zwischen der Krankensalbung "nach der Gewohnheit der römischen Kirche", wie er sie in Europa beobachten konnte, und der Praxis der Äthiopischen Kirche zu betonen suchte. Folglich erweist sich die von Martin Bucer aufgestellte These von dem Nicht-Vorhandensein der Krankensalbung in der Äthiopischen Kirche bei näherem Hinsehen entweder als Missverständnis ${ }^{38}$ oder als bewusst zugespitzte Interpretation, die der theologischen Polemik gegen die Kirche Roms dienen sollte.

Dieses Fallbeispiel legt einen bemerkenswerten Mechanismus der Transformation des äthiopisch-orthodoxen Wissens offen und zeigt, wie sehr protestantische imaginäre Entwürfe des äthiopischen Christentums letzten Endes mit binneneuropäischen theologischen Auseinandersetzungen verwoben waren. Indem reformatorisch gesinnten Theologen - und Martin Bucer stellt hier keine Ausnahme dar - die Kirche Äthiopiens als Argument in die Polemik gegen römisch-katholische Positionen heranzogen, erwähnten sie

35 Diese hatte sich in der Folgezeit durchgesetzt und wird heutzutage vornehmlich verwendet. Siehe den Text der liturgischen Ordnung in: Marius Chaîne, Le rituel éthiopien - Rituel de l'extrême-onction, in: Bess. 29 (4) (1913), S. 415-420; ders., Le rituel éthiopien - Rituel de l'extrême-onction, in: Bess. 30 (1) (1914), S. 12-41, S. 213-231; Anton Gladel, Übersetzung des Buches des Leuchters, d.i. der Gebete bei der Spendung der letzten Ölung nach äthiopischem Ritus, in: TThQ 77 (1924), S. 650-675.

36 Sтrонм (Hg.), Martin Bucers Deutsche Schriften, Bd. 11,3, S. $565 f$.

37 Uhlig / Bühring (Hg.), Damian de Góis' Schrift, S. 75 (Text), S. 251 (Übersetzung).

38 Da Șägga Zäjab sein Werk auf - wohl nicht perfektem - Portugiesisch verfasst hatte, könnten einige linguistische Missverständnisse bei der Übersetzung des Textes ins Latein entstanden sein. 
nur das, was sich als Untermauerung ihrer eigenen theologischen Ansichten verwenden ließ. Dabei wurden theologische Behauptungen von sehr unterschiedlichem Wahrheitsgehalt vermengt und weitertradiert: Man berief sich neben jenen Elementen äthiopisch-orthodoxer Glaubenspraxis, die in der Äthiopischen Kirche und im Protestantismus tatsächlich konvergent waren (etwa Austeilung des Abendmahls unter beiderei Gestalten), auch auf diejenigen, die gar nicht existierten, sondern bloß als Produkte der Missverständnisse beziehungsweise der Fehlinterpretationen zu betrachten sind (wie eben die Behauptung der Abwesenheit des Sakramentes der Krankensalbung in der Äthiopischen Kirche). In anderen Worten: Das äthiopisch-orthodoxe Wissen wurde einem Selektionsprozess unterzogen und funktionalisiert. Auf diese Weise ließen sich Bausteine jener »imaginärer Kirche« Äthiopiens hervorbringen, die im Laufe der Zeit ein zunehmend protestantisches Antlitz gewann.

\subsection{Topographien des Imaginären}

Will man das außerordentliche Interesse frühneuzeitlicher Protestanten am christlichen Kaiserreich am Horn von Afrika verstehen, so darf man den Blick nicht auf den innertheologischen Diskurs beschränken. Die Rezeption des äthiopischen Wissens hatte nicht nur dazu geführt, dass bisherige Vorstellungen vom äthiopischen Christentum einer tiefgreifenden Justierung unterzogen wurden, sondern auch dazu, dass Äthiopien selbst, und zwar sowohl als eine politische als auch eine geografische Größe, neu gedacht wurde. Diese Wandlung, die sich anhand kartographischer Repräsentationen Äthiopiens ablesen lässt, weist eine grundlegende Verschiebung der europäischen Meistererzählung von Äthiopien auf. Das »salomonische Narrativ« (äthiopische Imagination von sich selbst) und der Mythos vom Priesterkönig Johannes (europäische Imagination von Äthiopien) verflochten sich nämlich in einer solchen Art und Weise miteinander, dass man von einer »hybriden« Imagination sprechen kann. ${ }^{39}$

39 Zur frühneuzeitlichen europäischen Kartographie Äthiopiens siehe: Jeffrey JAYNEs, Christianity Beyond Christendom. The Global Christian Experience on Medieval Mappaemundi and Early Modern World Maps, Wiesbaden 2018; Rainer VoIgT, Cartography until the 18th Century, in: EAE 1, 2003, S. 686-688. Vgl. dazu George Wynn Brereton Huntingford, The Historical Geography of Ethiopia. From the First Century AD to 1704, Union Académique Internationale, Oxford 1989; Bertrand Hirsch, Cartographie et itinéraires. Figures occidentales du nord de l'Éthiopie aux XV et XVI siècles, in: Abbay 13 (1988), S. 91-122; Egon KlemP, Africa auf Karten des 12. bis 18. Jahrhunderts. 77 Lichtdrucke aus europäischen Kartensammlungen, Stuttgart 1968; Francesc Relaño, The Shaping of Africa. Cosmographic Discourse 
In dieser Hinsicht ist die Karte Afrikas aus dem Itinerarium Sacrae Scripturae, dem zunächst 1581 erschienenen Bestseller (es sind 61 Auflagen bekannt) des Hannoverschen Theologen und Geografen Heinrich Bünting (1545-1606), besonders aufschlussreich. ${ }^{40}$ Der Umstand, dass seine Landkarte auf einem Holzschnitt Sebastian Münsters basierte, den der Basler Universalgelehrter für die 1540 veröffentlichte Neuauflage der ptolemäischen Geographia Universalis, also noch vor der Lektüre des Werkes von Șägga Zä’ab, vorbereitet hatte, ${ }^{41}$ macht einen Vergleich der visuellen Repräsentationen Äthiopiens zweier protestantischer Gelehrter vor und nach dem Wissenstransfer über das "salomonischen Narrativ« möglich [siehe Abbildungen 6 und 7].

Der mittelalterliche Mythos vom Priesterkönig Johannes blieb weiterhin der zentrale Referenzpunkt, mit dessen Hilfe die beiden Kartographen das nordostafrikanische Kaiserreich konzeptualisierten. Dies äußerte sich bereits in der Benennung der äthiopischen Hauptstadt als Hamarich Sedes Pręte Iohan (beziehungsweise Hamarith Sedes Proto Iohanis bei Bünting): Während Sedes Pręte Iohan als »Sitz des Priesterkönig Johannes« übersetzt werden kann, bleibt das Wort Hamarich rätselhaft (möglicherweise könnte es auf eine fehlerhafte Wiedergabe von "Amhara", einer äthiopischen Provinz, zurückgeführt werden). Heinrich Bünting platzierte zudem - wohl als eine Anspielung auf das Priesteramt des mythologischen Königs - mitten in der Hauptstadt eine Kirche. Darüber hinaus bezeichnete er einen großen

and Cartographic Science in Late Medieval and Early Modern Europe, Aldershot 2002; Richard L. Betz, The Mapping of Africa. A Cartobibliography of Printed Maps of the African Continent to 1700, Goy-Houten 2007.

40 Heinrich Bünting, Itinerarium Sacrae Scripturae. Das ist, Ein Reisebuch, Uber die gantze heilige Schrifft, Helmstadt 1581. Dieser »Lehnstuhlreiseführer« über die heiligen Stätten Palästinas gilt als die vollständigste Sammlung des damaligen Wissens über die biblische Geografie. Vgl. Henk van der Heijden, Heinrich Büntings Itinerarium Sacrae Scripturae, 1581. Ein Kapitel der biblischen Geographie, in: Cartographica Helvetica 23 (2001), S. 5-14. Zu Heinrich Bünting siehe: Hans KuInge, Bünting, Heinrich, in: NDB 2, Berlin 1955, S. 741.

41 Sebastian Münster (Hg.), Geographia Vniversalis, Vetvs Et Nova. Complectens Clavdii Ptolemaei Alexandrini Enarrationis Libros VIII. Quorum primus nova translatione Pirckheimheri et accessione commentarioli illustrior quam hactenus fuerit, redditus est; Reliqui cum Graeco et aliis vetustis exemplaribus collati, in infinitis fere locis castigatiores facti sunt; Addita sunt insuper scholia, quibus exoleta urbium, montium, fluviorumque nomina ad nostri seculi morem exponuntur; Succedunt tabulae Ptolemaicae opera Sebastiani Munsteri novo paratae modo; His adiectae sunt plurimae novae tabulae, modernam orbis faciem literis et pictura explicantes, inter quas quaedam antehac Ptolemaeo non fuerunt additae; Ultimo annexum est compendium geographicae descriptionis, in quo varii gentium et regionum ritus et mores excplicantur; Praefixus est quoque universo operi index memorabilium populorum, civitatum, fluviorum, montium, terrarum, lacuum etc., Basel 1540. Vgl. JAYNES, Christianity Beyond Christendom, S. 334-343. 


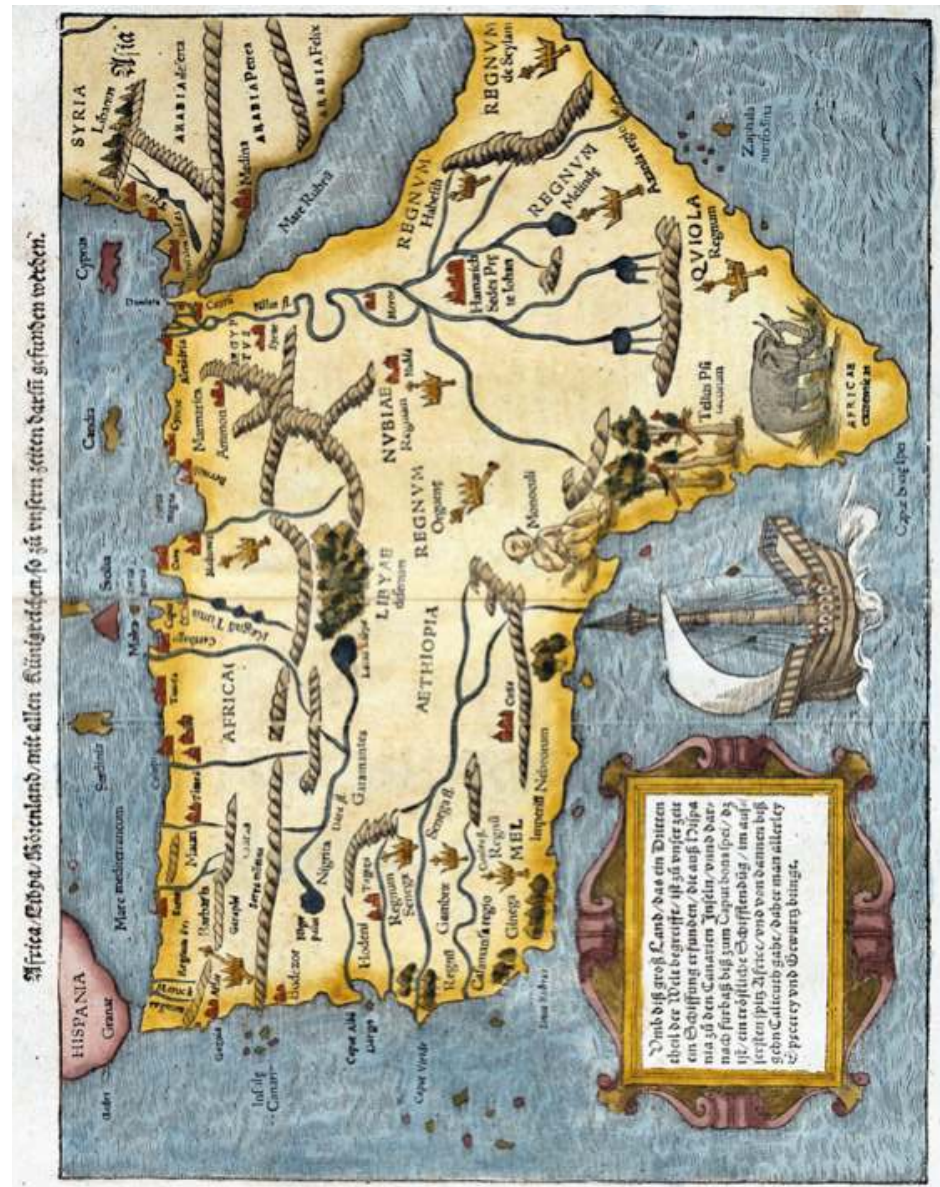

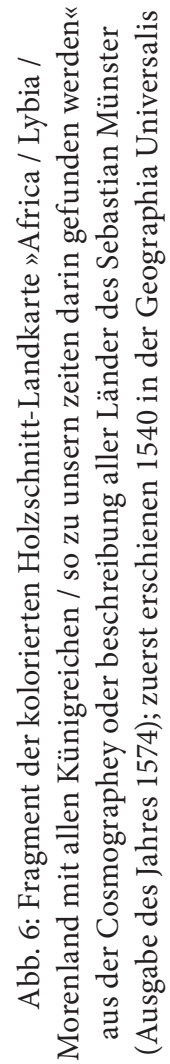




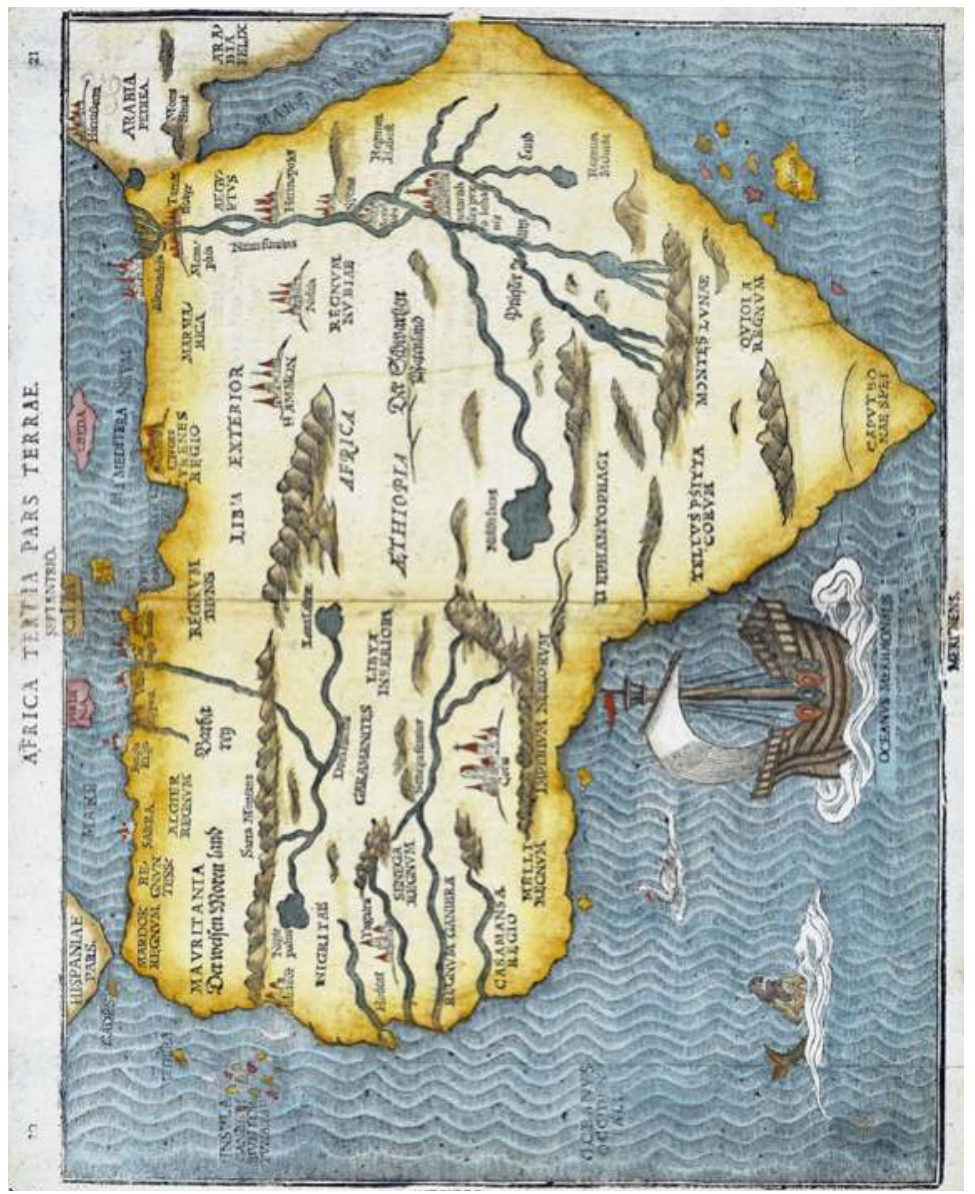




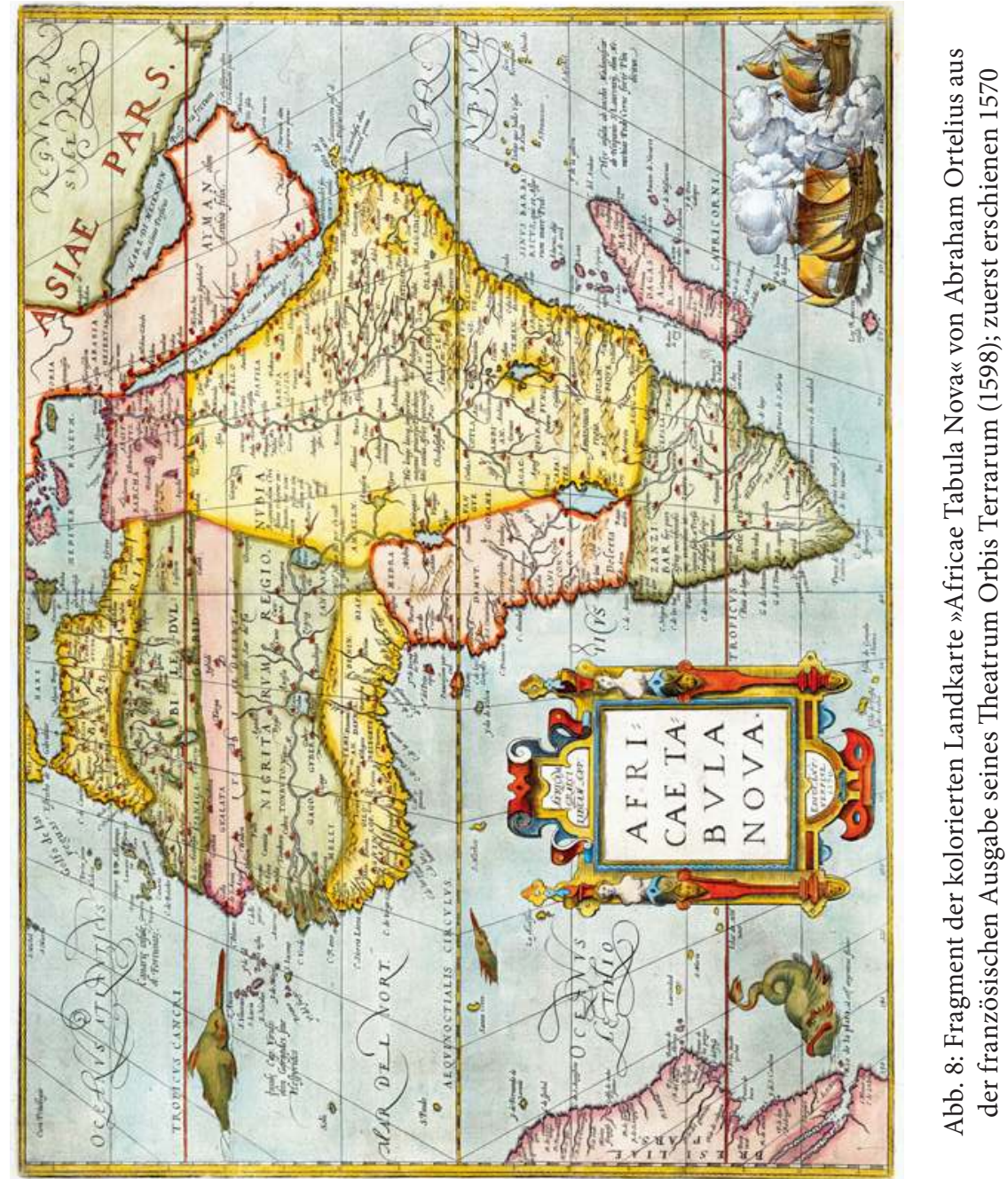




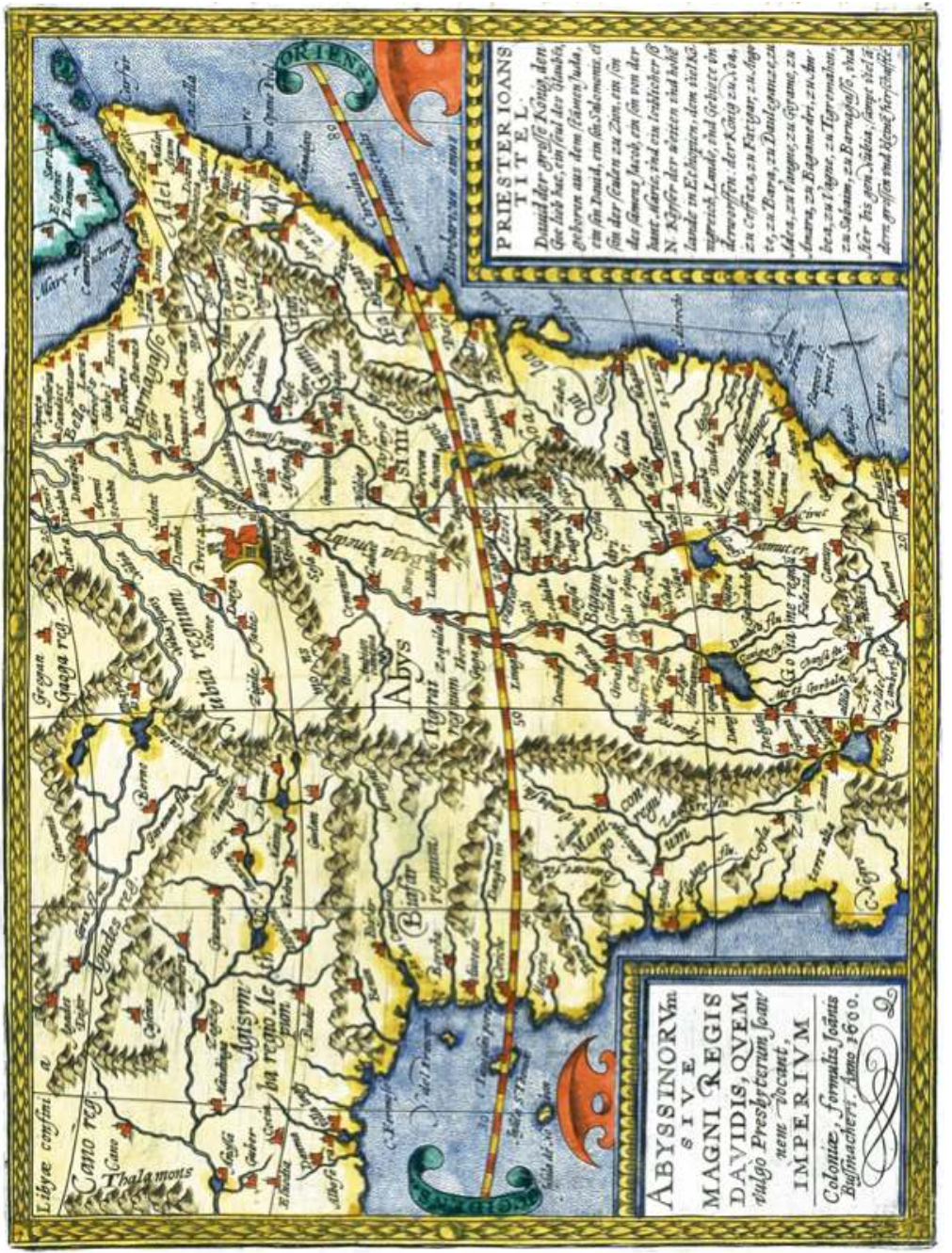

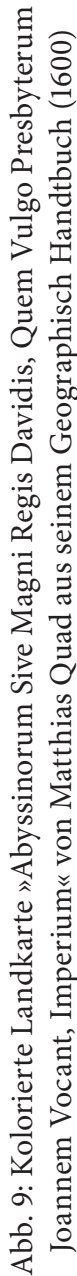


Teil von Ostafrika als »Priester Johans Land«. Gleichwohl zeugen einige Elemente der Karte Büntings von der Aneignung des »salomonischen Narrativs«: So stilisierte der Hannoveraner Meroe zur Herkunftsstadt der Königin von Saba, indem er es in Meroe Saba umbenannte, ${ }^{42}$ des Weiteren bewegte

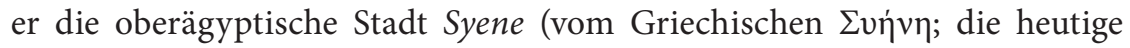
Assuan) in das Gebiet von Nordäthiopien, und somit ganz in die Nähe von Meroe Saba, und änderte dabei ihren Namen auf Syone. Diese könnte nun als die legendäre nordäthiopische Stadt Aksum beziehungsweise als deren

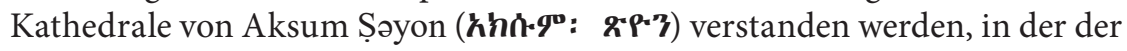
äthiopischen Tradition nach die - ebenfalls als "Zion« (Səyon; $\mathbf{R} \cdot \mathbf{P} \cdot \mathbf{p})$ ) bezeichnete - Bundeslade aufbewahrt wird. ${ }^{43}$

Während die Landkarte Büntings immer noch einen weitgehend schematischen Charakter trug, entstanden in der zweiten Hälfte des 16. Jahrhunderts die ersten Karten, die sich vom ptolemäischen Weltbild emanzipierten und die Grundlagen moderner Kartografie legten. Als zukunftsweisend gilt das Meisterwerk Gerhard Mercators (1512-1594): die große Weltkarte von 1569 Nova et aucta orbis terrae descriptio ad usum navigantium emendate accomodata, bei der zum ersten Mal eine winkeltreue Projektion (»MercatorProjektion«) verwendet wurde. ${ }^{44}$ Doch auch die moderne Kartografie, wie sowohl die Weltkarte Mercators als auch zahlreiche darauf basierende Karten des 16. und 17. Jahrhunderts zeigen, war auf äthiopisches Wissen angewiesen: Die in Europa vorhandenen äthiopischen Texte dienten als wichtige Informationsquelle, aus der man lokale Toponyme für die Herstellung neuer Landkarten entnehmen konnte. Da man allerdings nicht genau wusste, wo die jeweiligen Orte lagen, verteilte man sie auf der Karte ziemlich willkürlich.

Die imaginäre Topografie Äthiopiens zeichnete sich allerdings nicht nur durch räumliche Verschiebung einzelner Regionen und Ortschaften aus, sondern vor allem durch die Darstellung des Landes in überdimensionaler Größe. Europäische Kartographen ließen Äthiopien sich über eine Fläche erstrecken, die nahezu die Hälfte des gesamten afrikanischen Kontinents einnahm, wie beispielsweise auf der Karte Africae Tabula Nova von 1570 des

42 Vgl. dazu seine Ausführungen: BüNTING, Itinerarium Sacrae Scripturae, S. 141-144. $\mathrm{Zu}$ Meroe und dessen Verbindung zur äthiopischen Zivilisation siehe: Michael ZACH, Meroë, in: EAE 3, 2007, S. 937f.; Steffen Wenig, Meroe. Zentrum und Peripherie, in: Sergio Donadoni (Hg.), L'impero ramesside. Convegno internazionale in onore di Serio Donadoni, Roma 1997, S. 221-231.

43 Vgl. Steven Kaplan, Zion, in: EAE 5, 2014, S. 189-191.

44 Vgl. Friedrich Wilhelm KrÜCKEN, Ad maiorem Gerardi Mercatoris gloriam. Abhandlungen zum Leben und Werk Gerhard Mercators, Münster 2011, Bd. 5: Das Buch zur Karte Ad Usum Navigantium; Jaynes, Christianity Beyond Christendom, S. 373-380; Rodney Shirley, The Mapping of the World. Early Printed World Maps. 1472-1700, Riverside CT 2001, S. 137-142. 
Abraham Ortelius (1527-1598), eines der engen Mitarbeiter Mercators, zu sehen ist [siehe Abbildung 8]. ${ }^{45}$

Die räumliche Überdimensionalität des Äthiopischen Kaiserreichs korrelierte mit seinem außerordentlichen Stellenwert in der europäischen Imagination und muss daher auch bei der Analyse protestantischer Entwürfe der Äthiopischen Kirche immer mitgedacht werden. Diese Topografie kann sogar als ein wichtiger Faktor, der zur Entstehung der »imaginären Kirche« führte, betrachtet werden. Das Zusammenspiel von geografischer und theologischer Imagination lässt sich am Beispiel von Matthäus Dresser (1536-1607) veranschaulichen. ${ }^{46}$ In seinem De Statu Ecclesiae et Religionis in Aethiopia, sub precioso Ioanne, Oratio von 1584 berief sich der Theologe auf diese Topografie und betonte, dass Äthiopien »schier ganz Europae / oder der Christenheit gantzen theil / der grösse nach / zuvergleichen ist $«{ }^{47}$ Vor diesem Hintergrund lassen sich seine Aussagen in Bezug auf die Kongruenz von Protestantismus und äthiopischer Orthodoxie nicht zuletzt als ein Versuch deuten, den Protestantismus selbst machtpolitisch und theologisch aufzuwerten. Denn eine solche Kongruenz impliziert, dass die Anhänger des protestantischen Lagers (wenn dazu auch die orthodoxen Äthiopier mitgerechnet würden) in der Mehrheit gegenüber dem römischen Katholizismus seien.

Das protestantische Interesse an Äthiopien äußerte sich ebenfalls dadurch, dass man ihm auch eigene Landkarten widmete, und es nicht nur im Rahmen der Welt- oder Afrika-Karten darstellte. Ein in dieser Hinsicht interessantes Beispiel ist die Abyssinorum Sive Magni Regis Davidis, Quem Vulgo Presbyterum Joannem Vocant, Imperium des Matthias Quad (1557-1612) ${ }^{48}$ [siehe Abbildung 9]. Diese aus dem Jahr 1600 stammende Landkarte verdeutlicht, dass frühe moderne Kartografie keinesfalls eine Überwindung des Mythos vom Priesterkönig Johannes beziehungsweise eine "Entzauberung« Äthiopiens bedeutete. ${ }^{49}$

45 Vgl. Jaynes, Christianity Beyond Christendom, S. 383-392; Relaño, The Shaping of Africa, S. 62f., 208f.; Marcel P. R. van den Broecke, Ortelius Atlas Maps. An Illustrated Guide, Houten ${ }^{2} 2011$, S. 522-525. Siehe außerdem Beiträge in: Ders./Leon Voet (Hg.), Abraham Ortelius and the First Atlas. Essays Commemorating the Quadricentennial of His Death. 1598-1998, Utrecht 1998.

$46 \mathrm{Zu}$ Dresser siehe: Heinrich Grimm, Dresser (Drescher), Matthäus, in: NDB 4, Berlin 1959, S. 112.

47 Matthäus Dresser, De Statu Ecclesiae et Religionis in Aethiopia, sub precioso Ioanne, Oratio, Leipzig 1584, S. 88.

$48 \mathrm{Zu}$ Quad siehe: Peter H. Meurer, Quad, Matthias, in: NDB 21, Berlin 2003, S. $28 \mathrm{f}$.

49 Elemente von äthiopischem Selbstverständnis und europäischer Zuschreibung wurden auch dadurch miteinander vermengt, dass der äthiopische Kaiser Lebnä Dengel - wie aus der neben der Karte abgebildeten Tafel zu entnehmen war - mit dem Priesterkönig Johannes identifiziert wurde. Der Text der Tafel lautete: »Priester Ioans Titel. Dauid der grosse Konig, den Got lieb hat, ein Seul des Glaubens, geboren aus dem Stammen Juda, ein son Dauid, ein Son Salomonis, ein Son der Seulen zu 
Diese Topographien des Imaginären, die sowohl auf europäischen als auch auf äthiopischen - allerdings bereits im Laufe des Transfervorgangs modifizierten - Wissensbeständen beruhten, diese jedoch wiederum kontextuell anpassten und transformierten, können als visuelle Versinnbildlichung komplexer Hybridisierungsprozesse verstanden werden. Wie es im Folgenden zu zeigen sein wird, ist dieser Vorgang auch im Rahmen theologischer Diskursfelder zu beobachten.

\section{Erfindung einer Konfession: Konstruktionen des äthiopischen »Bekenntnisses«}

\subsection{David Chytraeus und die »Confessio Fidei Æthiopum»}

In der protestantischen Wahrnehmung äthiopischer Orthodoxie gingen Vorstellungen von Vertrautheit und Fremdartigkeit von Anfang an komplexe Verbindungen ein. Nichtsdestotrotz lässt sich auf makrohistorischer Ebene eine Tendenz beobachten, die mit Hilfe des am Fallbeispiel von Martin Bucer beschriebenen Mechanismus darauf abzielte, diese Ambivalenz dadurch zu reduzieren, das (vermeintlich) Verbindende hervorzuheben, zugleich aber alles Widersprüchliche möglichst $\mathrm{zu}$ harmonisieren, beziehungsweise $\mathrm{zu}$ ignorieren. Wohl am meisten zur Formierung und Verbreitung eines verklärt-protestantischen Bildes der Äthiopischen Kirche hat der Rostocker Theologieprofessor David Chytraeus (1530-1600), der von einigen als letzter »Vater der lutherischen Kirche« und als »Begründer einer protestantischen Ostkirchenkunde« bezeichnet wird, ${ }^{50}$ beigetragen.

Die Beschäftigung des Rostocker Theologen mit dem äthiopischen Christentum lässt sich bis in die frühen 1560er Jahre zurückverfolgen, in die Zeit seiner Arbeit an der Auslegung der Offenbarung Johannis, die zunächst 1563 erschien. ${ }^{51}$ Chytraeus zog die Kirche Äthiopiens bei der Auslegung einer

Zion, ein Son des Samens Jacob, ein Son von der Hand Marie, und ein leiblicher son $\mathrm{N}$. Keyser der weiten und hohen lande in Ethiopien, dem viel Konigreich, Lande, und Gebiete underworffen: der Konig zu Xoa, zu Ceffata, zu Fatigar, zu Angote, zu Bara, zu Dauleganze, zu Adea, zu Vangne, zu Goyame, zu Amara, zu Bagamedri, zu Ambea, zu Vagne, zu Tigremahon, zu Sabaim, zu Barnagasso, und Her bis gen Nubia; sampt viel andern grossen und kleinen Herschafften «.

$50 \mathrm{Vgl}$. (auch für eine kurze Einführung zu seiner Person sowie für die weiterführende Literatur) Peter F. BARTon, David Chyträus, in: TRE 8, Berlin u. a. 1981, S. 88-90, hier S. 88; Thomas Kaufmann, Chyträus (Kochhafe) David, in: RGG 2, Tübingen ${ }^{4} 2008$, Sp. 377f.; Benga, David Chytraeus; Gottfried Holtz, David Chytraeus und die Wiederentdeckung der Ostkirche, in: WZ(R).GS, 2 (1952-1953), S. 93-101.

51 David Chytraeus, Explicatio Apocalypsis Iohannis perspicua et brevis, Wittenberg 1563. Erste deutsche Ausgabe: Ders., Auslegung der Offenbarung Johannis darin viel Artickel Christlicher Lehr, viel Historien, und nötiger heilsamer Trost, in gegen 
Stelle des siebten Kapitels der Offenbarung heran, in der davon die Rede ist, dass »eine große Schar, die niemand zählen konnte, aus allen Nationen und Stämmen und Völkern und Sprachen« vor dem Thron Gottes stehen würde (Off 7,9). In seiner ekklesiologischen Deutung dieser Vision bezog Chytraeus sie auf die Gegenwart. Um zu beweisen, dass die Kirche Christi sich nicht allein »in diesem engen winckel Europae« befinde, sondern laut dem Wort Gottes an verschiedenen Enden der Erde zu finden sei, verweist er auf Äthiopien, wo »das Euangelium Christi / offentlich gepredigt wirdt/ und [...] die Christen und rechtglaubigen viel geruhiger/und sicherer/dan in Franckreich/Hispanien/und anderen orten Europae sitzen und leben «. ${ }^{52}$ Auffällig an diesem Satz ist nicht so sehr die Anspielung auf die europäischen Religionskriege, sondern vielmehr die Bezeichnung äthiopischer Christen als rechtgläubig.

Es ging Chytraeus dabei tatsächlich darum, zu behaupten, dass zwischen dem Luthertum und der äthiopischen Orthodoxie keine wesentlichen Unterschiede bestehen. Dies begründete er damit, dass »die form der lehr/unnd die Liturgia oder das ampt der Messe/in demselben theil Aphrice [...] sonderlich mit unserer kirchen/ordnung uber einkomme «. ${ }^{53}$ Ferner behauptete Chytraeus, dass in Äthiopien sowohl »der Artickel von vergebung der sünden/aus gnaden/umb des Opffers Christi willen" als auch »der rechte gebrauch des gantzen Sacraments [...] nit anders/als wie bey uns/geglaubt/gelehrt/ und gehalten werde ${ }^{54}{ }^{54}$ Konsequenterweise sah er die Lutheraner und die äthiopischen Christen- ähnlich wie bereits seine Lehrer Martin Luther und Philipp Melanchthon - als zu der einen wahren Kirche gehörig, was wiederum als Bestätigung des dritten Artikels des Apostolikums gedeutet wurde, der die Einheit der christlichen Kirche betont. ${ }^{55}$

wertigen Trübsalen und Zerruthungen der Kirchen, Uneinigkeit der Lehrer und andern Anfechtugnen nützlich erklert werden, Rostock 1568. Für einen Überblick der zahlreichen lateinischen und deutschen Ausgaben dieses Werkes im 16. Jahrhundert siehe: Thomas Kaufmann, Universität und lutherische Konfessionalisierung. Die Rostocker Theologieprofessoren und ihr Beitrag zur theologischen Bildung und kirchlichen Gestaltung im Herzogtum Mecklenburg zwischen 1550 und 1675, Gütersloh 1997, S. 628.

52 Chytraeus, Auslegung der Offenbarung, S. 201.

53 Ebd. Vgl. ders., Explicatio Apocalypsis, S. $155 f$.

54 Ders., Auslegung der Offenbarung, S. 201. Vgl. ders., Explicatio Apocalypsis, S. $155 f$.

55 Vgl. "Diese experientz und erfarung / bestettigt nun der Artickel unsers Christlichen glaubens / da wir sagen / Ich glaub ein heilige Christliche allgemeine kirchen/welche $\mathrm{zu}$ allen zeiten alhie auff erden erhalten/aus allen stimmen Israel/unnd aus allen orten auff erden/durch die Predigt des Euangelij gesamlet/ und vom heiligen Geist mit dem pfandt der ewigen Erbschafft/ versiegelt wirdt«. Ders., Auslegung der Offenbarung, S. 201f. 
Einen entscheidenden Beitrag zur Verbreitung der These von grundlegender Übereinstimmung von Luthertum und äthiopischer Orthodoxie leistete allerdings nicht die Auslegung der Offenbarung Johannis, wo sie zunächst formuliert worden war, sondern erst die Rede über den Zustand der Kirchen des Ostens, die Chytraeus am 18. Oktober 1569 im Rahmen seiner historischen Vorlesungen an der Universität Rostock öffentlich gehalten hatte. ${ }^{56}$ Nachdem diese Oratio im gleichen Jahr veröffentlicht worden war, erlangte sie eine beachtliche Resonanz in protestantischen Kreisen und wurde zum Standardwerk zur Orthodoxie: In einem Zeitraum von nur 15 Jahren, von 1569 bis 1584, erschien sie in 24 Auflagen. ${ }^{57}$

Die theologische Positionierung des Rostocker Professors lag keinesfalls an fehlender Information. Er bildete seine Meinung nicht nur anhand der Lektüre des Werks Șägga Zä̋abs, sondern war mit allen wichtigen Quellen, die im damaligen Europa zugänglichen waren, vertraut und befand sich somit auf dem besten Wissensstand seiner Zeit. So verweist Chytraeus seine Leser, die seine Einschätzung des äthiopischen Christentums überprüfen

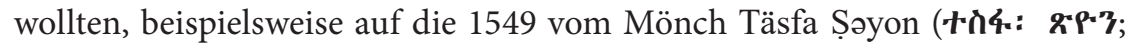
ca. 1508-1550) auf Latein herausgegebenen Texte der äthiopischen Liturgie und der Ordnungen der Taufe und Konfirmation..$^{58}$ Außer auf äthiopische Primärquellen berief er sich auch auf die Reisebeschreibung des Francisco

56 David Chytraeus, Oratio Davidis Chytraei, habita in Akademia Rostochiensi, cum post reditum ex Austria ad Chronici lectionem reverteretur. In qua de statu eccesiarum hoc tempore in Graecia, Asia, Africa, Ungaria, Boemia, etc. narrationes vera et cognitu non iniucunda exponuntur, Rostock 1569. Deutsche Übersetzung: Ders., Was zu dieser Zeit in Griechenland, Asien, Africa, unter des Türcken, und des Priester Johans Herrschafften, item in Ungern und Behemen, etc. der christlichen Kirchen Zustand sey: sampt etlichen Schreiben, so von Constantinopel, vom Berge Sinai, und andern Örten aus Orient, newlicher Zeit abgangen / erstlich von D. Davide Chytraeo lateinisch in Druck gefertiget; und jetzund von Henrico Arnoldo aus Churland in Liffland verdeudschet, [s. 1.] 1574. Vgl. dazu BENGA, David Chytraeus.

57 Für einen Überblick der zahlreichen lateinischen und deutschen Ausgaben dieses Werkes im 16. Jahrhundert, siehe: KaufmanN, Universität und lutherische Konfessionalisierung, S. 630.

58 Modus baptizandi, preces et benedictiones, quibus Ecclesia Aethiopum utitur, cum sacerdotes benedicunt puerperae, una cum infante Ecclesiam ingredienti, post quadragesimum puerperij diem.: Item orationes, quibus ijdem utuntur in Sacramento Baptismi et confirmationis, Missa, qua Ethiopes communiter utuntur, quae etiam Canon universalis appellatur, nunc primum ex Lingua Chaldea sive Aethiopica in Latinam conversa, Romae 1549. Die Ordnung der Liturgie wurde im gleichen Jahr auch separat gedruckt: Missa, qua Ethiopes communiter utuntur, quae etiam Canon universalis appellatur, nunc primum ex Lingua Chaldea sive Aethiopica in Latinam conversa, Romae 1549. Ein Jahr davor, 1548, gab Täsfa Șəyon bereits den Gəcəz-Text der Liturgie samt den drei am häufigsten verwendeten Anaphoren (die der Aposteln, des Herrn, und der Jungfrau) als Teil seines editio princeps des äthiopischen Neuen Testaments heraus: Testamentum Novum cum Epistola Pauli ad Hebreos tantum: cum concordantiis Euangelistarum Eusebii \& numeratione omnium verborum eorundem; Missale cum benedictione incensi ceræ etc., Romae 
Álvares ${ }^{59}$ die Weltgeschichte des Paolo Giovio $(1483-1552)^{60}$ sowie auf die bereits erwähnten Schriften, die von Damião de Góis herausgegeben worden waren.

Nichtsdestotrotz vermischten sich auch bei ihm zutreffende Angaben zur kirchlichen Situation in Äthiopien mit offenkundig falschen Aussagen, die der Legitimierung der Reformation mit dem Altersargument dienten. ${ }^{61}$ Als Beispiel lässt sich die Behauptung des Chytraeus anführen, dass äthiopische Priester "gleich uns die Euangelia und die wort der Consecration / in gemeiner dem volck bekanter sprach / one die Eleuation/sprechen ${ }^{62}{ }^{62}$ Allerdings wurden Gottesdienste in Äthiopien auf $\mathrm{G}^{\mathrm{c}} \partial \mathrm{z}$, einer damals schon nicht mehr gesprochenen Sprache, gefeiert. Ebenso war die Elevation, die Erhebung der Abendmahlselemente, - anders als Luther wandte sich Chytraeus gegen diese liturgische Handlung, weil er darin den Ausdruck des Opfercharakters der Eucharistie sah - durchaus Teil des äthiopischen Ritus. Doch tatsächlich schwerwiegende Transformationen des Wissens über das äthiopisch-orthodoxe Christentum in der Darstellung des Chytraeus geschahen auf eine subtilere Art und Weise, die im Folgenden näher erörtert werden.

Chytraeus mehrmals überarbeitete und erweiterte seine Oratio. Um die Authentizität seiner Darstellung zu belegen, fügte Chytraeus den späteren Ausgaben einen Anhang hinzu, in den Texte ostkirchlicher Provenienz aufgenommen wurden. Ab der Auflage von 1580 befand sich dort ein Schrift-

1548. Zur Person des Täsfa Șəyon, der auch als Petrus Aethiops bekannt war, und seiner Tätigkeit siehe: Alessandro BAUsı / Gianfranco FiACCADORI, Täsfa Șəyon, in: EAE 5, 2014, S. 525-528.

59 Francisco Álvares, Ho Preste Joam das Indias. Verdadera informaçam das terras do Preste Joam, segundo vio \& escreueo ho padre Francisco Aluarez capellã del Rey nosso senhor, Coimbra 1540. Deutsche Übersetzung: Ders., Warhafftiger Bericht Von den Landen/auch Geistlichem vnd Weltlichem Regiment/des Mechtigen Königs in Ethiopien/den wir Priester Johan nennen/wie solches durch die Kron Portugal mit besondern vleis erkündiget worden/Beschrieben durch Herrn Franciscum Aluares / so derhalben sechs Jahr lang an gedachts Priester Johans Hoffe verharren müssen / Aus der Portugallischen vnd Italianischen Sprach in das Deutsche gebracht/vnd zuuorn nie im Druck ausgangen, Eißleben 1566.

60 Vgl. Paolo Grovio, Pavli Iovii Novocomensis Episcopi Nvcerini Historiarvm Svi Temporis, Florentiae 1550. Das Kapitel über Äthiopien schrieb Paolo Giovio mithilfe des bereits erwähnten Mönchs Täsfa Șəyon.

61 Zum Altersargument im Kontext der Reformation siehe u. a.: Johannes BURKHARDT, Alt und Neu. Ursprung und Überwindung der Asymmetrie in der reformatorischen Erinnerungskultur und Konfessionsgeschichte, in: Peter Burschel u. a. (Hg.), Historische Anstöße. Festschrift für Wolfgang Reinhard zum 65. Geburtstag am 10. April 2002, Berlin 2002, S. 152-171; Wolf-Friedrich SchäUfele, Zur Begrifflichkeit von "alt" und »neu« in der Frühen Neuzeit, in: Christoph Kampmann u.a. (Hg.), Neue Modelle im Alten Europa. Traditionsbruch und Innovation als Herausforderung in der Frühen Neuzeit, Köln u. a. 2012, S. 18-36.

62 Chytraeus, Was zu dieser Zeit in Griechenland, Asien, Africa [...] der christlichen Kirchen Zustand sey, S. 32. 
stück unter dem Titel Confessio Fidei AEthiopum (»Das Glaubensbekenntnis der Äthiopier«). ${ }^{63}$ Dabei handelte es sich um nichts anderes als um einen Auszug aus dem Werk De Athiopum Moribus des Șägga Zä’ab. Indem Chytraues die Confessio Fidei Ethiopum zusammenstellte, ordnete er äthiopisch-orthodoxe Theologie in die Denkkategorien europäischer Bekenntnisbildung ein und machte die Kirche Äthiopiens selbst zu einer »Konfession«, die sich ana$\log \mathrm{zu}$ den sich im Laufe des 16. Jahrhunderts in Lateineuropa nach einem bekenntnisorientierten Prinzip konstituierten Glaubensgemeinschaften verstehen ließ. An dieser Stelle muss betont werden, dass Șägga Zä’ab keinesfalls den Anspruch erhoben hatte, eine Confessio (im frühneuzeitlichen Sinne des Wortes) der Äthiopischen Kirche zu verfassen. ${ }^{64}$ Ebensowenig entsprach der frühneuzeitliche Bekenntnisbegriff, der nun auf die Äthiopisch-Orthodoxe Kirche angewandt wurde, ihrem eigenen Selbstverständnis. ${ }^{65}$

Es gibt jedoch noch einen weiteren Grund, von der Erfindung einer äthiopischen Confessio durch Chytraeus zu sprechen: Vergleicht man die im Anhang der Oratio erschienene Confessio Fidei AEthiopum mit der Originalausgabe des Werkes des Ṣägga Zä̋ab, stellt man einen beträchtlichen redaktionellen Eingriff des Rostocker Theologieprofessors fest. David Chytraeus ließ all jene Abschnitte aus, die entweder Übereinstimmungen äthiopischorthodoxer Lehren und Riten mit denen der römisch-katholischen Kirche suggerierten oder aus einer protestantischen Sicht zu exotisch beziehungsweise $\mathrm{zu} » j u ̈ d i s c h$ «, erschienen. So fehlen in der Confessio Fidei Athiopum etwa die Passagen, die von der Verehrung der Gottesmutter und der Heiligen ${ }^{66}$ oder von den zahlreichen Fastenzeiten handelten. ${ }^{67}$ Ebenso wurden

63 Vgl. David Chytraeus, Oratio de statu ecclesiarum hoc tempore in Graecia, Asia, Africa, Ungaria, Boëmia, etc. cui Epistolae aliquot Patriarchae Byzantini, \& aliorum ex Oriente recens scriptae: aliaeque narrationes, lectu non indignae, nec inincundae, accesserunt, Wittenberg 1580, S. 118-133.

64 Zur Rolle der Bekenntnisschriften im Prozess der lateineuropäischen Konfessionalisierung siehe: Irene Dingel, Bekenntnisbildung und Konfessionalisierung. Strukturen und Verlaufsformen, in: Mihai D. Grigore / Florian KüHrer-WielaCH (Hg.), Orthodoxa Confessio? Konfessionsbildung, Konfessionalisierung und ihre Folgen in der östlichen Christenheit Europas, Göttingen 2018, S. 23-43, hier S. $29 f$.

65 Vgl. Irene Dingel, Evangelische Lehr- und Bekenntnisbildung im Spiegel der innerprotestantischen Auseinandersetzungen zur Zeit des Augsburger Religionsfriedens, in: Carl A. Hofmann (Hg.), Als Frieden möglich war. 450 Jahre Augsburger Religionsfrieden, Regensburg 2005, S. 51-61. Zum Unterschied zwischen einer vormodernen Bekenntnisbildung und einer frühneuzeitlichen (modernen) Konfessionsbildung siehe zudem: Vasilios N. MAKRIDEs, Konfessionalisierungsprozesse in der orthodox-christlichen Welt. Ein Periodisierungs- und Systematisierungsversuch, in: Grigore / Kührer-Wielach (Hg.), Orthodoxa Confessio?, S. 77-109, hier S. 81f.

66 Vgl. Uhlig / Bühring (Hg.), Damian de Góis' Schrift, S. 55, 57f., 61 (Text) und S. 215, 218-220, 229f. (Übersetzung).

67 Vgl. ebd., S. 60f., 76 (Text) und S. 228f., 253 (Übersetzung). 
die Abschnitte nicht aufgenommen, die über die Feier des Sabbats ${ }^{68}$ und die Stellung der alttestamentlichen Speiseverbote ${ }^{69}$ berichteten. All dies zeugt unmissverständlich von der Anpassung der Äthiopischen Kirche an die protestantischen Sichtweisen und bringt den Konstruktionscharakter dieses "Glaubensbekenntnisses« zutage.

Demzufolge ist David Chytraeus, der an der Abfassung der abschließenden Bekenntnisschrift des Luthertums (der Konkordienformel von 1577) beteiligt war, auch als Mit-Verfasser der ersten »Bekenntnisschrift« der Äthiopischen Kirche anzusehen. Doch wenn die lutherische Kirche ihre konfessionelle Formierung 1580 mit dem Erscheinen des Konkordienbuches vollendete, so markierte die zeitgleiche Veröffentlichung der Confessio Fidei Ethiopum erst einen Anfang protestantischer Konstruktionen des äthiopischen »Bekenntnisses«.

\subsection{Hiob Ludolf und die »Confessio Fidei Claudii Regis Æthiopiæ«}

Über Jahrzehnte hinweg war die Confessio Fidei AEthiopum das einzige in Europa mit der Äthiopischen Kirche assoziierte »Bekenntnis«. Dieser Sachverhalt änderte sich erst mit der »Entdeckung« einer weiteren äthiopischen "Bekenntnisschrift«, der bereits erwähnten Confessio Fidei Claudii Regis Æthiopice (oder einfach Confessio Claudii), in den 1660er Jahren. ${ }^{70}$ Ihre Veröffentlichung und schnelle Verbreitung in protestantischen Kreisen Europas demonstrierte in einer bisher nicht gegebenen Deutlichkeit, in welchem Umfang innereuropäische Konfessionsstreitigkeiten den Transfer und die Rezeption des äthiopisch-orthodoxen Wissens in der Frühen Neuzeit bedingten. Der Stellenwert der Confessio Claudii für protestantische Imagination lässt sich erst im Kontext einer ereignisreichen Geschichte protestantisch-jesuitischer Animosität, und des einzigartigen Platzes Äthiopiens darin, erschließen.

Die Vorstellung von Äthiopien als einem Ort, an welchem ein imaginärer Kampf um die theologische Hegemonie zwischen den Anhängern der Reformation und den Jesuiten geführt wurde, hatte sich unter protestantischen Intellektuellen spätestens in den 1580er Jahren herausgebildet. Diese Vorstellung lag nämlich bereits dem ersten konkreten Vorhaben einer protestantischen Äthiopien-Reise zugrunde, das 1583 von zwei Tübinger Professoren erarbeitet wurde: dem Gräzisten Martin Crusius $(1526-1607)^{71}$ und

68 Vgl. ebd., S. 61f., 84 (Text) und S. 230-232, 263 (Übersetzung).

69 Vgl. ebd., S. 79f., 82-84 (Text) und S. 257f., 260-263 (Übersetzung).

70 Vgl. Kapitel III.2.1»Umdeutungen des >salomonischen Narrativs««.

$71 \mathrm{Zu}$ Crucius siehe: Gerhard Philipp Wolf, Martin Crusius (1526-1607). Philhellene und Universitätsprofessor, in: FrLB 22, VGFG, Reihe VII A, Würzburg 2009, 
dem Theologen und Kanzler der Universität Tübingen Jakob Andreae (15281590). ${ }^{72}$ Der Plan, mit äthiopischen Christen in Kontakt zu treten, folgte ihrem kurz zuvor, 1581, endgültig gescheitertem Versuch, den Ökumenischen Patriarchen Jeremias II., mit welchem sie seit 1573 in einem Briefwechsel gestanden hatten, von der Rechtgläubigkeit der lutherischen Confessio Augustana zu überzeugen und auf dieser Basis eine theologische Annäherung mit der griechischen Orthodoxie zu erzielen. ${ }^{73}$ Nicht zuletzt aufgrund des von David Chytraeus gezeichneten Entwurfs äthiopischer Orthodoxie glaubten die Tübinger, nun die Kirche Äthiopiens für ihr Bekenntnis zu gewinnen. Daher plädierten sie dafür, einen Lutheraner mit Unterstützung seines Landesherrn nach Äthiopien zu entsenden, damit er dort die Sprache des Landes lernen und die Verbindung zur Kirche aufnehmen konnte. ${ }^{74}$

Die Argumente, die die Professoren dabei vorbrachten, speisten sich nicht nur aus der Überzeugung, dass die Kirche Äthiopiens und das Luthertum einander nahe stünden, sondern auch aus dem Ressentiment gegenüber den Jesuiten, die die Gegenreformation entscheidend vorantrieben. ${ }^{75}$ Die Kontaktaufnahme mit den äthiopischen Christen und die Erforschung der äthiopischen Sprache erschien aus ihrer Sicht umso dringender, als der Jesuitenorden, der sich eifrig mit fremden Sprachen befasse, bereits seit 1555 in Äthiopien tätig gewesen war. ${ }^{76}$ Zwar ist die von den Tübinger Theologen

S. 103-119; Hans Widmann, Crucius, Martin, in: NDB 3, Berlin 1957, S. 433f. sowie Richard CALIs, Reconstructing the Ottoman Greek World. Early Modern Ethnography in the Household of Martin Crusius, in: RenQ 72 (1) (2019), S. 148-193.

$72 \mathrm{Zu}$ Andreae, der ebenso wie David Chytraeus zu den Mitverfassern der Konkordienformel zählte, siehe: Johannes Wiesner, Andreae, Jakob, in: Horst-Rüdiger JARCK/Dieter LENT (Hg.), Braunschweigisches Biographisches Lexikon - 8. bis 18. Jahrhundert, Braunschweig 2006, S. 43f.; Christoph Weismann, Auf Kanzeln, Kathedern und in Kutschen. Jakob Andreae als Universitäts- und Kirchenpolitiker, in: Ulrich Köpf u.a. (Hg.), Die Universität Tübingen zwischen Reformation und Dreißigjährigem Krieg, Ostfildern 2010, S. 119-140.

$73 \mathrm{Vgl}$. Außenamt der Evangelischen Kirche in Deutschland (Hg.), Wort und Mysterium. Der Briefwechsel über Glauben und Kirche 1573 bis 1581 zwischen den Tübinger Theologen und dem Patriarchen von Konstantinopel, DOKÖF 2, Witten 1958; Wendebourg, Reformation und Orthodoxie.

74 Vgl. zu dem Vorhaben Hermann Ehmer, Die Reise des Tübinger Magisters Valentin Cless nach Nordafrika 1583 - Plan oder Wirklichkeit? Zugleich ein Beitrag zu den Anfängen der Arabistik in Deutschland, in: BWKG 107 (2007), S. 139-168, hier S. $153 f$.

75 Vgl. Briefe von Martin Crusius an Melchior Jäger von Gärtringen (1544-1611), dem Kammersekretär des Württembergischen Herzogs, in: Christian Friedrich ScHnuRRER, Biographische und litterarische Nachrichten von ehemaligen Lehrern der hebräischen Litteratur in Tübingen, Ulm 1792, S. 237-241.

76 Ebd., S. 240. Vgl. D'Alòs-Moner, Envoys of a Human God und Cohen, The Missionary Strategies. 
geplante Reise unterblieben, ${ }^{77}$ jedoch zog sich das von ihnen verwendete Argumentationsmuster, das Äthiopien als einen erweiterten Schauplatz des europäischen Konfessionskampfes ansah, durch die gesamte Frühe Neuzeit hindurch. ${ }^{78}$

77 In der Forschungsliteratur wird jedoch oft davon ausgegangen, dass sich 1583 der Tübinger Theologiestudent Valentin Cless (1561-1634) mit dem Ziel Äthiopien auf den Weg gemacht habe. Diese Vorstellung prägte wohl zunächst Julius Hartmann den Jüngeren (1836-1916), der Verfasser dieses von der Ausbreitung der württembergischen Reformation handelnden Abschnitts der Calwer Kirchengeschichte. Calwer Verlagsverein (Hg.), Württembergische Kirchengeschichte, Calw u.a. 1893, S. 385. Am ausführlichsten behandelte die Reise von Cless allerdings Professor Hansmartin Decker-Hauff (1917-1992) anlässlich des 500-jährigen Jubiläums der Universität Tübingen 1977. Demnach sollte dieser als Kaufmann verkleidet in Spanien und Nordafrika das Arabische erlernen, dann mit einer Karawane quer durch Nordafrika reisen und versuchen, die äthiopischen Christen zu erreichen, um deren Haltung gegenüber der lutherischen Theologie festzustellen. Trotz guter Vorbereitung und der Ausstattung mit Geld, Landkarten und den neuesten Abbildungen der auf seinem mutmaßlichen Reiseweg anzutreffenden Städte habe Cless - nach seinem Bekunden - Sala und Tagunit gesehen und eine weit östlich davon liegende Oasengruppe erreicht und war damit »bis hinter das fessanisch königreich" hinausgekommen. Er sei daraufhin aber - ohne Äthiopien zu erreichen - umgekehrt und 1585 wieder nach Tübingen gekommen, für seine weitere Zukunft allerdings als Versager gebrandmarkt gewesen. Vgl. Hansmartin Decker-Hauff/Wilfried Setzler (Hg.), Die Universität Tübingen von 1477 bis 1977 in Bildern und Dokumenten. 500 Jahre Eberhard-Karls-Universität Tübingen, Tübingen 1977, S. 83-87. Für diese Darstellung beruft sich Decker-Hauff auf die vermeintlich bis heute im Besitz der Familie Cless befindlichen handschriftlichen Erinnerungen von Valentin Cless, die dieser unter dem Titel Iter Fessanicus niedergelegt haben soll. Doch wie Hermann Ehmer - u. a. anhand der tatsächlichen Aufzeichnungen von Cless - zeigen konnte, gab es weder die Schrift Iter Fessanicus, noch fand diese Reise je statt. Valentin Cless habe vielmehr zur geplanten Reise in seinem Hausbuch geschrieben: "Ceterum infecta hac peregrinationem certas ob caussas « (»Übrigens ist die Reise aus bestimmten Gründen unterblieben«). Vgl. Hermann Ehmer, Die Reise des Tübinger Magisters Valentin Cless, in: BWKG 107 (2007), S. 139-168, hier S. 145f. Auch Martin Crucius, der Mitorganisator der Reise, berichtet in seiner Schwäbischen Chronik zum Jahr 1583: „In diesem Sommer hätten, erstlich Georg Weigenmaier, der Hebräischen Sprache bey uns Professor, und nach ihm Valentin Cläß, gerne eine Reise nach Africa und Arabien gethan, um die Sprachen solcher Länder daselbst zu lernen. Aber es ist nichts daraus geworden «. Martin Crucius, Schwäbische Chronik, Frankfurt a. M. 1733, Bd. 2, S. 353. Da in den letzten Jahren mehrfach unabhängig voneinander aufgezeigt wurde, dass einige bedeutsame Forschungsergebnisse von Decker-Hauff auf Quellenfälschungen basiert haben, liegt der Verdacht nahe, dass es sich im Fall einer angeblichen Reise von Valentin Cless um eine weitere Mystifizierung des Professors handelte. Vgl. bspw. Klaus Graf, Der Mythos der Staufer. Eine schwäbische Königsdynastie wird erinnert und instrumentalisiert, in: Schwäbische Heimat 61 (2010), S. 296-306; Tobias Weller, Auf dem Weg zum »staufischen Haus«. Zu Abstammung, Verwandtschaft und Konnubium der frühen Staufer, in: Hubertus Seibert / Jürgen Dendorfer (Hg.), Grafen, Herzöge, Könige. Der Aufstieg der Staufer und das Reich (1079-1152), Ostfildern 2005, S. 41-63, hier S. 56-63.

78 Vgl. bspw. Dresser, De Statu Ecclesiae. 
Als der äthiopische Kaiser Fasilädäs (4-n.n.e.గ; 1603-1667, r. 1632-1667) im Jahr 1633 die von seinem Vater Susənyos eingegangene Union mit der Kirche Roms aufgehoben und die Jesuiten aus dem Kaiserreich verbannt hatte, stieß diese Nachricht in Europa, wo noch der Dreißigjährige Krieg (1618-1648) tobte, auf die Bewunderung der Protestanten. Nicht nur sympathisierte man mit den orthodoxen Christen, die sich gegen die Jesuiten zu behaupteten wussten, sondern man dachte nun verstärkt auch über eine mögliche antikatholische Koalition nach. Während der Lübecker Peter Heyling, der 1636 als erster Protestant Äthiopien erreicht hatte, eine solche Allianz in geistigen Kategorien auffasste, ${ }^{79}$ lotete Ernst der Fromme, der an seinem Hofe äthiopistische Studien förderte, die Möglichkeit eines politischen Bündnisses aus. ${ }^{80}$

Es war in diesem geistesgeschichtlichen Kontext, dass Hiob Ludolf 1659 von dem Hamburger Theologen und Orientalisten Esdras Edzardus $(1629-1708)^{81}$ ein ihm bisher unbekanntes äthiopisches Manuskript gezeigt bekam. ${ }^{82}$ Neben dem populären Gebetbuch Arganonä Maryam

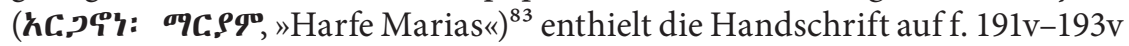
einen offensichtlich später hinzugefügten Text: eine dem äthiopischen Kaiser Gälawdewos zugeschriebene Apologie der äthiopischen Orthodoxie, die im Jahre 1555 als Antwort auf die Kritik der portugiesischen Jesuiten entstanden sein dürfte. ${ }^{84}$ In erster Linie befasste sich der Text mit dem Vorwurf, die äthiopischen Christen folgten den Juden, indem sie beschnitten werden, den Sabbat feiern und auf Schweinefleisch verzichten. Da Edzardus sich aktiv für die Mission unter den Juden einsetzte, ${ }^{85}$ lässt sich vermuten, dass dieses Manuskript die Aufmerksamkeit des Hamburger Theologen deswegen weckte und zu dessen Kauf führte, weil der Autor der Apologie gegen das Judentum argumentierte und jegliche Relevanz des mosaischen Gesetzes für die Kirche Äthiopiens bestritt.

79 Vgl. dazu Anm. 20 auf S. 29.

80 Vgl. Dominik Collet, Die Welt in der Stube. Begegnungen mit Außereuropa in Kunstkammern der Frühen Neuzeit, Göttingen 2007, S. 132-165.

$81 \mathrm{Zu}$ Edzardus siehe: Friedrich Wilhelm BAUTz, Edzard, Esdras, in: BBKL, Herzberg 1990, Bd. 1, Sp. 1464.

82 Vgl. Hiob Ludolf (Hg.), Confessio Fidei Claudii Regis Æthiopiæ, Cum Notis Et Versione Latina Jobi Ludolfi J. C. Antehac Sereniss. Electori Palatino Dedicata; Nunc verò edita, curâ et studio Johannis Michaelis Wanslebii Qui Liturgiam S. Dioscori Patriarchæ Alexandrini Æthiopicè et Latine addidit, London 1661, S. 2.

83 Vgl. Getatchew Haile, Arganonä Maryam, in: EAE 1, 2003, S. $329 f$.

84 Vgl. Ullendorff, The Confessio Fidei, S. 162f. Diese Handschrift wird heutzutage in der British Library unter der Nummer »Harl. 7629 « aufbewahrt. Vgl. August DiLLMANN, Catalogus codicum manuscriptorum orientalium qui in Museo Britannico asservantur, London 1847, Bd. 3: Codices Aethiopici, S. 52. Zum Problem der Datierung des Textes siehe: Conzelman (Hg.), Chronique de Galâwdêwos, S. XXVIIXXX. Siehe den Text dieser Handschrift im Anhang.

85 Vgl. Jutta Braden, Hamburger Judenpolitik im Zeitalter lutherischer Orthodoxie. 1590-1710, Hamburg 2001, S. 533f. 
Für Hiob Ludolf dürfte dieser Text gleich aus zwei Gründen außerordentlich bedeutsam gewesen sein. Vor allem bot er einen bisher fehlenden Kontrapunkt zu der - aus protestantischer Sicht problematischen und deswegen von David Chytraeus in der Confessio Fidei Ethiopum weitgehend zensierten - These Șägga Zä’abs vom »salomonischen«, also alttestamentlichen, Ursprung der besagten Praktiken. Zugleich ließ sich das Werk im Geiste des vorhandenen Ressentiments - wenngleich auch etwas anachronistisch als ein literarisches Denkmal des bitteren Scheiterns der Jesuiten und ihrer dunklen Machenschaften sehen. Ludolf hielt die »Entdeckung« dieses Textes, den er als Confessio Fidei Claudii Regis Æthiopioe bezeichnete, für so wichtig, dass er umgehend eine kommentierte lateinische Übersetzung vorbereitete. Diese wurde zusammen mit dem äthiopischen Originaltext bereits 1661 publiziert. Interessanterweise erschien die Confessio Claudii nicht nur als separater Druck, sondern auch als Anhang zur ersten Auflage von Ludolfs bahnbrechender Grammatica Æthiopica und Lexicon \#thiopico-Latinum. ${ }^{86}$ Somit wurde dieses »Bekenntnis« gewissermaßen zum äthiopischen Mustertext gemacht, zu einem Lehrmittel, anhand dessen europäische Studenten des $\mathrm{G}^{\mathrm{c}} \partial \mathrm{z}$ ihre Kenntnisse der Grammatik und Syntax üben sollten.

Obwohl Hiob Ludolf - anders als David Chytraeus - keine gravierenden Änderungen in dem von ihm bearbeiteten Text vornahm, beeinflusste er maßgeblich dessen Interpretation; und zwar mittels einer irreführenden Betitelung. Dass die Bezeichnung dieser Apologie als Confessio tatsächlich die Intention von dessen Verfasser verfehlt, kann der Kaiserchronik des Gälawdewos (die Ludolf allerdings nicht bekannt war) entnommen werden. Ihr zufolge handelte es sich bei diesem Text nicht um ein "Glaubensbekennt-

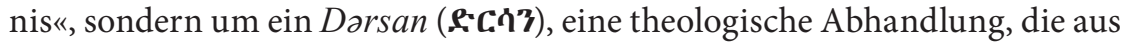
gegebenem Anlass verfasst worden war.

86 Ludolf (Hg.), Confessio Fidei Claudii und ders., Lexicon Æthiopico-Latinum. Ex omnibus libris impressis nonnullisque manuscriptis collectum et cum docto quodam Æthiope relectur accessit authoris Grammatica [...], London 1661. Im Jahre 1691 erschien zudem eine etwas veränderte Fassung der Confessio Claudii: Ders., Ad suam Historiam Æthiopicam antehac editam Commentarivs in quo Multa breviter dicta fusius narrantur: contraria reffelluntur: Atque hac occasione praeter res Aethiopicas multa Autorum, quaedam etiam S. Scripturae loca declarantur: Aliaque plurima Geographica, Historica et Critica, Inprimis verò Antiquitatem Ecclesiasticam illvstrantia, alibi haud facile obvia, exponuntur; vt variarvm observationvm loco haberi possit Cum Tabula Capitum, Figuris, [et] variis Indicibus locupletissimis Summam Operis habes initio Libri, Frankfurt a. M. 1691, S. 237-241. 


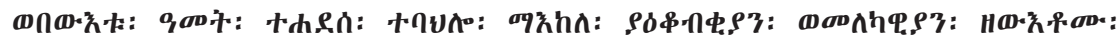

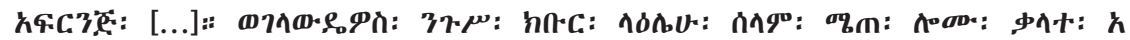

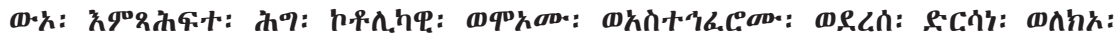

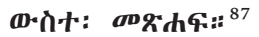

Und im selben Jahr kam es wieder zu Diskussionen zwischen den Jakobiten und den Melkiten, das heißt den Franken [...]. Und der glorreiche König Gälawdewos (Friede sei mit ihm!) antwortete ihnen mit Worten aus den Schriften des katholischen Gesetzes; und er besiegte sie und bedeckte sie mit Scham. Er verfaßte [zu diesem Thema] eine Abhandlung [Drrsan] und fügte sie in ein Buch ein.

Der Fall von protestantischer Rezeption der Confession Fidei Claudii Regis Æthiopice verdeutlicht, dass die Transformation des äthiopisch-orthodoxen Wissens nicht nur durch inhaltliche Veränderungen (wie beispielsweise im Fall von Chytraeus) erfolgte, sondern auch durch die Änderung des Status, der diesem Wissen zugeschrieben wurde. Und diese Art der Transformation war nicht weniger wirkungsmächtig. Denn einerseits suggerierte die von Ludolf gegebene Bezeichnung eine Normativität, die der Text in Äthiopien nie gehabt hatte, andererseits stellte sie ihn in eine Reihe mit europäischen Bekenntnissen der Frühen Neuzeit, denen er in keiner Weise entsprach. Höchst bemerkenswert ist zudem die Asymmetrie, die dadurch im Laufe der Rezeption der Confessio Claudii entstand: Während der Text in Europa in hohen Auflagen erschien und sich großer Popularität als genuiner Ausdruck des äthiopischen Christentums erfreute, dürfte er in Äthiopien selbst kaum bekannt gewesen sein, worauf die Tatsache hindeutet, dass bis heute lediglich ein einziges Manuskript äthiopischer Provenienz bekannt ist. ${ }^{88}$

Besonders aufschlussreich für das Verständnis des Stellenwerts der Confessio Fidei Claudii Regis Æthiopice in protestantischer Imagination ist die Tatsache, dass sie nicht nur unter rein wissenschaftlichem Gesichtspunkt im Kreis der Theologen und Orientalisten studiert wurde. Vielmehr wurde sie auch als eine erbauliche Lektüre angesehen und als solche in die Frömmigkeitsliteratur aufgenommen. So wählte der Prediger an der Nürnberger Sebalduskirche Johann Michael Dilherr (1604-1669) ${ }^{89} 1663$ als Abschluss seiner populären Erbauungsschrift Hohe Schul des höchsten Lehrers und sei-

87 Conzelman (Hg.), Chronique de Galâwdêwos, S. 81f.

88 Vgl. Ullendorff, The Confessio Fidei, S. 162f.

$89 \mathrm{Zu}$ Dilherr und seinem literarischen Wirken siehe: Gerhard Schröttel, Johann Michael Dilherr und die vorpietistische Kirchenreform in Nürnberg, Nürnberg 1962 sowie Willard James WiEtfeldt, The Emblem Literature of Johann Michael Dilherr (1604-1669). An Important Preacher, Educator and Poet in Nürnberg, Nürnberg 1975. 
ner Schüler, die sich explizit an »allerlei Stands-Personen« richtete, nichts anderes als Die Glaubens-Bekenntniß Claudii, deß Königs in Mohrenland, eine deutsche Übersetzung der Confessio Claudii. ${ }^{90}$

\subsection{Giacomo Baratti und die Erweiterung des »äthiopischen Glaubensbekenntnisses«}

Den Prozess der »Bekenntnisbildung« der »imaginären Kirche« Äthiopiens schloß ein 1670 in London veröffentlichtes Buch ab: The Late Travels of S. Giacomo Baratti, an Italian Gentleman, Into the Remote Countries of the Abissins, or of Ethiopia Interior. ${ }^{91}$ In seinem Vorwort dazu stellte der anonyme Herausgeber fest: Dies sei eine lang erwartete englische Übersetzung der Reisebeschreibung, die in Italien bereits in zwei Auflagen veröffentlicht und mit »universal applause « von der Leserschaft aufgenommen worden sei. An diesem Werk aus der Feder des Herrn Giacomo Baratti, eines italienischen Kaufmanns, lobte er vor allem die Genauigkeit der Information in Bezug auf das Christentum dieses afrikanischen Landes: »It is an excellent description of that Great Empire that is so near related unto us by Religion, and nevertheless at such a distance from us «. ${ }^{92}$

Würde man jedoch nach weiteren Informationen über diese ÄthiopienReise, die 1655 stattgefunden haben soll, oder nach der italienischen Originalausgabe der Reisebeschreibung suchen, würde nichts zu finden sein. Denn es handelte sich hierbei um ein Buch, das im protestantischen Milieu Großbritanniens direkt auf Englisch verfasst worden war. ${ }^{93}$

90 Johann Michael Dilherr, Hohe Schul des Höchsten Lehrers und Seiner Schüler, Das ist, Christliche Anweisung zu Gottseeliger Betrachtung des Lebens und der Lehre Jesu Christi und Seiner lieben Apostel und Evangelisten, Nürnberg 1663, S. 897-902.

91 Giacomo Baratti, The Late Travels of S. Giacomo Baratti, an Italian Gentleman, into the Remote Countries of the Abissins, or of Ethiopia Interior: Wwherein You Shall Find an Exact Account of the Laws, Government, Religion, Discipline, Customs, \&c. of the Christian People That Do Inhabit There, with Many Observations Which Some May Improve to the Advantage and Increase of Trade with Them. Together, with a Confirmation of This Relation Drawn from the Writings of Damianus de Goes, and Jo. Scaliger, Who Agree with the Author in Many Particulars, London 1670.

92 Ebd., Preface.

93 Vgl. Arthur Freeman, Hoax and Forgery, Whimsy and Fraud. Taxonomic Reflections on the Bibliotheca Fictiva, in: Walter Stephens / Earle A. Havens (Hg.), Literary Forgery in Early Modern Europe. 1450-1800, Baltimore 2019, S. 15-32, hier S. 23; Salvatore Tedeschi, Giacomo Baratti e il suo presunto viaggio in Abissinia, in: Africa 47 (1) (1992), S. 1-28; Francesco Surdich, La relazione sull'Etiopia di Giacomo Baratti, in: Fratelli Bozzi (Hg.), Miscellanea di storia delle esplorazioni II, Studi di storia delle esplorazioni 5, Genova 1977, S. 119-186; Giacomo Baratti's Late Travels into Ethiopia 1670. A Literary Forgery?, in: The Book Collector 30 (1-4) (1981), 
Die Wahl eines Italieners für die Rolle des Protagonisten dieser PseudoReisebeschreibung war dabei nicht zufällig. Vielmehr ließ sich Kritik an dem römischen Katholizismus auf diese Weise viel subtiler und überzeugender äußern. Dass äthiopische Orthodoxie und europäischer Protestantismus sich außerordentlich nahestehen, war die Idee, die das Herzstück der gesamten Darstellung bildete. Sie konnte - ausgedrückt von einem vermeintlich unvoreingenommenen Beobachter - so glaubwürdiger übermittelt werden. Als Vorbild diente dabei höchstwahrscheinlich der Lutheraner Peter Heyling, denn mehrere Einzelheiten dieser erfundenen Reise - bis hin zur Tatsache, dass Giacomo Baratti zusammen mit der Karawane des Abunä, des neuen äthiopischen Bischofs, nach Äthiopien gelangt sei - weisen eine Parallelität zur Reise des deutschen Protestanten im Jahre 1636 auf. ${ }^{94}$

Insgesamt hatte die Narration des Buches einen »hybriden" Charakter: Ein Amalgam aus erdichteten »Tatsachen« und freier Nacherzählung der Information, die aus den in Europa vorhandenen äthiopischen Quellen entnommen war, wurde für Beobachtungen des Giacomo Baratti ausgegeben. Diesem Prinzip folgte auch der Abschnitt, der vom äthiopischen "Glaubensbekenntnis" handelte. Als solches wurde dabei nichts anderes als ein Auszug aus dem Werk Șägga Zäoabs präsentiert. ${ }^{95}$ Nahezu 130 Jahre nach dem Erscheinen seiner Schrift prägte der äthiopische Geistliche weiterhin protestantische Imagination und blieb die zentrale Autorität im Bereich des äthiopischen Christentums. Ja, man suchte selbst die Authentizität der gesamten Pseudo-Reisebeschreibung mit Hilfe des Verweises auf ihre Übereinstimmung mit einigen Schilderungen Șägga Zäoabs - diese wurden extra im Anhang dazu publiziert - zu beweisen:

S. 549-551. Bis in die 1990er Jahre betrachtete man diese Pseudo-Reisebeschreibung in der Forschung meistens unkritisch als eine vertrauenswürdige historische Quelle. Vgl. bspw. Angela Codazzi, Baratti, Giacomo, in: Alberto M. Ghisalberti (Hg.), Dizionario biografico degli Italiani, Roma 1964, Bd. 6, S. 4f.; UHLIG / BüHrING (Hg.), Damian de Góis' Schrift, S. 218, 220, 253, 275; Steven Kaplan, The Beta Israel (Falasha) in Ethiopia. From Earliest Times to the Twentieth Century, New York u. a. 1992, S. 104, 194, 197; Hirsch, Damião de Gois, S. 227.

94 Vgl. Tedeschi, Giacomo Baratti, S. 25-27. Zu Heyling vgl. Anm. 20 auf S. 29.

95 Vgl. Baratti, The Late Travels, S. 124-128 und Uhlig/Bühring (Hg.), Damian de Góis' Schrift, S. 54-57 (Text), S. 213-218 (Übersetzung). Der Autor der PseudoReisebeschreibung fantasierte dabei auch zur Stellung des "Glaubensbekenntnisses" im liturgischen Leben der Äthiopischen Kirche: »This is their Creed, they often do repeat it in their Churches, especially every new Moon, with many gests which they have retained of their former Religions. The Priest that officiates says it alone, and three or four times the people do repeat these words, This is our Faith «. BARATTI, The Late Travels, S. 129. 
This Relation is agreeable to the account that we have formerly received of the Abyssins written by Damianus de Goes, a Portuguese, and received from Zaga Zabo [= Sägga Zä`ab], the Abyssin Ambassadour sent from the Neguz into Portugal to King John about the year 1526. Damianus de Goes contracted a Friendship with the Embassadour, and obliged him to discover unto him the customs and Religion of the Christians in Abassia, both Relation do agree in many things. I conceive that de Goes doth favour the interest of the Roman Religion in many particulars, but in others he declares how the Abyssins are different from the Papists; the Reader may consult the Author, a piece of it is here translated for puklick [sic!] satisfaction. ${ }^{96}$

Das »Glaubensbekenntnis« als solches war für die europäische Leserschaft also nicht neu. Das Novum bestand jedoch in der Behauptung, dass die Äthiopier diesem bereits bekannten Glaubensbekenntnis nach der Ausweisung der Jesuiten auf einem Kirchenkonzil eine Erweiterung zugefügt hätten:

Since thy have had knowledge of the Roman Catholick Religion, they have added something to their Creed by the consent of one of their general Assemblies, for they were careful to hinder their people from receiving any other Opinions than those that they had formerly embraced; for when they saw that our Priests and Jesuits were busie in drawing them to the faith of the Church of Rome, they published a little addition to their Creed, to inform every one of their judgments, \& hinder them to receive any opinions which they do not approve of. ${ }^{97}$

In diese rein fiktive Erweiterung des »Glaubensbekenntnisses«, die der Abgrenzung gegenüber dem römischen Katholizismus dienen sollte, wurden sowohl Aussagen in Bezug auf die Glaubensinhalte als auch in Bezug auf die Kirchenordnung aufgenommen. Während einige dieser Thesen den Überzeugungen der Äthiopischen Kirche tatsächlich entsprachen, so beispielsweise die Ablehnung des päpstlichen Primats oder das Recht äthiopischer Geistlicher auf Heirat, ${ }^{98}$ wiesen andere eine deutlich protestantische Handschrift auf und konnten so seitens orthodoxer Äthiopier nicht geteilt werden. Dies betrifft etwa die reformatorische Betonung der einzig und allein erlösenden Rolle des Todes Jesu oder auch die Weigerung, die Gottesmutter Maria und die Heiligen im Gebet anzurufen:

We believe that the Virgin Mary is a pure Virgin, before and after the Birth of Christ; as she is the Mother of God, she ought to be loved and respected accordingly, but we neither worship Her nor pray unto Her. [...]

96 Ebd., S. 175-176.

97 Ebd., S. 129.

98 Vgl. ebd., S. $131 f$. 
We believe that the holy Apostles, Saints, and Martyrs that are in glory did follow the foot-steps of our Saviour Christ, and that they have received from him the pardon of their sins, as we do. We believe that we must honour them with the holy Angels, but we do not approve of prayers made unto them, nor of the sufficiency of their Merits to benefit us, or the Church of Christ. [...]

We believe that none can be saved without the bloud of Jesus Christ, that it is sufficient to cleanse us from all our sins, without any other assistance, and that we are not to trust upon the Merits of the Apostles and Saints that were but sinful men as we were. ${ }^{99}$

Spezifisch protestantischer Duktus kam dabei in Form einer im Bekenntnis verankerten Respektierung der weltlichen Obrigkeit zutage. In der Erweiterung des "äthiopischen Glaubensbekenntnisses« verpflichtete man sich nämlich, allen voran dem weltlichen Herrscher, und erst dann dem unter seiner Macht stehenden Bischof, zu gehorchen: »We believe that we are bound to obey in Conscience our Supream Lord Giam Belul, and under him the Abuna of our Church, with all the rest of our Ecclesiastical and Civil Magistrates and Superiors, but no other «. ${ }^{100}$

Neben den Spuren protestantischer Glaubensüberzeugungen lässt sich in diesem Zusatz zum »äthiopischen Glaubensbekenntnis« auch ein Relikt der im mittelalterlichen und zum Teil noch frühneuzeitlichen Europa gängigen Verwechslung zwischen Äthiopien und Indien erkennen: So findet sich darin kurioserweise auch die Aussage, dass alle Bücher des Alten und Neuen Testaments durch den Apostel Thomas nach Äthiopien gelangt seien. ${ }^{101}$

Während im Fall von David Chytraeus und seiner Confessio Fidei Æthiopum die Transformation des äthiopisch-orthodoxen theologischen Wissens durch Umstellung und Auslassung einzelner Passagen eines authentischen äthiopischen Textes erfolgte; und während Hiob Ludolf den Prozess der Rezeption eines äthiopischen Textes, der Confessio Claudii, mit Hilfe seiner Betitelung und strategischer Verbreitung lenkte, so handelte es sich bei dem "anti-katholischen " Zusatz zum »äthiopischen Glaubensbekenntnis" aus dieser Pseudo-Reisebeschreibung um eine gezielte Fälschung des äthiopisch-orthodoxen Wissens.

Dabei sind alle diese Konstruktionen des äthiopischen »Bekenntnisses« nur im Zusammenhang mit der theologischen Positionierung ihrer jeweiligen europäischen Verfasser (beziehungsweise Herausgeber) zu verstehen. Denn diese spielte eine entscheidende Rolle bei der Selektion, Modifikation 
und Verwendung der Information, die entweder tatsächlich aus Äthiopien stammte oder als solche ausgegeben wurde. Umgekehrt übte das äthiopischorthodoxe Wissen, das zu einem bedeutenden Bestandteil protestantischer Imagination in der Frühen Neuzeit geworden war, auch einen Einfluss auf den europäischen Protestantismus aus.

Die Transformationsprozesse, die im Laufe protestantischer Rezeption des äthiopisch-orthodoxen theologischen Wissens in Gang gesetzt wurden, lassen sich daher mit Hilfe des heuristischen Zugangs der Allelopoiese beschreiben. ${ }^{102}$ Dieser betont die produktive Wechselseitigkeit komplexer Wandlungsprozesse, die sich zwischen einem Referenz- und einem Aufnahmebereich abspielen: Indem durch Agenten gewisse Aspekte aus einem Referenzbereich aufgegriffen und verarbeitet werden, erfährt nicht nur die Aufnahmekultur eine Modifikation, sondern gleichzeitig wird durch die spezifische Form der Aneignung die Referenzkultur konturiert und konstruiert. ${ }^{103}$

So wurde die »imaginäre Kirche« Äthiopiens zu einer bedeutenden Referenz innerhalb protestantischer Kontroverstheologie und Apologetik, die im frühneuzeitlichen Europa bekanntermaßen eine herausragende Rolle spielte und zur Herausbildung konfessioneller Identitäten entscheidend beitrug. Der Einfluss, welcher die »imaginäre Kirche« Äthiopiens auf die jeweiligen protestantischen Theologien und Konfessionskulturen ausübte, bedarf einer eingehenden Untersuchung. Jedenfalls stellen die hier analysierten äthiopischen »Bekenntnisse« nur einige wenige - wenngleich bedeutsame Fallbeispiele dar.

In Bezug auf die Pseudo-Reisebeschreibung, die unter dem Namen von Giacommo Baratti veröffentlicht wurde, lässt sich feststellen, dass sie eine folgenreiche Wirkungsgeschichte hatte. Jedenfalls führte dieser Text zur Stärkung des bereits vorhandenen Verbundenheitsgefühls gegenüber den äthiopischen Christen angesichts des gemeinsamen Gegners, der Jesuiten. So zog das 1679 publizierte Pamphlet mit dem vielsagenden Titel A Brief Account of the Rebellions and Bloudshed Occasioned by the Anti-Christian Practices of the Jesuits and Other Popish Emissaries in the Empire of Ethiopia explizit die Parallelen zwischen dem protestantischen England und dem orthodoxen Äthiopien, die in der Pseudo-Reisebeschreibung nur noch angedeutet und suggeriert wurden.

102 Der Begriff Allelopoiese wird aus dem griechischen allēlon (»gegenseitig«) und poiessis (»Hervorbringung«) abgeleitet.

103 Vgl. Philipp BrüllmanN u.a., Imagination, Transformation und die Entstehung des Neuen. Einleitung, in: Dies. (Hg.), Imagination, Transformation und die Entstehung des Neuen, Berlin u. a. 2014, S. 1-20, hier S. 8. 
Did the Popish Emissaries foment a Rebellion in England, to compass the Destruction of our Glorious Martyr King Charles? The same they practised in Ethiopia, not only to the great hazard of Adamas Saghed, but the actual Ruine of Za Dinghil, lawful Princes thereof. Have our Modern Jesuits veiled Murder under the Covert of their Chappels or Altars here? There they raised Strongholds and Fortresses under the Pretence of building Churches and Colledges. Have they secretly prepared Fire-bals and other Instruments of Mischief and Villany among us? In Abissinia they did also conceal. Warlike Engines in their Religious Houses. Have they drawn some of our English Subjects into the horrid Plot (lately discovered) against their Native Prince and Countrey? They did no less among the Abissins. Have they conspired the Introducing of a Foreign Power into Great Britain and Ireland? They likewise not only Designed to betray the Ethiopick Empire to the King of Portugal; but through their Treasonable Practices the Abissin Sea-coasts are actually delivered into the hands of the Turks. In a word, Have they plotted to Assassinate our Soveraign Lord the King? So they did to kill the Emperor Adamas. ${ }^{104}$

Die Pseudo-Reisebeschreibung wurde nicht nur in England und nicht nur von Anglikanern gelesen. Vielmehr ist davon auszugehen, dass sie eine weitreichende Ausstrahlungskraft hatte und von Protestanten in verschiedenen Gegenden Europas zur Kenntnis genommen wurde. Sowohl die Beschreibung der Äthiopischen Kirche, die nun so "protestantisch« ausfiel wie nie zuvor, als auch die Darstellung der Reise nach Äthiopien auf dem Landweg (die angesichts der Gerüchte über die Reise von Peter Heyling zusätzlich an Glaubwürdigkeit gewann), führte zur Wiederbelebung alter Pläne, Äthiopien zu erreichen. So plädierte 1673 der Hamburger Professor Rudolf Capell (1635-1684) an die Lutheraner unter expliziter Bezugnahme auf das Werk Barratis dafür, den Kontakt zu den äthiopischen Christen so schnell wie möglich aufzunehmen:

Es wäre herzlich zu wünschen/daß diesen Africanischen Christen/die Europaeische Lutheraner / [...] näher kommen/ und mit ihnen continuè communicieren könten / nicht umb rein Goldt außzugraben / [...] (wie ich dessen ein ziemlich groß Stück gesehen/welches meist rein außgegraben war) sondern von der Reinigkeit der Lehre mit ihnen zu handeln. ${ }^{105}$

104 Vgl. Johann Michael Wansleben, A Brief Account of the Rebellions and Bloudshed Occasioned by the Anti-Christian Practices of the Jesuits and Other Popish Emissaries in the Empire of Ethiopia. Collected Out of a Manuscript History Written in Latin by Jo. Michael Wansleben, a Learned Papist, London 1679, Preface.

105 Rudolf CAPELL, Wünschet von der Ewigen Göttlichen Majestät/allerley liebes und gutes / zeitlich und ewig, in: Ders., Norden / Oder Zu Wasser und Lande im Eise und Snee/mit Verlust Blutes und Gutes zu Wege gebracht/und fleissig beschriebene Erfahrung und Vorstellung des Norden, Hamburg 1678, S. 265-305, hier S. 282. Der Text wurde am 3. Februar 1673, also noch drei Jahre vor der Veröffentlichung 
Das Ziel dieses Vorhabens, das »offt durch böse Geister und Menschen verhindert" worden sei, sei nicht nur »an beyden Seiten [zu] erlernen und [zu] erfahren/wie weit wir von einander [...] in der Lehre und Leben gekommen [sind] «, sondern auch zu entscheiden, wie lange noch die europäischen Lutheraner und die äthiopischen Orthodoxen von einander entfernt "zu bleiben gedächten«. Sollte die so naheliegend erscheinende Einigung mit den Äthiopiern gelingen, so sollte in Kontakt mit den anderen orientalischen Christen - den »Syrern / Armeniern / denen in Persien / Indien / Tattarischen Grenzen und mehr andern « - treten. ${ }^{106}$ Die von europäischen Protestanten ins Leben gerufene »imaginäre Kirche« Äthiopiens führte demnach zur Herausbildung der Vorstellung, dass das Tor zum christlichen Orient für sie nirgendwo anders so günstig wie am Horn von Afrika liege.

\section{Alte Imaginationen und neues Wissen}

Es wäre also nicht gerechtfertigt, die Entstehung der »imaginären Kirche« Äthiopiens ausschließlich mit Hiob Ludolfs Historia Ethiopica in Verbindung zu bringen. Vielmehr ging dieser 1681 erschienenen Publikation ein langer Prozess der Rezeption und Transformation des äthiopisch-orthodoxen theologischen Wissens voran. Hiob Ludolf zeigte sich dabei vor allem als jemand, der dieses Wissen hervorragend systematisierte und neu ordnete. Wie Dominik Collet in Bezug auf die "protestantische« Erscheinung der Äthiopischen Kirche bei dem Thüringer Gelehrten trefflich anmerkt,

handelte es sich [hierbei] nicht allein um einen bewusst strategischen Umgang Ludolfs mit der Wahrheit, mit dem Ziel, seine protestantischen Zeitgenossen von der Machbarkeit eines Bündnisses mit den fremden zu überzeugen. Ludolfs gesamtes wissenschaftliches Arbeiten war darauf angelegt, die Welt aus den Büchern zu verstehen, und nicht umgekehrt. ${ }^{107}$

der deutschen Übersetzung der Pseudo-Reisebeschreibung, verfasst. Vgl. Giacomo Baratti, Reis-Beschreibung Sig. Giacomo Baratti, eines Edlen Italiäners/In die Entlegenen Länder der Abyssiner oder Innere Aethiopia. In welcher enthalten Eine umständige Erzehlung der Gesetz/Regierung / Religion / Policey/und Gebräuchen dieses Christlichen Volcks/so darinnen wohnen/neben vielen merckwürdigen Anweisungen/welche zu Beförderung der Handlung mit diesen Völckern dienen können. Hierbey ist angefüget / Was Damianus de Goes, und Jos. Scaliger von diesen Ländern geschrieben/welche in vielen Particularien mit dem Autore übereinkommen, in: Georg Friedrich Benaim (Hg.), Asiatische und Africanische Denkwürdigkeiten dieser Zeit, das ist, Beschreibung der Königreiche, Herrschaften und Länder des grossen Mongols, des grossen Neguz oder sogenannten Priester Johannes, Nürnberg 1676, S. 406-480.

106 CAPELL, Wünschet von der Ewigen Göttlichen Majestät, S. 282.

107 Vgl. Collet, Die Welt in der Stube, S. 152. 
Demnach schuf Ludolf die »imaginäre Kirche« Äthiopiens nicht, sondern verlieh ihr zusätzliche wissenschaftliche Legitimität. Auch die berühmten

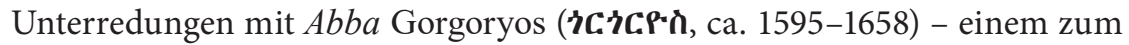
Katholizismus konvertierten äthiopischen Priester adliger Herkunft, der eine seiner wichtigsten Quellen war ${ }^{108}$ drehten sich um die Passagen aus europäischen Drucken, die der Gast kommentieren beziehungsweise korrigieren sollte. ${ }^{109}$ Die Themen waren daher fest vorgegeben und folgten ganz dem Kanon, den die älteren Werke etabliert hatten. Ludolfs Fragen konzentrierten sich daher vor allem auf die äußerlichen Aspekte des kirchlichen Lebens, die von früheren Reisenden beobachtet und detailliert beschrieben worden waren. Dazu gehörten beispielsweise Priesterehe, Sabbat, Abendmahl, Ehe, Taufe und Beschneidung. Da Ludolf besonders intensiv auf jene Berichte einging, die mit protestantischen Überzeugungen zu harmonieren schienen, so fühlte er sich nach diesen Gesprächen mit $A b b a$ Gorgoryos vor allem in seinen eigenen zuvor angelesenen Vorstellungen bestätigt. ${ }^{110}$ Das tatsächlich gelebte Christentum Äthiopiens trat hinter Ludolfs Wunschvorstellungen weitgehend zurück. Liest man manche Stellen, in denen Ludolf über äthiopische Christen spricht, - sie seien "witty and good-natur'd, not given to quarrels [...] being naturally Lovers of Justice and Equity, and very desirous of Learning ${ }^{111}$ - so scheinen diese frommen und gelehrsamen "afrikanischen Lutheraner« Spiegelbild seiner selbst zu sein.

108 Vgl. Wolbert G. C. SMidT, Gorgoryos and Ludolf. The Ethiopian and German ForeFathers of Ethiopian Studies. An Ethiopian Scholar's 1652 Visit to Thuringia, in: Ders. / Sophia Thubauville (Hg.), Cultural Research in Northeastern Africa. German Histories and Stories, Ityopis, Extra Issue 1, Frankfurt a. M. 2015, S. 11-25; ders., Abba Gorgoryos - ein integrer und ernsthafter Mann. Der Besuch eines äthiopischen Gelehrten in Thüringen 1652, in: Kerstin Volker-SaAd/Anna Greve (Hg.), Äthiopien und Deutschland. Sehnsucht nach der Ferne, München u.a. 2006, S. 48-57.

109 Vgl. Johannes Flemming, Hiob Ludolf. Ein Beitrag zur Geschichte der orientalischen Philologie [I], in: BASS I (1890), S. 537-582, hier S. 546. Neben Francisco Álvares' Beschreibung seiner Reise nach Äthiopien um 1520 nutzte Ludolf v. a. Texte deutlicher protestantischer Färbung: die Drucke des portugiesischen Humanisten Damiao de Góis sowie Matthäus Dressers Kompilation aus dem Jahr 1584.

110 Diese Besprechungen, die sich um theologische Belange handelten, wurden nicht nur in der Historia Æthiopica benutzt, sondern mündeten auch in eine separate Schrift: Theologia Aethiopica, hoc est religio et mores Habessinorum religionis Christianae dogmata praecipua duodecim capitibus comprehendens. Quondam Ernesti Saxoniae ducis jussu ex variis autoribus excerpta et Abba Gregorio Aethiopi proposita, cujus responsiones Jobus Ludolfus latinitate donavit. Dieses Werk war als Manuskript mehrfach in verschiedensten Bibliotheken vertreten, wurde aber erst im 20. Jahrhundert herausgegeben: Siegbert UhLIG, Hiob Ludolfs »Theologia Aethiopica«, ÄthF 14, Wiesbaden 1983.

111 Hiob Ludolf, An Abstract of the History of Ethiopia, or the Kingdom of Abessines, Written by Mr. Job Ludolphus, with What Is Observable from the Authors of 
Eine beachtliche Rolle bei der Festigung der Vorstellung, dass die Kirche Äthiopiens dem protestantischen Christentum außerordentlich nahe stehe, spielte im frühen 18. Jahrhundert Johann Christoph Harenberg (1696-1774). ${ }^{112}$ In seinem 1719 veröffentlichten Werk Kurtze Einleitung in die Aethiopische, sonderlich Habeßinische Alte und Neue Theologie unternahm der evangelische Theologe einen beachtlichen Systematisierungsversuch des gesamten zu seiner Zeit vorhandenen Wissens über die äthiopische Theologie- und Kirchengeschichte. ${ }^{113}$ In dieser Studie kam er zu der Schlussfolgerung, dass die Kirche Äthiopiens »die meisten Apostolischen und uhralten Christlichen Gebräuche bey sich finden lasse / und mit keiner als mit der Evangelischen/wenn ich die Ceremonien und Neben-Anbetungen ausnehme/genauer übereinstimme ${ }^{114}$ Dieses Zitat kann durchaus als charakteristisch für die protestantische Wahrnehmung der Kirche Äthiopiens im frühen 18. Jahrhundert gelten. Evangelische Theologen in Europa waren zwar bereits im Bilde über einige vorhandene Differenzen in der Frömmigkeitspraxis (»Ceremonien und Neben-Anbetungen«), doch in der Gesamtgewichtung vom äthiopischen Christentum attribuierten sie diesen eine untergeordnete Bedeutung. So war Herenberg der Überzeugung, dass unvoreingenommene akademische Auseinandersetzung mit der äthiopischen Theologie unverhohlen zeige, wie sehr diese der evangelischen gleichkomme. In dieser Kongruenz sah er indes auch ein erhebliches Potenzial für Glaubenserbauung seiner protestantischen Leserschaft: „Uberdem wird ein Evangelischer Christe noch mehr in der Wahrheit seiner Religion befestiger werden/wenn er siehet/daß in einem sehr entferneten Lande ein gleicher Grund des Glaubens blühe «. ${ }^{115}$

Die »imaginäre Kirche« Äthiopiens motivierte in der ersten Hälfte des 18. Jahrhunderts mehrere protestantische Versuche, mit den orthodoxen Christen Äthiopiens in Kontakt zu treten, die jedoch eine lange Zeit missglückten. ${ }^{116}$ Erst Ende Februar 1770 war es einem Protestanten - wohl zum

That Country, in: John HARRIs (Hg.), Navigantium atque Itinerarium Bibliotheca: or, a Compleat Collection of Voyages and Travels, London 1725, Bd. 1, S. 390-404, hier S. 392.

112 Zu Harenberg siehe: Uwe OHAINski, Harenberg, Johann Christoph, in: Horst-Rüdiger JARCK / Dieter Lent (Hg.), Braunschweigisches Biographisches Lexikon - 8. bis 18. Jahrhundert, Braunschweig 2006, S. 300f.

113 Johann Christoph Harenberg, Kurtze Einleitung in die Aethiopische, sonderlich Habeßinische Alte und Neue Theologie. Worinn die dahin gehörigen Scribenten, eine deutliche Kirchen-Historie, Wie auch die Lehr-Puncten und Kirchen-Gebräuche derer Heydnischen und Christlichen Einwohner in Aethiopien, sonderlich der Habeßinier Entworffen worden, Helmstedt 1719.

114 Harenberg, Kurtze Einleitung, S. 124.

115 Ebd., S. I.

116 Zur gescheiterten Äthiopienexpedition von Johann Michael Wansleben (16351679) siehe: Collet, Welt in der Stube, S. 132-165. Über die Versuche der Herrn- 
ersten Mal nach Peter Heyling - gelungen, Äthiopien zu erreichen. Dieser Protestant war der schottische Forschungsreisende James Bruce (1730-1794). Sein 1790 veröffentlichter Reisebericht in fünf Bändern Travels to Discover the Sources of the Nile, der sofort zum Bestseller wurde, ${ }^{117}$ stellte die »imaginäre Kirche« radikal in Frage.

Die tatsächliche Begegnung mit den äthiopischen Realitäten zeigte sich als zum Teil schockierend. Als Bruce in Gondär ankam, fand er ein sich im Umbruch befindendes politisches System vor, denn seine Ankunft fiel

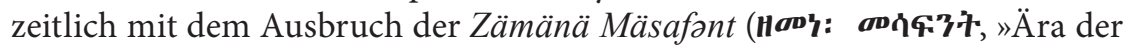
Richter« oder »Ära der Fürsten«) zusammen. ${ }^{118}$ Die zentralen Figuren am

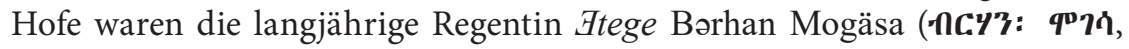

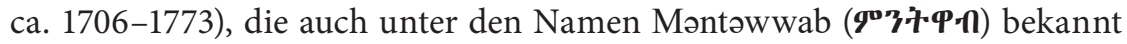

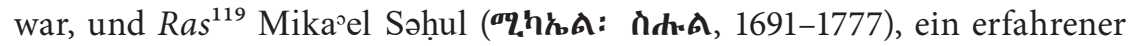
Kriegsherr aus Tegray, der versuchte, allmählich die ganze Macht in seinen Händen zu konsolidieren. ${ }^{120}$ Der eigentliche Kaiser Täklä Haymanot II.

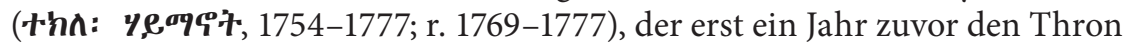

huter, Ätiopien zu erreichen, siehe: Arthur Manukyan, Konstantinopel und Kairo. Die Herrnhuter Brüdergemeine im Kontakt zum Ökumenischen Patriarchat und zur Koptischen Kirche. Interkonfessionelle und interkulturelle Begegnungen im 18. Jahrhundert, Würzburg 2010, S. 209-356.

117 James BRUCe, Travels to Discover the Source of the Nile. In the Years 1768, 1769, 1770, 1771, 1772, and 1773, Edinburgh 1790, 5 Bd.

118 In der traditionellen äthiopischen Historiografie wird damit die Periode von ca. 1770 bis 1855 bezeichnet, in der das Land durch Konflikte zwischen verschiedenen Kriegsherren gespalten war. Dieser Name bezieht sich auf das biblische Buch der Richter und die darin beschriebene politische Lage des Volkes Israel: »In jenen Tagen gab es keinen König in Israel; jeder tat, was in seinen Augen recht schien« (Ri 21,25). Für einen historischen Überblick siehe: Mordechai ABIR, Ethiopia. The Era of the Princes. The Challenge of Islam and the Reunification of the Christian Empire. 1769-1855, London u. a. 1968; Sophia DEGE, Zämänä mäsafənt, in: EAE 5, 2014, S. 122-129.

119 Ras (6n, wörtlich: »Kopf«) - der zweitgrößte Rang und Titel in der Hierarchie des äthiopischen Reiches. In der Zeit Məniləks II. wurde dieser Titel ausschließlich den Gouverneuren der wichtigsten Provinzen Äthiopiens verliehen. Vgl. BaIRU TAFLA, Civil Titles and Offices in the Reign of Emperor Menilek II. 1889-1913, in: Accademia Nazionale dei Lincei (Hg.), IV Congresso Internazionale di Studi Etiopici (Roma, 10-15 April 1972), Roma 1974, Bd. 1, S. 597-612; Denis Nosnitsin, Ras, in: EAE 4, 2010, S. 330 f.

120 Bərhan Mogäsa, die in den Quellen manchmal auch mit ihrem Taufnamen Wälättä

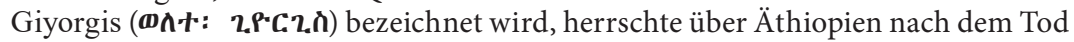
ihres Mannes Bäkaffa (П†4*; gest. 1730) zwischen 1730 und 1769, zunächst als Regentin bei ihrem Sohn Iyasu II. (h.PN-, 1723-1755; r. 1730-1755; Thronname Adyam Sägäd), der im Alter von 7 Jahren zum Kaiser wurde, und nach seinem Tod bei ihrem Enkel Iyo as I. ('.P.'hn, ca. 1749-1769; r. 1755-1769; Thronname: Adyam Sägäd), der als 6-jähriges Kind zum Herrscher wurde. Im Jahre 1769 ließ Ras Mika ${ }^{\circ} e l$ Səhul den inzwischen Erwachsenen Iyo ${ }^{\circ}$ as I., der sich nicht mehr beeinflussen ließ, töten und

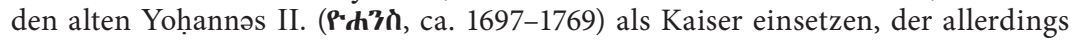
nach nur fünf Monaten starb. Täklä Haymanot II., Sohn des Yoḥannəs II., wurde 
bestiegen hatte und gerade 16 Jahre alt war, war völlig machtlos. ${ }^{121}$ Das Institut des Kaisertums sowie die Vorstellung, dass dessen Legitimität unmittelbar von der Zugehörigkeit zur »salomonischen Dynastie« abhänge, lebte weiterhin fort. Doch die Funktion des Kaisers wurde von der Machtausübung komplett abgekoppelt und ging kaum über das Repräsentative hinaus. Aus diesem Grund wurde James Bruce bei seinem ersten Besuch am kaiserlichen Hof in $\mathrm{Q}^{\mathrm{w}} ə \mathrm{sq} \mathrm{w}^{\mathrm{w}} \mathrm{am}$ bei Gondär ${ }^{122}$ durch Bərhan Mogäsa, und nicht durch den Kaiser, empfangen. Bei diesem Treffen in ihrer Residenz ergab sich ein bemerkenswertes theologisches Gespräch über die Differenz zwischen äthiopischer Orthodoxie und europäischem Protestantismus:

Our first discourse was about Jerusalem, the Holy Sepulchre, Calvary, the City of David, and the Mountain of Olives, with the situation of which she was perfectly well acquainted. She then asked me to tell her truly if I was not a Frank? »Madam, «said I, "If I was a Catholic, which you mean by Frank, there could be no greater folly than my concealing this from you in the beginning, [...] and, in confirmation of the truth I am now telling (she had a large bible lying on the table before her, upon which I laid my hand), I declare to you, by all those truths contained in this book, that my religion is more different from the Catholic than your's is: that there has been more blood shed between the Catholics and us, on account of the difference of religion, than ever was between you and the Catholics of this country; even at this day, when men are become wiser and cooler in many parts of the world, it would be full as safe for a Jesuit to preach in the market-place of Gondar, as for any priest of my religion to present himself as a teacher in the most civilized of Frank, or Catholic countries «. ${ }^{123}$

bereits der dritte Kaiser im Jahre 1769. Vgl. dazu: LaVerle Berry, Bərhan Mogäsa, in: EAE 1, 2003, S. 534f.; Sevir Chernetsov / Denis Nosnitsin, Iyasu II, in: EAE 3, 2007, S. 251f.; Theodore Natsoulas / Denis Nosnitsin, Iyo as I., in: EAE 3, 2007, S. 259f.; Jon Авbink, Mikael Səhul, in: EAE 3, 2007, S. 962-964; Sophia Dege, Yohannəs II, in: EAE 5, 2014, S. 70f.

121 Sein Thronname war Ṭəäb Sägäd. Zu ihm siehe: Donald Crummey, Täklä Haymanot II, in: EAE 4, 2010, S. 835f.

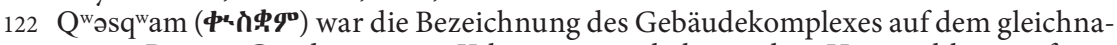
migen Berg in Gondär, wenige Kilometer westlich von dem Hauptschloss entfernt. Er wurde in den 1730er Jahren durch Bərhan Mogäsa errichtet und diente sowohl zu repräsentativen Zwecken als auch als Wohnsitz der Herrscherin. Dort wurde auch eine prächtige Kirche, Däbrä Säḥay Qwəsqwam, gebaut, zu der 200 Priester gehörten. Der äthiopische Name Q ${ }^{w} ə s q^{w} a m$ ist von dem koptischen Kōskam abgeleitet und bezieht sich ursprünglich auf einen Berg in Mittelägypten, wo laut der koptischen Tradition, die in Äthiopien rezipiert wurde, die Heilige Familie während der Flucht nach Ägypten blieb. Dort liegt das koptische Dayr al-Muharraq-Kloster, in dessen Nachbarschaft seit dem 13. Jahrhundert bis hin in die 1950er Jahre auch ein äthiopisches Kloster existierte, das als Stützpunkt äthiopischer Pilger auf dem Weg nach Jerusalem diente. Alessandro BAUsI, Qw ${ }^{\text {w }}$ q $^{\text {wam }}$ (Koskam) in Ethiopian Tradition, in: EAE 4, 2010, S. 318; LaVerle B. BERry, Qw ${ }^{\text {} ə s q}{ }^{w}$ am of Gondär, in: EAE 4, 2010, S. 318-320.

123 Bruce, Travels, Bd. 3, S. 207. 
Wie das Gespräch zeigt, wusste man im Äthiopien des 18. Jahrhunderts noch nichts über die Existenz des Protestantismus und vermutete in jedem Europäer zunächst einen Katholiken. Ganz offensichtlich wollte Bruce mit seiner Rede den Eindruck erwecken, dass die äthiopische Orthodoxie und der europäische Protestantismus - da sie beide unter dem römischen Katholizismus in der Geschichte zu leiden hatten - sich nahe stünden. Jedoch ging dieser Plan Bruces nicht ganz auf, denn Bərhan Mogäsa konfrontierte ihn sogleich mit einer Frage, in der er einen klaren Dissens zwischen der Glaubensvorstellung eines äthiopisch-orthodoxen Christen und eines »aufgeklärten" europäischen Protestanten gestehen musste.

»How is it then,« says she, "that you don't believe in miracles?" - "I see, Madam," said I, »Ayto Aylo ${ }^{124}$ has informed you of a few words that some time ago dropped from me. I do certainly believe the miracles of Christ and his apostles, otherwise I am no Christian; but I do not believe these miracles of latter times, wrought upon trifling occasions, like sports, and jugglers' tricks." - »And yet,« says she, »our books are full of them." - »I know they are, " said I, »and so are those of the Catholics: but I never can believe that a saint converted the devil, who lived, forty years after, a holy life as a monk; nor the story of another saint, who, being sick and hungry, caused a brace of partridges, ready-roasted, to fly upon his plate that he might eat them.« - He has been reading the Synaxar," says Ayto Aylo. "I believe so, "says she, smiling; »but is there any harm in believing too much, and is there not great danger in believing too little?" "Certainly,« continued I; »but what I meant to say to Ayto Aylo was, that I did not believe laying a picture upon Welled Hawaryat ${ }^{125}$ would recover him when delirious in a fever." She answered, »There is nothing impossible with God.« I made a bow of assent, wishing heartily the conversation might end there. ${ }^{126}$

Mit seiner Skepsis gegenüber überliefertem kirchlichem Wissen und Frömmigkeitspraktiken zeigte sich Bruce - und mit sich auch den Protestantismus, den er ungewollt in den Augen Bərhan Mogäsas repräsentierte, - als Verfechter der europäischen Aufklärung. Diese Selbstdarstellung - auch gegenüber seinem Leser - entsprach Bruces Ambitionen: Er wollte nicht einfach ein Abenteurer sein, sondern ein Aufklärer und Entdecker. Bruce beanspruchte die Rolle des synthetisierenden Gelehrten, der in verschiedensten

124 Gemeint ist der äthiopische Adlige Ato Haylu (Jen).

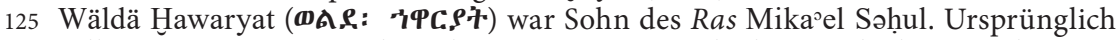
sollte James Bruce versuchen, den jungen Mann zu heilen. Doch als Bruce die Residenz erreichte, wurde er informiert, dass seine Hilfe nicht mehr nötig sei, denn »three great saints from Waldubba, one of whom had neither ate nor drank for twenty years of his life, had promised to come and cure Welled Hawaryat, by laying a picture of the Virgin Mary and the cross upon him«. BRUCE, Travels, Bd. 3, S. 206.

126 Ebd., S. 207f. 
Gebieten des Wissens - Anthropologie, Geografie, Geschichte, Botanik, ja selbst Theologie - Neuland betrat. ${ }^{127}$ Und als solcher unterzog Bruce auch das Bild des äthiopischen Christentums einer Revision und brach auch mit dem Bild von dessen Nähe zum europäischen Protestantismus:

$[\ldots]$ as to doctrine, I am perfectly convinced they are in every respect to the full as great heretics as ever the Jesuits represented them. [...] The two natures in Christ, the two persons, their unity, their equality, the inferiority of the manhood, doctrines, and definitions of the time of St Athanasius, are all wrapt up in tenfold darkness, and inextricable from amidst the thick clouds of heresy and ignorance of language. Nature is often mistaken for person, and person for nature; the same of the human substance. It is monstrous to hear their reasoning upon it. One would think, that every different monk, every time he talks, purposely broached some new heresy. ${ }^{128}$

Doch die Ergebnisse seiner Forschungsreise wurden in Europa mit großer Skepsis zur Kenntnis genommen. Man bekam Zweifel an der Glaubwürdigkeit des Schotten, weil er einerseits von dem komplexen Hofzeremoniell der äthiopischen Christen und deren Intelligenz berichtete, zugleich aber erzählte, dass sie rohes Fleisch äßen; in der Nähe von Aksum habe er sogar gesehen, wie Äthiopier von einem lebendigen Rind ein Stück Fleisch abgeschnitten und gleich gegessen hätten. Die europäischen Leser des 18. Jahrhunderts nahmen dies als einen unmöglichen Widerspruch wahr. Der Genuss von rohem Fleisch passte weder zu der europäischen Moralvorstellung noch zu den vorgefassten - und vor allem durch Ludolf geprägten Meinungen der Europäer von den äthiopischen Christen. Die Äthiopier seien eine christliche, wenn auch fremde, Nation und würden sich nicht so »barbarisch« verhalten.

Die alten Imaginationen vom äthiopischen Christentum waren so resistent, dass Bruce aufgrund der Kritik an seinen Darstellungen, deren man Unglaubwürdigkeit und Mangel an Kohärenz vorwarf, sogar zu einer Witz-

127 Bruce sammelte astronomisch-geografische Daten, Zeichnungen von Architektur, Flora und Fauna, getrocknete Exemplare von Pflanzen und Samen, äthiopische und arabische Manuskripte und führte ein Wetterjournal. Es war ihm besonders wichtig, weil Reisende in der außereuropäischen Welt und Gelehrte für die meisten von Bruces Zeitgenossen unterschiedliche Menschengruppen waren. Bis zum Ende des 17. Jahrhunderts war die Mehrzahl der Reiseberichte aus außereuropäischen Ländern nur erschienen, weil einfache Angestellte der Handelskompanien nach ihrer Rückkehr eine Einkommensquelle suchten. Vielen von ihnen riet ein gebildeter Unterstützer zur Publikation ihrer Berichte. Entsprechend wurden in der zweiten Hälfte des 18. Jahrhunderts die Informationen aus der Feder von Reisenden, die nicht speziell auf Beobachtung und Beschreibung vorbereitet waren, zunehmend kritisch betrachtet. Vgl. Anke Fischer-Kattner, Spuren der Begegnung. Europäische Reiseberichte über Afrika 1760-1860, Göttingen 2015, S. 152.

Bruce, Travels, Bd. 3, S. 321. Vgl. sein Kapitel über die Religion: Ebd., S. 313-357. 
figur in der Populärluktur gemacht wurde. ${ }^{129}$ So war beispielsweise eine Fortsetzung der Abenteuer des "Lügenbarons « Münchausen, die seit 1785 in englischer Sprache erschien, explizit mit einer Widmung für »Mr. Bruce, the Abyssinian Traveller « versehen. ${ }^{130}$ Eine Karikatur mit dem Titel An Abyssinian Breakfast, die von Isaac Cruikshank (1756-1810) im Jahre 1791 gezeichnet wurde [siehe Abbildung 10], griff direkt die umstrittenste Episode aus Bruces Reisebericht auf.

Bruce - in einen Kilt gekleidet und damit als Schotte, nicht als königstreuer »Englishman«, markiert - schneidet sich ungelenk ein Steak aus dem Hinterteil eines lebenden Rindes, wobei im Hintergrund zwei Menschen einen Löwen schlachten. Neben ihm sind sowohl historische als auch geografische Entdeckungen zu sehen, die er im Laufe der Reise gemacht haben soll. So wurden Bruces Beschreibung und Anspruch, ein aufgeklärter Forscher zu sein, vollkommen ins Lächerliche gezogen. ${ }^{131}$

$\mathrm{Zu}$ einem differenzierteren Blick auf die Person James Bruces und die Ergebnisse seiner Reise kam man erst im Laufe intensiver Auseinandersetzung in der europäischen Gelehrtenwelt in den kommenden Jahrzehnten. Man musste angesichts der Berichte anderer Reisender gestehen, dass der Verzehr von rohem Fleisch im christlichen Äthiopien tatsächlich üblich war, und dementsprechend das bisherige Äthiopienbild hinterfragen. Nicht zuletzt eröffnete Bruce neue Zugänge zum äthiopisch-orthodoxen theologischen Wissen, indem er zum ersten Mal die Handschriften mit dem Kabrä Nägäśt und dem Henochbuch nach Europa brachte.

Die alten Imaginationen vom äthiopischen Christentum dominierten somit im protestantischen Milieu bis hin zum späten 18. bis frühen 19. Jahrhundert, dem Zeitalter, als die unmittelbaren Kontakte zwischen den europäischen Protestanten und den äthiopischen Orthodoxen sich zu häufen begannen.

129 Vgl. Fischer-Kattner, Spuren der Begegnung, S. 145-148.

130 »Humbly dedicated to Mr. Bruce, the Abyssinian traveller, As the Baron conceives that it may be of some service to him, previous to his making another expedition into Abyssinia: But if this advice does not delight Mr. Bruce, the Baron is willing to fight him on any terms be pleases". Rudolf Erich RASPE, A Sequel to the Adventures of Baron Munchausen. Containing His Expedition into Africa, London 1792.

131 Unter der Karikatur war ein Auszug aus dem satirischen Gedicht von John Wolcot (1738-1819; Pseudonym: Peter Pindar) abgebildet: »There, which the squeamish souls Britain shocks, / Rich steaks devouring from the living ox; / Here, staring on thee from the realm of water, / Full many a virtuoso alligator; / There, Bruce informing queens, in naked pride, / The feel and colour of a Scotsman's hide; / Here of the genealogy a tree, / Branching from Solomon's wise trunk to thee«. Peter Pindar, A Complimentary Epistle to James Bruce, Esq. the Abyssinian Travaller, London 1790, S. $28 f$. 
Alte Imaginationen und neues Wissen

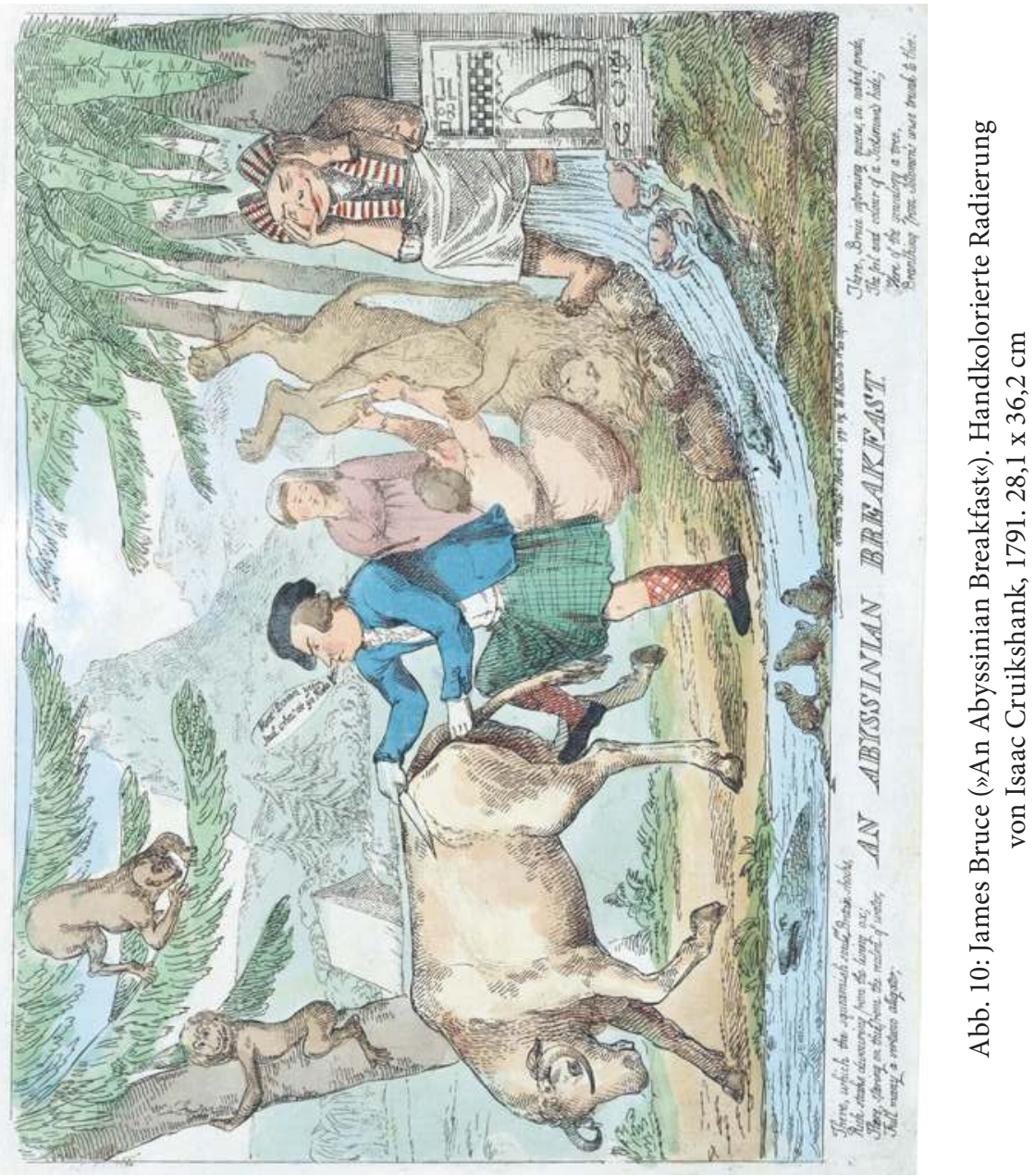





\section{IV. Äthiopische »Reformation«: Mission als Raum transkonfessioneller Differenzaushandlungen (1817-1844)}

\section{Der »Göttinger Geist« evangelischer Äthiopien-Mission}

They [= Ethiopian Christians] have, it seems, all our canonical books, and over and above, the book of Enoch's prophecies. But in these matters, I mean the religious, I am not all informed; my acquaintance, who have conversed with Mr. Bruce, having been more set upon getting knowledge of the manners and natural history of that country, than of either the civil and ecclesiastic. No wonder, considering, what brutes they are! Said I, brutes! I ought to have said Devils incarnate! [...] Corruptio optimi est pessima, and therefore, that a very corrupted christianity is worse, than no christianity at all. ${ }^{1}$

Auf diese Weise teilte der Präsident der britischen Royal Society John Pringle $(1707-1782)^{2}$ am 5. Juni 1774 seinem Göttinger Freund, dem Theologen und Orientalisten Johann David Michaelis (1717-1791), ${ }^{3}$ die neuesten Gerüchte über die Ergebnisse der Äthiopien-Reise von James Bruce mit. ${ }^{4}$ Dank enger Verbindung zu den britischen Gelehrtenkreisen waren die Professoren der Georg-August-Universität Göttingen nicht nur in der glücklichen Lage, die letzten Nachrichten über die exzeptionelle Reise von James Bruce noch längst vor der Veröffentlichung von deren Ergebnissen (und sogar vor dessen Rückkehr nach Großbritannien) zu erhalten, sondern sie waren selbst aktiv

Johannes Gottlieb BuHLE (Hg.), Literarischer Briefwechsel von Johann David Michaelis, Leipzig 1795, Zweyter Theil, S. 389f.

2 Über John Pringle: Sydney Selwyn, Sir John Pringle: Hospital Reformer, Moral Philosopher and Pioneer of Antiseptics, in: Medical History 10 (3) (1966), S. 266-274.

3 Zu Michaelis siehe: Maike Rauchstein, Fremde Vergangenheit. Zur Orientalistik des Göttinger Gelehrten Johann David Michaelis (1717-1791), Bielefeld 2017; Rudolf SMED, Johann David Michaelis und Johann Gottfried Eichhorn - zwei Orientalisten am Rande der Theologie, in: Bernd Moeller (Hg.), Theologie in Göttingen. Eine Vorlesungsreihe, Göttingen 1987, S. 58-82; Sabine MANGold, Eine "weltbürgerliche Wissenschaft « - Die deutsche Orientalistik im 19. Jahrhundert, Stuttgart 2004, S. 35-37 und S. 54-64. Am 23. Oktober 1774 kontaktierte Michaelis James Bruce sogar persönlich und machte ihn in einem lateinischen Brief darauf aufmerksam, dass ganz Europa die Veröffentlichung von »totum itinerarium« erwarte. Vgl. Fischer-KattNer, Spuren der Begegnung, S. 104.

4 Über die Beziehungen zwischen Michaelis und Pringle, der u.a. auch auswärtiges Mitglied der Göttinger Akademie der Wissenschaften war, siehe: Thomas Biskup, The University of Göttingen and the Personal Union. 1737-1837, in: Brendan Simms / Torsten Riotte (Hg.), The Hanoverian Dimension in British History. 1714-1837, Cambridge 2007, S. 128-159, hier S. 144-147. 
an der Herausbildung des neuen, dezidiert aufklärerischen, Diskurses über äthiopisches Christentum beteiligt. Dass ausgerechnet die Göttinger Wissenschaftler die Rezeption der Reisen zur Entdeckung der Quellen des Nils im deutschsprachigen Raum prägten, offenbart bereits dessen deutsche Ausgabe. ${ }^{5}$ Die Übersetzung des mehrbändiges Werks stammte vom Schriftsteller Johann Jacob Volkmann (1732-1803), dem Absolventen der Universität Göttingen; die Vorrede und ausführliche Anmerkungen zum Text verfassten zwei Göttinger Professoren, der Mediziner und Anthropologe Johannes Friedrich Blumenbach (1752-1840) ${ }^{6}$ sowie der Theologe und Orientalist Thomas Christian Tychsen (1758-1834). ${ }^{7}$

Anders als im englischen Kontext, wo provokant zugespitzte Schlussfolgerungen - wie bereits das Zitat aus dem Brief des John Pringle veranschaulicht - nicht unüblich waren, blieb der Göttinger Umgang mit den von James Bruce vorgelegten Beobachtungen betont sachlich. Diese Art entsprach dem "Göttinger Geist«, der für Göttingen typischen Gelehrtenkultur. ${ }^{8}$ Bemerkenswerterweise trug diese Göttinger Gelehrtenkultur der Spätaufklärung nicht nur dazu bei, dass die äthiopische Christentumsgeschichte verstärkt in den Fokus der deutschen Wissenschaft rückte. Vielmehr war sie auch für die Begründung einer evangelischen Äthiopien-Mission ausschlaggebend. Dieser Zusammenhang blieb in der bisherigen Forschung unberücksichtigt, was

5 James Bruce, Reisen zur Entdeckung der Quellen des Nils in den Jahren 1768, 1769, 1770, 1771, 1772 und 1773, Leipzig 1790-1791, 5 Bd.

6 Ebd., Bd. 1, S. III-XXIII und ebd., Bd. 5, S. 233-292.

7 Ebd., Bd. 5, S. 293-360.

8 Diese für Göttingen typische Gelehrtenkultur lässt sich als "rationalistisch in den Grundüberzeugungen, aber skeptisch gegenüber Verallgemeinerungen, historisch empirisch im argumentativen Vorgehen, gelehrt und reformkonservativ« beschreiben. Johannes Süssmann, [Rezension:] Luigi Marino, Praeceptores Germaniae. Göttingen 1770-1820, in: ASozG 37 (1997), S. 691f., hier S. 692. Der Historiker Karl Lamprecht verbindet die Entstehung des »Göttinger Geistes « mit der besonderen Stellung der Theologie an der neugegründeten Universität: »Der Göttinger Geist speziell kann durch nichts besser charakterisiert werden, als durch die Worte, in denen der erste Prorektor der Universität, der geistig vielfach angeregte Freiherr von Münchhausen, die Richtung der theologischen Fakultät bezeichnete: diese Fakultät sei weder mit solchen Männern zu besetzen, deren Lehren zum Atheismus oder Naturalismus leiten oder auch die Articulos fundamentales religionis evangelicae anfechten, noch auch mit solchen, welche ein evangelisches Papsttum behaupten, ihr ganzes System anderen aufdringen, diejenigen, so in gewissen das Fundamentum fidei nicht konzernierenden quaestionibus mit ihnen kein gleiches Sentiment führen, verketzern und die Libertatem conscientiae samt der Toleranz als unleidlich ansehen, wodurch nichts als unnötiger Streit und innerliche Unruhe zu entstehen pflege«. Karl LAMPRECHT, Deutsche Geschichte. Zweite Abteilung. Neuere Zeit. Zeitalter des individuellen Seelenlebens, Freiburg i. Br. 1905, 3. Bd: Erste Hälfte, S. 135. Vgl. auch Jörg BAUR, Die Anfänge der Theologie an der »wohl angeordneten evangelischen Universität« Göttingen, in: Jürgen von Stackelberg (Hg.), Zur Geistigen Situation der Zeit der Göttinger Universitätsgründung 1737. Eine Vortragsreihe aus Anlaß des 250-jährigen Bestehens der Georgia Augusta, Göttingen 1988, S. 9-56, hier S. 13-15. 
darauf zurückzuführen ist, dass eine solche Idee nicht von einem Theologen, sondern von einem Geografen, Carl Ritter (1779-1859), programmatisch begründet wurde. ${ }^{9}$

Im Zuge der Etablierung der wissenschaftlichen Geografie erschien 1817 die erste ausführliche Beschreibung des afrikanischen Kontinents im deutschsprachigen Raum. Die in Göttingen verfasste Darstellung Afrikas, die nicht zuletzt unter dem Eindruck des Werkes von James Bruce entstand [siehe Abbildung 10], ${ }^{10}$ eröffnete das insgesamt auf 21 Bände angelegte Großwerk Carl Ritters, dessen vollständiger Titel lautete: Die Erdkunde im Verhältnis zur Natur und Geschichte des Menschen, oder allgemeine vergleichende Geographie als sichere Grundlage des Studiums und Unterrichts in physikalischen und historischen Wissenschaften. ${ }^{11}$ Das mit dem Buch auf den Weg gebrachte Projekt einer Universalgeografie, das zugleich die Verbindung zwischen Natur und Mensch aus einer historischen Perspektive genauer in den Blick zu nehmen beabsichtigte, war bahnbrechend. ${ }^{12}$

9 Zur Person Ritters siehe: Hanno Beck, Carl Ritter. Genius der Geographie. Zu seinem Leben und Werk, Berlin 1979 sowie die Beiträge in Hans Richter (Hg.), Carl Ritter - Werk und Wirkungen. Beiträge eines Symposiums im 200. Geburtsjahr des Gelehrten. Quedlinburg, Gotha 1983; Karl Lenz (Hg.), Carl Ritter. Geltung und Deutung. Beiträge. Symposium anläßlich der Wiederkehr des 200. Geburtstages von Carl Ritter, Berlin 1981.

10 Allein im ersten Band von Ritters Geographie wird James Bruce über 50 Mal zitiert oder erwähnt.

11 Carl Ritter, Die Erdkunde im Verhältnis zur Natur und Geschichte des Menschen, oder allgemeine vergleichende Geographie als sichere Grundlage des Studiums und Unterrichts in physikalischen und historischen Wissenschaften. Berlin 1817, Erster Theil. Bereits fünf Jahre nach Erscheinen des ersten Bandes kam die überarbeitete Fassung der Afrikageografie auf den Markt. War Afrika in der ersten Auflage nur ein Teilband von gut 400 Seiten beschieden, so umfasste das 1822 in einem Band veröffentlichte neue Werk beachtliche 1000 Druckseiten. Hinzugekommen war eine Vielzahl von Erläuterungen, die die jeweils neuesten Erkenntnisse aufnahmen. Ders., Die Erdkunde im Verhältnis zur Natur und Geschichte des Menschen, oder allgemeine vergleichende Geographie als sichere Grundlage des Studiums und Unterrichts in physikalischen und historischen Wissenschaften, Berlin ${ }^{2} 1822$, Erster Theil, Erstes Buch: Afrika. Zu seinem Projekt einer Universalgeografie, das insgesamt etwa 30.000 Seiten umfasste, und speziell zur Rolle Afrikas in seiner geografischen Synthese siehe: Iris SchrödER, Das Wissen von der ganzen Welt. Globale Geographien und räumliche Ordnungen Afrikas und Europas 1790-1870, Paderborn u.a. 2011, S. 80-86 und S. 117-125.

12 Es brachte ihrem Autor ein hohes Ansehen; 1820 wurde Ritter nicht nur zum korrespondierenden Mitglied der Göttinger Königlichen Societät der Wissenschaften (heute: Akademie der Wissenschaften zu Göttingen) gewählt, sondern auch auf den ersten Lehrstuhl für Geografie in Deutschland, an der Universität Berlin, berufen. Vgl. Manfred Büttner, Carl Ritter, in: DBE 8, ${ }^{2} 2007$, S. 442f., hier S. 442; Holger Krahnke, Die Mitglieder der Akademie der Wissenschaften zu Göttingen 17512001, Göttingen 2001, S. 202. 
Einige Teile der Erdkunde stellten sich jedoch weniger als eine Beschreibung denn vielmehr als eine "Erfindung« Afrikas heraus. Angesichts des Mangels an verlässlicher Information über den Kontinent und der noch nicht völlig herausgearbeiteten Methoden der neuen Disziplin bestand die Ritter'sche Kunst, eine Afrikageografie zu verfassen, nicht zuletzt darin, »die methodische Unsicherheit und das zugleich vorhandene Wissensdefizit in wohlgewählte Worte zu kleiden ${ }^{13}{ }^{13}$ Außerdem trug das Werk dadurch zur "Erfindung" des Kontinents bei, dass es - nicht zuletzt, um die Wissenslücken zu schließen - empirisch nicht belegbare, aber durchaus weitreichende Hypothesen aufstellte. Carl Ritter versuchte aus der Beobachtung des »scheinbar Zufälligen« zur Erkenntnis des »wesentlich Gesetzmäßigen» zu gelangen, und in Folge dessen teilte er jedem Kontinent eine vermeintliche metaphysische Individualität zu, die ihn von allen anderen Kontinenten unterscheiden sollte. ${ }^{14}$ So sah Ritter in Afrika »bei aller innerlich untergeordneten Mannigfaltigkeit, doch dieselbe grandiose Einförmigkeit in der Natur, in der Pflanzen-, Thier- und Menschenwelt" und schrieb dem Erdteil sowie auch seinen Bewohnern große Uniformität und Einfachheit zu. ${ }^{15}$ Afrika war, Ritter folgend, ein »minder physisch mannigfaltig entwickeltes Erdindividuum ${ }^{16}{ }^{16}$

Allerdings ließ er, ausgehend aus dem Verhältnis von Hoch- und Flachland, das er für den Grundparameter hielt, ${ }^{17}$ zwei Ausnahmen gelten, von denen ein »höheres konstruktives Princip« angenommen werden könnte: Die eine war die »Mandingo-Terrasse«, die von den Mandinka bewohnten Höhenzüge in Westafrika; ${ }^{18}$ die andere war Äthiopien, das »Alpenland Habesch «

13 Schröder, Das Wissen von der ganzen Welt, S. 117.

14 Vgl. Ritter, Die Erdkunde, 1817, S. 12.

15 Ebd., S. $413 f$.

16 Ebd., S. 415.

17 Binäre Oppositionen waren von grundlegender Bedeutung für das Denksystem Ritters und wurden als zentrale analytische Kategorie auf verschiedenste Bereiche angewendet. Die am häufigsten verwendete Entgegensetzung war die des Hoch- und Tieflandes. Daraus leitete er seine Theorie der Ethnogenese afrikanischer Völker ab. An Herodot anknüpfend, behauptete Ritter, dass es in Afrika »nur zwei Stammvölker» gebe, »denen alle andern als Eingewanderte und Mischlinge sich zugesellt» hätten, und zwar »die des Hochlandes und des Tieflandes«. Ebd., S. 416.

18 Es ist naheliegend, dass Carl Ritter die Mandinka nicht ausschließlich aufgrund ihrer geografischen Lage zur Ausnahme erhob. Auch der historische Faktor war bedeutend. Die Mandinka definieren sich als Nachkommen des mittelalterlichen Königreiches Mali (auf dem Gebiet der heutigen Länder Gambia, Guinea, Guinea-Bissau, Elfenbeinküste, Mali, Mauretanien, Niger und Senegal), das den Transsaharahandel vom Magreb nach Westafrika kontrollierte. Somit konnten sie eine historische Kontinuität vorweisen, die für Ritter wichtig war. Zu den Mandinka siehe: Djibril Tamsir Niane, Histoire des Mandingues de l'ouest. Le royaume du Gabou, Paris 1989; Alpha Condé, Les sociétés traditionnelles mandingues, Niamey 1974; Charlotte QuinN, Mandingo Kingdoms of the Senegambia. Traditionalism, Islam, and European Expansion, Evanston 1972. 
im Nordosten des Kontinents. Dabei fasste er unter den "Habessiniern" ausschließlich die christliche Bevölkerung des äthiopischen Hochlandes ${ }^{19}$ und war der Meinung, dass die Äthiopier Nachkommen der alten Ägypter seien, und zwar einer "Kriegerkaste«, die im 7. Jahrhundert vor Christus dorthin ausgewandert sei. ${ }^{20} \mathrm{Da}$ er Ägypten nicht zu Afrika im eigentlichen Sinne zählte, suggerierte er damit einen außerafrikanischen Ursprung der Äthiopier. ${ }^{21}$

Laut Ritter seien beide »Culturländer« durch »wilde Opponenten « herausgefordert gewesen: Im Westen durch die »Fulani« (Fulbe), im Osten durch die »Galla«(Oromo). ${ }^{22}$ Indem Ritter Äthiopien sowie die Gebiete von Mandinka vom restlichen Afrika abhob, rückte er sie ins Zentrum der Aufmerksamkeit der sich für Afrika interessierenden Leserschaft. Dass die europäische Wahrnehmung Afrikas durch Ritters Ansichten nachhaltig geprägt wurde, ist unbestreitbar. ${ }^{23}$ Insbesondere galt dies für den deutschsprachigen Raum, wo es - anders als in Großbritannien und besonders in Frankreich - bis zum späten 19. Jahrhundert schlechthin keine weiteren großen Experten in dem Bereich der afrikanischen Geografie gab. ${ }^{24}$ Ein wesentlicher, bis jetzt jedoch noch kaum beachteter Aspekt der Ritter'schen Wirkungsgeschichte bildet sein Einfluss auf die Missionsbestrebungen auf dem afrikanischen Kontinent.

Carl Ritter stammte aus einer Quedlinburger pietistischen Familie und wurde durch die protestantischen Mystik des 18. Jahrhunderts, insbesondere durch die Schriften Nikolaus Ludwig von Zinzendorfs (1700-1760) und Gerhard Tersteegens (1697-1769), stark geprägt. ${ }^{25}$ Nicht nur betrachtete er seine Erforschung der Natur als eine religiöse Praxis, sondern ging auch davon aus, dass jede Wissenschaft aus der Wahrheit hervorgehen solle, die dem

19 Als Synonym zur Bezeichnung »Habessinier« benutzte er die Ausdrücke »habessinische Christen« oder, wenn auch seltener, »aethiopische Christen«. Vgl. bspw. RitTER, Die Erdkunde, 1817, S. 121, 131f., 137, 147f., 158, 160.

20 Ebd., S. $164 f$.

21 Ebd.

22 Vgl. ebd., S. 422. Zu den Fulbe siehe: Marguerite Dupire, Organisation sociale des Peul. Étude d'ethnographie comparée, Paris 1970 und Roger Botte u.a. (Hg.), Figures Peules, Paris 1999. Zu den Oromo siehe: Paul T. W. Baxter u.a. (Hg.), Being and Becoming Oromo. Historical and Anthropological Enquiries, Uppsala 1996; Mohammed Hassen, The Oromo of Ethiopia. A History. 1570-1860, Cambridge 1990.

23 Vgl. Thomas Zitelmann, Des Teufels Lustgarten. Themen und Tabus der politischen Anthropologie Nordostafrikas, Habil. Freie Universität Berlin 1999, S. 86; Matthias Fiedler, Zwischen Abenteuer, Wissenschaft und Kolonialismus. Der deutsche Afrikadiskurs im 18. und 19. Jahrhundert, Köln u.a. 2005, S. 96f.; Fischer-Kattner, Spuren der Begegnung, S. 41.

24 SchröDer, Das Wissen von der ganzen Welt, S. 122.

25 Zum generellen Einfluss der protestantischen Mystik des 18. Jahrhunderts auf Ritter vgl. BECK, Carl Ritter, S. 13f. 
Christentum bereits inhärent ist. ${ }^{26}$ Deswegen baut auch das System seiner Erdkunde auf starken theologischen Prämissen auf. Laut Ritter dürfe die Geografie nie nur beschreibendes Kompendium sein, nie nur einfache Darstellung von Gegebenheiten, sie müsse vielmehr den "Gesamtorganismus" verständlich machen. So strebte er in seiner Erdkunde eine Synthese von Raum und Zeit, von Natur und Kultur, von Partikularität und Universalität sowie von Materialität und göttlicher Präsenz an, und hier konkretisiert sich seine theologische Prämisse. Die physischen Faktoren seien die von Gott gegebene "Mitgift«, die "seit der ersten Schöpfungsanlage« so eingerichtet worden sei, dass sie auf die Entwicklung der Menschen und der Kultur einwirken könne. ${ }^{27}$ Jeder Erdteil »als Organ des planetarischen Organismus" habe sie zugeteilt bekommen, um eine ihm von Gott bestimmte Funktion in »dem Gange der Weltentwicklung« spielen zu können. ${ }^{28}$

Angesichts dieser Gedankenfigur stellte Manfred Büttner die These auf, dass Ritter gewissermaßen »die (calvinistisch-reformierte) Vorstellung von der doppelten Prädestination" in einer abgemilderten Form auf die Geografie übertragen habe. ${ }^{29}$ Doch im strengen Sinne kann davon keine Rede sein. Vielmehr greift Ritter in seiner Geografietheorie auf vorkantianisches Gedankengut zurück und versucht mit einer stark teleologisch ausgerichteten Physikotheologie eine kausalmechanische Betrachtung der Naturvorgänge zu überholen. ${ }^{30}$ Die von ihm beschriebene globale Geografie war aus

26 Vgl. dazu Schröder, Das Wissen von der ganzen Welt, S. 82f.; Andreas Schach, Carl Ritter (1779-1859). Naturphilosophie und Geographie. Erkenntnistheoretische Überlegungen, Reform der Geographie und mögliche heutige Implikationen, Münster 1996, S. 26-28. Als er 1796-1798 in Halle, einem anderen Zentrum des Pietismus, Kameralwissenschaften studierte, besuchte er u.a. auch Vorlesungen in Theologie. Vgl. BütTner, Carl Ritter, S. 442.

27 Carl Ritter, Über räumliche Anordnung auf der Außenseite des Erdballs und ihre Funktion im Entwicklungsgange der Geschichte, Berlin 1850, S. 26.

28 Ders., Einleitung zur allgemeinen vergleichenden Geographie, und Abhandlungen zur Begründung einer mehr wissenschaftlichen Behandlung der Erdkunde, Berlin 1852, S. 227 und S. 243. Dieser Text wurde bereits 1818 erstmals konzipiert. Vgl. Josef Birkenhauer, Traditionslinien und Denkfiguren. Zur Ideengeschichte der sogenannten Klassischen Geographie in Deutschland, Stuttgart 2001, S. 43.

29 BütTner, Carl Ritter, S. 442.

30 Birkenhauer, Traditionslinien und Denkfiguren, S. 46. Zu Ritters Verhältnis zu der Tradition der Aufklärung siehe: Manfred BüTtner, Wandlungen im teleologischen Denken von Wolff über Kant zu Ritter, in: Manfred BüttneR (Hg.), Carl Ritter. Zur europäisch-amerikanischen Geographie an der Wende vom 18. zum 19. Jahrhundert, Paderborn 1980, S. 145-178. Interessanterweise "entwindet« sich Ritter die Aufklärung ausgerechnet in den Jahren 1813-1819, die er in Göttingen verbrachte. Am intensivsten beschäftigte er sich mit den Schriften von Johann Gottfried von Herder (1744-1803) und Friedrich Schelling (1775-1854). Was Immanuel Kant (1724-1804) angeht, zeigte er sich hingegen demonstrativ desinteressiert. Faszinierend fand er zudem Johann Heinrich Pestalozzi (1746-1827), von dem er viele Gedanken übernahm. Vgl. Birkenhauer, Traditionslinien und Denkfiguren, S. 47f.; SCHACH, Carl Ritter, S. 52-74. 
seiner Sicht zwar für die gegenwärtigen Zustände entscheidend gewesen, jedoch sollte nicht nur sie die Zukunftsaussichten bestimmen. ${ }^{31}$ Ritters Weltanschauung war dementsprechend keineswegs deterministisch, vielmehr legte er hohen Wert - nicht zuletzt wegen seiner lutherisch-pietistischen Prägung - auf die Möglichkeit einer "persönlichen« Veränderung der einzelnen »Erdindividuen«. In Bezug auf den afrikanischen Kontinent äußerte sich dies in seiner radikalen Position gegen den Sklavenhandel, zu dessen Beendigung er einen Beitrag zu leisten versuchte, und seinem Engagement für die Mission, die er als »ein Princip der Bildsamkeit und der Erweckung zum sittlichen Bewußtseyn « betrachtete. ${ }^{32}$ Die Mission sollte dem ganzen Kontinent einen zivilisatorischen Impuls geben und eine neue Epoche in seiner Geschichte einleiten. ${ }^{33}$

Überlegungen bezüglich der Verbreitung des (protestantischen) Christentums in Afrika äußerte Ritter auch auf den Seiten seiner Erdkunde. Wenn er in der ersten Edition des Werkes von 1817 diese Idee nur vorsichtig andeutete, so legte er in der zweiten Auflage von 1822 bereits einen ausgereiften Plan dafür vor. Von seiner Metaphysik Afrikas ausgehend, trat er dafür ein, zunächst die beiden afrikanischen »Culturländer", Äthiopien im Osten und die Gebiete der Mandinka im Westen, zu missionieren, deren Bevölkerungen er als Hoffnungsträger sah. Damit zielte er darauf, die weitere Ausbreitung des Islam auf dem Kontinent zu verhindern. Er schlug die Gründung von Missionsstationen vor, die vom Horn von Afrika quer durch das mittlere Afrika zu den Höhenzügen Westafrikas reichen sollten. Diese "Kette von Missionen « sollte nicht nur die Evangelisierung des Kontinentes vorantreiben, sondern gleichzeitig auch als eine Verbindungsstraße zwischen Ostund Westküste dienen. ${ }^{34}$

Der Umstand, dass die Missionsstationen ausgerechnet in Äthiopien, einem bereits christlichen Land, begründet werden sollten, verlangte eine Erklärung. Dies führte Ritter dazu, den orthodoxen Äthiopiern ihr Christsein faktisch abzusprechen und sie als minderwertig und missionierungsbedürftig einzustufen. Ritter, der somit zu einem der ersten evangelischen Ideologen der Missionierung der orthodoxen Christen Äthiopiens wurde, bemühte sich, diese Ansicht "wissenschaftlich« zu untermauern. Folgendermaßen stellte er die äthiopisch-orthodoxen Christen auf den Seiten seiner Erdkunde dar:

31 Ebd., S. 124.

32 Ritter, Die Erdkunde, 1817, S. 415.

33 Ebd., S. $415 f$.

34 Ritter, Die Erdkunde, ${ }^{2} 1822$, S. 401. 
An der Ausübung ihres religiösen Cultus immer noch mit Strenge hängend, wie an der Feier der Feste, an Haltung der Fastentage, an Hersagung der Gebete, Besuchung der Kirchen, Anrufung der Heiligen u.d.gl., scheinen die mehrsten vom Christenthum selbst nur geringe Ahnung zu haben, ungeachtet die Geistlichkeit und die Fürsten immer in theologischen Fehden verwickelt waren. Nur das Kreuz, das auch der gemeinste Habessinier auf Stirn und Hand trägt, und der Rosenkranz sind häufig die einzigen Spuren ihres Christenthums und auch der Name desselben soll immer mehr in Vergessenheit gerathen, seitdem sie nach dem Tode des letzten Aboona Marcus abgeschnitten vom Patriarchen in Cairo, kein kirchliches von ihm eingesetztes Oberhaupt (Aboona) mehr in ihrer Mitte erhalten können. ${ }^{35}$

Seine Information über die gegenwärtige Lage in Äthiopien bezog Ritter vornehmlich aus den Berichten der britischen Reisenden James Bruce und Henry Salt (1780-1827). ${ }^{36}$ Seine Behauptung, es gebe in Äthiopien keinen Bischof, war bereits vor der Erscheinung der ersten Auflage seines Buches veraltet: Seit 1816 bekleidete Abunä Qerəllos (\$C. $\boldsymbol{n}^{\circ}$; gest. ca. 1828) das Amt, das zuvor acht Jahre vakant gewesen war. ${ }^{37}$ Davon abgesehen ist Ritters Argumentation an dieser Stelle bemerkenswert: Indem er den angeblichen Untergang des Christentums in Äthiopien auf die vorläufige Abwesenheit des Bischofs zurückführte, schrieb er ausgerechnet der hierarchischen Struktur der Kirche eine unabdingbare Bedeutung für das Christsein zu. Zusammen mit der These, dass die orthodoxen Äthiopier "nur geringe Ahnung« vom Christentum hätten, legitimierte er letztlich die Notwendigkeit einer »Reformation« in der Äthiopischen Kirche. Dieser sollte eine Missionierung Richtung Westafrika folgen, die wiederum in einer epochalen Bekehrung des ganzen Kontinentes münden sollte. Besonderes Gewicht verlieh dieser letztendlich utopischen Vision die Tatsache, dass sie in die große Synthese der »allgemeinen vergleichenden Geographie« eingebettet war und dadurch nicht nur als realisierbar, sondern auch als aus "wissenschaftlicher» Sicht notwendig erschien.

35 Ders., Die Erdkunde, 1817, S. 164f.

36 Bruce, Travels; Viscount Valentia George/Henry Salt, Voyages and Travels to India, Ceylon, the Red Sea, Abyssinia, and Egypt. In the Years 1802, 1803, 1804, 1805, and 1806, London 1809, 3 Bd.; Henry SAlt, A Voyage to Abyssinia, and Travels into the Interior of That Country, Executed Under the Orders of the British Government, in the Years 1809 and 1810, London 1814. Über die Reisen von Bruce und Salt nach Äthiopien siehe: Fischer-KatTneR, Spuren der Begegnung, S. 101-303.

37 Nach der traditionellen Rechnung war Abunä Qerəllos der 106. Metropolit Äthiopiens. Zu ihm siehe: Donald Crummey, Qerəllos, in: EAE 4, 2010, S. $290 \mathrm{f}$. 


\section{Die erste dauerhafte Begegnung:}

\section{Semantiken und Strategien wechselseitiger Alteritätskonstruktionen}

\subsection{Modalitäten der Begegnung}

Am Anfang des 19. Jahrhunderts befand sich das protestantische Missionswesen in seiner Aufbauphase und war bei der Festlegung seiner künftigen Einsatzfelder nicht zuletzt auf die Expertise der Wissenschaftler angewiesen. In diesem Kontext machte sich die anglikanische Church Missionary Society for Africa and the East (später: Church Missionary Society) ${ }^{38}$ die Idee Carl Ritters, die Äthiopisch-Orthodoxe Kirche zu reformieren, zu eigen. Das endgültige Ziel dieses Vorhabens war es, die Äthiopische Kirche dazu zu bewegen, ihre "missionarischen Aufgaben« gegenüber den Nachbarvölkern zu übernehmen. ${ }^{39}$

Die Church Missionary Society, die erste protestantische Mission mit dem Ziel Äthiopien, hatte nicht nur einen internationalen, sondern auch einen im Rahmen des Protestantismus - interkonfessionellen Charakter. Dementsprechend beruhte sie auf einem europaweiten Netzwerk von evangelischen Missionsgesellschaften und Unterstützer. ${ }^{40}$ Eine »Reformation « sollte in der Äthiopisch-Orthodoxen Kirche vor allem durch die Verbreitung der Heiligen Schrift in der amharischen Übersetzung erzielt werden. ${ }^{41}$ Im Zeitraum von

38 Die Missionsgesellschaft wurde 1799 auf der Welle der neuen Erweckungsbewegung in London gegründet. Zu ihrer Geschichte siehe: Eugene Sтоск, The History of the Church Missionary Society. Its Environment, Its Men and Its Work, London 1899, 3 Bd.; Murray Jocelyn, Proclaim the Good News. A Short History of the Church Missionary Society, London 1985. Vgl. Barry Hankins, The Second Great Awakening and the Transcendentalists, Westport CT 2004.

39 Samuel Gobat, Journal of a Three Years' Residence in Abyssinia, in Furtherance of the Objects of the Church Missionary Society, London 1834, S. VII.

40 Die Church Missionary Society hatte einen ausgesprochen transkonfessionellen Charakter. Als Ideal wurde das transkonfessionelle Modell der Herrnhuter Brüdergemeine übernommen. Vgl. Hermann Wellenreuther, Mission, Obrigkeit und Netzwerke. Staatliches Interesse und Missionarisches Wollen vom 15. bis ins 19. Jahrhundert, in: PuN 33 (2007), S. 193-213, hier S. 212. Nicht nur wurde sorgfältig jeder Hinweis auf die Anglikanische Kirche vermieden, auch in der Beschreibung der Qualifikationen derjenigen, die als Missionare ausgeschickt werden sollten, fehlten solche Andeutungen. Vgl. Paul Jenkins, The Church Missionary Society and the Basel Mission. An Early Experiment in Inter-European Cooperation, in: Kevin Ward / Brian Stanley (Hg.), The Church Mission Society and World Christianity. 1799-1999, Grand Rapids 2000, S. 43-65; John Clark, CMS and Mission in Britain. The Evolution of a Policy, in: Ebd., S. 319-343. So hatten alle Missionare, die im Auftrag der anglikanischen Missionsgesellschaft in Äthiopien tätig waren, entweder einen lutherischen oder reformierten Hintergrund. Sie alle waren Absolventen des Basler Missionsseminars und stammten, mit einziger Ausnahme des Schweizers Samuel Gobat, aus Deutschland.

41 Dabei handelte es sich um die Übersetzung aus der Feder des äthiopisch-orthodoxen Geistlichen Abu Rumi (in Äthiopien bekannt als Abba Abrəham, h·nc.y9; ca. 1750- 
1830 bis 1842 unternahmen die Missionare der Church Missionary Society mehrere Anläufe, sich in Äthiopien zu etablieren, jedoch blieben alle ihre Bemühungen erfolglos. ${ }^{42}$

1819), die er in Kairo aus einer arabischen Version anfertigte. Vgl. Michael KLEINER, Abu Rumi, in: EAE 1, 2003, S. 53f.; William JowetT, Christian Researches in the Mediterranean, London 1822, S. 197-204; Edward UllendorfF, Ethiopia and the Bible. The Schweich Lectures of the British Academy 1967, London 1968, S. 62-68. Die Übersetzung wurde durch den französischen Orientalisten Jean-Louis Asselin de Cherville (1772-1822) angeregt und erfolgte im Zeitraum von 1808 bis 1818. Das originale Manuskript, das 9539 Seiten im Oktavformat umfasste, verkaufte Cherville im April 1820, kurz nach dem Tod von Abu Rumi, an die British and Foreign Bible Society für die damals enorme Summe von $£ 1.250$. Mit der Vorbereitung und Herausgabe der gedruckten Edition der amharischen Bibel wurde der Bibliothekar der britischen Bibelgesellschaft, Thomas Pell Platt (1798-1852), beauftragt. Die Evangelien erschienen 1824, das ganze Neue Testament 1829 und die vollständige Bibel 1840. Thomas Pell Platt (Hg.), Evangelia Sancta, sub auspiciis D. Asselini rerum gallicarum apud Aegyptios procuratoris in linguam amharicam vertit Abu Rumi Habessinus, London 1824; ders. (Hg.), Testamentum Novum, Domini Nostri et Servatoris Jesu Christi sub auspiciis D. Asselini in linguam amharicam vertit Abu Rumi Habessinus, London 1829; ders. (Hg.), Biblica sacra amharice, sub auspiciis D. Asselini in linguam amharicam vertit Abu Rumi Habessinius, London 1840. Die Grundannahme, dass allein die Verteilung der Bibel für die Auslösung einer »Reformation" in der Kirche Äthiopiens ausreichen würde, ließ jedoch die Differenz der beiden Traditionen in der Frage nach der Exklusivität der Bibel als der Quelle der Kirchenlehre außer Acht. Ebenso wenig reflektierte sie die Tatsache, dass die Äthiopisch-Orthodoxe Kirche einen anderen Bibelkanon hatte und daher unter dem Wort »Bibel« eine deutlich umfangreichere Sammlung der Bücher verstand.

42 Für einen historischen Überblick siehe: Crummey, Priests and Politicians, S. 29-57; Arén, Evangelical Pioneers, S. 45-84. Die ersten zwei Missionare, die von der Church Missionary Society nach Äthiopien entsandt wurden, waren Samuel Gobat (1799-1879) und Christian Kugler (1801-1830). Zunächst reisten sie 1826 nach Ägypten, um dort erste Kontakte mit den äthiopischen Christen aufzunehmen und Amharisch zu lernen. Äthiopien erreichten sie im Februar 1830 und wurden von dem Herrscher der nordäthiopischen Provinz Təgray, däğğazmač Säbagadis Wäldu, freundlich empfangen. Im März reiste Gobat in die äthiopische Hauptstadt Gondär, wo er sechs Monate verbrachte und sich um die Verbreitung der protestantischen Lehren unter der Priesterschaft der äthiopisch-orthodoxen Kirche bemühte. Doch bald folgte eine Reihe tragischer Ereignisse: Ende des Jahres, am 29. Dezember 1830, kam Christian Kugler bei einem Jagdunfall ums Leben, und im Frühjahr 1831 wurde Säbagadis Wäldu in einer Schlacht getötet. Infolge der instabilen politischen Lage musste Gobat das Land verlassen. 1834 kehrte er - diesmal zusammen mit Carl Wilhelm (Charles William) Isenberg (1806-1864) - nach Äthiopien zurück. Doch bereits nach zwei Jahren musste er wegen einer Krankheit wieder nach Europa reisen und wurde durch Karl Heinrich Blumhardt (1807-1883) und Johann Ludwig Krapf (18101881) ersetzt. 1838 wurden alle evangelischen Missionare aufgrund der Konfrontation mit den äthiopisch-orthodoxen Geistlichen ausgewiesen. Der nächste Versuch, sich in Äthiopien zu etablieren, erfolgte 1839. Diesmal konnten die Missionare, einer Einladung von Naguś Śahlä Ślllase (1795-1847) folgend, nach Šäwa kommen.

Ständige Konfrontation mit den Vertretern der äthiopisch-orthodoxen Kirche und missglückte Bemühungen, sich in die politischen Machtkämpfe des Landes einzumischen, führten dazu, dass sie nach einigen Jahren eingestehen mussten, dass eine »innere Erneuerung« der äthiopischen Kirche nach protestantischem Maßstab nicht 
Dennoch hat dieses Missionsunternehmen eine herausragende historische Bedeutung: Es führte zu der ersten dauerhaften unmittelbaren Begegnung des äthiopischen Christentums mit dem europäischen Protestantismus. Zugleich wurde Mission zum primären Raum transkonfessioneller Differenzaushandlungen in der ersten Hälfte des 19. Jahrhunderts.

Die Frage nach der Aushandlung religiöser Differenz zwischen europäischen Missionaren und äthiopisch-orthodoxen Christen soll im Folgenden anhand der Analyse wechselseitiger Alteritätskonstruktionen behandelt werden. Die Konstruktion von Fremdheit und die Markierung von Differenz spielen im Zuge der Selbst- und Fremddefinition eine zentrale Rolle und sind wesentliches Merkmal bei der Definition kollektiver Identitäten. Die im Laufe dieser Interaktion hervorgebrachten Repräsentationen des Anderen sind besonders aufschlussreich, denn sie stellen nicht nur historische Momentaufnahmen des jeweiligen theologischen Standpunkts zur Zeit der Begegnung dar, sie wirken vielmehr zum Teil noch bis heute nach.

\section{$2.2 » I h r$ seyd Juden«: Äthiopische Orthodoxie als das Andere}

Die zentrale missionarische Strategie des Umgangs mit der Kirche Äthiopiens kann als Versuch ihrer diskursiven "Entchristlichung " beschrieben werden. Auf theologischer Ebene äußerte sich dieser Vorgang vor allem im Vorwurf des Synkretismus. Das Christentum in Äthiopien sei durch den Einfluss anderer Religionen bis zur Unkenntlichkeit umgeformt worden. Der angebliche Verlust christlicher Moral - eine besondere Rolle spielte dabei die Kritik an der Unsittlichkeit der äthiopischen Priester und Mönche - sollte diese These zusätzlich bekräftigen. ${ }^{43}$

zu erwarten war. Deswegen hielten sich die Missionare nicht mehr an die offizielle Strategie, nur noch die Heilige Schrift zu verteilen, sondern versuchten, protestantische Gemeinden zu gründen. Für diese Zwecke übersetzte Isenberg explizit konfessionelle Literatur ins Amharische: 1842 erschienen das anglikanische Book of Common Prayer sowie der Heidelberger Katechismus. Allerdings konnten die Missionare sie nicht mehr in Äthiopien verbreiten, denn im gleichen Jahr wurden sie abermals des Landes verwiesen und die Church Missionary Society gab das Missionsprojekt auf. $\mathrm{Zu}$ den einzelnen Missionaren siehe: Barbara Strebel, Gobat, Samuel, in: EAE 2, 2005, S. 818f.; Friedrich Sсніск, Samuel Gobat. Der Bischof von Jerusalem, Gießen 1958; Wilfred Heintze-Flad, Kugler, Christian, in: EAE 3, 2007, S. 446f.; Donald Crummey / Wolbert G. C. Smidt, Isenberg, Carl Wilhelm, in: EAE 3, 2007, S. 197f.; Eshetu Aвате, Blumhardt, Carolus Henricus, in: EAE 1, 2003, S. 598f.; Clemens GüTL, Johann Ludwig Krapf. »Do’ Missionar vo’ Deradenga« zwischen pietistischem Ideal und afrikanischer Realität, Münster 2001.

$43 \mathrm{Zu}$ Darstellungen der äthiopisch-orthodoxen Kirche in den Tagebüchern und Publikationen der Missionare siehe: Stanislau Paulau, Encountering the Ethiopian Orthodox Church in the Pre-Ecumenical Age. Some Remarks on the First Protes- 
Am häufigsten wurde äthiopisches Christentum in den Tagebüchern der Missionare jedoch als »jüdisch « bezeichnet. Dabei erhielt diese Markierung je nach Kontext der Aussage unterschiedliche semantische Schattierungen. ${ }^{4}$ "üdisch" sei bereits die Herkunft der Äthiopier: »Die Abessinier stammen ursprünglich von Juden her«, so Samuel Gobat, und »manche Merkmale dieses Ursprungs « seien an ihnen noch sichtbar. ${ }^{45}$ "üdisch" seien laut Gobat neben dem Einhalten des Sabbats »die Beschneidung beiderlei Geschlechts" und der Verzicht auf die »im Gesetze Mosis verbotenen Speise ${ }^{46}$ An das

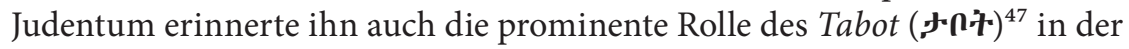
Äthiopisch-Orthodoxen Kirche: »Auch eine Bundeslade befindet sich in jeder

tant Missionaries in Ethiopia (1829-1843), in: Eloi FICQUeT u.a. (Hg.), Movements in Ethioipa, Ethiopia in Movement. Proceedings of the 18th International Conference of Ethiopian Studies, Los Angeles CA 2016, Bd. 1, S. 175-184.

44 Vgl. v. a. Gobat, Journal; Charles William Isenberg/Johann Ludwig Krapf, Journal of the Rev. Messrs. Isenberg and Krapf, Missionaries of the Church Missionary Society, Detailing Their Proceedings in the Kingdom of Shoa, and Journeys in Other Parts of Abyssinia, in the Years 1839, 1840, 1841, and 1842, London 1843; Carl Wilhelm Isenberg, Abessinien und die evangelische Mission. Erlebnisse in Aegypten, auf und an dem rothen Meere, dem Meerbusen von Aden, und besonders in Abessinien. Tagebuch meiner dritten Missionsreise vom Mai 1842 bis December 1843, Bonn 1844, Bd. 1.

45 Samuel Gobat, Abyssinien. Tagebuch des Missionars Samuel Gobat (Fortsetzung und Beschluß), in: MNGPM 2 (1834), S. 163-308, hier S 219. Diese Ansicht des europäischen Missionars ist erstaunlich, denn sie belegt die Rezeption der Erzählung des Kabrä Nägäśt, laut der sich die erstgeborenen Israeliten, die Mənilək bei seiner Reise mit der Bundeslade aus Jerusalem begleiteten, anschließend in Äthiopien niederließen. Diese Migrationsgeschichte suggerierte, dass nicht nur die kaiserliche Dynastie mit den Israeliten blutsverwandt sei, sondern auch das äthiopische Volk als Ganzes. Das Erstaunliche dabei ist, dass Samuel Gobat, der sonst äußerst kritisch gegenüber sowohl der äthiopisch-orthodoxen Tradition als auch der äthiopischen Geschichtsschreibung eingestellt war, dieses Narrativ für glaubwürdig hielt. Möglicherweise schienen ihm - aus einer europäisch-protestantischen Perspektive - die äthiopisch-orthodoxen Frömmigkeitspraktiken derart »unchristlich «, dass die einzige plausible Erklärung deren Existenz in der jüdischen Abstammung der Äthiopier gesucht wurde.

46 Ebd., hier S. 290.

47 Das Tabot, die aus Holz oder Stein ausgefertigte Altartafel, und das Mänbärä Tabot

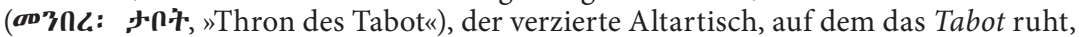
verkörpern die Bundeslade bzw. die Gesetzestafeln. Ohne diese kann kein Abend-

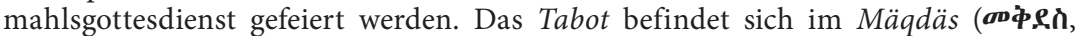
»Heiligtum«), dem zentralen Teil der Kirche, zu dem nur die Geistlichen Zutritt haben, und stellt das symbolische Zentrum des Gottesdienstes dar. In seiner Funk-

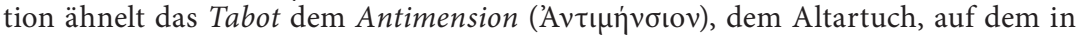
der byzantinischen Tradition die göttliche Liturgie gefeiert wird. Zu Tabot siehe: Stanislau Paulau, Auf der Suche nach dem Tabot. Zu einem vergessenen Kapitel in der Geschichte der Wechselbeziehungen zwischen deutscher Wissenschaft, Mission und äthiopischem Christentum, in: Claudia Rammelt u.a. (Hg.), Begegnungen in Vergangenheit und Gegenwart. Beiträge dialogischer Existenz. Eine freundschaftliche Festgabe zum 60. Geburtstag von Martin Tamcke, Berlin 2015, S. 286-295; Stuart 
Kirche [...]. Ihre Gegenwart macht den Tempel heilig; und nun rufen sie mit den alten Juden: Hier der Tempel des Herrn! Hier der Tempel des Herrn! « ${ }^{48}$

Die Vorstellung, das äthiopische Christentum sei »jüdisch $«{ }^{49}$ hatte jedoch noch eine tiefere Dimension. Im theologischen Denken der evangelischen Missionare fungierte das "Jüdische«, in Anlehnung an Luther, als Inbegriff der Werkgerechtigkeit. ${ }^{50}$ Die Werkgerechtigkeit diente als Negativfolie der in der Lehre Luthers postulierten Rechtfertigung sola gratia (»allein aus Gnade«) und sola fide (»allein durch den Glauben«) und stand für all das, was es zu überwinden galt, um Heil zu erlangen. Beispielhaft in dieser Hinsicht kann folgendes Urteil Samuel Gobats über das äthiopische Christentum gelten, das er am 7. Juli 1830, nur wenige Monate nach seiner Ankunft in Äthiopien, im Gespräch mit einem äthiopisch-orthodoxen Gelehrten in der damaligen Hauptstadt Gondär äußerte:

Ihr seyd Juden. [...] Zwar bekennet ihr Christum mit dem Munde, aber ihr verwerfet Ihn durch eure Handlungen; ihr haltet seine Gebote nicht, und darum habt ihr auch keinen Glauben. Der Apostel Paulus setzt das Merkmal der Juden darein, daß sie durch Werke gerecht werden wollen. Gerade so macht ihr es auch. Euer Fasten, eure Almosen und das Küssen der Kirchen soll euch gerecht machen vor Gott, und darum gelanget ihr auch nicht zur wahren Gerechtigkeit. Es thut dringend Noth, daß ihr euch bekehret, und anfanget, wahre Christen zu werden. ${ }^{51}$

Munro-Hay, Ark of the Covenant, in: EAE 1, 2003, S. 340f.; Emmanuel Fritsch, Mäqdäs, in: EAE 3, 2007, S. 765-767; Marilyn E. Heldman, Tabot, in: EAE 4, 2010 , S. 802-804; Emmanuel Fritsch, Tabot. Mänbärä tabot, in: EAE 4, 2010, S. 804-807. 48 Goвat, Abyssinien, S. 290.

49 Tatsächlich waren einige der Elemente, die die Missionare als »jüdisch«betrachteten, in vielen Kulturen des christlichen Orients beheimatet. So gelangten bspw. das Einhalten des »doppelten" Sabbats sowie die gottesdienstliche Verwendung des Tabot aus dem koptischen Ägypten nach Äthiopien. Ugo ZanetTI, Les lectionnaires coptes annuels. Basse-Égypte, Louvain-la-Neuve 1985, S. 133-143. Die Beschneidung und der Verzicht auf Schweinefleisch wurden hingegen von nahezu allen Bevölkerungsgruppen am Horn von Afrika unabhängig von ihrer Religionszugehörigkeit praktiziert und stellten kulturelle Phänomene dar, die nicht aus dem Alten Testament abgeleitet wurden. Die Darstellung dieser Praktiken als »jüdisch" war dementsprechend dem historisch-theologischen Horizont der europäischen Beobachter geschuldet und trug erheblich zur Exotisierung des äthiopischen Christentums bei.

$50 \mathrm{Zu}$ Einstellungen der deutschsprachigen Pietisten zum Judentum am Anfang des 19. Jahrhunderts siehe: Jan Carsten SchnurR, Weltreiche und Wahrheitszeugen. Geschichtsbilder der protestantischen Erweckungsbewegung in Deutschland 18151848, Göttingen 2011, S. 289-294.

51 Gobat, Abyssinien, S. $219 f$. 
Die Betonung des »üdischen« war insofern zentral für die Wahrnehmung und Beschreibung der Äthiopisch-Orthodoxen Kirche, als sie den Missionaren erlaubte, sie als gewissermaßen »nicht-christlich" aufzufassen und dadurch ihre eigene Tätigkeit zu legitimieren. ${ }^{52}$

Diese Sicht auf das äthiopische Christentum entfaltete im Prozess der europäischen Rezeption allerdings auch weitreichende Nebenwirkungen: Die Assoziierung der Äthiopier mit den Juden führte nämlich dazu, dass auf sie die antisemitischen Stereotype übertragen wurden. So verlangte beispielsweise der aus dem Umkreis der Missionare stammende Württemberger Karl Christian Friedrich Kielmayer (1804-1840) ${ }^{53}$ auf den Seiten des Tageblattes Das Ausland im November 1839, es sollte in den Beschreibungen Äthiopiens nicht mehr »im alten Schlendriane fort und fort von Abyssiniens Gastfreundschaft und seinem ritterlichen Volke gefabelt werden, in Vergleich mit welchem Europa's feigste Juden noch wahre Helden sind! $\aleph^{54}$ Des Weiteren forderte er dazu auf, »in neuen Auflagen von Geographien - besonders in Ritters sonst so vorzüglichem Werke - und in andern Schriften über Länderund Völkerkunde« das Bild Äthiopiens daraufhin zu revidieren.

Zwar erhoben die Missionare in ihren Schriften das »üdische« zum wesentlichen Differenzmerkmal des äthiopischen Christentums, doch in tatsächlichen Diskussionen mit den äthiopisch-orthodoxen Theologen sprachen sie dieses Thema selten an. Dies lag nicht zuletzt daran, dass die Glaubenspraktiken, die die Europäer als »jüdisch" markierten, kaum anhand der beliebtesten Argumentationstechnik der Missionare, dem Verweis auf

52 An sich war es nicht neu, einige Aspekte des äthiopischen Christentums in Verbindung mit dem Judentum zu sehen; so taten es bereits die Jesuiten im 16. und 17. Jahrhundert. Neu war jedoch, dass nun nahezu das gesamte äthiopische Christentum auf das »üdische« reduziert wurde: Die Frömmigkeitspraktiken, die ihren Ursprung angeblich in den Vorschriften des Alten Testaments hätten, dienten nicht nur als eine - wenn auch exotische - konfessionelle Besonderheit und als vermeintlicher Nachweis der Abstammung der Äthiopier von den alten Israeliten; im Lichte der protestantischen Theologie erschienen sie nun auch als Manifestation der sich um das Gesetz und die Werkgerechtigkeit drehenden »jüdischen « Religiosität, die dem Evangelium entgegengesetzt wurde.

53 Während seiner Äthiopien-Reisen wohne Kielmayer sogar eine Zeitlang bei den Missionaren. Vgl. William Cornwallis HARRIS, Gesandtschaftsreise nach Schoa und Aufenthalt in Südabyssinien 1841-1843. Zweite Abtheilung, Stuttgart 1846, S. XXXXII; IsenberG, Abessinien und die evangelische Mission, Bd. 1, S. 96-99.

54 Das Ausland. Ein Tagblatt für Kunde des geistigen und sittlichen Lebens der Völker 319 (15. November 1839), S. 1274. Auf eine ähnliche Weise betonte der deutsche Ethnologe und Geograf Richard Andree (1835-1912) in Bezug auf die Äthiopier nicht nur den »Formengeist, der allen Semiten eigen « sei. Zudem warnte er vor Stolz und Herrschsucht der Äthiopier, von denen »eigentlich kein Semite« frei sei. Richard Andree, Abessinien, das Alpenland unter den Tropen und seine Grenzländer, Malerische Feierstunden. Das Buch der Reisen und Entdeckungen. Neue illustrierte Bibliothek der Länder- und Völkerkunde zur Erweiterung der Kenntniß der Fremde, Leipzig 1869, S. 123. 
die Bibel, zu widerlegen waren. Vielmehr wurden verschiedenste Aspekte der Mariologie, sei es die Rolle Marias in der Soteriologie oder ihre liturgische Verehrung, zum Gegenstand der theologischen Auseinandersetzungen gemacht. ${ }^{55}$

Die Missionare sahen vor allem in der äthiopisch-orthodoxen Vorstellung, dass Maria frei von Sünden sei, einen grundlegenden Widerspruch zur Rechtfertigungslehre Luthers. Deswegen versuchten sie in zahlreichen Diskussionen zu beweisen, dass Maria »so gut, wie jeder andere Mensch, vor und nach der Geburt Christi eine Sünderin" gewesen sei. ${ }^{56}$ Darauf drängte insbesondere Samuel Gobat, der sich dabei gerne als kompromissloser Verfechter der theologischen Wahrheit inszenierte. ${ }^{57}$ Aus der Behauptung, Maria sei eine Sünderin gewesen, leiteten die Missionare zwei konkrete, stark normativ aufgeladene Forderungen an die äthiopischen Christen ab: Sie sollten Maria weder verehren noch sie als »Mutter Gottes« bezeichnen. Im Folgenden sollen diese beiden Forderungen näher analysiert werden, um dadurch einen Einblick in die theologische Argumentation der evangelischen Missionare zu gewinnen.

Bei aller pauschalen Missbilligung der Marienverehrung geriet ein Werk auf eine besondere Weise in die Kritik der Missionare, und zwar das

55 Zur Wahl der Mariologie als Hauptthema der theologischen Debatten mit orthodoxen Gelehrten trug zweifelsohne die Tatsache bei, dass die Missionare ausgerechnet in diesem Bereich auf ein breites Argumentationsinstrumentarium zurückgreifen konnten, das im Laufe der jahrhundertelangen evangelisch-katholischen Kontroversen erarbeitet worden war. Diese Themenwahl bot den evangelischen Missionaren aber darüber hinaus einige Vorteile: Einerseits konnten sie sich - etwa durch die Kritik an die Marienverehrung - unverkennbar von den in Äthiopien tätigen Katholiken abgrenzen, andererseits aber erlaubte ihnen das Thema, auch einige zentrale Ideen der eigenen Theologie anschaulich zu machen.

56 Samuel Goвat, Tagebuch des Missionars S. Gobat, von seinem dreijährigen Aufenthalte und seinen Reisen in Abyssinien, in: MNGPM 1 (1834), S. 69-156, hier S. 97. Zur Maria als Sünderin siehe auch: Ebd., S. 98f., 133, 135f.; GobAT, Abyssinien, S. 193, 207, 244. Vgl. ähnliche Ansichten auch bei Isenberg: Isenberg, Abessinien und die evangelische Mission, Bd. 1, S. 24; ders., Abessinien und die evangelische Mission, Bd. 2, S. 28, 34f., 51.

57 Vgl. Gobats zunächst selbstbewusst und optimistisch anmutenden Eintrag im Tagebuch vom 7. Juni 1830: „Ich weiß nicht, wie weit die Reisenden Recht hatten, wenn sie behaupten: man dürfe in Abyssinien nichts gegen die Jungfrau Maria und die Heiligen sagen, wenn man sich nicht großer Gefahr aussetzen wolle; täglich stosse ich gegen ihre Vorurtheile in diesem Stücke an, und ich habe noch keinen gesehen, welcher deßhalb böse auf mich geworden wäre. [...] Sie schließen daraus, daß ich kein Schmeichler bin wie jene, und daß ich die Lüge nicht ertragen kann«. GoвAT, Abyssinien, S. 204. Doch bereits wenige Wochen später bekam er aufgrund seines offensiven Verhaltens ein großes Misstrauen zu spüren und zweifelte daran, ob die Mission mit Erfolg gekrönt werden könne. Vgl. den Tagebucheintrag vom 7. Juni 1830. Ebd., S. 212. 


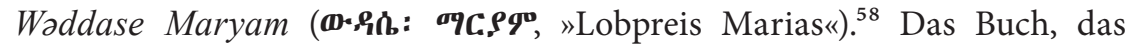
traditionellerweise Ephräm dem Syrer (ca. 306-373) zugeschrieben wird, umfasst sieben Gesänge, je einen für jeden Wochentag, und wird täglich im Gottesdienst vorgetragen. ${ }^{59}$ Das Hauptthema des Waddase Maryam ist die Inkarnation Christi; um die Geheimnisse der Menschwerdung Gottes und der immerwährenden Jungfräulichkeit Marias zu erläutern, bedient sich das Buch zahlreicher alttestamentlicher Typologien und einer symbolreichen poetischen Sprache. Die besondere Hochachtung, die das Waddase Maryam unter den orthodoxen Gläubigen genoss, veranschaulicht am besten wohl

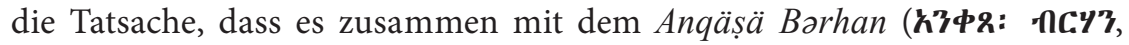
$»$ Tor des Lichtes« ${ }^{60}$ in den äthiopischen Psalter, das Mäzmurä Dawit

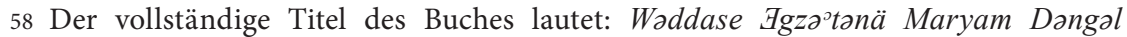

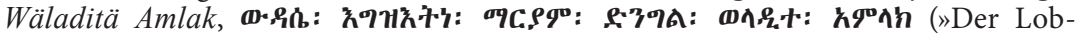
gesang unserer Herrin Maria, der jungfräulichen Gottesgebärerin«). Für eine kurze Einführung siehe: Stefan Weninger, Waddase Maryam, in: EAE 4, 2010, S. 1173f. Edition samt einer deutschen Übersetzung: Karl FrIEs, Weddase Marjam. Ein äthiopischer Lobgesang an Maria. Nach mehreren Handschriften herausgegeben und übersetzt, Leipzig 1892.

59 Wenn auch deutlich seltener, doch kommt es in der äthiopischen Tradition vor, dass das Waddase Maryam dem syrischen Poeten des 5.-6. Jahrhunderts, Simeon der

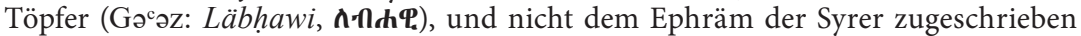
wird. Manchmal ist aufgrund der Verwechslung der beiden sogar von dem Ephräm

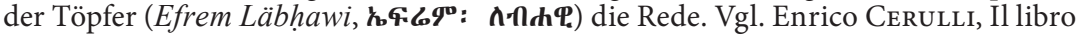
etiopico dei miracoli di Maria e le sue fonti nelle letterature del medio evo latino. Reale Università di Roma. Studi orientali, pubblicati a cura della Scuola orientale 1, Roma 1943, S. 296. Der kirchlichen Tradition zufolge war das Waddase Maryam bereits in der aksumitischen Zeit in Äthiopien bekannt, doch wahrscheinlich wurde der Text in der zweiten Hälfte des 14. Jahrhunderts aus einer heute verlorenen arabischen Vorlage ins Gəcəz übersetzt. Vgl. Roger W. Cowley, Patristic Introduction in the Ethiopian Andemta Commentary Tradition, in: OS 29 (1980), S. 39-49, hier S. 43. Der wissenschaftliche Konsens besteht darin, dass das Waddase Maryam den koptischen Theotokien nahesteht, die ihrerseits u.a. durch die Hymnen Ephräms beeinflusst wurden. Vgl. Magdi AwaD, Die sieben koptischen Theotokien, in: Joseph Tubiana/Sophia G. Vashalomidze (Hg.), Stabilisierung und Profilierung der koptischen Kirche im 4. Jahrhundert. Beiträge zur X. Internationalen Halleschen Koptologentagung 2006, Halle (Saale) 2007, S. 7-25; Verena BöLL, »Unsere Herrin Maria«. Die traditionelle äthiopische Exegese der Marienanaphora des Cyriacus von Behnesa, Wiesbaden 1998, S. 19-24; Sebastian Euringer, Der mutmaßliche Verfasser der koptischen Theotokien und des äthiopischen Weddâsê Mârjâm, in: OrChr 1 (1911), S. 215-226; Grohmann, Aethiopische Marienhymnen, S. 9-18.

60 Das Anqüșä Borhan wird am Sonntag zusätzlich zu dem entsprechenden Hymnus des Waddase Maryam gesungen. Der Titel »Tor des Lichtes« bezieht sich auf eine allegorische Auslegung der Ez 43,1-4 und Ez 44,1-2, wo unter dem Tor Maria und unter dem Licht Jesus Christus verstanden werden. Die Autorschaft wird Yared, dem berühmten Kirchenmusiker der aksumitischen Zeit, zugeschrieben. Wie Grohmann es zeigte, stellt das Anqäṣä Borhan eine Interpretation oder paraphrasierende Zusammenfassung des Sonntagshymus des Waddase Maryam dar. Text und deutsche Übersetzung: Ebd., S. 383-394. Siehe dazu auch: Getatchew Haile, Anqäșä Bərhan, 


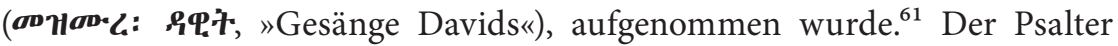
diente den Christen Äthiopiens als tägliches Gebetbuch und war mit Abstand das verbreitetste Manuskript im Land; wie kein anderes Buch prägte er die äthiopisch-orthodoxe Frömmigkeit. Viele Christen lernten die Hymnen aus dem Waddase Maryam auswendig, um mit deren Worten jederzeit beten zu können.

Die tiefe Verankerung dieser mariologischen Hymnen im Glaubensleben der äthiopisch-orthodoxen Christen erregte die Aufmerksamkeit der europäischen Missionare. ${ }^{62}$ Ihre Stellungnahmen hatten allerdings einen ausgeprägt missbilligenden Charakter: Sie sprachen von »unanständigsten Specialien $\aleph^{63}$ (Carl Isenberg) und »viele[n] Irrthümer ${ }^{64}$ (Samuel Gobat), die das Waddase Maryam enthalte. Doch nicht nur an dem Inhalt der Hymnen nahmen die Missionare Anstoß, sondern auch an der Tatsache, dass das Waddase Maryam ein Teil des äthiopischen Psalters war. Dies schien ihren grundsätzlichen Vorwurf, die Äthiopier würden keine ausreichende Unterscheidung zwischen dem »Wort Gottes« und den "Schriften der Menschen « machen, bestens zu bestätigen. Die »Schriften der Menschen«, auf die sie die Verehrung Marias zurückführten, seien im Gegensatz zum »Wort Gottes« fehlerhaft, und zwar »besonders seit dem vierten Jahrhundert «. ${ }^{65}$ Diese Aussage zielte darauf ab, den Stellenwert der für die äthiopisch-orthodoxe Theologie bedeutsamen Texte des patristischen Zeitalters, einschließlich das Waddase Maryam, zu mindern. Doch für die Begründung dieses Standpunktes führten sie keine Argumente an, die den Inhalt der sogenannten »Schriften der Menschen « betreffen, sondern versuchten, die Kirchenväter, denen diese Texte zugeschrieben werden, als wenig tugendhaft und deswegen auch

in: EAE 1, 2003, S. 278f.; Christopher LAsH, »Gate of Light«. An Ethiopian Hymn to the Blessed Virgin (Part I), in: ECR 4 (1972), S. 36-46; ders., "Gate of Light«. An Ethiopian Hymn to the Blessed Virgin (Part II), in: ECR 5 (1973), S. 143-156.

61 Das Mäzmurä Dawit oder einfach Dawit (-9中.中) stellt ein Kompendium mit einer erstaunlich stabilen manuskriptologischen Tradition dar. Nahezu alle Manuskripte enthalten außer dem Psalterium (bestehend aus 151 Psalmen) auch Mähalayä Näbiyat,

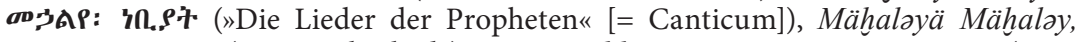

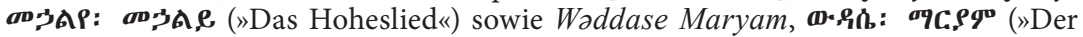

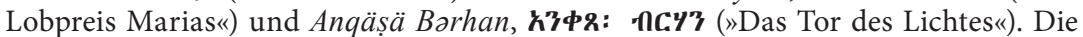
Psalmen werden auf die sechs Wochentage verteilt, die biblischen Cantica des Alten und Neuen Testaments am Sonntag gesungen. Das Mäzmurä Dawit ist mit Abstand das verbreitetste Manuskript in Äthiopien. Vgl. Marilyn E. Heldman, Psalter, in: EAE 4, 2010, S. 231-233; Sophia Dege-Müller, The Ethiopian Psalter. An Introduction to Its Codicological Tradition, in: The Anglo-Ethiopian Society News File Winter 2014, S. 16-22, hier S. 17.

62 Gobat, Abyssinien, S. 301. Zur Rolle des Waddase Maryam in der Glaubenspraxis der äthiopischen Christen: Heyer, Die Kirche Äthiopiens, S. 26, 71f., 178, 195.

63 Isenberg, Abessinien und die evangelische Mission, Bd. 1, S. 31.

64 Gobat, Tagebuch, S. 155.

65 Ebd. 
als wenig vertrauenswürdig zu präsentieren. Es galt also die Autorität der Autoren, die für das theologische Selbstverständnis der äthiopisch-orthodoxen Kirche von zentraler Bedeutung waren, in Frage zu stellen. So diagnostizierte Samuel Gobat beispielsweise bei Johannes Chrysostomos (ca. 349407) "manche Merkmale von Stolz und Eigenliebe«, Kyrill von Alexandria (ca. 376-444) ${ }^{66}$ unterstellte er hingegen einen »fleischliche[n] Eifer und ein[en] unchristliche[n] Verfolgungsgeist $«{ }^{67}$ Daraus leitete Gobat ab, dass auch ihre Schriften falsch und schädlich seien. ${ }^{68}$ Die Äthiopier seien folglich »bloße[n] Namenchristen« und solange sie »die Schriften der Menschen dem Worte Gottes gleichstellen«, würden sie »eine Beute des Verderbens « sein. ${ }^{69}$

Diese Position erlaubte es, unerwünschte theologische Diskussionen zu vermeiden. Waren die Missionare mit einer Frage über ein theologisches oder liturgisches Werk konfrontiert, lenkten sie das Gespräch von den Inhalten des Werkes auf dessen (mutmaßlichen) Autor ab, um dann zu zeigen, dass auch er nur ein Sünder gewesen sei. Diese Argumentation wurde auch in Bezug auf das Waddase Maryam verwendet. Dies zeigt ein Gespräch

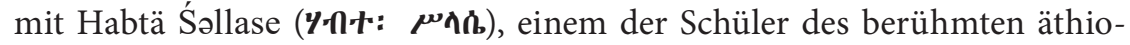

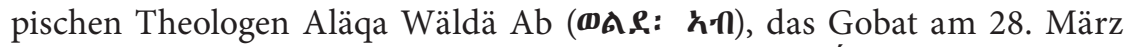
1830 in seinem Tagebuch dokumentierte. ${ }^{70}$ Als Habtä Śllase den Missionar fragte, ob sie in ihrer Kirche auch das Waddase Maryam verwendeten, antwortete Gobat:

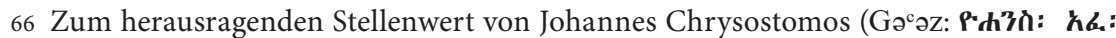

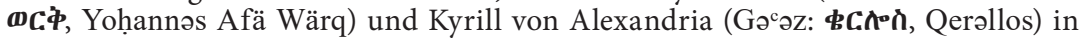
der äthiopischen Tradition siehe: Witold WiтA KowsKi, John Chrysostom, in: EAE 3, 2007, S. 293-295 und ders., Cyril of Alexandria, in: EAE 1, 2003, S. 844f.

67 Goвat, Tagebuch, S. 155.

68 Gobat setzte »das leibliche und geistliche Elend« des Landes damit in Verbindung, dass die Äthiopier den Schriften der Heiligen Väter übertriebene Aufmerksamkeit schenkten. Ebd.

69 Ebd.

70 Aläqa Wäldä $\mathrm{Ab}$ war einer der renommiertesten Exegeten der äthiopisch-orthodo-

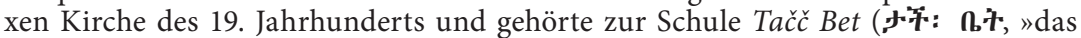
Unterhaus«; auch als die Gondär-Schule bekannt). Aufgrund seiner Talente in der Auslegung der sakralen Texte wurde er als »der Vater von Andəmta« bekannt. Sein Mämharan ( $\left.\boldsymbol{\sigma o g}^{\mathbf{D}} \mathbf{6} \mathbf{6} \mathbf{3}\right)$, die Lehrer-Schüler-Genealogie, zeichnet eine beeindruckende Linie der großen äthiopischen Gelehrten: Sein unmittelbarer Lehrer war der berühmte Śənä Krəstos, welcher seinerseits der Schüler von Mämhər Esdros war, der von $\exists$ Gčçäge Qalä Awadi unterrichtet wurde. Mit jedem dieser Namen ist eine Epoche in der Entwicklung der äthiopisch-orthodoxen Exegese verbunden. Tedros Abraha, Exegesis, in: EAE 2, 2005, S. 472-474, hier S. 473. Vgl. die Beschreibung der ersten Begegnung mit Wäldä Ab im Tagebuch Gobats (Eintrag vom 31. März 1830): »Diesen Morgen machte ich meinen ersten Besuch bei dem Alaka Waldab, welcher in ganz Abyssinien seiner Kenntnisse wegen gerühmt wird. Ich fand in ihm einen gutmüthigen Greis, der lahm ist, und sich alsobald auf sein Bett niedersetzte, um mir die Hand zu küssen, die er auch so zärtlich drückte, wie wenn er seit vielen Jahren mich gekannt hätte. Kaum war ich einen Augenblick bei ihm, so fing er an, mir zu sagen, wie er selbst und alle andern Abyssinier mit ihm gar schlechte Leute wären, welche in 
»Ich habe es gesehen, antwortete ich, aber wir nehmen dasselbe nicht als kirchlich an; denn wir haben keinen Beweis dafür, daß sein Inhalt von Gott eingegeben ist; auch wissen wir, daß es erst mehrere Jahrhunderte nach dem Tode der Maria geschrieben ist." - »Aber der heilige Ephrem ist ja sein Verfasser? « versetzte er. - „Ob Ephrem ein Heiliger war oder nicht, das weiß ich nicht. Ich glaube, es war viel Gutes in ihm; aber er ist einer von denen, die sich in Dinge mischen, die sie nicht gesehen haben, und Sachen behaupten, die sie nicht wissen. Vielleicht sind es seine Schriften, welche den Koran der Muselmanen erzeugt haben; wenigstens gebraucht sie Muhamed als Mittel, die Schüler desselben auf seine Seite zu bringen «. ${ }^{71}$

Die Argumentation Gobats zeigt, dass er nicht an einer Diskussion über den Inhalt des Waddase Maryam interessiert war. Vielmehr versuchte er Ephräm - dessen Autorschaft der mariologischen Hymnen er nicht in Frage stellte - in den Augen seines äthiopischen Gesprächspartners zu diskreditieren, indem er ihn indirekt für die Entstehung des Islam verantwortlich machte. Die These, Muhammed hätte Vieles von den Schriften Ephräms übernommen, stammte von dem britischen Orientalisten und anglikanischen Geistlichen Samuel Lee (1783-1852). ${ }^{72}$

Nicht nur mit den Lobpreisungen Marias rangen die protestantischen Missionare, auch die Bezeichnung "Mutter Gottes" - auf Gəcəz Wäladitä

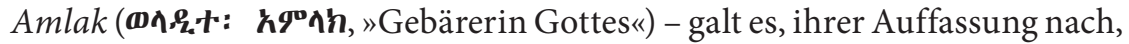
abzuschaffen. ${ }^{73}$ An der Tagesordnung war daher der Versuch, die orthodoxen Gläubigen davon abzuhalten, Maria als die »Mutter Gottes« anzuspre-

allen Kenntnissen weit zurückstehen. Ich antwortete ihm: `Ich der ganzen Welt seyen die Menschen nicht gut; aber selbst die Verkehrtheit unseres Herzens könne ein Mittel für uns werden, die Liebe Gottes gegen uns desto höher zu schätzen. Gott fordere von uns eben nicht viel Kenntnisse, aber viel Liebe. - >Ja, ja, fiel er mir ins Wort, wenn wir nur mehr Liebe zum Herrn und unter einander hätten! - Er wird für den gelehrtesten Mann in Abyssinien gehalten. Wirklich ist er auch mit allen Schriften wohl bekannt, welche in der äthiopischen Sprache vorhanden sind. Mit großem Fleiß hat er es auch dahin gebracht, daß er die arabische Sprache ziemlich fließend spricht. Als wir von einander schieden, bat er mich, ihn recht oft zu besuchen«. GoвAT, Tagebuch, S. 102.

71 Ebd., S. 95.

72 Diese Idee äußerte Lee zum ersten Mal im Kommentar zu dem von ihm herausgegebenen Briefwechsel zwischen dem CMS-Missionar Henry Martyns (1781-1812) und den muslimischen Gelehrten. Samuel LeE (Hg.), Controversial Tracts on Christianity and Mohammedanism by the Late Rev. Henry Martyn and Some of the Most Eminent Writers of Persia Translated and Explained, Cambridge 1824, S. 124-138. Lee stand der Church Missionary Society nahe und war aus diesem Zusammenhang Samuel Gobat auch persönlich bekannt; später wurde Lee sogar zum Herausgeber der englischen Übersetzung der Tagebücher des Schweizer Missionars.

73 In der äthiopischen Tradition verwendet man nicht nur die Bezeichnung »Mutter Gottes«, sondern auch einige weitere daraus abgeleitete Ehrentitel Marias, wie bspw.

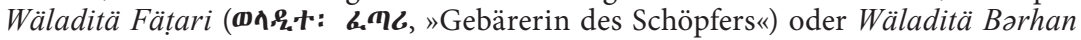

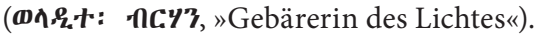


chen. Stattdessen sollte man sie als »Mutter Jesu« bezeichnen. ${ }^{74}$ Ausgerechnet dieser Vorschlag dürfte erheblich zur Selbst-Diskreditierung der Missionare

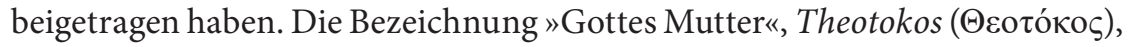
die mit der Theologie Kyrills von Alexandria verbunden war, war das Erbe des Ökumenischen Konzils von Ephesus von 431 und somit mit dem Selbstverständnis der äthiopischen Kirche und dessen Christologie auf engste verbunden. Gobats Vorschlag, auf diese Bezeichnung zu verzichten, richtete sich gegen die Theologie Kyrills von Alexandria und rückte die Missionare - so aus der Perspektive der äthiopisch-orthodoxen Theologen - in die Nähe von Nestorius (ca. 381-451), der in der äthiopischen Tradition ein Feindbild darstellte. Im theologischen Diskurs verfestigte sich sogar der Name GinmCP.n, Nastoryos, oder "inTC. Nastaros (so wie auch der daraus abgeleitete Adjek-

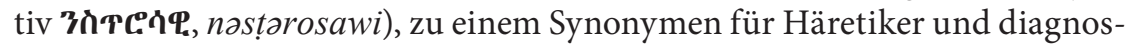
tizierte eine religiöse Devianz. ${ }^{75}$

Dabei ist Gobats Eifer, gegen die Bezeichnung »Mutter Gottes« zu polemisieren, allein auf seine persönlichen theologischen Ansichten zurückzuführen. Denn sowohl die anglikanische Kirche, in dessen Auftrag er in Äthiopien tätig war, als auch die lutherische Kirche, zu der die restlichen Missionare gehörten, bekennen sich ausdrücklich zur Bezeichnung "Mutter Gottes «. ${ }^{76}$ Dies tat auch Carl Isenberg, als er kurz vor seiner endgültigen Ausweisung, am 21. Mai 1842, vor einer Versammlung der Geistlichen und Würdenträger von Təgray die Fragen über seinen Glauben beantworten musste:

Wir betrachten die Jungfrau Maria als die grösste unter allen Weibern, weil sie gewürdigt worden sei, den Heiland der Welt zu gebären; und da er Gottmensch sei, so haben wir nichts dagegen, dass sie Mutter Gottes genannt werde, wie in dem, auch von uns anerkannten, Concil von Ephesus geschehen sei; aber von ihrer Fürbitte wissen wir nichts, da das geoffenbarte Wort Gottes uns nichts darüber sage. ${ }^{77}$

Dass ausgerechnet die Figur Marias eine zentrale Rolle in dieser transkonfessionellen Differenzaushandlung spielte, verdeutlichen auch die äthiopischorthodoxen Konstruktionen des europäischen Protestantismus.

74 Vgl. Gobat, Tagebuch, S. 94f., 97-99, 133f.

75 Gianfranco Fiaccadori, Nestorius, in: EAE 3, 2007, S. 1169-1171, hier S. 1170.

76 Siehe die Konkordienformel (1577), VIII.7: »Daher gleuben, leren und bekennen wir, das Maria nicht ein blossen, purlautern Menschen, sondern den wahrhafftigen Son Gottes empfangen und geboren habe, darumb sie auch recht die Mutter Gottes genennet wird und auch wahrhafftig ist«. Dingel (Hg.), Die Bekenntnisschriften, S. 1270.

77 Isenberg, Abessinien und die evangelische Mission, Bd. 1, S. 34. 


\subsection{Die »Feinde Marias« (Șärä Maryam):}

Europäischer Protestantismus als das Andere

Im Gegensatz zu protestantischen Ansichten bezüglich des äthiopisch-orthodoxen Christentums, die sich in zahlreichen Texten niederschlugen, lässt sich die äthiopische Wahrnehmung des europäischen Anderen aufgrund der ungünstigen Quellenlage deutlich schwerer rekonstruieren. Das handschriftlich überlieferte amharische Buch der Beseitigung der Lüge, die über den gerechten Abunä Yacaqcob erzählt wurde stellt den einzigen bis jetzt bekannten äthiopischen Text dar, der die frühe Begegnung zwischen den evangelischen Missionaren und äthiopisch-orthodoxen Christen thematisiert. ${ }^{78}$ Die Ankunft der ersten zwei evangelischen Missionare, Samuel Gobat und Carl Isenberg, in Äthiopien und die Reaktion der orthodoxen Bevölkerung auf sie wird dort folgendermaßen dargestellt:

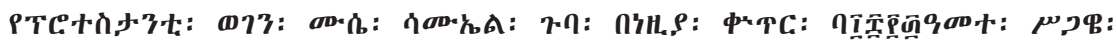

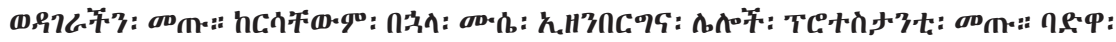

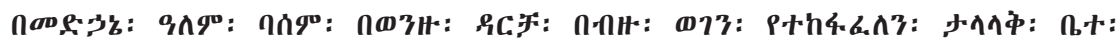

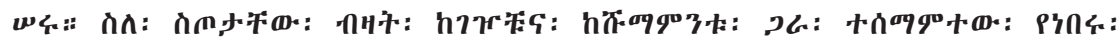

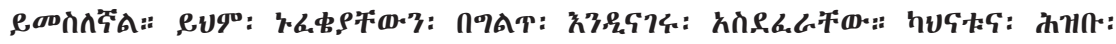

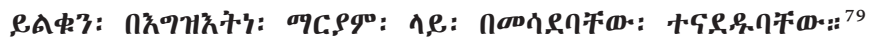

Im Jahre 1830 der Inkarnation kam Monsieur Samuel Guba [= Samuel Gobat] von den Protestanten zu unserem Land. Nach ihm kamen Monsieur Izänbärg [= Carl Isenberg] und andere Protestanten. Sie bauten große Häuser, die in viele Räume geteilt waren, in Adwa bei Mädhane Aläm und auf dem Fluss Assäm. Es scheint so zu sein, dass sie mit Hilfe zahlreicher Geschenke eine Vereinbarung mit den Machthabern und den Ältesten getroffen haben. Dies gab ihnen Mut, über ihre Häresie offen zu sprechen. Die Priester und das Volk wurden besonders durch Lästerungen gestört, die sie an unsere Herrin Maria richteten. ${ }^{80}$

78 Dieser amharische Text ist im Manuskript »Eth. 27« des Instituts für Orientstudien der Russischen Akademie der Wissenschaften überliefert. Der Text wurde vor Kurzem samt einer russischen Übersetzung publiziert: С. Б. Чернецов / В. М. Платонов, »Книга уничтожения лжи, возведенной на праведного Абуну Иакова« Такла Хайманота Такла Эгзиэ - одно из первых произведений амхарской литературы, in: Христианский Восток III (IX) (2001), S. 172-268. Der Autor des Werkes ist

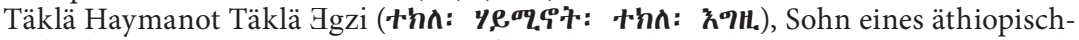
orthodoxen Priesters. Unter dem Einfluss des italienischen Lazaristen Justinus de Jacobis (1800-1860) konvertierte er jedoch zum Katholizismus.

79 Manuskript »Eth. 27« des Instituts für Orientstudien der Russischen Akademie der Wissenschaften, fol. $42 \mathrm{f}$.

80 Übersetzung - S.P. 
An einer anderen Stelle verdeutlicht dieses Werk, dass die Frage der Rolle Marias so kontrovers diskutiert geworden sei, dass einige orthodoxe Christen sogar in Zweifel gezogen hätten, dass die Missionare überhaupt Christen gewesen wären. ${ }^{81}$ Des Weiteren dokumentiert dieser Text die erste orthodoxe Konzeptualisierung des Protestantismus, indem er erzählt, dass orthodoxe

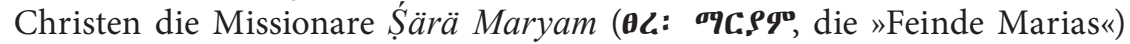

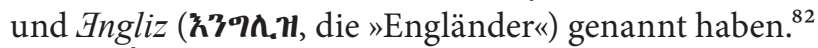

Der Șärä Maryam-Topos war nicht neu, vielmehr stammte er aus den mittelalterlichen theologischen Auseinandersetzungen innerhalb der äthiopischen Kirche. Er stellte somit eine bereits bestehende Kategorie dar, die nun auf die europäischen Missionare angewendet wurde, um sie in die äthiopisch-orthodoxe Denkwelt zu integrieren. In diesem Zusammenhang stellt sich jedoch die Frage: Welches theologische Programm verbirgt sich hinter diesem Topos in der äthiopisch-orthodoxen Tradition.

Die Verbreitung der Bezeichnung Șärä Maryam fand im 15. Jahrhundert statt, und zwar als Folge der theologischen Auseinandersetzungen zwischen

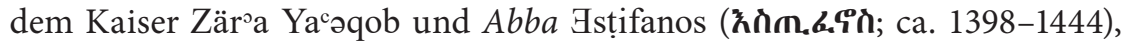
der die durch den Kaiser initiierten Kirchenreformen, vor allem aber die Verstärkung des Marienkultes, nicht in vollem Maße akzeptieren wollte.

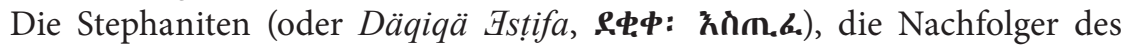
Abba Estifanos, wurden durch die Vertreter der Hofkirche als »Feinde Marias« bezeichnet und verfolgt. Es ist anzunehmen, dass der Nachhall der Polemik mit den Stephaniten und der Topos der Marienfeinde den äthiopisch-orthodoxen Gläubigen des 19. Jahrhunderts vor allem aus den liturgischen Texten bekannt war. Die populärste liturgische Hymne, die die Bezeichnung Șärä Maryam tradiert und somit einen Einblick in die Semantik der damit markierten religiöser Devianz ermöglicht, ist zweifellos das

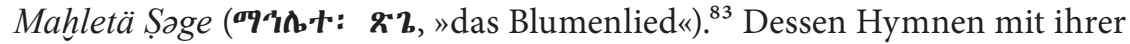

81 Vgl. ebd., fol. 43.

82 Vgl. ebd., fol. 53 und fol. 108.

83 Edition: Grohmann, Aethiopische Marienhymnen, S. 47-321. Für eine Einführung siehe: Навтемichael Kidane, Mahletä Șəge, in: EAE 3, 2007, S. 660f. In der Manuskriptentradition wird die Autorschaft des Textes abweichend entweder einem gewissen Abba Şəge Dəngel, Abba Gäbrä Maryam oder Abba Șəge Bərhan zugeschrieben. In einigen Handschriften fungiert ein »konvertierter Jude» (= Stephanit), Abba Gäbrä Maryam, von Däbrä Hanta als Koautor. Vgl. Getatchew Haile, A Catalogue of Ethiopian Manuscripts Microfilmed for the Ethiopian Manuscript Microfilm Library, Addis Ababa, and for the Monastic Manuscript Microfilm Library, Collegeville, Collegeville 1979, Bd. IV: Project Numbers 1101-1500, S. 329; ders., A Catalogue of Ethiopian Manuscripts Microfilmed for the Ethiopian Manuscript Microfilm Library, Addis Ababa, and for the Monastic Manuscript Microfilm Library, Collegeville, Collegeville 1981, Bd. V: Project Numbers 1501-2000, S. 446 und

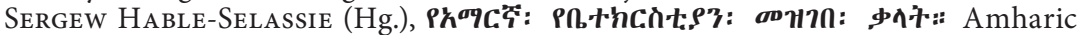
Church Dictionary, Heidelberg u.a. 1981 A. M. [1989 A.D.], Bd. 1, S. 481. Plausibel 
an poetischen Metaphern reichen Sprache, die das Wirken Gottes durch

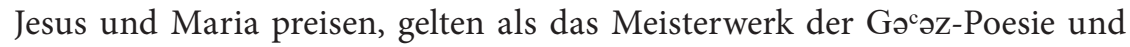
werden in der Kirche jährlich während der Zämänä Sage (Han': $\mathbf{q} \mathbf{2}$, »die Blumenzeit«) gesungen. ${ }^{84}$

Dabei hat das Buch den Anspruch, eine Art »neutestamentlicher Psalter» zu sein. ${ }^{85}$ Diese Symbolik wird dadurch zum Ausdruck gebracht, dass die

erscheint die Annahme Grohmanns, dass das Buch - mindestens zum Teil - durch einen anonymen Autor von bereits vorhandenen Strophen kompiliert wurde. GROHMANN, Aethiopische Marienhymnen, S. 65. Kürzlich wurde allerdings die Hypothese aufgestellt, dass der Text aus der Feder des berühmten Theologen Abba Giyorgis von Sägla stammen sollte. Fessehatzion Andemariam, Mariology in the "Mahleta Sege«. Abba Giyorgis Gassičča’s »Hymn of the Flower«, Salesian Pontifical University, Rome 1994. Diese Hypothese ist allerdings kaum zu halten, ohne die gesamte Periodisierung des gut dokumentierten Lebens von Abba Giyorgis von Sägla neu zu ordnen. Für die Abfassungszeit postuliert Adolf Grohmann als Terminus post quem

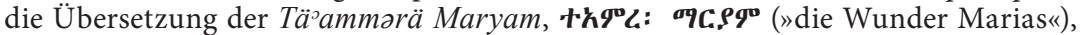
und die Komposition des Organon in den 1440er Jahren, die dem Autor bekannt waren. Auch die Erwähnung des Konzils von Däbrä Məțmaq (1450) im Text weist darauf hin, dass er in der zweiten Hälfte des 15. Jahrhunderts, in der Regierungszeit von Zäroa Yacəqob oder bald danach, verfasst wurde. Grohmann, Aethiopische Marienhymnen, S. 64. Zwei Manuskripte (EMML 1942, fol. 82a und EMML 1126, fol. 38b), die bis jetzt weder publiziert noch ediert oder übersetzt waren, beweisen jedoch, dass das Mahletä Sage in der zweiten Hälfte des 15. Jahrhunderts nicht nur bekannt geworden war, sondern ihre Verwendung im Gottesdienst bereits zum Gegenstand einer theologischen Auseinandersetzung wurde. Vgl. Getatchew Haile, Catalogue, Bd. V, S. 445f.; ders., Catalogue, Bd. IV, S. 32.

84 Als »Blumenzeit« bezeichnet man einen vierzigtägigen Abschnitt des liturgischen Kalenders der äthiopisch-orthodoxen Kirche zwischen dem 26. Mäskäräm und dem 5. Hədar (=6. Oktober bis 14. November). Vgl. Fritsch, The Liturgical Year, S. $116 \mathrm{f}$. In der Zeit wird insbesondere an die Flucht der Heiligen Familie nach Ägypten gedacht. Die Abschnitte des Textes werden jeden Tag während der Vigil in der Kirche vorgetragen, sodass das gesamte Blumenlied innerhalb einer Woche vollständig gelesen wird. Der Hymnus verteilt sich in folgender Weise auf die Tage der Woche: Montag: Strophen 1-22; Dienstag: Strophen 23-45; Mittwoch: Strophen 46-67; Donnerstag: Strophen 68-89; Freitag: Strophen 90-112; Samstag: Strophen 113-133; Sonntag: Strophen 134-156. Grohmann, Aethiopische Marienhymnen, S. 62.

85 Die Auffassung von dem Mahletä Şage als einer mariologischen Hymne, die in der Literatur inzwischen fest verankert ist, wird dem Text nicht gerecht, denn die mariologischen Ausführungen sind nicht isoliert, sondern vielmehr in einem engen Zusammenhang mit der Christologie zu deuten. Die Symbolik der Blume, die dem Buch den Namen gab, geht laut einer amharischen Einführung in die Theologie des Buches auf die Stelle Jes 11,1 zurück: "Und es wird ein Reis hervorgehen aus dem Stamm Isais und ein Zweig aus seiner Wurzel Frucht bringen«. Da diese Stelle laut der äthiopisch-orthodoxen Exegese auf Maria (»der Zweig«) und Jesus Christus (»die Frucht«) hinweisen soll, bezieht sich im Mahletä Șəge das äthiopische Wort Șəge, 8. 2 sowohl auf Maria als auch auf Jesus. Siehe die amharische Einführung in die Geschichte und die Theologie des Mahletä Şage in Ms. EMML 1312, fol. 34a-40b. Vgl. Getatchew Haile, Catalogue, Bd. IV, S. 329f. Um eine Verwirrung bei Nebeneinandervorkommen beider Namen zu vermeiden, hat Grohmann in seiner Übersetzung das Wort Sage, $\mathbf{8} \mathbf{z}$ in Bezug auf Maria stets als »Blume« und in Bezug auf Jesus als »Blüte« wiedergegeben. 
Zahl der Strophen im Mahletä Șəge, 151, der Zahl der Psalmen in der äthiopischen Version des Psalters gleicht. ${ }^{86}$ Als ein weiteres Element der Nachahmung des Psalters kann die Verwendung der Feindsymbolik betrachtet werden. In der Poetik des Mahletä Şage nimmt die literarische Figur des

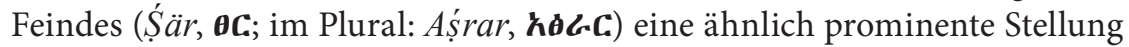
wie in den sogenannten $»$ Feind «- oder $»$ Vergeltungspsalmen $«$ ein. ${ }^{87}$ Für die Schilderungen des Psalters ist charakteristisch, dass die Feinde nicht nur als Exponenten von Gefahr und Unglück fungieren und das Schicksal des Beters bedrohen, sondern dass sie auch das Gottesbild infrage stellen. ${ }^{88}$ Daher wird das Wirken des Feindes in den Psalmen als widergöttlich eingeordnet. ${ }^{89}$ Das Mah̆letä Șəge setzt dieses theologische Verständnis des Feindes grundsätzlich fort, wendet ihn jedoch auf die zeitgenössischen Auseinandersetzungen um die Rolle Marias in der göttlichen Heilsökonomie an. Aus diesem Grund wurde aus dem oft stereotypisierten Feindbild des Psalters, der den konkreten Inhalt der Feindschaft in der Regel offen lässt, nun die "Feinde Marias"

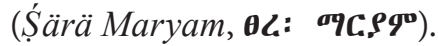

Dabei ist nicht zu vergessen, dass das Mahletä Şəge keine theologische Abhandlung im klassischen Sinne des Wortes war, sondern ein liturgischer Text. Dementsprechend war er vor allem für die regelmäßige Verwendung im Gottesdienst konzipiert und zielte darauf ab, vor allem zur Selbstvergewisserung der eigenen Glaubensgemeinschaft beizutragen. Das Feindbild Șärä Maryam sollte ebenso dazu dienen, die Polemik über die Mariologie in der äthiopisch-orthodoxen Kirche für endgültig abgeschlossen zu erklären und die Stephaniten sowie all diejenigen, die mit den Entscheidungen der äthiopischen Reichskirche nicht einverstanden waren, als Ketzer zu stigmatisieren. ${ }^{90}$

86 Vgl. Stefan Strelcyn, Le Psaume 151 dans la tradition Éthiopienne, in: JSSt 23 (2) (1978), S. 316-329.

87 Vgl. dazu Dharmakkan Dhanaraj, Theological Significance of the Motif of Enemies in Selected Psalms of Individual Lament, Wiesbaden 1992; Christian BÜRNING, »Gott möge ihnen einen Blitz ins Gesäß jagen!« Zu den Feindpassagen in den Psalmen, in: EuA 82 (2006), S. 128-138; Peter Riede, Im Netz des Jägers. Studien zur Feindmetaphorik der Individualpsalmen, Neukirchen 2000; und Peter RIEDE, Die Sprache der Bilder. Zur Bedeutung und Funktion der Metaphorik in den Feindpsalmen des Alten Testament am Beispiel der Psalmen 57 und 59, in: Ders. (Hg.), Schöpfung und Lebenswelt. Studien zur Theologie und Anthropologie des Alten Testaments, Leipzig 2009, S. 55-74.

88 Vgl. Othmar KeEL, Feinde und Gottesleugner. Studien zum Image der Widersacher in den Individualpsalmen, Stuttgart 1969. Dies findet ihre höchste Steigerung in der Behauptung, dass es keinen Gott gebe (vgl. Ps 10,4).

89 Christina Kumpmann, Schöpfen, Schlagen, Schützen. Eine semantische, thematische und theologische Untersuchung des Handelns Gottes in den Psalmen, Göttingen 2016, S. 173.

90 Zwar richtete sich die Kritik an die Stephaniten, doch das Ausmaß der Polemik und selbst die Notwendigkeit, diesem Thema im Mahlletä Șəge so viel Aufmerksamkeit 
Was genau zeichnete die »Feinde Marias« aus? Im Text findet man einige konkrete Eigenschaften, die ihnen zugeschrieben und zum Vorwurf gemacht werden. Ein Charakteristikum besteht darin, dass sie sich weigern, das Buch

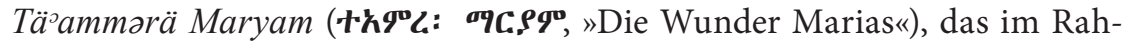
men der Reform Zär’a Yacəqobs verbreitet wurde und bis heute die äthiopisch-orthodoxe Frömmigkeit prägt, zu akzeptieren. ${ }^{91}$ Eine weitere zentrale Eigenschaft der »Feinde Marias" laut dem Maḩletä Șəge sei die Unwilligkeit, die Ikonen Marias zu verehren.

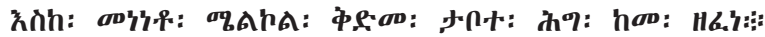

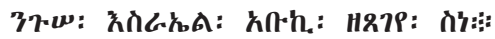

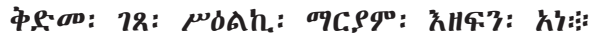

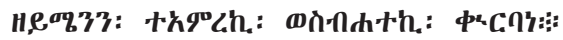

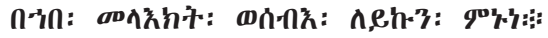

Wie vor der Bundeslade tanzte, bis ihn Michal verachtete, Der König Israels, dein Vater, der die Schönheit sprießen ließ, ${ }^{92}$

(So) tanze ich vor deinem Bild, Mariam.

Wer deine Wunder und die Darbringung deines Lobgesanges verachtet, Sei bei den Engeln und Menschen verachtet. ${ }^{93}$

Diese zwei zentralen Eigenschaften trafen auch auf die evangelischen Missionare zu. Somit ließ sich das Șärä Maryam-Topos auf die Protestanten anwenden und sie dadurch in ein bekanntes theologisches Schema einfügen. Von dem Erfolg dieser Kontextualisierung zeugt die Tatsache, dass die orthodoxen Christen bis heute die Protestanten nicht selten als Şärä Maryam bezeichnet. ${ }^{94}$

Die Anwendung dieses Topos erklärt zudem, warum einige orthodoxe Gläubige die evangelischen Missionare nicht für Christen hielten. Denn laut Mahletä Șəge seien die Feinde Marias also zugleich auch die Feinde ihres

zu schenken, zeigt, dass es nicht nur die Schüler von Gsțifanos im engen Sinne waren, die mit dessen Ideen sympathisierten, sondern auch andere Gläubige.

91 Es gibt bis jetzt weder eine kritische noch eine vollständige Edition dieses Textkorpus. Zur Einführung und Bibliographie siehe: Ewa BALICKA-Witakowska / Alessandro BAUsı, Tä’ammərä Maryam, in: EAE 4, 2010, S. 789-793.

92 Vgl. 2 Sam 6,16.

93 Grohmann, Aethiopische Marienhymnen, S. 82 (Text), S. 83 (Übersetzung).

94 Vgl. bspw. Agostinos Da Нево, Gli Etiopi e la Madonna. Aspetti dogmatici e devozionali, in: Mar. 21 (1) (1970), S. 369-403, hier S. 396; Michael Kleiner, Feinde Marias, der 500-Jahre-Missionsplan und 303 Fragen zum Thema »Wer ist Christus?«. Eindrücke von und Erfahrungen mit Religion aus einem Jahr in Äthiopien, in: Karl Pinggéra (Hg.), Tradition und Wandel im Land der Königin von Saba. Ansichten aus und zu Äthiopien, Hofgeismar 2011, S. 9-30, hier S. 28; Assta Bereket Gettu, Fear Not, for I am with You, Pittsburgh PA 2017, S. 546. 
Sohnes, Jesus, und dementsprechend keine Christen, sondern "Juden«,

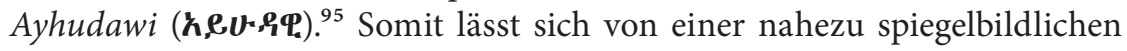
Erwiderung der missionarischen Alteritätskonstruktion der äthiopischen Orthodoxie als einer »jüdischen « Religion sprechen.

Ein weiteres aufschlussreiches Dokument zur Aushandlung der religiösen Differenz zwischen den ersten evangelischen Missionaren und den orthodoxen Christen Äthiopiens ist das 1841 in London publizierte amharisch-englische und englisch-amharische Wörterbuch von Carl Isenberg. ${ }^{96}$ Während der amharisch-englische Teil des Werkes den eigentlichen Sprachgebrauch dokumentiert, führt der englisch-amharische Teil unter anderem auch neue, auf Amharisch bis zu diesem Zeitpunkt noch fehlende Begriffe, ein. Dementsprechend reflektiert das Wörterbuch zum einen (im amharisch-englischen Teil), welche Bezeichnungen des Protestantismus in Äthiopien zu dem Zeitpunkt der Vorbereitung des Buches verwendet wurden, und zum anderen (im englisch-amharischen Teil) in welchen Kategorien die evangelischen Missionare versuchten, die entsprechenden Begriffe in die äthiopisch-orthodoxe Denkwelt einzuführen.

Das Wort "Reformation« übersetzte Isenberg ins Amharische mit Hilfe

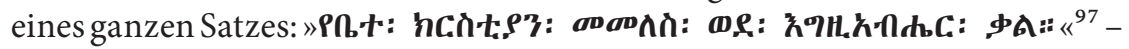
$»$ Rückkehr der Kirche zum Wort Gottes«. Hingegen, was den Begriff »Protestant« anging, entschied er sich dafür, ihn einfach in die äthiopische Schrift zu transliterieren. Doch bereits eine inkonsistente Schreibweise des Wortes

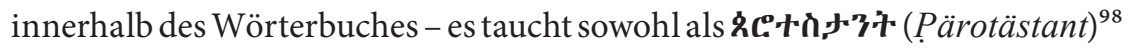

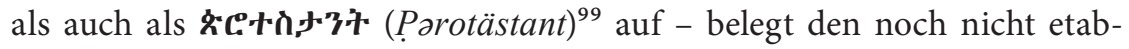
lierten Status dieser Bezeichnung. Um das Wort verständlich zu machen, schlug Isenberg seinen äthiopischen Lesern die folgende kurze Definition

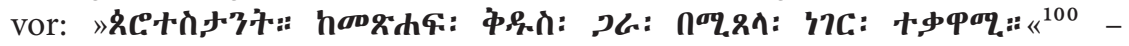
»Protestant; derjenige, der sich gegen die der Heiligen Schrift widersprechen-

Vgl. Grohmann, Aethiopische Marienhymnen, S. 84 (Text), S. 85 (Übersetzung). Zur Semantik des Begriffs "Juden" in der äthiopischen Theologie siehe: Steven Kaplan, Ayhud, in: EAE 1, 2003, S. 408-410 und Sophia Dege-Müller, Between Heretics and Jews. Inventing Jewish Identities in Ethiopia, in: Entangled Religions 6 (2018), S. 247-308.

96 Das Wörterbuch verfasste Isenberg nicht nur aus wissenschaftlichem Interesse, sondern vielmehr als ein Lehrmittel für die künftigen Missionare. Es war gedacht als "a channel for conveying the salutary influences of Evangelical Doctrine and of Christian Civilization, from enlightened Europe, over benighted Abyssinia!« Charles William Isenberg, Dictionary of the Amharic Language. In Two Parts: Amharic and English, and English and Amharic, London 1841, S. VII. Dabei war dies eines der ersten Wörterbücher der amharischen Sprache überhaupt.

97 Ebd., S. 167.

98 Ebd., S. 161.

99 Ebd., S. 187.

100 Ebd., S. 161. 
den Missetaten zur Wehr setzt«. Dieser Eintrag zeigt, dass die Missionare sich bemühten, den Protestantismus nicht konfessionell zu definieren, sondern ihn vielmehr als eine bestimmte Grundhaltung auszulegen. Gleichwohl bot diese Definition keinen eigenständigen Inhalt, sondern erklärte den Protestantismus ausschließlich durch die Negierung der »Misstaten «. ${ }^{101}$

Jedoch fand die von den Missionaren bevorzugte Selbstbezeichnung

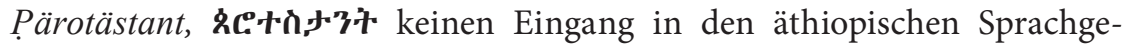
brauch. Wie Isenberg selbst in seinem Wörterbuch dokumentieren musste,

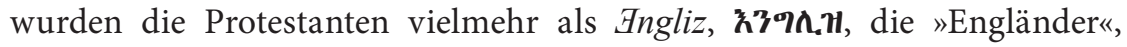
benannt. ${ }^{102}$ Insofern kann von einer bemerkenswerten Ausdifferenzierung in der äthiopischen Wahrnehmung der Europäer die Rede sein. Bis dahin

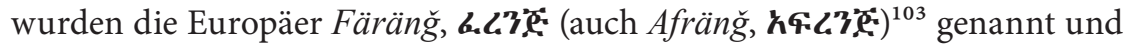
ihre nationale (beziehungsweise ethnische) und religiöse Identität als zusammenhängend betrachtet, was daraus resultierte, dass diese Bezeichnung die Zugehörigkeit zur römisch-katholischen Kirche implizierte. Die Ankunft der Protestanten zeigte jedoch die Grenzen dieses Begriffes auf und machte eine Ergänzung nötig. Die Wahl des Wortes Angliz dafür ist nachvollziehbar, denn die ersten Protestanten kamen im Auftrag der anglikanischen

101 Das im Wörterbuch dokumentierte Verständnis des Protestantismus kann als programmatisch für die Missionare der Church Missionary Society und ihren Arbeitsauftrag gesehen werden. Im Gegensatz zu den evangelischen Missionsgesellschaften, die später in Äthiopien tätig waren, zielten sie nicht darauf ab, neben der orthodoxen Kirche eine parallele kirchliche Struktur zu schaffen, sondern versuchten, die Änderungen innerhalb der Kirche zu provozieren. Ausgerechnet diese Vision spiegeln die von Isenberg vorgeschlagenen Definitionen des Protestantismus und der Reformation wider, die er für die äthiopischen Christen anknüpfungsfähig zu machen versuchte, indem er sie bewusst nicht konfessionell und von ihrem historischen Entstehungskontext losgelöst verstand.

102 Ebd., S. 137.

103 Diese Bezeichnung wurde im Mittelalter aus dem Arabischen entliehen und bezog sich zunächst auf die römisch-katholischen Europäer, wie es bereits Ludolf in seinem Lexikon verzeichnete. Ludolf, Lexicon Æthiopico-Latinum, S. 383. Vgl. Daniel KöNIG, Arabic-Islamic Views of the Latin West. Tracing the Emergence of Medieval Europe, Oxford 2015, S. 189-230. Eine ähnliche Bezeichnung wurde auch in anderen Kontexten des christlichen Orients verwendet. Enno LitTmanN, Fränkisch, in: Aufsätze zur Kultur- und Sprachgeschichte vornehmlich des Orients. Ernst Kuhn zum 70. Geburtstage am 7. Februar 1916 gewidmet von Freunden und Schülern, München 1916, S. 236-243, hier S. 238f. Hingegen wurden die Ausländer des orthodoxen Glaubens nicht als Färänğ, b.l'?' gesehen; für sie gab es verschiedene Bezeichnungen: Die Griechen wurden bezeichnet als Grek, $\mathbf{T} \mathbf{h}$ oder Şərc 2 , R:C. $\boldsymbol{\delta}$, die Russen als Moskob, $\mathbf{9}^{\mathbf{D}} \mathbf{n} \boldsymbol{h}-\mathbf{n}$ und der zunächst mit den Kopten assoziierte Begriff Gabș, ๆनी\% wurde für alle Orthodoxen, auch die Armenier, verwendet. Eine weitere Ausdifferenzierung in der Wahrnehmung und Bezeichnung der Europäer fand in Äthiopien im frühen 20. Jahrhundert statt. Vgl. Richard Pankhurst, Färänğ, in: EAE 2, 2005, S. 492f. Interessanterweise benutzt Isenberg in seinem Wörter-

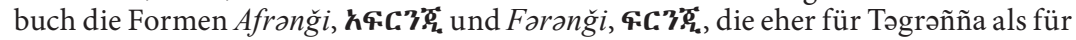
Amharisch typisch sind. Isenberg, Dictionary of the Amharic Language, S. 137. 
Missionsgesellschaft, doch ironischerweise waren sie alle deutscher (oder im Fall von Samuel Gobat schweizerischer) Herkunft und keiner von ihnen war »Engländer«. Die Tatsache, dass statt des von den Missionaren eingeführten Begriffes Pärotästant das Wort Bngliz benutzt wurde, belegt, dass der Protestantismus in erster Linie als etwas Ausländisches und Fremdes wahrgenommen wurde. Die Protestanten waren in den Augen der orthodoxen Äthiopier also nicht diejenigen, die sich gegen die der Heiligen Schrift widersprechenden Misstaten zur Wehr setzten, - wie es die Missionare gern gehabt hätten -, sondern vor allem die nicht-katholischen Europäer.

\section{Rückwirkungen missionarischer Konstruktionen von der äthiopischen Orthodoxie auf den europäischen Protestantismus}

\subsection{Kirchliches Liedgut: »Der Kämmerer aus Mohrenland»}

Zwar agierten die ersten evangelischen Missionare in Äthiopien im Namen der Anglikanischen Kirche und der Church Missionary Society, doch war das beachtliche Netzwerk ihrer Unterstützer vor allem im deutschsprachigen Raum verortet. Um die evangelische Mission in Äthiopien zu unterstützen, schrieb Christian Gottlob Barth (1799-1862), ${ }^{104}$ einer der Väter der württembergischen Erweckung, sogar ein Lied unter dem Titel Der Kämmerer aus Mohrenland, das zum Gebrauch in den Gottesdiensten und Missionsstunden gedacht war. ${ }^{105}$ Das Missionslied, das zunächst 1834 in der Zeitschrift der Basler Mission erschien, erlangte schnell Popularität und wurde in mehrere evangelische Liedersammlungen aufgenommen. ${ }^{106}$ Somit stellt das Lied

104 Zu Christian Gottlob Barth siehe: Werner Raup, Christian Gottlob Barth. Studien zu Leben und Werk, Stuttgart 1998.

105 Das Phänomen der Missionslieder ist in der pietistischen Frömmigkeit des 19. Jahrhunderts und ihrer missionarischen Begeisterung verwurzelt. Man war überzeugt, dass die Missionsarbeit nicht nur den »armen Heiden« draußen, sondern auch den »lauen Christen« in der Heimat galt. Um eine Rückwirkung der Mission auf das religiöse Leben in Deutschland zu erzielen, verbreitete man nicht nur Missionsliteratur und organisierte Missionsfeste, sondern integrierte die Missionslieder auch in das gottesdienstliche Leben. Es wird geschätzt, dass in der ersten Hälfte des 19. Jahrhunderts etwa 800 Missionslieder entstanden sind. Vgl. Ulrich GäBlER (Hg.), Der Pietismus im neunzehnten und zwanzigsten Jahrhundert, Göttingen 2000, S. 312.

106 Christian Gottlob Barth, Missions-Lied, in: MNGPM 2 (1834), S. 309-311. Vgl. auch ders., Christliche Gedichte, Stuttgart 1836, S. 148-150; Ludwig WürKerT (Hg.), Die biblischen Geschichten des alten und neuen Testaments in poetischer Bearbeitung von den besten Dichtern unserer Zeit, Weißen 1842, S. 360-363 (in dieser Ausgabe unter dem Titel Der Kämmerer aus Afrika) sowie Hermann Agathon Niemeyer (Hg.), Heilige Dichtungen zur Heiligen Geschichte, Bielefeld 1844, S. 177-179. 
eine "populäre« Stimme in einem sonst durch einen sehr engen Kreis von Wissenschaftlern und Missionaren geführten Diskurs um das äthiopische Christentum dar.

Strukturell besteht der Liedtext aus drei Teilen. ${ }^{107}$ Eröffnet wird er mit einer Nacherzählung von Apostelgeschichte 8,26-40, wo berichtet wird, wie »ein Mann aus Mohrenland, ein Kämmerer und Gewaltiger der Königin Kandaze in Mohrenland « durch den Apostel Philippus bekehrt und getauft wurde. Indem Luther in seiner Bibel das hebräische (Küšs) und das griechische Aïto $\pi$ í $\alpha$ (Aithiopía) als »Mohrenland « übersetzte, eliminierte er die geografische Bezugnahme des Urtextes, wie fiktiv diese auch immer gewesen sein mag. Im Lied wird das »Mohrenland « jedoch »Abyssinien« (die übliche Bezeichnung des äthiopischen Staates im damaligen deutschsprachigen Raum) und »Habesch (die Bezeichnung des äthiopischen Hochlandes) gleichgesetzt. Damit schlug der Liedtext eine Brücke zwischen der biblischen Geschichte und der zeitgenössischen geopolitischen Entität am Horn von Afrika und suggerierte eine historische Kontinuität der Missionsarbeit.

Im zweiten Teil des Liedes wird über die Verbreitung des Christentums im »Mohrenland « sowie über dessen zeitgenössischen - angeblich verfallenden - Zustand berichtet. Dafür wird das Symbol eines Gartens verwendet: Zwar sei das Saatkorn des Glaubens, das der Kämmerer aus dem Heiligen Land brachte, in Äthiopien zu einem Garten gewachsen, doch dieser verödete inzwischen und benötigte dringend einen neuen »Gärtner«. Es ist nicht schwer zu erahnen, dass mit »Gärtnern« die evangelischen Missionare gemeint waren.

Doch ach! wie stehet nun verheert

Des Kämm'rers schöner Garten!

Des Bodens Kraft so ausgezehrt

Von Unkraut aller Arten;

Der gute Same fast erstickt,

Und Zaun und Mauer weggerückt!

O laßt die Gärtner eilen,

$\mathrm{Daß}$ sie die Schäden heilen! ${ }^{108}$

Der dritte Teil des Liedes wendet sich nun direkt an die evangelischen Missionare sowie an die Missionsgemeinde in der Heimat, die die Missionare unterstützte und sich mit ihnen identifizierte. Beendet wird das Lied mit einer durchaus pathetischen Kulmination, die die Missionsarbeit mit Erfolg gekrönt sieht. 
Das Wort, ihr Gärtner, das ihr sä’t

In Abyssinerherzen,

Vom Schafe, ${ }^{109}$ das zur Schlachtbank geht,

Das Wort vom Mann der Schmerzen,

Von dem, der als ein Opferlamm

Einst für uns starb am Kreuzesstamm,

Das segne der Getreue

In Habesch nun auf's Neue!

Es wird mit euch zu jeder Zeit

Nach seinem Worte handeln;

In Kleider der Gerechtigkeit

Die Mohrenhaut verwandeln. ${ }^{110}$

Dereinst noch wird in frischem Grün

Des Kämm'rers alter Garten blüh'n,

Und nach des Winters Tagen

Viel edle Früchte tragen. ${ }^{111}$

Interessanterweise wird hier die religiöse Bekehrung der Äthiopier zum "wahren" Christentum auch mit der symbolischen Überwindung von deren äußerlicher Andersartigkeit verbunden: Das durch die europäischen Glaubensboten geprädigte Evangelium werde »in Kleider der Gerechtigkeit/Die Mohrenhaut verwandeln«. Die Anspielungen auf die Hautfarbe als Ausdruck der Alterität der Äthiopier wurde in der zweiten Version des Liedes, die 1836 erschien, sogar noch bekräftigt. Dort ließ Christian Gottlob Barth die Missionare nicht mehr »ins ferne heiße«, sondern nun »ins ferne dunkle« Mohrenland ziehen, um dort »die Mohrenfarbe [zu] wandeln«. Bemerkenswert ist auch, dass die Missionsarbeit bewusst als die Verkündigung Jesu anhand der Passage von Jesaja 53,7-8 dargestellt wird, jener Stelle, die Philippus laut Apostelgeschichte dem Kämmerer deutete. Somit wird die bereits am Anfang des Liedes angedeutete Identifikation der äthiopisch-orthodoxen Kirche mit dem Kämmerer und der evangelischen Missionare mit Philippus endgültig festgehalten.

Die Differenz zwischen den evangelischen Missionaren und den äthiopisch-orthodoxen Christen, die mit Hilfe der biblischen Gestalten des Apostel Philippus und des Kämmerers "aus Mohrenland" hergestellt wurde, implizierte nicht nur eine klare paternalistische Rollenverteilung (Erklärende-Zuhörende), sondern auch eine strikte Dichotomie (Christ-kein

109 In der späteren Version: „Vom Lamme«.

110 In der späteren Version: »Die Mohrenfarbe wandeln«.

111 Ebd., hier S. 310f. 
Christ). Gleichwohl ist zu betonen, dass die Identifikation der äthiopischen Kirche mit dem Kämmerer »aus Mohrenland « in sich außerdem eine Andeutung auf den angeblich »jüdischen " Charakter des äthiopischen Christentums enthielt. Betrachtet man das Lied in seiner Gänze, so kann von der Konstruktion einer doppelten Alterität die Rede sein: Die äthiopisch-orthodoxen Christen seien sowohl rassisch (»Mohren«) als auch religiös (»Juden«) anders.

Das Bild des äthiopischen Christentums, das in dem analysierten Lied aufgezeichnet wird, weist deutliche Ähnlichkeiten mit den missionarischen Darstellungen der Kirche Äthiopiens auf. Es besteht kein Zweifel daran, dass es auf die Berichte der europäischen Missionare zurückzuführen ist. Das Lied Der Kämmerer aus Mohrenland wurde zunächst selbst im Magazin für die neueste Geschichte der evangelischen Missions- und Bibelgesellschaften veröffentlicht, auf dessen Seiten die Tagebücher Samuel Gobats erschienen. Wie in den Schriften der Missionare so wurde auch im Lied eine doppelte - religiöse sowie kulturell-rassische - Fremdheit der äthiopischen Christen konstruiert.

Das äthiopische Christentum fand somit - selbst wenn nur »durch die Hintertür « und nur in einigen Gemeinden - Eingang in den deutschsprachigen evangelischen Gottesdienst. Dieses Lied kann somit als ein prominentes Fallbeispiel einer unmittelbaren Rückwirkung der evangelischen Mission in Äthiopien auf das protestantische Leben im deutschsprachigen Raum gelten.

\subsection{Missionsdiskurse im Wandel}

Am 16. März 1844, ein Jahr nachdem die Church Missionary Society die Missionstätigkeit am Horn von Afrika endgültig aufgegeben hatte, hielt Carl Ritter in Berlin einen Vortrag über Äthiopien: Ein Blick in das Nil-Quelland. Der Geograf, der als erster die Idee protestantischer Missionstätigkeit in Äthiopien als den Weg zur Missionierung des gesamten afrikanischen Kontinents programmatisch begründete, musste zugeben, dass Afrika erheblich komplexer gewesen sei, als er es vorher angenommen hatte, ${ }^{112}$ und sah sich nun zu einer partiellen Revision seines ursprünglichen Missionsprojektes veranlasst.

Ritter plädierte dafür, die Missionsbestrebungen nicht auf die äthiopischorthodoxe Kirche, die nun als unreformierbar galt, ${ }^{113}$ sondern auf die heid-

112 Carl Ritter, Ein Blick in das Nil-Quellland. Vortrag vom 16. März 1844, im Verein wissenschaftlicher Mittheilungen, Berlin 1844, S. 37f. Vgl. auch ders., Nachtrag zu Herrn C.W. Isenberg's Briefe über die Mission in Schoa, in: Monatsberichte über die Verhandlungen der Gesellschaft für Erdkunde zu Berlin 2 (7-9) (1840-1841), S. 93-98.

113 Das Scheitern des Vorhabens der evangelischen Missionare, die er als "Glaubenshelden« bezeichnete, führte Ritter ausschließlich auf die »Werkheiligkeit» der 
nischen « Oromo zu konzentrieren. Diese seien noch »durch keinen Pharisäerstolz verblendet« und würden daher "mit größerer Einfalt des Herzens die beseligenden Wahrheiten des Evangeliums « ergreifen. ${ }^{114}$ Somit kann man von einer Umkehr des in der Erdkunde dokumentierten Bildes christlicher Äthiopier als Kulturträger und der Oromo als deren »wilde« Herausforderer sprechen.

Entscheidend für diese Einschätzung waren die Berichte der Missionare, dass die vornehmlich durch die Oromo bewohnten Gebiete weitgehend frei von Sklaverei gewesen seien. ${ }^{115}$ Aus diesem Grund betrachtete Ritter, ein entschiedener Gegner der Sklaverei, die Oromo als moralisch überlegen, wenngleich auch weniger »Zivilisiert«, im Vergleich zu den christlichen Äthiopiern, die noch Sklavenhandel betrieben haben sollten. ${ }^{116}$ Möglicherweise wurde diese Darstellung der Oromo als "wilde«, aber moralisch unverdorbene Menschen durch die Schriften des schwedischen Mystikers Emanuel Swedenborg (1688-1772) inspiriert. ${ }^{17}$

äthiopischen Priester und die »Vorurteile des Volks« zurück. Ders., Ein Blick in das Nil-Quellland, S. 37. Wenn es aber um die Misserfolge der katholischen Mission in Äthiopien ging, war die Analyse Ritters deutlich anders. Das Scheitern deren Mission erklärte er mit dem Verweis auf die »hartnäckige Intoleranz der Europäischen Priester« und dessen »päbstlichen Stolz«. Ders., Die Erdkunde, 1817, S. 165.

114 Ders., Ein Blick in das Nil-Quellland, S. 38.

115 Ritter leitete daraus eine generelle Abwesenheit eines innerafrikanischen Sklavenhandels ab. Diese These kann man als die Fortsetzung der Debatte mit seinem Berliner Kollegen Georg Wilhelm Friedrich Hegel (1770-1831) interpretieren, der in der Sklaverei eine urafrikanische Institution gesehen hatte. Georg Wilhelm Friedrich Hegel, Vorlesungen über die Philosophie der Geschichte. Georg Wilhelm Friedrich Hegel's Werke. Vollständige Ausgabe, Berlin 1837, Bd. 9, S. 96f. Es ist hervorzuheben, dass Hegel im Übrigen die Grundthesen der Ritter'schen Theorie rezipierte und in den Vorlesungen über die Philosophie der Geschichte verwendete. So ist das gesamte Kapitel "Geographische Grundlage der Weltgeschichte» auf den Thesen der Erdkunde aufgebaut. Ebd., S. 75-100. Zu Hegels Rezeption der Ritter'schen Ideen siehe zudem: Dirk Stederoth, Hegels Philosophie des subjektiven Geistes. Ein komparatorischer Kommentar, Berlin 2001, S. 144-151.

116 Ritter, Ein Blick in das Nil-Quellland, S. 39. Sein Engagement für die Abschaffung der Sklaverei erschien ihm aus religiösen Gründen vordringlich. Siehe das ausführliche Vorwort zur deutschen Übersetzung einer zentralen Streitschrift der englischen Antisklavereibewegung: Ders., Die Nigerexpedition und ihre Bestimmung, in: Thomas Fowell Buxton (Hg.), Der afrikanische Sklavenhandel und seine Abhülfe, Leipzig 1841, S. IX-LXX.

117 Swedenborg glaubte, dass die Kirche in Europa untergehe, und behauptete, eine Offenbarung bekommen zu haben, dass im Inneren Afrikas hochmoralische Menschen lebten. Diese afrikanischen »Heiden« würden eine »himmlische Lehre« von Gott erhalten, und so entstehe dort »eine neue Kirche aus dem Himmel«, von der eine Erneuerung des Christentums und der ganzen Welt ausgehen würde. Johann Friedrich Immanuel TAFEL, Swedenborg's Lehre mit Rücksicht auf die Einwürfe gegen sie und auf die christliche Dogmatik in ihrer geschichtlichen Entwicklung, Stuttgart 1844, S. 413. An dieser Stelle verweist Tafel auf das Diarium Spirituale Swedenborgs. 
Die Idee, eine evangelische »Galla-Mission« in die Wege zu leiten, anstatt eine Reformation unter den äthiopisch-orthodoxen Christen anzustreben, für die Ritter sich in seinem Berliner Vortrag einsetzte, ${ }^{118}$ war jedoch nicht originär. Der Geograf hatte diesen Gedanken dem Missionar Johann Ludwig Krapf zu verdanken, ${ }^{119}$ der als der wichtigste Ideologe und Inspirator des neuen Missionsvorhabens gelten kann. ${ }^{120}$ Im Fall von Ritter und Krapf, die sich gut kannten und im regen Briefwechsel standen, kann von einer wechselseitigen produktiven Beeinflussung gesprochen werden. Denn der Missionar erarbeitete sein Projekt auf der Grundlage der Erdkunde Ritters. Er übernahm die Idee, eine Kette von Missionsstationen einzurichten, die von Ost- nach Westafrika führen würden. ${ }^{121}$ Jedoch sollten deren Ausgangspunkt nicht mehr die »habessinischen Christen« bilden, die sich gegenüber der evangelischen Missionierungsversuchen unempfindlich gezeigt hatten, sondern ausgerechnet deren Herausforderer - die Oromo.

Aus diesem Grund bemühte sich Krapf darum, das von Ritter geprägte Bild der Oromo umzukehren und die Oromo nunmehr als potenzielle Kulturträger darzustellen. Dabei blieb er dem von Ritter vorgeschlagenen dialektischen Paradigma verhaftet, das die "Galla» den »Habessiniern« entgegensetzte, deutete es aber um: Es sei die »Absicht Gottes, der alle Völkerbewegungen zum Guten kehrt, " gewesen, die Oromo als Geißel zu verwenden, um »die verderbte abessinische Christenheit [...] zu züchtigen «. ${ }^{122}$ Dementsprechend hielt Krapf die »Galla« für die »von Gott bestimmten Werkzeuge«, die zudem als »eine Vormauer« gegen die Verbreitung des Islam über die arabische Halbinsel hinaus dienten. ${ }^{123}$ Während bei Ritter in der

Dank der zahlreichen deutschen Übersetzungen gewann die Lehre Swedenborgs ab den 1820er Jahren rapid an Popularität im gesamten deutschsprachigen Raum, u. a. im Umfeld Carl Ritters. Vgl. Philip D. Curtin, The Image of Africa. British Ideas and Action. 1780-1850, Madison 1964, Bd. 1, S. 26f.; James John Garth Wilkinson, The African and the True Christian Religion. His Magna Charta. A Study in the Writings of Emanuel Swedenborg, London 1892, S. 145-153 sowie Zitelmann, Des Teufels Lustgarten, S. 167.

118 Eine evangelische Mission wollte Ritter allerdings unter der Mitwirkung »des britisch-indischen Handelsinteresses « etablieren. Ritter, Ein Blick in das Nil-Quellland, S. 39.

119 Zu Krapf siehe: Gütr, Johann Ludwig Krapf; Jochen Eber, Johann Ludwig Krapf. Ein schwäbischer Pionier in Ostafrika, Basel 2006.

120 Krapf hatte bereits 1839, noch in den Diensten der Church Missionary Society stehend, die ersten Versuche unternommen, eine Oromo-Missionsstation in der zentraläthiopischen Provinz Šäwa zu etablieren. Zwar war ihm dies nicht gelungen, aber seitdem propagierte er aktiv seine Vision einer Missionsarbeit unter den Oromo.

121 Johann Ludwig Krapf, Reisen in Ost-Afrika ausgeführt in den Jahren 1837-55. Erster Theil, Stuttgart 1858, S. 213 (Verweis auf Tagebucheintrag vom 16. August 1844).

122 Ebd., S. 94.

123 Ebd. 
Erdkunde ausschließlich von den »wilden Galla-Horden« die Rede war, ${ }^{124}$ so entwickelte Krapf bereits eine romantische Idee von einer noch ungeeinten und seiner selbst noch nicht bewussten »Galla-Nation «. ${ }^{125}$

Dank den Schriften Krapfs wurde Äthiopien zur wichtigsten Projektionsfläche, mit der zahlreiche sich um die Mitte des 19. Jahrhunderts formierende protestantische Missionsgesellschaften ihre Hoffnungen verbanden. Allein in den 1850er bis 1860er Jahren hatten es gleich drei evangelische Missionsgesellschaften unabhängig voneinander zu ihrem Ziel erklärt, Missionare nach Äthiopien zu entsenden: die deutsche Hermannsburger Mission, ${ }^{126}$ die Schweizer Pilgermission St. Chrischona ${ }^{127}$ sowie die schwedische Evangeli-

124 Ritter, Die Erdkunde, 1817, S. 112, 126, 132, 144, 151, 167, 195, 197, 213.

125 KRAPF, Reisen in Ost-Afrika, S. 94. Um seine deutschsprachigen Leser von ihrer potenziellen Bedeutung zu überzeugen, suggerierte Krapf in Anlehnung an den Germanenmythos, dass sie im Falle der Bekehrung der Oromo zum Christentum "dieselbe Bedeutung und Bestimmung erhalten werden, welche Gott den Deutschen in Europa angewiesen hat«. Ebd. Im Zuge der Projektion dieses völkischen Gedankengutes, das aus der aufkommenden deutschen Nationalbewegung des frühen 19. Jahrhunderts stammte, auf die Oromo, nannte er sie sogar - in Anlehnung an die Germanen - die »Ormanen« und dachte sich für sie eine entsprechende Landesbezeichnung aus: „Ormania«. Seine Vision fasste Krapf folgendermaßen zusammen: »Thre Bekehrung würde in Ostafrica einen unberechenbar gewaltigen Einfluß üben. Ich bin fest überzeugt, dass die göttliche Leitung die Völker dieser Nation für einen großen Zweck gerade hierher gestellt hat. Es ist das Deutschland von Africa. Denkt man sich das alte Germanien, so trifft fast jeder Zug seiner Volkseigenthümlichkeit mit diesem africanischen Ormanien zusammen; denn Orma nennt sich das Volk selbst, nicht Galla. Wie die alten Germanen sind sie in Stämme getheilt, die oft unter sich in blutiger Fehde liegen, deren jeder aber zäh seine Unabhängigkeit und Freiheit schützt. Wie die alten Germanen sind sie stolz auf ihren stattlichen Wuchs. Wie sie vernichten sie unbarmherzig die Stämme, die mit ihnen in Berührung kommen. Nur in der Religion stehen sie ihnen nicht gleich; die Ormas haben ein weit nicht so furchtbares Religionssystem, als die Germanen hatten«. Johann Ludwig KraPf, Abessinien, in: MNGPM 4 (1850), S. 1-121, hier S. 38f.

126 Die Hermannsburger Mission wurde 1849 gegründet. Um die Oromo zu erreichen, die als erstes und primäres Ziel der Missionsarbeit galten, wurde das Missionsschiff "Candace " gebaut. Jedoch sind zwei Versuche, 1853/1854 und 1857/1858, das »Land der Galla« zu erreichen, missglückt. Siehe: Ernst Bauerochse, Ihr Ziel war das Oromoland. Anfänge der Hermannsburger Missionsarbeit in Äthiopien, Münster 2006, S. 39-98; Georg Haccius, Die Kandaze. Das Missionsschiff der Hermannsburger Mission, Hermannsburg [1913]; Georg Haccius, Hannoversche Missionsgeschichte, Hermannsburg 1907, Teil 2: Insbesondere die Geschichte der Hermannsburger Mission von 1849 bis zum Tode von Louis Harms, S. 1-274.

127 Die Pilgermission St. Chrischona, die 1840 in der Nähe von Basel durch Christian Friedrich Spittler (1782-1867) gegründet worden war, hatte ihre ersten Laienmissionare im Jahre 1855 nach Äthiopien entsandt. Zur Geschichte ihrer Missionstätigkeit in Äthiopien siehe: Andreas Baumann, Die »Apostelstraße«. Eine außergewöhnliche Vision und ihre Verwirklichung, Gießen 1999; Friedrich Heyer, St. Chrischona in Äthiopien, in: Theo SundermeIER (Hg.), Fides pro mundi vita. Missionstheologie heute. Hans-Werner Gensichen zum 65. Geburtstag, Gütersloh 1980, S. 133-147; Barbara Strebel, »... den blinden Abessyniern die Augen aufzuthun«. ChrischonaPilgermissionare in Äthiopien (1856-1868). Geschichte eines gescheiterten Missi- 
sche Vaterlandsstiftung (Evangeliska Fosterlands-Stiftelsen). ${ }^{128}$ Somit wurde die zweite Hälfte des 19. Jahrhunderts durch eine verstärkte protestantische Missionstätigkeit in Äthiopien gekennzeichnet. ${ }^{129}$ Es ging weiterhin - wie bereits bei der Begründung des Projekts der äthiopischen "Reformation« durch Carl Ritter - um nichts weniger als um die Bekehrung des gesamten afrikanischen Kontinents. ${ }^{130}$

onsprojektes, Lizentiatsarbeit Universität Zürich 1999; Barbara STreben, Leben auf dem Missionsfeld. Chrischona-Pilgermissionare in Äthiopien (1856-1868), in: Aethiopica. International Journal of Ethiopian Studies 4 (2001), S. 121-157.

128 Die Missionsgesellschaft wurde 1856 gegründet. Zur Anfangsphase ihrer Tätigkeit in Äthiopien siehe: ArÉn, Evangelical Pioneers, S. 118-167.

129 An dieser Stelle sei nur auf einige Publikationen aus diesem Themenfeld verwiesen: Arén, Evangelical Pioneers; Verena Böll (Hg.), Ethiopia and the Missions. Historical and Anthropological Insights, Münster 2005; Getatchew Haile u. a. (Hg.), The Missionary Factor in Ethiopia. Papers from a Symposium on the Impact of European Missions on Ethiopian Society. Lund University, August 1996, Frankfurt a. M. 1998; Wolbert G.C. SmIDT, "Schwarze Missionare" in Äthiopien im Dienst der Errichtung einer Welt-Christokratie, in: Ulrich von der Hey deN / Holger STOECKER (Hg.), Mission und Macht im Wandel politischer Orientierungen. Europäische Missionsgesellschaften in politischen Spannungsfeldern in Afrika und Asien zwischen 1800 und 1945, Stuttgart 2005, S. 485-505; ders., Deutsche Briefe von Äthiopiern 1855-1869 aus dem Umkreis der protestantischen Mission zur Regierungszeit von Tewodros II., in: Scrinium. Revue de patrologie, d'hagiographie critique et d'histoire ecclésiastique 1 (2005), S. 287-316; ders., Deutsche Briefe von Äthiopiern aus der Protestantischen Mission. Vom Fall des Téwodros bis zur Unterwerfung des Königs Minílik (1869 bis 1878), in: Orientalia Parthenopea 8 (2008), S. 9-56; ders., Deutsche Briefe von Äthiopiern aus der Protestantischen Mission. Von der Reichseinigung unter Yohannis IV. bis zur großen Hungersnot (1879 bis 1889), in: Orientalia Parthenopea 9 (2009), S. 9-52.

130 Während Krapf selbst 1839 noch bewusst zugespitzt formulierte: »Gebt uns die Galla, so haben wir Central-Afrika« (KRAPF, Reisen in Ost-Afrika, S. 50), war diese These für Ludwig Harms (1808-1856), den Begründer der Hermannsburger Mission, bereits zu bescheiden. 1852 stellte er fest: »Wenn in Afrika erst die Galla bekehrt sind, so wird bald ganz Afrika bekehrt sein«. Ludwig Harms, Die ersten Missionsberichte von Louis Harms, Hermannsburg [1906], S. 14. 



\title{
V. Die Herrlichkeit der Könige: Verflechtungen politischer Theologien (27. Februar 1905)
}

\author{
1. Äthiopien und Deutschland: \\ »Christliche« Kaiserreiche auf dem Weg der Annäherung
}

Verflechtungen zwischen äthiopischer Orthodoxie und europäischem Protestantismus ließen auch den Bereich des Politischen nicht unbeeinflusst. Diese These soll im Folgenden am Beispiel der diplomatischen Annäherung zwischen Äthiopien und Deutschland begründet werden.

In einem ersten Schritt ist die Rolle der theologischen Diskurse beim Aufbau deutsch-äthiopischer Diplomatie im späten 19. bis frühen 20. Jahrhundert Gegenstand der Analyse. Daran anschließend werden in einem zweiten Schritt die Partikularitäten der jeweiligen politischen Theologien erörtert. Ihr Einfluss auf politisches Handeln und die Entwicklung bilateraler Beziehungen soll dabei mit Hilfe einer mikrohistorischen Perspektivierung auf die Ereignisse eines einzelnen Tages, des 27. Februar 1905 beziehungsweise des 20. Yäkkatit 1897 nach äthiopischer Zeitrechnung, exemplarisch herausgearbeitet werden.

1.1 Die Politiker als Theologen: Rhetorik christlicher Verbundenheit in der kaiserlichen Korrespondenz

Der äthiopische Kaiser Yohannəs IV. (P`h’ñ; 1837-1889, r. 1872-1889) hatte bereits in den früher 1870er Jahren durch Vermittlung des deutschen lutherischen Missionars Johannes Mayer (1831-1893) Kontakt zum neugegründeten Deutschen Kaiserreich aufgenommen. ${ }^{1}$ Insofern alternative diplomatische Kanäle, über die die politische Kommunikation zwischen Äthiopien und Deutschland hätte verlaufen können, nicht vorhanden waren, wurde die Korrespondenz in den folgenden Jahrzehnten zu einem zentralen Instrument der Außenpolitik. ${ }^{2}$

1 Zu Mayer siehe: Wolbert G. C. Smidt, Mayer, Johannes, in: EAE 3, 2007, S. $890 f$.

2 Der Briefwechsel ist bisher nur teilweise ediert. Vgl. BAIRU TAfla, Ethiopia and Germany. Cultural, Political and Economic Relations 1871-1936, Wiesbaden 1981, S. 188-303; Wolbert G.C. SmidT, »Annäherung Deutschlands und Aethiopiens«. Unbekannte Briefe des Kaisers Menelik II. und seines Gesandten 1907-08, in: Stefan 
Zur tragenden Säule des diplomatischen Diskurses, der sich in diesem Briefwechsel entfaltete, wurde die Vorstellung von einer von beiden Seiten geteilten christlichen Identität. So äußerte beispielsweise der Deutsche Kaiser Wilhelm I. (1797-1888; r. 1871-1888) die Überzeugung, dass Äthiopien und Deutschland auf eine grundlegende Weise durch die Zugehörigkeit zu "demselben theuern christlichen Glauben " miteinander verbunden seien. ${ }^{3}$ Um ein christliches Gemeinschaftsgefühl zu erzeugen, begann Yoḥannəs IV. wiederum seine Briefe nach Deutschland oft mit einer doxologischen Trinitätsformel ${ }^{4}$ und appellierte gerne an das Christsein seiner deutschen Briefadressaten: Von Wilhelm I. sprach er als einem "festen Christen"

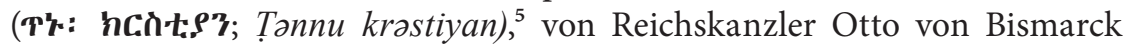
(1815-1898) darüber hinaus als einem "gütigen Menschen [und] perfekten

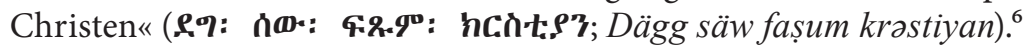

Dass es sich bei der Bezugnahme auf das gemeinsam Christliche nicht bloß um eine leere Floskel handelte, verdeutlicht die Tatsache, dass auch genuin theologische Themen zum Gegenstand des Austausches gemacht wurden. So berichtete Yohannəs IV., der auch persönlich ein lebhaftes Interesse an Theologie hatte, ${ }^{7}$ dem Deutschen Kaiser über die Abhaltung eines

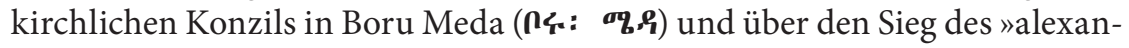

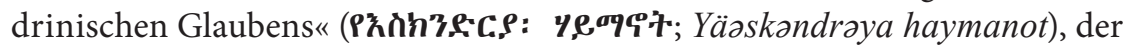

Brüne / Heinrich Scholler (Hg.), Auf dem Weg zum modernen Äthiopien. Festschrift für Bairu Tafla, Münster 2005, S. 197-224. Weitere noch nicht edierte Briefe befinden sich vornehmlich im Politischen Archiv des Auswärtigen Amtes in Berlin.

3 PA AA, Allg. A 3900. Brief von Wilhelm I. an Yohannos IV. vom 9. Juli 1880. Vgl. BAIRU TAFla, Ethiopia and Germany, S. 195-199.

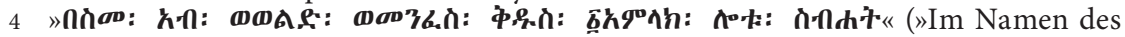
Vaters und des Sohnes und des Heiligen Geistes, eines Gottes, Ihm sei Lobpreis«). Vgl. PA AA, Allg. A 3233. Brief von Yoḥannəs IV. an Bismarck vom 11. Yäkkatit 1873 A.M. [= 17. Februar 1881] und PA AA, Allg. A 3233. Brief von Yoḥannəs IV. an Bismarck vom 11. Yäkkatit 1873 A. M. [= 17. Februar 1881]. Vgl. BAIrU TAFLA, Ethiopia and Germany, S. 200-205. Vgl. die Verwendung der Formel in der inner-äthiopischen und internationalen Korrespondenz der äthiopischen Monarchen in: Richard PAnkhurst, Letters from Ethiopian Rulers (Early and Mid-Nineteenth Century) Preserved in the British Library, the Public Record Office, Lambeth Palace, the National Army Museum, India Office Library and Records, Oriental Documents IX, London 1985.

5 PA AA, Allg. A 23/197. Brief von Yohannos IV. an Wilhelm I. vom 8. Nähase 1864 A. M. [= 13. August 1872]. Vgl. Bairu Tafla, Ethiopia and Germany, S. $188 f$.

6 PA AA, Allg. A 3233. Brief von Yoḥannəs IV. an Bismarck vom 11. Yäkatit 1873 A.M. [= 17. Februar 1881]. Vgl. BAIRU TAFla, Ethiopia and Germany, S. 204f.

7 Zur persönlichen Frömmigkeit des Kaisers und seinen theologischen Interessen siehe: Donald Crummey, Imperial Legitimacy and the Creation of Neo-Solomonic Ideology in 19th-Century Ethiopia, in: CEtAf 28 (109) (1988), S. 13-43, hier S. 28f.; ders., Orthodoxy and Imperial Reconstruction in Ethiopia. 1854-1878, in: JThS 19 (2) (1978), S. 427-442, hier S. 439-441. Dass sich Yohannos IV. aktiv mit theologi- 
dort errungen worden war. ${ }^{8}$ Dieses Konzil, das im Mai 1878 stattfand, wurde tatsächlich zu einem Meilenstein der äthiopischen Kirchengeschichte, denn es setzte den jahrhundertelangen internen christologischen Streitigkeiten ein Ende und erklärte die Täwah̆ado-Doktrin zum verbindlichen Bekenntnis der Äthiopisch-Orthodoxen Kirche. ${ }^{9}$

Die Tatsache, dass Yohannəs IV. nahezu die ganze Zeit seiner Herrschaft in militärische Auseinandersetzungen mit Muslimen involviert war, ${ }^{10}$ hinterließ deutliche Spuren darin, wie er in seinen Briefen nach Deutschland die Zugehörigkeit zum Christentum artikulierte: in der Opposition und der Abgrenzung gegenüber dem Islam. Die Gemeinschaft zwischen Äthiopien und Deutschland zeigte sich primär durch die Zugehörigkeit beider Länder zu einem imaginären Bund christlicher Mächte, die sich im Kampf gegen die

schen Fragen beschäftigte, bestätigt auch der 1880 als der erste Konsul des Deutschen Reiches am Hofe Yohannəs' IV. weilende Gerhard Rohlfs (1831-1896): »Bei einer der folgenden Audienzen, zu welchen man mich täglich abholte, hielt mir der Negus eine fast zweistündige Rede über die Vortrefflichkeit der abessinischen Religion, über die Einheit der Natur Jesu Christi u.s.w. Ich hütete mich wohl, ihm je zu widersprechen oder auch nur den Anschein zu erwecken, als ob ich nicht auch überzeugt wäre. Soll es schliesslich darauf ankommen, dass derjenige der christlichste sei, welcher am meisten und festesten glaubt, dann können sich die alten Aethiopier trösten: sie glauben alles, was in der Bibel Alten und Neuen Testaments steht. Und der jetzige Kaiser von Abessinien [...] kennt die Bibel wie kein anderer«. Gerhard RoHLfs, Meine Mission nach Abessinien. Auf Befehl Sr. Maj. des Deutschen Kaisers im Winter 1880/1881 unternommen von Gerhard Rohlfs, Leipzig 1883, S. $221 \mathrm{f}$.

8 Vgl. PA AA, Allg. A 1933. Brief von Yohannəs IV. an Wilhelm I. vom 11. Hədar 1872 A. M. [= 20. November 1879]. Vgl. Bairu Tafla, Ethiopia and Germany, S. 190-193. Über das Boru Meda-Konzil: Maurice de Coppet (Hg.), Chronique du règne de Ménélik II roi des rois d'Éthiopie, Librairie orientale et américaine, Paris 1930, Bd. I, S. 149-156; Richard Alan CAULK, Religion and State in Nineteenth Century Ethiopia, in: JetS 10 (1) (1972), S. 23-41. Zur Religionspolitik von Yohannəs IV. siehe: BAIRU Tafla, Between Religion and Politics. Reflecting on the Agelong Religious Policy of Imperial Ethiopia, in: Walter Raunig / Asfa-Wossen Asserate (Hg.), Juden, Christen und Muslime in Äthiopien. Ein Beispiel für abrahamische Ökumene, Dettelbach 2010, S. 45-56; Gabra Madhen Kidane, Yohanis IV. Religious Aspects of His Internal Policy, Haile Sellassie I University B. A. Thesis, 1972.

9 Vgl. Anm. 7 auf S. 15

10 Als die größten Auseinandersetzungen sind der Aufstand der muslimischen Oromo in Azäbo im Südosten von Təgray, der Abwehrkrieg gegen das osmanische Ägypten und abschließend der Krieg gegen die sudanesischen Mahdisten zu nennen, in dem Yohannəs IV. schließlich getötet wurde. Vgl. Adhana Mengstaab, Yohannes IV and Keren, in: Taddese Beyene u.a. (Hg.), Kaśa and Kaśa. Papers on the Lives, Times and Images of Tewodros II and Yohannes IV (1855-1889), Addis Abeba 1989, S. 247-252; ders., The Occupation of Keren by the Egyptians. 4 July 1872-10 April 1885, in: Tadesse Beyene u.a. (Hg.), Proceedings of the First National Conference of Ethiopian Studies. April 11-12 1990, Addis Abeba 1990, S. 367-381; Richard Alan Caulk, Yohannes IV, the Mahdists, and the Colonial Partition of North-East Africa, in: TransAfrican Journal of History 1 (2) (1971), S. 23-42. 


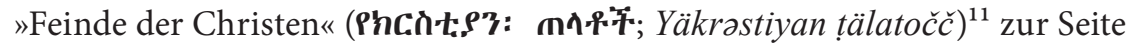
zu stehen hätten. ${ }^{12}$

In den Briefen des äthiopischen Kaisers, der sich um die Neubelebung des "salomonischen Narrativs" bemühte und sich als "König von Zion"

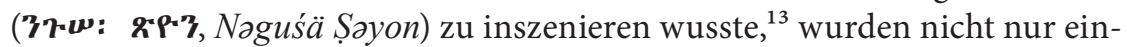

11 PA AA, Allg. A 23/197. Brief von Yohannəs IV. an Wilhelm I. vom 8. Nähase 1864 A. M. [= 13. August 1872]. Vgl. Bairu Tafla, Ethiopia and Germany, S. 188f.

12 Das Vorbild für diese angestrebte religiös-politische Allianz wurde aus der Geschichte genommen: Dafür diente v. a. die Erwähnung des berühmten - erst dank 400 zusätzlich aus Portugal eingetroffener Soldaten errungenen - Sieges über das Sultanat Adal im 16. Jahrhundert. Der von Aḥmad ibn Ibrāhīm al-Ḡāzī geführte Eroberungszug gegen das Äthiopische Kaiserreich war zunächst erfolgreich, und die letzendliche Wendung des Kriegsglücks wäre ohne die Hilfe der portugiesischen Expedition unter der Leitung von Christóvão da Gama (1516-1542), dem jüngsten Sohn von Vasco da Gama (1469-1524), in den Jahren 1541-1543 kaum zu erreichen gewesen. Dieses äußerst erfolgreiche Kapitel der militärischen europäisch-äthiopischen Kooperation, ein Beispiel transnationaler christlicher Gemeinschaft und Solidarität, wurde in den Briefen nach Berlin in Erinnerung gerufen und zu einer Parallele mit der zeitgenössischen Lage Äthiopiens gemacht. PA AA, Allg. A 3233. Brief von Yoḥannəs IV. an Wilhelm I. vom 11. Yäkkatit 1873 A. M. [= 17. Februar 1881]. Vgl. BAIRU TAFLA, Ethiopia and Germany, S. 200-203.

13 Die Herrschaft von Yohannəs IV. zeichnete sich durch eine enorme Achtung gegenüber dem »salomonischen Narrativ« und dem Kabrä Nägäśt aus, die auch die internationale Diplomatie nicht unbeeinflusst ließ. So beabsichtigte Yohannəs IV., die aus Äthiopien weggeführten Handschriften des Kəbrä Nägäśt erneut in Besitz zu nehmen, und machte dies auch zum Thema internationaler Verhandlungen. Im August 1872 schrieb er zwei Briefe an die britischen Autoritäten - einen an Queen Victoria (1819-1901) und einen an ihren Außenminister Granville George Leveson-Gower (1815-1891) - mit der nachdrücklichen Bitte um die Rückgabe eines Manuskripts des Kabrä Nägäst. Edward Ullendorff / Abraham Demoz, Two Letters from the Emperor Yohannes of Ethiopia to Queen Victoria and Lord Granville, in: BSOS 33 (1) (1969), S. 135-142. In den Briefen ist lediglich von einer Handschrift die Rede. Es ist daher unklar, ob Yoḥannəs IV. nicht wusste, dass die Briten zwei Handschriften hatten, oder ob er damit einverstanden war, dass eine davon in London blieb. Zu den auf Amharisch verfassten Briefen waren englische Übersetzungen beigefügt, die am Hofe von Yohannəs IV. vom Schotten John Kirkham (1835-1876) angefertigt worden waren. In den Briefen bezieht sich Yoḥannəs IV. auf das Kabrä Nägäśt als das Buch "which contains the law of the whole of Ethiopia« (so in der Übersetzung des Briefes an Leveson-Gower) oder das Buch "containing the whole of the laws of Ethiopia" (so in der Übersetzung des Briefes an die Queen Victoria). Vgl. ebd., S. 138 und 141. Diese Passage mit dem dahinter stehenden amharischen Ausdruck $\boldsymbol{V} \cdot \boldsymbol{n} \cdot \mathbf{n}$ i $\mathbf{A} \boldsymbol{\mathbf { T }}$ (Hulu sərat) - der jedoch eher als »die gesamte Verfassung « zu übersetzen wäre - belegt zum ersten Mal die inneräthiopische Sicht auf das Kəbrä Nägäśt als Grundlage der modernen Staatlichkeit und aktuelle Quelle zu dessen politischer Ordnung. Im Brief an Leveson-Gower wird vom Übersetzer direkt danach eine auf Amharisch fehlende Phrase hinzugefügt: "I pray you will find out who has got this book, and send it to me, for in my country, my people will not obey my orders without it«. Ebd., S. 141. Ob vom Übersetzer eigenwillig oder nach Wunsch von Yohannəs IV. eingefügt, schreibt dieser Satz der Handschrift eine nahezu sakrale Stellung zu, da die Menschen den Herrschaftsanspruch des Kaisers ohne deren physische Präsenz vermeintlich nicht anerkennen würden. 
zelne Personen, sondern auch die Staaten selbst als Subjekte der christlichen Gemeinschaft dargestellt. Dies gründete in einer im Kern theologischen Auffassung von staatlicher Ordnung. Diese Vorstellung brachte Yoḥannəs IV. mit Hilfe einer anthropomorphen Metapher zur Sprache: So setzte er in der Ansprache zu Beginn des bereits erwähnten Konzils in Boru Meda den Staat dem menschlichen Körper gleich, die Religion mit dessen Seele. ${ }^{14}$

Eine solche theologisch gefärbte Konzeptualisierung des Staates und der zwischenstaatlichen Gemeinschaft hatte weitreichende Implikationen für die äthiopische Wertung der europäischen Kolonisierung Afrikas, die um die Jahrhundertwende im Wesentlichen abgeschlossen war. (Äthiopien behielt dabei als nahezu einziges Land auf dem ganzen Kontinent seine Unabhängigkeit.) So stellte der Nachfolger von Yohannəs IV., der äthiopi-

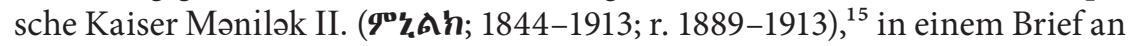
Wilhelm II. (1859-1941; r. 1888-1918) die Kolonisierungsprozesse am Horn von Afrika vornehmlich als eine Veränderung der religiösen Landschaft der Region dar und unterzog sie einer dezidiert theologischen Deutung:

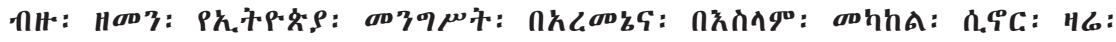

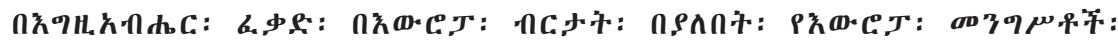

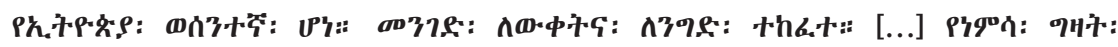

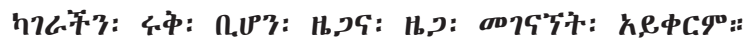

Der äthiopische Staat lebte seit vielen Jahrhunderten inmitten der Muslime und Heiden, jetzt aber sind die europäischen Mächte durch den Willen Gottes und durch die Bemühungen Europas von allen Seiten Nachbarn Äthiopiens geworden. Der Weg des Wissens und des Handels ist geöffnet. [...] Auch wenn das Territorium Deutschlands sehr weit von unserem Land entfernt liegt, werden sich Angehörige beider Staaten gewiss begegnen. ${ }^{16}$

14 »l est dit que, sans le corps, l'âme ne peut vivre; aussi nous avons tout d'abord opéré notre réconciliation et traité les affaires de l'empire. Dorénavant, nous allons nous occuper des affaires de la foi. La foi, comme il est dit, est le fondement, tout le reste est passager et périssable«. Coppet (Hg.), Chronique, Bd. I, S. 151. Vgl. auch: J.-B. CoulBEAUX, Histoire politique et religieuse d'Abyssinie depuis les temps les plus reculés jusqu'à l'avènement de Ménélick II, Paris 1929, Bd. 2, S. 481f.

15 Zu Mənilək II. siehe: Christopher Clapham, Mənilək II., in: EAE 3, 2007, S. 922-927; Harold G. Marcus, The Life and Times of Menelik II. Ethiopia 1844-1913, Lawrenceville NJ 1995; Chris Prouty, Empress Taytu and Menelik II. Ethiopia 1883-1910, London 1986.

16 PA AA, A 14623. Brief von Mənilək II. an Wilhelm II. vom 7. Hamle 1893 A.M. [= 14. Juli 1901]. Vgl. Bairu Tafla, Ethiopia and Germany, S. 230-233. Übersetzung - S.P. 
Diese Aussage ist nicht einfach der Rhetorik geschuldet, vielmehr akzentuiert sie den christlichen - und daher, aus der Sicht Məniləks II., gottge-

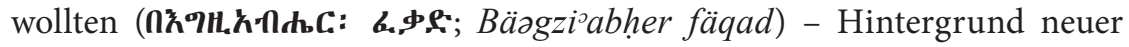
politischer Herrschaftsordnungen, und begrüßt sie als ein langersehntes Aufbrechen der religiösen Isolation, in der das christliche Äthiopien sich seit jeher befunden habe. Was die Ursachen dieser Isolation angeht, lassen sich in den Briefen unterschiedliche inhaltliche Akzentuierungen in den Abgrenzungen gegen die religiös Anderen feststellen: In einem Schreiben präsentiert Mənilək II. Äthiopien als »eine Insel der Christen im Ozean der

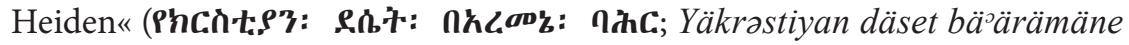
baḩr $),{ }^{17}$ in einem anderen Brief stellt er allerdings fest, dass es »die Wüste

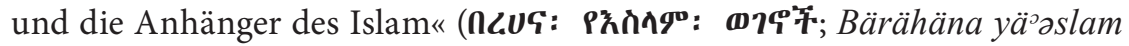
wägännočč) gewesen seien, die für eine lange Zeit den Kontakt mit den

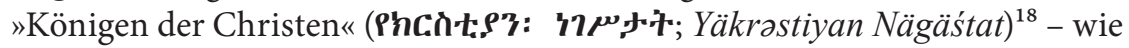
Mənilək II. die europäischen Herrscher bezeichnete - verhinderten. ${ }^{19}$ Die neuen europäischen Kolonien in der unmittelbaren Nähe Äthiopiens - es war von europäischen Kolonialgebieten buchstäblich eingekreist $-{ }^{20}$ wurden deswegen als die Enklaven des Christentums dargestellt, die eine lange Isolation des christlichen Äthiopiens durchbrochen hatten. In diesem Kontext erachtete Mənilək II. auch die deutsch-äthiopischen Kontakte als unvermeidlich und plädierte für eine engere Kooperation.

17 PA AA, A 6118. Brief von Mənilək II. an Wilhelm II. vom 14. Miyazya 1883 A. M. [=21. April 1891]. Vgl. Bairu Tafla, Ethiopia and Germany, S. 214-217.

18 Ebd.

19 PA AA, A 2829. Brief von Mənilək II. an Wilhelm II. vom 6. Tahśaś 1882 A.M. [= 15. Dezember 1889]. Vgl. ebd., S. 208-221. Der Nachdruck, mit dem Mənilək II. die nicht-christlichen Gemeinschaften für den bis daher mangelnden Kontakt Äthio-

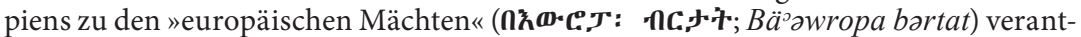
wortlich machte, hatte auch innenpolitische Gründe. Da die im Laufe der Ausbreitung Äthiopiens eroberten Gebiete, ähnlich wie die von europäischen Kolonialmächten beherrschten Teile Afrikas, vorwiegend von nicht-christlicher Bevölkerung bewohnt waren, bedeutete diese Expansion einen radikalen Wandel des Landes. In seiner Korrespondenz mit Wilhelm II. brachte Mənilək II. die europäische Expansion und seine Unterwerfungszüge am Horn von Afrika in einen unzweideutigen Zusammenhang und verwies auf das Christentum als Grund dieser Erfolge. Vgl. PA AA, A 6118. Brief von Mənilək II. an Wilhelm II. vom 14. Miyazya 1883 A. M. [=21. April 1891]. Vgl. Bairu Tafla, Ethiopia and Germany, S. 214-217. Dabei präsentierte Mənilək II. die Eingliederung der neuen Gebiete in das Äthiopische Kaiserreich als eine Wie-

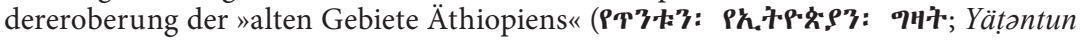
yä̊itวyopayan gazat).

20 Europäische Kolonialgebiete um das Äthiopische Kaiserreich: Italiens - Eritrea und Italienisch-Somaliland (der Süden und das Zentrum des heutigen Somalia); Großbritanniens - Sudan, Britisch-Ostafrika (das heutige Kenia) und das Britische Somaliland (Norden des heutigen Somalia); Frankreichs - Französisch-Somaliland (das heutige Dschibuti). 
Sowohl die äthiopischen (Yoḥannəs IV. und Mənilək II.) als auch die deutschen (Wilhelm I. und Wilhelm II.) Kaiser pflegten in ihrer Korrespondenz eine Rhetorik, die das gemeinsam Christliche in den Vordergrund rückte. Diese dezidiert transkonfessionelle Christentumsauffassung erwies sich als maßgebend für das Vorantreiben diplomatischer Annäherung zwischen den beiden Ländern im späten 19. bis frühen 20. Jahrhundert. Es gilt jedoch, sie vor dem Hintergrund der jeweiligen Konfessionskulturen und politischen Interessen der Akteure kritisch zu hinterfragen.

\subsection{Der Theologe als Politiker: Adolf Harnack und die deutsche Äthiopien-Diplomatie}

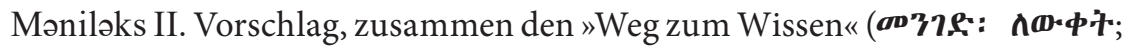
Mängäd läwaqqüt) zu beschreiten, dürfte bei dem orientbegeisterten Kaiser Wilhelm II. auf großen Zuspruch gestoßen sein. Jedenfalls erwies sich diese Idee für die Aufnahme konkreter Schritte der zwischenstaatlichen Beziehungen als viel wirkungsmächtiger als die - bis dahin nahezu schon rituell gewordene - gegenseitige Versicherung des gemeinsamen christlichen Glaubens. Auf deutscher Seite trug zum Erfolg dieses Vorschlages die Tatsache bei, dass die Wissenschaft zunehmend als entscheidendes Element in der Erlangung der »deutschen Weltgeltung « angesehen wurde und daher wissenschaftspolitische Interessen bei der Gestaltung der Außenpolitik verstärkt berücksichtigt wurden.

Das verstärkte Interesse der deutschen Regierung an den Verhältnissen in Äthiopien zeigt das ab dem Jahr 1902 deutlich ansteigende Volumen der »Akten betreffend die allgemeinen Verhältnisse zu Abessinien« im Auswärtigen Amt. ${ }^{21}$ Aufmerksam verfolgte und registrierte man in Berlin die aus deutschen Botschaften und Konsulaten eingehenden Berichte sowie internationale Presseartikel, die sich mit Äthiopien befassten. Viel Platz nahmen dabei die Berichte über die äthiopischen Gesandtschaften des Ras Mäkwännən

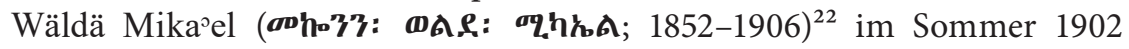
nach London und Paris ein, sowie weiterhin die Reisen des Oberhauptes

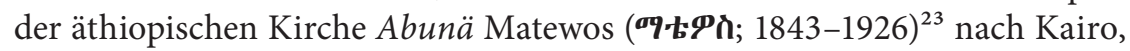

21 PA AA, R 14890.

22 Zu Ras Mäkwännən Wäldä Mika ${ }^{\supset} e l$, dem Herrscher der ostäthiopischen Provinz Harär und einem der engsten Verbündeten Məniləks II., siehe: Tim Carmichael, Mäkwännən Wäldä Mika ${ }^{\circ} e l$, in: EAE 3, 2007, S. 686f.

23 Abunä Matewos war Mönch im koptischen Pachomios-Kloster, bevor er nach Anfrage von Yohannəs IV. 1881 zusammen mit drei weiteren Mönchen zum Bischof geweiht wurde. Zunächst war er Bischof der Provinz Šäwa, aber als Mənilək II., dem er nahestand, 1889 Kaiser wurde, erlangte er die Erlaubnis des koptischen Papstes Kirellos V. (1831-1927), das damalige Oberhaupt der äthiopischen Kirche, 
Jerusalem, Sankt Petersburg und Konstantinopel, ebenfalls im Sommer 1902. Inhaltlich behandelten die Berichte und Pressestimmen überwiegend den jeweiligen Stand der äthiopischen Beziehungen zu den großen europäischen Mächten und umgekehrt deren Interessenpolitik gegenüber Äthiopien.

Den Akten kann man entnehmen, dass die im Sommer 1901 an Wilhelm II. gerichtete Einladung des äthiopischen Kaisers, den »Weg des Wissens und des Handels" zusammen zu beschreiten, in Berlin durchaus ernst genommen wurde. ${ }^{24}$ Als die deutschen Politiker der Frage nachgingen, ob die Entsendung einer diplomatischen Mission nach Addis Abeba an der Zeit und wünschenswert wäre, rückte Äthiopien auch ins Augenmerk der deutschen Wirtschaftskreise; viele Kaufleute sahen in dem afrikanischen Kaiserreich einen vielversprechenden und noch nicht erschlossenen Absatzmarkt. Eine zentrale Rolle spielte dabei der Konzessionsjäger Arnold Holtz. ${ }^{25}$ Die Reaktion des Auswärtigen Amtes auf die Eingaben des Berliner Geschäftsmanns

zu ersetzen. Die hier erwähnten Reisen nach Kairo, Jerusalem, Konstantinopel und Sankt Petersburg waren mit dem Versuch verbunden, das Problem um das Kloster Dayr as-Sulțān beizulegen. Somit wurde Matewos zum ersten Abunä, der sich auf eine Reise außerhalb Äthiopiens begab. Über ihn siehe: Steven Kaplan, Matewos, in: EAE 3, 2007, S. 867f.

24 PA AA, A 14623, Brief von Mənilək II. an Wilhelm II. vom 7. Hamle 1893 A.M. [= 14. Juli 1901]. Vgl. BAIRU TAfla, Ethiopia and Germany, S. 230-233. In Berlin wurde entschieden, diesem Antrag weder zuzustimmen noch abzusagen, sondern ihn zunächst dilatorisch zu behandeln und die Frage offenzulassen. So antwortete Kaiser Wilhelm II.: »Mit Interesse habe Ich aus dem Schreiben ersehen, daß Ew. Majestät die Frage des Abschlusses eines deutsch-abyssinischen Handelsvertrages anregen. Ich bin zu der Ansicht gelangt, daß zunächst eine nähere Prüfung des Vorschlags durch Meine Regierung stattzufinden hat, deren Ergebniß einer weiteren Mittheilung vorzubehalten sein wird«. PA AA, A 1584, Brief von Wilhelm II. an Mənilək II. vom 10. November 1901.

25 Über Holtz siehe: Bahru Zewde, Concessions and Concession-Hunters in PostAdwa Ethiopia. The Case of Arnold Holtz, in: Africa 45 (1990), S. 365-383; BAIRU TAFlA, Ethiopia and Germany, S. 100-104. Außerdem schilderte Arnold Holtz seine Erlebnisse in Äthiopien in zwei Büchern: Arnold Holtz, Im Auto zu Kaiser Menelik, Berlin 1908; ders., Am Tor der Tränen (Bab el Mandeb). Afrikanische Erlebnisse eines deutschen Kuriers, Berlin 1929. Holtz initiierte eine Informationskampagne in der Presse, wo er - wie bspw. in dem Artikel mit dem sprechenden Titel »Kommen wir wieder zu spät? « in der Neuen Preußischen Zeitung - darauf drängte, dass sich Deutschland nun »in letzter Stunde [um] einen guten Platz an der äthiopischen Sonne« bemühen solle. Neue Preußische Zeitung 332 (18. Juli 1903). Zahlreiche Artikel, in denen die Vorteile der wirtschaftlichen Beteiligung in Äthiopien dargestellt wurden, erschienen u.a. in solchen spezialisierten Zeitschriften wie Export und Deutsche Metall-Industrie-Zeitung. Für einen Überblick siehe: BAIRU Tafla, Ethiopia and Germany, S. 157-159. Im Juli 1903 richtete Holtz ein offizielles Gesuch an die Deutsche Reichsregierung und das Auswärtige Amt, in dem er beide Stellen bat, die Aufnahme diplomatischer Beziehungen mit Äthiopien wohlwollend zu prüfen, um den deutschen Handel in Äthiopien zu fördern; er selbst wolle sich an diesem Handel im Namen eines von ihm initiierten Firmensyndikats beteiligen und suche daher um Unterstützung der deutschen Regierung. PA AA, R 14890, Eingabe des Kaufmannes Arnold Holtz an Reichskanzler von Bülow vom 23. Juli 1903. Zu diesem Zweck schlug 
und seiner handelspolitischen Visionen war zurückhaltend bis skeptisch. Auch das Referat für überseeischen Handel gelangte in seinem Vermerk vom 15. August $1903 \mathrm{zu}$ der Einschätzung, dass »unsere wirtschaftlichen Beziehungen mit Abessinien zur Zeit noch nicht erheblich genug sind, um die Errichtung einer konsularischen Vertretung dort dringlich erscheinen $\mathrm{zu}$ lassen $«{ }^{26}$ Nichtsdestotrotz entschloss sich die deutsche Regierung Mitte 1904 - und zwar »unabhängig von Herrn Holtz« - eine kaiserliche Gesandtschaft nach Addis Abeba zu entsenden. ${ }^{27}$ Es muss angenommen werden, dass der Entscheidung, Beziehungen zum Hofe Məniləks II. aufzunehmen, andere Motive zugrunde gelegen haben müssen als wirtschaftliche. ${ }^{28}$

Die zu organisierende diplomatische Mission an den Hof des äthiopischen Kaisers war in vielerlei Hinsicht außergewöhnlich und erforderte Expertise, die im Auswärtigen Amt nicht vorhanden war. Um diese Lücke zu schließen, wurde ein Gutachten in Auftrag gegeben, das sich zu der Lage in Äthiopien sowie zu den zu verwendenden Strategien äußern sollte. Der deutschen Regierung sollte dabei niemand anderes beratend zur Seite stehen als Adolf Harnack (1851-1930; ab 1914 von Harnack), wohl der berühmteste Theologe seiner Generation.

Adolf Harnack gehörte nicht nur zu den bekanntesten Theologen seiner Zeit, sondern galt auch als die führende wissenschaftliche Gestalt Deutschlands. Allerdings verdankte er seinen Einfluss außer seiner beachtlichen wissenschaftlichen Produktivität und seinen wissenschaftsorganisatorischen Gaben auch seinen guten Kontakten zu den politischen Entscheidungsträgern. Harnack unterhielt enge Beziehungen sowohl zu Reichskanzler Bernhard von Bülow (1849-1929) als auch zu dem einflussreichen Politiker Friedrich Althoff (1839-1908), dem faktisch das gesamte Unterrichts- und Hochschulwesen in Preußen unterstellt war. ${ }^{29}$ Darüber hinaus gehörte der Theologieprofessor zum engen Vertrautenkreis Wilhelms II., und dies trotz Harnacks kritischer Reaktion auf die Position, die der Kaiser im Babel-Bibel-

Holtz vor, dass er die konsularische Vertretung des Deutschen Reiches in Äthiopien übernehmen könne. Vgl. PA AA, R 14890, Brief von Arnold Holtz an Friedrich Rosen vom 23. Juli 1903.

26 PA AA, R 14891, Vermerk des überseeischen Handelsreferats des Auswärtigen Amtes vom 15. August 1903.

27 PA AA, R 14915, Aufzeichnungen Friedrich Rosens über Arnold Holtz, 1905.

28 Dies verdeutlicht zudem die Tatsache, dass Wilhelm II. persönlich dem Kultusminister Konrad Studt (1838-1921; ab 1906 von Studt) die Zuständigkeit für die Vorbereitung und Durchführung der Reise - und nicht etwa seinem Kollegen aus dem Handelsministerium, Theodor Adolf Möller (1840-1925; ab 1905 von Möller), übertrug.

29 Vgl. Christian Nottmeier, Adolf von Harnack und die deutsche Politik 1890-1930. Eine biographische Studie zum Verhältnis von Protestantismus, Wissenschaft und Politik, Tübingen 2004, S. 288. 
Streit einnahm. ${ }^{30}$ Eines seiner zentralen Anliegen, das auch Wilhelm II. teilte, war die Verbindung zwischen »Weltpolitik« und Wissenschaft, die Harnack nebst der Wehrkraft als den wichtigsten »Pfeiler der Größe Deutschlands" ansah. ${ }^{31}$ Im Jahr 1904 - in dem die Entscheidung über die Entsendung einer außerordentlichen kaiserlichen Gesandtschaft nach Äthiopien fiel - wurde Harnack zeitweise wöchentlich zum Kaiser gebeten. ${ }^{32}$ In dieses Jahr fällt auch die verstärkte Beschäftigung Adolf Harnacks mit der Gestaltung der deutschen auswärtigen Kulturpolitik. Er selbst setzte sich in verschiedensten Gremien für die Beteiligung der Kirche und der Wissenschaft an der Gestaltung der Außenpolitik im Sinne der kulturellen Selbstdarstellung und aktiver Kulturpropaganda ein. ${ }^{33}$ Insofern verbanden sich bei seinen Unternehmungen kirchliche, wissenschaftliche sowie nationalpolitische Erwägungen. Diese schlugen sich auch in seinem Gutachten über die geplante deutsche diplomatische Mission nach Äthiopien nieder.

Durch seine gutachterliche Tätigkeit bekam Harnack die Möglichkeit, Einfluss auf die Politik zu nehmen und damit seine eigenen wissenschaftspolitischen Vorstellungen durchzusetzen. Da ihm dies durchaus bewusst

30 Auf das Bekenntnis des Kaisers zur positiven Theologie, das durch zahlreiche Zeitungen Europas gegangen war, folgte eine ebenso öffentliche Antwort von Adolf Harnack. Das Schreiben des Kaisers erklärte Harnack als ein Manifest persönlicher Frömmigkeit, das nicht die Freiheit der Forschung gefährden wolle. Darauf folgte eine längere - diesmal aber vertrauliche - Diskussion zwischen dem Theologen und dem Kaiser über Offenbarung und Wissenschaft. Siehe dazu: Stefan RebenICH, Theodor Mommsen und Adolf Harnack. Wissenschaft und Politik im Berlin des ausgehenden 19. Jahrhunderts. Mit einem Anhang: Edition und Kommentierung des Briefwechsels, Berlin u.a. 1997, S. 541-543. Über die Verwicklung Harnacks in die Politik des wilhelminischen Deutschlands vor dem Ersten Weltkrieg siehe: Christian Nottmeier, »Die Kunst, die Rede auf das zu bringen, was ich wünsche«. Adolf von Harnack und Wilhelm II., in: Jürgen Kampmann / Wilhelm HüffmeIER (Hg.), Wilhelm II. - Kaiser, König, Kirchenmann. Ein Herrscher, der niemals reif wurde, Bielefeld 2014, S. 79-111; NotTMEIER, Adolf von Harnack, S. 233-379.

31 Vgl. Adolf Harnack, Zur Kaiserlichen Botschaft vom 11. Oktober 1910. Begründung von Forschungsinstituten, in: Ders., Aus Wissenschaft und Leben. Reden und Aufsätze, Neue Folge, Gießen 1911, Bd. 1, S. 39-64, hier S. 57. Vgl. auch Christian Nottmeier, Protestantische Theologie und auswärtige Kulturpolitik. Das Beispiel Adolf von Harnack, in: Claus Arnold/Johannes Wischmeyer (Hg.), Transnationale Dimensionen wissenschaftlicher Theologie, Göttingen u.a. 2013, S. 71-87, hier S. 78f.

32 Vgl. Nottmeier, Adolf von Harnack, S. 251.

33 An dieser Stelle seien zwei Beispiele solchen Engagements in diesem Jahr genannt: 1904 wurde Harnack in den Vorstand des Allgemeinen Evangelisch-protestantischen Missionsvereins (später: Deutsche Ostasienmission) berufen, einem von liberalen Theologen dominierten Missionswerk, das in China und Japan tätig war. Er war außerdem einer der Initiatoren des ebenso 1904 ins Leben gerufenen deutsch-amerikanischen Professorenaustausches. Vgl. Nottmeier, Protestantische Theologie, S. 71-87; Rüdiger vom BRUCH, Weltpolitik als Kulturmission. Auswärtige Kulturpolitik und Bildungsbürgertum in Deutschland am Vorabend des Ersten Weltkrieges, Paderborn u. a. 1982, S. 46. 
war, konstatierte er zu Anfang seines Gutachtens die hohe Bedeutung des Christentums für die äthiopische Gesellschaft und Politik. Äthiopien sei ein »wenn auch verwildertes«, so doch »christliches Land« und dort stelle kirchliches und staatliches Leben - "wie fast überall im Orient« - eine Einheit dar. ${ }^{34}$ Deswegen sah Harnack auch das durch Mənilək II. eingeleitete Modernisierungspojekt mit den Überlieferungen der Kirche verbunden. Das äthiopische Kaiserpaar sei nach Harnacks Urteil nicht nur »in ihrer Weise religiös-kirchlich lebhaft interessiert", sondern auch »stolz auf ihr nationales (monophysitisches) Christentum $«{ }^{35}$ Diese Zuschreibungen waren nicht zufällig, vielmehr waren sie in seiner Theologie und Denkwelt verankert.

Theologie betrachtete Harnack in Anlehnung an Albrecht Ritschl (18221889) und unter dem Einfluss des geschichtlichen Denkens, das die zweite Hälfte des 19. Jahrhunderte beherrschte, als eine historische Wissenschaft. Die Aufgabe der Theologie sei es gewesen, die wesentlichsten Elemente des christlichen Glaubens herauszuarbeiten, die oft unter verwirrenden und belastenden Traditionen verborgen seien. ${ }^{36}$ Dogmengeschichte war für Harnack dementsprechend zuerst und vor allem Dogmenkritik, die mit den Mitteln der historischen Forschung dazu beitrug, den christlichen Glauben von dogmatischen Sätzen oder Glaubensvorschriften zu befreien und ihm seinen ursprünglichen Platz in einer individuell bestimmten religiösen Innerlichkeit zurückzugeben. ${ }^{37}$ Die verschiedenen Erscheinungen der Kirchengeschichte haben sich dabei an der Entstehungszeit des Christentums und dem ursprünglichen Evangelium messen zu lassen. ${ }^{38}$ Als Ideal sah Harnack ein einfaches, dogmenfreies Christentum, das sich unmittelbar auf die Botschaft Jesu gründete und das in seinen Augen die Grundlage von Luthers Reformation gebildet hatte. Er war überzeugt, dass mit dem Protestantismus das Ende des dogmatischen Christentums gekommen und es Aufgabe der Theologen sei, die Dogmen als Relikte einer vergangenen Zeit erkennbar werden zu lassen. Im Gegensatz zu diesem dogmenfreien Christentum stellte Harnack die orthodoxen - und zwar sowohl die byzantinischen als auch die

34 PA AA, R 14914, Nr. 19757. Immediatbericht des Cultus- und Finanzministers an Kaiser Wilhelm II., 22. Dezember 1904.

35 Ebd.

36 Vgl. Wolfgang A. Bienert, Die ökumenische Bedeutung von Harnacks Verständnis der Alten Kirche, in: Peter Gemeinhardt / Karl PingGéra (Hg.), Kirchengeschichte in ökumenischer Verantwortung. Ausgewählte Studien, Göttingen 2009, S. 29-51, hier S. 32.

37 Ebd., S. 35. Vgl. dazu bspw.: »Jede Religion gewinnt durch die Zeit nichts, sondern verliert nur. Wenn nicht immer wieder ein Sturmwind über sie herfegt und sie reinigt, erstickt sie in ihrem eigenen dürren Laube«. Adolf Harnack, Lehrbuch der Dogmengeschichte, Leipzig ${ }^{4}$ 1910, Bd. 2: Die Entwicklung des kirchlichen Dogmas I, S. 473 .

38 Vgl. Bienert, Die ökumenische Bedeutung, S. 31. 
orientalischen - Kirchen dar. So hält er in seinem Lehrbuch der Dogmengeschichte fest:

Wer heute den Zustand der griechischen Religion bei Orthodoxen und Monophysiten studiert, nicht nur die Religion des rohen Volkes, sondern auch das Cultusritual, die magischen Ceremonien und die Vorstellungen der gemeinen Priester und Mönche, der wird an vielen Stellen den Eindruck erhalten, dass es eine tiefere Stufe der Religion kaum geben kann. ${ }^{39}$

Die institutionell verfestigten orthodoxen Kirchen stellten für Harnack somit eine Negativfolie des »ursprünglichen« Christentums dar. In seinem Wesen des Christentums, einem der wirkmächtigsten theologischen Werke des deutschen Protestantismus, konstatierte er darüber hinaus: „Das System der orientalischen Kirchen ist als Ganzes und in seiner Struktur etwas dem Evangelium Fremdes ${ }^{40}{ }^{40}$

Der Grund für solche Urteile steht im Zusammenhang seiner Kritik an der »hellenistischen Überfremdung«, an der tatsächlichen oder vermeintlichen Unterwerfung der »originären« christlichen Religion unter die Metaphysik. ${ }^{41}$ Doch das erklärt noch nicht ganz sein auffallend scharfes antiorthodoxes Ressentiment. Seine Urteile über die orthodoxen Kirchen gehören zu den undifferenziertesten Teilen seines gesamten Oeuvres und erwecken über weite Strecken den Eindruck nicht nur des Pauschalurteils, sondern »des notorischen Vorurteils«, wie es Gunther Wenz trefflich bemerkte. ${ }^{42}$ Die antiorthodoxe Rhetorik Harnacks scheint ein Ausdruck des Abgrenzungsbedürfnisses des in Dorpat, im Ostseegouvernements des Russischen Reiches, geborenen und aufgewachsenen Baltendeutschen Richtung Osten zu sein. ${ }^{43}$

39 Harnack, Lehrbuch der Dogmengeschichte, S. 438.

40 Ders., Das Wesen des Christentums. Sechzehn Vorlesungen vor Studierenden aller Fakultäten im Wintersemester 1899/1900 an der Universität Berlin, Leipzig 1900, S. 156. Es ist bemerkenswert, dass nahezu alle Kritikpunkte, die Harnack gegen die orthodoxen Kirchen vortrug, seiner Kritik am Judentum - seinem theologischen Antijudaismus - entsprachen. Vgl. dazu Sonja Lukas-Klein, Das ist (christliche) Religion. Zur Konstruktion von Judentum, Katholizismus und Protestantismus in Adolf von Harnacks Vorlesungen über »Das Wesen des Christentums«, Berlin 2014, S. 147.

41 Vgl. Gunther Wenz, Offenbarung. Problemhorizonte moderner evangelischer Theologie, Göttingen 2005, S. 171.

42 Ebd. In diesem Zusammenhang sprach auch Ernst Benz von den negativen Urteilen Harnacks gegenüber den orthodoxen Kirchen - die auch stilistisch eine besondere Schärfe und Schroffheit aufweisen - als Ergebnis von »affektiven Impulsen« in dem sonst "so verbindlichen und liebenswürdigen Wesen" Harnacks. Ernst BENZ, Die Ostkirche im Lichte der protestantischen Geschichtsschreibung von der Reformation bis zur Gegenwart, Freiburg i. Br. u.a. 1952, S. 232.

43 Vgl. Gunther Wenz, Der Kulturprotestant. Adolf von Harnack als Christentumstheoretiker und Kontroverstheologe, München 2001, S. 77f.; NotTmeiER, Adolf von 
Das negative Bild des östlichen Christentums bei Harnack wurde wohl durch die Eindrücke seiner baltischen Jugendzeit bestimmt. Der nahezu das ganze 19. Jahrhundert tobende »Kulturkampf« um die Russifizierung des Baltikums hinterließ tiefe Spuren in der dortigen protestantischen Kirchlichkeit. An den Auseinandersetzungen des baltischen Luthertums mit der russischen Orthodoxie beteiligte sich mit großem Engagement auch Harnacks Vater Theodosius (1816-1889), Theologieprofessor an der Universität Dorpat. ${ }^{4}$ Die Haltung des baltischen Luthertums, die Harnack zweifellos erbte, äußerte sich Russland gegenüber in dem Gefühl nicht nur einer kulturellen und geistigen, sondern auch religiösen Überlegenheit. ${ }^{45}$ Zwar richtete sich sein Ressentiment ursprünglich gegen die russische Orthodoxie, doch übertrug er es später auch auf die anderen orthodoxen Kirchen. Dabei räumte er den Äthiopiern einen besonderen Platz in seinem Denksystem ein, wie es im Wesen des Christentums deutlich wird. Dort nahm Harnack eine Hierarchisierung unter den orthodoxen Kirchen vor und platzierte dabei die äthiopischen Christen zusammen mit den Kopten auf der niedrigsten Stufe:

Nichts ist trauriger zu sehen als diese Umwandlung der christlichen Religion aus einem Gottesdienst im Geist und in der Wahrheit zu einem Gottesdienst der Zeichen, Formeln und Idole! Man braucht gar nicht bis zu den religiös völlig verwahrlosten Gliedern dieser Christenheit, zu Kopten und Abessyniern [sic!] herunterzusteigen, um diese Entwicklung schaudernd zu erkennen - auch bei Syrern, Griechen und Russen ist es im ganzen nur um weniges besser. [...] Um diese Art von Religion aufzulösen, hat sich Jesus Christus ans Kreuz schlagen lassen [Hervorhebung Harnacks]; nun ist sie unter seinem Namen und seiner Autorität wieder aufgerichtet! ${ }^{46}$

Harnack, S. 23f. Ernst Benz berichtet über eine Mitteilung Professor Alivisatos' von der Universität Athen, der als langjähriger Schüler Adolf Harnacks in Berlin studierte. Dieser habe wiederholt mit Harnack Gespräche über den Grund seiner radikalen Abwertung der östlich-orthodoxen Kirche geführt. Harnack habe ihm gegenüber dabei offen zugegeben, dass sich seine Anschauung von der heutigen Form der östlich-orthodoxen Kirche im Wesentlichen durch die Russische Kirche gebildet habe, wie er sie in seiner Jugend kennengelernt habe. Benz, Die Ostkirche, S. 232.

$44 \mathrm{Vgl}$. Nottmeier, Adolf von Harnack, S. 23-25. Zu Theodosius Harnack siehe: Martin Doerne, Harnack, Theodosius Andreas, in: NDB 7, Berlin 1966, S. $690 \mathrm{f}$.

45 Vgl. Ernst Benz, Geist und Leben der Ostkirche, Hamburg 1957, S. 180; Wilhelm Kahle, Die Begegnung des baltischen Protestantismus mit der Russisch-Orthodoxen Kirche, Leiden u. a. 1959, S. 273.

46 Harnack, Das Wesen des Christentums, S. 148. Zu seiner späteren Position gegenüber den orthodoxen Kirchen vgl. Adolf von HARnACK, Der Geist der morgenländischen Kirche im Unterschied von der abendländischen, in: SPAW Erster Halbband (1913), S. 157-183. 
Dass ausgerechnet die afrikanischen Christen, die Äthiopier und die Kopten, in seinen Ausführungen als »religiös völlig verwahrlost« galten, kann auf eine rassistisch geprägte Klassifikationspraxis zurückgeführt werden. ${ }^{47}$

Im Kontext der diplomatischen Bemühungen sollte natürlich ein anderes Bild nach Außen transportiert werden. In seinem Gutachten sprach Harnack sich dafür aus, die große Tradition der deutschen Gelehrsamkeit im Bereich der Äthiopistik von Hiob Ludolf bis zu August Dillmann als Beweis der Wertschätzung des äthiopischen Christentums zu präsentieren. Zur Audienz bei dem äthiopischen Kaiser sollte die deutsche Gesandtschaft nach Harnacks Empfehlung mit einer wertvollen Gabe erscheinen, nämlich mit den wichtigsten auf Äthiopisch in Deutschland gedruckten theologischen Büchern. Diese »kleine Bibliothek von 1 bis 2 Dutzend Bücher[n] « sollte das beste Zeugnis des lebhaften deutschen Interesses an und Wohlwollen gegenüber dem Äthiopischen Kaiserreich ablegen.

Wir haben also allen Grund, wenn wir jetzt nach Abessinien gehen, unser Licht nicht unter den Scheffel zu stellen, sondern den Abessiniern zu zeigen, daß wir unter allen Nationen Europas ihre Sprache, Literatur und Geschichte am besten kennen. Der Kaiser und seine Priester und Gelehrten sollen erfahren, daß wir uns in Deutschland seit Generationen eingehend mit der Geschichte ihres Landes beschäftigen und daß wir gesammelt und studiert haben, was wir nur irgend erlangen konnten. Das wird den Abessiniern Respekt und Bewunderung unserer weltgeschichtlichen Umsicht und unserer Wissenschaft einflößen und in hohem Maße dazu beitragen, ihr Vertrauen zu gewinnen. ${ }^{48}$

Es sollte jedoch nicht nur Wissenschaft für Deutschland auf dem diplomatischen Feld nützlich werden, sondern auch das Umgekehrte sollte gelten. Nach Harnacks Plan sollte ein Gelehrter die deutsche Gesandtschaft begleiten, »der die Sprache, Kirche und Literatur dieses Volkes kennt«. Die für ihn vorgesehene Aufgabe bestand darin, zu verstehen, was das Land »noch" an alten äthiopischen Manuskripten besitzt und diese für die deutsche Wissenschaft - »sei es durch Schenkung des abessinischen Kaisers, sei es durch Kauf - besorgen. ${ }^{49}$

Dank des Gutachtens Harnacks standen Fragen um die Anwendung des bereits vorhandenen und die Gewinnung von neuem Wissen im Mittelpunkt der strategischen Überlegungen bezüglich der diplomatischen Mission nach Äthiopien. Die bereits vorhandenen Kenntnisse und Leistungen sollten einer-

47 Zur Frage nach dem Verhältnis von Rassismus und Antisemitismus im Wesen des Christentums siehe: LuKAS-KLEIN, Das ist (christliche) Religion, S. 142-148.

48 PA AA, R 14914, Nr. 19757. Immediatbericht des Cultus- und Finanzministers an Kaiser Wilhelm II., 22. Dezember 1904.

49 Ebd. 
seits dafür benutzt werden, Respekt und Bewunderung gegenüber Deutschland in Äthiopien hervorzurufen, andererseits aber wurde die diplomatische Mission - neben anderen Zwecken - selbst als Medium gesehen, mit Hilfe dessen neue Kenntnisse gewonnen werden sollten. Darin bestand die Besonderheit der deutschen diplomatischen Gesandtschaft. Kein anderes Land, das eine diplomatische Mission nach Äthiopien schickte, verband damit ein ambitioniertes wissenschaftliches Vorhaben.

Dass das Sammeln äthiopischer Handschriften zu einer der zentralen Aufgaben der deutschen Gesandtschaft wurde, lag nicht zuletzt an den wissenschaftspolitischen Ambitionen Harnacks. Als 1904 der Nachfolger für den zu emeritierten Direktor der Königlichen Preußischen Staatsbibliothek August Wilmanns (1833-1917) gesucht wurde, votierte Friedrich Althoff für Harnack, der bereits als Rektor der Humboldt-Universität in den Jahren 1900-1901 Erfahrung mit der preußischen Bibliothekspolitik gesammelt hatte. ${ }^{50}$ Anfang November 1904 - also wenige Wochen vor der Abfassung des »Äthiopien-Gutachtens « - signalisierte Harnack seine Einwilligung, das Amt zu übernehmen. ${ }^{51}$ Mit seiner neuen Position verband Harnack ein ambitioniertes Vorhaben: Die Bibliothek stellte für ihn nicht ein »isoliertes Institut« dar, "sondern den Mittelpunkt eines großen Systems, welches unser ganzes Vaterland umspannt ${ }^{52}$ Harnacks Vision war, mit der Leitung der Staatsbibliothek nicht nur einen Beitrag zur effizienten Wissenschaftsorganisation zu leisten, sondern sie zum neuen wissenschaftspolitischen Zentrum Deutschlands auszubauen. Somit wollte Harnack Deutschland dazu zu verhelfen, sich als weltweit führender Forschungsstandort zu etablieren. Damit verband er den Anspruch, ein umfassendes Bild außerdeutscher Wissenschaft und Kultur in den Beständen der Bibliothek bieten zu können. In seiner Antrittsrede als Bibliotheksdirektor sprach Harnack gar vom »nationalen Beruf« der Deutschen, »zu unserer eigenen Arbeit auch noch alles aufnehmen und doppelt wiedergeben [zu müssen], was wir empfangen ${ }^{53}{ }^{53}$

$\mathrm{Zu}$ den Beständen, deren Aufstockung und Verbesserung in den Augen Harnacks am nötigsten war, um mit den Bibliotheken Englands und Frank-

50 Nottmeier, Adolf von Harnack, S. 264.

51 Vgl. ebd. und Rudolf Vierhaus, Im Großbetrieb der Wissenschaft. Adolf von Harnack als Wissenschaftsorganisator und Wissenschaftspolitiker, in: Kurt Nowak / Otto Gerhard Oexle (Hg.), Adolf von Harnack. Theologe, Historiker, Wissenschaftspolitiker, VMPIEG 161, Göttingen 2001, S. 419-440, hier S. 422.

52 Adolf von Harnack, Ansprache bei der Übernahme der Generalverwaltung der Königlichen Bibliothek (1905), in: Axel von HarnaCK (Hg.), Aus der Werkstatt des Vollendeten. Als Abschluss seiner Reden und Aufsätze, Reden und Aufsätze, Gießen 1930, S. 3-6, hier S. 4.

53 Ebd., S. 5. Harnacks Einführung in das neue Amt erfolgte am 2. Oktober 1905 durch Kultusminister Studt. Als Generaldirektor leitete Harnack die Königliche Bibliothek bis zum Jahr 1921. Zu Harnack als Bibliotheksdirektor siehe: NotTmeier, Adolf von Harnack, S. 264, Anm. 157. 
reichs konkurrieren zu können, gehörten vor allem die orientalischen Manuskripte. Zu jener Zeit verfügte die Berliner Königliche Bibliothek mit ihren 87 äthiopischen Handschriften zwar über die größte Sammlung äthiopischer Manuskripte in Deutschland, doch im internationalen Vergleich schnitt sie nicht gut ab. ${ }^{54}$ Nach dem Plan Harnacks sollte dieser Sachverhalt durch die diplomatische Gesandtschaft nach Äthiopien zugunsten Deutschlands geändert werden.

Mit der Aufgabe, in Äthiopien im Rahmen der diplomatischen Mission Handschriften zu sammeln - und somit einen wichtigen Beitrag zum wissenschaftspolitischen Projekt Harnacks zu leisten - war auf Befehl Seiner Majestät des Kaisers und im Auftrag des Ministeriums der geistlichen, Unterrichts- und Medizinalangelegenheiten der Orientalist und Bonner Oberbibliothekar Johannes Flemming (1859-1914) beauftragt. Diese Entscheidung ist wohl nicht ohne Einflussnahme Harnacks getroffen worden, der Flemming persönlich kannte, und zwar durch die von ihm gemeinsam mit Theodor Mommsen (1817-1903) im Jahre 1891 konstituierte »KirchenväterCommission « der Preussischen Akademie der Wissenschaften. ${ }^{55}$ Johannes Flemming war insofern eine gute Wahl, als er bereits Erfahrungen mit der Gəəə⿸尸二 biblische äthiopische Kodizes sowie Handschriften, Papiere und Briefe von Hiob Ludolf; ${ }^{56}$ und um die Jahrhundertwende arbeitete er an der kritischen Edition und Übersetzung des äthiopischen Henoch-Buches, die 1901 und 1902 im Druck erschien. ${ }^{57}$ Allem Anschein nach konnte Adolf Harnack den Deutschen Kaiser von der Bedeutung seines Vorhabens überzeugen. Denn

54 Vgl. August Dillmann, Die Handschriften-Verzeichnisse der königlichen Bibliothek zu Berlin, Berlin 1878, Bd. 3: Verzeichnis der abessinischen Handschriften.

55 Zur Kirchenväterkommission und Harnacks Tätigkeit in ihr siehe: ReBenich, Theodor Mommsen und Adolf Harnack, S. 129-326 und ders. / Christoph MARKschies (Hg.), Protokollbuch der Kirchenväter-Kommission der Preußischen Akademie der Wissenschaften 1897-1928, Berlin u.a. 2000, S. 116 und 121. Die Bekanntschaft zwischen Johannes Flemming und Adolf Harnack ging später in eine engere wissenschaftliche Kooperation über, indem sie die neu entdeckten Oden Salomos gemeinsam bearbeiteten: Adolf Harnack / Johannes Flemming (Hg.), Ein jüdischchristliches Psalmbuch aus dem ersten Jahrhundert, TU 35,4, Leipzig 1910.

56 Wilhelm Meyer (Hg.), Die Handschriften in Göttingen, Berlin 1894, Bd. 3: Universitätsbibliothek. Nachlässe von Gelehrten, Orientalische Handschriften. Handschriften im Besitz von Instituten und Behörden, S. 308-314. Vgl. die Ausgabe der Briefe von Abba Gorgoryos an Ludolf: Flemming, Hiob Ludolf [I]; ders., Hiob Ludolf. Ein Beitrag zur Geschichte der orientalischen Philologie [II], in: BASS II (1894), S. 63-110.

57 Vgl. Johannes Flemming / Ludwig Radermacher (Hg.), Das Buch Henoch, GCS 5, Leipzig 1901; Johannes Flemming (Hg.), Das Buch Henoch. Äthiopischer Text mit Einleitung und Commentar, TU 22,1, Leipzig 1902. Das Buch wurde nicht nur von der von Harnack geleiteten "Kirchenväter-Commission" herausgegeben, sondern Harnack unterstützte Flemming tatkräftig durch seine Netzwerke bei der Erlangung einiger Materialien für diese Studie. Vgl. Flemming/Radermacher (Hg.), Das Buch Henoch, S. 13. 
Wilhelm II. äußerte sich auch selbst über die Wichtigkeit von Flemmings Aufgabe, "nach altchristlichen Handschriften zu forschen ", und spendete 10.000 Mark für ihren Erwerb. ${ }^{58}$ Das Sammeln der Gəcəว-Handschriften war derart bedeutsam für die Gesandtschaft, dass Flemming sogar die endgültige Reiseroute der diplomatischen Expedition beeinflussen konnte, indem er die für seine Studien vielversprechenden alten Kaiserstädte Gondär und Aksum auf das Programm setzte.

Warum wurde aber der Suche nach den Handschriften, die ursprünglich nur eine Nebenaufgabe der diplomatischen Mission sein sollte, so viel Gewicht und Aufmerksamkeit zugemessen? Viele hatten gehofft, so Flemming, dass durch die Expedition nicht nur äthiopische, sondern auch »uralte griechische oder koptische Handschriften, zumal der Bibel, daselbst zu Tage kommen möchten ${ }^{59}{ }^{59}$ Diesen wenig realistischen Erwartungen lagen offensichtlich die spektakulären Funde alter Codices zugrunde, die im 19. Jahrhundert - etwa im Katharinenkloster am Berg Sinai - gemacht wurden. ${ }^{60}$ Sie verdeutlichen aber, welche Handschriften privilegiert werden sollten. Der Interessenschwerpunkt lag nicht auf den äthiopischen Handschriften per se, sondern vor allem auf Handschriften, die - seien sie äthiopische, koptische oder griechische - Licht auf die alte christliche Geschichte werfen könnten. Nicht die Eigenart der äthiopischen Theologie und Kultur stand im Fokus, sondern der Versuch, einen Einblick in die urchristliche Welt zu erlangen, diejenige Welt, die mit Hilfe der historisch-kritischen Methode greifbar gemacht werden sollte. Dies aber war ein typisches Programm liberaler protestantischer Theologie, die zu Anfang des 20. Jahrhunderts unter dem Vorzeichen des Historismus stand. ${ }^{61}$

Zusammenfassend: Als die deutsche kaiserliche Sondergesandtschaft mit dem Dampfer »Friedrich der Große« am 25. Dezember 1904 von Neapel aus in See stach, hatte sie nicht nur den Auftrag, diplomatische Beziehungen zum Äthiopischen Reich aufzunehmen und einen Freundschafts- und Handels-

58 PA AA, R 14914, Nr. 19757. Immediatbericht des Cultus- und Finanzministers an Kaiser Wilhelm II., 22. Dezember 1904.

59 Johannes Flemming, Die neue Sammlung abessinischer Handschriften auf der Königlichen Bibliothek zu Berlin, ZfB 23, 1906, S. 9.

60 Man denke etwa an den Codex Sinaiticus, der 1844 von Konstantin von Tischendorf (1815-1874) entdeckt wurde. Das Bibel-Manuskript aus dem 4. Jahrhundert ist nicht nur die älteste vollständig erhaltene Abschrift des Neuen Testaments, sondern auch eine der bedeutendsten Handschriften des griechischen Alten Testaments.

61 Zur Entstehung des Historismus als spezifischer Ausprägung des kulturprotestantischen Denkstils und seinem Einfluss auf die evangelische Theologie sowie die Religionswissenschaft siehe: Michael Murrmann-KaHL, Die entzauberte Heilsgeschichte. Der Historismus erobert die Theologie. 1880-1920, Gütersloh 1992; Thomas Albert HowArD, Religion and the Rise of Historicism. W. M. L. de Wette, Jacob Burckhardt and the Theological Origins of Nineteenth-Century Historical Consciousness, Cambridge 2000 . 
vertrag auszuhandeln, sondern auch in Äthiopien altchristliche Forschungen im deutschen Namen voranzutreiben. Außer wissenschaftlicher Neugier und dem Wunsch, den Ruf Deutschlands durch spektakuläre Funde zu fördern, steckte dahinter auch die Hoffnung, mit Hilfe der neu aufzufindenden Handschriften sich der Antwort auf die Frage zu nähern, die - und diese Auffassung Harnacks teilten viele Theologen der Zeit - lediglich »mit den Mitteln der geschichtlichen Wissenschaft und mit der Lebenserfahrung, die aus erlebter Geschichte erworben ist«, zu beantworten sei. ${ }^{62}$ Und diese Frage war: »Was ist Christentum? was ist es gewesen, was ist es geworden? «" ${ }^{63}$

\section{Ein Tag, zwei Gottesdienste}

\subsection{Berlin: Wilhelm II. und die Weihe des Berliner Doms}

»Der heutige Tag brachte den Berlinern ein Schauspiel, das an Umfang und äußerem Glanz sobald nicht seinesgleichen findet«: Mit diesen Worten begann das Berliner Tageblatt vom 27. Februar 1905 seinen Bericht über eine herausragende Feier in der Reichshauptstadt - die Einweihung der neuen Oberpfarr- und Domkirche. ${ }^{64}$ Dem neuen Berliner Dom galt »die allgemeine Wallfahrt«, so dass die Menschenmenge, die sich dazu versammelt hatte, von der Schloßbrücke bis zum Brandenburger Tor reichte. ${ }^{65}$

Das neue Gotteshaus entstand am Standort einer kleineren, 1893 abgerissenen Kathedrale und sollte laut dem ursprünglichen Plan bereits 1900 eingeweiht werden. ${ }^{66}$ Insofern der Berliner Dom unter anderem die Funk-

62 Harnack, Das Wesen des Christentums, S. 4.

63 Ebd.

64 Berliner Tageblatt und Handels-Zeitung. Abend-Ausgabe 107 (27. Februar 1905), S. 3. Vgl. auch die tendenziell begeisterte Beschreibung der Einweihung des Berliner Doms in: Hamburgischer Correspondent und Neue Hamburgische Börsen-Halle. Abend Ausgabe 102 (27. Februar 1905), S. 3; Berliner Tageblatt 106 (27. Februar 1905) sowie Neue Preußische Zeitung (Kreuz-Zeitung) 98 (27. Februar 1905).

65 Berliner Tageblatt und Handels-Zeitung. Abend-Ausgabe 107 (27. Februar 1905), S. 3. 66 Ein Diskussionsprozess über die Ersetzung des bescheidenen Vorgängerbaus des Doms, der unter Friedrich dem Großen (1712-1786) errichteten barocken Domkirche, die zu Anfang des 19. Jahrhunderts von Karl Friedrich Schinkel (1781-1841) im klassizistischen Stil umgebaut worden war, dauerte mehrere Jahrzehnte. Bereits Friedrich Wilhelm IV. (1795-1861) sah die Kirche den Repräsentationsansprüchen der preußischen Monarchie nicht mehr gewachsen und ließ eine prunkvollere Domkirche bauen. Doch die Bauarbeiten waren infolge der Revolution von 1848 für Jahrzehnte zum Erliegen gekommen. Der Ruf nach einem repräsentativen Dom, der sich mit den großen Kirchen der Welt messen konnte, erneuerte sich nach der Reichsgründung. 20 Tage nach seinem Regierungsantritt 1888 ordnete Friedrich III. (18311888) an, eine neue Kathedrale zu bauen. Der neue Dom, der nach Plänen von Julius Raschdorff (1823-1914), Professor an der Technischen Hochschule Charlottenburg, 
tion der Hofkirche des preußischen Königshauses ausüben sollte, sah Wilhelm II. in ihm eine hervorragende Gelegenheit, seine politische Theologie zu manifestieren. Der Deutsche Kaiser hatte das gesamte Bauprojekt von der Planung bis zur Ausführung penibel kontrolliert und fortdauernd beeinflusst, so dass der ursprüngliche Weihetermin nicht zuletzt aufgrund seiner ständigen Änderungsvorschläge deutlich verzögert wurde ${ }^{67}$ Der neue Termin des Einweihungsfestes, der auf einen unspektakulären Montag fiel, war durchaus absichtsvoll gewählt worden - es war der 24. Hochzeitstag des deutschen Kaiserpaares.

Der monumentale Kuppelbau, der Erinnerungen an den Petersdom und die Hagia Sophia weckte, sollte den Betrachter mit ehrfürchtigem Staunen erfüllen. Dieses äußere Erscheinungsbild sowie der in den ausschmückenden Details überladene Stil der Kirche wurde von vielen Zeitgenossen als unangemessen, ja gar unevangelisch, empfunden und regelrecht bemängelt. ${ }^{68}$ Es

zu errichten war, sollte die Einheit des Reiches in der Person des Kaisers verkörpern. Jedoch starb Friedrich III. im gleichen Jahr, am 15. Juni 1888. Nach seinem Tod und dem Thronwechsel ließ der neue Kaiser Wilhelm II. am 9. Juli 1888 verlauten: »Es ist mein Wille, dass das Projekt der Errichtung eines Domes in meiner Haupt- und Residenzstadt Berlin, welches durch den allerhöchsten Erlaß meines in Gott ruhenden Herrn Vaters vom 29. März d. J. von neuem angeregt worden ist, mit allem Nachdruck gefördert werde. Die Ausführung dieses Planes nach den Absichten des hochseligen Kaisers und Königs Friedrich ist mir ein heiliges Vermächtnis. Ich wünsche, daß das Werk die Arbeit krönt, welche des verewigten Kaisers und Königs Majestät seit Jahren auf das Dombauprojekt verwandt hat. Ich genehmige hiermit, dass die auf Befehl meines Herrn Vaters gebildete Immediatkommission unverzüglich ihre Arbeiten beginnt«. Zitiert in Carl Schniewind, Der Dom zu Berlin. Geschichtliche Nachrichten vom alten Dom bei der Einweihung des neuen Doms, Berlin 1905, S. 76. Zur Geschichte des Berliner Doms siehe: Karl-Heinz KLIngenburg, Der Berliner Dom. Bauten, Ideen und Projekte vom 15. Jahrhundert bis zur Gegenwart, Berlin 1992; Carl-Wolfgang Schümann, Der Berliner Dom im 19. Jahrhundert, Berlin 1980; Julius Schneider, Die Geschichte des Berliner Doms. Von der Domstiftung im 15. Jahrhundert bis zum Wiederaufbau im 20. Jahrhundert, Berlin 1993; Helmut Engel/Wilhelm Hüffmeier (Hg.), Der Berliner Dom. Zur Geschichte und Gegenwart der Oberpfarr- und Domkirche zu Berlin, Berlin 2001.

67 Vgl. Klingenburg, Der Berliner Dom, S. 251-253. Um eigene Ideen bei dem von seinem Vater, Friedrich III., initiierten Dombau durchzusetzen, berief sich Wilhelm II. sogar auf fiktive Pläne des verstorbenen Monarchen und konnte so erfolgreich das Bauprogramm ändern. Vgl. ebd., S. 169-173 und Sснüмann, Der Berliner Dom, S. 245-293. Über die Rolle von Wilhelm II. bei dem Bau des Berliner Doms siehe auch: Godehard Hoffmann, Architektur für die Nation? Der Reichstag und die Staatsbauten des Deutschen Kaiserreichs 1871-1918, Köln 2000, S. 197-202.

68 In der Presse wurde der Bau nicht nur als stillos verurteilt, sondern auch als »eine Stätte der Anbetung im katholischen Sinne« eingestuft. Tägliche Rundschau 111 (7. März 1905), S. 8. Vgl. Chronik der christlichen Welt 13 (30. März 1905), S. $156 f$. Am deutlichsten fiel die Reaktion von Friedrich Naumann (1860-1919) aus: »Beim ersten Besuch überwog das Gefühl: so muß der Tempel des Herodes gewesen sein! Gutes Material, viel Marmor und Gold, überhaupt reelle Arbeit, aber keine Frömmigkeit und kein Kunsteindruck für die Gegenwart. [...] Man habe dem lieben Gott ein schönes Schloß gebaut«. Die Hilfe. Nationalsoziale Wochenschrift 9 (5. März 1905), 
ist jedoch anzunehmen, dass Wilhelm II. als Bauherr diese durchaus vorhersehbare Kritik wohlwissend in Kauf nahm. Ikonographisch lässt sich die Architektonik des Doms vornehmlich als Triumph der Reformation lesen. Diese Idee dominierte den ganzen Bau, fand ihren deutlichsten Ausdruck jedoch am Eingangsportal, das als Triumphbogen stilisiert war, und von einer segnenden Christusstatue gekrönt war. ${ }^{69}$ Auf den Triumph des Protestantismus sollte auch das neben der Statue angebrachte Bibelzitat hindeuten: "Unser Glaube ist der Sieg, der die Welt ueberwunden hat « (1 Joh 5,4). ${ }^{70}$ Das andere Zitat, das auf dem Portal zu sehen war, lautete: "Siehe, ich bin bei euch alle Tage bis an der Welt Ende« (Mt 28,20). Diese Verheißung Christi, die im Matthäusevangelium den sogenannten "Missionsbefehl« abschließt, wurde auf die Idee des Sieges der Reformation insofern bezogen, als man fest davon überzeugt war, dass der Protestantismus dank seiner Missionstätigkeit - diese erlebte am Anfang des 20. Jahrhunderts ihre Blütezeit - binnen Kurzem den Katholizismus als führende Weltreligion ablösen würde.

Das eigentliche Kirchenregiment Wilhelms II. als summus episcopus (oberster Bischof) beschränkte sich auf die Altpreußische Landeskirche und war mit seinem Amt als König von Preußen verbunden, doch als Kaiser sah er sich - obwohl er dazu kirchenrechtlich keine Befugnis hatte - für

S. 11. Naumann traf außerdem den Tenor der Pressestimmen angesichts des monumentalen Domcharakters, als er betonte, dass hier keine protestantische, sondern eine katholische Kirche anzutreffen sei: „Berlin hat eine Peterskirche bekommen, die sich zur großen Peterskirche verhält wie die königlich preußische Landeskirche zum römischen Katholizismus«. Ebd.

Unter den Kritikern befand sich selbst Oberhofprediger Ernst Dryander, der sich für die Zukunft wünschte, »durch Vereinfachung des Stils und Beseitigung der nicht organisch aus dem Ganzen herauswachsenden Figuren und Ornamente den Gesamteindruck zu bessern«. Ernst von Dryander, Erinnerungen aus meinem Leben, Bielefeld 1921, S. 219. Da der Oberhofprediger Mitglied der Dombaukommission war, bemühte er sich zusammen mit dem Präsidenten der Berliner Akademie der Künste, Anton von Werner (1843-1915), auf eine innere Neugestaltung des Doms hinzuwirken, blieb damit aber erfolglos.

69 Es ist jedoch anzumerken, dass die architektonische Botschaft des Triumphes nicht immer im Sinne Wilhelms II. wahrgenommen wurde: »Welchen Sinn hat der gewaltige Triumphbogen über der bescheidenen Tür in der Mitte? Drückt er irgend etwas Architektonisches aus, oder symbolisiert er an dieser Stelle irgendeinen kirchlichen Gedanken oder irgendein Gefühl überhaupt? Er prunkt, und das ist alles. Hunderte von Säulen, Pilaster, Gesimse, Bögen, Giebel, Statuen und andere Zierstücke prunken, prunken, prunken und sind ihrem Wesen nach nur ein immer wiederholtes Nichts«. Der Kunstwart. Halbmonatsschau über Dichtung, Theater, Musik, bildende und angewandte Künste 18 (1905), S. 803.

70 Jedenfalls kam eine solche Auslegung dieser Stelle beim Weihegottesdienst zum Ausdruck. So rief der Hofprediger Dryander dieses Zitat während der Weihe des Doms gleich fünfmal aus und sprach dabei von der evangelischen Kirche als der »triumphierenden Kirche« und der »Kirche des Vollendeten«. Ernst von Dryander, Die Herrlichkeit des Hauses Gottes. Zur Weihe des Berliner Doms am 27. Februar 1905, in: Ders., Gott und Mensch. Predigten und Reden, Halle (Saale) 1926, S. 118-122. 
alle evangelischen Kirchen in Deutschland zuständig und bemühte sich um deren Einigung. ${ }^{71}$ Eine solche »Einigung der evangelischen Kirchen Deutschlands" sei nichts weniger als "ein festes Ziel meines Lebens", so Wilhelm II. am 26. Dezember 1901 bei der Feier zur dreihundertjährigen Wiederkehr des Geburtstags Ernsts des Frommen. ${ }^{72}$ Es wurde über die Bildung einer Nationalkirche oder die Errichtung eines Kirchenbunds nachgedacht. ${ }^{73}$ Zwar ließen sich diese Ideen zum Bedauern Wilhelms II. nicht realisieren, doch zu den Meilensteinen auf diesem Wege kann zweifellos die Gründung des Deutschen Evangelischen Kirchenausschusses im Jahre 1903 zählen. ${ }^{74}$ Der Kirchenausschuss stellte eine ständige Vertretung der evangelischen Kirchen dar, ohne die Selbstständigkeit und die Kompetenzen der einzelnen Landeskirchen anzutasten und knüpfte seinem Selbstverständnis nach an das Corpus Evangelicorum, dem im Jahr 1653 konstituierten Zusammenschluss der lutherischen und reformierten Reichsstände des Heiligen Römischen Reiches Deutscher Nation, an. ${ }^{75}$

Es ist jedoch hervorzuheben, dass nicht nur die internen Beweggründe, etwa die theologischen Überlegungen oder kirchenpolitischen Ambitionen Wilhelms II., zu einer engeren Zusammenarbeit zwischen den evangelischen Landeskirchen führten, sondern auch die Erweiterung der deutschen Kolonialgebiete. Denn es war die preußische Landeskirche, die in weitem Umfang

$71 \mathrm{Zu}$ Wilhelms II. Wahrnehmung seiner höchstbischöflichen Position in der altpreußischen Landeskirche und zu seiner damit verbundenen Kirchenpolitik siehe: Benjamin Hasselhorn, Politische Theologie Wilhelms II., Berlin 2012, S. 123-136; Klaus Erich Pollmann, Das landeskirchliche Kirchenregiment unter Wilhelm II., in: Anselm Doering-Manteuffel / Kurt Nowak (Hg.), Religionspolitik in Deutschland. Von der frühen Neuzeit bis zur Gegenwart. Martin Greschat zum 65. Geburtstag, Stuttgart 1999, S. 165-176; ders., Wilhelm II. und der Protestantismus, in: Stefan SAmerski (Hg.), Wilhelm II. und die Religion. Facetten einer Persönlichkeit und ihres Umfeldes, Berlin 2001, S. 91-103, hier S. $96 f$.

72 Ernst Rudolf Huber / Wolfgang Huber (Hg.), Staat und Kirche im 19. und 20. Jahrhundert. Dokumente zur Geschichte des deutschen Staatskirchenrechts, Berlin ${ }^{2} 2014$, Bd. 3: Staat und Kirche von der Beilegung des Kulturkampfs bis zum Ende des Ersten Weltkriegs, S. 564, Anm. 2.

73 Siehe bspw.: Theodor Braun, Zur Frage der engeren Vereinigung der deutschen evangelischen Landeskirchen, Berlin 1902.

74 Der Kirchenausschuss beruhte maßgeblich auf der im Jahre 1851 gegründeten »Eisenacher Kirchenkonferenz«, die bis dahin einen organisatorischen Rahmen für gemeinsames Handeln der deutschen evangelischen Kirchen gab, trug aber nur beratenden Charakter. Zum Deutschen Evangelischen Kirchenausschuss siehe: Huber / Huber (Hg.), Staat und Kirche, S. 564-571 und Hartmut Sander, Der Deutsche Evangelische Kirchenausschuß (1903), in: Joachim RogGE/ Gerhard RuHBACH (Hg.), Die Geschichte der Evangelischen Kirche der Union, Leipzig 1994, Bd. 2: Die Verselbständigung der Kirche unter dem königlichen Summepiskopat (1850-1918), S. 355-372.

75 Kundgebung des Deutschen Evangelischen Kirchenausschusses an das deutsche evangelische Volk vom 10. November 1903, in: Huber / Huber (Hg.), Staat und Kirche, S. 569-571. 
stellvertretend Verantwortung für die Gemeinden in den Kolonien wahrnahm. ${ }^{76}$ Mit dem Ausschuss wurde zum ersten Mal ein Beschluss- und Exekutivorgan der evangelischen Kirchen in Deutschland erschaffen. Zu seinen Aufgaben erklärte er, die "gemeinsamen evangelisch kirchlichen Interessen« gegenüber den anderen deutschen wie ausländischen Kirchen- und nichtchristlichen Religionsgemeinschaften zu vertreten, die kirchliche Versorgung der "Evangelischen in den deutschen Schutzgebieten « zu organisieren sowie die kirchlichen Einrichtungen für »die evangelischen Deutschen im Auslande « zu fördern. ${ }^{77}$ Nicht zuletzt vor dem Hintergrund dieser deutschevangelischen Einigungsbestrebungen ließ Wilhelm II. dem Berliner Dom [siehe Abbildung 11] die Aufgabe zukommen, »der gesamten evangelischen Kirche einen charakteristisch grossartigen Ausdruck zu geben ${ }^{78}{ }^{78}$

Besonders aufschlussreich in dieser Hinsicht scheint die Komposition im Kuppelraum des Doms zu sein. Unter den Bildnissen der vier Evangelisten, die gemeinsam mit den Szenen aus der Apostelgeschichte ${ }^{79}$ die christliche Urgeschichte repräsentierten, waren dort acht große Statuen zu sehen. Neben den vier bedeutendsten Reformatoren, Martin Luther, Huldrych Zwingli, Philipp Melanchthon und Johannes Calvin, befanden sich vier Landesfürsten, die die Reformation unterstützen: Kurfürst Friedrich der Weise von Sachsen (1463-1525), Landgraf Philipp von Hessen (1504-1567) sowie Kurfürst Joachim II. von Brandenburg (1505-1571) und Herzog Albrecht von Preußen. Insofern zwei dieser vier Landesfürsten zu den Hohenzollern gehörten, handelte es sich dabei um eine überproportionale Hervorhebung der Rolle dieser Dynastie in der Reformationsgeschichte und somit auch um eine zusätzliche Legitimierung der Herrschaft Wilhelms II. Insgesamt gesehen, war in dieser Komposition das reformatorische Pathos zum Ausdruck

76 Vgl. Britta Wellnitz, Deutsche evangelische Gemeinden im Ausland. Ihre Entstehungsgeschichte und die Entwicklung ihrer Rechtsbeziehungen zur Evangelischen Kirche in Deutschland, Tübingen 2003, S. 93f. In einer Kundgebung von der Gründungsversammlung des Kirchenausschusses wurde ihre Aufgabe in Bezug auf die deutschen Kolonien sowie die deutsche Diaspora näher umrissen: »Die in die weite Welt ziehenden Landeskinder sollen doch weder deutscher Sprache und Sitte noch ihrer Kirche verloren gehen: unser Auge will ihnen in Liebe folgen. Und da auch gemeinsames Wirken mehr Erfolg verspricht, als noch so treu gemeinte vereinzelte Hilfe, so wollen wir den hervortretenden kirchlichen Notständen in den deutschen Kolonien wie in der Auslandsdiaspora unter möglicher Wahrung des Bekenntnisstandes gemeinsam begegnen «. Zitiert in: Ebd., S. 95.

77 Satzung des Deutschen Evangelischen Kirchenausschusses vom 13. Juni 1903, in: Huber / Huber (Hg.), Staat und Kirche, S. 565-568.

78 Zitiert in Jochen SchröDER, Die Baugestalt und das Raumprogramm des Berliner Doms als Spiegel der Ansprüche und Funktionen des Bauherrn Kaiser Wilhelms II., Diss. Philipps-Universität Marburg 2002, S. 176. Schröder spricht vom Dom sogar als »Denkmal der geeinten protestantischen Kirche«. Ebd., S. 162.

79 Diese Szenen waren: Die Steinigung des Stephanus, Pauli Bekenntnis, Petrus und Johannes heilen den Lahmen, Paulus auf dem Richtplatz in Athen. 


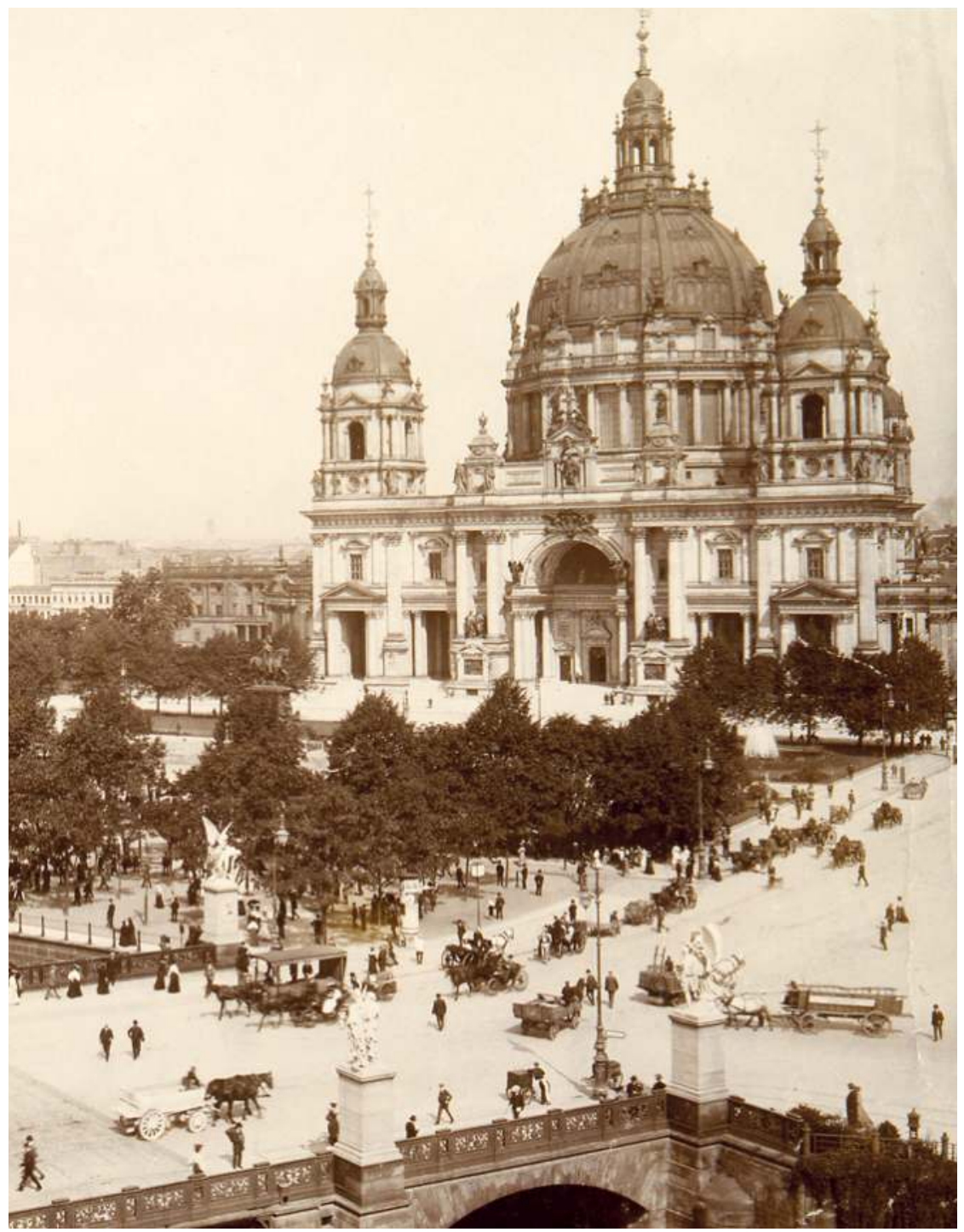

Abb. 11: »Blick über die Schloßbrücke auf den Lustgarten mit Altem Museum und Dom Berlin, 1905 (Ausschnitt). Max Missmann, FotoTechniken, Bildmaße: 21,9 x 28,0 cm. Inv.-Nr.: IV 84/194 V 
gebracht, durch das Wirken der Protagonisten der Reformation mitsamt deren weltlichen Beförderern zu den biblischen Wurzeln zurückgekehrt zu sein. Durch die gleichwertige Aufstellung der Reformatoren der lutherischen und reformierten Traditionen sollte diese Komposition zudem zur Demonstration der Einheit der großen protestantischen Konfessionen im Sinne der preußischen Kirchenpolitik dienen. Gleichzeitig verwies sie unmissverständlich auf die Befugnis der Schirmherrschaft weltlicher Obrigkeit, die christliche Lehre, die durch die Reformatoren wieder auf ihre vermeintlich ursprüngliche Gestalt zurückgeführt worden sei, in Reinheit und Einheit zu bewahren. Diese Befugnis, so die politische Theologie Wilhelms II., gelte nun primär dem Deutschen Kaiser, der durch das Gottesgnadentum dazu berufen sei, über die Kirche zu walten. ${ }^{80}$ Diese Idee wurde im Dom architektonisch reflektiert, indem die prächtige Kaiserloge sich über Kanzel und Altar erhob.

Wie die Weihe des Berliner Doms in aller Deutlichkeit zeigte, bestand die Ambition Wilhelms II. nicht nur darin, alle evangelischen Kirchen Deutschlands unter seiner Oberhoheit zu vereinen, sondern auch sich als Schirmherr des gesamten Weltprotestantismus und Berlin als dessen Zentrum verstanden zu wissen. Um die Weihefeier in diesem Sinne als ein Ereignis von gesamtevangelischer Bedeutung zu inszenieren, hatte der Deutsche Kaiser höchstpersönlich dazu die Vertreter »fremdländischer Souveräne« und die Repräsentanten des europäischen sowie US-amerikanischen Protestantismus eingeladen. ${ }^{81}$ Wilhelm II. hatte sich aktiv an der Ausarbeitung des

80 Wilhelm II. griff oft auf die Idee des Gottesgnadentums zurück. Dieses Phänomen fasst Thomas Benner in seiner Habilitationsschrift zur religiösen Dimension des Deutschen Kaisertums in Bezug auf Wilhelm II. - wohl etwas zugespitzt - folgendermaßen zusammen: „Wilhelm II. sah sich als Mittler zwischen Gott und den Untertanen, in der Rolle eines Hohenpriesters, der zwischen Himmel und Erde vermittelt, wie seine Reden, Predigten und Briefe belegen«. Thomas Hartmut Benner, Die Strahlen der Krone. Die religiöse Dimension des Kaisertums unter Wilhelm II. vor dem Hintergrund der Orientreise 1898, Marburg 2001, S. 357. Benner unterscheidet zwei Begründungsmuster des Kaisertums im Deutschen Reich nach 1871 »das alte ererbte dynastische« und »das neue charismatische Gottesgnadentum « der erfolgreichen Hohenzollern. Dabei weisen beide Varianten einen ausgesprochen religiösen Charakter auf. Vgl. ebd., S. 360. Zur Diskussion bzgl. der Kaiservorstellung Wilhelms II. und der Rolle des Gottesgnadentums siehe: Hasselhorn, Politische Theologie Wilhelms II., S. 62-78; Elisabeth Fenrenbach, Wandlungen des deutschen Kaisergedankens. 1871-1918, München u. a. 1969, S. 89-220; Dirk von Pezold, Cäsaromanie und Byzantinismus bei Wilhelm II., Köln 1971, S. 87-92; John Charles Gerald RöHL, Kaiser, Hof und Staat. Wilhelm II. und die deutsche Politik, München ${ }^{2} 2007$, S. 124f.; Hans Wilderotter, »Als Instrument des Herrn mich betrachtend «. Zum historischen und politischen Selbstverständnis, in: Ders. / Klaus Dieter PoHL (Hg.), Der letzte Kaiser. Wilhelm II. im Exil, Gütersloh 1991, S. 307-309.

81 Als Ehrengäste nahmen an der Feier Vertreter der lutherischen, reformierten und anglikanischen Kirchen aus den USA, Schweden, Norwegen, Dänemark, den Niederlanden und der Schweiz teil. 
Weihezeremoniells beteiligt und ließ aus diesem Anlass sogar zahlreiche Medaillen mit verschiedenen Motiven prägen, die die Verbindung zwischen der protestantischen Kirche und dem Deutschen Kaisertum hervorhoben. ${ }^{82}$

Die Einweihungsrede hielt der Oberhofprediger Ernst Dryander (18431922; seit 1918 von Dryander). ${ }^{83}$ Zwar trug sie in Anknüpfung an Haggai 2,7 $7^{84}$ die Überschrift »Die Herrlichkeit des Hauses Gottes«, doch Dryander behandelte nicht zuletzt die »Herrlichkeit des neugeeinten Deutschen Reiches« und dessen Kaisers. ${ }^{85}$ Deswegen hatten auch viele der anwesenden Geistlichen, so der Berichterstatter des Berliner Tageblattes, »außer dem Schmuck des Glaubens auch reichen Ordensschmuck mitgebracht. ${ }^{86}$ Letztendlich musste bei der Einweihung »nicht nur dem himmlischen, sondern auch dem irdischen Herrn Ehre erweisen werden $« .{ }^{87}$

Besonders wurden die Verdienste Wilhelms II. um die weltweite protestantische Kirche betont. Begann Dryander in seiner Rede von Wilhelm II. als dem »erste[n] Glied" der Domgemeinde zu sprechen, so erweiterte er sogleich den Geltungskreis auf die »deutsch-evangelische[n] Christenheit ${ }^{88}$ und sogar auf die protestantische Weltkirche:

Mit uns feiern heute edle Gäste, deutsche und stammverwandte evangelische Fürsten, Vertreter aller Provinzen unserer Landeskirche, ja aller Kirchen evangelischen Bekenntnisses aus dem deutschen Vaterlande und weit darüber hinaus bis über den Ozean, von wo uns noch gestern ein warmer Segensgruß verbündeter amerikanischer Kirchen gesandt wurde. Als erster Bekenner aber steht unter ihnen der Hohenzollernfürst, dem göttliche Fügung und der Lauf der Geschichte das hohe Amt zuwies, Hort und Hüter der Glaubensgüter der Reformation zu sein. ${ }^{89}$

Laut dem Oberhofprediger sei zur Weihe des Berliner Doms »eine evangelische Welt versammelt«, um unter der Schirmherrschaft des Deutschen Kaisers »als Kinder einer Reformation, entschlossen, über trennenden Unterschieden in Bekenntnis und Geschichte, in Kultus und Sitte einander die

82 Schneider, Die Geschichte des Berliner Doms, S. 69; Schümann, Der Berliner Dom, S. 254.

$83 \mathrm{Zu}$ Dryanders engem Verhältnis zu Wilhelm II. siehe: Bernd Andresen, Ernst von Dryander. Eine biographische Studie, Berlin u.a. 1995, S. 237-246; Pollmann, Wilhelm II. und der Protestantismus, S. 101f.

84 "Ich will dies Haus voll Herrlichkeit machen, spricht der HERR Zebaoth".

85 Reden bei der Einweihung des Doms zu Berlin am Montag d. 27. Februar 1905, Berlin 1905. Auch abgedruckt in: Dryander, Die Herrlichkeit des Hauses Gottes, S. 118122; ders., Erinnerungen aus meinem Leben, Bielefeld 1921, S. 122.

86 Berliner Tageblatt und Handels-Zeitung. Abend-Ausgabe 107 (27. Februar 1905), S. 4.

87 Ebd.

88 Ebd.

89 Ebd. 
Hand zu reichen, in der Gewißheit eines Glaubensgrundes, der tiefer liegt, als alle jene Unterschiede «. ${ }^{90}$ Diese universal-protestantischen Gedanken fortführend stellte Dryander den Berliner Dom in eine Reihe mit zwei anderen Kirchen, »deren Bedeutung weit über die Stätte hinausweist, an der sie erbaut sind «, und zwar mit der Wittenberger Schlosskirche und der evangelischen Erlöserkirche in Jerusalem. ${ }^{91}$ Zusammen stellten diese Städte eine Art sakrale Topographie des evangelischen Christentums dar: Jerusalem als Ursprungsort des Christentums, Wittenberg als die Reformationsstadt und Berlin als das gegenwärtige Zentrum des globalen Protestantismus. In diesem Kontext sollte die Einweihung des Berliner Doms nur als logische Fortsetzung und krönender Abschluss der zuvor begangenen Feierlichkeiten in Wittenberg (bei der Wiedereröffnung der Schlosskirche am 31. Oktober 1892) und in Jerusalem (bei der Weihe der Erlöserkirche am 31. Oktober 1898) angesehen werden, bei denen Wilhelm II. seine gesamtprotestantische Bedeutung bereits ins Spiel gebracht hatte. ${ }^{92}$

Doch wie ließ sich die Stellung Berlins als Zentrum des Weltprotestantismus begründen? Nach dem Gottesdienst ließ Wilhelm II. erklären, der Berliner Dom habe ein »Vorrecht darauf, als die »Mutterkirche des internationalen Protestantismus« betrachtet zu werden, und zwar aus zwei Gründen: Erstens, weil er die Kathedrale der Metropole des Landes sei, »in dem der Protestantismus geboren wurde«; zweitens, weil in ihm »der größte protestantische Herrscher seine Andacht verrichtet ${ }^{9{ }^{93}}$ Ironischerweise geriet die Weihezeremonie des Berliner Doms, die als Feier des Gesamtprotestantismus inszeniert wurde, ausgerechnet als nicht-protestantisch in Kritik. So schrieb beispielsweise das Hamburger Fremdenblatt:

Einem protestantischen Gewissen kann es nimmer einleuchten, daß ein solcher Pomp notwendig war, daß soviel Musik gemacht werden mußte, daß der Gesangschor in altertümlichen karmoisinroten Gewändern amtierte, die Kosleckschen Bläser dabei waren, die Prediger beim Weihgebet niederknieten und die Liturgien so sehr verteilt und wenig einfach in die Erscheinung traten. Es hätte nur noch gefehlt, daß der Weihrauch zum Himmel duftete, dann wäre der Unterschied zwischen protestantischem und katholischem Gottesdienst ganz verwischt. Wir vermissen in allem die Demut und Einfachheit des lutherischen Geistes und des Reformationsgedankens und ver-

90 Ebd.

91 Ebd. Diese zwei Einweihungsfeierlichkeiten dienten als Vorlage für die Weihe des Berliner Doms. Schümann, Der Berliner Dom, S. 254.

92 Vgl. Rochus Leonhardt, Religion und Politik im Christentum. Vergangenheit und Gegenwart eines spannungsreichen Verhältnisses, Baden-Baden 2017, S. 290.

93 Vgl. Chronik der christlichen Welt 13 (30. März 1905), S. 158; David Clay LaRge, Berlin. Biographie einer Stadt, München 2002, S. 73. 
muten, daß die hohe lutherische Geistlichkeit aller Länder, die zu der Einweihungsfeier geladen war, mit recht gemischten Gefühlen die präsumtive Hauptstätte des protestantischen Glaubens verlassen hat. ${ }^{94}$

Die letzte Vermutung des Autors war treffend, denn in der ausländischen Presse (vor allem in Großbritannien) wurde Wilhelms II. Idee, „für Berlin einen protestantischen Sankt Peters-Dom zu errichten $",{ }^{95}$ regelrecht verspottet. ${ }^{96} \mathrm{Ob}$ die Weihe des Doms tatsächlich zur gesamtevangelischen Verständigung und ökumenischen Einigung beitrug, darf daher bezweifelt werden. Doch es war sicherlich einer der prächtigsten Ausdrücke der politischen Theologie der deutschen Monarchie. Wie Martin Ohst treffend anmerkte, symbolisierte sich im Berliner Dom »eine sich selbst religiös deutende Monarchie «, ${ }^{97}$ und es lässt sich ergänzen: eine sich selbst religiös verherrlichende Monarchie.

Zur gleichen Zeit als Wilhelm II. seine politische Theologie bei der Weihe des Berliner Doms zum Ausdruck brachte, befand sich seine außerordentliche Gesandtschaft in Äthiopien. Die Delegation, mit deren Leitung der Orientalist und Diplomat, Vortragender Rat im Auswärtigen Amt, Friedrich

94 Zitiert in Chronik der christlichen Welt 13 (30. März 1905), S. 156f. Siehe auch den Eintrag im Tagebuch der berühmten Berliner Salonnière Baronin Hildegard von Spitzemberg (1843-1914): „Fürsten und `Spitzen` aus aller Herren Länder sind zusammengetrommelt worden, wie der sonst so vorsichtige [Kurt Eduard von] Derenthall sagte: rals gelte es einen St. Peter, nicht eine häßliche Berliner Kirche einzuweihen! Warum für solch rein preußische, höchstens deutsch-evangelische Ereignisse dieses übertriebene Gepränge, dieses kosmopolitische anspruchsvolle Gebaren, an dessen Wahrheit niemand glaubt und deshalb innerlich Widerspruch erhebt?« Rudolf VIERHaus (Hg.), Das Tagebuch der Baronin Spitzemberg. Aufzeichnungen aus der Hofgesellschaft des Hohenzollernreiches, DGQNJ 43, Göttingen ${ }^{5}$ 1989, S. 445.

95 Vgl. Deutsche Bauzeitung 18 (4. März 1905), S. 109.

96 V.a. die kirchlich-anglikanische Presse gefiel sich darin, die Lächerlichkeit eines solchen Anspruches, »Berlin als das Mekka der Protestanten« zu stilisieren, herauszustellen. Chronik der christlichen Welt 13 (3. März 1905), S. 158. Vgl. auch die Kritik in Church Times 42 (3. März 1905). Hingegen nahmen die offiziellen Vertreter der evangelischen Landeskirchen die entgegengesetzte Position ein. Durch den Deutschen Evangelischen Ausschuss priesen sie ein Jahr später, am 27. Februar 1906, den »Tag der Weihe des unter Eurer Majestät erfolgreicher Leitung in würdevoller Schöne neuentstandenen Domes in Berlin«. Die Weihe sei ein unvergessliches Zeugnis "von Eurer Majestät hochherzigem und bahnbrechendem Eintreten für eine Einigkeit der evangelischen Christenheit«. Gratulationsadresse des DEKA an Wilhelm II. und Auguste Viktoria zur Silberhochzeit am 27.02.1906, EZA 1/A2/424, pag. 83r. Zitiert in: Andresen, Ernst von Dryander, S. 131.

97 Martin Онsт, Die Preußische Union und ihre politische Bedeutung, in: Andreas Arndt u. a. (Hg.), Christentum - Staat - Kultur. Akten des Kongresses der Internationalen Schleiermacher-Gesellschaft in Berlin. März 2006, Berlin 2008, S. 165-180, hier S. 167. 
Rosen (1856-1935) beauftragt wurde ${ }^{98}$ bestand außerdem aus Legationssekretär Graf Victor von Eulenburg (1870-1908), Vizekonsul Edmund Schüler (1873-1952), Geheimsekretär Georg Becker, Kommerzienrat Carl Bosch (1851-1937), Oberbibliothekar Johannes Flemming, naturwissenschaftlichem Beirat Felix Rosen (1863-1925) und Stabsarzt Hans Vollbrecht (18601946). ${ }^{99}$ Im Namen Wilhelms II., der sich in Berlin als "größter protestantischer Herrscher « feiern ließ, führten sie in Addis Abeba Verhandlungen mit dem größten orientalisch-orthodoxen Herrscher, Mənilək II. ${ }^{100}$

\subsection{Addis Abeba: Die deutsche Sondergesandtschaft in Äthiopien}

Am selben Tag, dem 27. Februar 1905, und zwar zeitgleich mit der Weihe des Berliner Doms, fand die Begegnung der von Wilhelm II. entsandten diplomatischen Delegation mit dem äthiopischen Kaiser Mənilək II. statt.

Das erklärte Ziel der deutschen kaiserlichen Gesandtschaft war die Unterzeichnung eines zwischenstaatlichen Handels- und Freundschaftsabkommens mit dem Äthiopischen Reich. ${ }^{101}$ Die Aufgabe war durchaus brisant, denn die bisherige deutsche Afrika-Politik brachte den Staat in eine schwierige Lage: Einerseits befand sich Deutschland in einem Konflikt mit Frank-

Zu Friedrich Rosen siehe: Werner Daum, Gelehrter und Diplomat. Friedrich Rosen und die Begründung der diplomatischen Beziehungen zwischen Deutschland und Äthiopien, in: Walter Raunig/Steffen Wenig (Hg.), Afrikas Horn. Akten der Ersten Internationalen Littmann-Konferenz, Wiesbaden 2005, S. 265-281.

99 Begleitet wurde die Gruppe von einer aus neun Soldaten bestehenden Abteilung der Gardes du Corps sowie zwei deutschen Dienern. In Port Said wurden die Reisenden durch einen äthiopischen Dolmetscher sowie einen armenischen Koch und seinen Gehilfen ergänzt.

100 Der Verlauf der Reise sowie der diplomatischen Verhandlungen sind ausführlich dokumentiert worden: Außer einem nahezu 500-seitigen Band aus der Feder von Delegationsmitglied Felix Rosen (ein Bruder des kaiserlichen Gesandten Friedrich Rosen) liegen ebenso die Erinnerungen von Hans Vollbrecht und Carl Bosch vor: Felix Rosen, Eine deutsche Gesandtschaft in Abessinien, Leipzig 1907; Hans VolLBRECHT, Im Reiche des Negus Negesti Menelik II, Stuttgart u. a. 1906; Carl Bosch, Karawanen-Reisen. Erlebnisse eines deutschen Kaufmanns in Ägypten, Mesopotamien, Persien und Abessinien, Berlin 1928, S. 141-239.

1011905 unterhielt das Äthiopische Reich bereits diplomatische Beziehungen mit Frankreich (seit 1897), dem Vereinigten Königreich (seit 1897), Russland (seit 1898), Italien (seit 1889) und den Vereinigten Staaten von Amerika (seit 1904), noch nicht jedoch mit Deutschland. Die deutsche außerordentliche Gesandtschaft nach Äthiopien erhielt die Weisung, sich bei ihren Abmachungen mit der äthiopischen Regierung an dem Muster des englischen und amerikanischen Vertrags zu orientieren und sich auf allgemeine und grundsätzliche Vereinbarungen zu beschränken. Vgl. die für die deutsche Regierung verfasste Denkschrift über den deutsch-äthiopischen Freundschafts- und Handelsvertrag in: Stefan BRÜNE, Äthiopien - Unterentwicklung und radikale Militärherrschaft. Zur Ambivalenz einer scheinheiligen Revolution, Hamburg 1986, S. 254-257. 
reich um den Einfluss auf Marokko, das in einem für die Durchfahrt vom Atlantik zum Mittelmeer strategisch wichtigen Teil Nordafrikas lag, ${ }^{102}$ andererseits sah sich die deutsche Kolonialherrschaft in Afrika durch den organisierten Widerstand zunehmend herausgefordert. ${ }^{103}$ Diese sich auf afrikanischem Boden entfaltenden Ereignisse fanden eine erhebliche Resonanz in der deutschen Gesellschaft und wirkten sich in steigendem Maß auch auf die politische Stimmung im Lande aus. ${ }^{104}$ Desto wichtiger war es, einen erfolgreichen Vertrag mit dem christlichen Reich am Horn von Afrika abzuschließen.

102 Dieser Spannungszustand wurde später in der Historiografie als die »erste Marokko-Krise« bezeichnet. Um die deutsche Politik der »friedlichen Durchdringung « Marokkos gegen die in der französisch-britischen Entente cordiale 1904 festgeschriebene Dominanz Frankreichs auf dem Gebiet zu verteidigen, entschied sich Wilhelm II. sogar dafür, persönlich nach Marokko zu reisen. Sein Besuch des marokkanischen Tanger, der am 31. März 1905 - also nur wenige Wochen nach der Weihe des Berliner Doms - stattfand, sollte die deutschen Interessen und Ambitionen in Marokko unterstreichen. Das Ziel des demonstrativen kaiserlichen Besuches, die französisch-britische Annäherung zu beenden und den französischen Einfluss auf Marokko zu verringern, wurde allerdings nicht erreicht; vielmehr trat das Gegenteil ein. Zum Konflikt und dessen Ergebnissen siehe: Martin MaYer, Geheime Diplomatie und öffentliche Meinung. Die Parlamente in Frankreich, Deutschland und Großbritannien und die erste Marokkokrise 1904-1906, Düsseldorf 2002, S. 278-323. Zu Wilhelms II. Marokkoreise und ihrem Kontext siehe: Gunther MAI, Die Marokko-Deutschen 1873-1918, Göttingen 2014, S. 257-287; Jost DülfFer u.a., Das Deutsche Reich auf europäischem Konfrontationskurs. Die erste Marokkokrise 1905/1906, in: Militärgeschichtliches Forschungsamt (Hg.), Vermiedene Kriege. Deeskalation von Konflikten der Großmächte zwischen Krimkrieg und Erstem Weltkrieg 1865-1914, München 1997, S. 557-577.

103 So zog sich schon seit über einem Jahr in der Kolonie Deutsch-Südwestafrika (das heutige Namibia) der Widerstandskrieg der Herero und Nama hin. Insgesamt dauerte der Krieg von 1904 bis 1908 und mündete in einen Völkermord an den Herero und Nama. Siehe dazu v. a. Jürgen Zimmerer / Joachim Zeller (Hg.), Völkermord in Deutsch-Südwestafrika. Der Kolonialkrieg (1904-1908) in Namibia und seine Folgen, Berlin 2016; Reinhart Kössler / Henning Melber, Völkermord und Gedenken. Der Genozid an den Herero und Nama in Deutsch-Südwestafrika 1904-1908, in: Micha BRUMLIK / Irmtrud WojaK (Hg.), Völkermord und Kriegsverbrechen in der ersten Hälfte des 20. Jahrhunderts, Frankfurt a. M. 2004, S. 37-76. Desgleichen entwickelten sich in der Kolonie Deutsch-Ostafrika (die heutigen Tansania, Burundi und Ruanda) zunehmend Erhebungen gegen die deutsche Kolonialherrschaft, die 1905 in den blutigen - über drei Jahre dauernden - Maji-MajiKrieg mündeten. Diese Erhebung zeichnete sich durch eine breite Allianz zwischen Angehörigen verschiedener ethnischer Gruppen sowie ihre große Ausbreitung aus und gilt als einer der größten Kolonialkriege auf dem afrikanischen Kontinent. Vgl. dazu James Leonard Giblin/Jamie Monson (Hg.), Maji Maji. Lifting the Fog of War, Leiden u. a. 2010; Felicitas Becker / Jigal BeEZ (Hg.), Der Maji-Maji-Krieg in Deutsch-Ostafrika 1905-1907, Berlin 2005.

104 Ein prägnantes Beispiel für die Auswirkungen der Kolonialpolitik auf das innerdeutsche politische Geschehen ist die Regierungskrise in Berlin, die entstand, als die deutsche Regierung am 2. August 1906 im Reichstag einen Nachtragshaushalt in Höhe von 29 Millionen Mark für den Krieg in Deutsch-Südwestafrika beantragte. Das Geld sollte den deutschen »Schutztruppen« in der Kolonie helfen, die Aufstände der Nama (damals in Deutschland als »Hottentotten« bekannt) zu bekämpfen. Als 
In Addis Abeba hielten sich die Deutschen seit dem 12. Februar 1905 auf und hatten bereits einige Audienzen bei dem äthiopischen Kaiser gewährt bekommen. Die Verhandlungen blieben in diesen zwei Wochen jedoch ergebnislos. Am 27. Februar bot sich allerdings eine außerordentliche Gelegenheit, dies zu ändern, denn an diesem Tag stattete der äthiopische Kaiser der deutschen Gesandtschaft zum ersten Mal einen Besuch ab. Diese Begegnung im »Palais« von Ras Mäkwännən Wäldä Mika ${ }^{\circ} e l$, wo die Deutschen einquartiert wurden, - die erste in etwas informellerem Rahmen - lässt sich anhand der Berichte der Delegationsmitglieder sowie aus den Archivakten des Auswärtigen Amtes rekonstruieren.

Die Deutschen hofften, bei diesem »allerhöchsten Besuch« einen Durchbruch in den Verhandlungen zu erzielen. Entsprechend sorgfältig wurden alle Vorbereitungen getroffen. Besonders imposant sah die festliche Einrichtung des Empfangssalons aus: In der Mitte des Saales war für den Kaiser ein Diwan mit Kissen aufgestellt, zu dessen Rechten und Linken sich Stühle für die Mitglieder der deutschen Gesandtschaften befanden. Der ganze Boden wurde laut Kommerzienrat Carl Bosch außerdem mit Teppichen ausgelegt und an den Wänden wurden »Bilder von unserem Kaiser und Kaiser Menelik zwischen zwei großen deutschen Flaggen angebracht ${ }^{105}$.

Nachdem Mənilək II. bereits auf seinem Weg von Graf Victor von Eulenburg und der Garde du Corps begrüßt und mit einer Schar der ihn begleitenden Würdenträger bis zum Haus eskortiert worden war, wurde er von dem Orientalisten Friedrich Rosen in Empfang genommen. Bei dem Gespräch, das nach der Begrüßungszeremonie im Saal folgte, dolmetschten Alfred Ilg (1854-1916), ein am Hofe Məniləks II. als Staatsrat dienender Schweizer, ${ }^{106}$

die Abstimmung am 13. Dezember eine knappe Mehrheit von 177 zu 168 Stimmen gegen den Nachtragshaushalt ergab, wurde der Reichstag noch am selben Tag durch Reichskanzler Bernhard Fürst von Bülow auf Verordnung Wilhelms II. aufgelöst. Die sich anschließenden Neuwahlen wurden von den Zeitgenossen als »Hottentottenwahlen« bezeichnet. Siehe: Gerd Harder, Die Reichstagswahl des Jahres 1907 in ihrer Bedeutung für die deutsche Reichsgeschichte. Eine Untersuchung unter besonderer Berücksichtigung der kolonialen Probleme, Kiel 1975. Zu Kritik an diesen Kriegen kam es nicht nur von sozialdemokratischer und linksliberaler Seite, auch in anderen Schichten der Gesellschaft wurde sich gegen die deutsche Kolonialpolitik und die damit verbundenen Kriege - oft aus ökonomischen Gründen - geäußert. Vgl. Hans-Ulrich Wehler, Deutsche Gesellschaftsgeschichte, München 2008, Bd. 3: Von der »Deutschen Doppelrevolution« bis zum Beginn des Ersten Weltkrieges. 1849-1914, S. 1008-1011; Thomas NipPERdeY, Deutsche Geschichte 1866-1918, München 1992, Bd. 2: Machtstaat vor der Demokratie, S. 729.

105 Bosch, Karawanen-Reisen, S. 167.

106 Alfred Ilg diente dem äthiopischen Kaiser außerdem als Ingenieur, Architekt, Dolmetscher, Berater und Privatsekretär für auswärtige Angelegenheiten. Für Mənilək II. arbeitete er bereits seit dem Jahr 1878 und genoss sein vollständiges Vertrauen, was ihn zum einflussreichsten Ausländer am äthiopischen Kaiserhof 
und ein durch die deutschen Missionare ausgebildeter Äthiopier Gäbrä

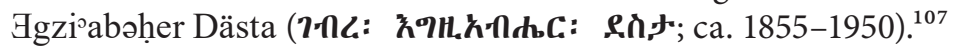

Über die Inhalte dieses Gesprächs äußerte sich nur Carl Bosch, und zwar sehr sparsam: Die Unterhaltung habe sich auf Höflichkeiten, die Besprechung der Rückreiseroute und den gegenseitigen Toast auf das Wohl des deutschen und des äthiopischen Kaisers beschränkt. ${ }^{108}$ Mənilək II. habe relativ bald den Wunsch geäußert, die militärischen Übungen der deutschen Garde du Corps anzusehen und habe sich bald danach verabschiedet. Im Reisebericht von Felix Rosen wird das Gespräch überhaupt nicht erwähnt. ${ }^{109}$ Laut seiner Schilderung habe es nach einer kurzen Bewirtung des äthiopischen Kaisers mit Marzipan und Danziger Goldwasser direkt zu dem vom Graf

machte. Zum Werdegang und zur Person Ilgs siehe: Heribert KüNG, Staatsminister Alfred Ilg (1854-1916). Ein Thurgauer am Hof Kaiser Meneliks II. von Äthiopien, Zürich 1999; BAIru Tafla, Ilg, Alfred, in: EAE 3, 2007, S. 120-122.

Gäbrä Hgzi’abəher Dästa hatte sich nicht nur als zuverlässiger Dolmetscher, sondern auch als ein unentbehrlicher Kulturvermittler erwiesen. Denn er kannte sich bestens mit Deutschland und Äthiopien sowie mit dem Protestantismus und der Orthodoxie aus. Er hatte in den 1860er und 1870er Jahren einer Einladung deutscher Missionare folgend zunächst eine deutsche Schule in Jerusalem besucht und danach in St. Chrischona bei Basel studiert. Nach einigen Jahren der Tätigkeit für die europäischen Missionsgesellschaften hatte er sich jedoch zu einer politischen Karriere entschlossen und seit 1889 unterschiedliche Posten unter Mənilək II. übernommen. Zu Gäbrä Ggzi abəher Dästa siehe: BAIRU TAfla, Gäbrä Ggziªbəher Dästa, in: EAE 2, 2005, S. 606f.; ders., Four Ethiopian Biographies: Däjjazmač Gärmamé, Däjjazmač Gäbrä-Egzi’abehér Moroda, Däjjazmač Balča and Käntiba Gäbru Dästa, in: JEtS 7 (2) (1969), S. 1-31, hier S. 22-31; BAhru Zewde, Pioneers of Change in Ethiopia. The Reformist Intellectuals of the Early Twentieth Century, Oxford u. a. 2002, S. 42-46; Wolbert G. C. SMIDT, »Schwarze Missionare« im Deutschland des 19. Jahrhunderts, in: Marianne Bechinaus-Gerst / Reinhard Klein-Arendt (Hg.), AfrikanerInnen in Deutschland und schwarze Deutsche - Geschichte und Gegenwart, Münster 2004, S. 41-56, 49-52. Doch obwohl Gäbrä Ggziªbəher Dästa evangelisch war und perfekt Deutsch sprach, hatten die Deutschen »trotz aller Berührungspunkte, die sich aus seiner deutschen Erziehung ergaben " und "trotz seiner Fähigkeiten und liebenswürdigen Seiten« ein Gefühl des Befremdens ihm gegenüber. Nach Auffassung Felix Rosens lag es daran, dass »er in seinem Denken und Fühlen ein ächter Abessinier geblieben war und Anschauungen vertrat, die uns Deutschen fremd erscheinen mußten«. Rosen, Eine deutsche Gesandtschaft, S. 297.

108 Bosch, Karawanen-Reisen, S. 167.

109 Felix Rosen, Professor für Botanik an der Universität Breslau, war ein Bruder des kaiserlichen Gesandten Friedrich Rosen und beteiligte sich an der Expedition als naturwissenschaftlicher Beirat. In dieser Funktion sollte er in erster Linie die äthiopische Pflanzenwelt erforschen und Specimina sammeln. Bedeutsam wurde Felix Rosen auch als Autor des Reiseberichtes der Expedition nach Äthiopien: Rosen, Eine deutsche Gesandtschaft - »einer jener klassischen Reiseberichte, die Wissensvermittlung, Forschung, Beobachtung von Sitten und Treiben mit der petite histoire verbinden, und - eher bewußt als unbewußt - das fremde Leben in sehr anrührender Weise zum Erfahrungshorizont der geliebten eigenen Kleinstadt kontrastieren«. Daum, Gelehrter und Diplomat, S. 272. Zu Rosens Biografie siehe: Hubert WinkLER, Felix Rosen, in: Berichte der Deutschen Botanischen Gesellschaft 43 (1925), S. 65-73. 
Eulenburg kommandierten Lanzenfechten gehen sollen (dabei konnte Rosen Mənilək II. photographieren; das Bild sei aber, so Rosens Meinung, der sich wohl eine exotischere Photographie gewünscht hatte, "wegen der halbeuropäischen Kleidung wenig vorteilhaft« geworden [siehe Abbildung 12]). ${ }^{110}$

Die publizierten Schilderungen der deutschen Delegationsmitglieder legen somit nahe, dass es sich lediglich um einen Höflichkeitsbesuch des äthiopischen Kaisers handelte. Dennoch verraten die archivalischen Quellen, dass ausgerechnet bei diesem Treffen eine weitgehende Einigung bezüglich der strittigen Fragen, die dem Abschluss eines völkerrechtlichen Abkommens zwischen Äthiopien und Deutschland noch im Wege standen, erzielt werden konnte. Noch am selben 27. Februar sendete Friedrich Rosen ein Telegramm an Wilhelm II., in dem er ihn über die Ereignisse des Tages informierte: "Kaiser Menelik beehrte mich heute mit seinem Besuch mit großem Gefolge und ließ sich dann von Gardes du Corps militärische Übungen vorführen. Alles wohl«. Danach ließ Rosen eine Nachricht folgen, die er als »vertraulich « markiert hatte: "Handelsvertragsverhandlung im besten Gange trotz anfänglicher Bedenken des Negus wegen nicht ausdrücklicher Anerkennung seiner Gerichtsbarkeit . $^{111}$

Eine wichtige Rolle bei den Verhandlungen spielte unter anderem die Tatsache, dass Friedrich Rosen von seinen Reisen sowie von den letzten Erfolgen der deutschen Archäologen im Vorderen Orient erzählte. Ein ganz besonderes Interesse soll Mənilək II. verraten haben, als Rosen von den deutschen Ausgrabungen in Babylonien zu sprechen kam, »die so manches neue Licht auf die in der Bibel behandelten Ereignisse geworfen haben $« .{ }^{112}$ Von der biblischen Archäologie ging Rosen zur Wichtigkeit »der axumitischen Alterthümer « und dem hohen Interesse über, das die deutsche Wissenschaft - und »in erster Linie Seine Majestät Kaiser Wilhelm II.« - an dieser hätte. ${ }^{113}$

110 Rosen, Eine deutsche Gesandtschaft, S. 276. Seine kurzen Notizen zum kaiserlichen Besuch beschränken sich auf die Äußerung des Bedauerns bzgl. des nicht gelungenen Bildes: »[...] der Kaiser trug den breiten Filzhut und Stiefeletten, während z. B. Ras Wolda Giorgis nach Landessitte barfuß erschienen war. Unvorteilhaft ist auf meinem Bilde namentlich, daß Menelik auf einem europäischen Stuhle, also in ungewohnter Weise sitzt, was seine sonst vorzügliche Haltung beeinträchtigt«. Ebd.

111 PA AA, R 14914, Nr. 3396, Friedrich Rosen an das Auswärtige Amt, 27. Februar 1905. Das Beharren des äthiopischen Kaisers auf die Anerkennung seiner Gerichtsbarkeit zeigt, dass es ihm wichtig war, durch das außenpolitische Engagement seine innenpolitische Stellung nicht zu gefährden.

112 Rosen, Eine deutsche Gesandtschaft, S. 266.

113 Dabei ist die Argumentation der deutschen Gesandten bemerkenswert, der Aksum zum gemeinsamen christlichen Erbe erklärt hat: Die Stadt sei für die Erforschung »der frühesten Perioden unserer [Hervorhebung - S. P.] Religion und Kultur « wichtig. PA AA, R 14917, Bericht Friedrich Rosens Nr. 16 vom 13. März 1905.

Zur Begeisterung Wilhelms II. für die Archäologie und zu seinem Engagement in diesem Bereich siehe die Beiträge in: Thorsten BeIgel/Sabine MANGold-WILL (Hg.), Wilhelm II. Archäologie und Politik um 1900, Stuttgart 2017. Leider werden 


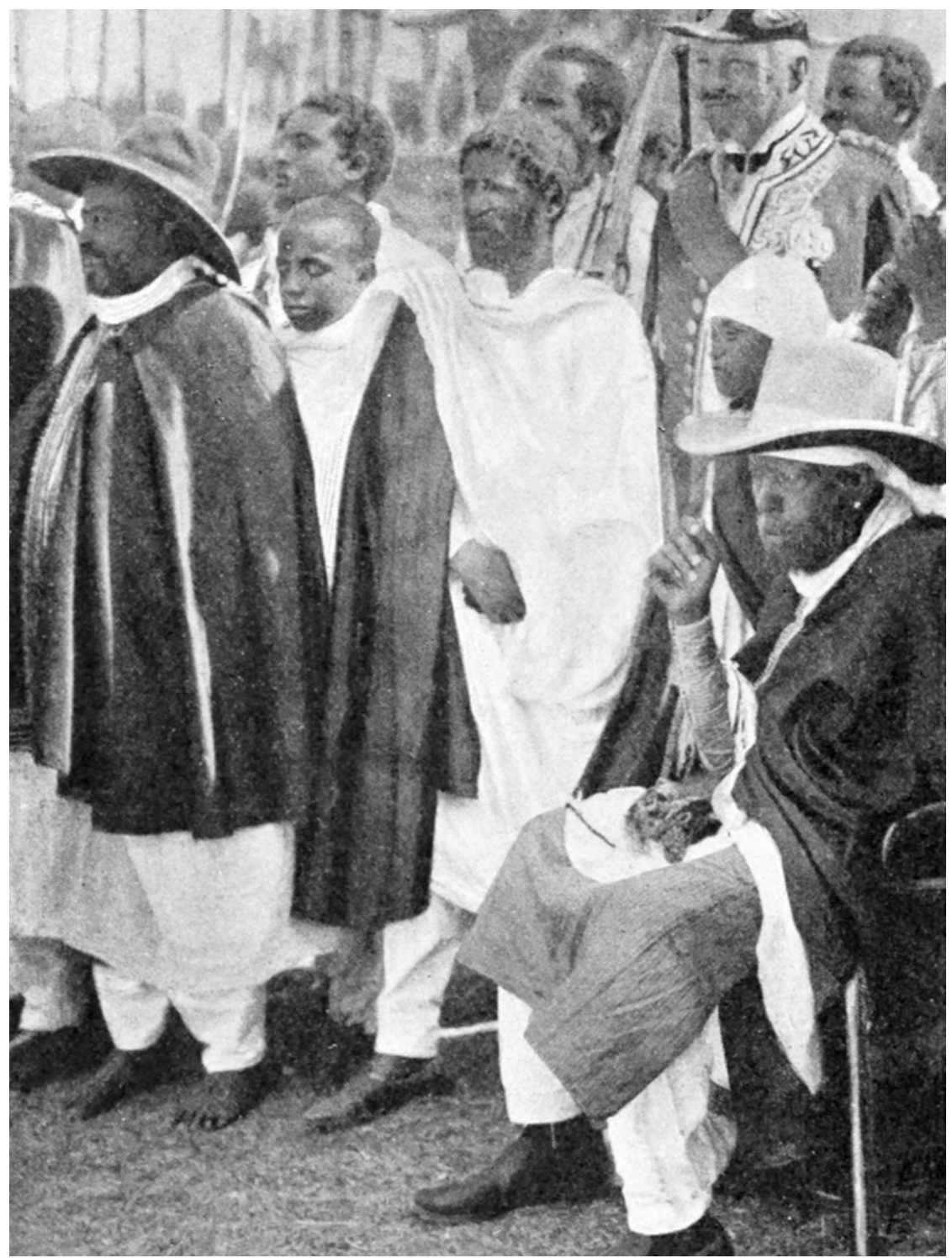

Abb. 12: „Der Negus (rechts) zu Besuch bei der deutschen Gesandtschaft (links: Ras Wolda Giorgis, Vizekönig von Kaffa)«, 27. Februar 1905 
Und so machte es sich scheinbar ganz von selbst, dass Menelik uns Deutschen das Recht zugestand, in der alten äthiopischen Hauptstadt Aksum Ausgrabungen zu machen, - hier vor allem konnte man ja hoffen, Spuren aus altchristlicher Zeit und vielleicht selbst einer noch älteren Kultur zu finden. [...] Das große Verständnis, das der Negus hier einer rein wissenschaftlichen Frage entgegenbrachte, ließ uns schon vermuten, daß der kluge Fürst, nach den Verhältnissen seines Landes, ein Förderer von Kunst und Wissenschaft sein würde. ${ }^{114}$

So die Schilderung Felix Rosens. Hätte er allerdings mehr von der äthiopischen Zion-Theologie oder der Stellung der Aksum Şəyon-Kirche, wo die Bundeslade sich befinden soll, - einer Kirche, die zudem am Anfang eines jeden Gottesdienstes und im ersten Morgengebet eines jeden orthodoxen Christen zu erwähnen ist - in der äthiopisch-orthodoxen Spiritualität gewusst, ${ }^{115}$ hätte er kaum angenommen, dass es dem äthiopischen Kaiser bei den Ausgrabungen in Aksum um eine »rein wissenschaftliche Frage« ging. Vielmehr erhoffte sich Mənilək II., dass deutsche Archäologen durch die Offenlegung von Aksums Glanz zur Zeit der Königin von Saba die Historizität des »salomonischen Narrativs« bestätigen würden.

Neben der Entscheidung über die baldigen archäologischen Ausgrabungen in Aksum, die zunächst strikt geheim gehalten werden sollten, ${ }^{116}$ wurde an jenem Tag eine weitere symbolträchtige Vereinbarung getroffen: Deutschland sollte in der Frage des Besitzverhältnisses des Jerusale-

in diesem Band die Ausgrabungen von Aksum außer Acht gelassen. Dennoch bietet er eine gute Einführung in den politischen und wissenschaftlichen Kontext dieser Unternehmungen und zeigt die Bedeutung der archäologischen Erschließung des Altertums in Wilhelms II. Herrschaftspraxis auf.

114 Rosen, Eine deutsche Gesandtschaft, S. 266f.

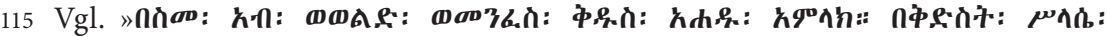

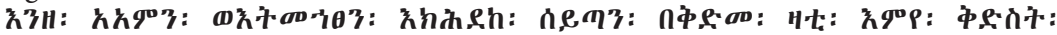

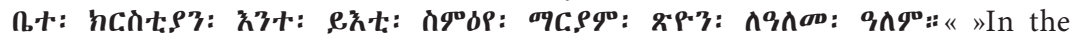
name of the Father, the Son and the Holy Spirit, One God. As I believe and take refuge in the Holy Trinity, I reject you, Satan, as I stand before this my mother the holy church which is my witness, Mary Zion (Māryām Șeyon) forever«. Emmanuel FrITSCH, Turning Everyday to Aksum Șeyon Unaware. King Zar’a Yāceqob's Kehedata Sayțān Identified in the First Prayer of the Day, in: Annales d'Ethiopie 28 (1) (2013), S. 363-372, hier S. 363.

116 Wilhelm II. und Friedrich Rosen befürchteten allem Anschein nach eine mögliche Fortsetzung des erst vor Kurzem beigelegten Babel-Bibel-Streites. Daher sollte die Nachricht über archäologische Ausgrabungen in Aksum, die die Frage nach der Authentizität der sich dort vermeintlich befindenden Bundeslade mit sich bringen könnte, vor deutschen Wissenschaftler zunächst verborgen gehalten werden. So findet sich eine handschriftliche Randbemerkung Wilhelms II. auf dem Telegramm Rosens: »Bravo Rosen! Hat seine Sache ganz vortrefflich gemacht! Soll hohe Dekoration erhalten! [...] Gelehrte lieber noch nicht informieren, die plaudern ebenso wie die alten Weiber«. PA AA, R 14914 sowie R 131418, Marginalie auf dem Telegramm von Friedrich Rosen an das Auswärtige Amt vom 10. März 1905. 


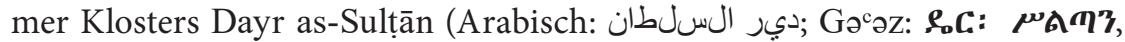
Der Ślțan), ${ }^{117}$ das zum Zankapfel in der Auseinandersetzung zwischen der äthiopischen und der koptischen Kirche geworden war, ${ }^{118}$ zugunsten $\ddot{\text { Äthi- }}$ opiens intervenieren. Wilhelm II., der selbst evangelisch war, sollte so zum Anwalt der äthiopischen Kirche in einem inner-orthodoxen Konflikt werden. ${ }^{119}$ Die monastische Niederlassung in Jerusalem war von erheblicher Bedeutung für Mənilək II., und dies nicht nur als wichtiges geistliches und

117 Die seit dem Mittelalter in Jerusalem ansässige äthiopisch-orthodoxe Gemeinde hatte ihre Blütezeit im 14. und 15. Jahrhundert erlebt, eine Zeit, in der sie im Besitz von vier Kapellen innerhalb der Grabeskirche und eines Klosters am Berg Zion gewesen war. Seit dem 16. Jahrhundert blieb ihr aber nur noch das Kloster Dayr as-Sulțān, das sich auf dem Dach der Helena-Kapelle der Grabeskirche befindet. Allerdings waren die Besitzrechte auf das Kloster spätestens seit dem 18. Jahrhundert zwischen den Äthiopiern und den Kopten umstritten. Die Koptische Kirche bezweifelte die äthiopischen Eigentumsansprüche am Kloster und war nur zur Anerkennung von Nutzungsrechten bereit. Eine neue Dimension der Eskalation wurde 1890 erreicht, als die Kopten zwei Kapellen schlossen und die äthiopische Gemeinde seitdem gezwungen war, ihre Gottesdienste in der Nähe dieser Kapellen unter freiem Himmel zu feiern. Zur Geschichte der Äthiopier in Jerusalem: Enrico Cerulli, Etiopi in Palestina: Storia della communità etiopica di Gerusalemme I, Collezione scientifica e documentaria. A cura del ministerio dell'Africa italiana 12, Roma 1943; ders., Etiopi in Palestina: Storia della communità etiopica di Gerusalemme II, Collezione scientifica e documentairia. A cura del ministerio dell'Affrica italiana 14, Roma 1947; Salvatore Tedeschi, Profilo storico di Dayr as-Sultan, in: JEtS 2 (2) (1964), S. 92-160 und Kirsten Stoffregen-Pedersen, The History of the Ethiopian Community in the Holy Land from the Time of Emperor Tewodros II till 1974, Jerusalem 1983.

118 Zur Geschichte des Streites um das Kloster: Tigab Bezie, Ethiopia’s Claim on Deir es-Sultan Monastery in Jerusalem. 1850s-1994. Roots, Litigation, Current Status, Saarbrücken 2011; Kirsten Stoffregen-Pedersen, Deir es-Sultan. The Ethiopian Monastery in Jerusalem, in: Quaderni di studi Etiopici 8-9 (1987-1988), S. 33-47; dies., The History of the Ethiopian Community; Борис Тураев, Абиссинский монастырь в Иерусалиме и его библиотека, in: Сообщения Православного Палестинского Общества XIV (II) (1903), S. 115-132.

119 Noch kurz vor der Ankunft der deutschen Gesandtschaft unternahm er einen weiteren Versuch, die Situation zugunsten der äthiopischen Kirche zu lösen, indem er 1905 Däğğazmač Mäšăša Wärqe (1852-1917) für Verhandlungen nach Jerusalem sowie Haylä Maryam Śärabyon (1863-1929) nach Istanbul zum Hof des Sultans des Osmanischen Reiches als dem Herrscher über Jerusalem entsandte. Diese diplomatischen Missionen brachten allerdings keine Ergebnisse. Deswegen wollte der äthiopische Kaiser nun Deutschland, das mit dem Osmanischen Reich gute Kontakte unterhielt, in diesen Prozess einbeziehen. Vgl. Kirsten Stoffregen-Pedersen, Mäšäša Wärqe, in: EAE 3, 2007, S. 831f. und Berhanu Gizaw Haile Mariam, Haylä Maryam Särabyon, in: EAE 2, 2005, S. 1058f. Dazu wurde Friedrich Rosen ein amharisches Dokument mit einer französischen Übersetzung übergeben, in dem zahlreiche frühere richterliche Entscheidungen bzgl. der Klosterbesitzrechte gesammelt worden waren. PA AA, A 14563, Rosen an Auswärtiges Amt vom 16. August 1905. Wahrscheinlich handelt es sich dabei um eine Übersetzung aus dem Arabi-

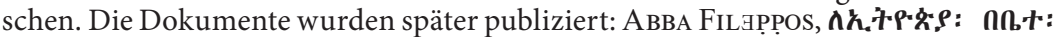

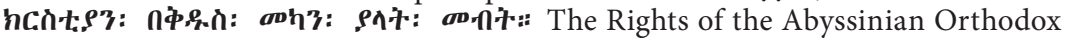
Church in the Holy Places, Jerusalem 1962. 
intellektuelles Zentrum der äthiopisch-orthodoxen Kirche, sondern auch als die Veranschaulichung seiner politischen Theologie: Der Name des Klosters, Dayr as-Sulțān (»Kloster des Herrschers«), sollte laut der äthiopischen Überlieferung darauf hinweisen, dass der Ort, an dem das Kloster steht, der Königin von Saba vom Herrscher Jerusalems, König Salomo, geschenkt worden sei. ${ }^{120}$

Der Besuch des äthiopischen Kaisers, den er der deutschen Delegation am 27. Februar abstattete, ebnete den Weg für die Unterzeichnung des DeutschÄthiopischen Freundschafts- und Handelsvertrags und machte die Aufnahme der diplomatischen Beziehungen zwischen den beiden Staaten möglich. ${ }^{121}$ In diesem Zusammenhang ist hervorzuheben, dass die beiden dabei getroffenen geheimen Abmachungen zutiefst mit der politischen Theologie Məniləks II. verbunden waren. Der äthiopische Kaiser zielte darauf ab, mit deutscher Hilfe das »salomonische Narrativ« im Kontext der Moderne neu aufzulegen und die Kontinuität des modernen Äthiopiens mit dem alten Aksumitischen Reich und dessen »biblischen« Wurzeln - so wie diese im Kəbrä Nägäśt präsentiert sind - herzustellen.

120 Kirsten Stoffregen-Pedersen, Dayr as-Sulțān, in: EAE 2, 2005, S. 117-119, hier S. 117. Was den konkreten Ort der äthiopischen Kapelle in der Grabeskirche angeht, soll es laut der äthiopischen Tradition die Kaiserin Helena (ca. 250-330), Mutter Konstantins des Großen (272-337), gewesen sein, die ihn bei dem Kirchenbau den Äthiopiern zuwies. Vgl. Coppet (Hg.), Chronique, Bd. II, S. $489 f$.

121 PA AA, Vertragsarchiv. Deutsch- Äthiopischer Freundschafts- und Handelsvertrag.

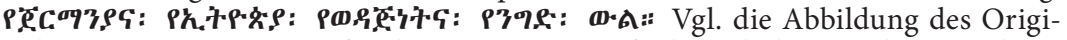
nals in Dag Zimen, Rosen für den Negus. Die Aufnahme diplomatischer Beziehungen zwischen Deutschland und Äthiopien 1905, Göttingen 2005, S. 47-50. Der abgeschlossene Vertrag war deutlich weitreichender als der englisch-äthiopische oder amerikanisch-äthiopische. Statt wie der englische und amerikanische Vertrag nur von Bewegungs- und Handlungsfreiheit, spricht der Artikel I des deutschen Vertrags von "voller Freiheit des Aufenthalts, der Reise, des Handels und Gewerbes«. Durch ausdrückliche Hervorhebung der Sicherheit der Person und des Eigentums in Artikel II erfährt Artikel I eine präzisierende Ergänzung. Artikel IV gibt den deutschen Reichsangehörigen und Schutzgenossen das Recht, Post- und Telegrapheneinrichtungen Äthiopiens und sonstige Verkehrsmittel zu denselben Bedingungen zu benutzen wie Einheimische oder Angehörige anderer Staaten. Artikel V garantiert beiden Vertragsstaaten das Recht der Bestellung beglaubigter Vertreter und sichert ihnen ausdrücklich volle Bewegungsfreiheit zu.

Der Deutsch-Äthiopische Freundschafts- und Handelsvertrag ist von den »Schutzverträgen « zu unterscheiden, die bspw. Adolf Lüderitz (1834-1886) 1883 in Südwestafrika, Adolph Woermann (1847-1911) oder Carl Peters (1856-1918) 1884 in West- und Ostafrika als Privat-Kolonisatoren mit den Bewohnern jener Gebiete schlossen, damit jedoch letztendlich deutsche Kolonien begründeten. Vgl. Norbert Berthold Wagner, Die deutschen Schutzgebiete. Erwerb, Organisation und Verlust aus juristischer Sicht, Baden-Baden 2002. 


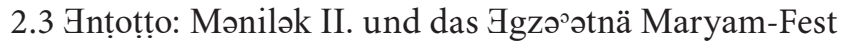

In seinen Erinnerungen verrät der Gesandtschaftsarzt, Hans Vollbrecht, ein Detail über den Kontext der Begegnung mit dem äthiopischen Kaiser, das auf den ersten Blick unbedeutend erscheinen mag: Mənilək II. stattete den entscheidenden Besuch bei der deutschen Delegation auf dem Weg zum Gottesdienst ab:

Am 27. Februar in aller Frühe begab sich die Kaiserin Taitu mit großem Gefolge zur Kirche nach Entotto, um dort wie alljährlich an diesem Tage eine Andacht zu verrichten. Sie saß eingehüllt in eine weite Schamma ${ }^{122}$ auf einem Maultier, über ihrem Kopfe wurde ein roter Schirm mit Goldfransen gehalten. Ein wenig später folgte der Kaiser, die Gelegenheit benützend, um im Vorbereiten bei uns einen Besuch zu machen. [...] Dann folgte der Kaiser seiner Gemahlin auf den Berg Entotto. ${ }^{123}$

In anderen Worten: Als das deutsche Kaiserpaar am 27. Februar 1905 die Weihe des neuen Doms in Berlin feierte, nahm das äthiopische Kaiserpaar am festlichen Gottesdienst in einer am Berg Gnțoṭto liegenden Kirche in der Nähe von Addis Abeba teil. Mənilək II. und seine Gemahlin

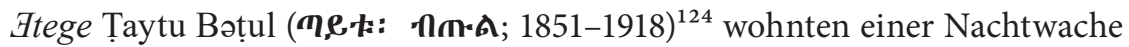

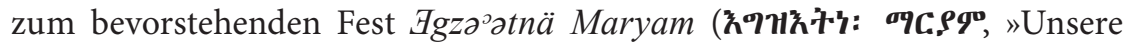
Herrin Maria«) bei, das in der Äthiopisch-Orthodoxen Kirche am 21. Tag eines jeden Monats in Erinnerung an alle Marienfeste des liturgischen Jahreskreises gefeiert wird. ${ }^{125}$ Besonders andachtsvoll wird dieses Fest in den Kirchen begangen, die - oder genauer gesagt: deren Tabot - Maria geweiht worden sind. ${ }^{126}$ Aus diesem Grund hatte sich das äthiopische Kaiserpaar an

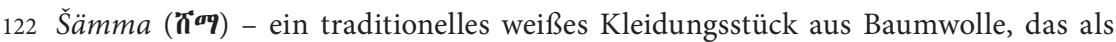
Umhang getragen wird. Da seine weiße Farbe üblicherweise mit Reinheit assoziiert wird, trägt man das Šämma beim Gottesdienstbesuch. Zu weiteren Funktionen des Š̈̈mma in der äthiopischen Gesellschaft und deren symbolischen Deutungen siehe: Edward Nicholson, The Production, History, Uses and Relationships of Cotton (Gossypium spp.) in Ethiopia, in: Economic Botany 14 (1960), S. 3-36; Michael Gervers, Clothing, in: EAE 1, 2003, S. 757-761.

123 Vollbrecht, Im Reiche des Negus, S. 113f. Zu Carl Bosch siehe: Martin Schultz, Abu Makina - der Vater der Maschine. Carl Bosch und die fotografische Dokumentation seiner diplomatischen Reisen 1903-1907, in: Mannheimer Geschichtsblätter 25 (2013), S. 103-116.

124 Zu ihrer Person siehe: Hanna Rubinkowska, Ṭaytu Bəțul, in: EAE 4, 2010, S. 878f.; Prouty, Empress Taytu and Menelik II.

125 Zum liturgischen Jahr der Äthiopisch-Orthodoxen Kirche und zur Rolle des monatlichen liturgischen Kreises siehe: Fritsch/Zanetti, Christian Calendar, S. 668-672.

126 Zum Tabot (小片) siehe Anm. 47 auf S. 130. 
diesem Tag in der Kirche Bnțtțto Maryam ( Die Kirche war auf einer Höhe von 3000 Meter am Berg Bnțotṭo gelegen, wo vor der Gründung der neuen Hauptstadt Addis Abeba im Jahre 1886 Mənilək II. residierte. ${ }^{128}$

Die Bedeutung des Ggzə`ətnä Maryam-Festes für das Selbstverständnis sowohl der äthiopischen Kirche als auch für das des äthiopischen Staates ist kaum zu überschätzen. Zwar wird das Fest in Erinnerung an alle Marienfeste des liturgischen Jahreskreises gefeiert, jedoch bezieht es sich in besonderer Weise auf zwei davon: das Gräfta (סLF;, Mariä Entschlafung) sowie

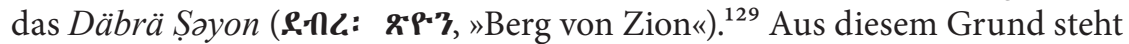

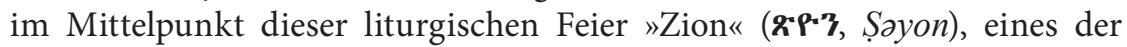
wichtigsten und zugleich komplexesten Symbole der äthiopisch-orthodoxen Theologie, die, an den biblischen Sprachgebrauch anknüpfend, als Ort der besonderen Gegenwart Gottes verstanden und primär mit der Bundeslade -

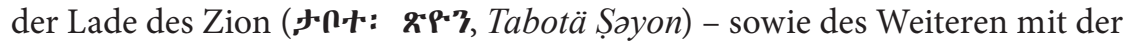
Gottesgebärerin Maria assoziiert wird.

Die Verbindung zwischen Zion, der Bundeslade und Maria stellt den zentralen Topos der äthiopisch-orthodoxen Theologie dar und wird auf mannigfache Weise in den homiletischen sowie hymnographischen Texten herausgearbeitet. ${ }^{130}$ Liturgisch wird diese Verbindung am Däbrä Șəyon und an

127 An der Stelle sei angemerkt, dass der äthiopische Kaiser von den Deutschen als besonders fromm wahrgenommen wurde. Vgl. bspw. die Bemerkung Vollbrechts: »Es würde an dem Charakterbilde dieses Herrschers etwas fehlen, wenn ich seinen religiösen Standpunkt nicht noch mit wenigen Worten streifen wollte. Menelik ist ein frommer Mann, sein Christentum ist ihm kein leerer Schall, sondern eine tief empfundene Herzenssache. [...] ein Zweifel an dem Gottesglauben und Gottvertrauen dieses Mannes Sünde wäre«. Vollbrecht, Im Reiche des Negus, S. 71f. Zu dieser Beschreibung passt auch die Tatsache, dass Mənilək II. und Țaytu anlässlich

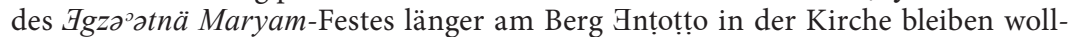
ten. Dieser Plan ließ sich jedoch nicht vollständig realisieren: »Am Abend brach ein Hundewetter los, Sturm, Regen, Donner und Blitz. Es wurde empfindlich kalt. Das Kaiserpaar, welches eigentlich zwei Tage oben in der Kirche bleiben wollte, kehrte ins Gibi [= Kaiserpalast] zurück«. Ebd., S. 114.

128 Über die Verlagerung der Hauptstadt nach Addis Abeba und die frühe Geschichte der Stadt siehe: Peter Garretson, A History of Addis Ababa. 1886-1910, Wiesbaden 2000 .

129 Die besondere Verbindung des झgzə`atnä Maryam mit diesen zwei Festen entsteht dadurch, dass sie ebenso am 21. Monatstag begangen werden: Das ${ }^{c}$ Aräfta am 21. Torr (entspricht dem 29. Januar des gregorianischen Kalenders, bzw. im Jahr vor einem Schaltjahr dem 30. Januar) und das Däbrä Şəyon (oft auch Hadar Şəyon,

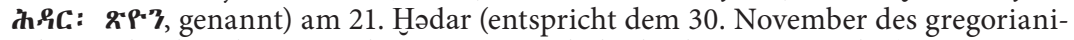
schen Kalenders, bzw. im Jahr vor einem Schaltjahr dem 1. Dezember).

130 So, wie die Bundeslade im Alten Bund das Gesetz Gottes in sich aufbewahrte und die Präsenz Gottes vergegenwärtigte, ist Maria, die in sich den Sohn Gottes beherbergte, die Bundeslade des Neuen Bundes. Vgl. bspw. eine solche Metapher

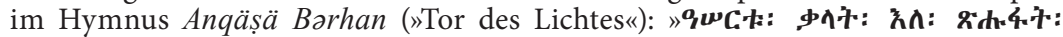

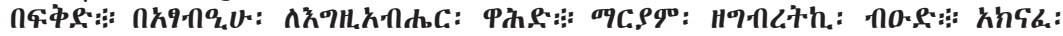




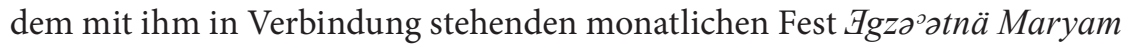
zum Ausdruck gebracht: An diesen Tagen wird nämlich nicht nur Marias gedacht, sondern es werden zugleich drei mit der Bundeslade zusammenhängende Ereignisse gefeiert, und zwar die Rückkehr der Bundeslade aus der Gefangenschaft bei den Philistern (1 Sam 6), ihre Wegführung aus Israel nach Äthiopien (so wie das Kəbrä Nägäśt sie schildert) sowie schließlich die

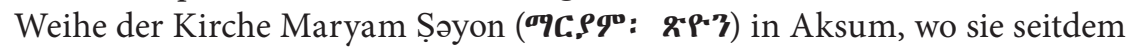
nach äthiopischer Überzeugung aufbewahrt wird. ${ }^{131}$

Dementsprechend kann dieser Gottesdienst als eine liturgische Vergegenwärtigung des »salomonischen" Narrativs des Kabrä Nägäśt gesehen werden, das Mənilək II. zum Kern seiner politischen Theologie machte. Der Gottesdienst, dem das äthiopische Kaiserpaar am Abend des 27. Februars 1905 beiwohnte, war - in ähnlicher Weise wie die Einweihung des Doms in Berlin - nicht nur ein religiöses, sondern zugleich auch ein zutiefst politisches Geschehen. Und zwar ein Geschehen, in dem die Architektur und Innenausstattung der Kirche - eine weitere Analogie zur Feier in Berlin eine bedeutende Rolle spielten [siehe Abbildung 13]. ${ }^{132}$

Mit dem Berliner Dom verband die Znțoțto Maryam-Kirche nicht nur der Umstand, dass auch ihre Weihe, die im Jahr 1887 stattfand, äußerst prunkvoll ausfiel, sondern ebenso die Tatsache, dass sie unter direkter kaiserlicher Anleitung gebaut wurde, um nicht nur eine theologische, sondern auch eine

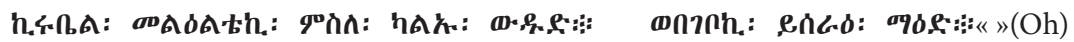
zehn Gebote, die geschrieben sind in (ihrer) Zahl/Mit den Fingern des einzigen Gottes, / Mariam, deren Anlage anders ist; / Die Flügel des Cherubs gemeinsam mit (denen) seines Genossen sind über dir / Und an deiner Seite ist der Tisch aufgestellt«. Grohmann, Aethiopische Marienhymnen, S. 384 (Text), S. 385 (Übersetzung).

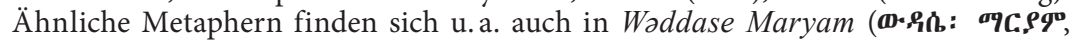

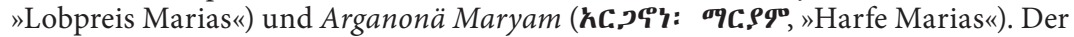
Symbolismus des Zion und seiner Verbindung mit Maria wird u. a. in der homile-

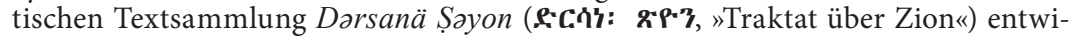
ckelt. Amsalu Tefera, The Ethiopian Homily, S. 39-62. Zur symbolischen Verbindung von Maria und Zion vgl. Getatchew Haile/Denis Nosnitsin, Mariology, in: EAE 3, 2007, S. 808-811; Ugo Zanetti, Church and Popular Veneration of St. Mary, in: EAE 3, 2007, S. 811-814. Das Konzept von "Zion« wird jedoch durch seine mariologische Komponente nicht ausgeschöpft, für seine weiteren Bedeutungen und Konnotationen siehe: Steven Kaplan, Zion, in: EAE 5, 2014, S. 189-191.

$131 \mathrm{Zu}$ dem Verlauf des Hadar Şyon-Gottesdienstes sowie zu den dabei zu verwendenden Bibellektionen siehe: Stuart Munro-HaY, The Quest for the Ark of the Covenant. The True History of the Tablets of Moses, London u.a. 2006, S. 233; Amsalu Tefera, The Ethiopian Homily, S. 44f.

132 Zur Geschichte der Znțotto Maryam-Kirche siehe v. a. die Einträge in der Chronik der Herrschaft von Kaiser Mənilək II.: Coppet (Hg.), Chronique, Bd. I, S. 170, 209231 und ders., Chronique, Paris 1931, Bd. II, S. 520f. Vgl. außerdem Haile Gabriel Dagne, The Establishment of Churches in Addis Abeba, in: Taddese Beyene (Hg.), Proceedings of the International Symposium on the Centenary of Addis Ababa. November 24-25, 1986, Addis Ababa 1987, S. 57-78. 
politische Botschaft zum Ausdruck zu bringen. ${ }^{133}$ Mənilək II. ließ unter die Wandmalereien der Kirche eine große Darstellung seiner legendären Vorgänger aufnehmen, des ersten äthiopischen Königs Mənilək und dessen Mutter, der Königin von Saba. Dies war eine gewichtige Innovation, denn bisher waren in der äthiopisch-orthodoxen kirchlichen Kunst weder die Darstellungen von König Mənilək noch die von der Königin von Saba bekannt. ${ }^{134}$ Was dieses Novum noch kühner machte, ist die Tatsache, dass das Bild von Mənilək unverwechselbar die Gesichtszüge seines Namensvetters Mənilək II. aufwies und die Darstellung der Königin von Saba Kaiserin Ṭaytu ähnelte. ${ }^{135}$

133 Der französische Reisende Jules Bobrelli (1852-1941), der in dieser Zeit am Hofe des äthiopischen Kaisers weilte, hinterließ in seinem Tagebuch eine Beschreibung der Weihe. Gewisse Ähnlichkeiten mit dem Ereignis in Berlin fallen bei der Bedeutung des Militärs und der Würdenträger auf. So lautet sein Eintrag für den 1. Oktober 1887: „De bonne heure, la cérémonie de l'installation du Tabot a été célébrée à l'église de Mariam. Le roi et l'Abouna, abrités sous des parasols rouges, se sont mis en route, précédés de superbes chevaux pompeusement harnachés. Les trompettes, les nagarit et les flûtes mêlaient leurs sons discordants. Tous les choums suivaient à pied. Au retour, les fusiliers de l'armée royale se sont placés sur les hauteurs, à l'est du guébi. Un premier coup de canon a annoncé la rentrée de Ménélik. Une décharge générale et une salve de trente coups de canon ont été le signal des réjouissances publiques. [...] Les chemins sont encombrés de prêtres revêtus de robes aux couleurs éclatantes; quelques-uns portent des coiffures à bandelettes, en étoffes dorées on argentées, qui rappellent les casques des Sarrasins«. Jules BorelLI, Éthiopie méridionale. Journal de mon voyage aux pays Amhara, Oromo et Sidama. Septembre 1885 a Novembre 1888, Paris 1890, S. 254f. Das feierliche Bankett (ף-nc, Gəbər) dauerte 4 Tage und wurde von über 20.000 (!) Gästen besucht. Der Franzose fühlte sich völlig überfordert von dem Ausmaß und der Länge der Feier, am dritten Tag notierte er in seinem Tagebuch: »Je barricade mon enceinte et je laisse passer les invités royaux«; am vierten Tag nur noch: »Au guébi, le festin dure toujours. Il est encore présidé par le roi et l'Abouna qui ont les defteras pour convives«. Ebd., S. 256. Siehe auch: Coppet (Hg.), Chronique, Bd. I, S. 231.

134 Stanislaw CHоJNACKI, A Survey of Modern Ethiopian Art, in: ZKA Sonderausgabe. Äthiopien (1973), S. 84-94, hier S. 84; Wilhelm STAUdE, Iconographie de la légende éthiopienne de la reine d'Azieb ou de Saba, in: JSAf 27 (1) (1957), S. 137-181, hier S. 150. Interessanterweise gab es seit spätestens dem 12. Jahrhundert viele Darstellungen der Königin von Saba in der westlichen kirchlichen Kunst. Gianfranco Fiaccadori, The Queen of Sheba in Western Culture, in: EAE 3, 2007, S. 677-679. Im deutschen Kontext sei bspw. auf die »jüngeren Bibelfenster« im Chor des Kölner Doms (ca. 1280) hingewiesen.

135 Vgl. Peter Garretson, Gnțoțto Maryam, in:EAE 2, 2005, S. 321; Richard Pankhurst, Some Notes for a History of Ethiopian Secular Art, in: Ethiopia Observer 10 (1) (1966), S. 5-80, hier S. 16f.; Ewa Balicka-Witakowska, The Iconography of the Deposition in Ethiopian Painting, in: Richard Pankhurst (Hg.), Proceedings of the First International Conference on the History of Ethiopian Art, London 1989, S. 14-22, hier S. 21. Die Beschreibung des Bildes findet man auch in den zeitgenössischen europäischen Reiseberichten, bspw. bei Percy Horace Gordon PowelLCоттоn, A Sporting Trip through Abyssinia. A Narrative of a Nine Months' Journey from the Plains of the Hawash to the Snows of Simien, with a Description of the Game, from Elephant to Ibex, and Notes on the Manners and Customs of the Natives, London 1902, S. 168. 


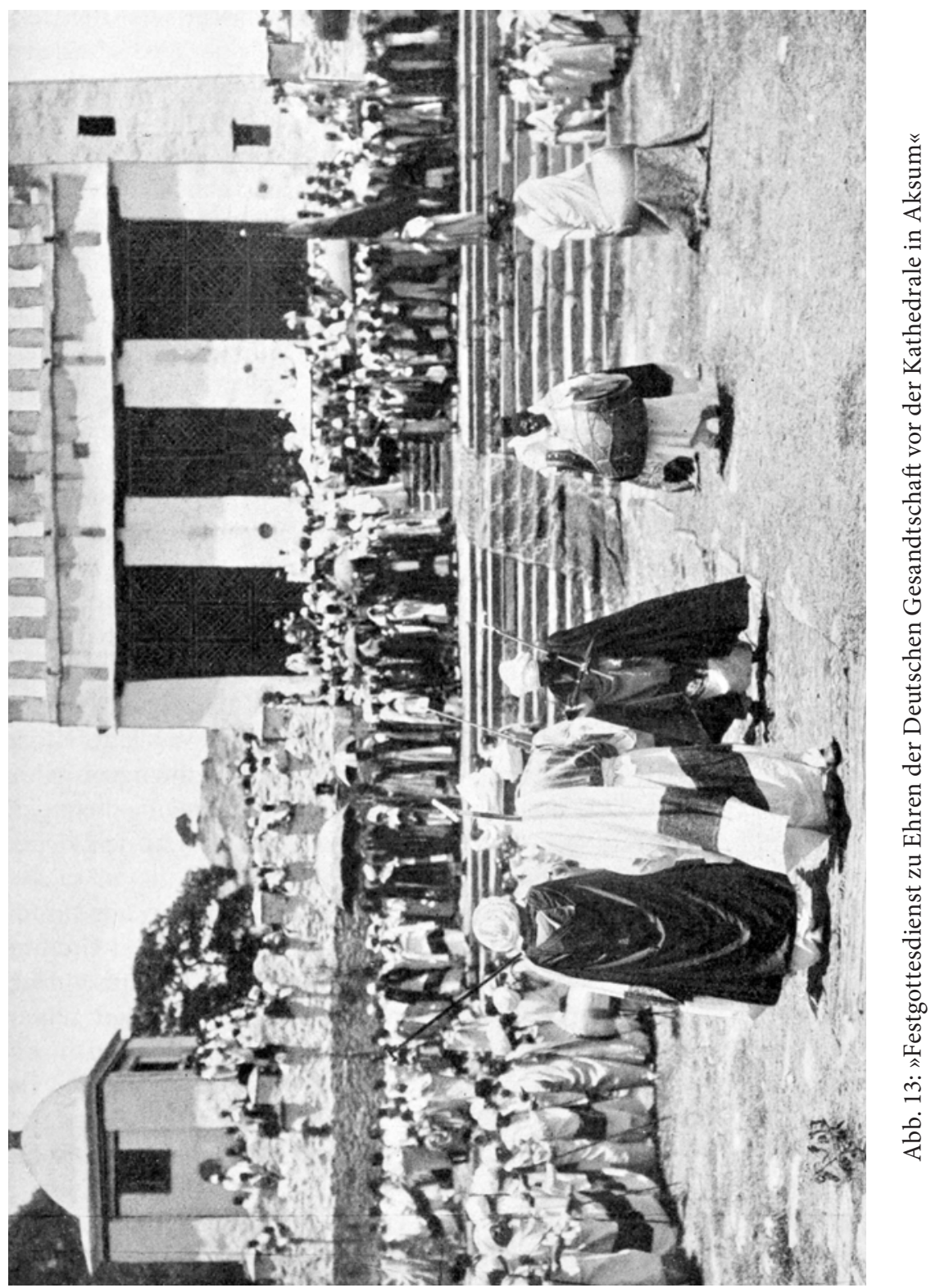


Das Gemälde stellte somit Mənilək II. als den Neubegründer des Reiches in eine Reihe mit dem legendären ersten König Äthiopiens und ließ ihn an dessen Herrlichkeit teilhaben.

Folglich kann man sowohl die Vereinbarungen, die am Vormittag zwischen dem äthiopischen Kaiser und dem deutschen Gesandten erzielt wurden, als auch den Gottesdienst, den das äthiopische Kaiserpaar am Nachmittag in der Ințotṭo Maryam-Kirche feierte, im Kontext der politischen Theologie Məniləks II. als einen Versuch verstehen, das religiöse Selbstverständnis des äthiopischen Staates neu zu definieren. ${ }^{136}$

\section{Ambivalenz des Christlichen}

\subsection{Perspektiven auf das »salomonische Narrativ«}

Die Forschung zur diplomatischen Annäherung zwischen Äthiopien und Deutschland erfasst nahezu ausschließlich Aspekte der wirtschaftlichen und realpolitischen Interessen. ${ }^{137}$ Eine nur auf diese Bereiche verkürzte Sicht läuft jedoch Gefahr, den für das Selbstverständnis der involvierten Akteure zweifellos bedeutsamen religiösen Faktor auszublenden und so der Komplexität dieser transnationalen Begegnung nicht gerecht zu werden. Das verdeutlicht die Analyse der äthiopisch-deutschen Beziehungen mit einer mikrohistorischen Perspektive und dem Fokus auf einen einzigen Tag, den 27. Februar 1905 (den 20. Yäkkatit 1897 nach äthiopischer Zeitrechnung).

Insofern sowohl das Äthiopische als auch das Deutsche Kaiserreich sich nicht zuletzt auch religiös - obschon auf verschiedene Weise - definierten und legitimierten, kam dem Christentum als dem wichtigsten gemeinsamen

136 Dieses Bedürfnis war besonders akut, nachdem Mənilək II. (zunächst noch als König der zentraläthiopischen Provinz Šäwa) in den 1880er und 1890er Jahren zeitgleich mit der europäischen Kolonisierung Afrikas - großräumige Gebiete im Süden, Osten und Westen in das Äthiopische Kaiserreich eingegliedert (und so dessen Territorium verdreifacht) sowie die Hauptstadt noch weiter nach Süden, zuletzt nach Addis Abeba, in nahezu 1000 Kilometer Entfernung von Aksum, verlegt hatte.

137 Siehe: Ursula GeHring-MünZEL, 100 Jahre deutsch-äthiopische diplomatische Beziehungen, in: Walter Raunig / Asfa-Wossen Asserate (Hg.), Orbis Aethiopicus. Ethiopian Art - a Unique Cultural Heritage and Modern Challenge, Lublin 2007, S. 67-101; Adelheid Zelleke, 100 Jahre Deutsch- ̈̈thiopischer Freundschafts- und Handelsvertrag 1905-2005, Bonn 2004; Zimen, Rosen für den Negus; Wolbert G. C. SMIDT, Five Centuries of Ethio-German Relations, in: Language Department of the German Foreign Office (Hg.), Ethio-German Relations, Addis Abeba 2004, S. 6-14; ders., Photos as Historical Witnesses. The First Ethiopians in Germany and the First Germans in Ethiopia. The History of a Complex Relationship, Münster 2015. Siehe außerdem auch: Rudolf Fechter, History of German Ethiopian Diplomatic Relations, in: ZKA Sonderausgabe. Äthiopien (1973), S. 149-156; DAUM, Gelehrter und Diplomat, S. 265-281; BAIrU TAFla, Ethiopia and Germany, S. 73-144. 
identitätsstiftenden Element ein besonders hoher Stellenwert zu. ${ }^{138}$ Wie Wilhelm II. sich in Berlin bei der Weihe des Doms als »Hort und Hüter der reformatorischen Glaubensgüter« feiern ließ, so präsentierte sich der äthiopische Kaiser Mənilək II. in der Gnțoțto Maryam-Kirche als der rechtmäßige Nachkomme der Königin von Saba und König Salomos, indem er dort das Ggza`atnä Maryam-Fest beging. Diese Ereignisse stehen plakativ für zwei politischen Theologien, die in ihren jeweils eigenen Varianten des Christentums verwurzelt sind und in der Regel isoliert betrachtet werden. Doch die diplomatischen Verhandlungen zwischen Mənilək II. und dem im Auftrag Wilhelms II. agierenden Friedrich Rosen, die am gleichen Tag in Addis Abeba stattfanden und deutliche theologische Komponente beinhalteten, zeigen exemplarisch, dass diese vermeintlich ausgesonderten Phänomene zutiefst miteinander verflochten waren.

Die Rolle des Christentums in der diplomatischen Annäherung zwischen Deutschland und Äthiopien war allerdings nicht so eindeutig, wie man auf den ersten Blick annehmen kann. Vielmehr hatte es eine zutiefst ambivalente Stellung. Dies lässt sich bereits am Beispiel des "salomonischen Narrativs" aufzeigen, welches auch bei den diplomatischen Verhandlungen eine bedeutende Rolle spielte.

Ausgerechnet im Jahre 1905 machte Carl Bezold ${ }^{139}$ das "salomonische Narrativ« in seiner vollständigen Version dem europäischen Leser bekannt, indem er seine kritische Edition und deutsche Übersetzung des Kəbrä Nägäśt veröffentlichte. ${ }^{140}$ Die Herrlichkeit der Könige wurde somit erstmalig in sei-

138 Heinrich Scholler, Mythos und Wirklichkeit Christlicher Imperien am Ende des Zweiten Jahrtausends. Äthiopien und die Deutsche Reichsidee, in: Verena BöLl u. a. (Hg.), Studia Aethiopica. In Honour of Siegbert Uhlig on the Occasion of his 65th Birthday, Wiesbaden 2004, S. 233-245, hier S. 237.

139 Zu Bezold siehe: Michael Kleiner, Bezold, Carl, in: EAE 1, 2003, S. 562; Franz Boll, Carl Bezold. Nachruf, im Namen der philosophischen Fakultät der Universität Heidelberg gesprochen bei der Beisetzung am 23.11.22, in: SHAW 14 (1923), S. 3-12; Friedrich Wilhelm Bautz, Bezold, Karl, in: BBKL, Herzberg 1990, Bd. 1, Sp. 574.

140 Bezold, Kebra Nagast, S. III. Bereits 1882 begann Carl Bezold die Arbeit an der Edition und deutschen Übersetzung des Kabrä Nägäśt, allerdings war sie unterbrochen: Seit 1888 widmete er sich im Auftrag der englischen Regierung der Katalogisierung der babylonisch-assyrischen Kujundschik-Sammlung. Die Tätigkeit im Britischen Museum nahm zwölf Jahre in Anspruch. Sein Werk präsentierte der Heidelberger Professor bereits am 6. Dezember 1902 bei der Sitzung der philosophischphilologischen und der historischen Classe der kaiserlichen bayerischen Akademie der Wissenschaften zu München. Vgl. Sitzung der philosophisch-philologischen und der historischen Classe vom 6. December 1902, in: SDAW.PH Jahrgang 1902 (1903), S. 432-435. Die Vorstellung des Buches übernahm der Classensekretär der philosophisch-philologische Classe der Akademie, Professor Wilhelm von Christ (1831-1906). Er betonte die Wichtigkeit des Buches, das seiner Meinung nach, »für das beste Muster dessen gelten [kann], was die schriftstellerische Kunst der Aethiopen zu leisten vermochte«. Ebd., S. 432. 
nem gesamten äthiopischen Text publiziert und in eine moderne europäische Sprache übersetzt. Die Edition rief nicht nur zahlreiche Reaktionen hervor, sondern wurde zur wichtigsten Publikation des Jahres im äthiopistischen Forschungsbereich erklärt. ${ }^{141}$ Während alle Rezensenten sich bezüglich der sorgfältigen Arbeit Bezolds und seiner vortrefflichen wissenschaftlichen Leistung einig waren, fiel das Urteil über das Kabrä Nägäśt selbst recht unterschiedlich aus. Nahezu alle Buchbesprechungen verband allerdings das Leitmotiv der bei der Lektüre empfundenen Seltsamkeit des Textes - er sei ein »sonderbares Werk«, so Johannes Flemming. ${ }^{142}$ Es war bezeichnend, dass diese Auffassung ebenfalls von namhaften Orientalisten zum Ausdruck gebracht wurde. So schrieb beispielsweise einer der überragenden Fachvertreter, Theodor Nöldeke (1836-1930):

Europäischem Urteil kann freilich das äthiopische Buch nach seinem Inhalt und seiner Anordnung keineswegs als ein Meisterwerk erscheinen. Die koptisch-abessinische Denkart ist eben von der unsrigen sehr verschieden! ${ }^{143}$

Woran lag es aber, dass selbst bei Wissenschaftlern, die sich jahrelang mit Texten orientalischer Provenienz auseinandergesetzt hatten, so ein Unbehagen gegenüber dem Kabrä Nägäśt zu spüren war? Ein Grund dafür mag die Vielschichtigkeit des Textes und die Komplexität seiner Komposition gewesen sein. So beklagte Hugo Greßmann (1877-1927) »einen Wirrwarr«, der den Text nur schwer nachvollziehbar mache: „Wer das Kebra Nagast [...] zum ersten Male liest, wird durch die Fülle des ungleichartigen Stoffes schier erdrückt «. ${ }^{144}$ Und das liege daran, dass geschichtliche und märchenhafte Züge, israelitische und christliche Anschauungen, neutestamentliche und kirchenhistorische Reminiszenzen, dogmatische Schriftbeweise und escha-

141 Franz Praetorius, Wissenschaftlicher Jahresbericht über die morgenländischen Studien im Jahre 1905. Die abessinischen Dialekte und das Sabäo-Minäische, in: ZDMG 60 (1906), S. 261-263, hier S. 261.

142 Johannes Flemming, [Rezension:] Kebra Nagast. Die Herrlichkeit der Könige. Nach den Handschriften in Berlin, London, Oxford und Paris zum ersten Mal im äthiopischen Urtext herausgegeben und mit deutscher Übersetzung versehen, in: GGA 11 (171) (1909), S. 903-912, hier S. 903.

143 Nöldeke Theodore, [Rezension:] Kebra Nagast. Die Herrlichkeit der Könige. Nach den Handschriften in Berlin, London, Oxford und Paris zum ersten Mal im äthiopischen Urtext herausgegeben und mit deutscher Übersetzung versehen, in: WZKM 19 (1905), S. 397-411, hier S. 397. Vgl. auch Nöldeke Theodore, Die äthiopische Literatur, in: Paul Hinneberg (Hg.), Die orientalischen Literaturen. Die Kultur der Gegenwart 1,7, Berlin u. a. 1906, S. 124-131, hier S. 128. Allerdings übersetzt Nöldeke in diesem Beitrag das Kabrä Nägäśt als »die Herrlichkeit des Königs [sic!]《.

144 Hugo Gressmann, [Rezension:] Kebra Nagast. Die Herrlichkeit der Könige. Nach den Handschriften in Berlin, London, Oxford und Paris zum ersten Mal im äthiopischen Urtext herausgegeben und mit deutscher Übersetzung versehen, in: ZDMG 60 (1906), S. 666-674, hier S. 666. 
tologische Prophezeiungen »bunt und regellos « neben einander stünden. ${ }^{145}$ Die Herrlichkeit der Könige (und somit auch das "salomonische Narrativ«) wurde zwar dem Wissensbestand der deutschen Gelehrsamkeit hinzugefügt, erschien aber befremdend, unverständlich und - da die innere Logik und Ästhetik des Werkes unzugänglich blieben - sogar unliterarisch.

Ausschlaggebend für diese Wertung war allerdings die gefühlte Diskrepanz zwischen der dem Kabrä Nägäśt zugeschriebenen religiös-mythischen literarischen Gattung und der Rolle, die es in dem politischen und gesellschaftlichen Leben Äthiopiens spielte. Dass die Herrlichkeit der Könige auch noch im 20. Jahrhundert als die Legitimationsgrundlage eines Staates gelten konnte, erschien höchst merkwürdig. Der Semitist Franz Praetorius (1847-1927), der in den 1870er Jahren selbst einen Teil des Kabrä Nägäśt ediert und übersetzt hatte, ${ }^{146}$ beschrieb es nun als »lediglich eine plumpe priesterliche Fiktion und Geschichtsfälschung zu Ehren Abessiniens «. ${ }^{147}$ Dabei störte ihn, dass es trotzdem in Äthiopien $» z u$ hohem Ansehen gelangt[e] und als wirkliche Geschichte angesehen« wurde. ${ }^{148}$

Zwar wurde die Historizität des »salomonischen Narrativs" in den Wissenschaftskreisen Deutschlands entschieden geleugnet, dennoch trugen die Deutschen zu dessen historischer Legitimierung maßgeblich bei. Denn es war im Rahmen der von Wilhelm II. unterstützten archäologischen Ausgrabungen in Aksum - diese war ein erstes Ergebnis der 1905 aufgenommenen diplomatischen Beziehungen -, in dem man im Frühjahr 1906 das vermeintliche Grab des legendären Mənilək identifiziert hatte. ${ }^{149}$ Dieser Fund förderte

145 Ebd. Bei der Lektüre der deutsch- und der englischsprachigen Rezensionen zu Bezolds Kəbrä Nägäśt-Edition erscheint der Unterschied der beiden akademischen Kulturen unübersehbar. Ein nahezu identischer zu dem hier zitierten Gedanken wird auch vom Engländer James A. Crichton vorgetragen, doch diametral anders bewertet: "Kebra Nagast presents a marvellous combination of national pride, religious zeal, and oriental morality, set in a half-Jewish, half-Christian framework of legend, and painted in the vivid colours of Eastern fancy«. James CRICHTON, Review: Kebra Nagast. Die Herrlichkeit der Könige. Nach den Handschriften in Berlin, London, Oxford und Paris zum ersten Mal im äthiopischen Urtext herausgegeben und mit deutscher Übersetzung versehen, in: RTP 1 (1906), S. 225-229, hier S. 228.

146 Franz Praetorius, Fabula de Regina Sabaea apud Aethiopes, Halle (Saale) 1870.

147 Ders., Wissenschaftlicher Jahresbericht, S. 261.

148 Ebd. In dieser Aussage drückte sich nicht nur die für den Historismus typische strikte Trennung zwischen der "wirklichen" und der "falschen" Geschichte aus, sondern auch - was für den orientalistischen Diskurs um 1900 als charakteristisch gelten kann - eine implizierte theologische Wertung. Da die meisten der um 1900 tätigen Orientalisten an den theologischen Fakultäten ausgebildet worden waren bzw. dort - in der Regel als Alttestamentler - Professuren innehatten, war die enge Wechselwirkung zwischen den orientalistischen und theologischen Diskursen nicht verwunderlich.

149 Vgl. Rosen, Eine deutsche Gesandtschaft, S. 475; Enno Littmann/Daniel Krencker, Vorbericht der deutschen Aksumexpedition, Berlin 1906, S. 30. 
die weitere Entwicklung der »neosalomonischen« politischen Theologie auf Basis des "salomonischen Narrativs" und ebnete sogar den Weg zur dessen Aufnahme in die erste Verfassung Äthiopiens. ${ }^{150}$

\subsection{Transkonfessionelle Praktiken der Diplomatie}

Am deutlichsten drückte sich die Ambivalenz des Christlichen paradoxerweise jedoch in jenen Praktiken aus, die darauf abzielten, das Gemeinsame zum Ausdruck zu bringen und dadurch die Zusammengehörigkeit zu symbolisieren.

Als eine solche transkonfessionelle Praxis der Diplomatie kann die gegenseitige Schenkung sakraler liturgischer Gegenstände betrachtet werden. So überreichten die deutschen Diplomaten der äthiopischen Kaiserfamilie bei der ersten Audienz am 19. Februar 1905 neben den bei solchen Gelegenheiten unerlässlichen Luxusartikeln, die in Deutschland gedruckte Edition des Henoch-Buches samt einigen anderen theologischen Werken auf $\mathrm{G}^{\mathrm{c}} \partial \mathrm{z}^{151}$ sowie »ein kostbares Altargerät [...], Weinkanne, Kelch und Oblatentel-

$150 \mathrm{Vgl}$. The law determines that the imperial dignity shall remain perpetually attached to the line of His Majesty Haile Selassie I, descendant of King Sahle Selassie, whose line descends without interruption from the dynasty of Menelik I, son of King Solomon of Jerusalem and the Queen of Ethiopia, known as the Queen of Sheba«. Chapter I, Art. 3, Constitution, July 16, 1931.

151 Felix Rosen beschrieb dies wie folgt: »Oberbibliothekar Flemming überreichte einen Stoß schön gebundener Bücher: alle die Werke, die in äthiopischer Sprache und Schrift in Deutschland gedruckt worden sind, obenauf seine eigenen Arbeiten. Diese Gabe bereitete dem Negus besondere Freude, und er durchblätterte sofort Buch für Buch, lobte die Klarheit und Gleichmäßigkeit der Typen und schlug hin und wieder eine Lieblingsstelle nach. Sichtlich machte es großen Eindruck auf ihn, $\mathrm{zu}$ sehen, daß die deutsche Wissenschaft sich längst mit der Sprache und Literatur seines Landes beschäftigt hatte, bevor noch an offizielle Beziehungen zwischen beiden Staaten gedacht worden war. Der Negus gab auch sogleich Befehl, unsrem Reisegenossen seine Studien über amharische [sic!] Manuskripte in jeder Weise zu erleichtern und ihm vor allen Dingen die kaiserliche Bibliothek im Gebi [= Kaiserpalast] und die Büchersammlung in den Kirchen der Stadt und Antottos [= Gnțoțto] zugänglich zu machen«. Rosen, Eine deutsche Gesandtschaft, S. 254f. Mit den eigenen Arbeiten von Flemming waren die zwei Bände der von ihm vorbereiteten Edition und Übersetzung des Henoch-Buches gemeint. Da die deutsche Delegation nicht ausreichend Zeit hatte, konnte Flemming keine Kopien der Manuskripte im Skriptorium der kaiserlichen Bibliothek bestellen, wie es bspw. der französische Forscher Casimir Mondon-Vidailhet (1847-1910) einige Jahren vorher gemacht hatte. Vgl. Marius Chaîne, Catalogue des Manuscripts Éthiopiens de la Collection Mondon-Vidailhet, Paris 1913. Mit den von Rosen erwähnten "amharische[n] Manuskripte[n] « sind hier eigentlich Gəcəz-Manuskripte gemeint. Nicht nur Felix Rosen, sondern auch andere Mitglieder der Delegation verwechselten ständig die Amharische Sprache mit dem Gəəoz. Vgl. Rosen, Eine deutsche Gesandtschaft, S. 159, 254f., 261, 338, 376f., 478; BoscH, Karawanen-Reisen, S. 163. 
ler « als Staatsgeschenke. ${ }^{152}$ Diese Gegenstände, die für die Eucharistiefeier bestimmt waren, hatten einen besonderen Symbolwert, denn sie versinnbildlichten die Verbundenheit der beiden Kaiserhäuser im christlichen Glauben, und zwar ungeachtet der Tatsache, dass zwischen ihnen keine Abendmahlsgemeinschaft bestand. Der Vergleich der von den Deutschen mitgebrachten Geschenke mit denen anderer diplomatischer Gesandtschaften zeigt, dass die Verwendung der explizit religiösen Symbolik eine Besonderheit der deutschen Äthiopien-Diplomatie war. ${ }^{153}$

Allerdings wurden diese Geschenke unterschiedlichen Interpretationen unterzogen. Dies wird bereits aus der Reaktion Məniləks II. ersichtlich, die in seiner tiefen Marienfrömmigkeit verwurzelt war.

Er [Mənilək II.] nahm alles mit großer Lebhaftigkeit und freundlich lächelnd entgegen. Besonders groß war aber seine Freude beim Anblick der beiden goldenen Altargeräte, die ich ihm als das Geschenk Ihrer Majestäten des Kaisers und der Kaiserin zu überreichen hatte. Ich fügte hinzu, dies Altargerät sei für eine vom Negus in Adis Alem

152 Rosen, Eine deutsche Gesandtschaft, S. 257. Allerdings konnten die eindrucksvollsten Geschenke, ein Lastwagen der Firma Daimler und eine Maschine zur Erzeugung elektrischen Lichtes, wegen technischer Mängel nicht übergeben werden. Umso größere Bedeutung kam daher den restlichen Gaben zu. Neben einem lebensgroßen Porträt des Deutschen Kaisers in Garde-du-Corps-Uniform und Kaiserkrone sowie einer Photographie der Kaiserin mit den Kindern war unter den deutschen Gaben an Mənilək II. und seine Gemahlin Kaiserin Țaytu auch ein Album mit Ansichten von Berlin und Potsdam sowie den Bildern der Hohenzollernfürsten.

153 Nur ein Jahr zuvor weilte die amerikanische diplomatische Mission am Hof des äthiopischen Kaisers; im März 1905, unmittelbar nach der deutschen Gesandtschaft, kam die kaiserliche Gesandtschaft von Österreich-Ungarn in Äthiopien an. Die Gaben der Amerikaner fielen recht bescheiden aus - »It is scarcely necessary to observe that the American Republic is not addicted to gift giving or receiving", so der Konsul Robert Peet Skinner (1866-1960). Außer einem Porträt von Präsident Theodore Roosevelt (1858-1919) und seinem Buch North American Big Game - dazu musste der Konsul bemerken: »I fear that His Majesty will never be able to read it« - wurden dem äthiopischen Kaiser eine Schreibmaschine und ein Magazingewehr überreicht. Robert Skinner, Abyssinia of To-day. An Account of the First Mission Sent by the American Government to the Court of the King of Kings (1903-1904), New York 1906, S. 119f. Die Geschenke der ÖsterreichischUngarischen Monarchie waren viel großzügiger. Es ist aber bezeichnend, dass keins davon auf das Christentum verwies. Rudolf Agstner zitiert in seiner Arbeit eine Archivakte, in der alle Geschenke der Habsburger Monarchie für den äthiopischen Kaiser präzise aufgelistet sind: »1. Ein Gebirgsgeschütz mit Munition, 2. Buch mit Abbildungen von k.u.k. Truppen 3. Etui mit 12 silbernen, innen vergoldeten mit Kaiserkrone und Ah. Monogramm gravierten Trinkbechern 4. Porträt S. k. u.k. Ap. Majestät in Rahmen 5. Zwei Teppiche 6. Sechs Rollen Seidenstoff weiß, rot und schwarz 7. Silberner Toilettenspiegel mit silbernem Lavoir und Kamm 8. Feine Seife und Parfum 9. 24 Flaschen Tokajer Essenz 1889, 36 Flaschen Ofner Adelberger, 36 Flaschen Herrschaftswein (österr. Gebirgswein)«. Rudolf Agstner, Vom k. u.k. Honorarkonsulat zur Österreichischen Botschaft. 100 Jahre österreichische Präsenz in Addis Abeba, in: RöHM 46 (2004), S. 419-448, hier S. 421. 
neu erbaute Kirche bestimmt, auf deren Bau er ganz besonders stolz ist. Der Negus war hierdurch sichtlich gerührt und bewunderte lange und eingehend die schöne Ausführung der in romanischem Stil durchgeführten Gefäße und flüsterte seiner Umgebung zu. »Die heilige Maria fängt früh an, Geschäfte zu machen «. ${ }^{154}$

Die wilhelminischen Geschenke wurden mit ebenso für die Liturgiefeier bestimmten Gegenständen, altehrwürdigen bronzenen Kirchengeräten (unter anderem einem Abendmahlskelch mit griechischer Inschrift), erwidert und damit die vom Deutschen Kaiser angedeutete christliche Einheit bejaht. ${ }^{155}$ Von hoher symbolischer Bedeutung war die Entscheidung Məniləks II., das

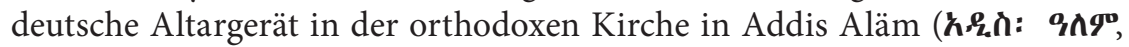
»Neue Welt«) zu verwenden.

Addis Aläm, das etwa 50 Kilometer westlich von Addis Abeba lag, war "Meneliks Sanssouci«, ${ }^{156}$ der beliebteste aller Residenzorte des Kaisers, wohin er auch seine Hauptstadt verlegen wollte. ${ }^{157}$ Seinem Plan zufolge sollte die dortige Däbrä Șəyon-Kirche, ${ }^{158}$ die sich zu der Zeit noch im Bau befand, die Kathedrale von Aksum repräsentieren ${ }^{159}$ und Addis Aläm selbst sollte zum »neuen Aksum« werden. Solch ein erheblicher Eingriff in die sakrale

154 PA AA, R 14915, Nr. 5516 Bericht Friedrich Rosens an Reichskanzler von Bülow vom 1. März 1905. Vgl. Rosen, Eine deutsche Gesandtschaft, S. 257; Bosch, KarawanenReisen, S. 164; VollbRecht, Im Reiche des Negus, S. 104f.

155 Rosen, Eine deutsche Gesandtschaft, S. 283. Zudem hat der äthiopische Kaiser das Altargerät in seinem Dankschreiben an Wilhelm II. explizit erwähnt. PA AA, R 14889. Brief von Mənilək II. an Wilhelm II. vom 7. Mäggabit 1897 A. M. [= 16. März 1905]. Für eine Edition des Briefes siehe: Bairu Tafla, Ethiopia and Germany, S. 240f.

156 Rosen, Eine deutsche Gesandtschaft, S. 298.

157 Zur Gründung von Addis Aläm und zu den Plänen Məniləks II., dorthin die Hauptstadt zu verlegen, siehe: Richard Pankhurst, Economic History of Ethiopia. 1800-1935, Addis Ababa 1968, S. 706-708.

158 Als sich die deutsche Gesandtschaft in Äthiopien aufhielt, war der Bau dieser Kirche, die das geistliche Zentrum des Reiches näher an dessen Hauptstadt rücken sollte, fast abgeschlossen.

159 Die Absicht, diese Kirche mit der Kathedrale von Aksum gleichzusetzen, brachte Mənilək II. in seiner Weiherede - die Weihe fand noch in demselben Jahr statt, und zwar am Däbrä Ṣəyon-Fest, am 30. November 1905 - explizit zum Ausdruck: „Nous avons fait son prestige égal à celui d'Aksoum et nous l'avons nommé Dèbrè-Tsione«. Coppet (Hg.), Chronique, Bd. II, S. 544. Darauf, dass es sich bei der Kirche um das neue Aksum handelte, wies außer dem Namen Däbrä Şyon ( $\boldsymbol{R}_{\mathbf{n}} \mathbf{L}: \mathbf{R} \cdot \boldsymbol{\rho} \cdot \boldsymbol{\eta} ;$; Berg

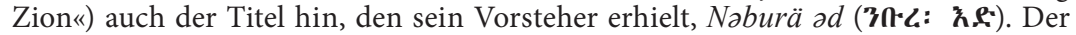
äthiopischen Tradition nach sollte der Naburä ad sogar Nachfolger des mit Mənilək aus Jerusalem nach Äthiopien gekommenen Asarja, dem Sohn des Hohepriesters Zadok (vgl. 1 Kön 4,2), sein. Für mehr Informationen zu diesem Titel und seiner historischen Genese siehe: Denis Nosnitsin, Nəburä əd, in: EAE 3, 2007, S. 1161f.;

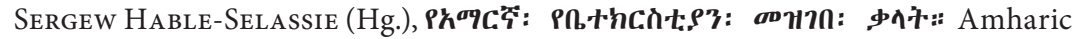
Church Dictionary, Heidelberg u.a. 1982 A. M. [1990 A.D.], Bd. 5, S. 29-32; CopPET (Hg.), Chronique, Bd. II, S. 450. Diesen Titel hatte ebenfalls der Vorsteher der 
Topografie konnte indes nicht allein von einem Menschen, und sei es auch der Kaiser, eigenmächtig vorgenommen werden; vielmehr bedurfte er - in Anlehnung an den im Kəbrä Nägäśt prototypisch dargestellten Fall der Übertragung der Bundeslade - einer göttlichen Sanktion. In der Chronik der Herrschaft Məniləks II. ${ }^{160}$ entspricht ihr die Erzählung über das Wunder, das Maria während der Konstruktion der Kirche bewirkt haben soll. ${ }^{161}$ Obwohl die Chronik insgesamt auf Amharisch geschrieben wurde, war diese Erzählung über das Wunder auf Gəcəz verfasst. Sie war also für die liturgische Verwendung und möglicherweise sogar für die Aufnahme in die

Kathedrale von Aksum inne, und er wurde im allgemeinen Bewusstsein eng mit der Idee des Schutzes der Bundeslade assoziiert; somit wurde Addis Aläm zum einzigen Ort außer Aksum, wo der Vorsteher der Kirche den Titel von Naburä ad trug.

160 Mənilək II. gab die Chronik in Auftrag und begleitete revidierend ihre Entstehung. Er ließ sie mit der Nacherzählung der Geschichte von Salomo und Makədda sowie ihrem Sohn Mənilək beginnen, um sich dann als in ihrer Tradition und Herrlichkeit stehenden Nachfahren zu präsentieren. Vgl. Coppet (Hg.), Chronique, Bd. I, S. VII und S. 1-14.

161 »Nous allons maintenant écrire en gueez le miracle que Notre-Dame Marie accomplit durant la construction de la grande église: Miracle accompli par notre souveraine à tous, la Vierge Marie, Mère de Dieu. Que sa prière et ses bénédictions soient avec notre roi Ménélik et notre reine Ouallètè-Mikaël, dans les siècles des siècles. Amen! Lorsque le règne de Ménélik II, élu de Dieu, roi des rois d'Éthiopie, arriva à sa trente-sixième année, le roi construisit une ville au pays de Miétta et la nomma Addis-alèm. Deux ans après le début de la construction de cette ville, son épouse, Itiéguié Taitou, lui dit: "Il vaut mieux pour nous que cet édifice devienne une église afin qu'il nous serve de guide vers le royaume des cieux«. Le roi, accédant à ses désirs, cessa la construction du palais royal déjà commencée et bâtit une église dédiée à Notre-Dame Marie, Mère de Dieu et l'appela Dèbrè-Tsione; il y fit placer un tabot de ce nom qui était auprès de lui depuis le début de son règne. Pendant qu'on élevait cette église, le roi des rois Ménélik arriva de Guènnèt où il devait plus tard faire bâtir une ville. Alors il commanda à son armée d'y travailler par groupes à tour de rôle. Cette église est très grande; elle mesure trente coudées de long. Ayant fait construire un échafaudage, il permit ainsi à un grand nombre de ses soldats de continuer leur travail et de monter jusqu'au faite. Or, cet échafaudage s'écroula et beaucoup de soldats tombèrent à terre et sur les pierres apportées pour la construction. Toute l'armée fut saisie de frayeur, car, comme ils étaient tombés de très haut, on les crut tous morts. Il y eut partout grande surprise et grande stupeur. Mais, de tous ceux qui étaient tombés, pas un seul ne fut blessé. Au sommet de l'échafaudage, un homme qui était resté suspendu à un morceau de bois de la toiture se mit à crier de tout son coeur: $O \mathrm{O}$ Sainte-Vierge, miséricordieuse et libératrice, secours-moi et sauve-moi de ce danger! « Marie, qui délivre ceux qui ont recours à elle, qui donne des grâces à ceux qui les demandent d'un coeur plein de confiance, le sauva par l'entremise d'un homme. Tous ceux qui étaient tombés de l'échafaudage se relevèrent et allèrent immédiatement rejoindre les autres pour continuer le travail commencé. Les témoins de ce prodigieux miracle rendirent gloire à Dieu et louèrent Notre-Dame Marie, Mère de Dieu. Ce miracle fut accompli en faveur de Ménélik II, à cause de la pureté de son cœur et parce que Marie l'aime plus que tous les autres rois. Que Sa prière soit avec notre roi Ménélik et avec notre reine Ouallètè-Mikaël dans les siècles des siècles! Amen!« Coppet (Hg.), Chronique, Bd. II, S. 497f. 


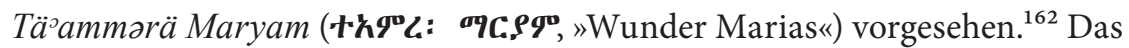
von Wilhelm II. geschenkte Altargerät gehörte zum Bestand ausgerechnet jener Kirche, die als das neue geistliche Zentrum der äthiopischen Orthodoxie und die Brücke zum "salomonischen Narrativ«, als das "neue Aksum", gedacht war.

Ein nicht weniger deutliches Beispiel transkonfessioneller diplomatischer Praxis ergab sich im "alten Aksum«. die deutsche Gesandtschaft erreichte Aksum auf ihrem Rückweg nach Europa am Ostersonntag, dem 30. April 1905. Sowohl der Ort als auch der Zeitpunkt boten Mənilək II. eine ausgezeichnete Möglichkeit, die Verbundenheit der beiden Kaiserreiche im christlichen Glauben ein letztes Mal vor der Abfahrt der deutschen Gesandtschaft aus Äthiopien zu betonen. Daher ließ der äthiopische Kaiser in Aksum zu Ehren der deutschen Delegation einen Gottesdienst halten. Als Vertreter eines verbündeten christlichen Reiches sollten die Mitglieder der deutschen kaiserlichen Gesandtschaft in das liturgische Geschehen der äthiopischorthodoxen Kirche aufgenommen werden, und zwar an einem besonders sakralen Ort, vor der berühmten Aksum Șəyon-Kirche. Die Bedeutung dieser Kirche war auch den Deutschen bekannt: Sie beherberge, so Felix Rosen, »die Bundeslade (Tabot) aus dem Tempel in Jerusalem mit den Gesetzestafeln«, die »Menilehek, der Sohn Salomos und der Königin von Saba, der Begründer der abessinischen Dynastie, « nach Äthiopien gebracht habe [siehe Abbildung 13]. ${ }^{163}$

Den besonderen Status, den Mənilək II. dem Besuch der deutschen kaiserlichen Gesandtschaft zudachte, betonte das Aqwa ${ }^{w} a m$ ( liturgische Tanz der äthiopischen Geistlichen und Däbtära. Dieser sowohl vom Gesang als auch von den traditionellen kirchlichen Musikinstrumenten der äthiopischen Kirche - dem Gebetsstock (Mäqqwamiya), dem Sistron (Șänașal) und der Trommel (Käbäro) - begleitete Tanz, diente dem Ausdruck einer besonderen geistlichen Freude und durfte nicht an den Fastentagen aufgeführt werden. ${ }^{164}$

$162 \mathrm{Zu}$ Tä̊ammərä Maryam, das neben der Bibel das verbreitetste Buch in Äthiopien, siehe Anm. 91 auf S. 143.

Diese Art der Legitimation der Errichtung eines "neuen Aksum« entsprach innerer Logik der äthiopischen theologischen Tradition. So befinden sich unter den Tä̊ammarä Maryam mindestens 19 Texte, die über die Wunder berichten, die im Zusammenhang mit der Bundeslade getätigt wurden. Vgl. Amsalu Tefer A, „Cycles of Zion" in Ethiopic Texts, in: Alessandro BAusi u.a. (Hg.), Essays in Ethiopian Manuscript Studies. Proceedings of the International Conference "Manuscripts and Texts, Languages and Contexts. The Transmission of Knowledge in the Horn of Africa«. Hamburg, 17-19 July 2014, Wiesbaden 2015, S. 145-152, hier S. 147.

163 Rosen, Eine deutsche Gesandtschaft, S. 467.

164 Dazu siehe: Kay Kaufman-Shelemay, Aqwaqwam, in: EAE 1, 2003, S. 293; Donald Nathan Levine, Wax and Gold. Tradition and Innovation in Ethiopian Culture, Chicago 1986, S. 26. 


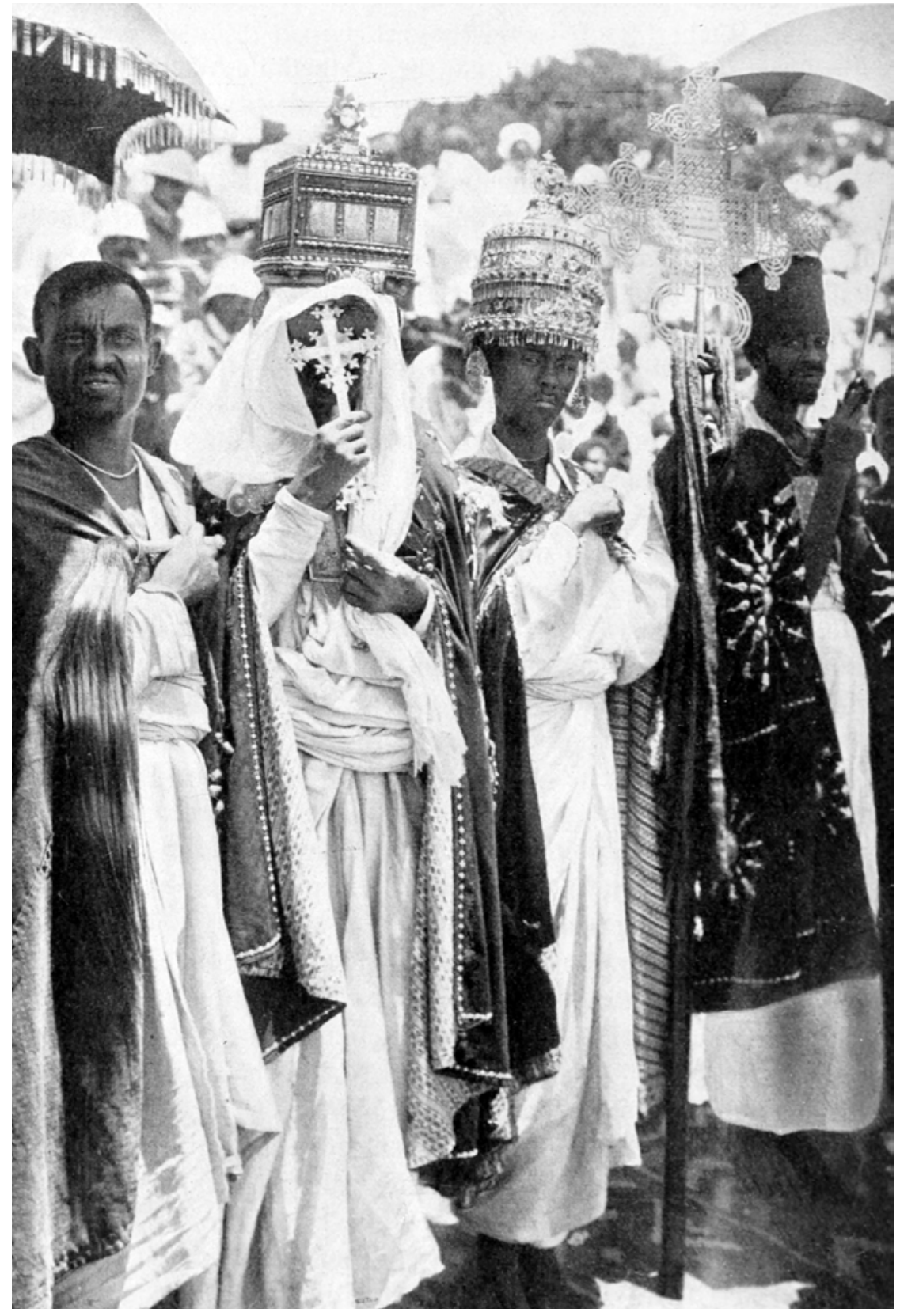

Abb. 14: »Assistierende Priester bei dem Festgottesdienst in Aksum mit den Weihgeschenken der letzten Kaiser« 
Diese Zeremonie vor der Aksum Șəyon-Kirche, die sich auf eine halbe Stunde ausdehnte, ließ die Deutschen an den israelitischen König David und seinen Tanz vor der Bundeslade denken. ${ }^{165}$ Dieser hatte sich »einst in ähnlicher Weise vollzogen«, meinte Carl Bosch. ${ }^{166}$

Der Festakt begann. Vier Geistliche traten, die symbolische Krücke über der linken Schulter, einander paarweise gegenüber zum heiligen Tanz, den der Gesang der Umstehenden begleitete; Musikanten schlugen auf riesigen silbernen Pauken den Rhythmus. Die Tanzenden schritten aufeinander zu, mit langsamem, wiegendem Gang; das eine Paar wich, das andre folgte und ließ die rituellen Rasseln zischen. Es war, als ob sie eine frohe, sieghafte Botschaft kündeten, vor der die andren, ihnen gegenüber, mit gesenkter Stirn zurückwichen, wie geblendet vom Licht der Wahrheit, vom Strahl des Glückes. Dann aber, in der Antistrophe, wechselten die Rollen, und mit kunstvollen Schritten voll feierlichen Ernstes bewegten sich die Priester auf den uralten Fliesen des Tempelplatzes. Die Tradition vergangener Jahrtausende spricht aus den äthiopischen Priestertänzen. ${ }^{167}$

Der Gottesdienst vor der Aksum Șəyon-Kirche hat die Diplomaten zutiefst beeindruckt. Insbesondere die liturgische Musik hinterließ einen tiefen Eindruck bei den Deutschen. "Sie weckt«, so Felix Rosen, »jenen mystischen Schauer, der das im Alltagsleben abgestumpfte Gemüt aufrüttelt, jenes Ungewisse, das in uns nachzittert, und lässt endlich die Macht ahnen, die stärkt und tröstet ${ }^{168}$

Derartige Gottesdienste wurden für die hohen Gäste in Adwa und in

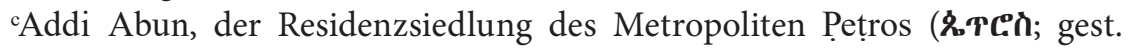

165 Vgl. 2 Sam 6,12-14.

166 Bosch, Karawanen-Reisen, S. 188. Felix Rosen fügt hinzu: "Die Abessinier selbst nennen den König David ihren Lehrmeister, der einst vor der Bundeslade tanzte, zum Klang der Psalmen, in die er seine Bewunderung für Jahve gegossen hatte«. Rosen, Eine deutsche Gesandtschaft, S. 468.

167 Ebd. Vgl. auch die Beschreibung des gleichen Gottesdienstes bei Carl Bosch: „Uns zu Ehren fand eine große Kirchenfeier statt. Wir saßen auf der [...] breiten Freitreppe bei glühend heißer Sonne. Vor uns tanzten auf dem mit Steinplatten belegten Vorhof der Kathedrale viele Gruppen von je vier Priestern in seltsamen langsamen melancholischen Bewegungen. Dazu wurde auf silbernen Pauken eine eintönige leise Musik gemacht «. Bosch, Karawanen-Reisen, S. 187f.

168 Rosen, Eine deutsche Gesandtschaft, S. 470. Hingegen brachte die Besichtigung dieser »heiligsten Kirche Äthiopiens" (Felix Rosen), die nach dem Gottesdienst stattfand, nur Enttäuschung hervor. Die Begegnung mit dem real existierenden Aksum des frühen 20. Jahrhunderts führte zu einer gewissen »Entzauberung« des »salomonischen Narrativs" in den Augen der deutschen Diplomaten: Das äthiopische Zion erschien ihnen weniger glorreich als erwartet, ja sogar als ein Ort »ohne Würde und Weihe«. Ebd., S. 470f. 
1917), ${ }^{169}$ organisiert. ${ }^{170}$ Während somit im Rahmen des diplomatischen Diskurses die Idee einer transkonfessionellen Verbundenheit zwischen den aus Europa angereisten Protestanten und den orthodoxen Christen Äthiopiens gefeiert wurde, zeichnete sich zur gleichen Zeit innerhalb des intraorthodoxen theologischen Diskurses eine entgegengesetzte Entwicklung ab. Die inzwischen unter einigen Gruppen der äthiopisch-orthodoxen Christen Eritreas und Nordäthiopiens zirkulierenden Ideen, die aus dem protestantischen Gedankengut entliehen worden waren, wurden als eine Gefahr für die Äthiopische Kirche identifiziert. Eines der ersten Dokumente, das von dieser Entwicklung zeugt, ist ausgerechnet ein Brief von Abunä Pețros, den er ungefähr ein Jahr vor der Ankunft der deutschen Gesandtschaft, am 17. Miyazya 1896 A. M. [= 25. April 1904 A. D.], an den Klerus von Təgray gesendet hatte. Unter den Anathematha, die in diesem Schreiben aufgeführt werden, finden sich nicht nur klassische Beschuldigungen aus der anti-katholischen Polemik, die auch gegen Protestanten gerichtet werden könnten, wie etwa der Dyophysitismus und das Filioque. Vielmehr wird dort eine »Irrlehre« in Bezug auf das Abednmahlsverständnis erwähnt, welche ausdrücklich mit dem Protestantismus in Verbindung gebracht wird. ${ }^{171}$

$169 \mathrm{Zu}$ Abunä Pețros siehe: Shiferaw Bekele, Pețros, in: EAE 4, 2010, S. 139 f.

170 Vgl. Rosen, Eine deutsche Gesandtschaft, S. 466-468, 482, 489; Bosch, Karawanen-Reisen, S. 176, 187f.

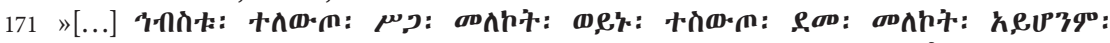

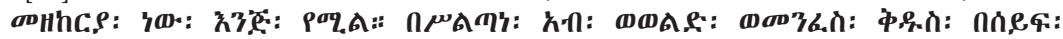

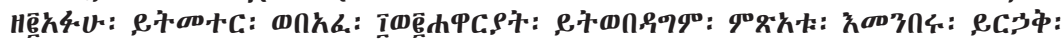

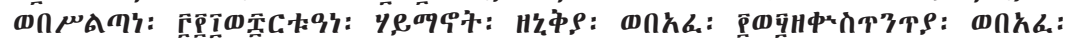

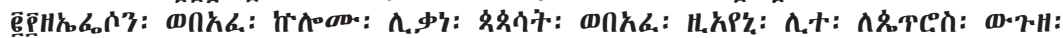

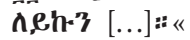

»[...] who says that the bread having changed does not become divine flesh and the wine having changed does not become divine blood but is [just] a reminder; by the authority of the Father and the Son and the Holy Spirit, may he be split by a twobladed sword, may he be excluded by the mouth of the 12 Apostles, and at the Second Coming may he be kept far from His throne, by the authority of the 318 Orthodox of Nicaea and by the mouth of the 150 Constantinople [fathers] and by the mouth of the 220 Ephesian [fathers] and by the mouth of all the bishops and by my own mouth of me Petros, may he be cursed «. Magdalena Krzyzanowska/Stéphane ANCEL, Early 20th Century Theological Controversies in Ethiopia. A Letter of the Coptic Metropolitan Pețros of 1904, in: Aethiopica. International Journal of Ethiopian Studies 17 (2014), S. 121-150, hier S. 140 (Text), S. 146 (Übersetzung).

Vom Abendmahl als einem bedeutenden Differenzpunkt zeugt zudem die Bezeichnung, die zu der Zeit den Protestanten gegeben wurde - F 116.中. (Nazrawi). Laut dem Lexikographen Joseph Baeteman hat dieses amharische Wort - in Anlehnung an die biblische Tradition von Nasiräer - eine semantische Verbindung mit der Enthaltsamkeit und Verzicht. Joseph Baeteman, Dictionnaire Amarigna-Français, suivi d'un vocabulaire Français-Amarigna, Dire-Daoua 1929, S. 539. In diesem Fall geht es jedoch um den Verzicht auf die Heilige Kommunion in der ÄthiopischOrthodoxen Kirche. Thomas Leiper Kane, Amharic-English Dictionary, Wiesba- 
Die Ausbreitung des protestantischen Gedankenguts am Horn von Afrika, nicht zuletzt auch unter einigen äthiopisch-orthodoxen Priestern und Gläubigen, forderte die Kirche Äthiopiens auf neuartige Weise heraus. Als Reaktion auf diese Entwicklung ist die Entstehung einer neuen Gattung äthiopisch-orthodoxer theologischer Literatur im frühen 20. Jahrhundert zu verzeichnen, die dezidiert darauf ausgerichtet war, protestantische "Irrlehren « zu widerlegen. $\mathrm{Zu}$ den wichtigsten Werken dieses Genres gehören das

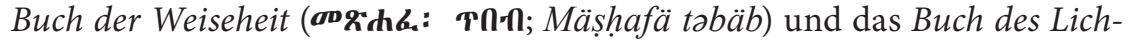

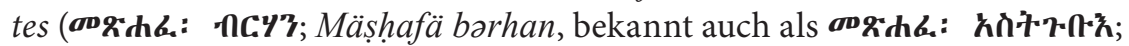
Mäșhafä astəgubu’ə). ${ }^{172}$ Diese auf Amharisch verfassten Texte zirkulierten unter orthodoxen Gelehrten in handschriftlicher Form und boten ihnen ein theologisches Gerüst, das dabei helfen sollte, die äthiopisch-orthodoxen Lehren angesichts der protestantischen Sichtweisen zu rechtfertigen.

Der Protestantismus wurde von nun an nicht mehr nur als der Glaube der Europäer angesehen, wie es noch im 19. Jahrhundert der Fall gewesen war.

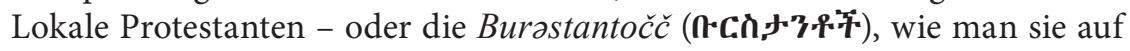
Amharisch bezeichnete, - wurden vielmehr zu einem festen Bestandteil der äthiopischen Wirklichkeit. Bemerkenswerterweise fand in diesem Kontext auch die erste Bezugnahme auf Martin Luther im Rahmen des äthiopischorthodoxen theologischen Diskurses statt. Dies geschah im Werk unter dem Titel Auseinandersetzung und Rechtsstreitigkeit zwischen Orthodoxen

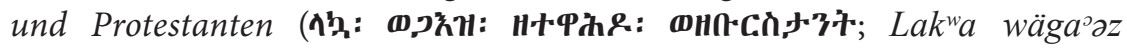
zätäwaḩado wäzäburastant), welches einen tatsächlich stattgefundenen Fall der orthodox-protestantischen Kontroverse über den Stellenwert des Fastens im christlichen Leben zu dokumentieren suchte. ${ }^{173}$ Dort werden folgende an die Protestanten gerichteten Worte in den Mund eines äthiopisch-orthodoxen Theologen gelegt:

den 1990, Bd. 1: v-ל, S. 1023 dokumentiert ein ähnliches Wort - hl. (Näsara). Kane gibt allerdings eine allgemeine Bedeutung von »Christ« an und weist darauf hin, dass es aus dem Arabischen für »die Christen"-نصارى (Nașārā) - stammt.

172 EMML 1064, fol. 447a-478a; EMML 1074, fol. 89a-144b; EMML 1233, fol. 5a-24b und fol. 29a-89b; EMML 1315, fol. 116b-152b; EMML 2950, fol. 3a-38b; JE 747E, fol. 2a-58b; Bodleian Ms. Aeth. e. 14, fol. 2a-27a. Vgl. Macober, Catalogue, Bd. III, S. 406, 417f.; Getatchew Haile, Catalogue, Bd. IV, S. 217-219, 335f.; Getatchew Haile / William Macober, A Catalogue of Ethiopian Manuscripts Microfilmed for the Ethiopian Manuscript Microfilm Library, Addis Ababa, and for the Monastic Manuscript Microfilm Library, Collegeville, Collegeville 1983, Bd. VII: Project Numbers 2501-3000, S. 256; William MaсомвеR, Final Inventory of the Microfilmed Manuscripts of the Ethiopian Orthodox Church, Jerusalem, Provo 1995, S. 234f.; Edward Ullendorff, Catalogue of Ethiopian Manuscripts in the Bodleian Library, Oxford 1951, Bd. II, S. $20 \mathrm{f}$.

$173 \mathrm{Zu}$ diesem Werk siehe Stanislau Paulau, Interconfessional Dialogue and Traditional Litigation in Early $20^{\text {th }}$-Century Eritrea. Introducing an Unpublished Manuscript, in: Zemenfes Tsighe u.a. (Hg.), International Conference on Eritrean Studies 20-22 July 2016. Proceedings, Asmara 2018, Bd. 1, S. 143-155. Der 
P忄,

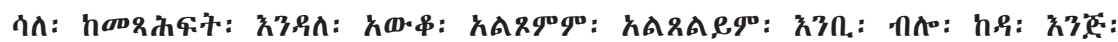

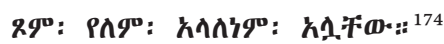

Es [das Fasten] wurde zur Vergebung der Sünden initiiert und praktiziert. Als sich euer Vater Luther [im Original: $\mathbf{\Lambda . \$} \mathbf{A}$., Litor] von uns trennte, wies er [diese Tradition] zurück, die er aus der Schrift kannte, indem er sich bewusst weigerte, [zu bestimmten Zeiten] zu fasten und zu beten. Er sagte uns jedoch nicht, dass es kein Fasten geben sollte. ${ }^{175}$

Hervorzuheben ist nicht nur die Tatsache, dass Luther in dieser Passage als »Vater« der äthiopischen Protestanten dargestellt wird, sondern auch, dass auf seine Theologie orthodoxerseits rekurriert wird, um gegen bestimmte theologische Positionierungen des äthiopischen Protestantismus zu argumentieren. Dabei wird die Reformation - in Form der postulierten Trennung Luthers "von uns« - in das Geschichtsbewusstsein der Äthiopisch-Orthodoxen Kirche integriert.

Die »Entdeckung« des Protestantismus als eines nun äthiopischen (und nicht bloß europäischen) Phänomens am Anfang des 20. Jahrhunderts sowie dessen scharfe Verurteilung innerhalb der Kirche Äthiopiens - und zwar parallel zu einem gleichzeitig transkonfessionell geführten diplomatischen Diskurs -, zeugt von der Ambivalenz des Christlichen. Eine Weitere Dimension dieser Ambivalenz verdeutlichen sowohl die Auseinandersetzung europäischer Orientalisten mit der zentralen Quelle der äthiopischen (politischen) Theologie, dem Kabrä Nägäśt, als auch die Bekanntschaft deutscher Diplomaten mit der gelebten Tradition der Äthiopischen Kirche, die darin verwurzelt war. Aufgrund der unterschiedlichen konfessionellen und kulturellen Referenzrahmen blieb dem Christentum trotz aller Bemühungen, es im Rahmen des deutsch-äthiopischen diplomatischen Diskurses transkonfessionell aufzufassen, ein erhebliches Entfremdungspotential inhärent. Noch mehr als das: Wie Carl Bosch in Bezug auf die Erfahrung der

Text ist in folgenden Manuskripten überliefert: EMML 1064, fol. 478ab, 415a-417b; EMML 1074, fol. 144b-150a; EMML 1233, fol. 89b-96b; EMML 3557, fol. 9b-25a, 36a-54a. Vgl. William Macober, A Catalogue of Ethiopian Manuscripts Microfilmed for the Ethiopian Manuscript Microfilm Library, Addis Ababa, and for the Monastic Manuscript Microfilm Library, Collegeville, Collegeville 1978, Bd. III: Project Numbers 701-1100, S. 407, 417; Getatchew Haile, Catalogue, Bd. IV, S. 217-219; ders., A Catalogue of Ethiopian Manuscripts Microfilmed for the Ethiopian Manuscript Microfilm Library, Addis Ababa, and for the Monastic Manuscript Microfilm Library, Collegeville, Collegeville 1987, Bd. IX: Project Numbers 35014000, S. 39. Ms. EMML 1074, fol. 148b-194a. 
deutschen Sondergesandtschaft zugibt - und dies lässt sich wohl auf viele seiner Zeitgenossen übertragen -, begleitete sie bei der Berührung mit der Äthiopisch-Orthodoxen Kirche stets ein Gefühl von Befremden: »Alles war fremdartig und seltsam für uns $«{ }^{176}$ Letzten Endes war es für sie das andere Christentum.

176 Bosch, Karawanen-Reisen, S. 176. Vgl. auch eine ähnliche Bemerkung bei Rosen, Eine deutsche Gesandtschaft, S. 93. 


\section{Fazit}

Trotz - oder vielleicht gerade wegen - erheblicher räumlicher Distanz und theologischer Differenz gingen äthiopische Orthodoxie und europäischer Protestantismus seit dem Zeitalter der Reformation wiederholt komplexe Verbindungen miteinander ein. Diese sind allerdings weitgehend in Vergessenheit geraten oder wurden - wie anhand des Empfehlungsschreibens Martin Luthers für Abba Mika el beispielhaft gezeigt werden konnte - in einem Prozess der "Konfessionalisierung der Erinnerung" aus dem konfessionellen Gedächtnis verdrängt. Die vorliegende Untersuchung hatte zum Ziel, einen Beitrag zur Wiederentdeckung dieser vergessenen Verflechtungsgeschichte zu leisten.

Um der Komplexität dieser Verflechtungsgeschichte Rechnung zu tragen, wurde sie unter vier analytisch wie zeitlich unterschiedlichen Blickwinkeln exemplarisch untersucht. Nun gilt es abschließend, die daraus gewonnenen Erkenntnisse im Sinne der Histoire croisée aus einer übergeordneten Perspektive zu betrachten, nämlich derjenigen ihrer Verschränkung miteinander.

In Bezug auf den Protestantismus ist deutlich geworden, dass das äthiopische Christentum eine nicht zu unterschätzende Rolle im Prozess dessen Herausbildung gespielt hatte. Zunächst ist hier auf die Begegnung der Wittenberger Reformatoren mit dem äthiopischen Mönch Abba Mika ${ }^{0} \mathrm{el}$ im Jahre $1534 \mathrm{zu}$ erinnern, welche die erste dokumentierte Begegnung von Protestantismus und Orthodoxie sowie die einzige persönliche Berührung Martin Luthers mit dem Oriens christianus darstellt. Die Bedeutung dieses Zusammentreffens liegt indes vor allem in seiner theologischen Dimension: Die beiden Seiten kamen zu einer Übereinstimmung in den zentralen Glaubensfragen, ja sogar zu der Überzeugung, zu der einen Kirche Jesu Christi zu gehören.

Auch handelte es sich bei diesem Dialog keineswegs um eine folgenlose theologiegeschichtliche Kuriosität. Vielmehr lässt sich nachweisen, dass die Vorstellung von der Verbundenheit im Glauben mit den Christen Äthiopiens einen bedeutsamen Bezugspunkt im theologischen Denken des Wittenberger Reformators - so jedenfalls im Zeitraum von 1534 bis 1538 - bildete. Zu einem gewissen Grad förderte diese Vorstellung sogar die Konsolidierung des sich noch formierenden Luthertums: Einerseits stellte diese Auffassung eine Form der ekklesiologischen Selbstvergewisserung dar, andererseits wurde sie - wie es am Beispiel des Abendmahlsverständnisses veranschaulicht werden konnte - zur weiteren Abgrenzung des Luthertums sowohl vom 
Katholizismus als auch von anderen Strömungen innerhalb des reformatorischen Lagers verwendet. Somit war Luthers »transkonfessionelle« Entgrenzung gegenüber den orthodoxen Christen Äthiopiens eng mit der Herausbildung und Festigung konfessioneller Grenzen in Lateineuropa verwoben.

Frühneuzeitliche Verflechtungen von europäischem Protestantismus und äthiopischer Orthodoxie trugen auch keineswegs einen episodischen Charakter. Wie sich anhand der breiten Rezeption des besprochenen Werks von Șägga Zä’ab sowie der äthiopischen »Glaubensbekenntnisse« belegen lässt, hatte die äthiopisch-orthodoxe Theologie in der gesamten Frühen Neuzeit eine anhaltende Anziehungskraft auf protestantisches theologisches Denken. Auf die Texte äthiopisch-orthodoxer Provenienz wurde nicht nur im Kontext anti-katholischer Polemik (wie etwa im Fall von Martin Bucer), sondern auch im Zusammenhang mit der biblischen Exegese und der frühen protestantischen Geschichtsschreibung (so beispielsweise David Chytraeus) zurückgegriffen. Sie wurden darüber hinaus in die Erbauungsliteratur aufgenommen und als solche dem protestantischen Leser empfohlen (wie bei Johann Michael Dilherr). Diese protestantischen Aneignungen des äthiopisch-orthodoxen theologischen Wissens, die mit je eigenen Sinnzuschreibungen einhergingen, hatten zur Folge, dass die äthiopische Orthodoxie selbst in diesem Prozess neu, und zwar in Kategorien des frühneuzeitlichen Konfessionsparadigmas, definiert wurde.

Protestantische imaginäre Entwürfe des äthiopischen Christentums waren Bestandteil eines transkonfessionellen theologischen Diskurses, der sich zwischen Europa und dem Horn von Afrika abspielte und sich durch eine Asymmetrie auszeichnete. Da diese Tatsache in der Theologiegeschichte bisher unbemerkt und unreflektiert blieb, muss dies ausdrücklich hervorgehoben werden: Im Laufe der gesamten Frühen Neuzeit dominierte der Wissenstransfer aus dem »orthodoxen Äthiopien« ins »protestantische Europa«, sodass äthiopisch-orthodoxe Theologie auf protestantisches Denken, und nicht etwa umgekehrt, wirkte. Daher lässt sich protestantische Imagination vom äthiopischen Christentum nicht zuletzt als Form der Rezeption des äthiopisch-orthodoxen theologischen Wissens verstehen.

Diese intellektuellen Entwicklungen sind jedoch nicht nur im Rahmen der europäischen Theologiegeschichte von Bedeutung. Dem kontinuierlichen Wissenszuwachs über die Kirche Äthiopiens in den protestantischen Kreisen Europas im 17. und 18. Jahrhundert folgte die wachsende Wahrnehmung theologischer Differenz zwischen den beiden Varianten des Christentums. Diese führte ihrerseits zur Entstehung des Projektes einer »äthiopischen Reformation«. Durch die daraus entstandene Missionsinitiative entfaltete ab dem 19. Jahrhundert auch der Protestantismus seinen Einfluss auf die äthiopische Orthodoxie. Zwar war dieses protestantische Missionsunternehmen transkonfessionell angelegt, dennoch trug es in der Praxis 
maßgeblich zur Verfestigung konfessioneller Grenzen zwischen äthiopischer Orthodoxie und europäischem Protestantismus bei. Auf der äthiopischen Seite äußerte sich die Abgrenzung gegenüber den Protestanten in einer verstärkten Akzentuierung der Mariologie sowie in der Aktualisierung der damit verbundenen spätmittelalterlichen theologischen Tradition, die mit dem Kaiser Zär’a Yacəqob verbunden ist. Auf protestantischer Seite hatte das Scheitern des Versuchs, eine Reformation in der Kirche Äthiopiens auszulösen, eine grundlegende Transformation des gesamten Missionsdiskurses zum Ergebnis.

Indes blieben die konfessionellen Grenzen je nach Kontext durchaus wandlungsfähig, wie sich bei der diplomatischen Annäherung zwischen Äthiopien und Deutschland im späten 19. und frühen 20. Jahrhundert zeigte. In diesem Zusammenhang ist vor allem auf die dezidiert transkonfessionell ausgerichtete Rhetorik, die Mənilək II. und Wilhelm II. in ihrem Austausch pflegten, sowie auf die liturgische Inszenierung der Gemeinsamkeit hinzuweisen, welche die christliche Verbundenheit beider Länder auf eine unmittelbar erfahrbare Weise zur Erscheinung bringen sollte. Dabei war diese diplomatische Annäherung von erheblicher Bedeutung für die Konsolidierung der äthiopischen Orthodoxie: Die von Wilhelm II. initiierten und unterstützten archäologischen Ausgrabungen in Aksum lieferten eine "wissenschaftliche" Legitimierung des »salomonischen Narrativs«. Dies machte den Kern des äthiopisch-orthodoxen Selbstverständnisses auch im Kontext der Moderne artikulierbar und trug maßgeblich zur weiteren Entwicklung einer »neosalomonischen" politischen Theologie in Äthiopien bei.

Aus einer übergeordneten analytischen Perspektive erscheinen äthiopische Orthodoxie und europäischer Protestantismus folglich nicht nur als Akteure, sondern zugleich auch als Produkte jener transkonfessionellen Verflechtungen, die sie miteinander eingingen. So lässt sich hinter dem bisweilen ambivalenten Wechselspiel von Abgrenzung und Annäherung eine Relationalität erkennen, welche diese Varianten des Christentums in ihrem historischen Werden mitbedingte und sie auf diese Weise mit der Geschichte des jeweils anderen Christentums verwob. 



\section{Quellen- und Literaturverzeichnis}

\section{Quellen}

\section{a) Manuskripte}

Biblioteca Apostolica Vaticana:

Ms. Vat. et. 47.

Bibliothèque nationale de France, Paris:

Ms. Éthiopien d'Abbadie 69.

Ms. Coll. Dupuy 796.

Bibliothèque Sainte-Geneviève, Paris:

Ms. 1458.

Bodleian Library, Oxford:

Ms. Aeth. e. 14.

British Library, London:

Ms. BL Harl. 7629.

Ethiopian Manuscript Microfilm Library, Addis Abeba/The Hill Museum and Manuscript Library, Collegeville:

Ms. EMML 1064.

Ms. EMML 1074.

Ms. EMML 1126.

Ms. EMML 1233.

Ms. EMML 1315.

Ms. EMML 1480.

Ms. EMML 1942.

Ms. EMML 2950.

Ms. EMML 3557.

Ms. EMML 5538.

Ethiopian Orthodox Patriarchate, Jerusalem:

Ms. JE 747E.

Forschungsbibliothek Gotha der Universität Erfurt:

Ms. Chart. B 1483.

Herzog August Bibliothek Wolfenbüttel:

Cod. Guelf. 107 Helmst.

Cod. Guelf. 214 Gud. Lat. $4^{\circ}$.

Cod. Guelf. 64.4 Extrav.

Institut für Orientstudien der Russischen Akademie der Wissenschaften,

Sankt Petersburg:

Ms. Eth. 27 [= ИВР РАН Эф. 27]. 
Österreichische Nationalbibliothek, Wien:

Ms. ÖN Cod. Aeth. 4.

Stadtbibliothek Trier:

Ms. 1880/1444.

Universitätsbibliothek Basel:

Ms. O III 4.

Universitätsbibliothek Leipzig:

Ms. 2630.

\section{b) Archivbestände}

Evangelisches Zentralarchiv, Berlin:

EZA 1/A2/424.

Politisches Archiv des Auswärtigen Amts, Berlin:

PA AA, A 14563.

PA AA, A 14623.

PA AA, A 1584.

PA AA, A 1933.

PA AA, A 23/197.

PA AA, A 2829.

PA AA, A 3233.

PA AA, A 3900.

PA AA, A 6118.

PA AA, R 131418.

PA AA, R 14889.

PA AA, R 14890.

PA AA, R 14891.

PA AA, R 14914.

PA AA, R 14915.

PA AA, R 14917.

PA AA, Vertragsarchiv. Deutsch-Äthiopischer Freundschafts- und Handelsvertrag.

\section{c) Zeitungen}

Berliner Tageblatt.

Berliner Tageblatt und Handels-Zeitung. Abend Ausgabe.

Church Times.

Das Ausland. Ein Tagblatt für Kunde des geistigen und sittlichen Lebens der Völker.

Deutsche Bauzeitung.

Deutsche Metall-Industrie-Zeitung.

Die Hilfe. Nationalsoziale Wochenschrift.

Export.

Hamburger Fremdenblatt.

Neue Preußische Zeitung (Kreuz-Zeitung). 


\section{d) Gedruckte Quellen}

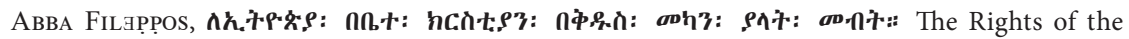
Abyssinian Orthodox Church in the Holy Places, Jerusalem 1962.

Álvares, Francisco, Ho Preste Joam das Indias. Verdadera informaçam das terras do Preste Joam, segundo vio \& escreueo ho padre Francisco Aluarez capellã del Rey nosso senhor, Coimbra 1540.

-, Warhafftiger Bericht Von den Landen/auch Geistlichem vnd Weltlichem Regiment/des Mechtigen Königs in Ethiopien/den wir Priester Johan nennen/wie solches durch die Kron Portugal mit besondern vleis erkündiget worden/Beschrieben durch Herrn Franciscum Aluares / so derhalben sechs Jahr lang an gedachts Priester Johans Hoffe verharren müssen / Aus der Portugallischen vnd Italianischen Sprach in das Deutsche gebracht/vnd zuuorn nie im Druck ausgangen, Eißleben 1566.

Andree, Richard, Abessinien, das Alpenland unter den Tropen und seine Grenzländer, Malerische Feierstunden. Das Buch der Reisen und Entdeckungen. Neue illustrierte Bibliothek der Länderund Völkerkunde zur Erweiterung der Kenntniß der Fremde, Leipzig 1869.

Aston, Edward (Hg.), The manners, lauues, and customes of all nations collected out of the best vvriters [...], London 1611.

Außenamt der Evangelischen Kirche in Deutschland (Hg.), Wort und Mysterium. Der Briefwechsel über Glauben und Kirche 1573 bis 1581 zwischen den Tübinger Theologen und dem Patriarchen von Konstantinopel, DOKÖF 2, Witten 1958.

Baratti, Giacomo, Reis-Beschreibung Sig. Giacomo Baratti, eines Edlen Italiäners/In die Entlegenen Länder der Abyssiner oder Innere Aethiopia. In welcher enthalten Eine umständige Erzehlung der Gesetz/Regierung / Religion / Policey / und Gebräuchen dieses Christlichen Volcks/so darinnen wohnen/neben vielen merckwürdigen Anweisungen/welche zu Beförderung der Handlung mit diesen Völckern dienen können. Hierbey ist angefüget/ Was Damianus de Goes, und Jos. Scaliger von diesen Ländern geschrieben/welche in vielen Particularien mit dem Autore übereinkommen, in: Benaim, Georg Friedrich (Hg.), Asiatische und Africanische Denkwürdigkeiten dieser Zeit, das ist, Beschreibung der Königreiche, Herrschaften und Länder des grossen Mongols, des grossen Neguz oder sogenannten Priester Johannes, Nürnberg 1676, S. 406-480.

-, The Late Travels of S. Giacomo Baratti, an Italian Gentleman, Into the Remote Countries of the Abissins, or of Ethiopia Interior. Wwherein You Shall Find an Exact Account of the Laws, Government, Religion, Discipline, Customs, \&c. of the Christian People That Do Inhabit There, with Many Observations Which Some May Improve to the Advantage and Increase of Trade with Them. Together, with a Confirmation of This Relation Drawn from the Writings of Damianus de Goes, and Jo. Scaliger, Who Agree with the Author in Many Particulars, London 1670.

BArth, Christian Gottlob, Missions-Lied, in: MNGPM 2 (1834), S. 309-311.

BAsset, Rene, Deux lettres éthiopiennes du XVIe siècle, in: Giornale della Società Asiatica Italiana 3 (1889), S. 58-79.

Beckingham, Charles Fraser/Huntingford, George Wynn Brereton (Hg.), The Prester John of the Indies. A True Relation of the Lands of the Prester John; Being the Narrative of the Portuguese Embassy to Ethiopia in 1520. Written by Father Francisco Alvarez. Works Issued by the Hakluyt Society. Second Series 114-115, Cambridge 1961, Bd. 1-2.

Bettenson, Henry Scowcroft/Maunder, Chris (Hg.), The Documents of the Christian Church, Oxford 2011

Bezold, Carl, Kebra Nagast. Die Herrlichkeit der Könige. Nach den Handschriften in Berlin, London, Oxford und Paris zum ersten Mal im äthiopischen Urtext herausgegeben und mit deutscher Übersetzung versehen, ABAW.PP 23, München 1905.

Borelli, Jules, Éthiopie méridionale. Journal de mon voyage aux pays Amhara, Oromo et Sidama. Septembre 1885 a Novembre 1888, Paris 1890.

Bosch, Carl, Karawanen-Reisen. Erlebnisse eines deutschen Kaufmanns in Ägypten, Mesopotamien, Persien und Abessinien, Berlin 1928.

Bottschafft des groszmechtigsten Konigs David aus dem grossen und hohen Morenland den man gemeinlich nennet Priester Johann an Babst Clemens den siebenden zu Bononia vorhort in offnem consistorio am XXIX. Tag Januarii anno M.D.XXXIII, Dresden 1533. 
Bottschafft des groszmechtigsten Konigs David aus dem grossen und hohen Morenland den man gemeinlich nennet Priester Johann an Babst Clemens den siebenden zu Bononia vorhort in offnem consistorio am XXIX. Tag Januarii anno M.D.XXXIII, Nürnberg 1533.

BRUCE, James, Reisen zur Entdeckung der Quellen des Nils in den Jahren 1768, 1769, 1770, 1771, 1772 und 1773, Leipzig 1790-1791, 5 Bd.

-, Travels to Discover the Source of the Nile. In the Years 1768, 1769, 1770, 1771, 1772, and 1773, Edinburgh 1790, 5 Bd.

Budge, Ernest Alfred Thompson Wallis, The Book of the Saints of the Ethiopian Church. A Trans-

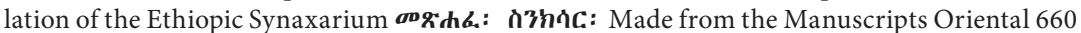
and 661 in the British Museum, Cambridge 1928, Bd. III: Magâbît, Mîyâzyâ, Genbôt (March 7 - June 4).

Buhle, Johannes Gottlieb (Hg.), Literarischer Briefwechsel von Johann David Michaelis, Leipzig 1795, Zweyter Theil.

Büntıng, Heinrich, Itinerarium Sacrae Scripturae. Das ist, Ein Reisebuch, Uber die gantze heilige Schrifft, Helmstadt 1581.

CAPELL, Rudolf, Wünschet von der Ewigen Göttlichen Majestät/allerley liebes und gutes / zeitlich und ewig, in: Ders., Norden/Oder Zu Wasser und Lande im Eise und Snee/mit Verlust Blutes und Gutes zu Wege gebracht/ und fleissig beschriebene Erfahrung und Vorstellung des Norden, Hamburg 1678, S. 265-305.

Чернецов, С.Б./В.М. Платонов, »Книга уничтожения лжи, возведенной на праведного Абуну Иаковаж Такла Хайманота Такла Эгзиэ - одно из первых произведений амхарской литературы, in: Христианский Восток III (IX) (2001), S. 172-268.

Chytraeus, David, Auslegung der Offenbarung Johannis darin viel Artickel Christlicher Lehr, viel Historien, und nötiger heilsamer Trost, in gegen wertigen Trübsalen und Zerruthungen der Kirchen, Uneinigkeit der Lehrer und andern Anfechtugnen nützlich erklert werden, Rostock 1568.

-, Explicatio Apocalypsis Iohannis perspicua et brevis, Wittenberg 1563.

-, Oratio Davidis Chytraei, habita in Akademia Rostochiensi, cum post reditum ex Austria ad Chronici lectionem reverteretur. In qua de statu eccesiarum hoc tempore in Graecia, Asia, Africa, Ungaria, Boemia, etc. narrationes vera et cognitu non iniucunda exponuntur, Rostock 1569.

-, Oratio de statu ecclesiarum hoc tempore in Graecia, Asia, Africa, Ungaria, Boëmia, etc. cui Epistolae aliquot Patriarchae Byzantini, \& aliorum ex Oriente recens scriptae: aliaeque narrationes, lectu non indignae, nec inincundae, accesserunt, Wittenberg 1580.

-, Was zu dieser Zeit in Griechenland, Asien, Africa, unter des Türcken, und des Priester Johans Herrschafften, item in Ungern und Behemen, etc. der christlichen Kirchen Zustand sey: sampt etlichen Schreiben, so von Constantinopel, vom Berge Sinai, und andern Örten aus Orient, newlicher Zeit abgangen/ erstlich von D. Davide Chytraeo lateinisch in Druck gefertiget; und jetzund von Henrico Arnoldo aus Churland in Liffland verdeudschet, [s. 1.] 1574.

Codazzi, Angela, Baratti, Giacomo, in: Ghisalberti, Alberto M. (Hg.), Dizionario biografico degli Italiani, Roma 1964, Bd. 6, S. 4f.

Conti Rossini, Carlo (Hg.), Documenta ad illustrandam historiam, CSCO 54, 58, Louvain 1909-1910, Bd. I: Liber Axumae.

- / Ricci, Lanfranco (Hg.), Il libro della luce del negus Zar'a Yā̄ qob (Mașhafa BERHĀN) II, CSCO 261, 262 [CSCO.Ae 51, 52], Louvain 1965.

Conzelman, William Eliot (Hg.), Chronique de Galâwdêwos (Claudius). Roi d'Ethiopie (1540-1559), Paris 1895.

Coppet, Maurice de (Hg.), Chronique du règne de Ménélik II roi des rois d'Éthiopie, Librairie orientale et américaine, Paris 1930-1931, 2 Bd.

Crucius, Martin, Schwäbische Chronik, Frankfurt a. M. 1733, Bd. 2.

Dilherr, Johann Michael, Hohe Schul des Höchsten Lehrers und Seiner Schüler, Das ist, Christliche Anweisung zu Gottseeliger Betrachtung des Lebens und der Lehre Jesu Christi und Seiner lieben Apostel und Evangelisten, Nürnberg 1663.

Dingel, Irene (Hg.), Die Bekenntnisschriften der Evangelisch-Lutherischen Kirche. Vollständige Neuedition, Göttingen 2014. 
Dresser, Matthäus, De Statu Ecclesiae et Religionis in Aethiopia, sub precioso Ioanne, Oratio, Leipzig 1584.

Dryander, Ernst von, Die Herrlichkeit des Hauses Gottes. Zur Weihe des Berliner Doms am 27. Februar 1905, in: Ders., Gott und Mensch. Predigten und Reden, Halle (Saale) 1926, S. 118-122.

-, Erinnerungen aus meinem Leben, Bielefeld 1921.

Enders, Ludwig (Hg.), Dr. Martin Luther's Briefwechsel. Briefe vom Februar 1534 bis Juli 1536, Frankfurt a.M. 1903, Bd. 10.

Erasmus, Desiderius, Ecclesiastes: Sive de ratione concionandi. Libri quatuor, opus recens, nec antehac à quoquam excusum, Basel 1535.

Flemming, Johannes (Hg.), Das Buch Henoch. Äthiopischer Text mit Einleitung und Commentar, TU 22,1, Leipzig 1902.

-, Die neue Sammlung abessinischer Handschriften auf der Königlichen Bibliothek zu Berlin, ZfB 23, 1906.

- / Radermacher, Ludwig (Hg.), Das Buch Henoch, GCS 5, Leipzig 1901.

Freeman, Arthur, Hoax and Forgery, Whimsy and Fraud. Taxonomic Reflections on the Bibliotheca Fictiva, in: Stephens, Walter / Havens, Earle A. (Hg.), Literary Forgery in Early Modern Europe. 1450-1800, Baltimore 2019, S. 15-32.

Fries, Karl, Weddase Marjam. Ein äthiopischer Lobgesang an Maria. Nach mehreren Handschriften herausgegeben und übersetzt, Leipzig 1892.

George, Viscount Valentia/SAlt, Henry, Voyages and Travels to India, Ceylon, the Red Sea, Abyssinia, and Egypt. In the Years 1802, 1803, 1804, 1805, and 1806, London 1809, 3 Bd.

Getatchew Haile, The Ethiopian Orthodox Church's Tradition on the Holy Cross, Texts and Studies in Eastern Christianity 10, Leiden u. a. 2018.

-, The Homily of Zär ${ }^{\supset a}$ Yac ${ }^{c}$ qob in Honour of St. John the Evangelist, EMML 1480, ff. 48r-52v, in: OrChr 67 (1983), S. 144-166.

Giacomo Baratti's Late Travels into Ethiopia 1670. A Literary Forgery?, in: The Book Collector 30 (1-4) (1981), S. 549-551.

Giovio, Paolo, Pavli Iovii Novocomensis Episcopi Nvcerini Historiarvm Svi Temporis, Florentiae 1550 .

Gladel, Anton, Übersetzung des Buches des Leuchters, d.i. der Gebete bei der Spendung der letzten Ölung nach äthiopischem Ritus, in: TThQ 77 (1924), S. 650-675.

Gоват, Samuel, Abyssinien. Tagebuch des Missionars Samuel Gobat (Fortsetzung und Beschluß), in: MNGPM 2 (1834), S. 163-308.

-, Journal of a Three Years' Residence in Abyssinia, in Furtherance of the Objects of the Church Missionary Society, London 1834.

-, Tagebuch des Missionars S. Gobat, von seinem dreijährigen Aufenthalte und seinen Reisen in Abyssinien, in: MNGPM 1 (1834), S. 69-156.

Góis, Damião de, Fides, Religio, Moresque Æthiopum. Sub imperio Preciosi Johannis degentium una cum enarratione confoederationis ac amicitiae inter ipsos Æthiopum imperatores et reges Lusitaniae initae [...], Lovanii 1540.

- (Hg.), Legatio magni Indorum Imperatoris Presbyteri Ioannis, ad Emanuelem Lusitaniae Regem, Anno Domini. M. D.XIII, Antwerpen 1532.

Grébaut, Sylvain, La règle de Santo Stefano dei Mori, in: ROC 27 (3) (1929-1930), S. 214-219.

Grohmann, Adolf, Aethiopische Marienhymnen, ASAW.PH 33 (4), Leipzig 1919.

Harenberg, Johann Christoph, Kurtze Einleitung in die Aethiopische, sonderlich Habeßinische Alte und Neue Theologie. Worinn die dahin gehörigen Scribenten, eine deutliche Kirchen-Historie, Wie auch die Lehr-Puncten und Kirchen-Gebräuche derer Heydnischen und Christlichen Einwohner in Aethiopien, sonderlich der Habeßinier Entworffen worden, Helmstedt 1719.

Harnack, Adolf von, Ansprache bei der Übernahme der Generalverwaltung der Königlichen Bibliothek (1905), in: Harnack, Axel von (Hg.), Aus der Werkstatt des Vollendeten. Als Abschluss seiner Reden und Aufsätze, Reden und Aufsätze, Gießen 1930, S. 3-6.

Harnack, Adolf von, Das Wesen des Christentums. Sechzehn Vorlesungen vor Studierenden aller Fakultäten im Wintersemester 1899/1900 an der Universität Berlin, Leipzig 1900. 
-, Der Geist der morgenländischen Kirche im Unterschied von der abendländischen, in: SPAW Erster Halbband (1913), S. 157-183.

-, Lehrbuch der Dogmengeschichte, Leipzig ${ }^{4} 1910$, Bd. 2: Die Entwicklung des kirchlichen Dogmas I.

-, Zur Kaiserlichen Botschaft vom 11. Oktober 1910. Begründung von Forschungsinstituten, in: Ders., Aus Wissenschaft und Leben. Reden und Aufsätze, Neue Folge, Gießen 1911, Bd. 1, S. 39-64.

-/ Flemming, Johannes (Hg.), Ein jüdisch-christliches Psalmbuch aus dem ersten Jahrhundert, TU 35,4, Leipzig 1910.

Harris, William Cornwallis, Gesandtschaftsreise nach Schoa und Aufenthalt in Südabyssinien 1841-1843. Zweite Abtheilung, Stuttgart 1846.

Hegel, Georg Wilhelm Friedrich, Vorlesungen über die Philosophie der Geschichte. Georg Wilhelm Friedrich Hegel's Werke. Vollständige Ausgabe, Berlin 1837, Bd. 9.

Holtz, Arnold, Am Tor der Tränen (Bab el Mandeb). Afrikanische Erlebnisse eines deutschen Kuriers, Berlin 1929.

-, Im Auto zu Kaiser Menelik, Berlin 1908.

Huber, Ernst Rudolf/Huber, Wolfgang (Hg.), Staat und Kirche im 19. und 20. Jahrhundert. Dokumente zur Geschichte des deutschen Staatskirchenrechts, Berlin ${ }^{2} 2014$, Bd. 3: Staat und Kirche von der Beilegung des Kulturkampfs bis zum Ende des Ersten Weltkriegs.

IsenberG, Carl Wilhelm, Abessinien und die evangelische Mission. Erlebnisse in Aegypten, auf und an dem rothen Meere, dem Meerbusen von Aden, und besonders in Abessinien. Tagebuch meiner dritten Missionsreise vom Mai 1842 bis December 1843, Bonn 1844, Bd. 1.

-, Abessinien und die evangelische Mission. Erlebnisse in Aegypten, auf und an dem rothen Meere, dem Meerbusen von Aden, und besonders in Abessinien. Tagebuch meiner dritten Missionsreise vom Mai 1842 bis December 1843, Bonn 1844, Bd. 2.

-, Dictionary of the Amharic Language. In Two Parts. Amharic and English, and English and Amharic, London 1841.

-/ KRAPF, Johann Ludwig, Journal of the Rev. Messrs. Isenberg and Krapf, Missionaries of the Church Missionary Society, Detailing Their Proceedings in the Kingdom of Shoa, and Journeys in Other Parts of Abyssinia, in the Years 1839, 1840, 1841, and 1842, London 1843.

KAnE, Thomas Leiper, Amharic-English Dictionary, Wiesbaden 1990, Bd. 1: $\boldsymbol{v}-\mathbf{t}$.

KLEMP, Egon, Africa auf Karten des 12. bis 18. Jahrhunderts. 77 Lichtdrucke aus europäischen Kartensammlungen, Stuttgart 1968.

KraPf, Johann Ludwig, Abessinien, in: MNGPM 4 (1850), S. 1-121.

-, Reisen in Ost-Afrika ausgeführt in den Jahren 1837-55. Erster Theil, Stuttgart 1858.

Kropp, Manfred (Hg.), Die Geschichte des Lebna-Dengel, Claudius und Minas, CSCO 503 [CSCO Ae 83], Louvain 1988.

Krzyzanowska, Magdalena/AnCel, Stéphane, Early 20th Century Theological Controversies in Ethiopia. A Letter of the Coptic Metropolitan Pețros of 1904, in: Aethiopica. International Journal of Ethiopian Studies 17 (2014), S. 121-150.

LAsH, Christopher, "Gate of Light«. An Ethiopian Hymn to the Blessed Virgin (Part I), in: ECR 4 (1972), S. 36-46.

-, »Gate of Light «. An Ethiopian Hymn to the Blessed Virgin (Part II), in: ECR 5 (1973), S. 143-156.

LeE, Samuel (Hg.), Controversial Tracts on Christianity and Mohammedanism by the Late Rev. Henry Martyn and Some of the Most Eminent Writers of Persia Translated and Explained, Cambridge 1824.

Legatio David Æthiopiae Regis ad sanctiss. D.N. Clementem Papam VII una cum obedientia eidem sanctiss. D. N. praestita, Bononiae 1533.

Legatio David Æthiopiae Regis. Bottschafft des groszmechtigsten Konigs David aus dem grossen und hohen Morenland den man gemeinlich nennet Priester Johann an Babst Clemens den siebenden zu Bononia vorhort in offnem consistorio am XXIX. Tag Januarii anno M.D.XXXIII, Nürnberg 1533.

Le Grand, Joachim, A Dissertation upon Mr. Ludolf's History of Abyssinia, in: A Voyage to Abyssinia. By Father Jerome Lobo, a Portuguese Jesuit, London 1735, S. 185-396. 
- (Hg.), Relation historique d'Abyssinie du R. P. Jérôme Lobo, S. J. Traduite du Portugais, continuée et augmentée de plusieurs dissertations, lettres et mémoires, Paris 1728.

Littmann, Enno, Abyssinian Apocalypses, in: AJSL 19 (2) (1903), S. 83-95.

-/ Krencker, Daniel, Vorbericht der deutschen Aksumexpedition, Berlin 1906.

Ludolf, Hiob, Ad suam Historiam Æthiopicam antehac editam Commentarivs in quo Multa breviter dicta fusius narrantur: contraria reffelluntur: Atque hac occasione praeter res Aethiopicas multa Autorum, quaedam etiam S. Scripturae loca declarantur: Aliaque plurima Geographica, Historica et Critica, Inprimis verò Antiquitatem Ecclesiasticam illvstrantia, alibi haud facile obvia, exponuntur; vt variarvm observationvm loco haberi possit Cum Tabula Capitum, Figuris, [et] variis Indicibus locupletissimis Summam Operis habes initio Libri, Frankfurt a.M. 1691.

-, An Abstract of the History of Ethiopia, or the Kingdom of Abessines, Written by Mr. Job Ludolphus, with What Is Observable from the Authors of That Country, in: Harris, John (Hg.), Navigantium atque Itinerarium Bibliotheca: or, a Compleat Collection of Voyages and Travels, London 1725, Bd. 1, S. 390-404.

- (Hg.), Confessio Fidei Claudii Regis Æthiopiae, Cum Notis Et Versione Latina Jobi Ludolfi J.C. Antehac Sereniss. Electori Palatino Dedicata; Nunc verò edita, curâ et studio Johannis Michaelis Wanslebii Qui Liturgiam S. Dioscori Patriarchæ Alexandrini Æthiopicè et Latine addidit, London 1661.

-, Historia Æthiopica, Sive Brevis \& succincta descriptio Regni Habessinorvm, Quod vulgo male Presbyteri Iohannis vocatur, Frankfurt a. M. 1681.

-, Lexicon Æthiopico-Latinum. Ex omnibus libris impressis nonnullisque manuscriptis collectum et cum docto quodam Æthiope relectur accessit authoris Grammatica [...], London 1661.

Luther, Martin, WA 6, 1888.

-, WA 26, 1909.

-, WA 30, 1910.

-, WA 37, 1910.

-, WA 38, 1912.

-, WA 41, 1910.

-, WA 46, 1912.

-, WA 47, 1912.

- , WA $59,1982$.

-, WA.B 7, 1937.

-, WA.TR 4, 1916.

-, WA.TR 5, 1919.

Manlius, Johannes (Hg.), Epistolarum D. Philippi Melanchthonis Farrago, Basel 1565.

Melanchthon, Philipp, CR 2, 1835.

-, MBW 10, 1998.

-, MBW.T 6, 2005.

Missa, qua Ethiopes communiter utuntur, quae etiam Canon universalis appellatur, nunc primum ex Lingua Chaldea sive Aethiopica in Latinam conversa, Romae 1549.

Modus baptizandi, preces et benedictiones, quibus Ecclesia Aethiopum utitur, cum sacerdotes benedicunt puerperae, una cum infante Ecclesiam ingredienti, post quadragesimum puerperij diem.: Item orationes, quibus ijdem utuntur in Sacramento Baptismi et confirmationis, Missa, qua Ethiopes communiter utuntur, quae etiam Canon universalis appellatur, nunc primum ex Lingua Chaldea sive Aethiopica in Latinam conversa, Romae 1549.

More, John (Hg.), The Legacye or Embassate of the Great Emperour of Inde Prester Iohñ, vnto Emanuell Kynge of Portyngale, in the Yere of Our Lorde M.v.C.xiii. Of the Fayth of the Indyans, Ceremonyes, Relygyons \&c. Of the Patryarche \& His Offyce. Of the Realme, State, Power, Maiesty, and Order of the Courte of Prester Iohñ, London 1533.

Münster, Sebastian (Hg.), Geographia Vniversalis, Vetvs Et Nova. Complectens Clavdii Ptolemaei Alexandrini Enarrationis Libros VIII. Quorum primus nova translatione Pirckheimheri et accessione commentarioli illustrior quam hactenus fuerit, redditus est; Reliqui cum Graeco et aliis vetustis exemplaribus collati, in infinitis fere locis castigatiores facti sunt; Addita sunt in- 
super scholia, quibus exoleta urbium, montium, fluviorumque nomina ad nostri seculi morem exponuntur; Succedunt tabulae Ptolemaicae opera Sebastiani Munsteri novo paratae modo; His adiectae sunt plurimae novae tabulae, modernam orbis faciem literis et pictura explicantes, inter quas quaedam antehac Ptolemaeo non fuerunt additae; Ultimo annexum est compendium geographicae descriptionis, in quo varii gentium et regionum ritus et mores excplicantur; Praefixus est quoque universo operi index memorabilium populorum, civitatum, fluviorum, montium, terrarum, lacuum etc., Basel 1540.

MÜNSTER, Sebastian, Cosmographia. Beschreibung aller Lender durch Sebastian Munsterum in welcher begriffen aller Völcker Herschafften, Stetten und namhafftiger Flecken Herkomēn, Sitten, Gebreüch, Ordnung, Glauben, Secten und Hantierung durch die gantze Welt und fürnemlich Teütsche Nation, Basel 1544.

Niemeyer, Hermann Agathon (Hg.), Heilige Dichtungen zur Heiligen Geschichte, Bielefeld 1844.

OudenRijn, Marcus van den (Hg.), Helenae Aethiopum reginae queae feruntur preces et carmina, CSCO 208, 211 [CSCO.Ae 39, 40], Louvain 1961.

PANKhurst, Richard, Letters from Ethiopian Rulers (Early and Mid-Nineteenth Century) Preserved in the British Library, the Public Record Office, Lambeth Palace, the National Army Museum, India Office Library and Records, Oriental Documents IX, London 1985.

Pereira, Francisco Maria Esteves (Hg.), Chronica de Susenyos, rei de Ethiopia, Lisboa 1892-1900, Bd. 1-2.

Peucer, Caspar (Hg.), Epistolae selectiores aliquot Philippi Melanthonis, Wittenberg 1565.

PIndar, Peter, A Complimentary Epistle to James Bruce, Esq. the Abyssinian Travaller, London 1790.

Platt, Thomas Pell (Hg.), Biblica sacra amharice, sub auspiciis D. Asselini in linguam amharicam vertit Abu Rumi Habessinius, London 1840.

- (Hg.), Evangelia Sancta, sub auspiciis D. Asselini rerum gallicarum apud Aegyptios procuratoris in linguam amharicam vertit Abu Rumi Habessinus, London 1824.

- (Hg.), Testamentum Novum, Domini Nostri et Servatoris Jesu Christi sub auspiciis D. Asselini in linguam amharicam vertit Abu Rumi Habessinus, London 1829.

Potken, Johannes (Hg.), Psalterium Davidis et Cantica aliqua. Canticum canticorum, Romae 1513.

Powell-Cotton, Percy Horace Gordon, A Sporting Trip through Abyssinia. A Narrative of a Nine Months' Journey from the Plains of the Hawash to the Snows of Simien, with a Description of the Game, from Elephant to Ibex, and Notes on the Manners and Customs of the Natives, London 1902.

Praetorius, Franz, Fabula de Regina Sabaea apud Aethiopes, Halle (Saale) 1870.

-, Wissenschaftlicher Jahresbericht über die morgenländischen Studien im Jahre 1905. Die abessinischen Dialekte und das Sabäo-Minäische, in: ZDMG 60 (1906), S. 261-263.

RAsPe, Rudolf Erich, A Sequel to the Adventures of Baron Munchausen. Containing His Expedition into Africa, London 1792.

Rauwolf, Leonhard, Aigentliche beschreibung der Raiß, so er vor diser Zeit gegen Auffgang inn die Morgenländer, fürnemlich Syriam, Judaeam, Arabiam, Mesopotamiam, Babyloniam, Assyriam, Armeniam selbs volbracht, Augsburg 1583.

Rebenich, Stefan/Markschies, Christoph (Hg.), Protokollbuch der Kirchenväter-Kommission der Preußischen Akademie der Wissenschaften 1897-1928, Berlin u. a. 2000.

Reden bei der Einweihung des Doms zu Berlin am Montag d. 27. Februar 1905, Berlin 1905.

Reinink, Gerrit Jan (Hg.), Die syrische Apokalypse des Pseudo-Methodius, CSCO 540, 541 [CSCO.S 220, 221], Louvain 1993.

Ritter, Carl, Die Erdkunde im Verhältnis zur Natur und Geschichte des Menschen, oder allgemeine vergleichende Geographie als sichere Grundlage des Studiums und Unterrichts in physikalischen und historischen Wissenschaften, Berlin 1817, Erster Theil.

-, Die Erdkunde im Verhältnis zur Natur und Geschichte des Menschen, oder allgemeine vergleichende Geographie als sichere Grundlage des Studiums und Unterrichts in physikalischen und historischen Wissenschaften, Berlin ${ }^{2} 1822$, Erster Theil, Erstes Buch: Afrika.

-, Die Nigerexpedition und ihre Bestimmung, in: Buxton, Thomas Fowell (Hg.), Der afrikanische Sklavenhandel und seine Abhülfe, Leipzig 1841, S. IX-IXX. 
-, Ein Blick in das Nil-Quellland. Vortrag vom 16. März 1844, im Verein wissenschaftlicher Mittheilungen, Berlin 1844.

-, Einleitung zur allgemeinen vergleichenden Geographie, und Abhandlungen zur Begründung einer mehr wissenschaftlichen Behandlung der Erdkunde, Berlin 1852.

-, Nachtrag zu Herrn C. W. Isenberg's Briefe über die Mission in Schoa, in: Monatsberichte über die Verhandlungen der Gesellschaft für Erdkunde zu Berlin 2 (7-9) (1840-1841), S. 93-98.

-, Über räumliche Anordnung auf der Außenseite des Erdballs und ihre Funktion im Entwicklungsgange der Geschichte, Berlin 1850.

Rohlfs, Gerhard, Meine Mission nach Abessinien. Auf Befehl Sr. Maj. des Deutschen Kaisers im Winter 1880/1881 unternommen von Gerhard Rohlfs, Leipzig 1883.

Rosen, Felix, Eine deutsche Gesandtschaft in Abessinien, Leipzig 1907.

SALT, Henry, A Voyage to Abyssinia, and Travels into the Interior of That Country, Executed Under the Orders of the British Government, in the Years 1809 and 1810, London 1814.

Schnurrer, Christian Friedrich, Biographische und litterarische Nachrichten von ehemaligen Lehrern der hebräischen Litteratur in Tübingen, Ulm 1792.

Schütze, Gottfried (Hg.), D. Martin Luthers bisher grossentheils ungedruckte Briefe. Nach der Sammlung des Hrn. D. Gottf. Schütze, aus dem Latein übersetzt, Leipzig 1784, Bd. 2.

- (Hg.), D. Martin Luthers bisher ungedruckte Briefe, Leipzig 1781, Bd. 2.

Sergew Hable-Selassie, The Ge'ez Letters of Queen Eleni and Libne Dingil to John, King of Portugal, in: Accademia Nazionale dei Lincei (Hg.), IV Congresso Internazionale di Studi Etiopici (Roma, 10-15 April 1972), Roma 1974, Bd. 1, S. 547-566.

Sitzung der philosophisch-philologischen und der historischen Classe vom 6. December 1902, in: SDAW.PH Jahrgang 1902 (1903), S. 432-435.

Skinner, Robert, Abyssinia of To-day. An Account of the First Mission Sent by the American Government to the Court of the King of Kings (1903-1904), New York 1906.

Smidt, Wolbert G.C., "Annäherung Deutschlands und Aethiopiens«. Unbekannte Briefe des Kaisers Menelik II. und seines Gesandten 1907-08, in: BRÜNE, Stefan/SCHOLLER, Heinrich (Hg.), Auf dem Weg zum modernen Äthiopien. Festschrift für Bairu Tafla, Münster 2005, S. 197-224.

-, Deutsche Briefe von Äthiopiern aus der Protestantischen Mission. Vom Fall des Téwodros bis zur Unterwerfung des Königs Minílik (1869 bis 1878), in: Orientalia Parthenopea 8 (2008), S. 9-56.

-, Deutsche Briefe von Äthiopiern aus der Protestantischen Mission. Von der Reichseinigung unter Yohannis IV. bis zur großen Hungersnot (1879 bis 1889), in: Orientalia Parthenopea 9 (2009), S. 9-52.

-, Deutsche Briefe von Äthiopiern 1855-1869 aus dem Umkreis der protestantischen Mission zur Regierungszeit von Tewodros II., in: Scrinium. Revue de patrologie, d'hagiographie critique et d'histoire ecclésiastique 1 (2005), S. 287-316.

Strohm, Christoph (Hg.), Martin Bucers Deutsche Schriften, Martini Buceri Opera Omnia. Series I, bearbeitet von Thomas Wilhelmi, Gütersloh 2006, Bd. 11,3: Schriften zur Kölner Reformation.

- (Hg.), Martin Bucers Deutsche Schriften, Martini Buceri Opera Omnia. Series I, bearbeitet von Thomas Wilhelmi, Gütersloh 2011, Bd. 13: Unionsschriften 1542-1545.

Testamentum Novum cum Epistola Pauli ad Hebreos tantum. Cum concordantiis Euangelistarum Eusebii \& numeratione omnium verborum eorundem; Missale cum benedictione incensi ceræ etc., Romae 1548.

Thомpson, Nicholas (Hg.), De vera et falsa caenae dominicae administratione (1546), SMRT 184 [Martin Bucer: Opera Latina 6], Leiden 2014.

Uhlig, Siegbert, Hiob Ludolfs »Theologia Aethiopica«, ÄthF 14, Wiesbaden 1983.

-/ Bühring, Gernot (Hg.), Damian de Góis' Schrift über Glaube und Sitten der Äthiopier, ÄthF 39, Wiesbaden 1994.

Ullendorff, Edward, The Confessio Fidei of King Claudius of Ethiopia, in: JSSt 32 (1) (1987), S. 159-176.

- / Aвraham Demoz, Two Letters from the Emperor Yohannes of Ethiopia to Queen Victoria and Lord Granville, in: BSOS 33 (1) (1969), S. 135-142. 
Vierhaus, Rudolf (Hg.), Das Tagebuch der Baronin Spitzemberg. Aufzeichnungen aus der Hofgesellschaft des Hohenzollernreiches, DGQNJ 43, Göttingen ${ }^{5} 1989$.

-, Im Großbetrieb der Wissenschaft. Adolf von Harnack als Wissenschaftsorganisator und Wissenschaftspolitiker, in: Nowak, Kurt/Oexle, Otto Gerhard (Hg.), Adolf von Harnack. Theologe, Historiker, Wissenschaftspolitiker, VMPIEG 161, Göttingen 2001, S. 419-440.

Vollbrecht, Hans, Im Reiche des Negus Negesti Menelik II, Stuttgart u. a. 1906.

Wansleben, Johann Michael, A Brief Account of the Rebellions and Bloudshed Occasioned by the Anti-Christian Practices of the Jesuits and Other Popish Emissaries in the Empire of Ethiopia. Collected Out of a Manuscript History Written in Latin by Jo. Michael Wansleben, a Learned Papist, London 1679.

Wendt, Kurt (Hg.), Das Maṣḥafa Milād (Liber Nativitatis) und Maṣhafa Sellāsē (Liber Trinitatis) des Kaisers Zar'a Yā‘qob [Textus] II, CSCO 235 [CSCO.Ae 43], Louvain 1963.

- (Hg.), Das Maṣhafa Milād (Liber Nativitatis) und Maṣhafa Sellāsē (Liber Trinitatis) des Kaisers Zar'a Yā‘qob [Versio] I, CSCO 222 [CSCO.Ae 42], Louvain 1963.

- (Hg.), Das Mașhafa Milād (Liber Nativitatis) und Mașhafa Sellāsē (Liber Trinitatis) des Kaisers Zar'a Yā‘qob [Versio] II, CSCO 236 [CSCO.Ae 44], Louvain 1963.

Würkert, Ludwig (Hg.), Die biblischen Geschichten des alten und neuen Testaments in poetischer Bearbeitung von den besten Dichtern unserer Zeit, Weißen 1842.

Wette, Wilhelm Martin Leberecht de (Hg.), Dr. Martin Luthers Briefe, Sendschreiben und Bedenken, vollständig aus den verschiedenen Ausgaben seiner Werke und Briefe, aus andern Büchern und noch unbenutzten Handschriften gesammelt, kritisch und historisch bearbeitet, Berlin 1827, Bd. 4.

YAqob Beyene (Hg.), Giyorgis di Saglā. Il libro del Mistero (Mäṣhafa Mesțir) [II] [Text], CSCO 532 [CSCO.Ae 97], Louvain 1993.

- (Hg.), Giyorgis di Saglā. Il libro del Mistero (Mäṣḥafa Mesțir) [II] [Versio], CSCO 533 [CSCO.Ae 98], Louvain 1993.

-, L’unzione di Christo nella teologia etiopica, OCA 215, Roma 1981.

\section{Literatur}

Aввink, Jon, Mateus, in: EAE 3, 2007, S. $866 f$.

-, Mika el Səhul, in: EAE 3, 2007, S. 962-964.

AвIr, Mordechai, Ethiopia. The Era of the Princes. The Challenge of Islam and the Reunification of the Christian Empire. 1769-1855, London u.a. 1968.

Adelheid Zelleke, 100 Jahre Deutsch-Äthiopischer Freundschafts- und Handelsvertrag 1905-2005, Bonn 2004.

Adhana MengstaAb, The Occupation of Keren by the Egyptians. 4 July 1872-10 April 1885, in: Tadesse Beyene u.a. (Hg.), Proceedings of the First National Conference of Ethiopian Studies. April 11-12 1990, Addis Abeba 1990, S. 367-381.

-, Yohannes IV and Keren, in: Taddese Beyene u.a. (Hg.), Kaśa and Kaśa. Papers on the Lives, Times and Images of Tewodros II and Yohannes IV (1855-1889), Addis Abeba 1989, S. 247-252.

Afework Hailu, Jewish Cultural Elements in the Ethiopian Orthodox Täwahədo Church, in: Gorgias Eastern Christian Studies 55 (2020).

Agstner, Rudolf, Vom k.u.k. Honorarkonsulat zur Österreichischen Botschaft. 100 Jahre österreichische Präsenz in Addis Abeba, in: RöHM 46 (2004), S. 419-448.

Amsalu Tefera, "Cycles of Zion« in Ethiopic Texts, in: Bausi, Alessandro u.a. (Hg.), Essays in Ethiopian Manuscript Studies. Proceedings of the International Conference "Manuscripts and Texts, Languages and Contexts. The Transmission of Knowledge in the Horn of Africa«. Hamburg, 17-19 July 2014, Wiesbaden 2015, S. 145-152.

-, Colophonic Reflections on Dərsanä Șəyon and Kəbrä Nägäśt, in: Aethiopica. International Journal of Ethiopian Studies 17 (2014), S. 78-89. 
-, The Ethiopian Homily on the Ark of the Covenant. Critical Edition and Annotated Translation of Dərsanä Șəyon, Leiden 2015.

Andresen, Bernd, Ernst von Dryander. Eine biographische Studie, Berlin u. a. 1995.

Arén, Gustav, Evangelical Pioneers in Ethiopia. Origins of the Evangelical Church Mekane Yesus, Stockholm 1978.

Arndt, Agnes u.a. (Hg.), Vergleichen, verflechten, verwirren? Europäische Geschichtsschreibung zwischen Theorie und Praxis, Göttingen 2011.

Asendorf, Ulrich, Die Theologie Luthers nach seinen Predigten, Göttingen 1988.

Asghedom, Samuel, Contributo dell'Ospizio di Santo Stefano degli Abissini agli studi etiopici in Europa, in: IV Congresso Internazionale di Studi Etiopici (Roma, 10-15 April 1972), Roma 1974, Bd. 1, S. 389-404.

Assta Bereket Gettu, Fear Not, for I am with You, Pittsburgh PA 2017.

Aubin, Jean, Damião de Góis dans une Europe évangelique, in: Humanitas 31-32 (1979-1980), S. $1-56$.

-, L’ambassade du Prêtre Jean à D. Manuel, in: Mare Luso-Indicum 3 (1976), S. 1-56.

-, Le Prêtre Jean devant la censure portugaise, in: Bulletin des etudes Portugaises et Brésiliennes Paris 41 (1980), S. 33-57.

Awad, Magdi, Die sieben koptischen Theotokien, in: Tubiana, Joseph/VASHALomidze, Sophia G. (Hg.), Stabilisierung und Profilierung der koptischen Kirche im 4. Jahrhundert. Beiträge zur X. Internationalen Halleschen Koptologentagung 2006, Halle (Saale) 2007, S. 7-25.

Aymro Wondmagegnehu / Motovu, Joachim, The Ethiopian Orthodox Church, Addis Abeba 1970.

Batteman, Joseph, Dictionnaire Amarigna-Français, suivi d'un vocabulaire Français-Amarigna, Dire-Daoua 1929.

Bahru Zewde, Concessions and Concession-Hunters in Post-Adwa Ethiopia. The Case of Arnold Holtz, in: Africa 45 (1990), S. 365-383.

-, Pioneers of Change in Ethiopia. The Reformist Intellectuals of the Early Twentieth Century, Oxford u.a. 2002.

Bairu Tafla, Between Religion and Politics. Reflecting on the Agelong Religious Policy of Imperial Ethiopia, in: Raunig, Walter/Asfa-Wossen Asserate (Hg.), Juden, Christen und Muslime in Äthiopien. Ein Beispiel für abrahamische Ökumene, Dettelbach 2010, S. $45-56$.

-, Civil Titles and Offices in the Reign of Emperor Menilek II. 1889-1913, in: Accademia Nazionale dei Lincei (Hg.), IV Congresso Internazionale di Studi Etiopici (Roma, 10-15 April 1972), Roma 1974, Bd. 1, S. 597-612.

-, Ethiopia and Germany. Cultural, Political and Economic Relations 1871-1936, Wiesbaden 1981.

-, Four Ethiopian Biographies. Däjjazmač Gärmamé, Däjjazmač Gäbrä-Egzi’abehér Moroda, Däjjazmač Balča and Käntiba Gäbru Dästa, in: JEtS 7 (2) (1969), S. 1-31.

-, Gäbrä Ggziªbəḥer Dästa, in: EAE 2, 2005, S. 606f.

-, Ilg, Alfred, in: EAE 3, 2007, S. 120-122.

Balicka-Witakowska, Ewa, The Iconography of the Deposition in Ethiopian Painting, in: Pankhurst, Richard (Hg.), Proceedings of the First International Conference on the History of Ethiopian Art, London 1989, S. 14-22.

-/ BAusi, Alessandro, Tä’ammərä Maryam, in: EAE 4, 2010, S. 789-793.

Bandrés, José L. / Zanetti, Ugo, Christology, in: EAE 1, 2003, S. 728-732.

BArth, Christian Gottlob, Christliche Gedichte, Stuttgart 1836.

BArton, Peter F., David Chyträus, in: TRE 8, Berlin u.a. 1981, S. 88-90.

BAuer, Gisa, Evangelisch-orthodoxe Religionsgespräche im 16. Jahrhundert, in: Dingel, Irene u.a. (Hg.), Zwischen theologischem Dissens und politischer Duldung. Religionsgespräche der Frühen Neuzeit, Göttingen 2018, S. 43-60.

Bauerochse, Ernst, Ihr Ziel war das Oromoland. Anfänge der Hermannsburger Missionsarbeit in Äthiopien, Münster 2006.

Baum, Wilhelm, Die Verwandlungen des Mythos vom Reich des Priesterkönigs Johannes. Rom, Byzanz und die Christen des Orients im Mittelalter, Klagenfurt 1999. 
Baumann, Andreas, Die »Apostelstraße«. Eine außergewöhnliche Vision und ihre Verwirklichung, Gießen 1999.

BAur, Jörg, Die Anfänge der Theologie an der »wohl angeordneten evangelischen Universität« Göttingen, in: Stackelberg, Jürgen von (Hg.), Zur Geistigen Situation der Zeit der Göttinger Universitätsgründung 1737. Eine Vortragsreihe aus Anlaß des 250-jährigen Bestehens der Georgia Augusta, Göttingen 1988, S. 9-56.

BAusi, Alessandro, La leggenda della Regina di Saba nella tradizione etiopica, in: Battiato, Fabio u.a. (Hg.), La Regina di Saba. Un Mito fra Oriente e Occidente, Napoli 2016, S. 91-162.

-, Languages and Cultures of Eastern Christianity. Ethiopian, Oxford 2012.

-, Qw ${ }^{\text {wsqwam }}$ (Koskam) in Ethiopian Tradition, in: EAE 4, 2010, S. 318.

-/ Fiaccadori, Gianfranco, Täsfa Șəyon, in: EAE 5, 2014, S. 525-528.

Bautz, Friedrich Wilhelm, Bezold, Karl, in: BBKL, Herzberg 1990, Bd. 1, Sp. 574.

-, Edzard, Esdras, in: BBKL, Herzberg 1990, Bd. 1, Sp. 1464.

Baxter, Paul T.W. u.a. (Hg.), Being and Becoming Oromo. Historical and Anthropological Enquiries, Uppsala 1996.

Beck, Hanno, Carl Ritter. Genius der Geographie. Zu seinem Leben und Werk, Berlin 1979.

BECK, Ulrich/GrAnde, Edgar, Jenseits des methodologischen Nationalismus. Außereuropäische und europäische Variationen der Zweiten Moderne, in: Soziale Welt. Zeitschrift für sozialwissenschaftliche Forschung 61 (2010), S. 187-216.

Becker, Felicitas / Beez, Jigal (Hg.), Der Maji-Maji-Krieg in Deutsch-Ostafrika 1905-1907, Berlin 2005.

Bedford-Strohm, Heinrich u.a. (Hg.), African Christian Theologies and the Impact of the Reformation, Wien u.a. 2017.

Beigel, Thorsten / Mangold-Will, Sabine (Hg.), Wilhelm II. Archäologie und Politik um 1900, Stuttgart 2017.

Belcher, Wendy Laura (Hg.), The Jesuits in Ethiopia (1609-1641). Latin Letters in Translation, Wiesbaden 2017.

-/ Kleiner, Michael (Hg.), The Life and Struggles of Our Mother Walatta Petros. A SeventeenthCentury African Biography of an Ethiopian Woman, Princeton NJ 2015.

Benga, Daniel, David Chytraeus (1530-1600) als Erforscher und Wiederentdecker der Ostkirchen. Seine Beziehungen zu orthodoxen Theologen, seine Erforschungen der Ostkirchen und seine ostkirchlichen Kenntnisse, Giessen ${ }^{2} 2012$.

-, Philipp Melanchthon und der christliche Osten. Bis heute unbekannte Begegnungen Melanchthons aus den Jahren 1541 und 1556 mit orthodoxen Christen, in: OrthFor 16 (2002), S. 19-38.

Benner, Thomas Hartmut, Die Strahlen der Krone. Die religiöse Dimension des Kaisertums unter Wilhelm II. vor dem Hintergrund der Orientreise 1898, Marburg 2001.

Benz, Ernst, Die Ostkirche im Lichte der protestantischen Geschichtsschreibung von der Reformation bis zur Gegenwart, Freiburg i. Br. u. a. 1952.

-, Die östliche Orthodoxie und das kirchliche Selbstbewußtsein der Reformation, in: Ders./ ZANDER, Lev, Evangelisches und orthodoxes Christentum in Begegnung und Auseinandersetzung, Hamburg 1952, S. 101-160.

-, Geist und Leben der Ostkirche, Hamburg 1957.

-, Wittenberg und Byzanz. Zur Begegnung und Auseinandersetzung der Reformation und der östlich-orthodoxen Kirche, München ${ }^{2} 1971$.

Berhanu Gizaw Haile Mariam, Huaylä Maryam Śärabyon, in: EAE 2, 2005, S. 1058f.

Berry, Laverle, Bərhan Mogäsa, in: EAE 1, 2003, S. $534 f$.

-, Qwosqwam of Gondär, in: EAE 4, 2010, S. 318-320.

Betz, Richard L., The Mapping of Africa. A Cartobibliography of Printed Maps of the African Continent to 1700, Goy-Houten 2007.

BEylot, Robert, Le millénarisme, article de foi dans l’Église Éthiopienne au XVme siècle, in: RSEt 25 (1971-1972), S. 31-43.

Bienert, Wolfgang A., Die ökumenische Bedeutung von Harnacks Verständnis der Alten Kirche, in: Gemeinhardt, Peter/ Pinggéra, Karl (Hg.), Kirchengeschichte in ökumenischer Verantwortung. Ausgewählte Studien, Göttingen 2009, S. 29-51. 
Birkenhauer, Josef, Traditionslinien und Denkfiguren. Zur Ideengeschichte der sogenannten Klassischen Geographie in Deutschland, Stuttgart 2001.

Biskup, Thomas, The University of Göttingen and the Personal Union. 1737-1837, in: Simms, Brendan/Riotte, Torsten (Hg.), The Hanoverian Dimension in British History. 1714-1837, Cambridge 2007, S. 128-159.

Blackburn, Elizabeth, The Legacy of »Prester John« by Damião de Goes and John More, in: Moreana 4 (14) (1967), S. 37-98.

Boavida, Isabel, The Cross Brought to Goa and Portugal by Libnä Dingil's Envoy Mathew, in: Ramos, Manuel Joo / BoAvida, Isabel (Hg.), The Indigenous and the Foreign in Christian Ethiopian Art. On Portuguese-Ethiopian Contacts in the 16th-17th Centuries. Papers from the Fifth International Conference on the History of Ethiopian Art (Arrábida, 26-30 November 1999), Aldershot 2004, S. 136-142.

Boll, Franz, Carl Bezold. Nachruf, im Namen der philosophischen Fakultät der Universität Heidelberg gesprochen bei der Beisetzung am 23.11.22, in: SHAW 14 (1923), S. 3-12.

BöLl, Verena (Hg.), Ethiopia and the Missions. Historical and Anthropological Insights, Münster 2005.

-, »Unsere Herrin Maria«. Die traditionelle äthiopische Exegese der Marienanaphora des Cyriacus von Behnesa, Wiesbaden 1998.

Botтe, Roger u.a. (Hg.), Figures Peules, Paris 1999.

Braden, Jutta, Hamburger Judenpolitik im Zeitalter lutherischer Orthodoxie. 1590-1710, Hamburg 2001.

Brandt, Peter, Bible Canon, in: EAE 1, 2003, S. 571-573.

-, Geflecht aus 81 Büchern. Zur variantenreichen Gestalt des äthiopischen Bibelkanons, in: Aethiopica. International Journal of Ethiopian Studies 3 (2000), S. 79-115.

Brann, Eva T.H., The World of the Imagination. Sum and Substance, Lanham 1991.

BraukÄMPER, Ulrich, A History of the Hadiyya in Southern Ethiopia, Wiesbaden 2012.

Braun, Theodor, Zur Frage der engeren Vereinigung der deutschen evangelischen Landeskirchen, Berlin 1902.

Brecht, Martin, Martin Luther, Stuttgart 1987, Bd. 3: Die Erhaltung der Kirche: 1532-1546.

Brincken, Anna-Dorothee von den, Johann Potken aus Schwerte, Probst von St. Georg in Köln, der erste Äthiopologe des Abendlandes, in: Blum, Hans (Hg.), Aus kölnischer und rheinischer Geschichte, Köln 1969, S. 81-115.

Broecke, Marcel P. R. van den, Ortelius Atlas Maps. An Illustrated Guide, Houten ${ }^{2} 2011$.

-/ Voet, Leon (Hg.), Abraham Ortelius and the First Atlas. Essays Commemorating the Quadricentennial of His Death. 1598-1998, Utrecht 1998.

Brüllmann, Philipp u.a., Imagination, Transformation und die Entstehung des Neuen. Einleitung, in: Dies. (Hg.), Imagination, Transformation und die Entstehung des Neuen, Berlin u.a. 2014, S. 1-20.

Brüne, Stefan, Äthiopien - Unterentwicklung und radikale Militärherrschaft. Zur Ambivalenz einer scheinheiligen Revolution, Hamburg 1986.

Budde, Gunilla u.a. (Hg.), Transnationale Geschichte. Themen, Tendenzen und Theorien, Göttingen ${ }^{2} 2010$.

BüHLER, Peter, Der Abendmahlsstreit der Reformatoren und seine aktuellen Implikationen, in: ThZ 35 (4) (1979), S. 228-241.

BurkhardT, Johannes, Alt und Neu. Ursprung und Überwindung der Asymmetrie in der reformatorischen Erinnerungskultur und Konfessionsgeschichte, in: Burschel, Peter u.a. (Hg.), Historische Anstöße. Festschrift für Wolfgang Reinhard zum 65. Geburtstag am 10. April 2002, Berlin 2002, S. 152-171.

Burmeister, Karl Heinz, Sebastian Münster. Versuch eines biographischen Gesamtbildes, Basel ${ }^{2} 1969$.

BürNING, Christian, »Gott möge ihnen einen Blitz ins Gesäß jagen!« Zu den Feindpassagen in den Psalmen, in: EuA 82 (2006), S. 128-138.

Büttner, Manfred, Carl Ritter, in: DBE 8, ${ }^{2} 2007$, S. $442 \mathrm{f}$. 
-, Wandlungen im teleologischen Denken von Wolff über Kant zu Ritter, in: Ders. (Hg.), Carl Ritter. Zur europäisch-amerikanischen Geographie an der Wende vom 18. zum 19. Jahrhundert, Paderborn 1980, S. 145-178.

Buzi, Paola / Bausi, Alessandro, Shenute of Atripe, in: EAE 4, 2010, S. 648-650.

Calis, Richard, Reconstructing the Ottoman Greek World. Early Modern Ethnography in the Household of Martin Crusius, in: RenQ 72 (1) (2019), S. 148-193.

Calwer Verlagsverein (Hg.), Württembergische Kirchengeschichte, Calw u. a. 1893.

CAQuot, André, La royauté sacrale en Éthiopie, in: AEt 2 (1957), S. 205-218.

CARmichael, Tim, Mäkwännən Wäldä Mika’el, in: EAE 3, 2007, S. $686 f$.

CaulK, Richard Alan, Religion and State in Nineteenth Century Ethiopia, in: JEtS 10 (1) (1972), S. 23-41.

-, Yohannes IV, the Mahdists, and the Colonial Partition of North-East Africa, in: TransAfrican Journal of History 1 (2) (1971), S. 23-42.

Cerulli, Enrico, Etiopi in Palestina. Storia della communità etiopica di Gerusalemme I, Collezione scientifica e documentaria. A cura del ministerio dell'Africa italiana 12, Roma 1943.

-, Etiopi in Palestina. Storia della communità etiopica di Gerusalemme II, Collezione scientifica e documentairia. A cura del ministerio dell'Affrica italiana 14, Roma 1947.

-, Il libro etiopico dei miracoli di Maria e le sue fonti nelle letterature del medio evo latino. Reale Università di Roma. Studi orientali, pubblicati a cura della Scuola orientale 1, Roma 1943.

-, Scritti teologici etiopici dei secoli XVI-XVII, Città del Vaticano 1958, Bd. I: Tre opuscoli dei Mikaeliti, Studi e testi 198.

Chaîne, Marius, Catalogue des Manuscripts Éthiopiens de la Collection Mondon-Vidailhet, Paris 1913.

-, Le rituel éthiopien - Rituel de l'extrême-onction, in: Bess. 29 (4) (1913), S. 415-420.

-, Le rituel éthiopien - Rituel de l'extrême-onction, in: Bess. 30 (1) (1914), S. 12-41, 213-231.

-, Un monastère éthiopien à Rome au XVe et XVIe siècle, in: MFOB 5 (1911), S. 1-36.

Cherroun, Amélie/Hirsch, Bertrand, The Muslim-Christian Wars and the Oromo Expansion. Transformations at the End of the Middle Ages (ca. 1500-ca. 1650), in: Kelly, Samatha (Hg.), A Companion to Medieval Ethiopia and Eritrea, Leiden u. a. 2020, S. 454-476.

Chernetsov, Sevir, Aleni, in: EAE 2, 2005, S. 253f.

-, The Role of Catholicism in the History of Ethiopia of the First Half of the 17th Century, in: Delange, Étienne/Lepage, Claude (Hg.), Études Éthiopiennes. Actes de la Xe conférence internationale des études éthiopiennes. Paris, 24-28 août 1988, Paris 1994, S. 205-212.

- / Nosnitsin, Denis, Iyasu II, in: EAE 3, 2007, S. $251 f$.

Снолnаскі, Stanislaw, A Survey of Modern Ethiopian Art, in: ZKA Sonderausgabe. Äthiopien (1973), S. 84-94.

Clapham, Christopher, Mənilək II, in: EAE 3, 2007, S. 922-927.

Clark, John, CMS and Mission in Britain. The Evolution of a Policy, in: Ward, Kevin / Stanley, Brian (Hg.), The Church Mission Society and World Christianity. 1799-1999, Grand Rapids 2000, S. 319-343.

Cohen, Leonardo, Susənyos, in: EAE 4, 2010, S. 770-772.

-, The Missionary Strategies of the Jesuits in Ethiopia (1555-1632), Wiesbaden 2009.

-/ MartíneZ, Andreu, Jesuits in the 16th and 17th Cent., in: EAE 3, 2007, S. 277-281.

Collet, Dominik, Die Welt in der Stube. Begegnungen mit Außereuropa in Kunstkammern der Frühen Neuzeit, Göttingen 2007.

Condé, Alpha, Les sociétés traditionnelles mandingues, Niamey 1974.

Conrad, Sebastian/Randeria, Shalini, Geteilte Geschichten. Europa in einer postkolonialen Welt, in: Dies. (Hg.), Jenseits des Eurozentrismus. Postkoloniale Perspektiven in den Geschichts- und Kulturwissenschaften, Frankfurt a. M. u. a. 2002, S. 9-49.

Coulbeaux, J.B., Histoire politique et religieuse d'Abyssinie depuis les temps les plus reculés jusqu'à l'avènement de Ménélick II, Paris 1929, Bd. 2.

Cowley, Roger W., The Biblical Canon of the Ethiopian Orthodox Church Today, in: OS 23 (1974), S. 318-323.

-, Patristic Introduction in the Ethiopian Andemta Commentary Tradition, in: OS 29 (1980), S. 39-49. 
Crichton, James, Review: Kebra Nagast. Die Herrlichkeit der Könige. Nach den Handschriften in Berlin, London, Oxford und Paris zum ersten Mal im äthiopischen Urtext herausgegeben und mit deutscher Übersetzung versehen, in: RTP 1 (1906), S. 225-229.

Crummey, Donald, Imperial Legitimacy and the Creation of Neo-Solomonic Ideology in 19th-Century Ethiopia, in: CEtAf 28 (109) (1988), S. 13-43.

-, Orthodoxy and Imperial Reconstruction in Ethiopia. 1854-1878, in: JThS 19 (2) (1978), S. 427-442.

-, Priests and Politicians. Protestant and Catholic Missions in Orthodox Ethiopia. 1830-1868, Oxford 1972.

-, Qerəllos, in: EAE 4, 2010, S. $290 f$.

-, Täklä Haymanot II, in: EAE 4, 2010, S. 835f.

-/ Smidt, Wolbert G. C., Isenberg, Carl Wilhelm, in: EAE 3, 2007, S. $197 f$.

Curtin, Philip D., The Image of Africa. British Ideas and Action. 1780-1850, Madison 1964, Bd. 1. D'Alòs-Moner, Andreu Martínez, Envoys of a Human God. The Jesuit Mission to Christian Ethiopia. 1557-1632, Leiden u.a. 2015.

DAniels, David, Luther and Ethiopian Christianity, in: Ludwig, Frieder u.a. (Hg.), Reformation in the Context of World Christianity. Theological, Political and Social Interactions between Africa, Asia, the Americas and Europe, Wiesbaden 2019, S. 21-31.

Dannenfeldt, Karl, Leonhard Rauwolf. A Lutheran Pilgrim in Jerusalem. 1575, in: ARG 55 (1) (1964), S. 18-36.

DAum, Werner, Gelehrter und Diplomat. Friedrich Rosen und die Begründung der diplomatischen Beziehungen zwischen Deutschland und Äthiopien, in: Raunig, Walter/WEnIG, Steffen (Hg.), Afrikas Horn. Akten der Ersten Internationalen Littmann-Konferenz, Wiesbaden 2005, S. 265-281.

DAvis, Asa, Background to the Zaga ZaAb Embassy. An Ethiopian Diplomatic Mission to Portugal (1529-1539), in: Studia 32 (1971), S. 211-302.

-, The Sixteenth Century Jihād in Ethiopia and the Impact on Its Culture, in: Journal of the Historical Society of Nigeria 2 (1963), S. 567-592.

De Lorenzi, James, Red Sea Travelers in Mediterranean Lands. Ethiopian Scholars and Early Modern Orientalism, ca. 1500-1668, in: KAveY, Allison B. (Hg.), World-Building and the Early Modern Imagination, New York 2010, S. 173-200.

Decker-Hauff, Hansmartin/Wilfried Setzler (Hg.), Die Universität Tübingen von 1477 bis 1977 in Bildern und Dokumenten. 500 Jahre Eberhard-Karls-Universität Tübingen, Tübingen 1977.

Dege-Müller, Sophia, Between Heretics and Jews. Inventing Jewish Identities in Ethiopia, in: Entangled Religions 6 (2018), S. 247-308.

-, The Ethiopian Psalter. An Introduction to Its Codicological Tradition, in: The Anglo-Ethiopian Society News File Winter 2014, S. 16-22.

Dege, Sophia, Yohannəs II, in: EAE 5, 2014, S. 70 f.

-, Zämänä mäsafənt, in: EAE 5, 2014, S. 122-129.

DerridA, Jacques, Dem Archiv verschrieben. Eine Freudsche Impression, Berlin 1997.

Dewender, Thomas / Welt, Thomas (Hg.), Imagination - Fiktion - Kreation. Das kulturschaffende Vermögen der Phantasie, München u.a. 2003.

Dhanaraj, Dharmakkan, Theological Significance of the Motif of Enemies in Selected Psalms of Individual Lament, Wiesbaden 1992.

DiHLE, Albrecht, The Conception of India in Hellenistic and Roman Literature, in: PCPS 10 [190] (1964), S. 15-23.

Dillmann, August, Catalogus codicum manuscriptorum orientalium qui in Museo Britannico asservantur, London 1847, Bd. 3: Codices Aethiopici.

-, Die Handschriften-Verzeichnisse der königlichen Bibliothek zu Berlin, Berlin 1878, Bd. 3: Verzeichnis der abessinischen Handschriften.

DingeL, Irene, Bekenntnisbildung und Konfessionalisierung. Strukturen und Verlaufsformen, in: Grigore, Mihai D./ Kührer-Wielach, Florian (Hg.), Orthodoxa Confessio? Konfessionsbildung, Konfessionalisierung und ihre Folgen in der östlichen Christenheit Europas, Göttingen 2018, S. 23-43. 
-, Evangelische Lehr- und Bekenntnisbildung im Spiegel der innerprotestantischen Auseinandersetzungen zur Zeit des Augsburger Religionsfriedens, in: Hofmann, Carl A. (Hg.), Als Frieden möglich war. 450 Jahre Augsburger Religionsfrieden, Regensburg 2005, S. 51-61.

Doerne, Martin, Harnack, Theodosius Andreas, in: NDB 7, Berlin 1966, S. $690 \mathrm{f}$.

Döpmann, Hans-Dieter, Das Verhältnis Luthers und der Lutheraner zu den orthodoxen Kirchen, in: ThLZ 109 (5) (1984), S. 321-334.

DülfFer, Jost u.a., Das Deutsche Reich auf europäischem Konfrontationskurs. Die erste Marokkokrise 1905/1906, in: Militärgeschichtliches Forschungsamt (Hg.), Vermiedene Kriege. Deeskalation von Konflikten der Großmächte zwischen Krimkrieg und Erstem Weltkrieg 1865-1914, München 1997, S. 557-577.

Dupire, Marguerite, Organisation sociale des Peul. Étude d'ethnographie comparée, Paris 1970.

EBER, Jochen, Johann Ludwig Krapf. Ein schwäbischer Pionier in Ostafrika, Basel 2006.

Ehmer, Hermann, Die Reise des Tübinger Magisters Valentin Cless nach Nordafrika 1583 - Plan oder Wirklichkeit? Zugleich ein Beitrag zu den Anfängen der Arabistik in Deutschland, in: BWKG 107 (2007), S. 139-168.

Engel, Helmut/ Hü fameier, Wilhelm (Hg.), Der Berliner Dom. Zur Geschichte und Gegenwart der Oberpfarr- und Domkirche zu Berlin, Berlin 2001.

Eshetu Abate, Blumhardt, Carolus Henricus, in: EAE 1, 2003, S. $598 f$.

Esposito, Elena, Soziales Vergessen. Formen und Medien des Gedächtnisses der Gesellschaft, Frankfurt a.M. 2002.

EurInger, Sebastian, Der mutmaßliche Verfasser der koptischen Theotokien und des äthiopischen Weddâsê Mârjâm, in: OrChr 1 (1911), S. 215-226.

-, San Stefano dei Mori (Vatikanstadt) in seiner Bedeutung für die abessinische Sprachwissenschaft und Missionsgeschichte, in: OrChr 32 (3) (1935), S. 38-59.

Fechter, Rudolf, History of German Ethiopian Diplomatic Relations, in: ZKA Sonderausgabe. Äthiopien (1973), S. 149-156.

Fehrenbach, Elisabeth, Wandlungen des deutschen Kaisergedankens. 1871-1918, München u.a. 1969.

Feist Hirsch, Elisabeth, Damião de Goes und die Reformation, in: ThZ 6 (1950), S. 39-58.

-, Damião de Gois, in: ContEras 1, 1985, S. 114-117.

-, Damião de Gois. The Life and Thought of a Portuguese Humanist. 1502-1574, The Hague 1967.

FeLD, Helmut, Ignatius von Loyola. Gründer des Jesuitenordens, Köln u. a. 2006.

Feldtkeller, Andreas, Sieben Thesen zur Missionsgeschichte, Berlin 2000.

Fernández, Victor Manuel u. a., The Archeology of the Jesuit Missions in Ethiopia (1557-1632), Leiden u.a. 2017.

Fessehatzion Andemariam, Mariology in the »Mahleta Sege«. Abba Giyorgis Gassičča’s »Hymn of the Flower«, Salesian Pontifical University, Rome 1994.

FIACCADORI, Gianfranco, »India« as Name of Ethiopia, in: EAE 3, 2007, S. 145-147.

-, Nestorius, in: EAE 3, 2007, S. 1169-1171.

-, Noguś, in: EAE 3, 2007, S. 1162-1166.

-, Prester John, in: EAE 4, 2010, S. 209-216.

-, Santo Stefano dei Mori, in: EAE 4, 2010, S. 528-532.

-, The Queen of Sheba in Western Culture, in: EAE 3, 2007, S. 677-679.

-, Venezia, l'Etiopia e l'Europa, in: Barbieri, Giuseppe / Fiaccadori, Gianfranco (Hg.), »Nigra sum sed formosa". Sacro e bellezza dell'Etiopia cristiana, Crocetta del Montello 2009, S. 27-48.

Fiedler, Matthias, Zwischen Abenteuer, Wissenschaft und Kolonialismus. Der deutsche Afrikadiskurs im 18. und 19. Jahrhundert, Köln u. a. 2005.

Fischer-Kattner, Anke, Spuren der Begegnung. Europäische Reiseberichte über Afrika 1760-1860, Göttingen 2015.

Flemming, Johannes, [Rezension:] Kebra Nagast. Die Herrlichkeit der Könige. Nach den Handschriften in Berlin, London, Oxford und Paris zum ersten Mal im äthiopischen Urtext herausgegeben und mit deutscher Übersetzung versehen, in: GGA 11 (171) (1909), S. 903-912.

-, Hiob Ludolf. Ein Beitrag zur Geschichte der orientalischen Philologie [I], in: BASS I (1890), S. 537-582. 
-, Hiob Ludolf. Ein Beitrag zur Geschichte der orientalischen Philologie [II], in: BASS II (1894), S. $63-110$.

Fritsch, Emmanuel, Mäqdäs, in: EAE 3, 2007, S. 765-767.

-, Qəddase, in: EAE 4, 2010, S. 271-275.

-, Tabot. Mänbärä tabot, in: EAE 4, 2010, S. 804-807.

-, The Liturgical Year of the Ethiopian Church. The Temporal Seasons and Sundays, Addis Ababa 2001.

-, Turning Everyday to Aksum Șeyon Unaware. King Zar’a Yā̄eqob's Kehedata Sayțān Identified in the First Prayer of the Day, in: Annales d'Ethiopie 28 (1) (2013), S. 363-372.

- / Zanetti, Ugo, Christian Calendar, in: EAE 1, 2003, S. 668-672.

FüsSEL, Stephan, Das Buch der Bücher. Die Luther-Bibel von 1534. Eine kulturhistorische Einführung, Köln 2002.

GäBler, Ulrich (Hg.), Der Pietismus im neunzehnten und zwanzigsten Jahrhundert, Göttingen 2000.

Gabra Madhen Kidane, Yohanis IV. Religious Aspects of His Internal Policy, Haile Sellassie I University B. A. Thesis, 1972.

Garretson, Peter, A History of Addis Ababa. 1886-1910, Wiesbaden 2000.

-, Ințoțto Maryam, in: EAE 2, 2005, S. 321.

Gehring-MÜnZeL, Ursula, 100 Jahre deutsch-äthiopische diplomatische Beziehungen, in: RAUnig, Walter/Asfa-Wossen Asserate (Hg.), Orbis Aethiopicus. Ethiopian Art - a Unique Cultural Heritage and Modern Challenge, Lublin 2007, S. 67-101.

GeIss-Wunderlich, Jürgen, Eine Büchersammlung der Lutherzeit. Aspekte der Erforschung von Blocks Gelehrtenbibliothek, in: Ders. / Gummelt, Volker (Hg.), Johannes Block. Der pommersche Reformator und seine Bibliothek, Leipzig 2018, S. 13-22.

-, Katalog der erhaltenen Bücher aus Blocks Gelehrtenbibliothek, in: Ders./Gummelt, Volker (Hg.), Johannes Block. Der pommersche Reformator und seine Bibliothek, Leipzig 2018, S. $179-238$.

-/ Gummelt, Volker (Hg.), Johannes Block. Der pommersche Reformator und seine Bibliothek, Leipzig 2018.

Gennrich, Paul Wilhelm, Damião de Goes, in: ARG 39 (1942), S. 197-220.

Gervers, Michael, Clothing, in: EAE 1, 2003, S. 757-761.

Getatchew Haile, A Catalogue of Ethiopian Manuscripts Microfilmed for the Ethiopian Manuscript Microfilm Library, Addis Ababa, and for the Monastic Manuscript Microfilm Library, Collegeville, Collegeville 1979, Bd. IV: Project Numbers 1101-1500.

-, A Catalogue of Ethiopian Manuscripts Microfilmed for the Ethiopian Manuscript Microfilm Library, Addis Ababa, and for the Monastic Manuscript Microfilm Library, Collegeville, Collegeville 1981, Bd. V: Project Numbers 1501-2000.

-, A Catalogue of Ethiopian Manuscripts Microfilmed for the Ethiopian Manuscript Microfilm Library, Addis Ababa, and for the Monastic Manuscript Microfilm Library, Collegeville, Collegeville 1987, Bd. IX: Project Numbers 3501-4000.

-, Anqäṣä Bərhan, in: EAE 1, 2003, S. 278-279.

-, Arganonä Maryam, in: EAE 1, 2003, 329f.

-, Baḥrəy. Mäșḥafä Baḥrəy, in: EAE 1, 2003, S. $446 f$.

-, Ethiopian Orthodox (Täwaḩədo) Church. History from Ancient Times till the Second Half of the 19th Century, in: EAE 2, 2005, S. 414-421.

-, Religious Controversies and the Growth of Ethiopic Literature in the Fourteenth and Fifteenth Centuries, in: OrChr 65 (1981), S. 102-136.

-, The Missionary Factor in Ethiopia. Papers from a Symposium on the Impact of European Missions on Ethiopian Society. Lund University, August 1996, Frankfurt a. M. 1998.

-, Zämikaelites, in: EAE 5, 2014, S. 131-133.

-/ Macober, William, A Catalogue of Ethiopian Manuscripts Microfilmed for the Ethiopian Manuscript Microfilm Library, Addis Ababa, and for the Monastic Manuscript Microfilm Library, Collegeville, Collegeville 1983, Bd. VII: Project Numbers 2501-3000.

-/ Nosnitsin, Denis, Mariology, in: EAE 3, 2007, S. 808-811. 
Giblin, James Leonard/Monson, Jamie (Hg.), Maji Maji. Lifting the Fog of War, Leiden u. a. 2010.

Girma Beshah / Wolde Aregay, Merid, The Question of the Union of the Churches in LusoEthiopian Relations (1500-1632), Lisbon 1964.

Graf, Klaus, Der Mythos der Staufer. Eine schwäbische Königsdynastie wird erinnert und instrumentalisiert, in: Schwäbische Heimat 61 (2010), S. 296-306.

Grafton, David D., Piety, Politics, and Power. Lutherans Encountering Islam in the Middle East, Eugene 2009.

Grébaut, Sylvain, Contribution à l'histoire du couvent éthiopien San-Stefano-dei-Mori, in: ROC 26 (3) (1927-1928), S. 211-218.

-/ Tisserant, Eugène, Bybliothecae apostolicae Vaticanae codices manu scripti recensiti iussu Pii XI Pontificis maximi, Codices Aethiopici Vaticani et Borgiani, Barberinianus orientalis 2, Rossianus 865, Città del Vaticano 1935, Bd. I: Enarratio codicum.

Gressmann, Hugo, [Rezension:] Kebra Nagast. Die Herrlichkeit der Könige. Nach den Handschriften in Berlin, London, Oxford und Paris zum ersten Mal im äthiopischen Urtext herausgegeben und mit deutscher Übersetzung versehen, in: ZDMG 60 (1906), S. 666-674.

Grieser, Alexandra u.a., Imaginationsgeschichte, in: Traut, Lucia/Wilke, Annette (Hg.), Religion - Imagination - Ästhetik. Vorstellungs- und Sinneswelten in Religion und Kultur, Göttingen 2015, S. 383-386.

Grillmeier, Alois, Jesus der Christus im Glauben der Kirche, unter Mitarbeit von Theresia Hainthaler, Freiburg i.Br. u.a. 1990, Bd. II/4: Die Kirche von Alexandrien mit Nubien und Äthiopien ab 451.

Grimm, Heinrich, Dresser (Drescher), Matthäus, in: NDB 4, Berlin 1959, S. 112.

Grohmann, Adolf, Die im Äthiopischen, Arabischen und Koptischen erhaltenen Visionen Apa Schenute's von Atripe. I. Die im Äthiopischen erhaltenen Visionen, in: ZDMG 67 (1913), S. 187-267.

Gumilev, Lew, Searches for an Imaginary Kingdom. The Legend of the Kingdom of Prester John, Cambridge 1987.

GüTL, Clemens, Johann Ludwig Krapf. „Do’ Missionar vo’ Deradenga« zwischen pietistischem Ideal und afrikanischer Realität, Münster 2001.

Haberland, Eike, Hiob Ludolf. Father of Ethiopian Studies in Europe, in: Pankhurst, Richard / Снолмаскі, Stanisław (Hg.), Proceedings of the Third International Conference of Ethiopian Studies, Addis Ababa [3-7 April] 1966, Addis Ababa 1969-1970, S. 131-136.

-, Untersuchungen zum äthiopischen Königtum, Wiesbaden 1965.

Habtemichael Kidane, Eucharist, in: EAE 2, 2005, S. 448-450.

-, Mahletä Şge, in: EAE 3, 2007, S. $660 f$.

-, Səbḥätä Fəqur, in: EAE 4, 2010, S. 589f.

Haccius, Georg, Die Kandaze. Das Missionsschiff der Hermannsburger Mission, Hermannsburg [1913].

-, Hannoversche Missionsgeschichte, Hermannsburg 1907, Teil 2: Insbesondere die Geschichte der Hermannsburger Mission von 1849 bis zum Tode von Louis Harms.

HAGE, Wolfgang, Das orientalische Christentum, Stuttgart 2007.

Hahn, Alois, Erinnerung und Prognose. Zur Vergegenwärtigung von Vergangenheit und Zukunft, Opladen 2003.

Haile Gabriel Dagne, The Establishment of Churches in Addis Abeba, in: Taddese Beyene (Hg.), Proceedings of the International Symposium on the Centenary of Addis Ababa. November 24-25, 1986, Addis Ababa 1987, S. 57-78.

Hall, Ashley H., Philip Melanchthon and the Cappadocians. A Reception of Greek Patristic Sources in the Sixteenth Century, Göttingen 2014.

Hammerschmidt, Ernst, Die äthiopistischen Studien in Deutschland (von ihren Anfängen bis zur Gegenwart), in: AEt 6 (1) (1965), S. 255-277.

-, Jewish Elements in the Cult of the Ethiopian Church, in: Journal of Ethiopian Studies 3 (2) (1965), S. 1-12.

Hankins, Barry, The Second Great Awakening and the Transcendentalists, Westport CT 2004. 
Harder, Gerd, Die Reichstagswahl des Jahres 1907 in ihrer Bedeutung für die deutsche Reichsgeschichte. Eine Untersuchung unter besonderer Berücksichtigung der kolonialen Probleme, Kiel 1975.

Hardt, Tom G.A., The Confessional Principle. Church Fellowship in the Ancient and in the Lutheran Church, in: Logia. A Journal of Lutheran Theology VIII (2) (1999), S. 21-30.

Harms, Ludwig, Die ersten Missionsberichte von Louis Harms, Hermannsburg [1906].

Hasselhorn, Benjamin, Politische Theologie Wilhelms II., Berlin 2012.

Нево, Agostinos da, Gli Etiopi e la Madonna. Aspetti dogmatici e devozionali, in: Mar. 21 (1) (1970), S. 369-403.

Heijden, Henk van der, Heinrich Büntings Itinerarium Sacrae Scripturae, 1581. Ein Kapitel der biblischen Geographie, in: Cartographica Helvetica 23 (2001), S. 5-14.

HeIn, Martin, Das Schicksal des Franz Magera. Ein Beitrag zum Verhältnis von Reformation und Türkenkriegen, in: ARG 73 (1982), S. 308-313.

Heintze-Flad, Wilfred, Kugler, Christian, in: EAE 3, 2007, S. $446 f$.

Heldman, Marilyn E., Psalter, in: EAE 4, 2010, S. 231-233.

-, Tabot, in: EAE 4, 2010, S. 802-804.

-, Trinity in Art, in: EAE 4, 2010, S. 994-996.

Henriques, Guilherme (Hg.), Ineditos Goesianos, Lisboa 1898, Bd. 2: O processo na Inquisição, documentos avulsos, notas.

Hering, Gunnar, Orthodoxie und Protestantismus, in: Hunger, Herbert (Hg.), JÖB 31/2, Wien 1981, S. 823-874.

Hermann, Adrian u.a. (Hg.), Transcontinental Links, Enlarged Maps, and Polycentric Structures. A Special Issue on the "Munich School of World Christianity«, in: The Journal of World Christianity 6 (1) (2016).

Heyer, Friedrich, Die Kirche Äthiopiens. Eine Bestandsaufnahme, Berlin u.a. 1971.

-, St. Chrischona in Äthiopien, in: Sundermeier, Theo (Hg.), Fides pro mundi vita. Missionstheologie heute. Hans-Werner Gensichen zum 65. Geburtstag, Gütersloh 1980, S. 133-147.

Hirsch, Bertrand, Cartographie et itinéraires. Figures occidentales du nord de l'Éthiopie aux XV et XVI siècles, in: Abbay 13 (1988), S. 91-122.

Hoffmann, Godehard, Architektur für die Nation? Der Reichstag und die Staatsbauten des Deutschen Kaiserreichs 1871-1918, Köln 2000.

Hoffmann, Gottfried, Kirchenväterzitate in der Abendmahlskontroverse zwischen Oekolampad, Zwingli, Luther und Melanchthon. Legitimationsstrategien in der inner-reformatorischen Auseinandersetzung um das Herrenmahl, Göttingen ${ }^{2} 2011$.

Holtz, Gottfried, David Chytraeus und die Wiederentdeckung der Ostkirche, in: WZ(R).GS, 2 (1952-1953), S. 93-101.

HoRn, Jürgen, Untersuchungen zu Frömmigkeit und Literatur des christlichen Ägypten. Das Martyrium des Viktor, Sohnes des Romanos. Einleitung in das koptische Literaturwerk, Diss. Georg-August-Universität Göttingen 1988.

HowArD, Thomas Albert, Religion and the Rise of Historicism. W.M.L. de Wette, Jacob Burckhardt and the Theological Origins of Nineteenth-Century Historical Consciousness, Cambridge 2000.

Huntingford, George Wynn Brereton, The Historical Geography of Ethiopia. From the First Century AD to 1704, Union Académique Internationale, Oxford 1989.

Jansen, Reiner, Studien zu Luthers Trinitätslehre, Bern 1976.

Jaynes, Jeffrey, Christianity Beyond Christendom. The Global Christian Experience on Medieval Mappaemundi and Early Modern World Maps, Wiesbaden 2018.

Jenkins, Paul, The Church Missionary Society and the Basel Mission. An Early Experiment in Inter-European Cooperation, in: WARD, Kevin/Stanley, Brian (Hg.), The Church Mission Society and World Christianity. 1799-1999, Grand Rapids 2000, S. 43-65.

Jocelyn, Murray, Proclaim the Good News. A Short History of the Church Missionary Society, London 1985.

Jowett, William, Christian Researches in the Mediterranean, London 1822. 
Junge, Martin, Global Perspectives on the Reformation, in: Burghardt, Anne/Sinn, Simone (Hg.), Global Perspectives on the Reformation. Interactions between Theology, Politics and Economics, Leipzig 2017, S. 9-17.

Kahle, Wilhelm, Die Begegnung des baltischen Protestantismus mit der Russisch-Orthodoxen Kirche, Leiden u. a. 1959.

Kalu, Obgu U., Ethiopianism and the Roots of Modern African Christianity, in: Gilley, Sheridan / STANLEY, Brian, The Cambridge History of Christianity, Cambridge u. a. 2006, Bd. 8: World Christianities, c. 1815-c. 1914, S. 576-592.

Kamphausen, Erhard, Anfänge der kirchlichen Unabhängigkeitsbewegung in Südafrika. Geschichte und Theologie der Äthiopischen Bewegung. 1872-1912, Bern u. a. 1976.

Kaplan, Steven, Ayhud, in: EAE 1, 2003, S. 408-410.

-, Matewos, in: EAE 3, 2007, S. 867f.

-, The Beta Israel (Falasha) in Ethiopia. From Earliest Times to the Twentieth Century, New York u.a. 1992.

-, Zion, in: EAE 5, 2014, S. 189-191.

-/ Derat, Marie-Laure, Zär’a Yacəqob, in: EAE 5, 2014, S. 146-150.

Karmiris, Johannes, Luther und Melanchthon über die Orthodoxe Kirche (I), in: Kyrios 6 (2) (1966), S. 77-104.

-, Luther und Melanchthon über die Orthodoxe Kirche (II), in: Kyrios 6 (3) (1966), S. 150-173.

Kaufman-Shelemay, Kay, Aqwaqwam, in: EAE 1, 2003, S. 293.

Kaufmann, Thomas, Chyträus (Kochhafe) David, in: RGG 2, Tübingen ${ }^{4} 2008$, Sp. $377 f$.

-, Einleitung. Transkonfessionalität, Interkonfessionalität, binnenkonfessionelle Pluralität. Neue Forschungen zur Konfessionalisierungsthese, in: Greyerz, Kaspar von u.a. (Hg.), Interkonfessionalität - Transkonfessionalität - binnenkonfessionelle Pluralität. Neue Forschungen zur Konfessionalisierungsthese, Heidelberg 2003, S. 9-15.

-, Universität und lutherische Konfessionalisierung. Die Rostocker Theologieprofessoren und ihr Beitrag zur theologischen Bildung und kirchlichen Gestaltung im Herzogtum Mecklenburg zwischen 1550 und 1675, Gütersloh 1997.

Keel, Othmar, Feinde und Gottesleugner. Studien zum Image der Widersacher in den Individualpsalmen, Stuttgart 1969.

Kelly, Samantha, Medieval Ethiopian Diasporas, in: Dies. (Hg.), A Companion to Medieval Ethiopia and Eritrea, Leiden u. a. 2020, S. 425-453.

-/ Nosnitsin, Denis, The Two Yohannəses of Santo Stefano degli Abissini, Rome. Reconstructing Biography and Cross-Cultural Encounter through Manuscript Evidence, in: Manuscript Studies: A Journal of the Schoenberg Institute for Manuscript Studies 2 (2) (2017), S. 392-426.

Khater, Antoine/Burmester, Oswald Hugh Ewart (Hg.), History of the Patriarchs of the Egyptian Church, Known as the History of the Holy Church, Cyril II - Cyril V (A. D. 1235-1894), Caire 1970.

Kitromilides, Paschalis, Orthodoxy and the West. Reformation to Enlightenment, in: Angold, Michael (Hg.), The Cambridge History of Christianity, Cambridge 2006, Bd. 5: Eastern Christianity, S. 187-209.

Kleiner, Michael, Abu Rumi, in: EAE 1, 2003, S. 53f.

-, Bezold, Carl, in: EAE 1, 2003, S. 562.

-, Feinde Marias, der 500-Jahre-Missionsplan und 303 Fragen zum Thema »Wer ist Christus?«. Eindrücke von und Erfahrungen mit Religion aus einem Jahr in Äthiopien, in: Pinggéra, Karl (Hg.), Tradition und Wandel im Land der Königin von Saba. Ansichten aus und zu Äthiopien, Hofgeismar 2011, S. 9-30.

-, Gälawdewos, in: EAE 2, 2005, S. $656 f$.

-, Ləbnä Dəngəl, in: EAE 3, 2007, S. 535-537.

-, Sägga Zä’ab, in: EAE 4, 2010, S. 455f.

Klinge, Hans, Bünting, Heinrich, in: NDB 2, Berlin 1955, S. 741.

Klingenburg, Karl-Heinz, Der Berliner Dom. Bauten, Ideen und Projekte vom 15. Jahrhundert bis zur Gegenwart, Berlin 1992.

Knobler, Adam, Mythology and Diplomacy in the Age of Exploration, Leiden u. a. 2016. 
KönIg, Daniel, Arabic-Islamic Views of the Latin West. Tracing the Emergence of Medieval Europe, Oxford 2015.

Koschorke, Klaus (Hg.), Außereuropäische Christentumsgeschichte, Göttingen 2006.

-, Außereuropäische Christentumsgeschichte (Asien, Afrika, Lateinamerika). Forschungsstand und Perspektiven einer neuen Disziplin, in: Jahrbuch für europäische Überseegeschichte 2 (2002), S. 137-163.

-, Polyzentrische Strukturen der globalen Christentumsgeschichte, in: Friedui, Richard u.a. (Hg.), Intercultural Perceptions and Prospects of World Christianity, Frankfurt a.M. 2010, S. 105-126.

-, Veränderte Landkarten der globalen Christentumsgeschichte, in: KZG 22 (1) (2009), S. 187-210.

Kössler, Reinhart/ Melber, Henning, Völkermord und Gedenken. Der Genozid an den Herero und Nama in Deutsch-Südwestafrika 1904-1908, in: Brumlik, Micha/ WojaK, Irmtrud (Hg.), Völkermord und Kriegsverbrechen in der ersten Hälfte des 20. Jahrhunderts, Frankfurt a. M. 2004, S. 37-76.

Krahnke, Holger, Die Mitglieder der Akademie der Wissenschaften zu Göttingen 1751-2001, Göttingen 2001.

KrüCKen, Friedrich Wilhelm, Ad maiorem Gerardi Mercatoris gloriam. Abhandlungen zum Leben und Werk Gerhard Mercators, Münster 2011, Bd. 5: Das Buch zur Karte Ad Usum Navigantium.

Kumpmann, Christina, Schöpfen, Schlagen, Schützen. Eine semantische, thematische und theologische Untersuchung des Handelns Gottes in den Psalmen, Göttingen 2016.

KüNG, Heribert, Staatsminister Alfred Ilg (1854-1916). Ein Thurgauer am Hof Kaiser Meneliks II. von Äthiopien, Zürich 1999.

Kurt, Andrew, The Search for Prester John, a Projected Crusade and the Eroding Prestige of Ethiopian Kings, c.1200-c.1540, in: JMedHist 39 (3) (2013), S. 297-320.

Lamprecht, Karl, Deutsche Geschichte. Zweite Abteilung. Neuere Zeit. Zeitalter des individuellen Seelenlebens, Freiburg i. Br. 1905, Bd. 3: Erste Hälfte.

LARge, David Clay, Berlin. Biographie einer Stadt, München 2002.

Lawrance, Jeremy, The Middle Indies. Damião de Góis on Prester John and the Ethiopians, in: Renaissance Studies 6 (3-4) (1992), S. 316-324.

Lehmann, Hartmut, Einleitung. Europäisches und globales Christentum in der Frühen Neuzeit, in: SchjørRing, Jens Holger / HJElm, Norman A. (Hg.), Geschichte des globalen Christentums, Stuttgart 2017, Teil 1: Frühe Neuzeit, S. 19-44.

Lenz, Karl (Hg.), Carl Ritter. Geltung und Deutung. Beiträge. Symposium anläßlich der Wiederkehr des 200. Geburtstages von Carl Ritter, Berlin 1981.

Leonessa, Mauro da, Santo Stefano Maggiore degli Abissini e le relazioni romano-etiopiche, Vatican 1929.

LeOnhardt, Rochus, Religion und Politik im Christentum. Vergangenheit und Gegenwart eines spannungsreichen Verhältnisses, Baden-Baden 2017.

Levine, Donald Nathan, Wax and Gold. Tradition and Innovation in Ethiopian Culture, Chicago 1986.

Lilienfeld, Fairy von, Über einige Probleme der Lehre von »Kirchengeschichte« im »ökumenischen « Zeitalter. Kirchengeschichtsschreibung und das Gedächtnis der Kirche, in: FeLmy, Karl Christian u.a. (Hg.), Sophia - Die Weisheit Gottes. Gesammelte Aufsätze 1983-1995, Erlangen 1997, S. 22-39.

-, Zum Wesen der Kirche. Einheit, Kontinuität und Universalität der heiligen katholischen und apostolischen Kirche in der Theologie Martin Luthers und in der »eucharistischen Ekklesiologie« des 20. Jahrhunderts, in: Felmy, Karl Christian u.a. (Hg.), Sophia - Die Weisheit Gottes. Gesammelte Aufsätze 1983-1995, Erlangen 1997, S. 1-21.

Littmann, Enno, Fränkisch, in: Aufsätze zur Kultur- und Sprachgeschichte vornehmlich des Orients. Ernst Kuhn zum 70. Geburtstage am 7. Februar 1916 gewidmet von Freunden und Schülern, München 1916, S. 236-243.

Lopes, Marília dos Santos, Writing New Worlds. The Cultural Dynamics of Curiosity in Early Modern Europe, Newcastle upon Tyne 2016. 
Ludwig, Frieder, Globale Christentumsgeschichte, in: VF 57 (2) (2012), S. 106-116.

Lukas-Klein, Sonja, Das ist (christliche) Religion. Zur Konstruktion von Judentum, Katholizismus und Protestantismus in Adolf von Harnacks Vorlesungen über "Das Wesen des Christentums«, Berlin 2014.

Lusını, Gianfrancesco, Aksum. Mäșhafä Aksum, in: EAE 1, 2003, S. $185 f$.

Macober, William, A Catalogue of Ethiopian Manuscripts Microfilmed for the Ethiopian Manuscript Microfilm Library, Addis Ababa, and for the Monastic Manuscript Microfilm Library, Collegeville, Collegeville 1978, Bd. III: Project Numbers 701-1100.

-, Final Inventory of the Microfilmed Manuscripts of the Ethiopian Orthodox Church, Jerusalem, Provo 1995.

MAI, Gunther, Die Marokko-Deutschen 1873-1918, Göttingen 2014.

MaKrides, Vasilios N., Konfessionalisierungsprozesse in der orthodox-christlichen Welt. Ein Periodisierungs- und Systematisierungsversuch, in: Grigore, Mihai D./ KüHrer-Wielach, Florian (Hg.), Orthodoxa Confessio? Konfessionsbildung, Konfessionalisierung und ihre Folgen in der östlichen Christenheit Europas, Göttingen 2018, S. 77-109.

MANGOLD, Sabine, Eine »weltbürgerliche Wissenschaft« - Die deutsche Orientalistik im 19. Jahrhundert, Stuttgart 2004.

Manukyan, Arthur, Konstantinopel und Kairo. Die Herrnhuter Brüdergemeine im Kontakt zum Ökumenischen Patriarchat und zur Koptischen Kirche. Interkonfessionelle und interkulturelle Begegnungen im 18. Jahrhundert, Würzburg 2010, S. 209-356.

MarCoccI, Giuseppe, A consciência de um império. Portugal e o seu mundo (Sécs. XV-XVII), Coimbra 2012.

-, Gli umanisti italiani e l'impero portoghese. Una interpretazione della Fides, Religio, Moresque Æthiopum di Damião de Góis, in: Rinascimento 45 (2005), S. 307-366.

-, Prism of Empire. The Shifting Image of Ethiopia in Renaissance Portugal (1500-1570), in: Berbara, Maria/Enenkel, Karl A.E. (Hg.), Portuguese Humanism and the Republic of Letters, Leiden 2012, S. 447-464.

Marcus, Harold G., The Life and Times of Menelik II. Ethiopia 1844-1913, Lawrenceville NJ 1995.

Markschies, Christoph, Luther und die altkirchliche Trinitätstheologie, in: Ders. / Trowitzsch, Michael (Hg.), Luther - zwischen den Zeiten. Eine Jenaer Ringvorlesung, Tübingen 1999, S. 37-85.

Maron, Gottfried, Ignatius von Loyola. Mystik - Theologie - Kirche, Göttingen 2001.

Marrassini, Paolo, Kəbrä Nägäśt, in: EAE 3, 2007, S. 364-368.

Martikainen, Jouko, Christologische und trinitätstheologische Aporien der östlichen Kirche aus der Sicht Luthers, in: Heubach, Joachim (Hg.), Luther und die trinitarische Tradition. Ökumenische und philosophische Perspektiven, Erlangen 1994, S. 71-94.

Matheus, Michael, »Sola fides sufficit». 'Deutsche` Akademiker und Notare in Rom 1510/1512, in: Ders. u. a. (Hg.), Martin Luther in Rom. Die Ewige Stadt als kosmopolitisches Zentrum und ihre Wahrnehmung, Berlin 2017, S. 379-405.

Mayer, Martin, Geheime Diplomatie und öffentliche Meinung. Die Parlamente in Frankreich, Deutschland und Großbritannien und die erste Marokkokrise 1904-1906, Düsseldorf 2002.

MaYerson, Philip, A Confusion of Indias. Asian and African India in the Byzantine Sources, in: JAOS 113 (1993), S. 167-174.

McLean, Matthew, The Cosmographia of Sebastian Münster. Describing the World in the Reformation, Burlington VT 2007.

Mebratu Kiros Gebru, Liturgical Cosmology. The Theological and Sacramental Dimensions of Creation in the Ethiopian Liturgy, Diss. University of St. Michael's College, Toronto 2012.

Mehedintu, Viorel, Martin Luther und die Ostkirche, in: ÖR 32 (1983), S. 291-309.

Mejer, Wolfgang, Der Buchdrucker Hans Lufft zu Wittenberg, Leipzig ${ }^{2} 1923$.

Merid Wolde Aregay, Literary Origins of Ethiopian Millenarianism, in: Gromyko, Anatoly (Hg.), Proceedings of the Ninth International Congress of Ethiopian Studies. Moscow, 26-29 August 1986, Moscow 1988, Bd. 5, S. 161-172.

-, Millenarian Traditions and Peasant Movements in Ethiopia. 1500-1855, in: Rubenson, Sven (Hg.), Proceedings of the Seventh International Conference of Ethiopian Studies. University of Lund, 26-29 April 1982, Addis Ababa u.a. 1984, S. 257-262. 
Meurer, Peter H., Quad, Matthias, in: NDB 21, Berlin 2003, S. $28 f$.

Meyer, Wilhelm (Hg.), Die Handschriften in Göttingen, Verzeichniss der Handschriften im Preussischen Staate, Berlin 1894, Bd. 3: Universitätsbibliothek. Nachlässe von Gelehrten, Orientalische Handschriften. Handschriften im Besitz von Instituten und Behörden.

Mohammed Hassen, The Oromo of Ethiopia. A History. 1570-1860, Cambridge 1990.

Mundhenk, Christiane, Briefe, in: Frank, Günter (Hg.), Philipp Melanchthon. Der Reformator zwischen Glauben und Wissen. Ein Handbuch, Berlin u. a. 2017, S. 303-319.

Munro-HaY, Stuart, Ark of the Covenant, in: EAE 1, 2003, S. $340 \mathrm{f}$.

-, The Quest for the Ark of the Covenant. The True History of the Tablets of Moses, London u.a. 2006.

Murrmann-Kahl, Michael, Die entzauberte Heilsgeschichte. Der Historismus erobert die Theologie. 1880-1920, Gütersloh 1992.

Muth, Franz-Christoph, Aḥmad b. Ibrāhīm al-Ġāzī, in: EAE 1, 2003, S. 155-158.

NAgel, Alexander-Kenneth, Urbi et Orbi. Transnationale religiöse Netzwerke, in: MALETZKy, Martina u.a. (Hg.), Arbeit, Organisation und Mobilität. Eine grenzüberschreitende Perspektive, Frankfurt a. M. 2013, S. 133-155.

Natsoulas, Theodore/ Nosnitsin, Denis, Iyoªs I, in: EAE 3, 2007, S. $259 \mathrm{f}$.

Niane, Djibril Tamsir, Histoire des Mandingues de l'ouest. Le royaume du Gabou, Paris 1989.

Nicholson, Edward, The Production, History, Uses and Relationships of Cotton (Gossypium spp.) in Ethiopia, in: Economic Botany 14 (1960), S. 3-36.

Nikolaou, Theodor, Die orthodox-lutherischen Beziehungen im 16. Jahrhundert, in: ÖI 14/15 (1980), S. 7-10.

Nipperdey, Thomas, Deutsche Geschichte 1866-1918, München 1992, Bd. 2: Machtstaat vor der Demokratie.

Nöldeke, Theodore, [Rezension:] Kebra Nagast. Die Herrlichkeit der Könige. Nach den Handschriften in Berlin, London, Oxford und Paris zum ersten Mal im äthiopischen Urtext herausgegeben und mit deutscher Übersetzung versehen, in: WZKM 19 (1905), S. 397-411.

-, Die äthiopische Literatur, in: Hinneberg, Paul (Hg.), Die orientalischen Literaturen. Die Kultur der Gegenwart 1,7, Berlin u.a. 1906, S. 124-131.

Nosnitsin, Denis, Liqä Kahənat, in: EAE 3, 2007, S. $578 f$.

-, Nəburä əd, in: EAE 3, 2007, S. 1161f.

-, Ras, in: EAE 4, 2010, S. 330f.

Nottmeier, Christian, „Die Kunst, die Rede auf das zu bringen, was ich wünsche«. Adolf von Harnack und Wilhelm II., in: KapmanN, Jürgen / HüffmeIER, Wilhelm (Hg.), Wilhelm II. Kaiser, König, Kirchenmann. Ein Herrscher, der niemals reif wurde, Bielefeld 2014, S. 79-111.

-, Adolf von Harnack und die deutsche Politik 1890-1930. Eine biographische Studie zum Verhältnis von Protestantismus, Wissenschaft und Politik, Tübingen 2004.

-, Protestantische Theologie und auswärtige Kulturpolitik. Das Beispiel Adolf von Harnack, in: Arnold, Claus/Wischmeyer, Johannes (Hg.), Transnationale Dimensionen wissenschaftlicher Theologie, Göttingen u.a. 2013, S. 71-87.

Nurhussein, Nadia, Black Land. Imperial Ethiopianism and African America, Princeton u.a. 2019.

Nüssel, Friederike/ Grosshans, Hans-Peter (Hg.), Lutherische Theologie in außereuropäischen Kontexten. Eine Zusammenschau aus Anlass des 500. Reformationsjubiläums, Leipzig 2017.

Oberdorfer, Bernd, Filioque. Geschichte und Theologie eines ökumenischen Problems, Göttingen 2001.

Ohainski, Uwe, Harenberg, Johann Christoph, in: Jarck, Horst-Rüdiger/Lent, Dieter (Hg.), Braunschweigisches Biographisches Lexikon - 8. bis 18. Jahrhundert, Braunschweig 2006, S. $300 \mathrm{f}$.

OHst, Martin, Die Preußische Union und ihre politische Bedeutung, in: Arndt, Andreas u.a. (Hg.), Christentum - Staat - Kultur. Akten des Kongresses der Internationalen Schleiermacher-Gesellschaft in Berlin. März 2006, Berlin 2008, S. 165-180.

Oмоцо, Tom Joseph, Luther in Africa, in: Коцв, Robert u.a. (Hg.), The Oxford Handbook of Martin Luther's Theology, Oxford 2014, S. $621 \mathrm{f}$. 
Pankhurst, Richard, Economic History of Ethiopia. 1800-1935, Addis Ababa 1968.

-, Färänğ, in: EAE 2, 2005, S. 492f.

-, Some Notes for a History of Ethiopian Secular Art, in: Ethiopia Observer 10 (1) (1966), S. 5-80.

Parreira do Amaral, Marcelo, Globalisierung im Fokus vergleichender Forschung, in: Freitag, Christine (Hg.), Methoden des Vergleichs. Komparatistische Methodologie und Forschungsmethodik in interdisziplinärer Perspektive, Opladen u. a. 2014, S. 117-139.

Patriarchate of the Ethiopian Orthodox Täwaḩədo Church (Hg.), The Ethiopian Orthodox Täwaḩdo Church: Faith, Order of Worship and Ecumenical Relations, Addis Abeba 1996.

- (Hg.), The Church of Ethiopia. A Panorama of History and Spiritual Life, Addis Abeba 1970.

Patschovsky, Alexander, Semantics of Mohammed and Islam in Joachim of Fiore, in: Yuval, Israel Jacov/ Ben-Shalom, Ram (Hg.), Conflict and Religious Conversation in Latin Christendom. Studies in Honour of Ora Limor, Turnhout 2014, S. 115-131.

Paulau, Stanislau, Auf der Suche nach dem Tabot. Zu einem vergessenen Kapitel in der Geschichte der Wechselbeziehungen zwischen deutscher Wissenschaft, Mission und äthiopischem Christentum, in: Rammelt, Claudia u. a. (Hg.), Begegnungen in Vergangenheit und Gegenwart. Beiträge dialogischer Existenz. Eine freundschaftliche Festgabe zum 60. Geburtstag von Martin Tamcke, Berlin 2015, S. 286-295.

-, Encountering the Ethiopian Orthodox Church in the Pre-Ecumenical Age. Some Remarks on the First Protestant Missionaries in Ethiopia (1829-1843), in: FicQuet, Eloi u. a. (Hg.), Movements in Ethioipa, Ethiopia in Movement. Proceedings of the 18th International Conference of Ethiopian Studies, Los Angeles CA 2016, Bd. 1, S. 175-184.

-, Interconfessional Dialogue and Traditional Litigation in Early $20^{\text {th }}$-Century Eritrea. Introducing an Unpublished Manuscript, in: Zemenfes Tsighe u. a. (Hg.), International Conference on Eritrean Studies 20-22 July 2016. Proceedings, Asmara 2018, Bd. 1, S. 143-155.

PĂVăLUCĂ, Vasilică Mugurel, Einige schriftliche Verweise Martin Luthers auf die Ostkirche, in: Review of Ecumenical Studies Sibiu 9 (3) (2017), S. 360-370.

Pawlikowski, John T., The Judaic Spirit of the Ethiopian Orthodox Church. A Case Study in Religious Acculturation, in: Journal of Religion in Africa 4 (3) (1971-1972), S. 178-199.

Pezold, Dirk von, Cäsaromanie und Byzantinismus bei Wilhelm II., Köln 1971.

Piovanelli, Pierluigi, Connaissance de Dieu et sagesse humaine en Éthiopie. Le traité explication de la divinité attribué aux hérétiques »mikaélites«, in: Muséon 117 (2004), S. 193-227.

-, Les controverses théologiques sous le roi Zar ${ }^{\supset a} Y^{\bar{a}} \supset$ əqob (1434-1468) et la mise en place du monophysisme éthiopien, in: Le Boulluec, Alain (Hg.), La controverse religieuse et ses formes, Paris 1995, S. 189-228.

-, The Apocryphal Legitimation of a "Solomonic« Dynasty in the Kəbrä Nägäśt. A Reappraisal, in: Aethiopica. International Journal of Ethiopian Studies 16 (2013), S. 7-44.

Plajer, Dietmar, Auftrag und Grenzen. Zu den Anfängen lutherisch-orthodoxer Beziehungen im 16. Jahrhundert, in: Review of Ecumenical Studies Sibiu 10 (1) (2018), S. 90-103.

Pollmann, Klaus Erich, Das landeskirchliche Kirchenregiment unter Wilhelm II., in: DoeringManteuffel, Anselm/Nowak, Kurt (Hg.), Religionspolitik in Deutschland. Von der frühen Neuzeit bis zur Gegenwart. Martin Greschat zum 65. Geburtstag, Stuttgart 1999, S. 165-176.

-, Wilhelm II. und der Protestantismus, in: SAMERSKI, Stefan (Hg.), Wilhelm II. und die Religion. Facetten einer Persönlichkeit und ihres Umfeldes, Berlin 2001, S. 91-103.

Pósfay, George, »The Whole Christian Church on Earth « - Luther's Conception of the Universality of the Church, in: BLTS 72 (1992), S. 20-43.

Prouty, Chris, Empress Taytu and Menelik II. Ethiopia 1883-1910, London 1986.

Quinn, Charlotte, Mandingo Kingdoms of the Senegambia. Traditionalism, Islam, and European Expansion, Evanston 1972.

Rauchstein, Maike, Fremde Vergangenheit. Zur Orientalistik des Göttinger Gelehrten Johann David Michaelis (1717-1791), Bielefeld 2017.

Raup, Werner, Christian Gottlob Barth. Studien zu Leben und Werk, Stuttgart 1998.

Rebenich, Stefan, Theodor Mommsen und Adolf Harnack. Wissenschaft und Politik im Berlin des ausgehenden 19. Jahrhunderts. Mit einem Anhang. Edition und Kommentierung des Briefwechsels, Berlin u. a. 1997. 
Reinink, Gerrit Jan, Ps.-Methodius. A Concept of History in Response to the Rise of Islam, in: Cameron, Averil/Lawrence, Conrad I. (Hg.), The Byzantine and Early Islamic Near East, Princeton NJ 1992, Bd. 1: Problems in the Literary Source Material, S. 149-187.

Relaño, Francesc, The Shaping of Africa. Cosmographic Discourse and Cartographic Science in Late Medieval and Early Modern Europe, Aldershot 2002.

Rhodokanakis, Nikolaus, Die äthiopischen Handschriften der K. K. Hofbibliothek zu Wien, SAWW.PH CLI, Wien 1906.

Richter, Hans (Hg.), Carl Ritter - Werk und Wirkungen. Beiträge eines Symposiums im 200. Geburtsjahr des Gelehrten. Quedlinburg, Gotha 1983.

Ricoeur, Paul, La mémoire, l'histoire, l'oubli, Paris 2000.

Riede, Peter, Die Sprache der Bilder. Zur Bedeutung und Funktion der Metaphorik in den Feindpsalmen des Alten Testament am Beispiel der Psalmen 57 und 59, in: Riede, Peter (Hg.), Schöpfung und Lebenswelt. Studien zur Theologie und Anthropologie des Alten Testaments, Leipzig 2009, S. 55-74.

-, Im Netz des Jägers. Studien zur Feindmetaphorik der Individualpsalmen, Neukirchen 2000.

Rogers, Francis, The Quest for Eastern Christians. Travels and Rumor in the Age of Discovery, Minneapolis 1962.

RöHL, John Charles Gerald, Kaiser, Hof und Staat. Wilhelm II. und die deutsche Politik, München ${ }^{2} 2007$.

Rubinkowska, Hanna, 马tege, in: EAE 2, 2005, S. 392.

-, Taytu Bəțul, in: EAE 4, 2010, S. 878f.

RÜTHER, Kirsten, Kannte Luther Afrika? Afrika kennt Luther! Eine Skizze zu Luther im südlichen Afrika, in: Medick, Hans / Scнмidт, Peer (Hg.), Luther zwischen den Kulturen. Zeitgenossenschaft - Weltwirkung, Göttingen 2004, S. 337-372.

Salvadore, Matteo, Gaining the Heart of Prester John. Loyola's Blueprint for Ethiopia in Three Key Documents, in: World History Connected 10 (3) (2013), URL: <https://worldhistory connected.press.uillinois.edu/10.3/forum_salvadore.html>.

-, The African Prester John and the Birth of Ethiopian-European Relations. 1402-1555, London u.a. 2017.

-, The Ethiopian Age of Exploration. Prester John's Discovery of Europe. 1306-1458, in: Journal of World History 21 (4) (2011), S. 593-627.

-, The Jesuit Mission to Ethiopia (1555-1634) and the Death of Prester John, in: Kavey, Allison B. (Hg.), World-Building and the Early Modern Imagination, New York 2010, S. 141-171.

-, Tsega Ze'ab, in: Akyeampong, Emmanuel K./Gates JR., Henry Louis (Hg.), Dictionary of African Biography, Oxford 2012, Bd. 6: Tertu - Zwang, S. $64 \mathrm{f}$.

SANCEAU, Elaine, Portugal in Quest of Prester John, London 1943.

SANDER, Hartmut, Der Deutsche Evangelische Kirchenausschuß (1903), in: Rogge, Joachim/ RuHBACH, Gerhard (Hg.), Die Geschichte der Evangelischen Kirche der Union, Leipzig 1994, Bd. 2: Die Verselbständigung der Kirche unter dem königlichen Summepiskopat (1850-1918), S. 355-372.

Selwyn, Sydney, Sir John Pringle: Hospital Reformer, Moral Philosopher and Pioneer of Antiseptics, in: Medical History 10 (3) (1966), S. 266-274.

SchaCH, Andreas, Carl Ritter (1779-1859). Naturphilosophie und Geographie. Erkenntnistheoretische Überlegungen, Reform der Geographie und mögliche heutige Implikationen, Münster 1996.

SCHÄUfELE, Wolf-Friedrich, Zur Begrifflichkeit von »alt« und »neu« in der Frühen Neuzeit, in: Kampmann, Christoph u.a. (Hg.), Neue Modelle im Alten Europa. Traditionsbruch und Innovation als Herausforderung in der Frühen Neuzeit, Köln u. a. 2012, S. 18-36.

Schicк, Friedrich, Samuel Gobat. Der Bischof von Jerusalem, Gießen 1958.

SchneIder, Julius, Die Geschichte des Berliner Doms. Von der Domstiftung im 15. Jahrhundert bis zum Wiederaufbau im 20. Jahrhundert, Berlin 1993.

SchneIder, Pierre, L'Éthiopie et l'Inde. Interférences et confusions aux extrémités du monde antique, Roma 2004. 
SCHNEIDER, Wolfgang Ludwig, Gedächtnis, Interpretation und Organisation im Kontext religiöser Kommunikation, in: Bohn, Cornelia/ Willems, Herbert (Hg.), Sinngeneratoren. Fremd- und Selbstthematisierung in soziologisch-historischer Perspektive, Konstanz 2001, S. 263-289.

Schniewind, Carl, Der Dom zu Berlin. Geschichtliche Nachrichten vom alten Dom bei der Einweihung des neuen Doms, Berlin 1905.

SCHNURR, Jan Carsten, Weltreiche und Wahrheitszeugen. Geschichtsbilder der protestantischen Erweckungsbewegung in Deutschland 1815-1848, Göttingen 2011.

Scholler, Heinrich, Mythos und Wirklichkeit Christlicher Imperien am Ende des Zweiten Jahrtausends. Äthiopien und die Deutsche Reichsidee, in: Böll, Verena u.a. (Hg.), Studia Aethiopica. In Honour of Siegbert Uhlig on the Occasion of his 65th Birthday, Wiesbaden 2004, S. 233-245.

Schreiber, Heinrich, Die Reformation Lübecks, Halle (Saale) 1902.

Schröder, Iris, Das Wissen von der ganzen Welt. Globale Geographien und räumliche Ordnungen Afrikas und Europas 1790-1870, Paderborn u. a. 2011.

Schröder, Jochen, Die Baugestalt und das Raumprogramm des Berliner Doms als Spiegel der Ansprüche und Funktionen des Bauherrn Kaiser Wilhelms II., Diss. Philipps-Universität Marburg 2002.

Schröttel, Gerhard, Johann Michael Dilherr und die vorpietistische Kirchenreform in Nürnberg, Nürnberg 1962.

Schultz, Martin, Abu Makina - der Vater der Maschine. Carl Bosch und die fotografische Dokumentation seiner diplomatischen Reisen 1903-1907, in: Mannheimer Geschichtsblätter 25 (2013), S. 103-116.

Schulze, Thies, Einleitung, in: Ders. / MüLler, Christian (Hg.), Grenzüberschreitende Religion. Vergleichs- und Kulturtransferstudien zur neuzeitlichen Geschichte, Göttingen 2013, S. 9-25.

Schümann, Carl-Wolfgang, Der Berliner Dom im 19. Jahrhundert, Berlin 1980.

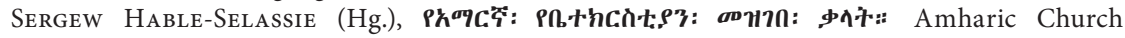
Dictionary, Heidelberg u. a. 1981 A. M. [1989 A. D.], Bd. 1.

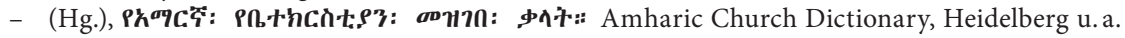
1982 A. M. [1990 A.D.], Bd. 5.

Shiferaw Bekele, Pețros, in: EAE 4, 2010, S. $139 \mathrm{f}$.

Shirley, Rodney, The Mapping of the World. Early Printed World Maps. 1472-1700, Riverside CT 2001.

Simon, Matthias, Johann Manlius, der erste Herausgeber von Melanchthonsbriefen, in: ZBKG 24 (1955), S. 141-149.

Slenczka, Reinhard, Melanchthon und die orthodoxe Kirche des Ostens, in: Haustein, Jörg (Hg.), Philipp Melanchthon. Ein Wegbereiter für die Ökumene, Göttingen 1997, S. 98-119.

Smed, Rudolf, Johann David Michaelis und Johann Gottfried Eichhorn - zwei Orientalisten am Rande der Theologie, in: Moeller, Bernd (Hg.), Theologie in Göttingen. Eine Vorlesungsreihe, Göttingen 1987, S. 58-82.

Smidt, Wolbert G.C., Abba Gorgoryos - ein integrer und ernsthafter Mann. Der Besuch eines äthiopischen Gelehrten in Thüringen 1652, in: Volker-SAAD, Kerstin/Greve, Anna (Hg.), Äthiopien und Deutschland. Sehnsucht nach der Ferne, München u. a. 2006, S. 48-57.

-, Gorgoryos and Ludolf. The Ethiopian and German Fore-Fathers of Ethiopian Studies. An Ethiopian Scholar's 1652 Visit to Thuringia, in: Ders. / Thubauville, Sophia (Hg.), Cultural Research in Northeastern Africa. German Histories and Stories, Ityopis, Extra Issue 1, Frankfurt a. M. 2015, S. 11-25.

-, "Schwarze Missionare» im Deutschland des 19. Jahrhunderts, in: Bechnaus-Gerst, Marianne/Klein-Arendt, Reinhard (Hg.), AfrikanerInnen in Deutschland und schwarze Deutsche - Geschichte und Gegenwart, Münster 2004, S. 41-56.

-, "Schwarze Missionare« in Äthiopien im Dienst der Errichtung einer Welt-Christokratie, in: Heyden, Ulrich von der/Stoecker, Holger (Hg.), Mission und Macht im Wandel politischer Orientierungen. Europäische Missionsgesellschaften in politischen Spannungsfeldern in Afrika und Asien zwischen 1800 und 1945, Stuttgart 2005, S. 485-505.

-, Five Centuries of Ethio-German Relations, in: Language Department of the German Foreign Office (Hg.), Ethio-German Relations, Addis Abeba 2004, S. 6-14. 
-, Mayer, Johannes, in: EAE 3, 2007, S. 890f.

-, Photos as Historical Witnesses. The First Ethiopians in Germany and the First Germans in Ethiopia. The History of a Complex Relationship, Münster 2015.

Šoltés, Peter, Migration und konfessionelle Pluralität an der nordöstlichen Peripherie des Königreichs Ungarn im 17. und 18. Jahrhundert, in: MARINELli-KönIG, Gertraud/ Preisinger, Alexander (Hg.), Zwischenräume der Migration. Über die Entgrenzung von Kulturen und Identitäten, Bielefeld 2011, S. 157-175.

Staude, Wilhelm, Iconographie de la légende éthiopienne de la reine d'Azieb ou de Saba, in: JSAf 27 (1) (1957), S. 137-181.

Stederoth, Dirk, Hegels Philosophie des subjektiven Geistes. Ein komparatorischer Kommentar, Berlin 2001.

STоск, Eugene, The History of the Church Missionary Society. Its Environment, Its Men and Its Work, London 1899, 3 Bd.

Stoffregen-Pedersen, Kirsten, Dayr as-Sulțān, in: EAE 2, 2005, S. 117-119.

-, Deir es-Sultan. The Ethiopian Monastery in Jerusalem, in: Quaderni di studi Etiopici 8-9 (1987-1988), S. 33-47.

-, Is the Church of Ethiopia a Judaic Church?, in: Warszawskie Studia Teologiczne 12 (2) (1999), S. 203-216.

-, Mäšäša Wärqe, in: EAE 3, 2007, S. 831f.

-, The History of the Ethiopian Community in the Holy Land from the Time of Emperor Tewodros II till 1974, Jerusalem 1983.

Strebel, Barbara, »... den blinden Abessyniern die Augen aufzuthun«. Chrischona-Pilgermissionare in Äthiopien (1856-1868). Geschichte eines gescheiterten Missionsprojektes, Lizentiatsarbeit Universität Zürich 1999.

-, Gobat, Samuel, in: EAE 2, 2005, S. 818f.

-, Leben auf dem Missionsfeld. Chrischona-Pilgermissionare in Äthiopien (1856-1868), in: Aethiopica. International Journal of Ethiopian Studies 4 (2001), S. 121-157.

Strelcyn, Stefan, Le Psaume 151 dans la tradition Éthiopienne, in: JSSt 23 (2) (1978), S. 316-329.

STRUCK, Bernhard u.a., Introduction. Space and Scale in Transnational History, in: IHR 33 (4) (2011), S. 573-584.

Suermann, Harald, Die geschichtstheologische Reaktion auf die einfallenden Muslime in der edessenischen Apokalyptik des 7. Jahrhunderts, Frankfurt a. M. 1985.

Surdich, Francesco, La relazione sull'Etiopia di Giacomo Baratti, in: BozzI, Fratelli (Hg.), Miscellanea di storia delle esplorazioni II, Studi di storia delle esplorazioni 5, Genova 1977, S. 119-186.

Süssmann, Johannes, [Rezension:] Luigi Marino, Praeceptores Germaniae. Göttingen 1770-1820, in: ASozG 37 (1997), S. $691 \mathrm{f}$.

Suttner, Ernst Christoph, Die Krankensalbung (das »Öl des Gebets«) in den altorientalischen Kirchen, in: EL 89 (1975), S. 371-396.

TAFEL, Johann Friedrich Immanuel, Swedenborg's Lehre mit Rücksicht auf die Einwürfe gegen sie und auf die christliche Dogmatik in ihrer geschichtlichen Entwicklung, Stuttgart 1844.

Tedeschi, Salvatore, Giacomo Baratti e il suo presunto viaggio in Abissinia, in: Africa 47 (1) (1992), S. 1-28.

-, Profilo storico di Dayr as-Sultan, in: JetS 2 (2) (1964), S. 92-160.

Tedros Abraha, Exegesis, in: EAE 2, 2005, S. 472-474.

-, Täwaḥədo, in: EAE 4, 2010, S. 873-875.

-, Trinity, in: EAE 4, 2010, S. 990-994.

Tesfazghi UQBit, Current Christological Positions of Ethiopian Orthodox Theologians, Roma 1973.

Thomaz, Luís Filipe, L’idée impériale manueline, in: Aubin, Jean (Hg.), La découverte, le Portugal et l'Europe. Actes du colloque célébrée à Paris le 26, 27 et 28 mai 1988, Paris 1990, S. 35-103.

-, Portugal, Relations with, in: EAE 4, 2010, S. $180 \mathrm{f}$.

Tigab Bezie, Ethiopia's Claim on Deir es-Sultan Monastery in Jerusalem. 1850s-1994. Roots, Litigation, Current Status, Saarbrücken 2011. 
Traut, Lucia/Wilke, Annette, Einleitung, in: Dies. (Hg.), Religion - Imagination - Ästhetik. Vorstellungs- und Sinneswelten in Religion und Kultur, Göttingen 2015, S. 17-69.

Trimingham, John Spencer, Islam in Ethiopia, London u. a. 2008.

Тuвасн, Jürgen, Ludolf, Hiob, in: BBKL, Herzberg 1993, Bd. 5, Sp. 317-325.

Тураев, Борис, Абиссинский монастырь в Иерусалиме и его библиотека, in: Сообщения Православного Палестинского Общества XIV (II) (1903), S. 115-132.

UhLIG, Siegbert, Ludolf, Hiob, in: EAE 3, 2007, S. 601-603.

Ullendorff, Edward, Catalogue of Ethiopian Manuscripts in the Bodleian Library, Oxford 1951, Bd. II.

-, Ethiopia and the Bible. The Schweich Lectures of the British Academy 1967, London 1968.

-, Hebraic-Jewish Elements in Abyssinian (Monophysite) Christianity, in: Journal of Semitic Studies 1 (3) (1956), S. 216-256.

-, The Two Zions. Reminiscences of Jerusalem and Ethiopia, Oxford 1988.

Voigt, Rainer, Cartography until the 18th Century, in: EAE 1, 2003, S. 686-688.

Volz, Hans, Martin Luthers deutsche Bibel. Entstehung und Geschichte der Lutherbibel, Hamburg 1978.

vom BRUCH, Rüdiger, Weltpolitik als Kulturmission. Auswärtige Kulturpolitik und Bildungsbürgertum in Deutschland am Vorabend des Ersten Weltkrieges, Paderborn u. a. 1982.

WAGNER, Norbert Berthold, Die deutschen Schutzgebiete. Erwerb, Organisation und Verlust aus juristischer Sicht, Baden-Baden 2002.

WAGNER, Oskar, Luther - Osteuropa und die griechisch-orthodoxe Kirche, in: Kyrios 4 (1964), S. 69-90.

Wehler, Hans-Ulrich, Deutsche Gesellschaftsgeschichte, München 2008, Bd. 3: Von der »Deutschen Doppelrevolution« bis zum Beginn des Ersten Weltkrieges. 1849-1914.

Weiler, Tanja, Heinrich VIII. und die englische Reformation. Der lange Weg zum Bruch mit Rom, Hamburg 2014.

Weismann, Christoph, Auf Kanzeln, Kathedern und in Kutschen. Jakob Andreae als Universitäts- und Kirchenpolitiker, in: KöpF, Ulrich u.a. (Hg.), Die Universität Tübingen zwischen Reformation und Dreißigjährigem Krieg, Ostfildern 2010, S. 119-140.

Wellenreuther, Hermann, Mission, Obrigkeit und Netzwerke. Staatliches Interesse und Missionarisches Wollen vom 15. bis ins 19. Jahrhundert, in: PuN 33 (2007), S. 193-213.

Weller, Tobias, Auf dem Weg zum »staufischen Haus«. Zu Abstammung, Verwandtschaft und Konnubium der frühen Staufer, in: Seibert, Hubertus / Dendor fER, Jürgen (Hg.), Grafen, Herzöge, Könige. Der Aufstieg der Staufer und das Reich (1079-1152), Ostfildern 2005, S. 41-63.

Wellnitz, Britta, Deutsche evangelische Gemeinden im Ausland. Ihre Entstehungsgeschichte und die Entwicklung ihrer Rechtsbeziehungen zur Evangelischen Kirche in Deutschland, Tübingen 2003.

Wendebourg, Dorothea, Reformation und Orthodoxie. Der ökumenische Briefwechsel zwischen der Leitung der Württembergischen Kirche und Patriarch Jeremias II. von Konstantinopel in den Jahren 1573-1581, Göttingen 1986.

WendT, Kurt, Die theologischen Auseinandersetzungen in der äthiopischen Kirche zur Zeit der Reformen des XV. Jahrhunderts, in: Accademia nazionale dei Lincei (Hg.), Atti del Convegno Internazionale di Studi Etiopici (Roma 2-4 aprile 1959). Problemi Attuali di Scienza e di Cultura 48, Roma 1960, S. 137-146.

Wenig, Steffen, Meroe. Zentrum und Peripherie, in: Donadoni, Sergio (Hg.), L'impero ramesside. Convegno internazionale in onore di Serio Donadoni, Roma 1997, S. 221-231.

Weninger, Stefan, Waddase Maryam, in: EAE 4, 2010, S. 1173f.

Wenz, Gunther, Der Kulturprotestant. Adolf von Harnack als Christentumstheoretiker und Kontroverstheologe, München 2001.

-, Offenbarung. Problemhorizonte moderner evangelischer Theologie, Göttingen 2005.

Werner, Michael, Beyond Comparison. Histoire Croisée and the Challenge of Reflexivity, in: HTh 45 (2006), S. 30-50.

-, Kulturtransfer und Histoire croisée. Zu einigen Methodenfragen der Untersuchung soziokultureller Interaktionen, in: Braese, Stephan/Vogel-Klein, Ruth (Hg.), Zwischen Kahlschlag 
und Rive Gauche. Deutsch-französische Kulturbeziehungen 1945-1960, Würzburg 2015, S. 21-42.

- / Zimmermann, Bénédicte, Vergleich, Transfer, Verflechtung. Der Ansatz der Histoire croisée und die Herausforderung des Transnationalen, in: GeGe 28 (2002), S. 607-636.

Wessel, Günther, Von einem, der daheim blieb, die Welt zu entdecken. Die Cosmographia des Sebastian Münster oder Wie man sich vor 500 Jahren die Welt vorstellte, Frankfurt a. M. 2004.

Widmann, Hans, Crucius, Martin, in: NDB 3, Berlin 1957, S. 433 f.

Wiesner, Johannes, Andreae, Jakob, in: JARCK, Horst-Rüdiger/LENT, Dieter (Hg.), Braunschweigisches Biographisches Lexikon - 8. bis 18. Jahrhundert, Braunschweig 2006, S. $43 \mathrm{f}$.

Wietfeldt, Willard James, The Emblem Literature of Johann Michael Dilherr (1604-1669). An Important Preacher, Educator and Poet in Nürnberg, Nürnberg 1975.

Wilderotter, Hans, »Als Instrument des Herrn mich betrachtend «. Zum historischen und politischen Selbstverständnis, in: Ders. / PoHL, Klaus Dieter (Hg.), Der letzte Kaiser. Wilhelm II. im Exil, Gütersloh 1991, S. 307-309.

Wilkinson, James John Garth, The African and the True Christian Religion. His Magna Charta. A Study in the Writings of Emanuel Swedenborg, London 1892.

Wimmer, Andreas/Nina Glick Schiller, Methodological Nationalism, the Social Sciences, and the Study of Migration. An Essay in Historical Epistemology, in: Internaional Migration Review 37 (2003), S. 576-610.

Winkler, Hubert, Felix Rosen, in: Berichte der Deutschen Botanischen Gesellschaft 43 (1925), S. $65-73$.

Wion, Anaïs, Onction des malades, funérailles et commémorations. Pour une histoire des textes et des pratiques liturgiques en Éthiopie chrétienne, in: Afriques 3 (2011), URL: <http://journals. openedition.org/afriques/921> (12.09.2019).

Witakowski, Witold, Cyril of Alexandria, in: EAE 1, 2003, S. $844 f$.

-, John Chrysostom, in: EAE 3, 2007, S. 293-295.

Witt, Christian Volkmar, Protestanten. Das Werden eines Integrationsbegriffs in der Frühen Neuzeit, Tübingen 2011.

Wolf, Gerhard Philipp, Martin Crusius (1526-1607). Philhellene und Universitätsprofessor, in: FrLB 22, VGFG, Reihe VII A, Würzburg 2009, S. 103-119.

WRIEDT, Markus, Einheit in der Vielfalt. Die weltweite Inanspruchnahme des Christlichen als Gegenstand der theologisch verantworteten Geschichtsschreibung, in: ETSt 6 (2) (2015), S. 197-213.

Yesenaq, The Ethiopian Tewahedo Church. An Integrally African Church, Nashville 1997.

ZACH, Michael, Meroë, in: EAE 3, 2007, S. 937f.

Zanetti, Ugo, Church and Popular Veneration of St. Mary, in: EAE 3, 2007, S. 811-814.

-, Les lectionnaires coptes annuels. Basse-Égypte, Louvain-la-Neuve 1985.

-, Unction, in: EAE 4, 2010, S. 1020f.

Zimen, Dag, Rosen für den Negus. Die Aufnahme diplomatischer Beziehungen zwischen Deutschland und Äthiopien 1905, Göttingen 2005.

Zimmerer, Jürgen / Zeller, Joachim (Hg.), Völkermord in Deutsch-Südwestafrika. Der Kolonialkrieg (1904-1908) in Namibia und seine Folgen, Berlin 2016.

Zitelmann, Thomas, Des Teufels Lustgarten. Themen und Tabus der politischen Anthropologie Nordostafrikas, Habil., Freie Universität Berlin 1999.

Zürn, Michael, Politik in der postnationalen Konstellation. Über das Elend des methodologischen Nationalismus, in: LANDFRIED, Christine (Hg.), Politik in einer entgrenzten Welt, Köln 2001, S. 181-203. 



\section{Abbildungsnachweis}

1: Martin Luthers Empfehlungsschreiben für Abba Mikael. Herzog August Bibliothek Wolfenbüttel: Cod. Guelf. 107 Helmst., fol. 10v (C) Herzog August Bibliothek Wolfenbüttel

2: Manuskript aus dem äthiopisch-orthodoxen Kloster in Rom mit der Angabe, dass es Mika ${ }^{0}$ el gehört. Biblioteca Apostolica Vaticana: Manuskript Vat. et. 47, fol. 215r @ Biblioteca Apostolica Vaticana

3: Eigenhändige Unterschrift von Șägga Zä’ab im Fides, Religio, Moresque Aethiopum. Bayerische Staatsbibliothek München, H.afr. 3148, S. 94, urn:nbn:de:bvb:12-bsb10311109-2 @ Bayerische Staatsbibliothek München (NoC-NC 1.0)

4: Abschrift von Martin Luthers Empfehlungsschreiben für Abba Mika ${ }^{2}$ l. Ms. Universitätsbibliothek Basel, O III 4, fol. 124v

(C) Universitätsbibliothek Basel

5: Abschrift von Martin Luther Empfehlungsschreiben für Abba Mika ${ }^{0}$ l.

Ms. Universitätsbibliothek Basel, O III 4, fol. 125r

(C) Universitätsbibliothek Basel

6: Fragment der kolorierten Holzschnitt-Landkarte »Africa / Lybia / Morenland mit allen Künigreichen / so zu unsern zeiten darin gefunden werden« aus der Cosmographey oder beschreibung aller Länder des Sebastian Münster (Ausgabe des Jahres 1574); zuerst erschienen 1540 in der Geographia Universalis. () »Götzfried Antique Maps« (www.vintage-maps.com)

7: Fragment der kolorierten Holzschnitt-Landkarte »Africa Tertia pars Terrae» aus Heinrich Büntings Itinerarium Sacrae Scripturae (1581).

(C) „Götzfried Antique Maps« (www.vintage-maps.com)

8: Fragment der kolorierten Landkarte »Africae Tabula Nova« von Abraham Ortelius aus der französischen Ausgabe seines Theatrum Orbis Terrarum (1598); zuerst erschienen 1570. (C) »Götzfried Antique Maps« (www.vintage-maps.com)

9: Kolorierte Landkarte »Abyssinorum Sive Magni Regis Davidis, Quem Vulgo Presbyterum Joannem Vocant, Imperium« von Matthias Quad aus seinem Geographisch Handtbuch (1600). (C) „Götzfried Antique Maps« (www.vintage-maps.com)

10: James Bruce (»An Abyssinian Breakfast«). Handkolorierte Radierung von Isaac Cruikshank, 1791. 28,1 x 36,2 cm. (C) National Portrait Gallery, London

11: „Blick über die Schloßbrücke auf den Lustgarten mit Altem Museum und Dom Berlin, 1905« (Ausschnitt). Max Missmann, FotoTechniken, Bildmaße: 21,9 x 28,0 cm. Inv.-Nr.: IV 84/194 V. (c) Stiftung Stadtmuseum Berlin. Reproduktion: Christel Lehmann, Berlin 
12: »Der Negus (rechts) zu Besuch bei der deutschen Gesandtschaft (links: Ras Wolda Giorgis, Vizekönig von Kaffa)«, 27. Februar 1905. @ Felix Rosen, Eine deutsche Gesandtschaft in Abessinien, Leipzig 1907, S. 275 (CC BY 4.0) ....

13: "Festgottesdienst zu Ehren der Deutschen Gesandtschaft vor der Kathedrale in Aksum«. () Felix Rosen, Eine deutsche Gesandtschaft in Abessinien, Leipzig 1907, S. 469 (CC BY 4.0)

14: »Assistierende Priester bei dem Festgottesdienst in Aksum mit den Weihgeschenken der letzten Kaiser«. ( F Felix Rosen, Eine deutsche Gesandtschaft in Abessinien, Leipzig 1907, S. 472 (CC BY 4.0)

15: Autograph des Briefs von Philipp Melanchthon an Benedikt Pauli, 31. Mai 1534. Jagiellonen-Bibliothek, Krakau, Autographen Sammlung aus der ehem. Preußischen Staatsbibliothek zu Berlin, Slg. Radowitz Nr. 89r ( ) JagiellonenBibliothek, Krakau ....

16: Autograph des Briefs von Philipp Melanchthon an Benedikt Pauli, 31. Mai 1534. Jagiellonen-Bibliothek, Krakau, Autographen Sammlung aus der ehem. Preußischen Staatsbibliothek zu Berlin, Slg. Radowitz Nr. 89v @ JagiellonenBibliothek, Krakau 


\section{Abkürzungsverzeichnis}

Die Abkürzungen richten sich, soweit nicht anders angegeben, nach Siegfried M. Schwertner, IATG ${ }^{3}$. Internationales Abkürzungsverzeichnis für Theologie und Grenzgebiete: Zeitschriften, Serien, Lexika, Quellenwerke mit bibliographischen Angaben, Berlin / Boston ${ }^{3} 2014$. Ansonsten bedeuten:

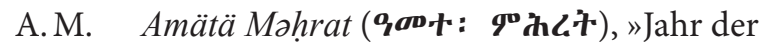
Barmherzigkeit« (bei Jahresangaben nach äthiopischer Zeitrechnung)

EAE 1 Siegbert Uhlig (Hg.), Encyclopaedia Aethiopica,'Wiesbaden 2003, Bd. 1: A-C

EAE 2 Siegbert Uhlig (Hg.), Encyclopaedia Aethiopica, Wiesbaden 2005, Bd. 2: D-Ha

EAE 3 Siegbert Uhlig (Hg.), Encyclopaedia Aethiopica, Wiesbaden 2007, Bd. 3: He-N

EAE 4 Siegbert Uhlig (Hg.), Encyclopaedia Aethiopica, Wiesbaden 2010, Bd. 4: O-X

EAE 5 Alessandro BAUsI (Hg.), Encyclopaedia Aethiopica, Wiesbaden 2014, Bd. 5: Y-Z, Supplementa, Addenda et Corrigenda, Maps, Index

EMML Ethiopian Manuscript Microfilm Library

EZA Evangelisches Zentralarchiv

PA AA Politisches Archiv des Auswärtigen Amts 



\title{
Anhänge
}

\author{
Anhang 1 \\ Philipp Melanchthons Brief an Benedikt Pauli über \\ die Ankunft von Abba Mika ${ }^{\top}$ l, 31. Mai 1534
}

Lateinischer Originaltext ${ }^{1}$

Eximio viro d[omino] Benedicto Paulo, doctori utriusque iuris, suo patrono observando.

S. D. Miror vobis hoc tempore, quo tantum est alioqui publicorum periculorum ac negociorum, etiam hunc erronem Arabem curae esse. Venit huc sine commendatione aliqua. Locutus est pauca cum Luthero per interpretem, qui scit Italice, qui est scholasticus noster. Is ait eum valde corrupte Italicum loqui, idque mihi etiam videtur. Latine parum admodum scit. Tantum de trinitate dixit Luthero sententiam orientalis ecclesiae convenientem cum occidentali ecclesia. Nec possumus satis colloqui, cum nullam occidentalem linguam recte calleat, nec Latinam, nec Italicam, nec Graecam. Interrogavi, an sciret Graece scribere. Negat se nosse characteres Graecos, sed vulgare Graecum scire - credo, sicut Italicum scit. Et tamen si scribere posset, utcunque intelligeremus. Hospes est Valtin Ebrart, et habet viaticum. Cras audio iterum abiturum esse. Videtur mihi homo ingeniosus esse, sed cum colloqui non possimus perfecte, de magnis rebus non possum satis iudicare, quid habeat vel iudicii vel doctrinae. Invitavi ad me hoc vespere ad cenam una cum interprete. Vidi multos similes Arabes, sed omnes indoctos et nullam linguam eruditam scientes. Reipub[licae] nihil ab eo periculi esse puto. Bene valete. Dominica Trinitatis 1534.

Philippus. 


\section{Deutsche Übersetzung ${ }^{2}$}

Dem vortrefflichen Mann, Herrn Benedikt Pauli, Doktor beider Rechte, seinem ehrwürdigen Schutzherrn.

Seid gegrüßt. Ich bin erstaunt, dass ihr euch in dieser Zeit, in der es sonst so viele öffentliche Gefahren und Aufgaben gibt, auch um diesen umherwandernden Orientalen ${ }^{3}$ Gedanken macht. Er ist hierher ohne jegliche Empfehlung gekommen. Er sprach ein wenig mit Luther mithilfe eines Dolmetschers, eines unserer Gelehrten, der Italienisch kann. Dieser [der Gelehrte] sagte, er [der Gast] spreche ein sehr gebrochenes Italienisch, und so scheint es mir auch. Des Lateinischen ist er nicht im ausreichenden Maße mächtig. Nur bezüglich der Trinität sagte er Luther, dass die Meinung der morgenländischen Kirche mit der der abendländischen Kirche übereinstimme. Wir konnten uns nicht ausreichend austauschen, denn er konnte keine abendländische Sprache fließend sprechen, weder Latein noch Italienisch noch Griechisch. Ich fragte, ob er Griechisch schreiben könne. Er verneinte, dass er griechische Buchstaben kenne, allerdings konnte er einfaches Griechisch ich glaube, so wie er Italienisch kann. Und nichtsdestoweniger konnte er so schreiben, dass wir es verstanden. Sein Gastgeber ist Valentin Eberhart, und er hat Reisegeld. Ich hörte, morgen wird er wieder fortgehen. Er scheint mir ein scharfsinniger Mensch zu sein, aber da wir uns mit ihm nicht vollständig verständigen konnten, kann ich in den großen Fragen nicht hinreichend beurteilen, was für eine Meinung oder Lehre er hat. Ich habe ihn heute Abend zusammen mit einem Dolmetscher zu mir zum Abendessen eingeladen. Ich habe schon viele ähnliche Orientalen gesehen, aber sie alle waren ungelehrt und verstanden keine gelehrte Sprache. Ich glaube, von ihm geht keine Gefahr für das Gemeinwesen aus. Lebt wohl. Am Trinitatissontag [= 31. Mai] 1534 .

Philipp. siehe S. 45. 


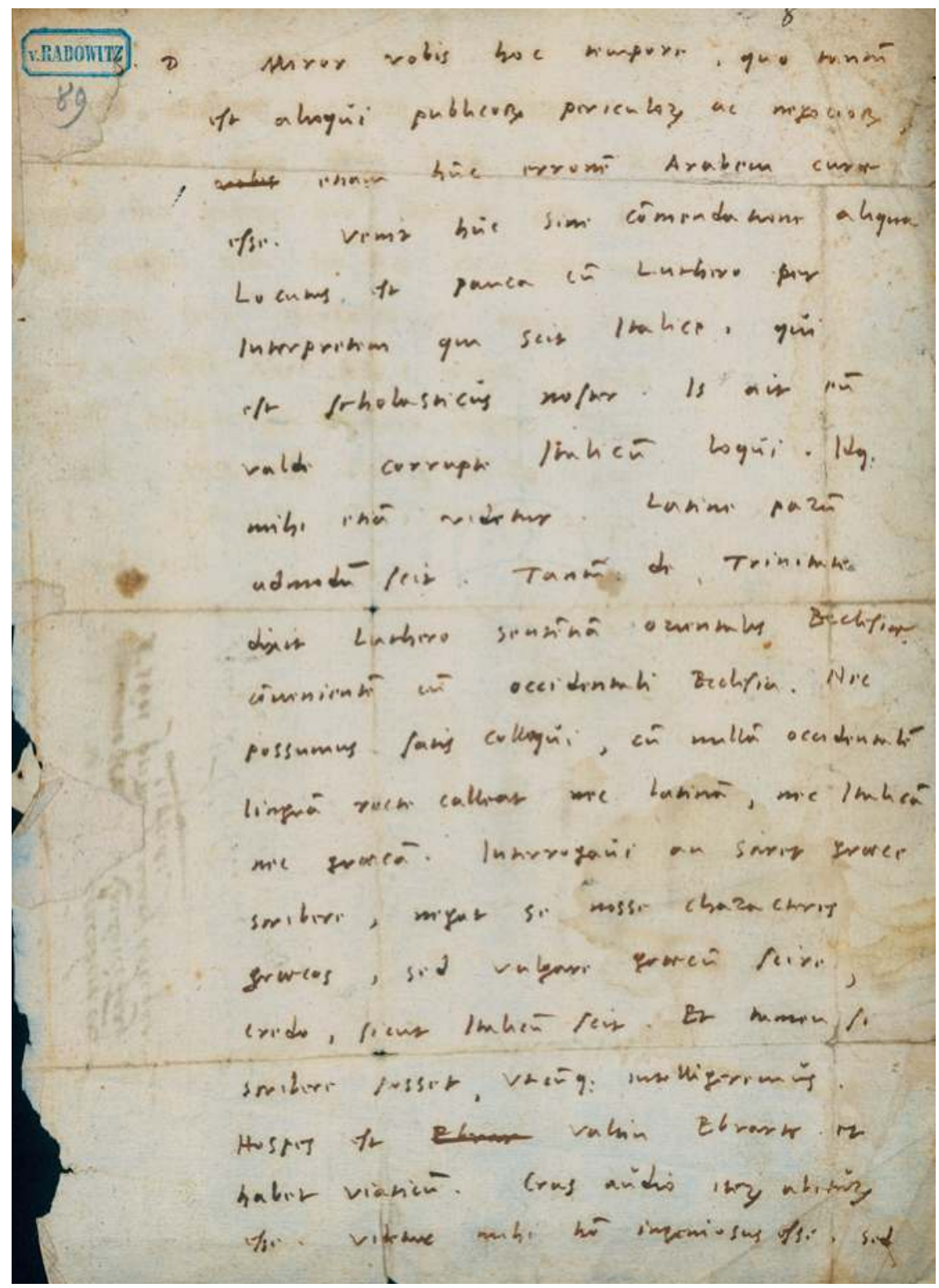

Abb. 15: Autograph des Briefs von Philipp Melanchthon an Benedikt Pauli, 31. Mai 1534. Jagiellonen-Bibliothek, Krakau, Autographen Sammlung aus der ehem. Preußischen Staatsbibliothek zu Berlin, Slg. Radowitz Nr. 89r 


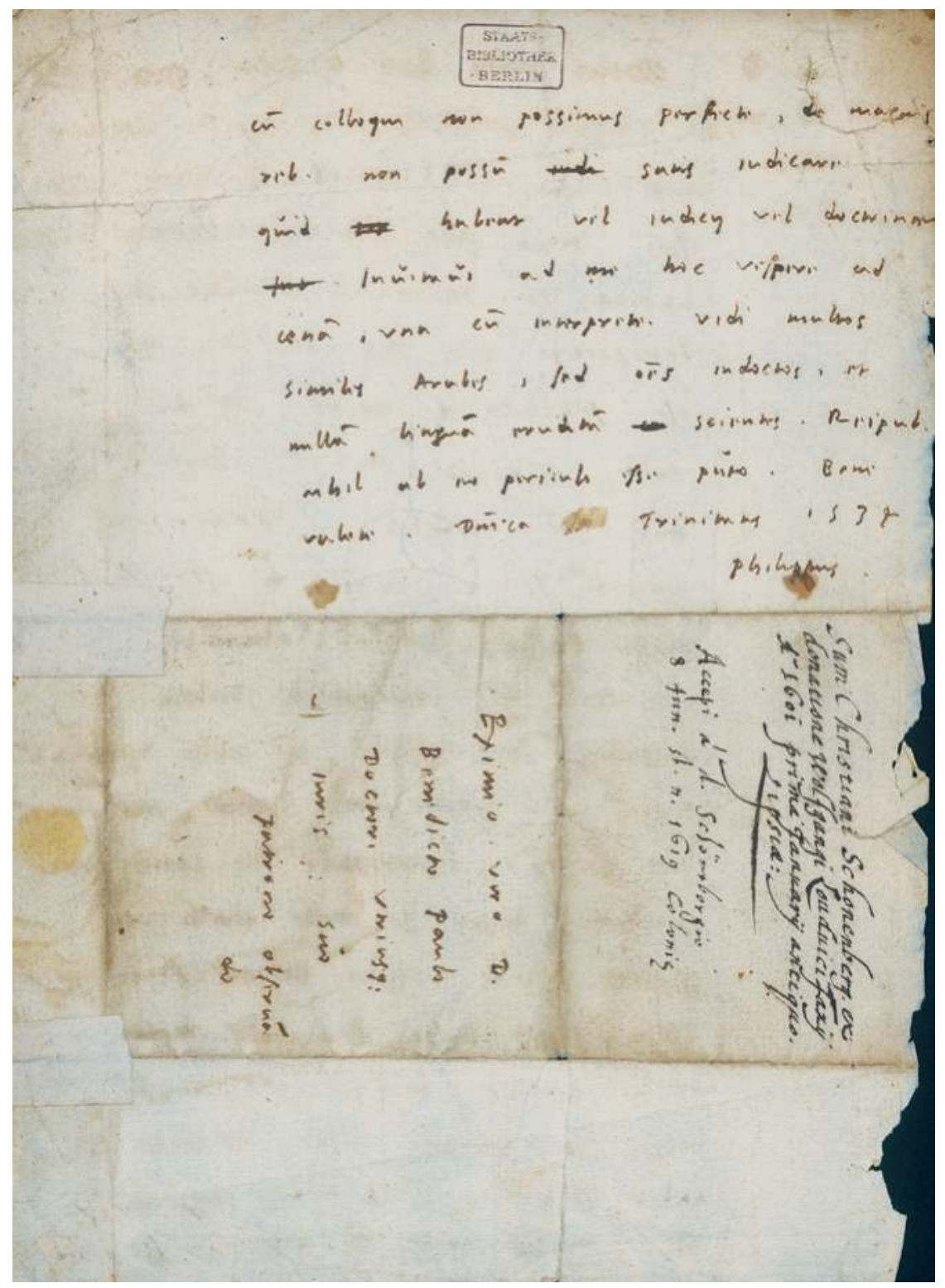

Abb. 16: Autograph des Briefs von Philipp Melanchthon an Benedikt Pauli, 31. Mai 1534. Jagiellonen-Bibliothek, Krakau, Autographen Sammlung aus der ehem. Preußischen Staatsbibliothek zu Berlin, Slg. Radowitz Nr. 89v 
Die »Confessio Claudii« nach dem Manuskript BL Harl. $7629^{4}$

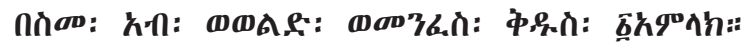

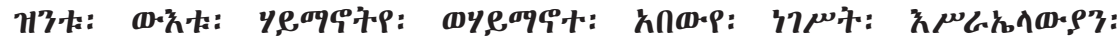

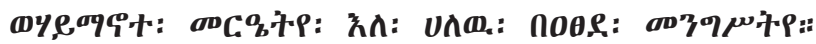

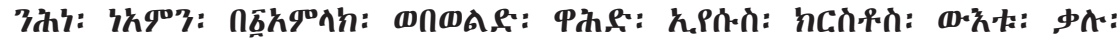

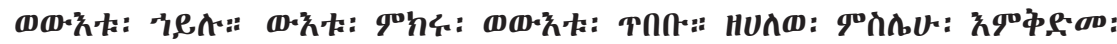

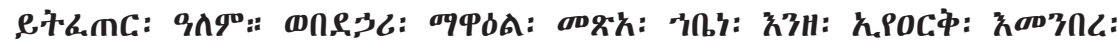

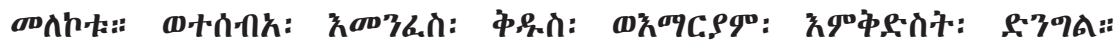

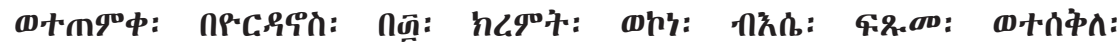

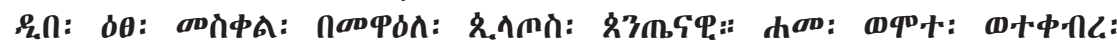

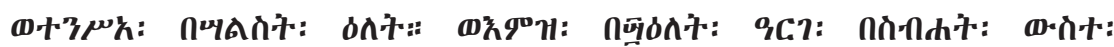

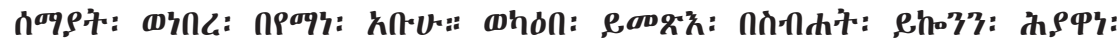

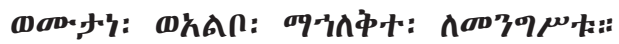

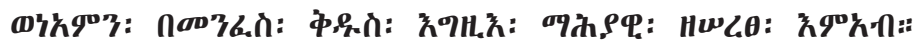

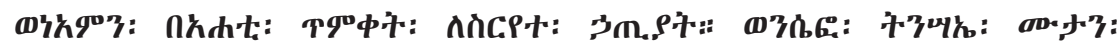
ก出,

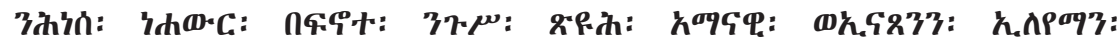

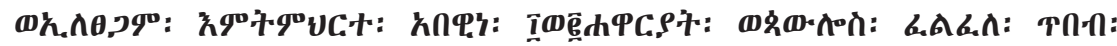

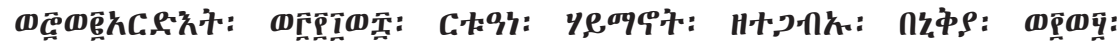

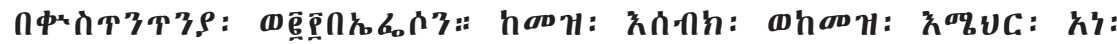

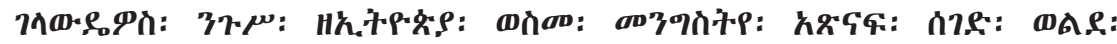

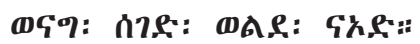

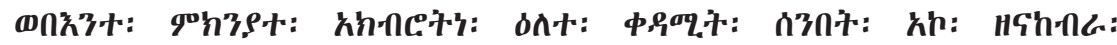

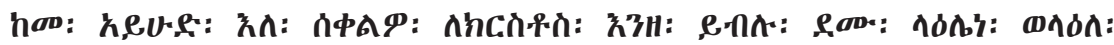

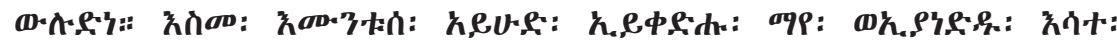

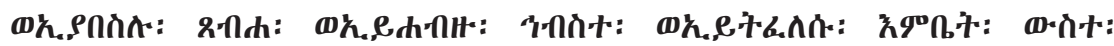
ก.7::

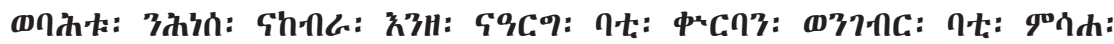

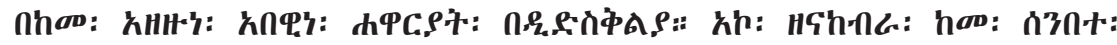

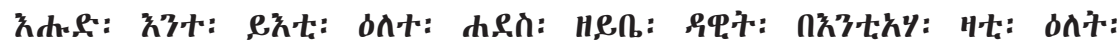

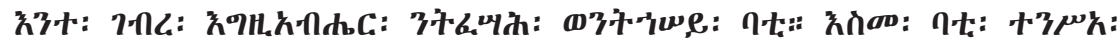

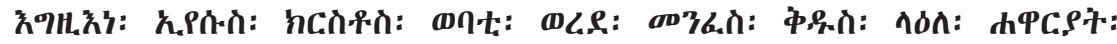

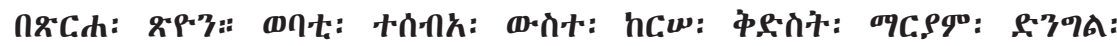

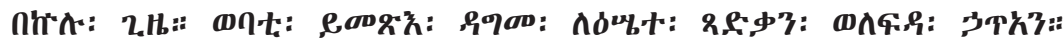

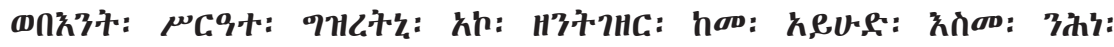

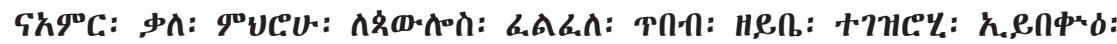

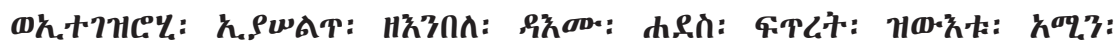




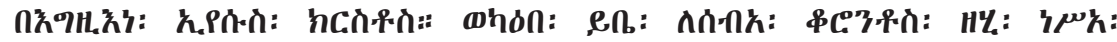
ๆาll: h.

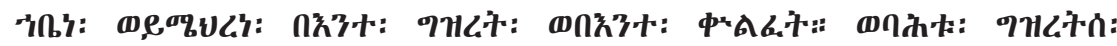

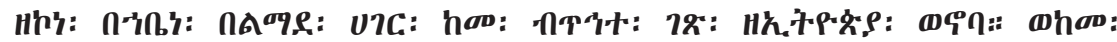

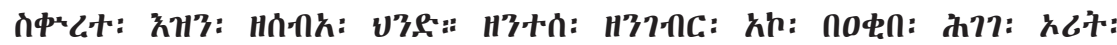

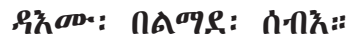

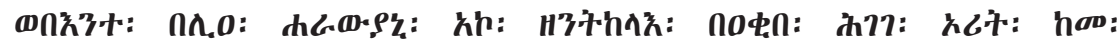
h,

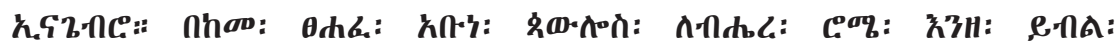

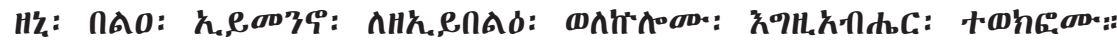

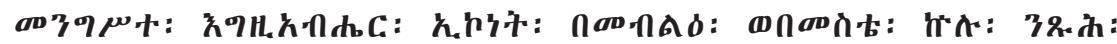

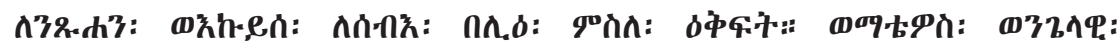

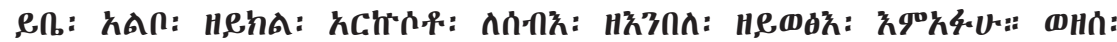

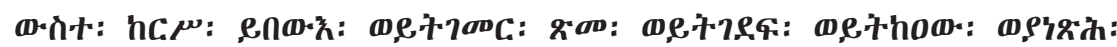

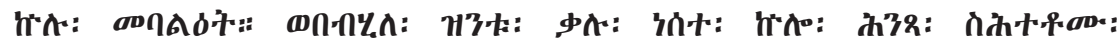

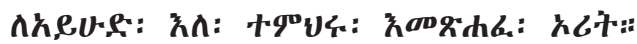

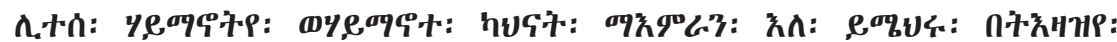

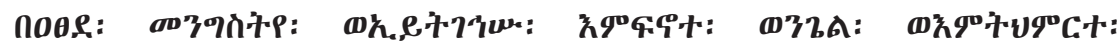

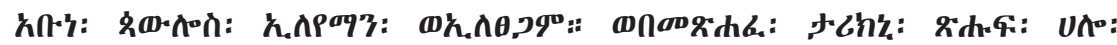

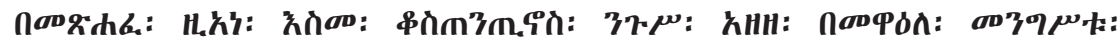

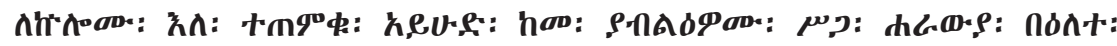

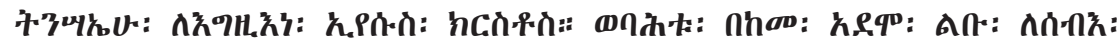

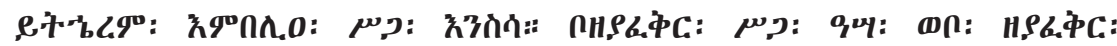
กत.o:

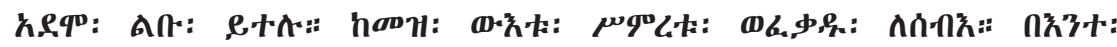

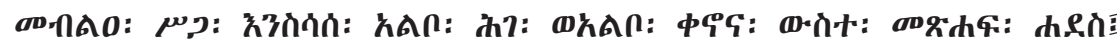

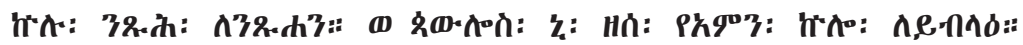

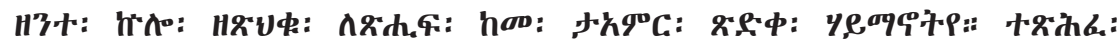

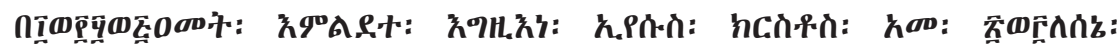

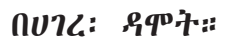




\section{Anhang 3}

Die »Glaubens-Bekenntniß Claudii, deß Königs in Mohrenland«.

Die »Confessio Claudii« in deutscher Übersetzung von Johann Michael Dilherr ${ }^{5}$

Im Nahmen des Vatters/und des Sohns/und des heiligen Geistes/als des einigen GOttes. Diß ist mein Glaub / und meiner Vätter Glaub / der Israelitischen Königen; und der Glaub meines Volcks / in den Grenzen meines Reichs. Wir glauben an einen GOTT / und an Seinen einigen Sohn / Jesum Christum: der da ist Sein Wort/Seine Macht/Sein Rath/Seine Weisheit: Der mit Ihm gewesen ist/ehe denn die Welt erschaffen wurde. In den lezten Zeiten ist Er zu uns kommen: jedoch nicht also; daß Er von dem Thron Seiner Göttlichen Majestät abgetreten währe: Und ist Mensch worden/aus dem heiligen Geist / und aus der Marien / der heiligen Jungfrauen: Und ist getaufft worden im Jordan; da Er dreissig Jahr alt wahr: Und ist ein vollkommener Mensch worden; und gehangen am Holz des Creuzes/zu Pontii Pilati Zeiten; hat gelidten; ist gestorben/und begraben worden; und/am dritten Tage/wider auferstanden: Darnach/am vierzigsten Tag/in aller Herrlichkeit/aufgefahren gen Himmel; und sizet nun zur Rechten Seines Vatters. Und wird widerkommen mit Herrlichkeit / zu richten die Lebendigen und die Todten: Und Seines Reichs wird kein Ende sein. Wir glauben auch an den heiligen Geist/den lebendigmachenden HErrn/der vom Vatter ausgegangen: Und glauben eine Tauff/zur Vergebung der Sünden: Und hoffen eine Auferstehung der Todten/zum zukünftigen Leben in Ewigkeit. Amen.

Wir wandeln aber auf dem richtigen/ebnen/und wahren Pfad: und weichen/weder zur Rechten/noch zur Lincken/ab/von der Lehre unserer Vätter; der zwölf Apostel; Pauli des Bruns der Weßheit; der Siebenzig Jünger; und der dreihundert- und achtzehen Rechtglaubigen/welche versamlet wahren zu Nicea; und der hundert und funfzig zu Constantinopel/und der zweihundert/die zu Epheso beisammen wahren. Also vermelde/und also lehre ich Claudius, König in Mohrenland/und der Beinahme meines Königsreichs Atznaf-saged, der Sohn Wanag-Sagedi, samt dem Sohn Naodi. Was aber unsre Feierung des alten Sabbaths anbelangt: so feiern wir wahrlich! denselbigen nicht/wie die Juden; die Christum gecreuziget/und dabei gesagt haben: Sein Blut komm über uns/und über unsere Kinder! Dieweil die jenigen Jüden weder Wasser schöpfen/noch ein Feuer anzünden/noch eine Speise kochen/noch Brod backen/noch von eine Hauß in das andre wandeln. Wir aber feiren den Sabbath also: daß wir unsre Gaben/auf den 
Tisch des HErrn opfern / und unser Abendmahl daran halten: gleich wie uns unsere Vätter/die Apostel/in dem Buch von der Lehre/zu thun befohlen haben. Wir feiern aber auch denselbigen / nicht als wir den Sabbath des erste Feier-Tags; welches ein neuer Tag ist/von welchem David spricht: Das ist der Tag/den uns der HErr gemacht hat; lasset uns daran freuen/und frölich sein. Dieweil an demselbigen unser HErr Jesus Christus auferstanden/und der heilige Geist über die Apostel / in dem Beth-Hauß Zions / herab gefahren: Und weil auch an demselbigen Tag Christus/in dem Leib der heiligen Marien/als der immerwärenden Jungfrauen/Fleisch und Blut an sich genommen; und eben an demselbigen widerkommen wird: zur Belohnung der Gerechten / und Abstraffung der Sünden.

Was aber die Art und Weis der Beschneidung anbelangt: so beschneiden wir nicht / wie die Juden; dieweil wir wissen die Worte und Lehre Pauli / deß Bruns der Weißheit/welcher spricht: Beschnitten werden / ist nichts nüze; und nicht beschnitten werden/hilft auch niemand. Und widerum spricht er/zu den Corinthiern/also: Der die Beschneidung angenommen/nehme nicht an die Vorhaut. Alle Bücher der Paulinischen Lehre sind bei uns zu finden: und die berichten uns von der Beschneidung/und Vorhaut. Die Beschneidung aber ist hie zu Land gebröuchlich; gleich wie die Zerschneidung des Angesichts in Mohrenland/und Nubien; oder gleich wie die Durchbohrung des Ohrs bei den Indianern. Was nun aber wir hier innen thun; das geschicht nicht etwan zu Beobachtung des Mosaischen Gesezes: sondern allein aus LandsGewonheit der Menschen.

Das Schweinen-Fleisch essen betreffend; so ist uns dasselbige/wegen Beobachtung des Mosaischen Gesezes/wie den Juden/nicht verbothen: Sintemal wir uns/weder für dem jenigen/der davon isst/ein Schen tragen/und ihn deswegen für unrein halten; noch dem jenigen/der nicht davon isst/zum essen nöthigen. Gleich wie unser Vatter Paulus/zu den Römern/spricht: Wer da isset; der verachte den andern nicht/der da nicht isset: Denn der HErr nihmt sie alle auf. Das Reich GOttes ist nicht Essen und Trincken; sondern den Reinen ist alles rein. Es ist aber dem Menschen nicht guth; daß er mit Aergeriß esse. Und der Evangelist Matthæus spricht: Es kan den Menschen nichts verunreinigen; als was aus seinem Munde geht. Denn alles das jenige / was in den Leib gehet / und in dem Magen behalten wird; das wird endlich durch den Abtritt ausgeworffen / und ausgeschüttet; und macht alle Speisen rein. In dem er nun aber diese Wort geredt / hat er dardurch der Jüden Irrthum allerdings über einen Hauffen geworffen: den sie/aus dem Mosaischen Gesez-Buch / geschöpfet hatten.

Meine Religion aber/samt der gelehrten Priester Religion/die/auf meinen Befehl/in meinem Reich/lehren/ist diese: daß sie von dem Weg deß Evangelii / und von der Lehre unsers Vatters Pauli / weder zur Rechten / noch $\mathrm{zu}$ Lincken/abweichen sollen. Ferner/so stehet im Buch / Tarich genannt/als 
in unserm Buch / also geschrieben: wie daß der König Constantinus, in den Tagen seiner Regierung/befohlen: alle getauffte Juden sollten/am Tag der Auferstehung unsers HErrn Jesu Christi/Schweinen Fleisch speisen. Jedoch aber/nach dem es ein jeder für guth ansiht/mag er sich von dem Fleischessen der Thiere gar wohl enthalten: Denn manche belustigen sich mit FischFleisch; etliche essen gern Hüner-Fleisch; manche enthalten sich des SchaafFleisches: und thut also ein jeder hierinnen nach seinem Beliebe; nach dem er es für gut ansiht. Soclher massen verhält sich das Wohlbehagen und der Wille des Menschen. Vom Fleisch-essen aber der Thiere auf Erden/findet sich weder Gesez/noch Regel/im Neuen Testament; sondern den Reinen ist alles rein. Und Paulus spricht: Wer da glaubt; der esse von alle.

Das ist also das jenige / welches ich Schrifftlich bezeugen wollen: damit du die Warheit meiner Religion wissen mögest. Gegeben im Jahr M.D.L.V. nach der Geburth unsers Herrn Jesu Christi/ den 29. Tag Jun. im Königreich Damot. 


\section{Anhang 4 \\ Ergänzung zum »äthiopischen Glaubensbekenntnis» laut Giacomo Baratti ${ }^{6}$}

Since thy have had knowledge of the Roman Catholick Religion, they have added something to their Creed by the consent of one of their general Assemblies, for they were careful to hinder their people from receiving any other Opinions than those that they had formerly embraced; for when they saw that our Priests and Jesuits were busie in drawing them to the faith of the Church of Rome, they published a little addition to their Creed, to inform every one of their judgments, \& hinder them to receive any opinions which they do not approve of.

We believe that the Virgin Mary is a pure Virgin, before and after the Birth of Christ; as she is the Mother of God, she ought to be loved and respected accordingly, but we neither worship Her nor pray unto Her. We believe that the Cross of Christ is a useful sign, it was upon it that he suffered for our sins, and purchased unto us Salvation with his own bloud; His Cross is a scandal to the Jews, and a folly to the Gentles, but to us Christians it is in much esteem and honour, we believe that the Cross of Christ is sufficient to redeem us, as S. Paul hath taught us, but the outward sign and use of it we employ more for distinction, than out of duty: And that we may never think it a scorn to wear the badge of our Profession.

We believe that S. Peter was the first of the Apostles, that the Stone that Christ mentions upon which his Church is built, is his Law and Faith; which Law is established upon the Prophets and Apostles, unto them was granted the power of governing the Church, of binding and loosing, and to them was committed the keys of the Kingdom of Heaven. But we do not acknowledge the Superiority that his Successors the Popes of Rome do derive from S. Peter; nor do we believe that he ever had any priviledge which the others did not enjoy. We believe that the holy Apostles, Saints, and Martyrs that are in glory did follow the foot-steps of our Saviour Christ, and that they have received from him the pardon of their sins, as we do. We believe that we must honour them with the holy Angels, but we do not approve of prayers made unto them, nor of the sufficiency of their Merits to benefit us, or the Church of Christ. We believe that it is well done to confess our sins before the Ministers of the Church, for by their prayers we may be assisted and comforted. We receive all the books of the Old and New Testament, as they were delievered unto us by S. Thomas, without any addition or innovation. We believe that our Clergy have liberty to Marry, as the Apostles and Disciples of our Saviour were, but 
that it is not lawful for a Priest to have two Wives or a Concubine. We believe that we are bound to obey in Conscience our Supream Lord Giam Belul, and under him the Abuna of our Church, with all the rest of our Ecclesiastical and Civil Magistrates and Superiors, but no other. We religiously believe that there is a place where the less Regenerate persons do go after this life, which is neither Hell, nor Heaven; what it is, and what the souls do suffer it it, we are not able to define. We believe that none can be saved without the bloud of Jesus Christ, that it is sufficient to cleanse us from all our sins, without any other assistance, and that we are not to trust upon the Merits of the Apostles and Saints that were but sinful men as we were. We believe that there shall be a day of Judgement where Christ shall appear in glory to Judge all men, that we must all appear before him to give an account of our actions, and that after that we shall all either go to hell or heaven; the wicked to everlasting burning, and the Righteous to eternal bliss. Amen.

This is the faith that the subjects of Precious Giam, which we are to maintain until the coming of our Lord Jesus Christ. God grant us grace that we may never forsake it, notwithstanding all the persecutions and perswasions of the enemies of Christianity.

This addition was lately made, since the Portugueses and other Europeans have travelled into those parts; for when some Religious men did endeavour to perswade the Emperour to submit to the See of Rome, and joyn with the other Christian Princes in their obedience to the Popes power. 


\section{Deutsche Übersetzung ${ }^{7}$}

Wir glauben/daß die Jungfrau Maria vor und nach der Geburt Christi eine reine Jungfrau geblieben; so fern sie die Mutter Gottes ist/solle sie um deßwillen geehret und geliebet werden/wir thun ihr aber keine Goettliche Ehre/ noch beten sie an.

Wir glauben/daß das Creutz Christi ein nutzliches Zeichen sey/auf diesem hat er vor unsere Suende gelitten/und mit seinem eigenen Blut unsere Erloesung erworben: Sein Creutz ist den Juden ein Aergerniß/und den Heiden eine Thorheit / uns Christen aber ist es eine hochschätzbare Ehre / und glauben wir / daß das Creutz Christi genugsam sey/ uns zu erloesen / wie uns S. Paulus gelehret hat; das aeusserliche Ansehen aber und Gebrauch desselben halten wir mehr von andern unterschieden/als daß wir es verehren solten: sonderlich aber schaemen wir uns nicht/dasselbe als Kennzeichen unsers Glaubens an uns zu tragen.

Wir glauben/daß der heilige Petrus der vorderste Apostel gewesen/daß der Stein / dessen Christus gedencket/ daß er seine Kirche bauen wolle/ sein Glaub und Gesetz gewesen/welches Gesetz gegruendet ist auf die Propheten und Apostel/denen die Mache/die Ritche zu regieren; und zu binden/und zu lesen/gegeben worden/denen auch die Schluessel zum Himmelreich anvertrauet seyn.

Wir erkennen aber nicht an/daß die Obermacht seiner Nachfolger/der Paepste zu Rom/von S. Peter herkomme; glauben auch nicht/daß er einige mehrere Freyheit/als die andere/gehabt habe.

Wir glauben/daß die heilige Apostel/Heilige/und Maertyrer/welche nun in der Seligkeit seyn/den Fußstapffen unsers Heilandes Christi nachgefolget/und daß sie von Ihme erlanget haben Vergebung ihrer Suenden / so wol/als auch wir.

Wir glauben/daß wir sie ehren sollten/wie die heiligen Engel/wir billigen aber nicht die Anbetung/so ihnen beschihet/auch nicht/ daß die Genugthuung ihrer Verdienste uns und der Kirchen Christi zu statten komme.

Wir glauben / daß es wolgethan sey/vor einem Kirchendiener die Suende zu bekennen / dann durch ihr Gebet können wir Huelff und Trost erlangen.

Wir nehmen alle Buecher deß Alten und Neuen Testamentes/wie sie uns von dem $\mathrm{H}$. Thoma uebergeben worden / ohne einigen Zusatz oder Neurung. Wir glauben/daß unsere Kirchendiener die Freyheit haben sich zu verehlichen/wie die Apostel und Diener Christi auch gehabt haben/daß es aber nicht zulaessig sey/daß ein Priester- zwey Weiber/noch eine Beyschlaefferin habe. 
Wir glauben / daß wir unserm Gewissen verbunden seyn / unserm hoechsten Herrn / Giam Belul, und unter ihme dem Abuna unserer Kirche und unsern uebrigen Geistlichen und Weltlichen Obrigkeiten und Oberherren/und keinem andern / untertthaenig zu seyn / und zu gehorsamen.

Wir sind der guten Meinung/daß ein Ort sey/wohin die nicht genugsam Wiedergeborne nach diesem Leben kommen/welcher weder Himmel noch Hoelle ist; was es sey/und was die Seelen in demselben leiden/vermoegen wir nicht zu beschreiben.

Wir glauben/daß niemand koenne selig werden/ohne durch das Blut Jesu Christi/welches genugsam ist uns von allen unsern Suenden zu reinigen / ohne eines andern Zuthung/daß wir uns verlassen duerfften auf das Verdienst der Apostel/und der Heiligen/welche auch Suender gewesen sind/gleichwie wir.

Wir glauben / daß ein Gerichts-Tag kommen werde / an welchem Christus in Glori und Herrlichkeit erscheinen werde / zu richten alle Menschen; daß wir vor demselben erscheinen/und Rechenschafft geben muessen alles unsers Thuns/und daß hierauf wir entweder in die Hoelle gehen muessen/oder in den Himmel; die Gottlosen in das ewige Feuer/die Gerechte aber in das ewige Leben / Amen.

Dieses ist der Glaub/den wir/deß Würdigen Giams Unterthanen behalten/bis auf die Zukunfft unsers Herrn Jesu Christi. Gott verleihe uns die Gnade/daß wir solchen nimmermehr verlassen/ungeachtet aller Verfolgungen / und Beredungen der Feinde der Christenheit. 


\section{Anhang 5}

Missionslied »Der Kämmerer aus Mohrenland ${ }^{8}$

\section{Ein Kämmerer aus Mohrenland}

Saß still auf seinem Wagen,

Ein kostbar Buch in seiner Hand,

Im Herzen viele Fragen:

"Was meinet doch wohl der Prophet? ${ }^{9}$

»Wer ist's, von dem geschrieben steht,

»Der, wie ein Lamm gebunden,

»Zur Schlachtbank geht voll Wunden?«

Und wie er so die Straße fährt, Vertieft in Dunkelheiten,

Ein Wanderer sich zu ihm kehrt:

»Kannst du das Wort auch deuten?»

»Wie kann ich, so mir Niemand zeigt

»Den Namen, den die Schrift verschweigt?

"Bist du der Mann, zu lehren,

»So komm, ich will dich hören«.

Philippus setzt sich neben ihn:

Nun wird's dem Kämm'rer tagen.

Die dunklen Nebelwolken flieh'n,

Es lösen sich die Fragen.

Daß mit dem Schlachtschaf der Prophet

Den Jesus meint von Nazareth,

Der uns vom Fluch erledigt,

Das wird ihm nun gepredigt.

Der Kämmerer war froh daran;

Und als sie im Verlaufe ${ }^{10}$

Der Reise einem Flusse nah'n,

So bat er um die Taufe.

8 Der Text folgt der ersten Ausgabe des Liedes: Barth, Missions-Lied, S. 309-311.

Die in den Fußnoten angegebenen abweichenden Varianten basieren sich auf der Version von 1836, die auch allen späteren Ausgaben zugrunde liegt: Ders., Christliche Gedichte, S. 148-150.

9 In der Version von 1836: „Wen meinet doch auch der Prophet?«.

10 In der Version von 1836: „Und als sie nun im Laufe«. 
Er sprach: Ich glaub', daß Jesus Christ "Der Sohn des großen Gottes ist!"

Gleich war Philippus munter,

Und taucht den Kämm'rer unter.

Und fröhlich zog, als er verschwand,

Der Kämm'rer seine Straßen

In's ferne heiße ${ }^{11}$ Mohrenland,

Als ging's auf weichem Rasen. ${ }^{12}$

Und in der Heimath früh und spät

Ward bald das Saatkorn ausgesä't,

Das er in sel'gen Stunden ${ }^{13}$

Bei Gaza einst gefunden.

Doch ach! wie stehet nun verheert

Des Kämm'rers schöner Garten!

Des Bodens Kraft so ausgezehrt

Von Unkraut aller Arten;

Der gute Same fast erstickt,

Und Zaun und Mauer weggerückt!

$O$ laßt die Gärtner eilen,

Daß sie die Schäden heilen!

Das Wort, ihr Gärtner, das ihr sä't

In Abyssinerherzen,

Vom Schafe, ${ }^{14}$ das zur Schlachtbank geht,

Das Wort vom Mann der Schmerzen,

Von dem, der als ein Opferlamm

Einst für uns starb am Kreuzesstamm,

Das segne der Getreue

In Habesch nun auf's Neue!

11 In der Version von 1836: »dunkle«.

12 In der Version von 1836: "auf welchem Rasen«.

13 In der Version von 1836: »in seel'gen Stunden«.

14 In der Version von 1836: „Vom Lamme«. 
Es wird mit euch zu jeder Zeit

Nach seinem Worte handeln;

In Kleider der Gerechtigkeit

Die Mohrenhaut verwandeln. ${ }^{15}$

Dereinst noch wird in frischem Grün

Des Kämm'rers alter Garten blüh'n,

Und nach des Winters Tagen

Viel edle Früchte tragen.

15 In der Version von 1836: »Die Mohrenfarbe wandeln«. 


\section{Register $^{1}$}

\section{Ortsregister}

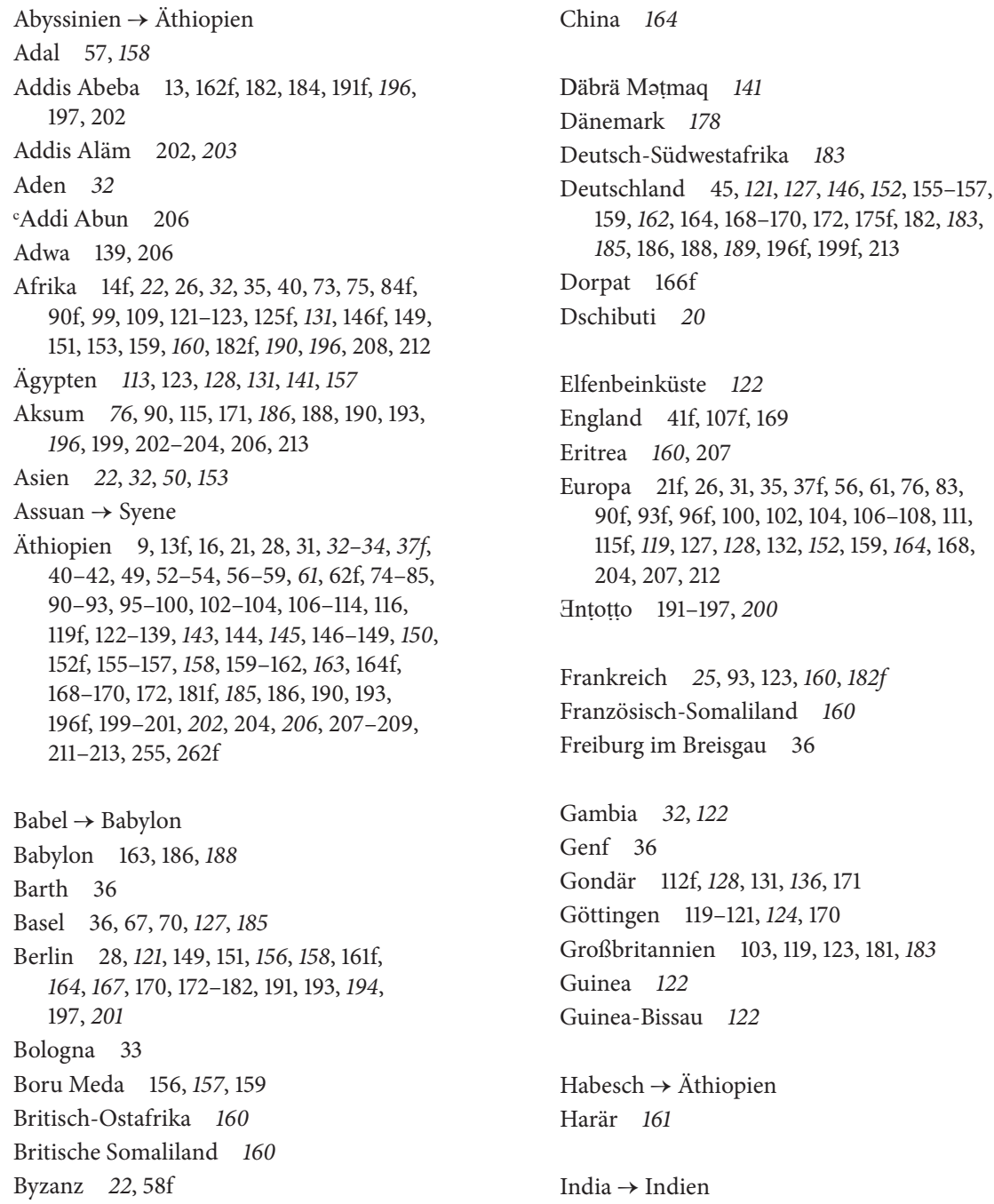

1 Kursiv gesetzte Seitenangaben verweisen auf Anmerkungen. 
Indien 13f, 38, 106, 109

Israel $37,73,112,143,193$

Istanbul $\rightarrow$ Konstantinopel

Italien $103,160,182$

Italienisch-Somaliland 160

\section{Japan 164}

Jerusalem $26,28,32,58,76 f, 113,130,162$, $180,185,189 f, 202,204$

Kairo $\quad 26,112,128,161,162$

Kenia 160

Kongo 32

Konstantinopel 44, 46, 58, 59, 162, 189

Kōskam 113

Krakau 30

Lissabon $\quad 32,35,37 f, 59$

London 37, 41f, 127, 103, 144, 158, 161

Lübeck 27, 35, 100

Mali 122

Marokko 183

Mauretanien 122

Mekka 32, 181

Meroe 90

Mohrenland $\rightarrow$ Äthiopien

Morenland $\rightarrow$ Äthiopien

Namibia 183

Neapel 171

Niederlande 178

Niger 32

Nikosia 26

Nizäa $43,44,46$

Norwegen 178
Österreich-Ungarn 201

Paris 37, 40f, 161

Persien 109

Portugal 31, 32, 37, 54, 64, 81, 95, 105, 108,158

Potsdam 201

Preußen 53, 163, 174, 176

Qwəsq $^{w} a m \quad 113$

Rio de Oro 32

Rom $27,28,35,37,40,42,50,53,54,56$, 58f, 62f, 82f, 100, 105, 258-260

Rostock 92, 93, 94, 96

Russland 167, 182

Sala 99

Sankt Petersburg 162

Šäwa $128,151,161,196$

Schweden 178

Schweiz 36,178

Senegal 122

Somalia 160

Spanien 93, 99

Straßburg $25,35,80,82$

Sudan 160

Syene 90

Tanger 183

Tagunit 99

Təgray $112,128,138,157,207$

Vereinigte Staaten von Amerika $\quad 81,182$

Wittenberg 13f, 22, 25, 27f, 30f, 35, 37, 41-46, 49-53, 55f, 61, 63-67, 71, 180, 212 


\section{Personenregister}

Abrəham, Abba $\rightarrow$ Abu Rumi

Abu Rumi $127 f$

Admas Mogäsa $\rightarrow$ Gleni

Adyam Sägäd $\rightarrow$ Iyasu II.

Aḥmad ibn Ibrāhīm al-Ġāzī 57, 158

Albrecht von Preußen, Herzog 53, 176

Althoff, Friedrich $\quad 163,169$

Álvares, Francisco $\quad 32,62,95,110$

Ambrosius von Mailand 44

Andreae, Jakob 98

Andree, Richard 132

Asarja 77, 202

Athanasius von Alexandria 115

Augustinus von Hippo 44

Ayto Aylo $\rightarrow$ Haylu

Bäkaffa 112

Baratti, Giacomo 103f, 107, 109, 258

Barth, Christian Gottlob 146, 148

Bäynä Ləḥkəm $\rightarrow$ Mənilək

Becker, Georg 182

Benga, Daniel 30

Benner, Thomas 178

Bezold, Carl 76, 197f, 199

Bərhan Mogäsa, Btege 112-114

Bismarck, Otto von 156

Block, Johannes 36

Blumenbach, Johannes Friedrich 120

Blumhardt, Karl Heinrich 128

Bobrelli, Jules 194

Bosch, Carl 182, 184f, 191, 206, 209

Brecht, Martin 27

Bruce, James 112-116, 119-121, 126

Bucer, Martin 25, 36, 80-84, 92, 212

Bülow, Bernhard von 163, 184

Bünting, Heinrich 85,90

Büttner, Manfred 124

Calvin, Johannes $\quad 36,176$

Capell, Rudolf 108

Capito, Wolfgang 36

Cherville, Jean-Louis Asselin de 128

Christ, Wilhelm von 197

Chytraeus, David 92-98, 101f, 106, 212

Claudius $\rightarrow$ Gälawdewos
Clemens VII., Papst $\quad 34 f, 46,54$

Cless, Valentin 99

Crichton, James A. 199

Crucius, Martin 97, 99

Cruikshank, Isaac 116

David, König von Israel $\quad 48,113,206,256$

Dawit I., Kaiser von Äthiopien 60

Dawit II., Kaiser von Äthiopien $\rightarrow$ Ləbnä Dəngəl

Decker-Hauff, Hansmartin 99

Dilherr, Johann Michael 102, 212, 255

Döpmann, Hans-Dieter 30

Dresser, Matthäus 91, 110

Dryander, Ernst $\quad 174,179 \mathrm{f}$

Edzardus, Esdras 100

Ehmer, Hermann 99

Enders, Ludwig 71

Ephräm der Syrer 134, 137

Erasmus, Desiderius 36

Ernst I, Herzog von Sachsen-GothaAltenburg 74, 100, 175

Eulenburg, Victor von 182, 186

Gleni, Atege 33, 54, 59

Gstifanos, Abba 140, 143

Farel, Guillaume 36

Fasilädäs, Kaiser von Äthiopien 100

Fiqțor 61-63

Flemming, Johannes $\quad$ 170f, 182, 198, 200

Friedrich II., König von Preußen 172

Friedrich III., Deutscher Kaiser $172 f$

Friedrich III., Kurfürst von Sachsen 176

Friedrich Wilhelm IV., König von Preußen 172

Gäbrä Hgzioabəher Dästa 185

Gäbrä Maryam, Abba $\quad 140$

Gälawdewos, Kaiser von Äthiopien 78f, 82, 97, 100-103, 106

Gama, Christóvão da 158

Gama, Vasco da 158

Giovio, Paolo 95

Giyorgis von Sägla $\quad 62,141$ 
Gobat, Samuel 128, 130f, 133, 135-139, 146,149

Goes, Damian $\rightarrow$ Góis, Damião de

Góis, Damião de 32, 35f, 38, 81, 95, 105

Gorgoryos, Abba 110,170

Greßmann, Hugo 198

Grynaeus, Simon 36

Hardt, G. A. Tom 27

Harenberg, Johann Christoph 111

Harms, Ludwig 153

Harnack, Adolf 163-170, 172

Harnack, Theodosius 167

Hartmann, Julius 99

Haylä Maryam Śärabyon 189

Haylu, Ato 114

Hegel, Georg Wilhelm Friedrich 150

Hedio, Kaspar 36

Heinrich der Seefahrer 32

Heinrich VIII., König von England 41f

Heyer, Friedrich 28

Heyling, Peter $\quad 27,100,104,108,112$

Ilg, Alfred 184, 185

Isenberg, Carl Wilhelm 128f, 133, 135, 138f, $144 \mathrm{f}$

Iyasu II., Kaiser von Äthiopien 112

Iyooas I., Kaiser von Äthiopien 112

Jeremias II., Ökumenischer Patriarch 49, 98

Jesus Christus $13,43,54,63,103,106$, $134,138,141,144,148,157,165,167,211$, 255-257, 259, 261-263

Joachim von Fiore 56

Joachim II., Kurfürst von Brandenburg 176

João III., König von Portugal 34, 43, 59

Johannes Chrysostomos 136

Johnson, Samuel 73

Kielmayer, Karl Christian Friedrich 132

Kirellos V., koptischer Papst 161

Kirkham, John 158

Knobler, Adam 31

Königin von Saba 75f, 78-80, 90, 188, 190, 194, 197, $203 \mathrm{f}$

Krapf, Johann Ludwig $\quad$ 128, 151f, 153

Kugler, Christian 128
Kyrill von Alexandria $\quad 62,136,138$

Lamprecht, Karl 120

Le Grand, Joachim 74

Leveson-Gower, George 158

Ləbnä Dəngəl, Kaiser von Äthiopien 33, $37,38,43,46,54,60 f$

Licanate, Christoforo $\rightarrow$ Ṣägga Zä̉ab

Loyola, Ignatius von 40, 42

Lüderitz, Adolf 190

Ludolf, Hiob 73f, 97, 100-102, 106, 109f, $115,145,168,170$

Lufft, Hans 41

Luther, Martin 13f, 22, 24f, 27, 28, 30f, 35, 36f, 41, 43-45, 49-51, 52, 53, 55f, 65-67, 70-72, 81f, 95, 131, 133, 147, 165, 176, 208f, 211f, $249 \mathrm{f}$

Magera, Franciscus 30

Makədda $\rightarrow$ Königin von Saba

Mäkwännən Wäldä Mikael $\quad$ 161, 184

Manlius, Johannes 67, 70

Manuel I., König von Portugal 32, 33f, 43, $54,56,59$

Maqeda $\rightarrow$ Königin von Saba

Margalho, Pedro 35

Maria 40, 54, 59, 100, 105, 133-143, 191-193, 202-204, 260

Marqos, Bischof in Äthiopien 33, 62

Mäšäša Wärqe 189

Mateus, äthiopischer Gesandte 33

Matewos, Abunä 161,162

Mayer, Johannes 155

Meilech $\rightarrow$ Mənilək

Melanchthon, Philipp 22, 24-26, 30, 35, 42f, 44, 45, 49, 52, 55, 67, 70, 93, 176, 249

Mercator, Gerhard $90 \mathrm{f}$

Methodios, Bischof von Olympos 57

Mənilək 76-78, 130, 194, 199

Mənilək II., Kaiser von Äthiopien 112, 159-161, 163, 165, 182, 184-197, 201-204, 213

Məntəwwab $\rightarrow$ Bərhan Mogäsa

Michaelis, Johann David 119

Mika $^{\circ}$ el Səhul 112, 114

Mika ${ }^{\circ}$ l, Abba 14, 21f, 25-27, 30f, 37f, 41f, 44f, 49-55, 56, 61, 63-67, 70-72, 81, 211, 249

Mommsen, Theodor 170 
Mondon-Vidailhet, Casimir 200

More, John 34

More, Thomas 34

Mose 48, 78, 81, 130

Münchhausen, Freiherr von 120

Münster, Sebastian $\quad$ 80f, 85

Naumann, Friedrich $173 f$

Nestorius 138

Noach 58

Nöldeke, Theodor 198

Ortelius, Abraham 91

Pauli, Benedikt $\quad 22,42,45,249 f$

Paulus, Apostel 78, 94, 131, 176, 255-257, 260

Peters, Carl 190

Pețros IV., Abunä 207

Petrus, Apostel 21, 176, 260

Petrus Aethiops $\rightarrow$ Täsfa Șəyon

Peucer, Caspar 70

Philipp I., Landgraf von Hessen 176

Philippus, Apostel 147f, $262 \mathrm{f}$

Pindar, Peter $\rightarrow$ Wolcot, John

Platt, Thomas Pell 128

Potken, Johannes 26

Praetorius, Franz 199

Priesterkönig Johannes 21f, 31, 32, 35, 56, $59,82,84 f, 91$

Pringle, John $119 f$

Qerəllos, Bischof in Äthiopien 126

Qerəllos $\rightarrow$ Kyrill von Alexandria

Quad, Matthias 91

Raschdorff, Julius 172

Rauwolf, Leonhard 28

Ritschl, Albrecht 165

Ritter, Carl 121-127, 132, 149-151, 153

Rohlfs, Ferhard 157

Roosevelt, Theodore 201

Rosen, Felix 185, 188, 200, 204, 206

Rosen, Friedrich $\quad$ 181f, 184, 186, 189, 197

Säbagadis Wäldu 128

Ṣägga Zäªb 37f, 42, 48, 51, 54, 61, 64, 67, $75-83,85,94,96,101,104 f, 212$
Śahlä Śəllase 128

Salomo 59, 75-78, 80, 91, 170, 190, 197, 203, 204

Salt, Henry 126

Sāwīris ibn al-Muqaffac 60

Schenute von Atripe 61-63

Schinkel, Karl Friedrich 172

Schüler, Edmund 182

Schütze, Gottfried 70

Şəge Brrhan, Abba 140

Şəge Dəngel, Abba 140

Shem 58

Simeon der Töpfer 134

Sinoda $\rightarrow$ Schenute von Atripe

Skinner, Robert Peet 201

Spittler, Christian Friedrich 152

Stephanus 176

Susənyos, Kaiser von Äthiopien $\quad 40,100$

Swedenborg, Emanuel 150, 151

Täklä Haymanot II., Kaiser von Äthiopien 112

Täklä Haymanot Täklä Ggzi 139

Täsfa Șəyon 94, 95

Ṭaytu Bəțul, Btege １91, 192, 194, 201

Tersteegen, Gerhard 123

Ţəbäb Sägäd $\rightarrow$ Täklä Haymanot II.

Thomas Wäldä Samusel 26

Tischendorf, Konstantin von 171

Tychsen, Thomas Christian 120

Victoria, Königin des Vereinigtes Königreichs 158

Viktor, Sohn des Romanos $\rightarrow$ Fiqtor

Vilhegas, Diogo Ortiz de 35

Volkmann, Johann Jacob 120

Vollbrecht, Hans $\quad$ 182, 191, 192

Wälättä Giyorgis $\rightarrow$ Bərhan Mogäsa

Waldseemüller, Martin 14

Wenz, Gunther 166

Werner, Anton von 174

Wette, Wilhelm Martin Leberecht de 70

Wilhelm I., Kaiser von Deutschland 156, 158, 161

Wilhelm II., Kaiser von Deutschland 159, $160,161,162,163 f, 171-183,184,186,188$, 189, 197, 199, 202, 204, 213 
Wilmanns, August 169

Woermann, Adolph 190

Wolcot, John 116

Yohannos II., Kaiser von Äthiopien 112

Yoḥannəs IV., Kaiser von Äthiopien 155-157, 158, 159, 161

Yoḥannəs Afä Wärq

$\rightarrow$ Johannes Chrysostomos
Zacharias 60

Zadok 202

Zagazabo $\rightarrow$ Șägga Zäab

Zaga Zabo $\rightarrow$ Șägga Zä’ab

Zämika’el 47

Zär’a Yacəqob, Kaiser von Äthiopien 33, $46-49,56,82,140,141,143,213$

Zegazabo $\rightarrow$ Șägga Zä’ab

Zinzendorf, Nikolaus Ludwig von

Zurara, Gomes Eanes de 32

Zwingli, Huldrych 27, 49f, 176 

